\title{
Surfaces of intermetallics: Quasicrystals and beyond
}

by

\section{Chad David Yuen}

A dissertation submitted to the graduate faculty

in partial fulfillment of the requirements for the degree of

DOCTOR OF PHILOSOPHY

\author{
Major: Physical Chemistry \\ Program of Study Committee: \\ Patricia A. Thiel, Major Professor \\ James W. Evans \\ Gordon J. Miller \\ Thomas Greenbowe \\ Mark Gordon
}

Iowa State University

Ames, Iowa

2012

Copyright (C) Chad David Yuen, 2012. All rights reserved. 
Dedicated to my wonderful family, friends, and everybody who had played a crucial role in my life. 


\section{TABLE OF CONTENTS}

CHAPTER 1. General Introduction 1

Dissertation Organization $\quad 4$

References 4

CHAPTER 2. Weak Bonding of $\mathrm{Zn}$ in an Al-Based Approximant, Based $\begin{array}{ll}\text { on Surface Measurements } & 6\end{array}$

$\begin{array}{ll}\text { Abstract } & 6\end{array}$

$\begin{array}{ll}\text { 1. Introduction } & 7\end{array}$

2. Experimental Details 9

3. Clean Surface: Experimental Results and Interpretation 13

$\begin{array}{ll}\text { 3.1 Depth profiling with XPS at room temperature } & 13\end{array}$

$\begin{array}{ll}3.2 \text { Annealing } & 14\end{array}$

3.2.1 Variable temperature annealing: Compositional evolution $\begin{array}{ll}\text { from XPS } & 15\end{array}$

3.2.2 Constant temperature annealing: Compositional evolution from XPS 16

$\begin{array}{ll}3.3 \mathrm{STM} & 17\end{array}$

$\begin{array}{ll}\text { 3.3.1 STM image features } & 17\end{array}$

$\begin{array}{ll}\text { 3.3.2 Sample roughness from STM } & 19\end{array}$

4. Surface Oxidation 20

4.1 Oxidation in UHV 21

$\begin{array}{ll}\text { 4.2 Air-oxidized samples } & 23\end{array}$

4.3 Comparison between oxidation conditions 24

$\begin{array}{ll}\text { 5. Conclusions } & 25\end{array}$

$\begin{array}{ll}\text { Acknowledgements } & 27\end{array}$ 
$\begin{array}{ll}\text { References } & 28\end{array}$

$\begin{array}{ll}\text { Figure Captions } & 31\end{array}$

Tables 33

$\begin{array}{ll}\text { Figures } & 38\end{array}$

CHAPTER 3. Structure of the Clean $\mathrm{Gd}_{5} \mathrm{Ge}_{4}(010)$ Surface 60

$\begin{array}{ll}\text { Abstract } & 60\end{array}$

$\begin{array}{ll}\text { 1. Introduction } & 61\end{array}$

2. Experimental Procedures $\quad 62$

3. Background: Bulk Phases 66

$\begin{array}{ll}3.1 \mathrm{Gd}_{5} \mathrm{Ge}_{4} & 66\end{array}$

$\begin{array}{ll}3.2 \mathrm{Gd}_{5} \mathrm{Ge}_{3} \text { Thin Plates } & 67\end{array}$

4. Experimental Results 67

$\begin{array}{ll}\text { 4.1 XPS } & 67\end{array}$

4.1.1 XPS: Initial Depth-Profiling after Air Exposure (Sample \#1)

4.1.2 XPS: Surface Composition as a Function of Annealing

Temperature in UHV (Sample \#1, \#2, and \#3) 68

4.1.3 XPS: Depth-Profiling after Annealing at Different

Temperatures in UHV (Samples \#1, \#2, and \#3) 69

4.1.4 Summary and Analysis of XPS Data 71

$\begin{array}{ll}4.2 \text { STM } & 72\end{array}$

4.2.1 STM: General Comments 72

4.2.2 STM: Sample \#1 73

4.2.2.1 STM Images after Sputtering at Room Temperature

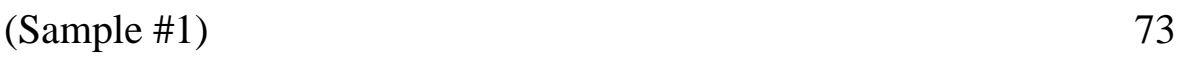

4.2.2.2 STM Images after Annealing at $900 \mathrm{~K}$ (Sample \#1) 74 
4.2.2.3 STM Images after Annealing above 900 K (Sample $\# 1)$

4.2.3 STM: Sample \#2 75

4.2.3.1 STM Images after Annealing to $900 \mathrm{~K}$ (Sample \#2)

75

4.2.3.2 STM Images after Annealing Above 900 K (Sample \#2)

$\begin{array}{ll}\text { 4.2.4 Summary of STM Data } & 80\end{array}$

5. Comparison of STM Results (Section 4.2) with Bulk Structure 81

6. Characterizing $\mathrm{Gd}_{5} \mathrm{Ge}_{3}$ Thin Plates (Samples \#2 and \#4) 85

6.1 Characterizing $\mathrm{Gd}_{5} \mathrm{Ge}_{3}$ Thin Plates: Optical Microscopy

(Sample \#4) $\quad 85$

6.2 Characterizing $\mathrm{Gd}_{5} \mathrm{Ge}_{3}$ Thin Plates: SEM, AES and SAM (Sample \#4) 85

6.3 Characterizing $\mathrm{Gd}_{5} \mathrm{Ge}_{3}$ Thin Plates: SEM (Sample \#2) 88

6.4 Characterizing $\mathrm{Gd}_{5} \mathrm{Ge}_{3}$ Thin Plates: STM (Sample \#2) 89

$\begin{array}{ll}\text { 7. Conclusions } & 91\end{array}$

$\begin{array}{ll}\text { Acknowledgements } & 91\end{array}$

$\begin{array}{ll}\text { References } & 92\end{array}$

$\begin{array}{ll}\text { Figure Captions } & 95\end{array}$

$\begin{array}{ll}\text { Tables } & 101\end{array}$

$\begin{array}{ll}\text { Figures } & 109\end{array}$

$\begin{array}{ll}\text { Appendix } & 145\end{array}$

CHAPTER 4. Preferential Surface Oxidation of $\mathrm{Gd}$ in $\mathrm{Gd}_{5} \mathrm{Ge}_{4}$

$\begin{array}{ll}\text { Abstract } & 153\end{array}$

$\begin{array}{ll}\text { 1. Introduction } & 153\end{array}$

2. Materials and methods 154 
3. Results 155

4. Discussion 157

$\begin{array}{lr}\text { 5. Conclusions } & 159\end{array}$

$\begin{array}{ll}\text { Acknowledgements } & 159\end{array}$

$\begin{array}{lr}\text { References } & 159\end{array}$

$\begin{array}{ll}\text { Figure Captions } & 162\end{array}$

$\begin{array}{ll}\text { Figures } & 163\end{array}$

$\begin{array}{ll}\text { Appendix } & 167\end{array}$

CHAPTER 5. Interaction of Au with the NiAl (110) Surface 175

$\begin{array}{ll}\text { 1. Introduction } & 175\end{array}$

2. Experimental Procedures 177

3. Experimental Results and Discussion $\quad 180$

$\begin{array}{ll}3.1 \text { Growth at } 200 \mathrm{~K} \text { and } 300 \mathrm{~K} & 181\end{array}$

$\begin{array}{ll}\text { 3.2 Thermal Treatments above } 300 \mathrm{~K} & 182\end{array}$

4. Discussion 184

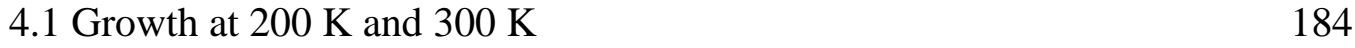

$\begin{array}{ll}\text { 4.2 Thermal effects above } 300 \mathrm{~K} & 186\end{array}$

$\begin{array}{ll}\text { 5. Conclusions } & 188\end{array}$

$\begin{array}{lr}\text { Acknowledgements } & 188\end{array}$

$\begin{array}{lr}\text { References } & 189\end{array}$

$\begin{array}{lr}\text { Figure Captions } & 192\end{array}$

$\begin{array}{ll}\text { Tables } & 195\end{array}$

$\begin{array}{lr}\text { Figures } & 198\end{array}$ 
CHAPTER 6. A Comparison of the Ag and Au Structures on NiAl (110) using XPD and STM

1. Introduction

2. Experimental Details

225

3. Experimental Results: Ag on NiAl (110) 228

3.1 STM, XPD, and LEED for Ag on NiAl (110) 228

3.2 Comparing SSC Models with XPD Patterns for Ag on NiAl (110)

4. Experimental Results: Au on NiAl (110)

4.1 STM, XPD, and LEED for Au on NiAl (110)

5. Conclusions

Acknowledgements 233

References

Figure Captions

Figures 


\section{CHAPTER 1}

\section{General Introduction}

The goal of this work is to characterize surfaces of intermetallics, including quasicrystals. Achieving this goal requires techniques to determine surface composition and surface structure of these materials. However, there is very little work in characterizing such surfaces (other than quasicrystals and closely-related periodic systems), and so there are new opportunities in this direction.

Intermetallics are usually metal rich compounds where the stoichiometry is fixed (or can vary over a very narrow range), corresponding to a specific chemical identity of an atom occupying any given site [1]. However, their mechanical, catalytic, magnetic, and surface properties are highly desirable for certain applications. For instance, aluminides have high strength and stiffness at elevated temperatures [2], Gd-Ge compounds exhibit magnetocaloric properties that may lead to new refrigeration and other energy conversion technologies [3], and $\mathrm{Al}_{13} \mathrm{Fe}_{4}$ holds promise as a cheap and environmentally friendly hydrogenation catalyst [4].

A particularly interesting subset of intermetallics are quasicrystals. They were first discovered by Daniel J. Shechtman in 1982 [5]. They are aperiodic structures that usually have forbidden rotational symmetries, such as fivefold or tenfold axes [6]. The first materials discovered were icosahedral. Later, decagonal quasicrystals were discovered by Chattopadhyay et al. [7] and Bendersky [8]. Surface studies of quasicrystals are important because they shed light on the atomic and electronic surface 
structures, and how those may be related to phenomena such as epitaxy $[6 ; 9 ; 10]$, low friction [11], wetting by liquids [12], and resistance to oxidation [13] - in all of which the quasicrystals exhibit unusual and potentially useful surface properties.

In this work, surface characterization is primarily focused on composition and structure using X-ray photoelectron spectroscopy (XPS) and scanning tunneling microscopy (STM) performed under ultrahigh vacuum (UHV) conditions. XPS provides critical information on the surface composition and the chemical state of the elements. STM is used to characterize the surface structure by determining the topography of the surface. Surfaces need to be studied in UHV conditions because it is the only possible environment where such surfaces can be prepared and maintained from outside contamination such as oxygen and carbon.

Surface composition can be determined from the area underneath the curve of a photoelectron peak in XPS. We can apply this value to a general expression in determining the atomic concentration, $C_{x}$, in the sample,

$$
C_{x}=\frac{A_{x} / S_{x}}{\sum A_{i} / S_{i}}
$$

$A$ corresponds to the area underneath the curve of the photoelectron peak, $S$ corresponds to the atomic sensitivity factor of the photoelectron peak to scale the measured intensities, these values were taken from [14], the subscript " $x$ " corresponds to the element of interest and " $i$ " is an index that runs over all of the elements in the sample. Equation (1), enables the determination of surface chemical composition, which is useful in comparing surfaces versus bulk composition. 
Chemical states of the elements are shown by the variations in binding energies of the photoelectron peaks as determined by XPS. For instance, pure metals typically tend to have lower binding energies than oxide metals. Therefore, we can measure the difference in binding energies of a photoelectron peak from a clean metal and an oxidized metal and see if the metal oxidizes.

STM complements XPS in characterizing surfaces. The surface topography provided by STM is most useful when scanning smooth surfaces, i.e. a step-terrace morphology. In general, step-terraces can be achieved after several cleaning cycles. Studying clean surfaces is ideal in finding the correct atomic structure without being contaminated by outside environment. A cleaning cycle is define as sputtering and annealing [15]. In such a cycle, sputtering is a process of removing material from the surface by ion bombardment [15] and annealing is heating the sample to a specific temperature for an amount of time to repair the surface damage from sputtering [15]. With preparation of a step-terrace morphology using a sputter-annealing regimen in UHV, the surface can be used to determine the atomic structure with STM.

We apply these techniques generally on the clean surface, but in some cases, we can also apply these techniques after an adsorption of a molecule or a metal on surfaces as well. This can help us understand the chemical interaction between the molecule or metal and the surface. With metal adsorption, we can also study the self-assembly of metal nanostructures on surfaces. Self-assembly involves spontaneous arrangement into ordered structures [16]. In this work, it means that a nanostructure builds itself on surfaces. This may provide practical insights into creating useful nanostructures. 


\section{Dissertation Organization}

In this dissertation, five chapters focus on characterizing clean surfaces and other types of systems on surfaces. They are: (1) Weak bonding of $\mathrm{Zn}$ in an Al-Based approximant, based on surface measurements (a part of this chapter was published in Philosophical Magazine in 2010); (2) Structure of the clean $\mathrm{Gd}_{5} \mathrm{Ge}_{4}$ (010) surface; (3) Preferential surface oxidation of $\mathrm{Gd}$ in $\mathrm{Gd}_{5} \mathrm{Ge}_{4}$ (a part of this chapter was published in Applied Surface Science in 2012); (4) The interaction of Au on the binary NiAl (110) surface; and (5) A comparison of the Ag and Au structures on NiAl (110) using XPD and STM. Following the five chapters are appendices that document a standard procedure for using CasaXPS software, and an experimental database of STM, XPS, SEM, AES, SAM, XPD, and LEED.

\section{$\underline{\text { References }}$}

[1] C.D. Yuen, B. Unal, D. Jing, P.A. Thiel, Philosophical Magazine 91 2879-2888.

[2] T. Duguet, P.A. Thiel, Progress in Surface Science 87 47-62.

[3] V.K. Pecharsky, J.K.A. Gschneidner, Physical Review Letters 78 (1997) 44944497.

[4] M. Armbruster, et al., Nature Materials 11 (2012) 690-693.

[5] P.A. Thiel, Progress in Surface Science 75 (2004) 69-86.

[6] H.R. Sharma, M. Shimoda, A.P. Tsai, Advances in Physics 56 (2007) 403-464.

[7] K. Chattopadhyay, S. Ranganathan, G.N. Subbanna, N. Thangaraj, Scripta Metallurgica 19 (1985) 767-771.

[8] L. Bendersky, Physical Review Letters 55 (1985) 1461-1463. 
[9] V. Fournee, P.A. Thiel, Journal of Physics D-Applied Physics 38 (2005) R83R106.

[10] V. Fournée, J. Ledieu, P.A. Thiel, Journal of Physics: Condensed Matter 20 (2008).

[11] J.Y. Park, P.A. Thiel, Journal of Physics-Condensed Matter 20 (2008) -.

[12] J.M. Dubois, V. Fournee, P.A. Thiel, E. Belin-Ferre, Journal of PhysicsCondensed Matter 20 (2008) -.

[13] D. Rouxel, P. Pigeat, Progress in Surface Science 81 (2006) 488-514.

[14] J.F. Moulder, J. Chastain, W.F. Stickle, P.E. Sobol, K.D. Bomben, Handbook of x-ray photoelectron spectroscopy: a reference book of standard spectra for identification and interpretation of XPS data, Physical Electronics, 1995.

[15] K. Oura, V.G. Lifshits, A.A. Saranin, A.V. Zotov, M. Katayama, Surface Science: An Introduction, Springer, Verlag, 2003.

[16] G.M. Whitesides, B. Grzybowski, Science 295 (2002) 2418-2421. 


\title{
CHAPTER 2
}

\section{Weak Bonding of $\mathrm{Zn}$ in an Al-Based Approximant, Based on Surface Measurements}

\author{
Chad D. Yuen, ${ }^{1,2}$ Baris Unal, ${ }^{1,3,4}$ Dapeng Jing, ${ }^{1,2}$ and Patricia A. Thiel ${ }^{1,2,3,}$ \\ ${ }^{1}$ Ames Laboratory, Iowa State University, Ames, Iowa 50011 \\ ${ }^{2}$ Department of Chemistry, Iowa State University, Ames, Iowa 50011 \\ ${ }^{3}$ Department of Material Science and Engineering, Iowa State University, Ames, Iowa \\ 50011 \\ ${ }^{4}$ Present address: Department of Chemical Engineering, Massachusetts Institute of \\ Technology, Boston, Massachusetts \\ "Parts of this chapter was published in "Philosophical Magazine, 2010"
}

\begin{abstract}
$\underline{\text { Abstract }}$
We have studied two surfaces of a new Al-Pd-Zn approximant using mass spectrometry, X-ray photoemission spectroscopy (XPS) and scanning tunneling microscopy (STM). Zn is bonded weakly in this approximant, perhaps as weakly as in elemental $\mathrm{Zn}$. This is based upon three observations: the high vapor pressure of $\mathrm{Zn}$ above the approximant (detectable in the gas phase at $600 \mathrm{~K}$ ); preferential sputtering of $\mathrm{Zn}$ (contrary to the usual preferential sputtering of Al in Al-rich quasicrystals); and preferential surface segregation of $\mathrm{Zn}$. We further show that preferential segregation and perhaps incipient evaporation - causes the surface to roughen, preventing it from forming a terrace-step morphology. Finally, our data show that at low $\mathrm{O}_{2}$ pressures, Al oxidizes. In air, $\mathrm{Zn}$ oxidizes as well. All results and conclusions are similar for the twofold and pseudo-ten-fold surfaces.
\end{abstract}




\section{Introduction}

In 1982, quasicrystals were discovered by Daniel J. Shechtman [1]. They are aperiodic structures that usually have forbidden rotational symmetries, such as fivefold or tenfold axes [2]. The first materials discovered were icosahedral. Later, decagonal quasicrystals were discovered by Chattopadhyay et al. [3] and Bendersky [4]. Surface studies of quasicrystals are important because they shed light on the atomic and electronic surface structures, and how those may be related to phenomena such as epitaxy $[2 ; 5 ; 6]$, friction [7], wetting by liquids [8], and oxidation [9] - in all of which the quasicrystals exhibit unusual and potentially useful properties.

In this work, we studied a newly-discovered $\mathrm{Al}_{57} \mathrm{Pd}_{30} \mathrm{Zn}_{13}$ approximant, which is an approximant to a quasicrystal. Approximant is defined as periodic crystals that are closely related to quasicrystalline phases and the local clusters of atoms are common to both the approximant and quasicrystal [10].This approximant had been found by Dr. Srinivasa Thimmaiah, in the group of Prof. Gordon Miller, while working on a project supported by the Department of Energy at the Ames Laboratory.

Structurally, a decagonal quasicrystal has three families of high-symmetry axes [2]: a single periodic tenfold (10f) axis and two groups of five aperiodic twofold (2f) axes. As shown in Fig. 1, the $10 \mathrm{f}$ axis is along the decagonal rod while the $2 \mathrm{f}$ axes are perpendicular to the $10 \mathrm{f}$. In the plane of the $2 \mathrm{f}$ axes, five of the $2 \mathrm{f}$ axes are perpendicular to the faces of the decagonal rod, while the other five bisect the angle between each pair in the first family, i.e. the second set is rotated by approximately $18^{\circ}$ with respect to the first, in the $2 \mathrm{f}$ plane. The growth facets along the sides of the rod are perpendicular to one 
set of $2 \mathrm{f}$ axes. In the approximant, we studied two samples, the pseudo-ten-fold (10f) surface and the two-fold (2f) surface.

Our goal was to determine the composition and structure of this surface under conditions typically applied to prepare a clean surface in ultrahigh vacuum, i.e. sputtering followed by annealing. The optimal outcome would have been to observe a terrace-step structure under conditions of annealing that did not cause significant segregation or evaporation of any of the constituent elements. The terrace-step structure could then have been analyzed in terms of its atomic structure, and this structure compared with the bulk structure model to shed light on the surface terminations. This approach has been carried out for several of the Al-rich quasicrystals [11-14]. Regarding the Al-Pd-Zn material, however, a major concern was the high vapor pressure of elemental Zn. This normally precludes $\mathrm{Zn}$ and its alloys from being used or studied in ultrahigh vacuum, because $\mathrm{Zn}$ can evaporate and contaminate the chamber, leading to spurious detection of $\mathrm{Zn}$ in subsequent samples. This fear of instrument degradation has prevented surface scientists from analyzing $\mathrm{Zn}$ and its alloys with some of the most powerful surface probes, such as X-ray photoemission spectroscopy (XPS) and scanning tunneling microscopy (STM). Our hope a priori was that the chemical potential of $\mathrm{Zn}$ in the Al-Pd-Zn approximant would be significantly lower than that of elemental $\mathrm{Zn}$. Indeed, the surface of quasicrystalline Ag-In- $\mathrm{Yb}$ has been annealed and characterized successfully in UHV, despite the rather high vapor pressure of elemental $\mathrm{Yb}$ [15].

The Al-Pd-Zn phase is an orthorhombic 5/3 approximant, with bulk lattice constants of $\mathrm{a}=2.36 \mathrm{~nm}, \mathrm{~b}=3.24 \mathrm{~nm}$, and $\mathrm{c}=1.67 \mathrm{~nm}$. Its bulk composition is $57 \mathrm{at} \%$ $\mathrm{Al}, 30$ at\% $\mathrm{Pd}$, and 13 at\% $\mathrm{Zn}$. It is structurally similar to a known Al-Os-Ir phase. It 
melts congruently at $1045 \mathrm{~K}$. The synthesis and analysis of this material will be reported elsewhere.

\section{Experimental Details}

We first measured the effective pressure of $\mathrm{Zn}$ over an $\mathrm{Al}-\mathrm{Pd}-\mathrm{Zn}$ sample as a function of sample temperature. A small piece of the two-fold Al-Pd-Zn sample was used to perform this experiment. It was characterized by Energy Dispersive Spectroscopy (EDS) by Jim Anderegg and William Yuhasz. A detailed description of how it was oriented and grown is discussed below. This was done using a UTI 100C quadrupole mass spectrometer in a test chamber with a total base pressure of about $1 \times 10^{-7}$ Torr, and with the sample in a Knudsen-type cell with a $0.8 \mathrm{~mm}$ diameter orifice. The distance between the cell and the quadrupole is $300 \mathrm{~mm}$. As we started to increase the temperature, the sample was being held roughly 2 minutes per degree. As shown in Fig. 2, the gas-phase $\mathrm{Zn}$ level first rose above its baseline reading of $5 \times 10^{-10}$ Torr when the sample reached a temperature of $600 \mathrm{~K}$, thereby setting an upper limit on the temperature to be used in UHV work. Given the configuration of the test chamber, we can estimate that a net $\mathrm{Zn}$ pressure of $2 \times 10^{-10}$ Torr above baseline (the detection limit) corresponds to a pressure at the Knudsen cell of about $10^{-4 \pm 1}$ Torr, which is close to the equilibrium vapor pressure of elemental $\mathrm{Zn}\left(10^{-3} \mathrm{Torr}\right)$ at $600 \mathrm{~K}$. Thus, the vapor pressure of $\mathrm{Zn}$ in the approximant is about the same as that in the elemental metal, to within about one order of magnitude. 
The Al-Pd-Zn specimens used for UHV studies were synthesized by William Yuhasz, working at the Materials Preparation Center at Ames Laboratory DOE [16]. The sample numbers for the pseudo-ten-fold (10f) and two-fold (2f) Al-Pd-Zn approximant is HTB-3-108 and WMY-1-134a. Ingots were grown using two techniques. These were the flux-growth technique and the Bridgman technique.

The Bridgman technique produced a large ingot. However, the area of single grains within the ingot proved to be no larger than $1 \mathrm{~mm}^{2}$, based on Laue. A circular sample, $12 \mathrm{~mm}$ wide and $1.5 \mathrm{~mm}$ thick, was prepared from the Bridgman ingot. This sample contained a grain whose surface was perpendicular to the 10f axis, and whose position was marked with electrical discharge machining. See Fig. 3a. Based on Laue, the grain was oriented within \pm 1 degree of the $10 \mathrm{f}$ axis. The other grains were within \pm 10 degrees of each other.

Flux growth produced smaller specimens. Because they tended to grow fast in the 10f direction, they were elongated (as shown in Fig. 1) and hence large enough for preparing $2 \mathrm{f}$ samples but not $10 \mathrm{f}$ samples. A rectangular $2 \mathrm{f}$ sample, $0.7 \mathrm{~mm}$ in length by $0.3 \mathrm{~mm}$ in width by $0.2 \mathrm{~mm}$ in thickness was prepared from the flux-grown specimen. Based on Laue, this sample had a uniform 2 f orientation within \pm 1 degree.

The samples were polished using standard metallographic techniques, down to $0.25 \mu \mathrm{m}$ diamond paste. Both samples were then sonicated with acetone and methanol, and fixed on tantalum plates. They were held in place with spot-welded tantalum wires. When the 2f sample was fixed onto the sample plate, a fracture line appeared in the middle, probably at a pre-existing grain boundary. In order to distinguish between the 
two grains, the left region will be called "Side A" and the right "Side B," as shown in Fig. 3b.

The samples were then transferred to an UHV chamber that was equipped with a sputter gun, Omicron $\mathrm{x}$-ray source $(\mathrm{Mg} \mathrm{K} \alpha)$, Omicron EA 125 hemispherical electron energy analyzer, and an Omicron variable-temperature STM. The base pressure of the chamber was below $7.7 \times 10^{-11}$ Torr throughout the experiments. The sample was sputtered with $\mathrm{Ar}^{+}$ions at 0.5 to $1.5 \mathrm{keV}$ energy, with the incident beam at an angle of $45^{\circ}$ to the surface plane and the sample at $\mathrm{T}=300 \mathrm{~K}$. The $10 \mathrm{f}$ sample was sputtered at three different positions (each position was sputtered at constant time) in order to cover the entire area, while the $2 \mathrm{f}$ sample was sputtered at one position since the sample was small. The sputter beam diameter is in the range of $3 \mathrm{~mm}$ to $18 \mathrm{~mm}$ FWHM. Sputtering procedures of the sample are listed in section 3 below.

The sample plate temperature was measured using chromel-alumel thermocouple wires that were connected to the stainless steel sample plate. The voltage output was measured without using an ice-water reference. The voltages were converted to temperatures using standard K-type thermocouple data [17] and adding 25 degrees to compensate for room temperature.

STM was used to study the surface morphology and surface roughness of the AlPd-Zn approximant. The RMS roughness values were calculated from the STM images using WSxM scanning probe microscopy software [18]. A tungsten tip was used to scan the images with a bias voltage of $-1 \mathrm{~V}$. The tunneling current was set at $0.2 \mathrm{nA}$ and 0.5 nA. A single STM image takes 2 minutes. All STM images were acquired with the sample at room temperature. In the annealing experiments, after desired annealing time, 
the heating power is shutdown to let the sample cool down to room temperature. STM was used after the sample was cooled for 45 minutes.

Gas exposures are reported in units of Langmuir, $\mathrm{L}\left(1 \mathrm{~L} \equiv 1 \times 10^{-6}\right.$ Torr s). Oxygen exposure was achieved by backfilling the Omicron chamber with research grade oxygen $(99.99 \%)$ to a constant pressure of $10^{-8}$ Torr to $10^{-7}$ Torr, as needed.

XPS data were analyzed using CasaXPS software [19]. The CasaXPS software analyzes both spectral and imaging data from quantifying surface composition to thickness measurements for spectra and images. It is mainly designed for XPS and Auger data but can also be used for other techniques such as SIMS. The XPS source was perpendicular to the sample plate, and the take-off angle (defined as the angle between the entrance axis of the analyzer and the sample surface) was $45^{\circ}$. Spectra were acquired in one of two ways: Over a broad energy range, $1150 \mathrm{eV}$ to $0 \mathrm{eV}$, with low energy resolution (“survey"); or over smaller energy ranges with higher resolution. These ranges were tailored to reveal the $\mathrm{Zn} 2 \mathrm{p}$ binding energy from $1075 \mathrm{eV}$ to $1000 \mathrm{eV}$, the $\mathrm{Pd} 3 \mathrm{~d}$ binding energy from $400 \mathrm{eV}$ to $300 \mathrm{eV}$, the $\mathrm{Pd} 3 \mathrm{p}$ and $\mathrm{O} 1 \mathrm{~s}$ binding energy from $570 \mathrm{eV}$ to $510 \mathrm{eV}$ or the $\mathrm{Al} 2 \mathrm{p}$ binding energy from $100 \mathrm{eV}$ to $50 \mathrm{eV}$. The analysis size in our XPS was less than $1.5 \mathrm{~mm}$ in diameter. The angular acceptance angle was $\pm 8^{\circ}$. The aperture size that was used in the EA 125 analyzer was $6 \mathrm{~mm} \times 12 \mathrm{~mm}$.

The reported surface compositions from the XPS data was taken from the smaller energy ranges of the individual peaks. The reason why we chose the individual peak spectra was due to the uncertainty when comparing to the survey spectra. The uncertainty of the surface composition between the survey spectra and the smaller energy ranges of the individual peak spectra were $1.15 \% \mathrm{Al}, 5.23 \% \mathrm{Pd}$, and $21.8 \% \mathrm{Zn}$, 
respectively. These uncertainties were calculated by taking the ratio of the composition between the survey spectra and the individual peak spectra.

\section{Clean Surface: Experimental Results and Interpretation}

\subsection{Depth profiling with XPS at room temperature}

Our first goal was to determine the asymptotic composition of the surface during sputtering. To this end, we started with samples that had been introduced_from air to UHV, without any prior UHV treatment. Figure 4 a shows the initial overview spectrum. The initial overview spectrum shows high intensity contamination peaks such as carbon and oxygen. Other contaminants such as $\mathrm{S}$ and Ag were also not detected by XPS. The metal peaks such as $\mathrm{Al}, \mathrm{Pd}$, and $\mathrm{Zn}$ showed low concentrations. This was expected since the sample was exposed to air. The sample was then sputtered at $300 \mathrm{~K}$ for two minutes. XPS was measured again, and this process was repeated several times until the sample had been sputtered a total of 24 minutes. After this period, the sputtering process was increased from two to five minutes in between the XPS runs until the surface had been sputtered a total of 54 minutes. At this point the sputter time was increased again between XPS runs from five minutes to ten minutes, until the sample was clean by XPS. XPS did not detect contamination peaks such as $\mathrm{C}$ and $\mathrm{O}$ after several sputtering cycles. The $\mathrm{O}$ peak, however, was more difficult to detect since it overlaps with the $\mathrm{Pd} 3 \mathrm{p}_{3 / 2}$ peak. A ratio was taken between the (O 1s and the $\mathrm{Pd} 3 \mathrm{p}_{3 / 2}$ peak) with the pure $\mathrm{Pd} 3 \mathrm{~d}$ peak. As expected, the ratio decreased throughout several cycles of sputtering until the ratio held constant. This indicates there was only $\mathrm{Pd}$. While the contamination peaks 
were gone, the $\mathrm{Pd}$ peak intensities increased dramatically while the $\mathrm{Al}$ and $\mathrm{Zn}$ peaks decreased slightly due to sputtering. This will be discussed below. The total sputtering time was 204 minutes. Figure $4 \mathrm{~b}$ shows the final overview spectrum at the end of the experiment, for the $10 \mathrm{f}$ sample.

A similar sequence was employed to clean the two-fold sample, where the initial sputtering time was five minutes. Again, XP spectra were acquired between sputtering. The sputtering time was then increased to 10 minutes between spectra. The total sputtering time required to clean the two-fold sample was 40 minutes according to XPS. Initial and final overview spectra are shown in Fig. 4c,d.

The depth profile itself is shown in Fig. 5. After extensive sputtering, the surface compositions of the two samples approached asymptotic limits in the range of $\mathrm{Al}_{62-67} \mathrm{Pd}_{29}$ ${ }_{32} \mathrm{Zn}_{3-6}$, which is $\mathrm{Al-rich}$ by $5-10$ at $\%$ and $\mathrm{Zn}$-poor by $7-10$ at $\%$, relative to the bulk composition of $\mathrm{Al}_{57} \mathrm{Pd}_{30} \mathrm{Zn}_{13}$. These results are shown in Table 1, along with the bulk composition for reference. This reveals preferential sputtering of $\mathrm{Zn}$, contrary to the preferential sputtering of Al that is usually seen in Al-rich quasicrystals. Light atomic weight and weak interatomic bonding are known to favor preferential sputtering [20]. Since $\mathrm{Zn}$ is heavier than $\mathrm{Al}$, its preferential sputtering most likely reflects weaker bonding in the solid.

\subsection{Annealing}

Our second goal was to determine the effect of heating on surface composition. Two types of temperature programs were employed. The first consisted of heating to sequentially higher temperatures, and monitoring composition vs. temperature. We refer 
to this as variable temperature annealing. The second consisted of heating to a fixed temperature of $460-480 \mathrm{~K}$ and monitoring composition vs. time. We refer to this as fixed temperature annealing. The variable temperature experiments are presented first.

\subsubsection{Variable temperature annealing: Compositional evolution from XPS}

The pseudo-ten-fold sample was first cleaned by $\mathrm{Ar}^{+}$sputtering for 10 minutes. After XPS, the sample was annealed at $380 \mathrm{~K}$ for 2 hours. The sample was then cooled down to room temperature for XPS analysis. This experimental process (sputtering, annealing for two hours, cooling down, and measuring XPS) was repeated again with annealing temperatures of $430 \mathrm{~K}, 460 \mathrm{~K}$, and $510 \mathrm{~K}$. The final cycle consisted of annealing at $540 \mathrm{~K}$ for 10 minutes. Higher temperatures were not used because of the possibility of $\mathrm{Zn}$ evaporation. The results are shown in Fig. 6a. The error bars at $300 \mathrm{~K}$ represent the range of surface concentrations after five similar sputtering preparations at $300 \mathrm{~K}$. From Fig. 6a, it is clear that $\mathrm{Zn}$ concentration began to increase rather abruptly above $400 \mathrm{~K}$, accompanied by decreasing $\mathrm{Al}$ and $\mathrm{Pd}$ concentrations. The fact that the $\mathrm{Zn}$ concentration eventually exceeded its bulk concentration by a significant amount-more than a factor of two-means that $\mathrm{Zn}$ segregated to the surface, partially replacing both $\mathrm{Al}$ and Pd.

The two-fold sample was treated similarly, except the annealing temperatures were different: $380 \mathrm{~K}, 430 \mathrm{~K}, 470 \mathrm{~K}$, and $510 \mathrm{~K}$, all for a constant time of 2 hours. The results are shown in Fig. 6b. The result resembles that for the pseudo-ten-fold surface: Above $400 \mathrm{~K}, \mathrm{Zn}$ segregated to the surface, displacing both Al and Pd. Note that XPS provides a depth-weighted average composition over the top 5-10 nm of material, or 
approximately $25-50$ atomic layers. It is possible that $\mathrm{Zn}$ covered the entire surface above $400 \mathrm{~K}$, and that $\mathrm{Al}$ and Pd XPS signals mainly originated below the $\mathrm{Zn}$ layer.

The final compositions of both samples are shown in Table 2, along with the bulk composition for reference.

In both samples, the surface composition reached that of the bulk at about 460$470 \mathrm{~K}$. This observation prompted the following set of experiments, in which the samples were held in that temperature range for extended periods of time in the hope that the quasicrystalline approximant phase could stabilize at the surface.

\subsubsection{Constant temperature annealing: Compositional evolution from XPS}

The initial pseudo-ten-fold surface was prepared, as before, by sputtering for 10 minutes at $300 \mathrm{~K}$. After XPS, the quasicrystal was annealed at $460 \mathrm{~K}$ for 30 minutes, and re-cooled to room temperature for XPS. This cycle (anneal, cool, and measure XPS) was repeated three more times, for a total of two hours of heating at $460 \mathrm{~K}$. The results are shown in Fig. 7a. The treatment of the two-fold sample was the same, except that annealing times were variable, consisting of 60 minutes, 90 minutes, and 120 minutes at constant temperature of $480 \mathrm{~K}$. The results are shown in Fig. 7b. It is clear that $\mathrm{Zn}$ segregated under these conditions as well. We conclude that surface segregation of $\mathrm{Zn}$ occurs very readily in this material.

The final compositions of both samples are shown in Table 3, along with the bulk composition for reference.

In the constant-temperature and variable-temperature annealing experiments, the pseudo-ten-fold and the two-fold samples yielded similar results. For both, the $\mathrm{Zn}$ 
surface concentration increased as temperature or time increased, while the $\mathrm{Al}$ and $\mathrm{Pd}$ surface concentrations decreased. However, there is some discrepancy between the two types of annealing experiments, and this holds true for both the pseudo-ten-fold and twofold surfaces. For instance, from Fig. 6A, after the pseudo-ten-fold surface was annealed for two hours at $460 \mathrm{~K}$, the concentrations of $\mathrm{Al}, \mathrm{Pd}$, and $\mathrm{Zn}$ were $53 \%, 22 \%$, and $26 \%$, respectively. From Fig. 7A, after the same cumulative treatment ( $\mathrm{T}=460 \mathrm{~K}$, two hours) the surface concentrations were $57 \%, 28 \%$, and $15 \%$. Both of these data sets should match up at this specific temperature and time. The $2 \mathrm{f}$ surface shows a similar discrepancy. In Fig. 6B (at $\mathrm{T}=480 \mathrm{~K}, \mathrm{t}=2 \mathrm{hrs}$ ), the surface concentrations of $\mathrm{Al}, \mathrm{Pd}$, and $\mathrm{Zn}$ were approximately $61 \%, 22 \%$, and $17 \%$, while in figure $7 \mathrm{~B}$, the concentrations were $58 \%, 14 \%$, and $28 \%$ after treatment at the same temperature and time. However, the temperature-time programs were not identical in the two kinds of experiments; the annealing interruptions in the constant-temperature experiment might have affected surface compositions.

\subsection{STM}

\subsubsection{STM image feature}

The pseudo-ten-fold sample was annealed at $440 \mathrm{~K}, 490 \mathrm{~K}$, and $545 \mathrm{~K}$ for 15 minutes each. Between heating, it was cooled to room temperature for STM imaging. The micrographs are shown in Fig. 8. The surface was very rough, with no evidence of a terrace-step type structure even after the $545 \mathrm{~K}$ treatment. The two-fold sample was treated similarly, except that the annealing temperatures were different (400 K and 520 K) and the annealing time was longer (two hours). Both Side A and Side B were imaged, 
and results are shown in Fig. 9. After annealing at $400 \mathrm{~K}$ (Fig. 9A-B), the surface was again very rough, but after annealing at $520 \mathrm{~K}$ (Fig. 9C-D), some hint of a terrace-step structure emerged. Where they were visible, the maximum width of the terraces was about 10 to $15 \mathrm{~nm}$.

The heights of steps can be a fundamental clue to the surface structure. The step heights are revealed in the line profiles shown in Fig. 10A-F. Step heights were variable, but there seems to be a significant cluster of values in the range $0.23-0.26 \mathrm{~nm}$, and perhaps another cluster in the range $0.35-0.43 \mathrm{~nm}$. It is difficult to judge the significance of these step heights, but $0.23-0.26 \mathrm{~nm}$ is consistent with interplanar spacings between close-packed planes of many elemental metals. Considering the metals in the quasicrystal, the spacings between close-packed planes are $0.27 \mathrm{~nm}$ for elemental $\mathrm{Zn}$, and $0.23 \mathrm{~nm}$ for both $\mathrm{Al}$ and $\mathrm{Pd}$. However, the second cluster of step heights falls short of being twice the value of the first, so they could not result from simple step bunching.

It is also interesting to compare the data for equivalent $2 \mathrm{f}$ surfaces of other decagonal, Al-rich quasicrystals. Based upon STM studies, these surfaces all have steps with minimum height $\left(d_{0}\right)$ and other steps whose heights $\left(d_{1}, d_{2}\right.$, etc) are related to $d_{0}$ by the Golden Mean, tau $=1.618 \ldots$ However, the exact values are rather scattered. For instance, on the equivalent $2 \mathrm{f}$ surface of Al-Cu-Co Duguet et al. find $\mathrm{d}_{0}=0.47 \pm 0.05 \mathrm{~nm}$ [21]. On Al-Ni-Co, Groening et al. report $\mathrm{d}_{0}=0.24 \mathrm{~nm}$ and $\mathrm{d}_{1}=0.39 \mathrm{~nm}$ [22], while Park et al. find $\mathrm{d}_{0}=0.19 \mathrm{~nm}$ and $\mathrm{d}_{1}=0.47 \mathrm{~nm}$ [23]. Of course, one would not expect to find exactly the same values for different alloys, but these values give some idea of what might be expected. The range of values reported here for Al-Pd- $\mathrm{Zn}$ is very similar to the values found by Groening et al. for Al-Ni-Co. 


\subsubsection{Sample roughness from STM}

The roughness of these surfaces was evaluated quantitatively after various surface treatments. Figure 11 shows the rms roughness, $w$, as a function of image area for individual experiments. As expected, it always increases toward an asymptotic value at large image size [24].

Figure 11A shows the roughness of the $10 \mathrm{f}$ surface after annealing at three different temperatures for 15 minutes each. Normally, one expects roughness to decrease as temperature increases (for temperatures below the roughening transition), because the rate of surface and near-surface diffusion increases. However, this variation of $w$ with T did not occur. There was no difference in $w$ after annealing at $440 \mathrm{~K}$ and $490 \mathrm{~K}$, and at $545 \mathrm{~K} w$ actually increased. This increase may be due to incipient evaporation of $\mathrm{Zn}$. (Recall from Sec. 2 that $\mathrm{Zn}$ could be detected in the gas phase starting at $600 \mathrm{~K}$.)

Figure 11A also shows data for the two-fold sample, after annealing at $400 \mathrm{~K}$ and $520 \mathrm{~K}$ for two hours each. These treatments produced no difference in $w$ for a fixed sample location. However, the two regions of the sample did show a difference in roughness of about $1 \mathrm{~nm}$. This might be due to uneven heating across the sample (cf. Fig. 2). But what is interesting in Fig. 11A, is the roughness at $300 \mathrm{~K}$ (sputtering, no annealing). It shows the surface to be smoother than when the approximant is annealed at high temperatures. Normally, one expects $w(\mathrm{~T})$ to be decreasing function for a surface that is initially prepared by sputtering. In other words, one expects annealing to heal the damage induced by sputtering and smoothen the surface. Figure 11B shows that this expectation is met for three other metallic samples that have been studied in our laboratory: (1) the (110) surface of a crystalline binary alloy, $\mathrm{NiAl}$; (2) a $\mathrm{Zr}-\mathrm{Ni}-\mathrm{Cu}-\mathrm{Al}$ 
metallic glass; and (3) the two-fold surface of a quasicrystal, decagonal $\mathrm{Al}-\mathrm{Cu}-\mathrm{Co}$. However, the roughnesses of the two Al-Pd-Zn surfaces behave differently. For them, $w(\mathrm{~T})$ starts high and increases strongly.

The limiting values of $w$ in Fig. 11, 2-4 $\mathrm{nm}$, are very large relative to the roughness of other surfaces with which we have worked. For instance, Fig. 11B compares data for the pseudo-ten-fold and two-fold Al-Pd-Zn surfaces with data for a $\mathrm{Zr}-\mathrm{Ni}-\mathrm{Cu}-\mathrm{Al}$

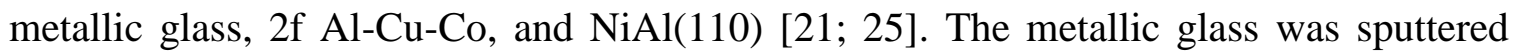
with $\mathrm{Ar}^{+}$ions for 21 minutes at $1.5 \mathrm{keV}$ energy, with the incident beam normal $\left(90^{\circ}\right)$ to the surface at $\mathrm{T}=300 \mathrm{~K}$. After both samples were sputtered, it was then held at $520 \mathrm{~K}$ for two hours. Both sides of the two-fold Al-Pd-Zn sample were rougher than the glass by at least a factor of two. The glass consisted of metals with relatively low vapor pressures. This suggests that in the approximant, segregation and/or sublimation of $\mathrm{Zn}$ substantially enhances surface roughness. This would also explain the fact that the approximants surface roughness does not decrease with increasing temperature, as expected; the contribution from segregation and/or sublimation would increase with increasing temperature. This would also explain why the roughness is less after sputtering, but before annealing, than at high annealing temperatures. STM settings, such as tunneling current and tip bias voltage did not affect $w$ which is shown in Table 4 .

\section{Surface Oxidation}

In this set of experiments, our goal was to determine which elements in the quasicrystal were most prone to oxidation. In other studies of Al-rich quasicrystals and 
their approximants, it had been found that $\mathrm{Al}$ was usually the only metal to oxidize upon exposure to oxygen or dry air. The $\mathrm{Al}$ formed a passivating layer of pure or nearly-pure alumina, accompanied by some segregation of $\mathrm{Al}$ even at room temperature.

In the experiments with $\mathrm{Al}-\mathrm{Pd}-\mathrm{Zn}$, the surface was oxidized under two conditions. The most gentle condition, corresponding to the lowest chemical potential of oxygen, was exposure of the clean surface to a low pressure of oxygen in UHV. The most aggressive condition, corresponding to the highest chemical potential of oxygen, was exposure of the polished surface to air.

\subsection{Oxidation in $U H V$}

The 10f sample was first cleaned by $\mathrm{Ar}^{+}$sputtering, then annealed at $440 \mathrm{~K}$ for 20 minutes. After the sample had been cooled to room temperature, it was exposed to $\mathrm{O}_{2}$ in the following sequence: $0.2 \mathrm{~L}, 1 \mathrm{~L}, 10 \mathrm{~L}, 100 \mathrm{~L}$, and $200 \mathrm{~L}$ for a total of $300 \mathrm{~L}$. Before and after each exposure, the XP spectrum was recorded. In between the $100 \mathrm{~L}$ and $200 \mathrm{~L}$ $\mathrm{O}_{2}$ exposures, the sample was annealed at $430 \mathrm{~K}$ for 20 minutes. The XP spectra are shown in Fig. 12, and the surface composition as a function of $\mathrm{O}_{2}$ exposure is given in Table 5. In order to make sure oxygen was exposed on the surface, a ratio was taken between the $\mathrm{O}$ 1s and $\mathrm{Pd} 3 \mathrm{p}$ peak with the pure Pd 3d peak. As expected, the ratio increased from 0.42 at $0 \mathrm{~L}$ of $\mathrm{O}_{2}$ to 0.57 at $300 \mathrm{~L}$ of $\mathrm{O}_{2}$.

Figure $12 \mathrm{~A}$ shows the progression of the $\mathrm{Zn} 2 \mathrm{p}_{3 / 2}$ peak. Between the initial spectrum and the one after $300 \mathrm{~L}$ exposure, there was no distinguishable change in the position or shape, indicating that $\mathrm{Zn}$ did not oxidize. However, the intensity decreased with oxygen adsorption, because $\mathrm{Zn}$ was increasingly screened by an upper aluminum 
oxide layer (see below). Figure 12B shows the region of the spectrum that encompassed the $P d 3 d_{3 / 2}$ and $3 d_{5 / 2}$ peaks. There was no detectable shift or change in shape of the Pd $3 d_{3 / 2,5 / 2}$ peaks. Therefore, the Pd did not oxidize under these conditions. This is not surprising, since oxidation of Al-Pd-Mn quasicrystals has been thoroughly studied, and Pd has never been found to oxidize under any conditions in that system.

The oxygen 1s peak has a binding energy of $532 \mathrm{eV}$, which overlaps the $\mathrm{Pd} 3 \mathrm{p}_{3 / 2}$ at a binding energy of $531 \mathrm{eV}$. This region of the spectrum is shown in Fig. 12C. In order to see if there was any oxygen on the surface, a clean XPS spectrum was used to find the basis area ratio in the $\mathrm{Pd} 3 \mathrm{p}_{3 / 2}$ peak and the $\mathrm{Pd} 3 \mathrm{~d}$ peak. When oxygen was being exposed on the surface, an area ratio was performed by using the overlap of $(\mathrm{O} 1 \mathrm{~s}$ and $\mathrm{Pd}$ $\left.3 \mathrm{p}_{3 / 2}\right)$ and the $\mathrm{Pd} 3 \mathrm{~d}$ peaks. The $\mathrm{O} 1 \mathrm{~s}$ contribution was then carried out by the difference between the two ratios. The $\mathrm{O} 1 \mathrm{~s}$ contribution to $\left(\mathrm{O} 1 \mathrm{~s}\right.$ and $\left.\mathrm{Pd} 3 \mathrm{p}_{3 / 2}\right)$ area is shown in Fig. 13 as a function of $\mathrm{O}_{2}$ exposure. The $\mathrm{O} 1 \mathrm{~s}$ contribution increased, indicating the surface was oxidized. A close-up view from $0 \mathrm{~L}$ to $20 \mathrm{~L}$ of oxygen exposure is also shown in Fig. 13. The oxygen adsorbed species increased over a period of time until it reached full saturation. This took about $10 \mathrm{~L}$ of oxygen exposure. However, this trend was interrupted at $100 \mathrm{~L}$ of oxygen exposure since the surface was annealed at $430 \mathrm{~K}$ for 20 minutes and was then cooled down to $300 \mathrm{~K}$. Exposing $200 \mathrm{~L}$ of oxygen onto the surface did not increase the $\mathrm{O} 1 \mathrm{~s}$ contribution. Hence, the surface was already saturated by oxygen.

Figure $12 \mathrm{D}$ shows that the $\mathrm{Al} 2 \mathrm{p}$ peak initially had a shoulder at high binding energy, and this shoulder increased in relative intensity as oxygen exposure increased. The clean Al 2p peak had a binding energy of $72.7 \mathrm{eV}$. After $300 \mathrm{~L} \mathrm{O}_{2}$ had been exposed 
on the surface, the Al 2p peak had a binding energy of $72.5 \mathrm{eV}$. However, a shoulder was seen on the left side of the $\mathrm{Al} 2 \mathrm{p}$ peak. The shoulder had a higher binding energy between $76 \mathrm{eV}$ and $74 \mathrm{eV}$. This indicates that there was some oxidation of Al. It is likely that a thin skin of aluminum oxide formed, and the XPS peak at lower binding energy originated from metallic Al below this oxide layer. Such a situation has been observed in other Al-rich quasicrystals.

\subsection{Air-oxidized sample}

Information is also available from the evolution of XPS peaks as the sample was sputtered, after air exposure. These data are shown in Fig. 14, and they correspond to the depth profile shown in Fig. 5.

As the initial surface was sputtered, the Zn $2 \mathrm{p}_{3 / 2}$ peak in Fig. 14A clearly showed a shift from $1023 \mathrm{eV}(\mathrm{ZnO})$ to $1021.5 \mathrm{eV}(\mathrm{Zn})$, for a total binding energy shift of $1.5 \mathrm{eV}$. The change from $\mathrm{ZnO}$ to $\mathrm{Zn}$ started after 39 minutes of sputtering. As sputtering proceeded, the peak first broadened and then became narrower. Presumably, the broadening was due to coexistence of the $\mathrm{ZnO}$ and $\mathrm{Zn}$ peaks at an intermediate stage. According to the handbook of $\mathrm{x}$-ray photoelectron spectroscopy, the $\mathrm{ZnO}$ peak is in the range between $1021.8 \mathrm{eV}$ and $1022.5 \mathrm{eV}$ while the $\mathrm{Zn} 2 \mathrm{p}$ peak is in the range between $1021.5 \mathrm{eV}$ and $1021.8 \mathrm{eV}$ [26]. This matched closely with our results. We therefore conclude that $\mathrm{Zn}$ oxidized as a result of air exposure, in contrast to exposure in UHV.

Figure $14 \mathrm{~B}$ shows that the $\mathrm{Pd} 3 \mathrm{~d}_{3 / 2}$,5/2 peaks are invariant during sputtering (held constant at $336 \mathrm{eV}$ ), except for an increase in intensity which can presumably be attributed to removal of a blanketing oxide. The handbook of x-ray photoelectron 
spectroscopy showed the $\mathrm{Pd} 3 \mathrm{~d}$ peak between $335.1 \mathrm{eV}$ and $335.5 \mathrm{eV}$ and $\mathrm{PdO}$ between $336.2 \mathrm{eV}$ and $336.7 \mathrm{eV}$ [26]. This indicates that Pd does not oxidize, even in air.

Figure $14 \mathrm{C}$ shows a clear shift in the $\mathrm{Al} 2 \mathrm{p}$ peak position, from $75 \mathrm{eV}\left(\mathrm{Al}_{2} \mathrm{O}_{3}\right)$ to $72.5 \mathrm{eV}$ (Al metal), for a total binding energy shift of $2.5 \mathrm{eV}$. The handbook of x-ray photoelectron spectroscopy had $\mathrm{Al} 2 \mathrm{p}$ between $72.5 \mathrm{eV}$ and $73 \mathrm{eV}$ and $\mathrm{Al}_{2} \mathrm{O}_{3}$ between $73.5 \mathrm{eV}$ and $74.8 \mathrm{eV}$ [26]. Our results matched perfectly well with the XPS handbook. The shift from $\mathrm{Al}_{2} \mathrm{O}_{3}$ to $\mathrm{Al}$ was detectable after 54 minutes of sputtering. The predominance of the $\mathrm{Al}_{2} \mathrm{O}_{3}$ peak on the initial surface indicates that the surface was more extensively oxidized (the oxide was thicker) in air, than after $300 \mathrm{~L} \mathrm{O}_{2}$ exposure in UHV (Fig. 12D). Again, this is similar to observations previously reported for other Al-rich quasicrystals [27-29].

Note that $\mathrm{ZnO}$ began shifting to $\mathrm{Zn}$ earlier than $\mathrm{Al}$ oxide began shifting to $\mathrm{Al}$. This suggests that the $\mathrm{Zn}$ oxide was thinner than the $\mathrm{Al}$ oxide, and in fact the two coexisted at the top of the surface layer. It is probable the oxide was a chemically-mixed $(\mathrm{Al}, \mathrm{Zn})$ oxide, rather than consisting of distinct domains of $\mathrm{Zn}$ and $\mathrm{Al}$ oxides. We suggest that the compositional sequence from the top was: Mixed $\mathrm{Zn}$ and $\mathrm{Al}$ oxides, then Al oxide plus metallic $\mathrm{Zn}$, then metallic $\mathrm{Al}, \mathrm{Zn}$, and $\mathrm{Pd}$.

\subsection{Comparison between oxidation conditions}

After UHV oxygen exposure, there was partial oxidation of Al, but no detectable oxidation of $\mathrm{Zn}$ or $\mathrm{Pd}$. After air exposure, there was oxidation of both $\mathrm{Al}$ and $\mathrm{Zn}$, but not $\mathrm{Pd}$. This suggests that the elements are most susceptible to oxidation in the sequence $\mathrm{Al}>$ $\mathrm{Zn}>\mathrm{Pd}$. This hypothesis is consistent with the sequence of enthalpies of formation of 
oxides of $\mathrm{Al}, \mathrm{Zn}$, and $\mathrm{Pd}$. At room temperature, they are: $-1632 \mathrm{~kJ} / \mathrm{mol}$ for $\mathrm{Al}_{2} \mathrm{O}_{3},-348$ $\mathrm{kJ} / \mathrm{mol}$ for $\mathrm{ZnO}$, and $-85 \mathrm{~kJ} / \mathrm{mol}$ for $\mathrm{PdO}$ [30]. The heat of formation per M-O bond of aluminum oxide, palladium oxide, and zinc oxide are: $5.20 \mathrm{eV}, 2.47 \mathrm{eV}$, and $2.60 \mathrm{eV}$ [31]. These numbers were arrived by taking the bond energy and dividing it by the number of bonds. This was then converted from $\mathrm{kJ} / \mathrm{mol}$ to $\mathrm{eV}$. Studies of other Al-rich quasicrystals such as Al-Cr-Fe, Al-Cu-Fe, Al-Pd-Mn, and Al-Cu-Fe-Cr all show Al to be the only metal that oxidizes in vacuum. ${ }^{12}$

Table 6A provides the surface compositions of Al-Pd-Zn after oxidation under the two conditions, as well as the compositions of the clean surface and the bulk. For comparison, Table 6B lists the surface compositions of Al-Pd-Mn under the same two conditions. These comparisons show that oxidation of Al-Pd-Zn, both in air and in vacuum, causes stronger enrichment in $\mathrm{Al}$, than does oxidation of Al-Pd-Mn. For instance, after $300 \mathrm{~L}$ exposure at room temperature in vacuum, the Al-Pd-Mn sample is $+3 \%$ enriched in $\mathrm{Al}$ relative to the bulk composition, and the $\mathrm{Al}-\mathrm{Pd}-\mathrm{Zn}$ sample is $+21 \%$ enriched in $\mathrm{Al}$ relative to the bulk composition. The reason for this difference in response is not clear.

\section{Conclusions}

The main goal of this study was to determine whether the Al-Pd-Zn approximant could be prepared with a surface morphology that would lend itself to surface structure determination. Our conclusion is that it cannot. The reason is that $\mathrm{Zn}$ strongly segregates to the surface, and evaporates at relatively low temperature (detectable in the gas phase at 
$600 \mathrm{~K}) . \mathrm{Zn}$ segregation and evaporation occur before the surface and near-surface region can rearrange into the necessary terrace-step morphology. It appears that $\mathrm{Zn}$ segregation and/or evaporation exacerbate the surface roughness. This conclusion rests partly upon the fact that the surface did not become smoother as temperature increased above room temperature (and $\mathrm{Zn}$ segregation, and eventually $\mathrm{Zn}$ evaporation, set in). In fact, in one case the surface became rougher upon annealing. This conclusion is also based upon comparison with the surface roughness of a metallic glass that had been sputtered and annealed similarly — the glass was less than half as rough as the approximant. We can also conclude that $\mathrm{Zn}$ is bonded very weakly in the approximant, perhaps as weakly as in elemental $\mathrm{Zn}$. This is based upon several observations. The first is the high vapor pressure of $\mathrm{Zn}$, which we estimate to be about $10^{-4}$ Torr above the approximant at $600 \mathrm{~K}$. This is the same order-of-magnitude as the vapor pressure above elemental $\mathrm{Zn}$ at $600 \mathrm{~K}$. The second is the preferential sputtering of $\mathrm{Zn}$. Preferential sputtering is favored by good mass-match with the incident ion, and weak bonding in the solid. In other Al-rich quasicrystals, $\mathrm{Al}$ is always removed preferentially, but in this material it is $\mathrm{Zn}$, even though $\mathrm{Zn}$ is a worse mass-match to the $\mathrm{Ar}^{+}$ion than Al. Therefore, the preferential sputtering of $\mathrm{Zn}$ must be due to its weak bonding in the solid. The third is the fact that $\mathrm{Zn}$ segregates to the surface. In general, three factors promote surface segregation of one metal over other constituents in an alloy: Large atomic radius, low surface energy, and low bond energy in the alloy. $\mathrm{Zn}$ is actually the smallest of the atoms in $\mathrm{Al}-\mathrm{Pd}-\mathrm{Zn}$, so size is not responsible. Elemental $\mathrm{Zn}$ has the lowest surface energy, but it is only slightly lower than $\mathrm{Al}\left(0.99 \mathrm{~J} / \mathrm{m}^{2}\right.$ for the close-packed surface of $\mathrm{Zn}$ vs. $1.2 \mathrm{~J} / \mathrm{m}^{2}$ for $\mathrm{Al}$ and 1.9 
$\mathrm{J} / \mathrm{m}^{2}$ for $\mathrm{Pd}$ ) [32]. It is reasonable that low cohesive energy also promotes the segregation of $\mathrm{Zn}$ in this system.

Finally, we find that under mild oxidation conditions $\left(10^{-8}-10^{-7}\right.$ Torr $\mathrm{O}_{2}$ at room temperature), $\mathrm{Al}$ is the only metal to oxidize. Under harsher conditions (air at room temperature), $\mathrm{Al}$ and $\mathrm{Zn}$ both form oxides, and the oxide is thicker. Oxidized $\mathrm{Zn}$ is more localized at the surface than oxidized Al. Comparing the results from the two types of oxidation experiments, the propensity for oxidation in this material must be $\mathrm{Al}>\mathrm{Zn}>\mathrm{Pd}$, which is consistent with thermodynamic data for the pure oxides.

\section{Acknowledgements}

This work was supported by the Office of Science, Basic Energy Sciences, Materials Sciences and Engineering Division of the US Department of Energy (USDOE). This manuscript has been authorized by Iowa State University of Science and Technology under Contract No. DE-AC02-07CH11358 with the US Department of Energy. We are indebted to Srinivasa Thimmaiah and Gordon Miller for allowing us to collaborate on their newly discovered phase. We thank William Yuhasz, James Anderegg and Srinivasa Thimmaiah for growing and characterizing the bulk samples. 


\section{$\underline{\text { References }}$}

[1] P.A. Thiel, Progress in Surface Science 75 (2004) 69-86.

[2] H.R. Sharma, M. Shimoda, A.P. Tsai, Advances in Physics 56 (2007) 403-464.

[3] K. Chattopadhyay, S. Ranganathan, G.N. Subbanna, N. Thangaraj, Scripta Metallurgica 19 (1985) 767-771.

[4] L. Bendersky, Physical Review Letters 55 (1985) 1461-1463.

[5] V. Fournee, P.A. Thiel, Journal of Physics D-Applied Physics 38 (2005) R83R106.

[6] V. Fournée, J. Ledieu, P.A. Thiel, Journal of Physics: Condensed Matter 20 (2008).

[7] J.Y. Park, P.A. Thiel, Journal of Physics-Condensed Matter 20 (2008) --

[8] J.M. Dubois, V. Fournee, P.A. Thiel, E. Belin-Ferre, Journal of PhysicsCondensed Matter 20 (2008) -.

[9] D. Rouxel, P. Pigeat, Progress in Surface Science 81 (2006) 488-514.

[10] A.I. Goldman, R.F. Kelton, Reviews of Modern Physics 65 (1993) 213-230.

[11] L. Barbier, D. Gratias, Progress in Surface Science 75 (2004) 177-189.

[12] Z. Papadopolos, G. Kasner, J. Ledieu, E.J. Cox, N.V. Richardson, Q. Chen, R.D. Diehl, T.A. Lograsso, A.R. Ross, R. McGrath, Physical Review B 66 (2002) 184207.

[13] H.R. Sharma, V. Fournée, M. Shimoda, A.R. Ross, T.A. Lograsso, A.P. Tsai, A. Yamamoto, Physical Review Letters 93 (2004) 165502.

[14] T. Cai, V. Fournée, T. Lograsso, A. Ross, P.A. Thiel, Physical Review B 65 (2002) 140202. 
[15] H.R. Sharma, M. Shimoda, K. Sagisaka, H. Takakura, J.A. Smerdon, P.J. Nugent, R. McGrath, D. Fujita, S. Ohhashi, A.P. Tsai, Physical Review B Submitted (2009).

[16] Samples were synthesized at the Materials Preparation Center, Ames Laboratory USDOE, Ames, IA, USA.

[17] G.W. Burns, M.G. Scroger, G.F. Strouse, M.C. Croarkin, W.F. Guthrie, National Institute of Standards and Technology Monograph 175 (1993) 630.

[18] I. Horcas, R. Fernandez, J.M. Gomez-Rodriguez, J. Colchero, J. Gomez-Herrero, A.M. Baro, Review of Scientific Instruments 78 (2007) -.

[19] See www.CasaXPS.com.

[20] C.J. Jenks, J.W. Burnett, D.W. Delaney, T.A. Lograsso, P.A. Thiel, Applied Surface Science 157 (2000) 23-28.

[21] T. Duguet, et al., Physical Review B 80 (2009) 024201.

[22] O. Groening, R. Widmer, P. Ruffieux, P. Groening, Philosophical Magazine 86 (2006) 773.

[23] J.Y. Park, D.F. Ogletree, M. Salmeron, R.A. Ribeiro, P.C. Canfield, C.J. Jenks, P.A. Thiel, Physical Review B 72 (2005) 220201.

[24] I. Heyvaert, J. Krim, C. Van Haesendonck, Y. Bruynseraede, PRE 54 (1996) 349.

[25] D.P. Jing, B. Unal, F.L. Qin, C. Yuen, J.W. Evans, C.J. Jenks, D.J. Sordelet, P.A. Thiel, Thin Solid Films 517 (2009) 6486-6492.

[26] J.F. Moulder, W.F. Stickle, P.E. Sobol, K.D. Bomben, Handbook of X-ray Photoelectron Spectroscopy: a reference book of standard spectra for identification and interpretation of XPS data, Perkin-Elmer Corporation, Physical Electronics Division, Eden Prairie, Minnesota, 1992. 
[27] S.L. Chang, J.W. Anderegg, P.A. Thiel, Journal of Non-Crystalline Solids 195 (1996) 95-101.

[28] P.J. Pinhero, J.W. Anderegg, D.J. Sordelet, M. Besser, P.A. Thiel, Philosophical Magazine B 79 (1999) 91.

[29] V. Demange, J.W. Anderegg, J. Ghanbaja, F. Machizaud, D.J. Sordelet, M. Besser, P.A. Thiel, J.M. Dubois, Applied Surface Science 173 (2001) 327-338.

[30] D.D. Wagman, W.H. Evans, V.B. Parker, R.H. Schumm, I. Halow, S.M. Bailey, K.L. Churney, R.L. Nuttall, The NBS tables of chemical thermodynamic properties: Selected values for inorganic and C1 and C2 organic substances in SI units, American Chemical Society and American Institute of Physics, Washington D.C., 1982.

[31] CRC Handbook of chemistry and physics, CRC Press, Boca Raton, Fla., 2002.

[32] L. Vitos, A.V. Ruban, H.L. Skriver, J. Kollar, Surface Science 411 (1998) 186202. 


\section{$\underline{\text { Figure Captions }}$}

\section{Figure 1}

A decagonal quasicrystal has three families of high-symmetry axes: a single periodic tenfold (10f) axis and two groups of five aperiodic twofold (2f) axes. (a) is a schematic diagram of a decagonal quasicrystal; (b) Al-Pd-Zn decagonal quasicrystal which was grown by William Yuhasz at the Materials Preparation Center, Ames Laboratory USDOE, Ames, Iowa USA.

\section{Figure 2}

A piece of Al-Pd-Zn sample was heated in a tested chamber in order to measure the effective pressure of $\mathrm{Zn}$ as a function of sample temperature. At $600 \mathrm{~K}$, the gas-phase of $\mathrm{Zn}$ rose above its baseline of $5 \times 10^{-10}$ Torr.

\section{Figure 3}

A schematic diagram of the Al-Pd-Zn samples. (a) a 10f Al-Pd-Zn polygrained sample, where a marked area is a single grain as noted by "S"; (b) a $2 \mathrm{f} \mathrm{Al-Pd-Zn} \mathrm{single} \mathrm{grained}$ sample, where a fracture line appeared in the middle, the left region noted as "Side A" and the right "Side B".

\section{Figure 4}

XP survey spectra of the $10 \mathrm{f}$ and $2 \mathrm{f}$ samples. (a) 10f initial survey spectrum after it was introduce from air to UHV; (b) clean 10f final survey spectrum after 204 minutes of sputtering; (c) $2 \mathrm{f}$ initial survey spectrum after it was introduce from air to UHV; (d) clean $2 \mathrm{f}$ final survey spectrum after 40 minutes of sputtering.

\section{Figure 5}

XPS depth profile of $\mathrm{Al}, \mathrm{Pd}$, and $\mathrm{Zn}$ after the $10 \mathrm{f}$ sample was introduced from air to UHV.

\section{Figure 6}

Variable temperature annealing: Compositional evolution from XPS. (a) a 10f Al-Pd-Zn sample was annealed at temperatures of $380 \mathrm{~K}, 430 \mathrm{~K}, 460 \mathrm{~K}$, and $510 \mathrm{~K}$ for 2 hours while the final cycle was annealed at a temperature of $540 \mathrm{~K}$ for 10 minutes; (b) a $2 \mathrm{f} \mathrm{Al-}$ Pd-Zn sample was annealed at temperatures of $380 \mathrm{~K}, 430 \mathrm{~K}, 470 \mathrm{~K}$, and $510 \mathrm{~K}$ for 2 hours. The error bars in (a) and (b) at $300 \mathrm{~K}$ represent the range of surface concentrations after five similar sputtering preparations.

\section{Figure 7}

Constant temperature annealing: Compositional evolution from XPS. (a) a 10f Al-Pd-Zn sample was annealed at a constant temperature of $460 \mathrm{~K}$ for every 30 minutes; (b) a $2 \mathrm{f}$ Al-Pd-Zn sample was annealed at a constant temperature of $480 \mathrm{~K}$ at different annealing times of 30 minutes, 60 minutes, 90 minutes, and 120 minutes. 


\section{Figure 8}

STM images of a $10 \mathrm{f} \mathrm{Al-Pd-Zn} \mathrm{sample} \mathrm{that} \mathrm{was} \mathrm{annealed} \mathrm{at} \mathrm{given} \mathrm{temperatures} \mathrm{for} 15$ minutes and then cooled down to $300 \mathrm{~K}$. All images are $250 \times 250 \mathrm{~nm}$. The tunneling conditions are (a) $\mathrm{I}=0.5 \mathrm{nA}$ and $\mathrm{V}$-tip $=-1 \mathrm{~V}$; (b) $\mathrm{I}=0.2 \mathrm{nA}$ and $\mathrm{V}$-tip $=-1 \mathrm{~V}$; and (c) I $=0.2 \mathrm{nA}$ and $\mathrm{V}$-tip $=-1 \mathrm{~V}$.

\section{Figure 9}

STM imaging of a $2 \mathrm{f} \mathrm{Al-Pd-Zn} \mathrm{sample} \mathrm{that} \mathrm{was} \mathrm{annealed} \mathrm{at} \mathrm{given} \mathrm{temperatures} \mathrm{for} 2$ hours and then cooled down to $300 \mathrm{~K}$. Side A (left side of the fracture) are figures (a) and (c) while Side B (right side of the fracture) are figures (b) and (d). All images are $250 \mathrm{~nm} \times 250 \mathrm{~nm}$. The tunneling conditions for all images are $\mathrm{I}=0.5 \mathrm{nA}$ and V-tip $=-1$ V.

\section{Figure 10}

STM images and line profiles of the $2 f$ sample (a) through (f). The $2 f$ sample was annealed at $520 \mathrm{~K}$ for 2 hours and then cooled down to $300 \mathrm{~K}$ for STM. STM figure sizes are as follows: (a) $100 \mathrm{~nm} \times 100 \mathrm{~nm}$, (b) $73 \mathrm{~nm} \times 73 \mathrm{~nm}$, (c) $87 \mathrm{~nm} \times 87 \mathrm{~nm}$, (d) $87 \mathrm{~nm} \times$ $87 \mathrm{~nm}$, (e) $85 \mathrm{~nm} \times 85 \mathrm{~nm}$, and (f) $108 \mathrm{~nm} \times 108 \mathrm{~nm}$. The tunneling conditions for all images are $\mathrm{I}=0.5 \mathrm{nA}$ and $\mathrm{V}$-tip $=-1 \mathrm{~V}$.

\section{Figure 11}

Annealing results for the $10 \mathrm{f}$ and $2 \mathrm{f}$ samples. (a) a $10 \mathrm{f} \mathrm{Al-Pd-Zn} \mathrm{sample} \mathrm{was} \mathrm{held} \mathrm{at} \mathrm{the}$ given temperature for 15 minutes, then cooled to $300 \mathrm{~K}$ for STM imaging; (b) a $2 \mathrm{f} \mathrm{Al-Pd-}$ Zn sample was held at the given temperature for 2 hours, then cooled to $300 \mathrm{~K}$ for STM imaging; (c) both the $2 \mathrm{f} \mathrm{Al-Pd-Zn}$ and the $\mathrm{Zr}-\mathrm{Ni}-\mathrm{Cu}-\mathrm{Al}$ metallic glass samples were annealed at $520 \mathrm{~K}$ for 2 hours, then cooled down to $300 \mathrm{~K}$ for STM imaging.

\section{Figure 12}

XP spectra for oxidation in UHV. (a) Zn 2p; (b) Pd 3d; (c) O 1s and Pd 3p; (d) Al 2p. Oxygen exposure is indicated by numbers. (1) clean surface; (2) $0.2 \mathrm{~L} \mathrm{O}_{2}$; (3) $1 \mathrm{~L} \mathrm{O}_{2}$; (4) $10 \mathrm{~L} \mathrm{O}_{2}$; (5) $100 \mathrm{~L} \mathrm{O}_{2}$; (6) annealed at $430 \mathrm{~K}$ for 20 minutes, then cooled down to $300 \mathrm{~K}$; (7) $300 \mathrm{~L} \mathrm{O}_{2}$.

\section{Figure 13}

$\mathrm{O} 1 \mathrm{~s}$ contribution to the $\left(\mathrm{O} 1 \mathrm{~s}\right.$ and $\left.\mathrm{Pd} 3 \mathrm{p}_{3 / 2}\right)$ area as a function of $\mathrm{O}_{2}$ exposure. A close up view is shown as well between $0 \mathrm{~L}$ to $20 \mathrm{~L}$ of $\mathrm{O}_{2}$ exposure.

\section{Figure 14}

XP air-oxidized spectra after the 10 sample was introduce from air to UHV. (a) $\mathrm{Zn} 2 \mathrm{p}_{3 / 2}$; (b) Pd 3d; (c) Al 2p. 


\section{Tables}

\section{Table 1}

Final surface composition of $\mathrm{Al}, \mathrm{Pd}$, and $\mathrm{Zn}$ for the $10 \mathrm{f}$ and $2 \mathrm{f}$ samples after several cycles of sputtering. Bulk composition is also shown as reference.

\begin{tabular}{|l|c|c|c|}
\hline & Al & Pd & Zn \\
\hline 10f (204 minutes) & $67 \%$ & $30 \%$ & $3 \%$ \\
\hline 2f (40 minutes) & $62 \%$ & $32 \%$ & $6 \%$ \\
\hline Bulk & $57 \%$ & $30 \%$ & $13 \%$ \\
\hline
\end{tabular}

Table 2

Variable temperature annealing: compositional evolution from XPS. The final compositions for the $10 \mathrm{f}$ and $2 \mathrm{f}$ samples that was annealed at given temperatures and was then cooled down to $300 \mathrm{~K}$.

\begin{tabular}{|l|c|c|c|}
\hline & Al & Pd & Zn \\
\hline $\mathbf{1 0 f}(\mathbf{5 4 0} \mathbf{~ K})$ & $49 \%$ & $21 \%$ & $30 \%$ \\
\hline $\mathbf{2 f}(\mathbf{5 1 3} \mathbf{~ K})$ & $53 \%$ & $14 \%$ & $33 \%$ \\
\hline Bulk & $57 \%$ & $30 \%$ & $13 \%$ \\
\hline
\end{tabular}


Table 3

Constant temperature annealing: compositional evolution from XPS. The final compositions for the $10 \mathrm{f}$ and $2 \mathrm{f}$ samples that was annealed at given temperatures and was then cooled down to $300 \mathrm{~K}$.

\begin{tabular}{|l|c|c|c|}
\hline & Al & Pd & Zn \\
\hline $\mathbf{1 0 f}(\mathbf{4 6 0} \mathbf{~ K})$ & $52 \%$ & $22 \%$ & $26 \%$ \\
\hline $\mathbf{2 f}(\mathbf{4 7 8} \mathbf{K})$ & $58 \%$ & $22 \%$ & $20 \%$ \\
\hline Bulk & $57 \%$ & $30 \%$ & $13 \%$ \\
\hline
\end{tabular}


Table 4

RMS surface roughness held constant at different STM settings such as tunneling current and tip bias voltage.

\begin{tabular}{|l|l|l|l|l|}
\hline Approximant & $\begin{array}{c}\text { Surface Area } \\
(\mathrm{nm} \times \mathrm{nm})\end{array}$ & $\begin{array}{c}\text { Tunneling } \\
\text { Current } \\
(\mathrm{nA})\end{array}$ & $\begin{array}{c}\text { Bias } \\
\text { Voltage (V) }\end{array}$ & $\begin{array}{c}\text { RMS surface } \\
\text { roughness (nm) }\end{array}$ \\
\hline $10 \mathrm{f}$ & $100 \times 100$ & 0.5 & -2 & 0.4953 \\
\hline $10 \mathrm{f}$ & $100 \times 100$ & 0.5 & +2 & 0.6737 \\
\hline $10 \mathrm{f}$ & $100 \times 100$ & 0.5 & +1 & 0.8044 \\
\hline $10 \mathrm{f}$ & $100 \times 100$ & 0.5 & -1 & 0.8337 \\
\hline $2 \mathrm{f}$ & $50 \times 50$ & 0.5 & -1 & 0.3897 \\
\hline $2 \mathrm{f}$ & $50 \times 50$ & 0.5 & +1 & 0.3852 \\
\hline $2 \mathrm{f}$ & $100 \times 100$ & 0.5 & -1 & 0.5860 \\
\hline $2 \mathrm{f}$ & $100 \times 100$ & 0.5 & +1 & 0.5805 \\
\hline $2 \mathrm{f}$ & $500 \times 500$ & 0.5 & -1 & 0.7766 \\
\hline $2 \mathrm{f}$ & $500 \times 500$ & 0.5 & +1 & 0.7969 \\
\hline $2 \mathrm{f}$ & $1000 \times 1000$ & 0.5 & -1 & 0.847 \\
\hline $2 \mathrm{f}$ & $1000 \times 1000$ & 0.5 & +1 & 0.8208 \\
\hline
\end{tabular}


Table 5

Surface composition of $\mathrm{Al}, \mathrm{Pd}$, and $\mathrm{Zn}$ as a function of $\mathrm{O} 2$ exposure when surface was exposed to oxygen in UHV. Bulk composition is also shown as a reference.

\begin{tabular}{|l|c|c|c|}
\hline \multicolumn{1}{|c|}{ O $_{\mathbf{2}}$ Exp. (L) } & Al (\%) & Pd (\%) & Zn (\%) \\
\hline $\mathbf{0}$ & 60 & 33 & 7 \\
\hline $\mathbf{0 . 2}$ & 64 & 30 & 6 \\
\hline $\mathbf{1}$ & 64 & 30 & 5 \\
\hline $\mathbf{1 0}$ & 66 & 29 & 3 \\
\hline $\mathbf{1 0 0}$ & 66 & 31 & 2 \\
\hline $\begin{array}{l}\mathbf{1 0 0} \text { (Annealed at 430 } \\
\text { Cooled 20 minutes, then }\end{array}$ & 69 & 29 & 1 \\
\hline $\mathbf{3 0 0}$ & & & 13 \\
\hline Bulk to 300 K) & 69 & 30 & 30 \\
\hline
\end{tabular}




\section{Table 6A}

Surface composition of $\mathrm{Al}, \mathrm{Pd}$, and $\mathrm{Zn}$ after oxidation under two conditions, as well as the clean surface and the bulk as reference. The percent changed in Al relative to clean surface and the bulk is also shown.

\begin{tabular}{|l|c|c|c|c|c|}
\hline & $\begin{array}{c}\% \\
\mathbf{A l}\end{array}$ & $\begin{array}{c}\% \\
\mathbf{P d}\end{array}$ & $\begin{array}{c}\% \\
\mathbf{Z n}\end{array}$ & $\begin{array}{c}\% \Delta \mathrm{Al} \\
\text { relative to } \\
\text { clean } \\
\text { surface }\end{array}$ & $\begin{array}{c}\% \Delta \mathrm{Al} \\
\text { relative to } \\
\text { bulk }\end{array}$ \\
\hline Bulk Composition & 57 & 30 & 13 & - & - \\
\hline Clean Surface Composition & 60 & 33 & 6.8 & - & - \\
\hline $\begin{array}{l}\text { After exposure to oxygen in } \\
\text { vacuum at 300 K (300 L) }\end{array}$ & 69 & 30 & 1.4 & +15 & +21 \\
\hline After exposure to air at 300 K & 85 & 6.9 & 8.03 & +42 & +49 \\
\hline
\end{tabular}

\section{Table 6B}

Surface composition of $\mathrm{Al}, \mathrm{Pd}$, and $\mathrm{Mn}$ after oxidation under two conditions, as well as the clean surface and the bulk as reference. The percent changed in Al relative to clean surface and the bulk is also shown.

\begin{tabular}{|l|c|c|c|c|c|}
\hline & $\begin{array}{c}\% \\
\mathbf{A l}\end{array}$ & $\begin{array}{c}\% \\
\mathbf{P d}\end{array}$ & $\begin{array}{c}\% \\
\mathbf{M n}\end{array}$ & $\begin{array}{c}\% \Delta \mathrm{Al} \\
\text { relative to } \\
\text { clean } \\
\text { surface }\end{array}$ & $\begin{array}{c}\% \Delta \mathrm{Al} \\
\text { relative to } \\
\text { bulk }\end{array}$ \\
\hline Bulk Composition & 70 & 21 & 9 & - & - \\
\hline Clean Surface Composition & 70.5 & 23.1 & 6.4 & - & - \\
\hline $\begin{array}{l}\text { After exposure to oxygen in } \\
\text { vacuum at 300 K (> 80 L) }\end{array}$ & 72.1 & 21 & 6.9 & +2.3 & +3 \\
\hline After exposure to air at 300 K & 89.5 & 8.3 & 2.2 & +27 & +28 \\
\hline
\end{tabular}




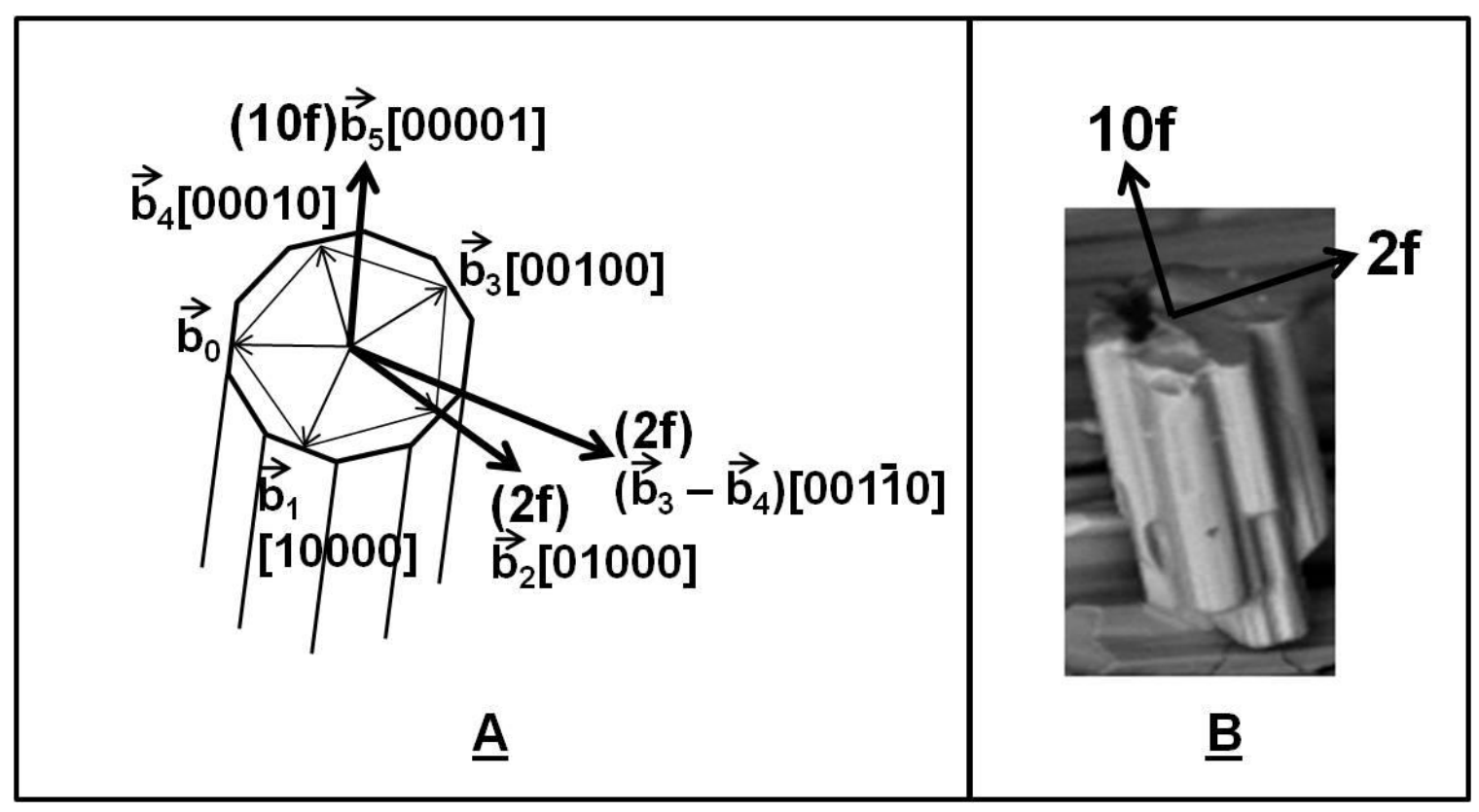

Figure 1 


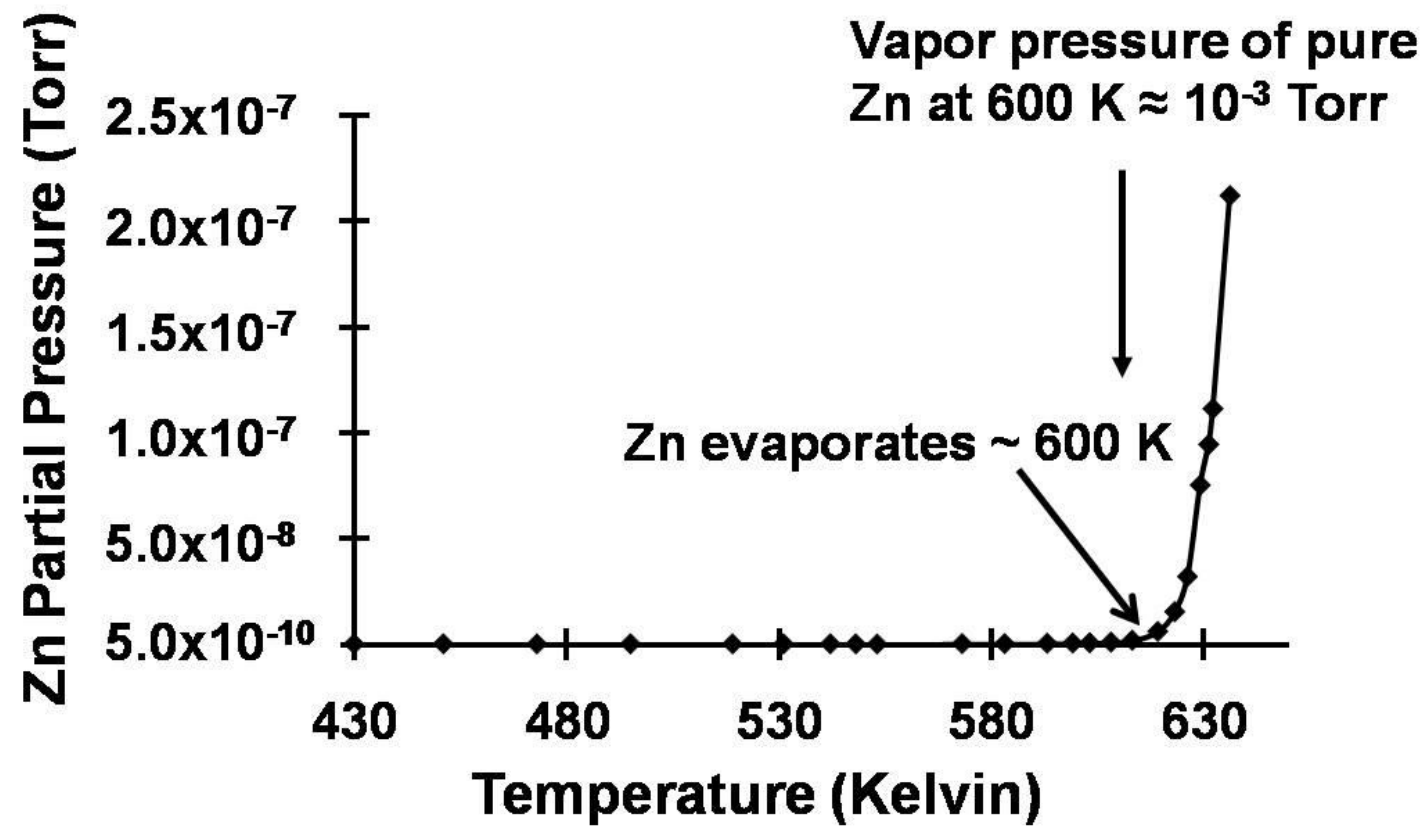

Figure 2 

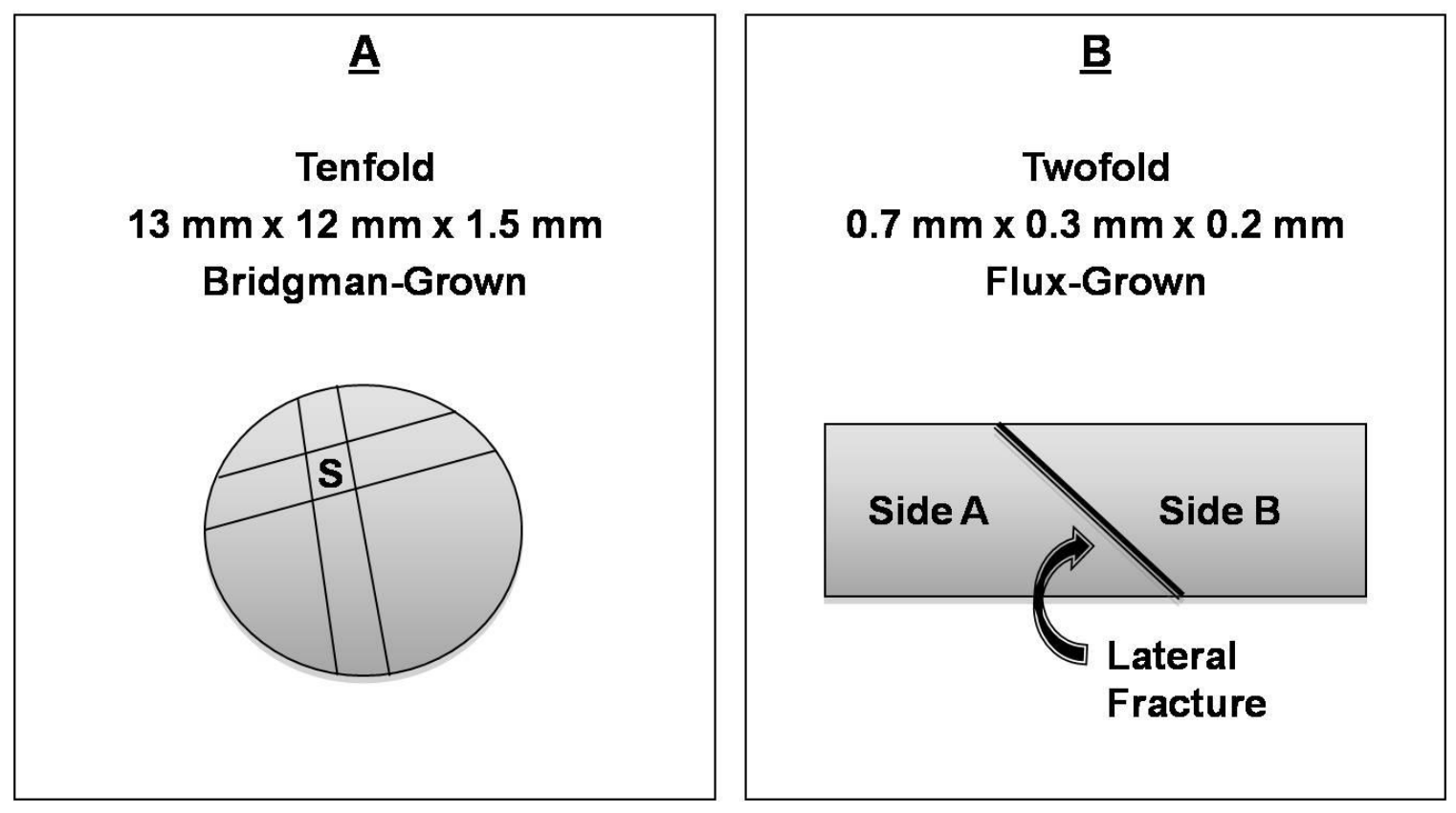

Figure 3 
$\underline{A}$

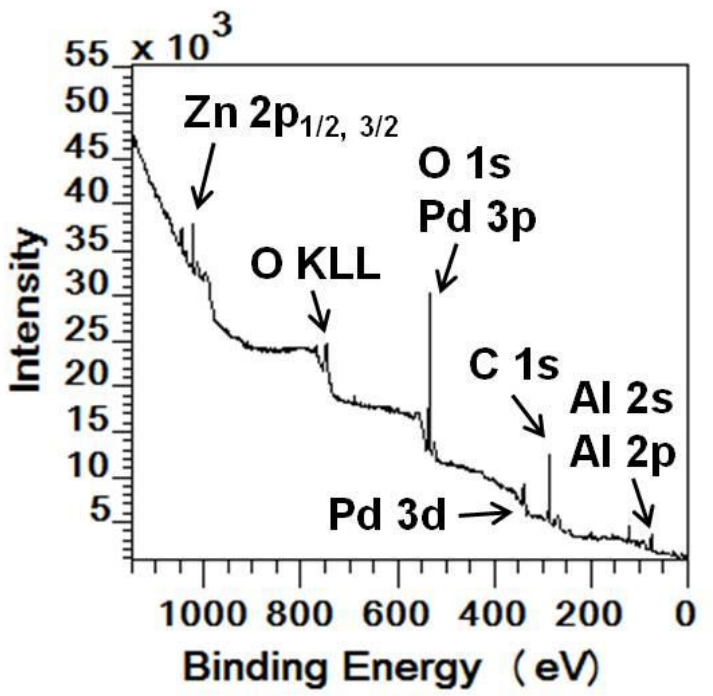

B

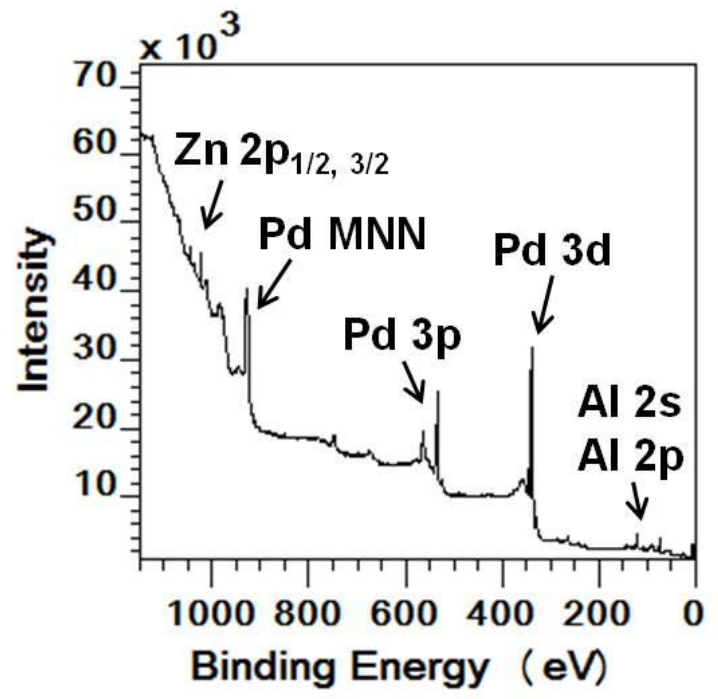

$\underline{\mathrm{C}}$

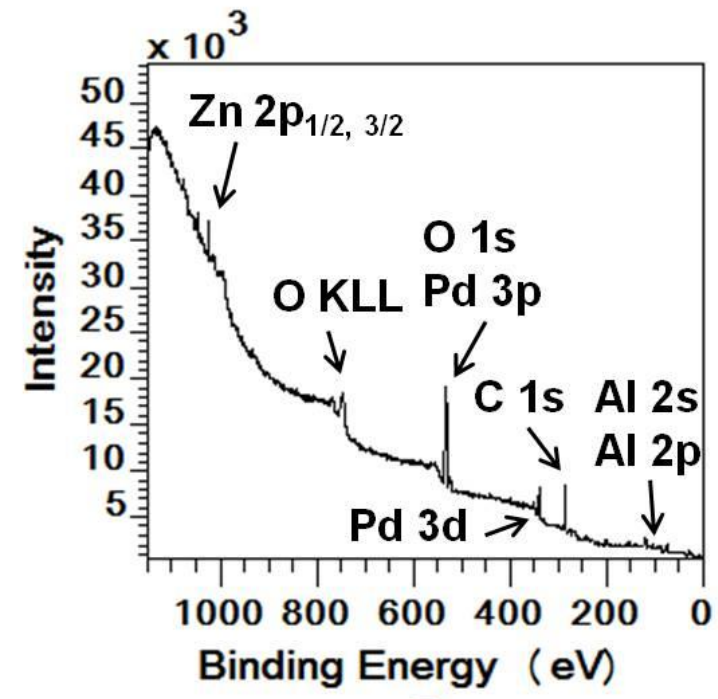

D

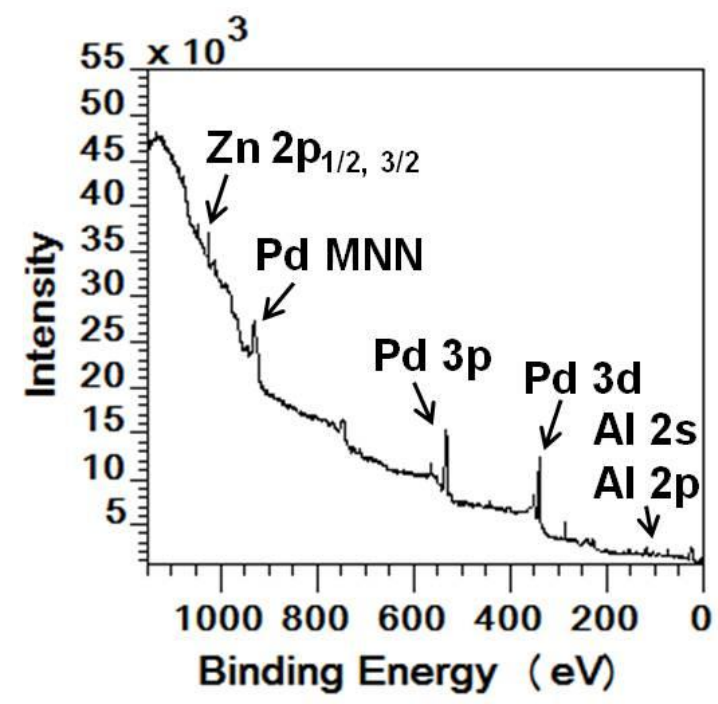

Figure 4 


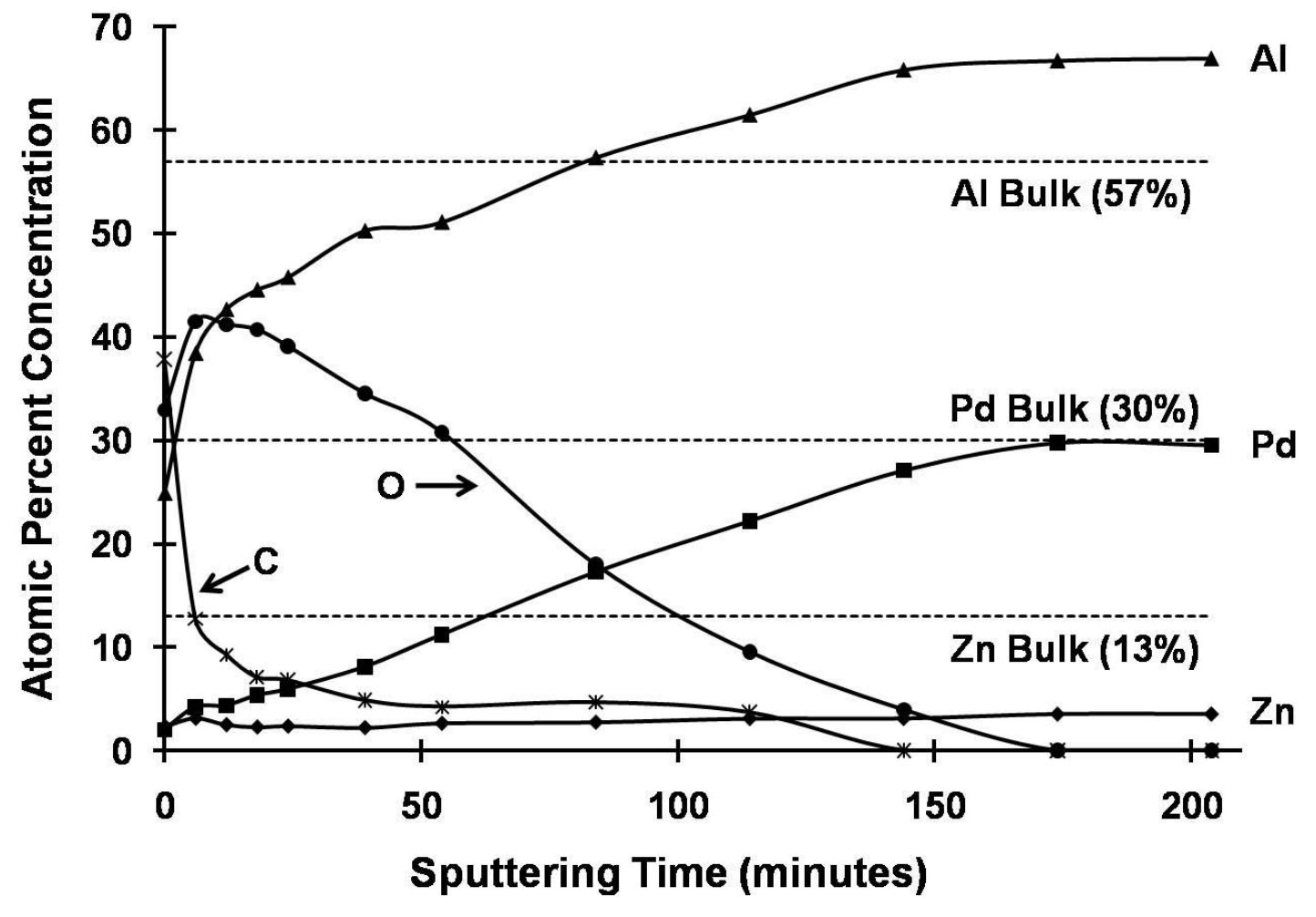

Figure 5 

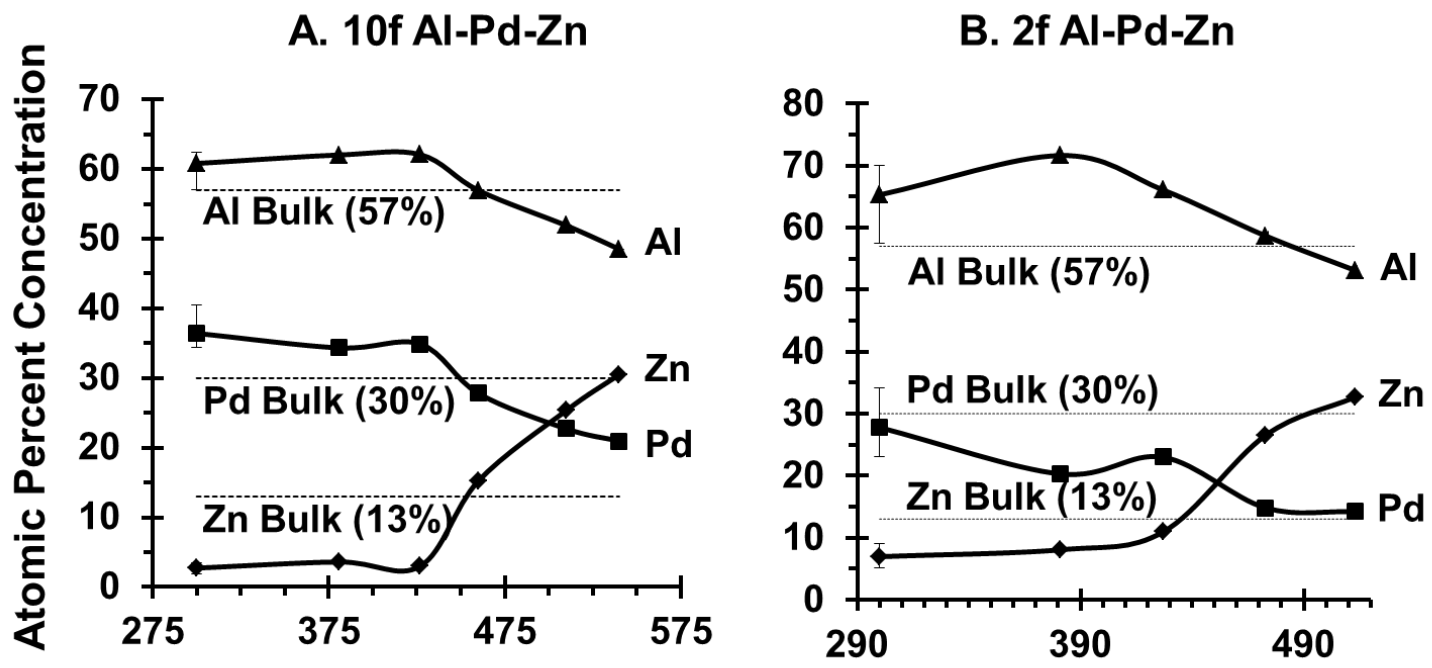

Annealing Temperature (Kelvin)

Figure 6 

A. $10 f \mathrm{Al}-\mathrm{Pd}-\mathrm{Zn}$
B. $2 f \mathrm{Al}-\mathrm{Pd}-\mathrm{Zn}$

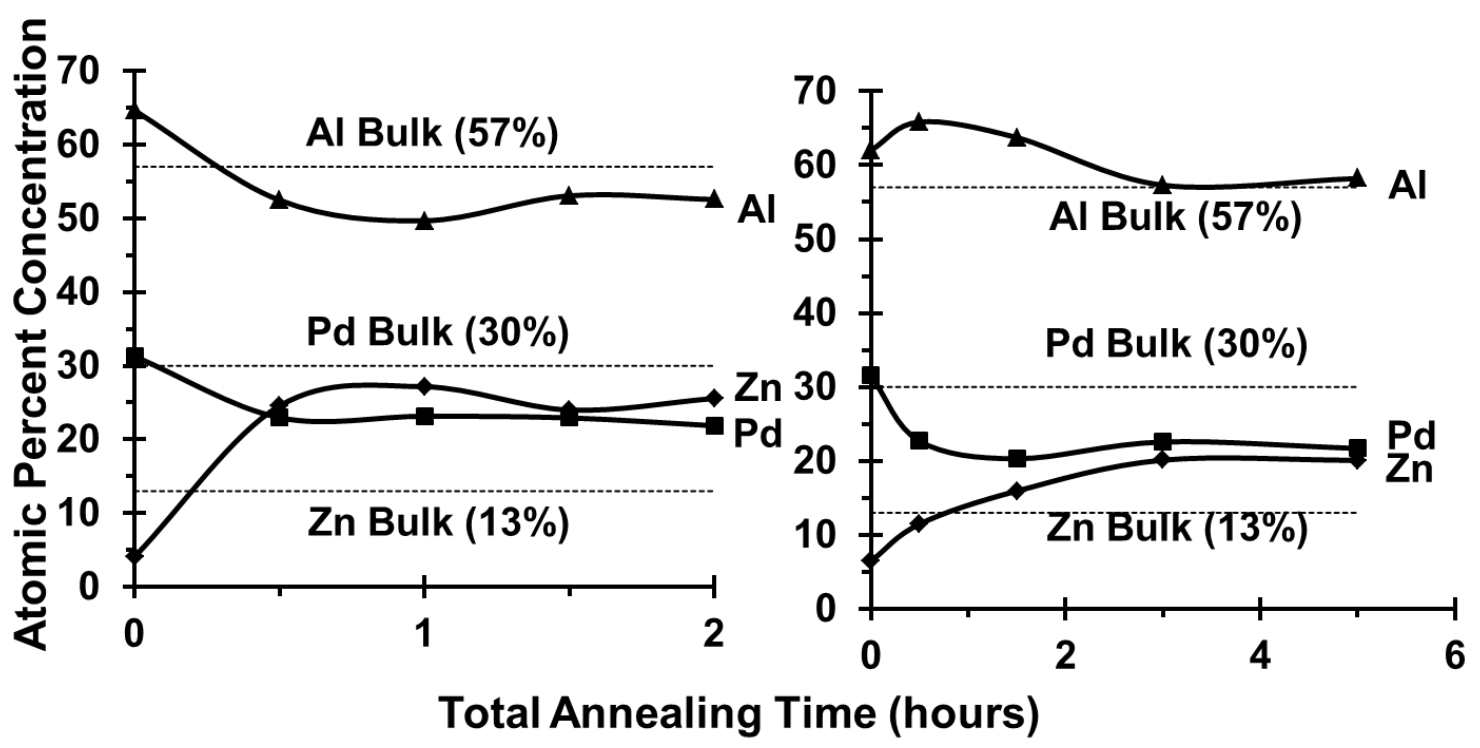

Figure 7 


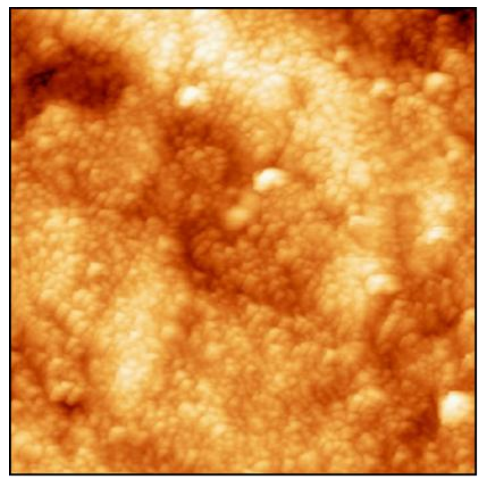

$440 \mathrm{~K}$

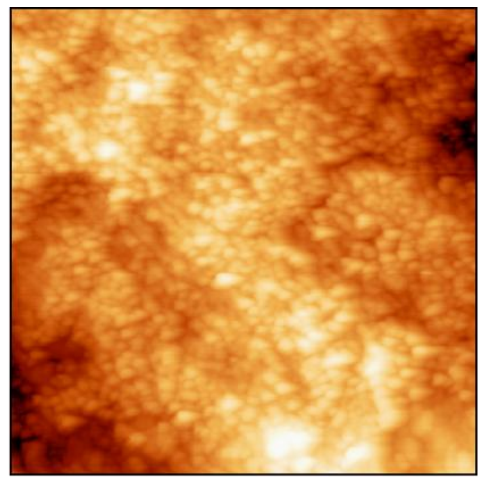

$490 \mathrm{~K}$

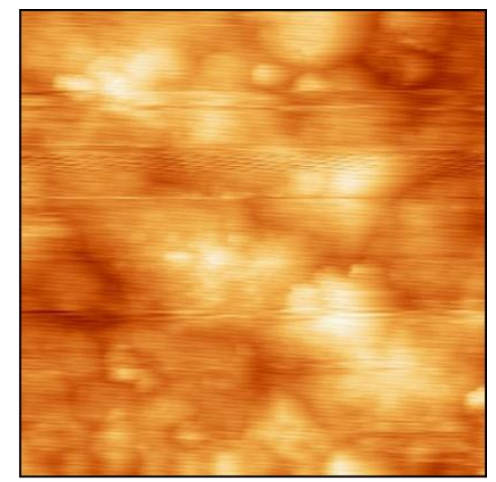

$545 \mathrm{~K}$

Figure 8 


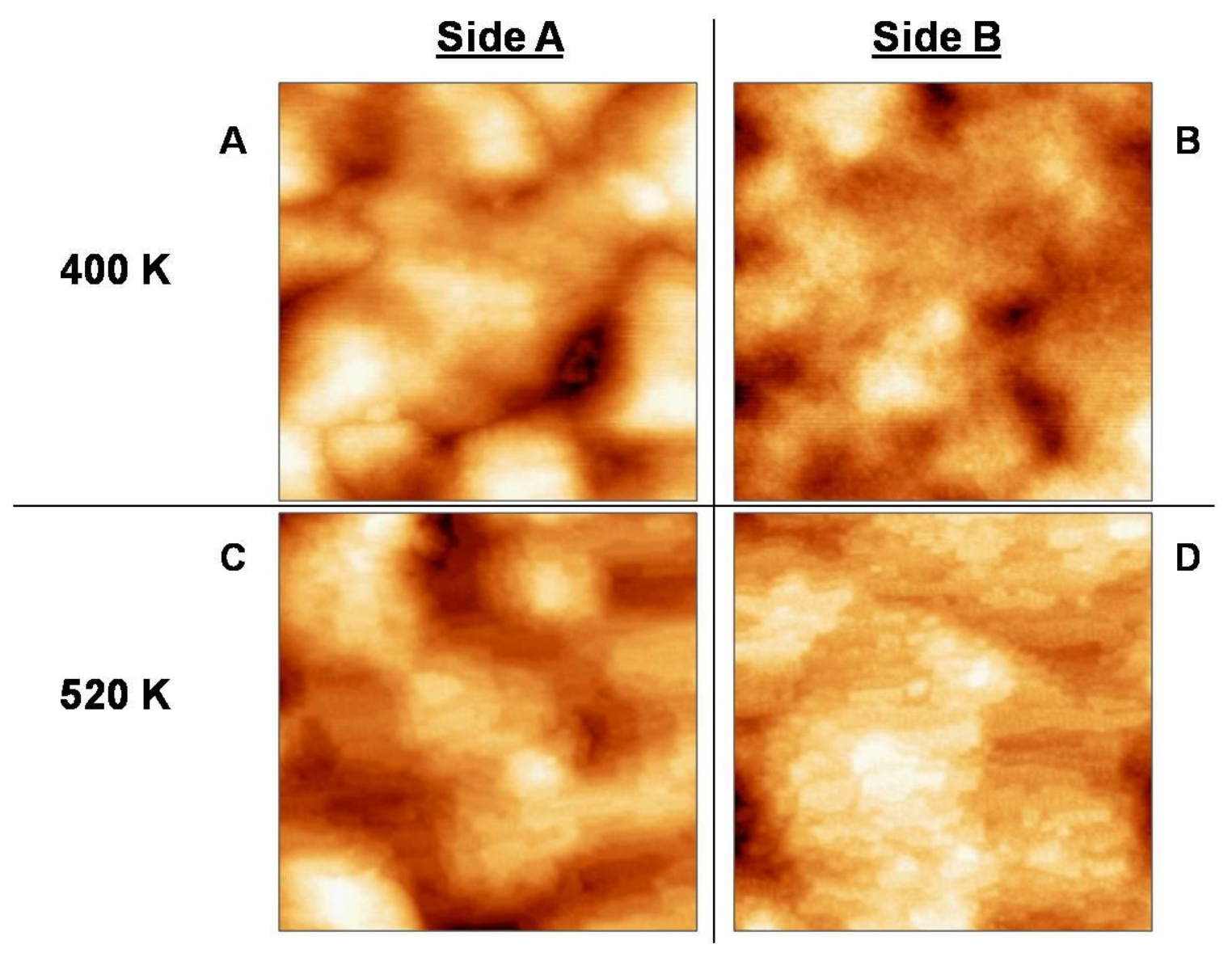

Figure 9 

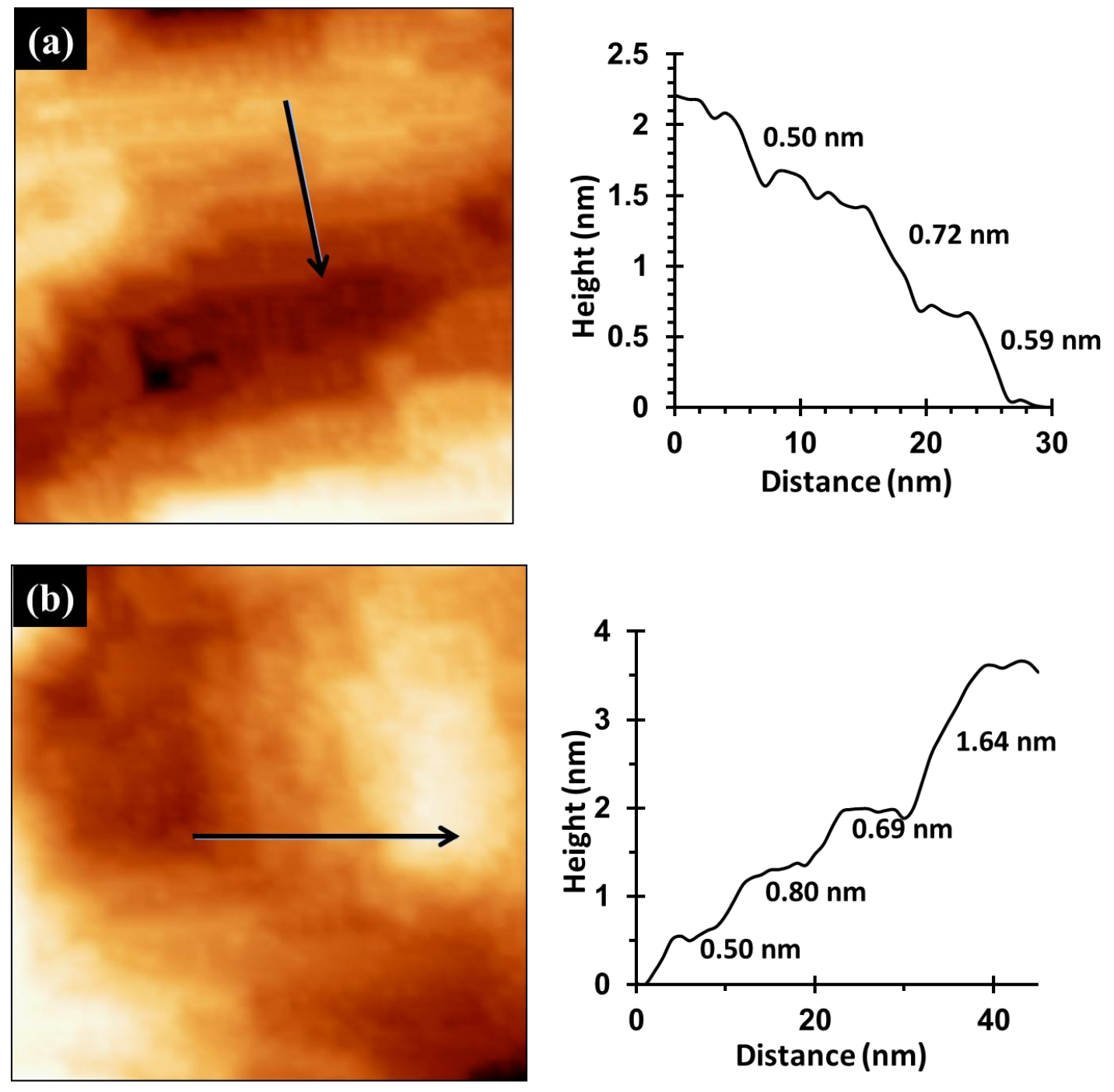

Figure 10 

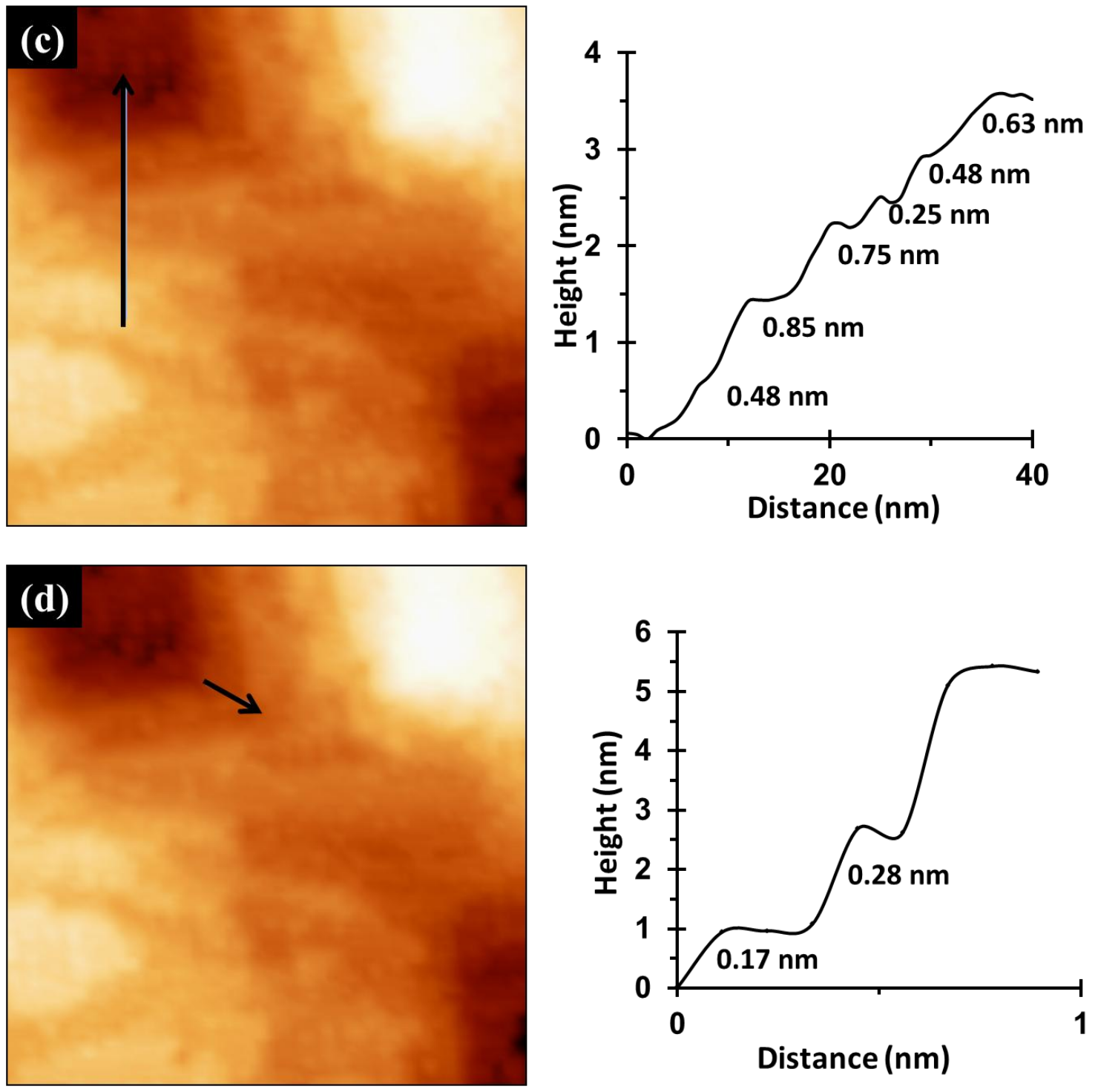

Figure 10 (Continue) 

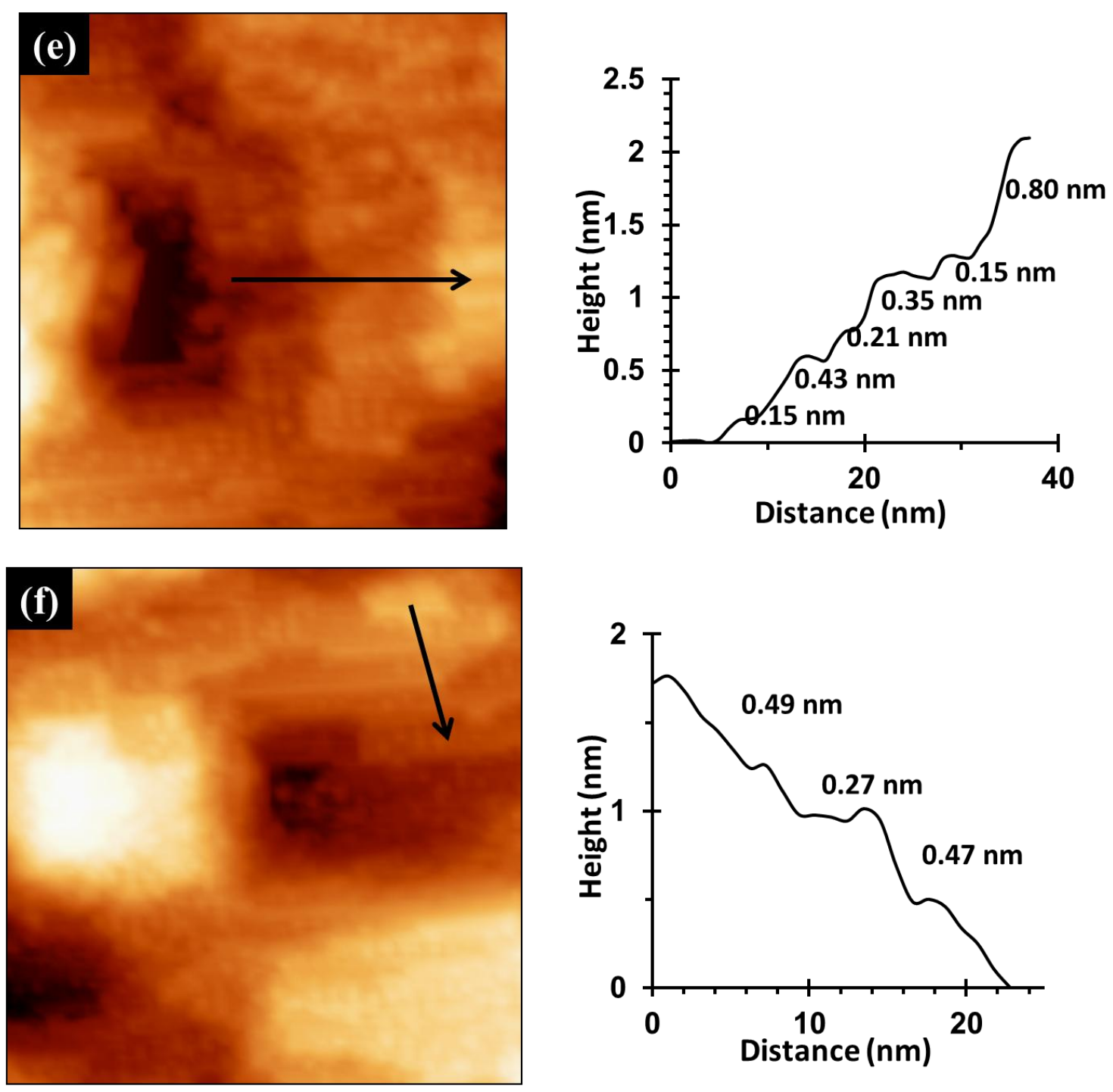

Figure 10 (Continue) 


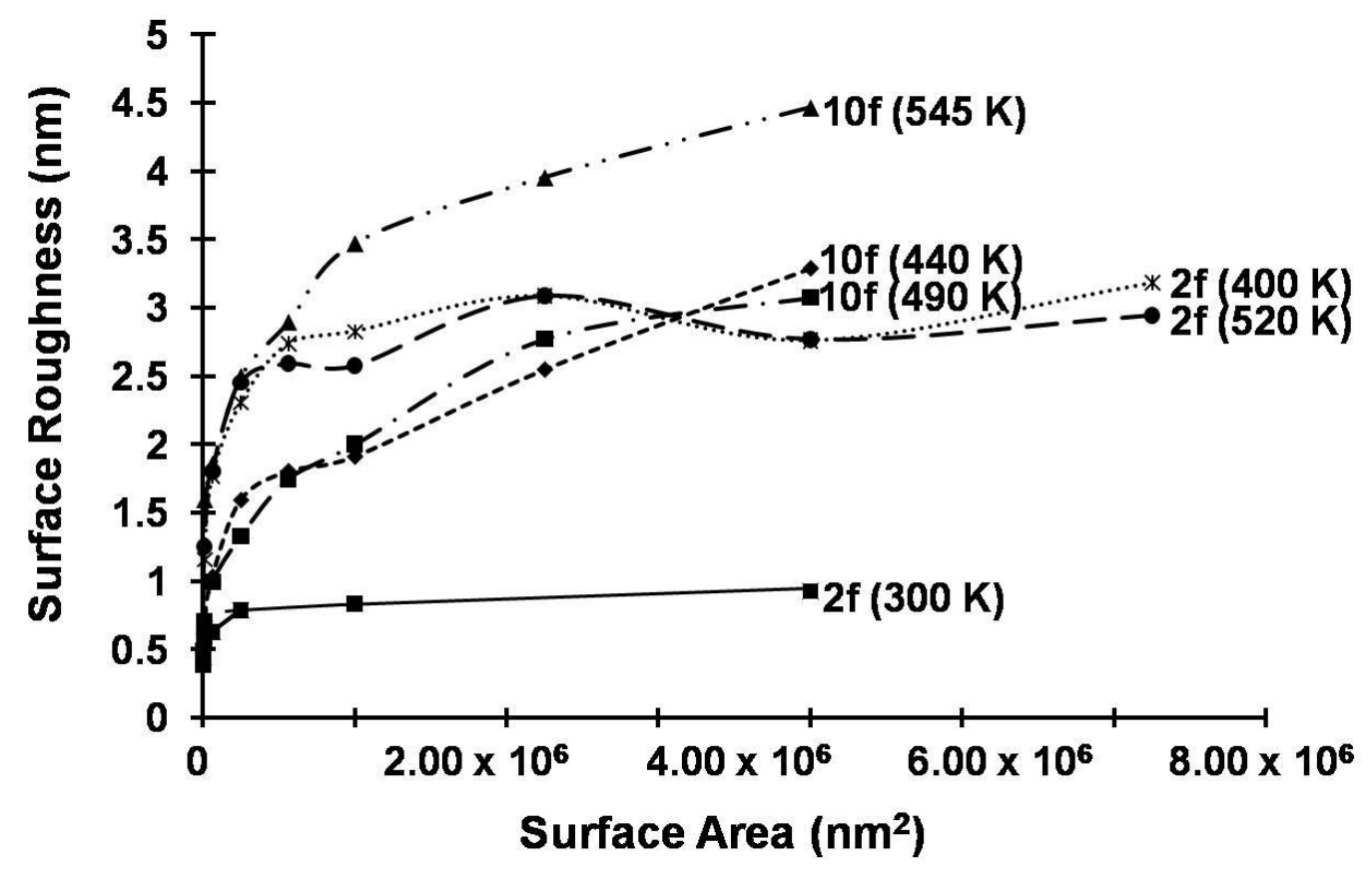

Figure 11A 


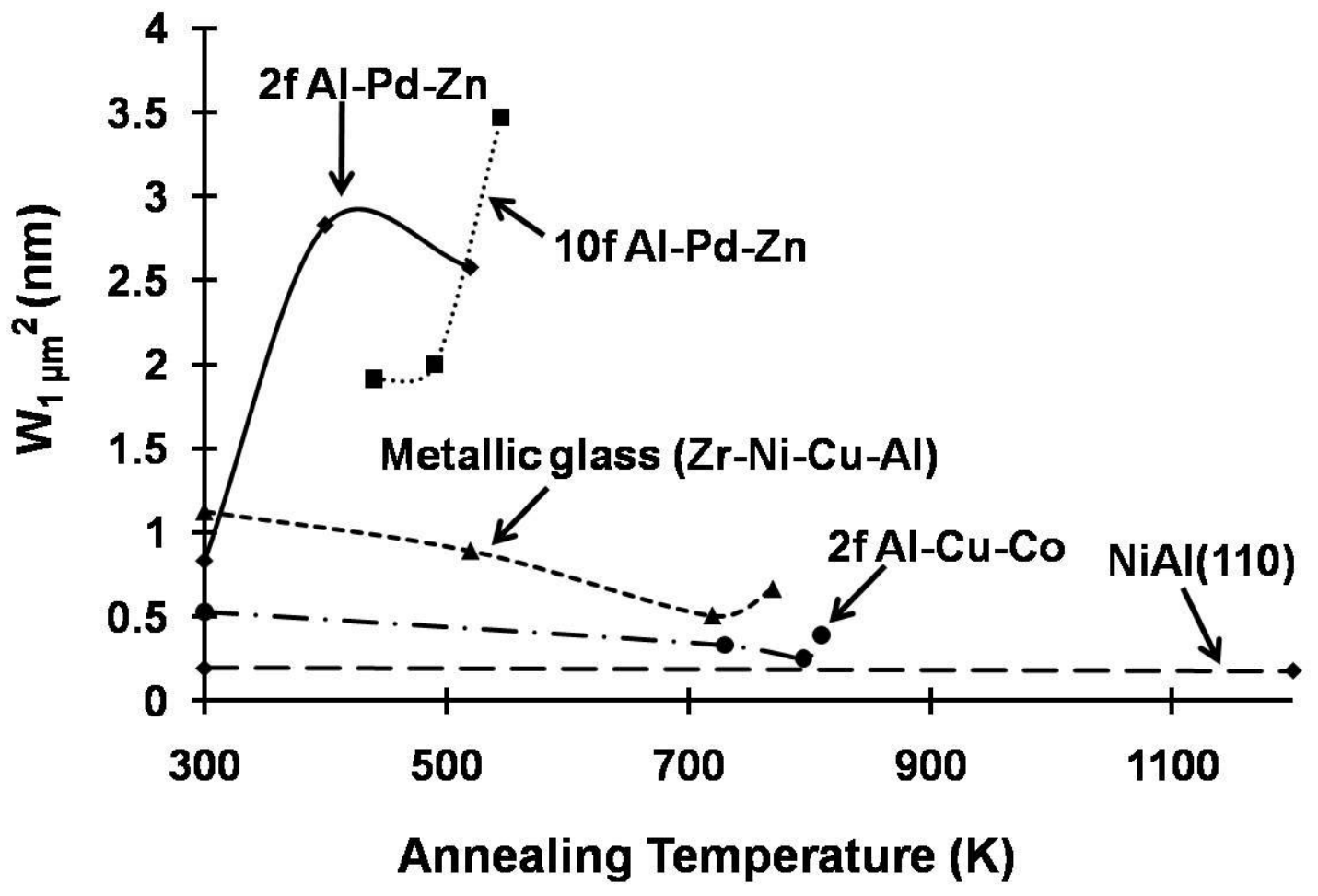

Figure 11B 


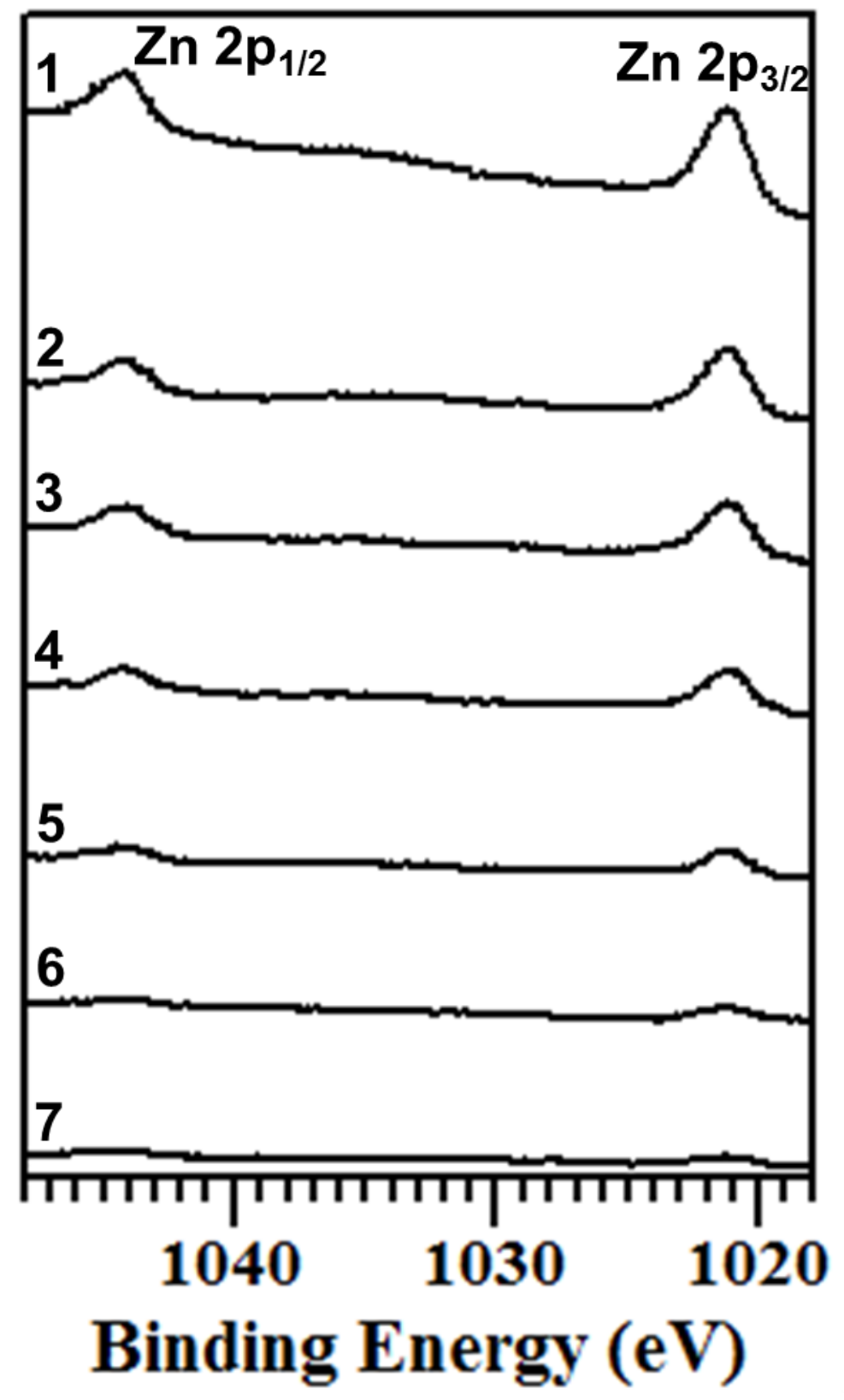

Figure 12A 


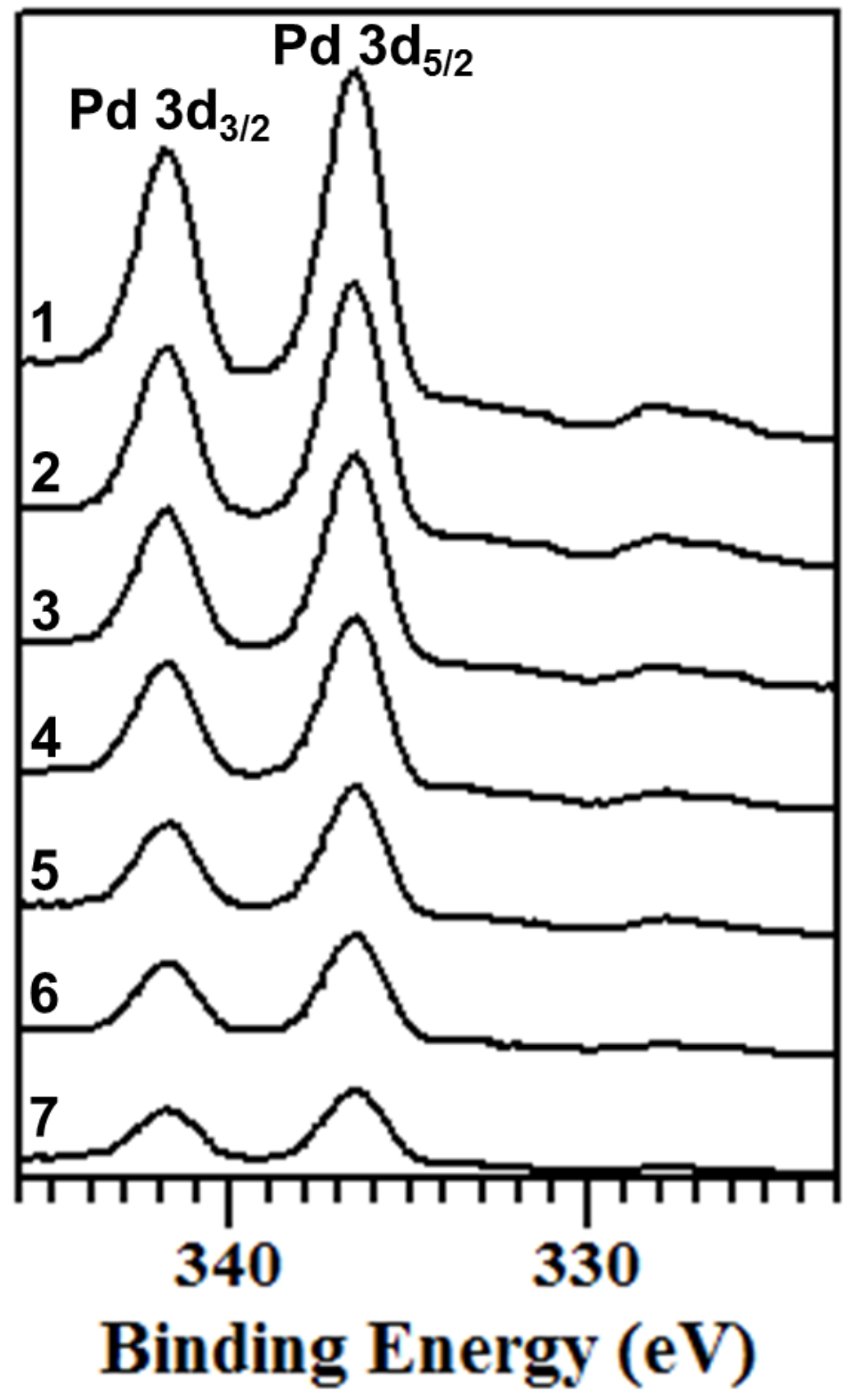

Figure 12B 


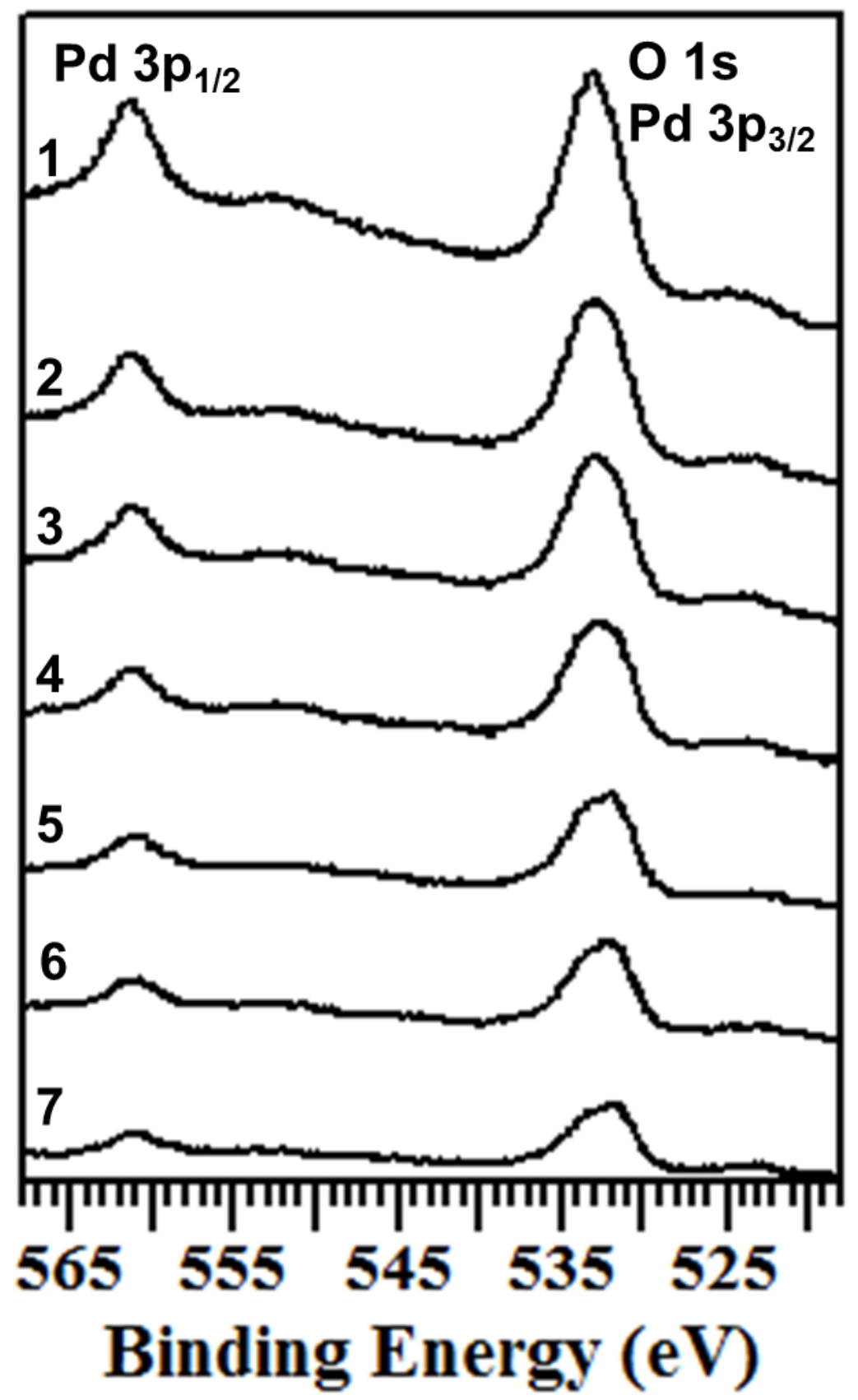

Figure 12C 


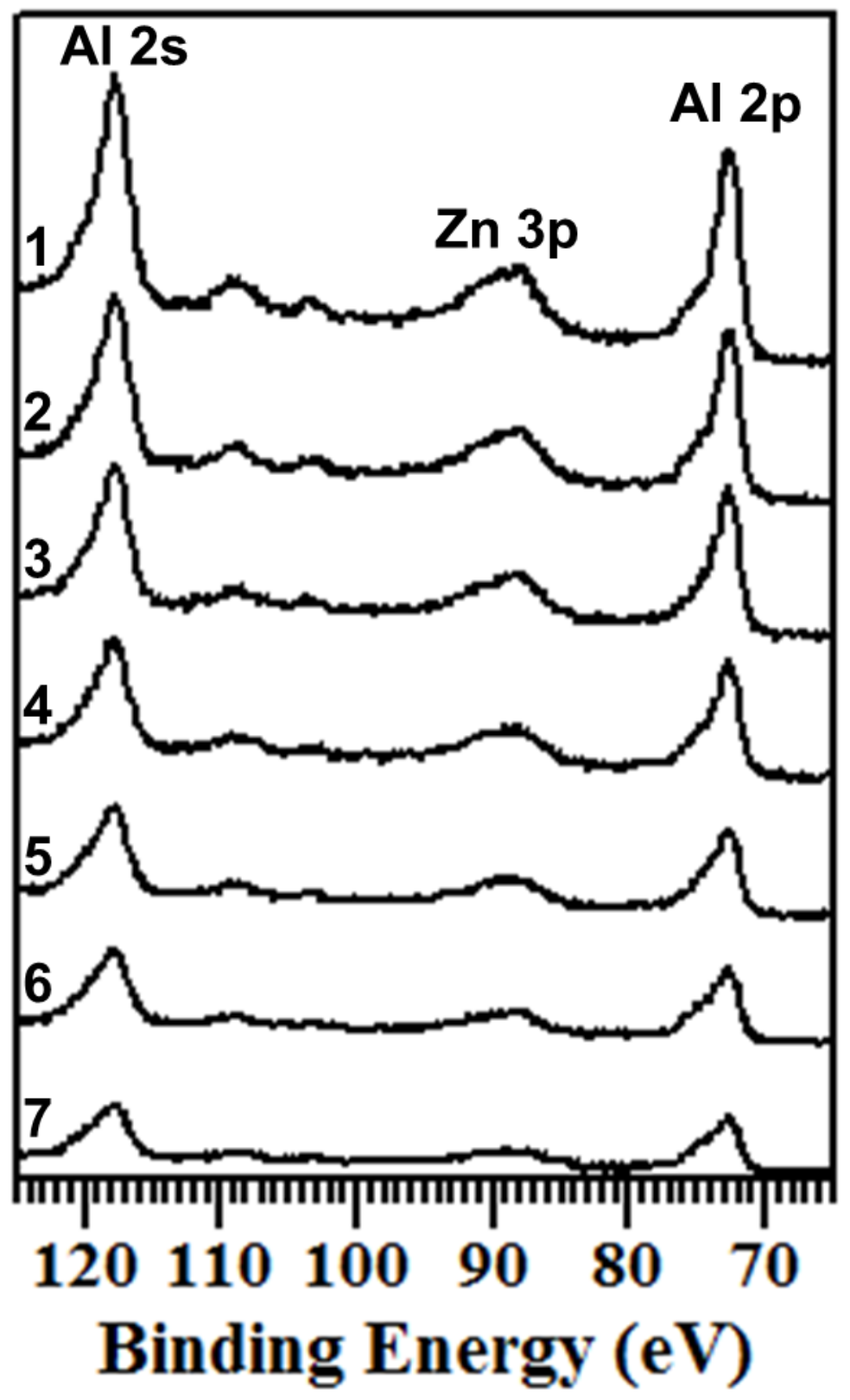

Figure 12D 


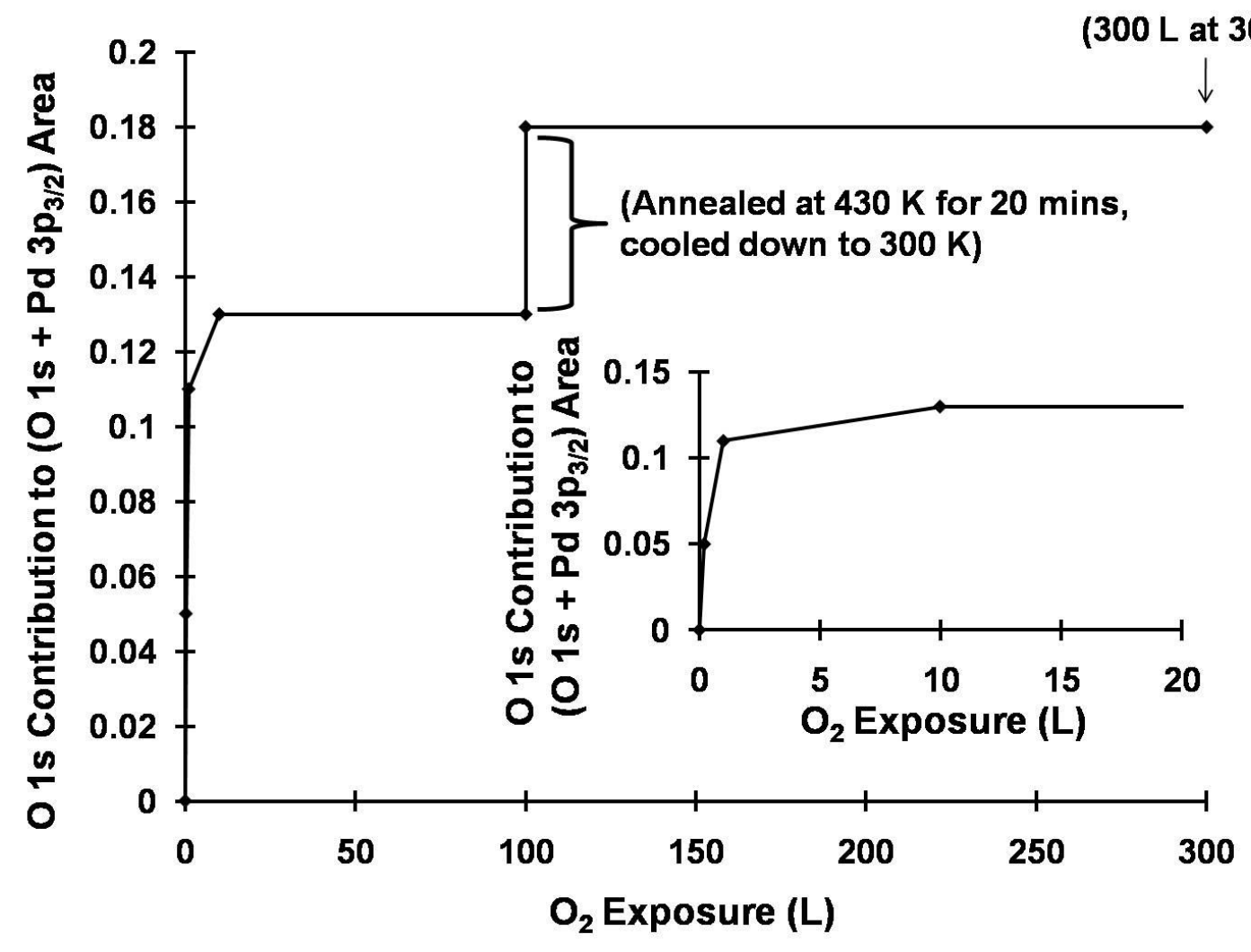

Figure 13 


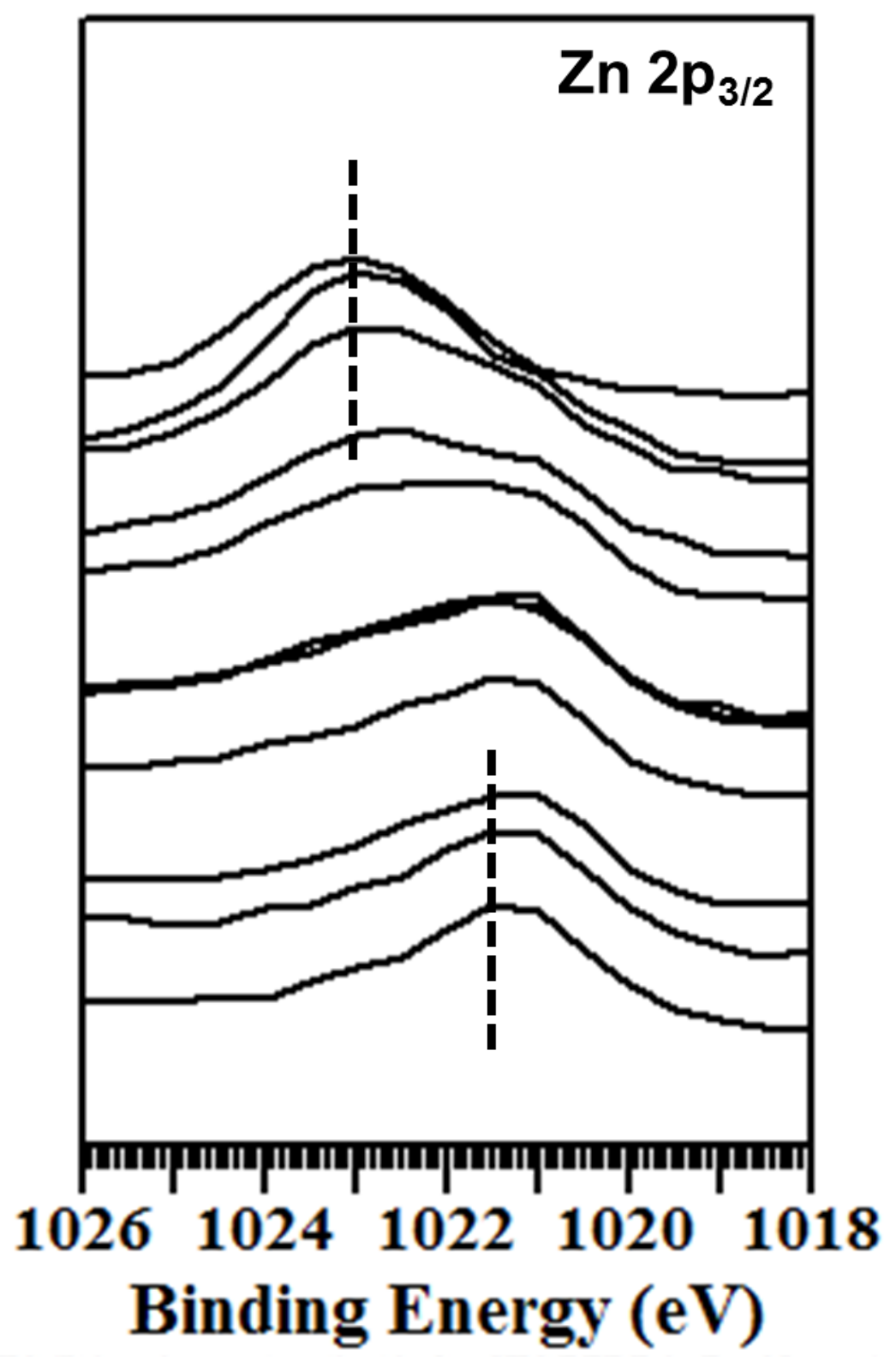

Figure 14A 


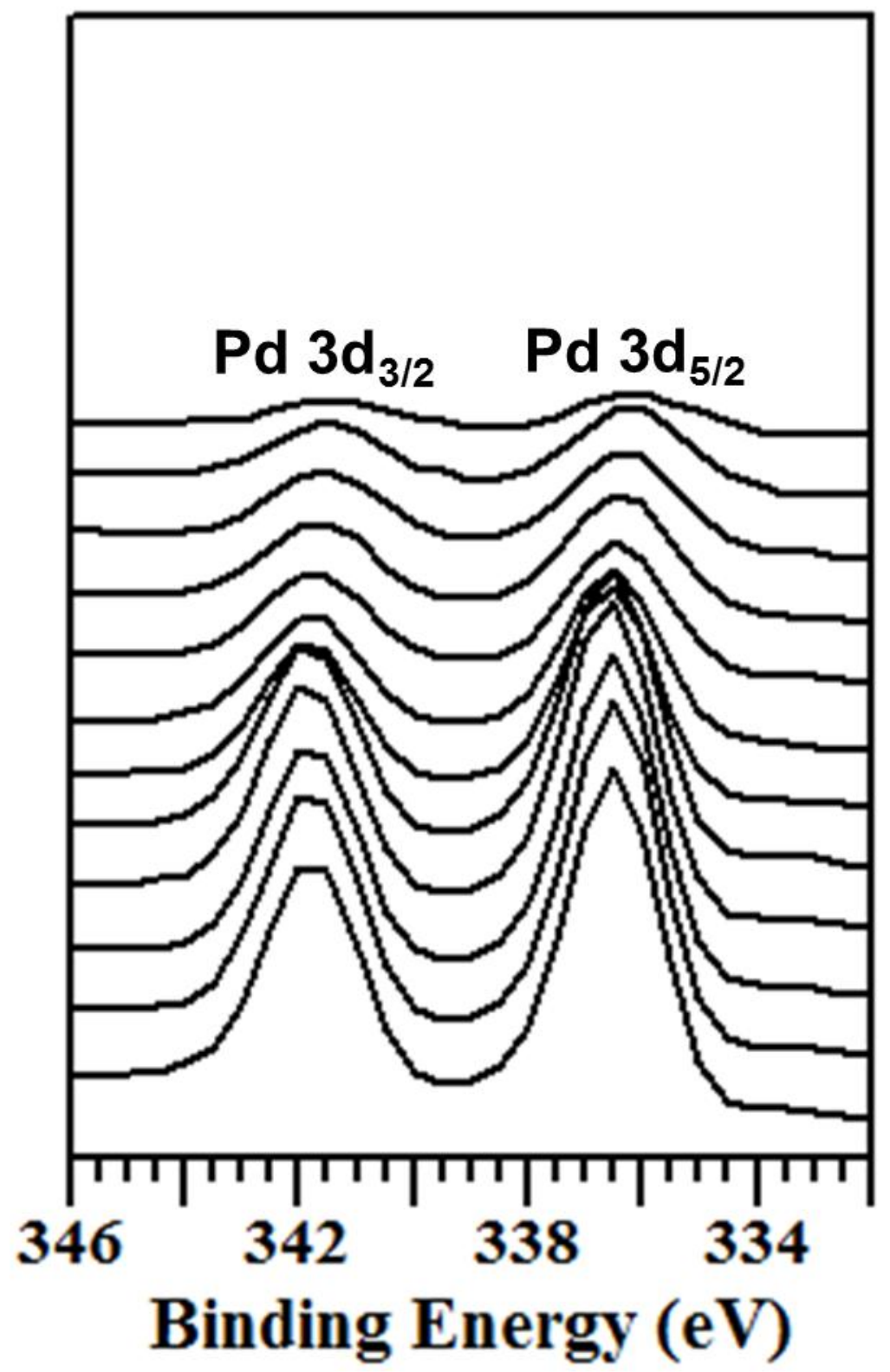

Figure 14B 


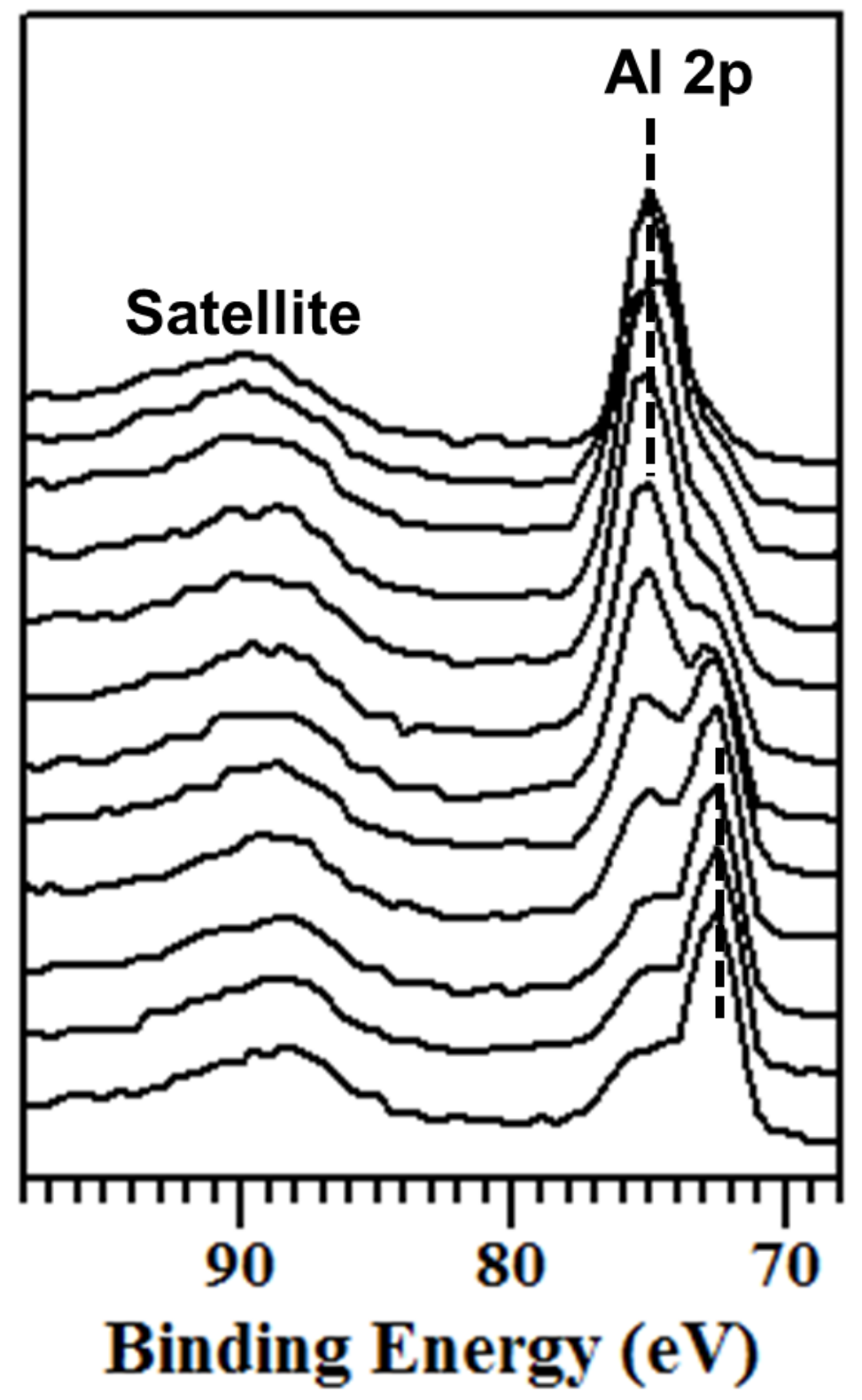

Figure 14C 


\title{
CHAPTER 3
}

\section{Structure of the Clean $\mathrm{Gd}_{5} \mathrm{Ge}_{4}(010)$ Surface}

\author{
Chad D. Yuen, ${ }^{1,2}$ Gordon J. Miller, ${ }^{1,2}$ and Patricia A. Thiel ${ }^{1,2,3}$
}

\footnotetext{
${ }^{1}$ Ames Laboratory, Iowa State University, Ames, Iowa, 50011

${ }^{2}$ Department of Chemistry, Iowa State University, Ames, Iowa 50011

${ }^{3}$ Department of Material Science and Engineering, Iowa State University, Ames, Iowa 50011
}

\section{$\underline{\text { Abstract }}$}

We have characterized four different samples of the (010) surface of $\mathrm{Gd}_{5} \mathrm{Ge}_{4}$. Using X-ray photoelectron spectroscopy, data from samples \#1-3 show the surface composition is the same as the bulk composition within \pm 5 atomic $\%$, both after sputtering and after annealing at various temperatures. Using scanning tunneling microscopy, data from samples \#1-2 show the surface exhibits two main types of terraces, which have much different fine structures. The two types of terraces alternate across the surface. Under some conditions they have comparable areas and the alternation is visually striking. Under other conditions a single type dominates, but the second type is still discernible as part of a step bunch. Step heights between similar terraces correspond well to the separation between equivalent layers along the $\langle 010\rangle$ direction in the bulk structure, and step heights between dissimilar terraces correspond to the distance between certain dissimilar but dense layers. However, the fine structure on the terraces does not correlate with the bulk structure, and we suggest that there is significant surface 
reconstruction. In addition, data from scanning electron microscopy, optical microscopy, Auger electron spectroscopy and Auger electron microscopy reveal small amounts of a $\mathrm{Gd}_{5} \mathrm{Ge}_{3}$ secondary phase at the surface of sample \#4.

\section{Introduction}

The $\mathrm{Gd}_{5} \mathrm{Ge}_{4}$ binary alloy and its psuedobinary $\mathrm{Gd}_{5}\left(\operatorname{SixGe}_{1-\mathrm{x}}\right)_{4}$ have been extensively investigated for their magnetic and thermomagnetic properties [1-3]. These alloys or compounds are promising materials for magnetic refrigeration near or below room temperature $[4 ; 5]$. They were discovered in the 1960 s by Smith et al. [6] and Holtzberg et al. [7], separately.

We choose the (010) surface because the closest-packed planes in the bulk are (010)-type, meaning that this is likely to be the most stable surface.

In addition, it is well-established that a small amount of a secondary phase is always present in single-crystal samples of $\mathrm{Gd}_{5} \mathrm{Ge}_{4}$ and other closely-related compounds. The secondary phase is $\mathrm{Gd}_{5} \mathrm{Ge}_{3}$. More details of this secondary phase are discussed later.

The primary goal of the present work is to study the structure and composition of the $\mathrm{Gd}_{5} \mathrm{Ge}_{4}$ (010) surface, and to compare these features with its bulk characteristics. A secondary goal is to characterize the surfaces of the lines of $\mathrm{Gd}_{5} \mathrm{Ge}_{3}$ phase within the $\mathrm{Gd}_{5} \mathrm{Ge}_{4}(010)$ surface.

In Section 2, we describe our experimental procedures. In Section 3, we provide background about the bulk structures of $\mathrm{Gd}_{5} \mathrm{Ge}_{4}$ and $\mathrm{Gd}_{5} \mathrm{Ge}_{3}$. In Section 4, we present the experimental results of our study by using XPS and STM. In Section 5, we compare our 
STM results with the bulk structure of $\mathrm{Gd}_{5} \mathrm{Ge}_{4}$. In Section 6, we characterize the $\mathrm{Gd}_{5} \mathrm{Ge}_{3}$ thin plates on the $\mathrm{Gd}_{5} \mathrm{Ge}_{4}$ surface using SEM, AES, OM, STM, and SAM.

\section{Experimental Procedures}

A single crystal of $\mathrm{Gd}_{5} \mathrm{Ge}_{4}$ was synthesized at the Materials Preparation Center (MPC) of the Ames Laboratory [8]. Appropriate quantities of Gd, 99.996\% pure (wt. \%) and Ge, 99.999\% pure, were cleaned and arc melted several times under an argon atmosphere. The arc melted button was then used as the charge material in a tri-arc crystal pulling unit. A tungsten rod was used as the seed material, which resulted in a randomly oriented $\mathrm{Gd}_{5} \mathrm{Ge}_{4}$ crystal. A detailed description of the tri-arc method is available elsewhere [9].

The as-grown $\mathrm{Gd}_{5} \mathrm{Ge}_{4}$ crystal was oriented, by back-reflection Laue, to within \pm $0.25^{\circ}$ of the (010) direction. The crystallographic direction was verified on the basis of an X-ray diffraction (XRD) two-theta scan of the single crystal face. From the single crystal, four oriented samples were cut by spark erosion. Samples \#1 and \#2 had dimensions of $10.4 \mathrm{~mm}$ x $1.9 \mathrm{~mm} \times 2.9 \mathrm{~mm}$, and $10.0 \mathrm{~mm}$ x $2.0 \mathrm{~mm}$ x $1.6 \mathrm{~mm}$, respectively. Each rectangular sample was polished on one of its (010) faces using standard metallographic techniques. The final abrasive was $1 / 4$ micron diamond paste. Once polished, two 0.127 mm thick tantalum foils were spot-welded onto a tantalum plate to hold each sample in place for analysis. In this text, the $\mathrm{Gd}_{5} \mathrm{Ge}_{4}$ samples are called sample \#1 (MPC hmd-1-73) sample \#2 (MPC dls-7-68-2), sample \#3 (MPC dlw-1-97), and sample \#4 (MPC dlw-1- 
1). Of these, samples \#1, \#2, and \#4 were taken from the same ingot (MPC Ingot \#Ta-2113) and sample \#3 was taken from a different ingot (MPC Ingot \#Ta-2-115).

The first three samples were used for experiments in an Omicron ultrahigh vacuum (UHV) chamber with base pressure $\leq 1.0 \times 10^{-10}$ mbar. The chamber was equipped with an ion sputter gun, mass spectrometer, and other basic UHV instrumentation. X-ray photoelectron spectroscopy (XPS) experiments were performed with an Omicron X-ray source (Al $\mathrm{K} \alpha)$, Variable Temperature Scanning Tunneling Microscopy (VT-STM), and an Omicron EA 125 hemispherical electron energy analyzer. This chamber will be referred to as the STM/XPS UHV chamber.

Ion bombardment was used to clean each sample. The sample was bombarded with $\mathrm{Ar}^{+}$ions at $1.5 \mathrm{KeV}$ energy, with the incident beam at an angle of $45^{\circ}$ to the surface plane and the sample held at $300 \mathrm{~K}$. The chamber was back-filled with Ar to a pressure of $2 \times 10^{-6}$ mbar. Typical sputtering duration was 9 minutes total -3 minutes on each of the 3 different positions of the sample (left and right sides, and middle).

Each cleaning cycle consisted of sputtering and heating, where the heating served to heal the surface damage induce by sputtering. A pyrolitic born nitride (PBN) element was mounted on the manipulator, below the sample plate, and could be heated resistively. Annealing was achieved by slowly increasing the heating current at a rate of $0.2-0.3 \mathrm{~A}$ every 4 minutes until the desired temperature was reached. Temperature was maintained for 30 and 60 minutes in XPS and STM experiments, respectively. Power supply settings of $38.8 \mathrm{~V}$ and $1.7 \mathrm{~A}$ were adequate to maintain temperature at $900 \mathrm{~K}$. The sample was then cooled slowly by decreasing the current by $0.2-0.3$ A every 4 minutes. With this regimen, it took about 40 minutes to cool from $900 \mathrm{~K}$ to almost $300 \mathrm{~K}$, for an average 
cooling rate of $15 \mathrm{~K} / \mathrm{min}$ starting from $900 \mathrm{~K}$. Starting from $1200 \mathrm{~K}$, the average cooling rate was $20 \mathrm{~K} / \mathrm{min}$. Typical temperature-power and temperature-time programs are shown during sample cooling, starting from $900 \mathrm{~K}$ and from $1200 \mathrm{~K}$, both for sample \#1 and sample \#2, in Fig. 1.

The sample temperature was measured by several means. The simplest, but least accurate, was a K-type thermocouple spotwelded to the manipulator. The source of error with this method was the fact that the thermocouple was not directly attached to the sample, but rather to the sample plate. Hence, one could expect the temperature at the thermocouple to be lower than at the sample. A more accurate method was optical pyrometry, which was limited to temperatures above $900 \mathrm{~K}$ due to emissivity and is somewhat inconvenient. Because of its drawbacks, optical pyrometry was used only occasionally to check temperature. A third method relied simply on the heating power. Previously, a relationship had been established between the sample temperature and heating power for this instrument, by attaching a thermocouple directly to a sample, temporarily[10]. In our experiments, we found that when the Gd-Ge sample temperature from the power reading was $1200 \mathrm{~K}$, the pyrometer read $1190 \mathrm{~K}$ (a difference of only 10 $\mathrm{K}$ ) and the thermocouple read $1055 \mathrm{~K}$ (lower-as expected-by $135 \mathrm{~K}$ ). Temperatures reported in this paper are based on the power calibration.

For sample \#2, a temperature gradient existed on the surface during annealing. Optical pyrometry showed that the two sides were hotter than the middle of the sample. Specifically, the pyrometer showed that the middle was coolest, the right side $10 \mathrm{~K}$ hotter, and the left side $20 \mathrm{~K}$ hotter than the middle, at a nominal temperature of $900 \mathrm{~K}$ from the power calibration. There was no measurable temperature gradient on sample \#1. 
The XPS source was perpendicular to the sample plate, and the take-off angle (the angle between the entrance axis of the analyzer and the sample surface plane) was $45^{\circ}$. The angular acceptance range was $\pm 8^{\circ}$. The aperture used in the EA 125 analyzer was 6 $\mathrm{mm} \times 12 \mathrm{~mm}$. The most intense photoelectron peaks of $\mathrm{Gd}$ and $\mathrm{Ge}$ were the $\mathrm{Gd} 3 \mathrm{~d}_{5 / 2}$ peak at a binding energy of $1186 \mathrm{eV}$, and the Ge $2 \mathrm{p}_{1 / 2}$ peak at $1248 \mathrm{eV}$. XP spectra were analyzed with CasaXPS software [11].

STM was used to study the surface morphology of each $\mathrm{Gd}_{5} \mathrm{Ge}_{4}(010)$ sample. Data processing was performed by WSxM scanning probe microscopy software [12]. A tungsten tip was used, and tip bias voltages ranged from $-1 \mathrm{~V}$ to $+1 \mathrm{~V}$. The tunneling current was set at $0.5 \mathrm{nA}$. A single STM image could be acquired in $\sim 2$ minutes. All STM was carried out with the sample at room temperature. If the sample had been annealed, it was allowed to equilibrate for one hour after the heating power supply was turned off completely, before STM began.

Some experiments were performed in another chamber, equipped for scanning electron microscopy (SEM), scanning Auger electron microscopy (SAM), and Auger electron spectroscopy (AES). In this chamber, the base pressure was $\leq 10^{-9}$ mbar. The system was a JEOL Jamp-7830F Field Emission Auger Microprobe. The $\mathrm{Gd}_{5} \mathrm{Ge}_{4}(010)$ sample was held in a homebuilt Mo sample holder. 


\section{Background: Bulk Phases}

\section{$3.1 \mathrm{Gd}_{5} \mathrm{Ge}_{4}$}

The binary $\mathrm{Gd}_{5} \mathrm{Ge}_{4}$ alloy is a line compound that contains 55 at. \% Gd and 45 at. $\%$ Ge. According to the published phase diagram (Fig. 2) [13], peritectic decomposition to $\mathrm{Gd}_{5} \mathrm{Ge}_{3}$ occurs at $\sim 1970 \mathrm{~K}$, with the liquidus at $2073 \mathrm{~K}$ [14]. Thermal analysis was performed on a portion of the MPC-grown $\mathrm{Gd}_{5} \mathrm{Ge}_{4}$ sample, and results were consistent with the published information. Lattice parameters, space groups, and prototypes of all the Gd-Ge binary alloys are presented in Table 1 as reference $[13 ; 15 ; 16]$.

$\mathrm{Gd}_{5} \mathrm{Ge}_{4}$ is an orthorhombic $\mathrm{Sm}_{5} \mathrm{Ge}_{4}$-type structure with space group Pnma, $\mathrm{Z}=4$, and lattice parameters $\mathrm{a}=0.769 \mathrm{~nm}, \mathrm{~b}=1.482 \mathrm{~nm}$, and $\mathrm{c}=0.778 \mathrm{~nm}$. It contains 36 atoms in the unit cell $[17 ; 18]$. The crystal structure is shown in Figure 3(a). The rectangular box in 3(a) represents the unit cell. As shown in Figure 3(a), the orthorhombic structure is built by stacking pseudo-two dimensional slabs along the (010) direction (along the $\mathrm{b}$ axis). Each slab contains five planes consisting of $\mathrm{Gd}$, Ge, or a mixture of $\mathrm{Gd}$ and $\mathrm{Ge}$ atoms. The slabs repeat at separations of $0.741 \mathrm{~nm}$ along the $\mathrm{b}$ direction, which is half the $\mathrm{b}$ lattice constant, $1.482 \mathrm{~nm}[1 ; 2 ; 14 ; 19]$.

The top two planes of atoms in the (010) surface are depicted in Fig. 3(b). The large dark blue circles represent the Gd atoms and the small light blue circles represent the Ge atoms. The bulk unit cell, shown by the rectangle, is nearly square, being 0.769 $\mathrm{nm}$ and $0.778 \mathrm{~nm}$ on the edges. 


\section{2 $\mathrm{Gd}_{5} \mathrm{Ge}_{3}$ Thin Plates}

In 1999, linear features were first reported on the $\mathrm{Gd}_{5}\left(\mathrm{Si}_{\mathrm{x}} \mathrm{Ge}_{1-\mathrm{x}}\right)_{4}$ surface by Szade et al [20], on the basis of Scanning Electron Microscopy (SEM) Auger Electron Spectroscopy (AES), and optical microscopy. The authors determined that these linear features were not grain boundaries, nor were they parallel to any crystallographic directions with low indices.

Since then, these linear features have been identified as thin plates of $\mathrm{Gd}_{5}(\mathrm{Si}, \mathrm{Ge})_{3}$ [21-24] which has the hexagonal $\mathrm{Mn}_{5} \mathrm{Si}_{3}$-type structure[25; 26]. Analogous features have been found on $\mathrm{Gd}_{5} \mathrm{Ge}_{4}$ surfaces, as well as on $\mathrm{RE}_{5} \mathrm{Si}_{4}, \mathrm{RE}_{5}\left(\mathrm{Si}_{1-\mathrm{x}} \mathrm{Ge}_{\mathrm{x}}\right)_{4}$, and $\mathrm{RE}_{5} \mathrm{Ge}_{4}$ surfaces, where RE is either Gd, Tb, Dy, and Er lanthanides [21]. For $\mathrm{Gd}_{5} \mathrm{Ge}_{3}$, the lattice parameters are $\mathrm{a}=\mathrm{b}=0.8546 \mathrm{~nm}$ and $\mathrm{c}=0.6410 \mathrm{~nm}[13 ; 15 ; 23 ; 27]$. This phase is included in Table 1. The $\mathrm{Gd}_{5} \mathrm{Ge}_{3}$ alloy has a bulk composition of 63 at. \% Gd and 37 at. $\% \mathrm{Ge}[28]$. The thin plates reportedly intersect at angles of $80^{\circ}$ when viewed along the (010) direction [23], cover 1 to $6 \%$ of the surface area [24] and are about $250 \mathrm{~nm}$ wide [23]. The reasons for the consistent presence of this second phase are unknown, but it appears to form via a solid-state reaction during cooling [23].

\section{$\underline{\text { 4. Experimental Results }}$}

\subsection{XPS}

\subsubsection{XPS: Initial Depth-Profiling after Air Exposure (Sample \#1)}

Immediately after the $\mathrm{Gd}_{5} \mathrm{Ge}_{4}(010)$ sample was placed in the STM/XPS UHV chamber, surface compositional analysis with XPS was conducted. Fig. 4 shows the 
surface composition as a function of sputter time (the depth profile) during the initial cleaning cycle. At the beginning, carbon and oxygen peaks have high intensity. No other contaminants such as sulfur are detected. In addition, low concentrations of Gd and Ge are detected. This is expected since the surface had been exposed to air, which typically leaves a thick layer of oxygen and carbon contamination. After a total of 118 minutes of sputtering, the oxygen and carbon are undetectable and the surface composition (from XPS) is 56 at. \% Gd and 44 at. \% Ge, very close to the bulk composition of 55 at. \% Gd and 45 at. $\%$ Ge.

4.1.2 XPS: Surface Composition as a Function of Annealing Temperature in UHV (Sample \#1, \#2, and \#3)

In these experiments, the $\mathrm{Gd}_{5} \mathrm{Ge}_{4}$ (010) sample was annealed at temperatures ranging from $400 \mathrm{~K}$ to $1200 \mathrm{~K}$ for 30 minutes. After annealing, the sample was slowly cooled to room temperature for XPS analysis. At this point, the intensities of the Ge $2 \mathrm{p}_{1 / 2}$ and the $\mathrm{Gd} 3 \mathrm{~d}_{5 / 2}$ photoelectron peaks were measured.

Figure 5(a) shows the result for sample \#1. On this sample, two of the annealing temperature data points-900 K and $1200 \mathrm{~K}$-were measured twice to check reproducibility. This is reflected in the error bars (which are quite large at $1200 \mathrm{~K}$ ). Note that the error bar on the Ge concentration at $1200 \mathrm{~K}$ is shifted laterally, to prevent confusing overlap with the Gd error bar. At all temperatures, the surface composition is within \pm 5 at. $\%$ of the bulk. The data suggest that there may be a decrease in Gd at high temperatures, but the error bars are so large at high temperature that this conclusion is dubious. For this reason, the experiment was performed again on a different sample. 
Figure 5(b) shows the result for sample \#2. On this sample, all of the annealing temperatures were replicated. Data from the two runs are very consistent. Between $300 \mathrm{~K}$ and $500 \mathrm{~K}$, there are minor variations in concentration, but a stable plateau seems to exist between 500 and $900 \mathrm{~K}$. Above $900 \mathrm{~K}$, minor variations again occur. In addition, the opened squares and diamonds in Figure 5(b) is the result from sample \#3. At all temperatures, the surface composition is within \pm 5 at. $\%$ of the bulk for both sample \#2 and sample \#3.

4.1.3 XPS: Depth-Profiling after Annealing at Different Temperatures in UHV (Samples \#1, \#2, and \#3)

The procedure described in Section 4.1.2 was followed, except that after initial measurement of the Ge and Gd peak intensities, the surface was subjected to 2-minute intervals of $\mathrm{Ar}^{+}$sputtering. XPS was measured between each interval, until a total sputtering time of 10 minutes had elapsed. Sample \#1 was used for all these experiments except for the $900 \mathrm{~K}$ annealing treatment. There, sample \#2 was used and also, total sputtering time was longer, 28 minutes.

Figure 6(a-b) shows the surface concentration as a function of sputtering time for Gd and Ge. The two curves are complementary, as they must be since the alloy is binary, but both are shown for completeness. The horizontal dotted lines in Figure 6(a-b) show the bulk concentrations of $\mathrm{Gd}(55$ at. \%) and $\mathrm{Ge}(45$ at. \%), for reference.

Throughout the depth profiles, measured compositions are within \pm 5 at. $\%$ of the bulk concentration. 
The depth profiles show cyclic variations in composition. This is especially obvious in Figure 6(c) and Figure 6(d), where the curves are separated vertically and ordered in sequence of annealing temperature. For Gd, sputtering always causes an initial increase in concentration. If the surface is annealed between 500 and $900 \mathrm{~K}$, maxima at 2 and 6 minutes of sputtering time are consistently produced. Of course, for Ge, the results are complementary. If the surface is annealed below $500 \mathrm{~K}$, the maxima and minima are not so regular, although the initial increase in Gd content is always manifest. The oscillations are self-consistent between 500 and $900 \mathrm{~K}$. They are very small at $900 \mathrm{~K}$, although this may be related to the fact that a different sample (\#2) was used for the 900 K experiment than for the others (\#1).

Depth-profiling was also done on Sample \#3. In this case, the sputtering interval was shortened (from 2 minutes to 30 seconds) in order to obtain a denser set of data points as a function of time. Otherwise, its treatment and treatment history were similar to those of Samples \#1 and \#2. Depth profiles were measured after annealing at four temperatures: $700 \mathrm{~K}, 900 \mathrm{~K}, 1100 \mathrm{~K}$, and $1200 \mathrm{~K}$. Figure 7(a-d) shows the result. The horizontal dotted lines in Figures 7(a-b) show the bulk concentration of Gd (55 at. \%) and Ge (45 at. \%) for reference, and all experimental data are plotted against the same ordinate. As with Samples \#1 and \#2, the compositions are always within \pm 5 at. $\%$ of the bulk concentration. Unlike Samples \#1 and \#2, the concentrations move steadily closer to the bulk composition as depth profiling proceeds, with the initial concentrations being slightly Gd-depleted and Ge-rich. Another difference with respect to Samples \#1 and \#2 is that in Sample \#3, the Gd concentration always decreases during the first one or two sputtering cycles. This effect may be seen more clearly in Figure $7(\mathrm{c}-\mathrm{d})$, where the 
experimental curves are displaced vertically for clarity and so do not overlap. Most curves show a maximum in Gd concentration after about 2 minutes, consistent with Fig. 6 where the sputtering intervals were 2 minutes. It is possible that the density of data points in Fig. 6 was not sufficient to reveal the true trends in the data.

However, given the discrepancies between the different depth profiling experiments, further work would be necessary to determine which (if any) of the trends in concentration vs. depth is reproducible and significant. No conclusions about the depth profiles can be drawn at present, except that the concentrations are always within \pm 5 at $\%$ of the bulk.

\subsubsection{Summary and Analysis of XPS Data}

Based upon the data from all three types of XPS experiments (Sections 4.1.14.1.3), neither preferential sputtering nor preferential segregation occurs, to within \pm 5 at $\%$. This is true over a temperature range of $300 \mathrm{~K}$ to $1200 \mathrm{~K}$.

Preferential sputtering occurs when an element is removed at a rate that is disproportionately high relative to its bulk composition[29]. Light atomic mass and weak interatomic bonding both favor preferential removal. Gd and Ge have atomic masses of $157 \mathrm{amu}$ and $73 \mathrm{amu}$, respectively, so the atomic mass difference alone would favor preferential loss of Ge. Since Ge is not removed preferentially, chemical bonding must be influential.

It might be tempting to hypothesize that Gd-rich and Ge-rich planes/layers are alternately exposed as sputtering progresses, leading to the observed oscillations in concentration during depth profiling (Section 4.1.3). However, to our knowledge such a 
regular variation in layer termination with ion sputtering has not been observed in any system previously. On the contrary, it is generally thought that sputtering induces such severe damage that planar terminations do not survive, and this is often corroborated by STM images showing very rough surfaces-without terraces-after ion bombardment. As the following section shows, rough surfaces also result from ion sputtering of the $\mathrm{Gd}_{5} \mathrm{Ge}_{4}$ sample.

4.2 STM

\subsubsection{STM: General Comments}

In the STM data for both sample \#1 and \#2, there will be two main types of terraces: those which are relatively smooth, and those which are covered by small bumps, about 0.3-0.4 $\mathrm{nm}$ high on average. We will denote terraces without bumps as "A," and those with bumps as "B." The "A" terraces are also distinguished by a fine structure containing parallel lines (always running diagonally through the images), about $0.04 \mathrm{~nm}$ high and separated by about $1.0 \mathrm{~nm}$. More details are given in following sections.

In the STM data, it will be useful to consider the quantitative dimensions of certain features that are observed repeatedly. These dimensions are heights of steps between terraces, heights and areas of bumps on B-terraces, and depths of pits. While the features themselves are robust, the conditions under which they are observed will varybetween samples, between regions of a given sample, and between annealing treatments. We find it useful to collect the dimensions of these features in tables, in order to facilitate comparison of values measured under different conditions. Table 2 provides heights of steps between similar terraces, i.e. steps that separate two A-terraces or two B-terraces. 
Step heights are always determined in such a way that bumps or pits do not contribute to the value. Table 3 summarizes heights of steps between dissimilar terraces, i.e. steps that separate A- and B-terraces. Tables 4-7 gives various characteristics of the bumps on Bterraces: Their heights, average individual area, fraction surface coverage, and number density. Table 8 provides depths of pits that form at $1200 \mathrm{~K}$ on one of the samples. Each Table specifies the sample and the conditions that correspond to a given value.

The experimental sequence was as follows. First, an extensive set of XPS and STM experiments was performed on sample \#1. Next, an extensive set of STM experiments was performed on sample \#2. The STM data from these two samples will be discussed separately. These two samples were cut from the same ingot, as noted in Section 2.

\subsubsection{STM: Sample \#1}

\subsubsection{STM Images after Sputtering at Room Temperature (Sample \#1)}

This sample was introduced into the STM/XPS UHV chamber from air, then subjected to 18 cleaning cycles and 9 depth-profiles (Fig. 6 and Section 4.1.3) prior to STM.

Figure 8 shows typical STM images of this surface after annealing at $900 \mathrm{~K}$, then sputtering at room temperature. The surface is very rough, as shown by the line profiles, where peak-to-peak heights are $\geq 4 \mathrm{~nm}$. Once, a region with small terraces was found, shown in Fig. 9. Figures 9(b) and (d) show a portion of Fig. 9(a) (enclosed by a box) at successively higher magnification. Terraces, about 50-100 nm wide and decorated with protrusions, are visible. The step heights between these small terraces are $0.75 \pm 0.16 \mathrm{~nm}$. 
These terraces may be remnants of those produced by high-temperature annealing (discussed below), which somehow survived the subsequent ion bombardment process. We emphasize that these terraces are not characteristic of the freshly sputtered surface; the great majority of the surface is rough, with no terraces apparent.

Table 2 shows the step heights on the middle, right, and left sides of this sample after sputtering, followed by annealing to different temperatures. The row labeled " 300 K" corresponds to the data in Fig. 8 and Fig. 9. There is only one entry in this row, since terraces were observed in only one location at $300 \mathrm{~K}$.

\subsubsection{STM Images after Annealing at $900 \mathrm{~K}$ (Sample \#1)}

For STM studies, $900 \mathrm{~K}$ was the lowest annealing temperature used. After annealing at $900 \mathrm{~K}$, most of sample \#1 was rough. A few terraces were found; examples are shown in Fig. 10. The heights of A-A or B-B are $0.75 \pm 0.16 \mathrm{~nm}$ (see Table 2). The heights of downgoing B-to-A (height of B-terraces) and A-to-B (height of A-terraces) steps are $0.35 \pm 0.07 \mathrm{~nm}$ and $0.39 \pm 0.07 \mathrm{~nm}$, respectively (see Table 3). Further, small circular bumps are visible on terraces. They can be seen in Fig. 10(c) and Fig. 10(d). Terraces with bumps like this are called B-terraces. The bumps have an average height of $0.38 \pm 0.09 \mathrm{~nm}$ and the average individual bump area is $2.68 \pm 0.80 \mathrm{~nm}^{2}$ (see Tables 4-5) The fractional area covered by bumps on B-terraces and the number density by bumps are $16 \%$ and $0.06 \mathrm{~nm}^{-2}$ (see Tables 6-7). 


\subsubsection{STM Images after Annealing above 900 K (Sample \#1)}

For this sample, the next annealing temperatures were $1050 \mathrm{~K}$ and $1100 \mathrm{~K}$. Figure 11 and Figure 12 show representative STM images after these treatments. The major terraces remain the B-terraces, covered by small bumps.

For this sample, a significant change occurs after annealing at $1200 \mathrm{~K}$. Relative to $1150 \mathrm{~K}$, the A-terraces are broader, and they alternate with the B-terraces. Figure 13 shows representative STM images after the sample had been annealed at $1150 \mathrm{~K}$ and Figure 14 shows representative STM images after the sample had been annealed at 1200 K. On the other hand, the areal size of bumps on the B-steps, and their number density, are both significantly higher than at $900 \mathrm{~K}$. This suggests that the bumps change upon annealing to sufficiently high temperatures.

\subsubsection{STM: Sample \#2}

\subsubsection{STM Images after Annealing to $900 \mathrm{~K}$ (Sample \#2)}

This sample was introduced into the STM/XPS UHV chamber from air, then subjected to 11 cleaning cycles. Each cycle consisted of annealing at $900 \mathrm{~K}$, and a depth profile (900 K curve in Figure 6), prior to STM. A step-terrace morphology was visible over most of this surface after annealing at $900 \mathrm{~K}$. In this respect it was much different than sample \#1, which was very rough after the $900 \mathrm{~K}$ anneal (Figure $900 \mathrm{~K} 1$ and Section 4.2.2).

Examples of STM images from this sample are shown in Figure 15. Figure 15(a) and Figure 15(b) are from the coolest part of the sample (the middle), Figure 15(d) and Figure 15(e) are from the intermediate region (right side), and Figure 15(g) and Figure 
15(h) are from the hottest part (left side). Figure 15(c), Figure 15(f), and Figure 15(i) are line profiles that correspond to the black horizontal lines in Figure 15(b), Figure 15(e), and Figure 15(h), respectively.

Terraces are almost all A-type in the middle and on the right side of the sample (see Figures 15(a-b) and 15(d-e)). The step heights from the line profiles in those areas (Figure 15(c) and Figure 15(f)) are $0.74 \pm 0.09 \mathrm{~nm}$, respectively. Very small regions of another terrace type, presumably B-type, are observed sometimes protruding at the Aterrace step edges. Two cases are encircled in Figure 15(b) and (e).

On the hottest region of the sample, B-type terraces are more prominent than on the cooler regions. This is illustrated by Figure 15(g) and Figure 15(h). Based on the line profile in Figure 15(i), the step heights range from $0.3 \mathrm{~nm}$ to $0.5 \mathrm{~nm}$, i.e. significantly less than step heights on the smoother terraces in Figure 15(a-b) and Figure 15(d-e). It is also very interesting that $\mathrm{A}$ - and $\mathrm{B}$-terraces alternate in sequence.

The preponderance of A-type steps after $900 \mathrm{~K}$ annealing makes this sample different than sample \#1, where there were only a few terraces and those were mostly Btype, after $900 \mathrm{~K}$ annealing. It is also interesting that the alternating sequence of A- and B-terraces was observed on both samples, but after annealing at different temperatures. For sample \#1, the A/B alternation was seen after annealing to $1200 \mathrm{~K}$ (Figure 14), whereas for sample \#2 it was seen after annealing to only $900 \mathrm{~K}$ (Figure 15).

At high magnification, we see the features shown in Figure 16(a) on the Aterraces. The most prominent motifs are parallel, diagonal rows. The diagonal rows are all in one direction, going from the top right corner down to the bottom left corner of the image. In other words, there are no rotational domains. The spacing between the rows is 
$1.04 \pm 0.03 \mathrm{~nm}$ and the height of the rows is $0.04 \pm 0.01 \mathrm{~nm}$ (where the baseline is taken as the minimum between the rows). The angle of the rows is $68^{\circ} \pm 1^{\circ}$. This angle is measured relative to the bottom edge of the image.

In addition to the diagonal rows, white bumps (protrusions) and black holes (depressions) appear throughout Figure 16(a). A line profile is given in Figure 16(b). The protrusions are $0.10 \pm 0.03 \mathrm{~nm}$ high, and the depressions are $0.09 \pm 0.02 \mathrm{~nm}$ deep (relative to the same baseline, i.e. the minimum between rows). The protrusions cover 12 $\%$ of the surface, while the depressions cover $17 \%$. The heights of these protrusions is significantly lower than the heights of the bumps on the B-steps, meaning that they probably have a different origin.

On the other hand, as shown in Figure 16(c), the fine structure on the B-terraces contains no diagonal motif. Rather, small circular bumps are visible on the surface. The heights of these bumps are $0.40 \pm 0.05 \mathrm{~nm}$, which is in good agreement with the height of $0.38 \pm 0.09 \mathrm{~nm}$ measured for the bumps on B-terraces on Sample \#1 after annealing at the same temperature (see Tables 4-7).

Figure 17 shows both types of fine structure on several different terraces. In all cases, the diagonal row or the bump motif is visible, although sometimes not as clearly as in Figure 16. The diagonal rows have parallel orientation on all A-terraces.

\subsubsection{STM Images after Annealing Above 900 K (Sample \#2)}

This sample was annealed at $1050 \mathrm{~K}$ and $1200 \mathrm{~K}$. After $1050 \mathrm{~K}$, major terraces are all B-type, step edges are rounder, and some small A-terraces are visible. These surface features are shown in Figure 18. Figure 18(a) and Figure 18(b) are taken in the 
coolest (middle) part of the sample, while Figure 18(c) and Figure 18(d) are taken from the intermediate (right) part, and Figure 18(e) and Figure 18(f) from the hottest (left) side. The major step heights are $0.74 \pm 0.11 \mathrm{~nm}$, as shown in Table 2. Where A-terraces are separable, their step heights are $0.35 \pm 0.08 \mathrm{~nm}$ (Table 3 ). The heights of bumps on Bterraces are $0.32 \pm 0.09 \mathrm{~nm}$ (Table 4$)$.

In addition to these basic surface features, pits are common, which can be seen especially well in the low-magnification images on the left side of Figure 18. The pits are irregular in shape but have a depth of $0.76 \pm 0.11 \mathrm{~nm}$. This value is shown in Table 5, which includes depths of pits at different positions and after annealing at different temperatures.

After annealing at $1200 \mathrm{~K}$, the B-terraces are gone. In the cool middle of the sample, Figures 19(a-b), terraces are smooth and the step heights are $0.73 \pm 0.07 \mathrm{~nm}$. This is very similar to the step heights at the lower annealing temperatures-see Table 2.

On the warm right side of the sample, an increased number of pits exist. They can be seen in Figures 19(c) and 19(d). The pits have a height of $0.80 \pm 0.08 \mathrm{~nm}-$ see Table 5. On the hot left side, pits also exist. In addition, features that we will call vacancy-voids have also appeared in the fine structure as well as inside the vacancy-pit. This can be seen in Figures 19(e-h). In the figures, pits are deep holes that have a height of $0.76 \pm 0.09 \mathrm{~nm}$ (Table 5). On the other hand, the vacancy-voids are shallow, flat regions that have a height of $0.17 \pm 0.04 \mathrm{~nm}$ on the terrace (fine structure) and $0.12 \pm 0.04 \mathrm{~nm}$ in the vacancy-pits.

On the terraces, we resolve two different structures. The first is the diagonal row structure characteristic of the A-terraces. The second is a checkerboard pattern that seems 
to emanate from down-going step edges. Figure 20 shows the two types of surface structures. Figure 20(a) is a raw image, and Figure 20(b) is the same image after differentiation, which emphasizes boundaries between regions and thus makes the diagonal-row phase more distinguishable from the checkerboard phase. Figure 20(c) is a magnified view of the black box in Figure 20(b), which encompasses both structures.

Figure 20(d) is the profile of the line in Figure 20(c), which also crosses both structures. The checkerboard patches are separated from the diagonal row structure by a ridge, marked by an asterisk $(*)$ in the line profile of Figure 20(d). From the image in Figure 20(c), the ridge has a height of $0.16 \pm 0.04 \mathrm{~nm}$. Furthermore, the line profile in Figure 20(d) shows a height difference of $0.04 \mathrm{~nm}$ between the two structures.

For the diagonal row structure, the height of the rows is $0.04 \pm 0.01 \mathrm{~nm}$ (relative to the valley between them), and the separation between rows is $0.90 \pm 0.02 \mathrm{~nm}$. Relative to the structure observed at $900 \mathrm{~K}$ annealing, the row height is identical and the row separation is slightly smaller $(0.90 \pm 0.02 \mathrm{~nm}$ vs. $1.04 \pm 0.03 \mathrm{~nm})$. In addition, the angle is slightly smaller, $61^{\circ} \pm 1^{\circ}$ relative to $900 \mathrm{~K}$. A clear difference is that after $1200 \mathrm{~K}$ annealing, the diagonal rows show fewer protrusions and depressions. It is not clear whether the differences between the diagonal row structure at $900 \mathrm{~K}$ and $1200 \mathrm{~K}$ are significant enough to signal two different surface phases.

Figure 20(e) is a higher-magnification view of the checkerboard structure. The angle between the two principle axes is $96 \pm 1^{\circ}$. The average surface unit cell length is $0.44 \pm 0.04 \mathrm{~nm}$ along the near-horizontal direction and $0.40 \pm 0.03 \mathrm{~nm}$ along the nearvertical direction. We conclude that the surface unit cell is square or nearly so. 


\subsubsection{Summary of STM Data}

The progression of surface structures on the two samples is summarized in Table 6. While there are differences between the two sets of data, they have the following features in common.

1) There are two main types of terraces, A- and B-type.

- A-terraces have parallel lines, interspersed with shallow depressions and low protrusions.

- Characteristics of the fine structure on A-terraces:

- Parallel lines are $1.04 \mathrm{~nm}$ apart and $0.04 \mathrm{~nm}$ high.

- Parallel lines (aka diagonal lines) have same orientation on all A-terraces.

- Low protrusions are $0.10 \mathrm{~nm}$ high and shallow depressions are $0.09 \mathrm{~nm}$ deep. Their total areas are comparable, suggesting that they may be related.

- B-terraces have bumps that are 0.3-0.4 nm high (Table 4).

- A- and B-terraces alternate. Under some conditions they have about equal areas and the alternation is striking (cf. sample \#1 at $1200 \mathrm{~K}$ in Figure $1200 \mathrm{~K} 1$ and sample \#2 at $900 \mathrm{~K}$ in Figure $15(\mathrm{~g}-\mathrm{h}))$. Under other conditions one terrace constitutes the majority, but even then, there are small protrusions at step edges that are probably extensions of the other terrace.

- Step heights are rather robust: 
- Steps that separate A-A or B-B terraces are $0.75 \mathrm{~nm}$ high (Table 2).

- Steps that separate A-B terraces are 0.3-0.4 nm high (Table 3).

- In one experiment, a striking checkerboard pattern was adjacent to a A-like structure.

- Its surface unit cell is square or nearly so.

- Lateral dimensions are $0.40 \mathrm{~nm}$ and $0.44 \mathrm{~nm}$.

- Angle between basis vectors is $96^{\circ}$.

These features will be used to correlate surface structure with bulk structure in Section 5 .

\section{Comparison of STM Results (Section 4.2) with Bulk Structure}

For purposes of discussion, it is convenient to divide the surface information into two parts:

1) Step heights, and lateral arrangement of terraces; and

2) Fine structure on the terraces.

Part (1) consists of these specific facts.

- A- and B-terraces alternate.

- Steps that separate A-A or B-B terraces are $0.75 \mathrm{~nm}$ high.

- Steps that separate A-B terraces are 0.31-0.39 $\mathrm{nm}$ high.

The objective is to see whether the bulk structure can be terminated in a way that is consistent with these observations. Consider the representation of the bulk in Figure 21. This shows that, perpendicular to the $\langle 010\rangle$ axis, there are three kinds of dense planes. Two are pure Gd, and one is mixed Ge-Gd. The two pure, dense Gd planes are 
mirror images. One way to describe their difference is that one has a dilute layer of Ge above, and the other has a dilute layer of Ge below. We will name the three dense planes $\mathrm{Gd}_{\mathrm{d} 1}, \mathrm{Gd}_{\mathrm{d} 2}$, and $\mathrm{Ge}-\mathrm{Gd}_{\mathrm{d}}$ as shown in the Figure. There are also two kinds of dilute (sparse) planes of Ge atoms, labeled $\mathrm{Ge}_{\mathrm{s} 1}$ and $\mathrm{Ge}_{\mathrm{s} 2}$.

First, it is apparent that the measured separation between A-A or B-B planes, 0.75 $\mathrm{nm}$, is half the b-axis, $1.48 \mathrm{~nm}$. This is entirely reasonable, since the bulk unit cell consists of two equivalent slabs that are stacked in the b-direction.

Second, we can rule out the possibility that terraces A and B are dense Gd and Ge-Gd planes (or vice-versa). If that were the case, the A-B step height would be either 0.21 or $0.53 \mathrm{~nm}$ based on the bulk structure. Both values are incompatible with our experimental data, for which the average values range from 0.31 to $0.39 \mathrm{~nm}$ (Table 3 , right two columns). Furthermore, one might well expect that both of the dense Gd planes would serve as terminations, in addition to the Ge-Gd plane, since the dense Gd planes are rather similar to one another. Then there would be three different terminations, not two as observed.

On the other hand, if terraces $\mathrm{A}$ and $\mathrm{B}$ are $\mathrm{Gd}_{\mathrm{d} 1}$ and $\mathrm{Gd}_{\mathrm{d} 2}$ planes, there is a good match with the data. The A-B step height would be 0.32 and $0.42 \mathrm{~nm}$ based on the bulk structure, which is much more compatible with the experimental range of average values, 0.31 to $0.39 \mathrm{~nm}$. Furthermore, there would be only two types of terminations and they would alternate, as observed. We conclude that the A- and B-terminations correspond to $\mathrm{Gd}_{\mathrm{d} 1}$ and $\mathrm{Gd}_{\mathrm{d} 2}$ planes, although we do not know which is which based upon this analysis.

Part (2), the fine structure on the terraces, consists of these facts: 
- A-terraces have parallel lines, interspersed with shallow depressions and low protrusions.

- Parallel lines are $1.04 \mathrm{~nm}$ apart and $0.04 \mathrm{~nm}$ high.

- Parallel lines have identical orientation on all A-terraces.

- Low protrusions are $0.10 \mathrm{~nm}$ high and shallow depressions are $0.09 \mathrm{~nm}$ deep. Their total areas are comparable, suggesting that they are related.

- B-terraces have bumps that are 0.3-0.4 nm high.

- A checkerboard pattern was found embedded in an A-like terrace.

- Its lateral dimensions are $0.40 \mathrm{~nm}$ and $0.44 \mathrm{~nm}$.

- The angle between its basis vectors in the surface plane is $96^{\circ}$.

A natural question is, what is relationship between the parallel lines on the Aterraces and the bulk atomic structure? In order to answer this, it is necessary to determine the orientation of the bulk basis vectors $\vec{a}$ and $\vec{c}$, which are illustrated in Figure 3. We made this determination in two independent ways. One relied on the presence of the $\mathrm{Gd}_{5} \mathrm{Ge}_{3}$ secondary phase in the $\mathrm{Gd}_{5} \mathrm{Ge}_{4}$ sample [23]. This phase forms thin plates which, on (010) surface, lie in two different directions that do not intersect at right angles. The bulk basis vector $\vec{a}$ bisects the acute angle, and the vector $\vec{c}$ bisects the obtuse angle. We identified the orientation of the secondary phase plates using optical microscopy, and made the assignment of $\vec{a}$ and $\vec{c}$ in our sample based on this information. The second way was to use X-ray diffraction, which was performed by Dr. Deborah Schlagel in the Materials Preparation Center of the Ames Laboratory. (A small portion was cut from 
Sample \#2 for this purpose.) Both of these approaches were consistent. The resultant vectors $\vec{a}$ and $\vec{c}$ are shown in Figure 16; the accuracy of this determination is believed to be about $\pm 5^{\circ}$. The parallel lines in the STM image make an angle of about $28^{\circ}$ with $\vec{c}$. This orientation is shown by the straight diagonal line in Figure 3. It appears that there is no simple relationship between the orientation of the parallel lines in the STM images and the bulk-terminated structure. We therefore suggest that the surface of this material deviates from the bulk-terminated structure.

The B-terraces have bumps that are 0.3-0.4 $\mathrm{nm}$ high. Their height is the same as the spacing between adjacent dense Gd-pure planes, as shown in Figure 21. Perhaps these bumps are regions where the B-terraces are 'rebuilding' into A-terraces. If that is the case, however, the bumps seem unexpectedly stable in the sense that they are observed over a broad range of annealing temperatures.

Finally, the identity of the checkerboard pattern is interesting. Among known phases in the Gd-Ge system, it fits reasonably well with GdGe. This material is orthorhombic with lattice constants $\mathrm{a}=0.42 \mathrm{~nm}$ and $\mathrm{c}=0.40 \mathrm{~nm}$. The lateral dimensions of the checkerboard phase measured with STM are 0.44 and $0.40 \mathrm{~nm}$. Only a small depletion of $\mathrm{Gd}$ (or enrichment in $\mathrm{Ge}$ ), relative to $\mathrm{Gd}_{5} \mathrm{Ge}_{4}$, would be needed to stabilize this phase. 


\section{Characterizing Gd ${ }_{5} \underline{G e}_{3}$ Thin Plates (Samples \#2 and \#4)}

The goal of this part of the project was to identify the 5:3 plates, to determine whether they undergo any changes after different surface treatments, and to understand their effect on STM.

\subsection{Characterizing $\mathrm{Gd}_{5} \mathrm{Ge}_{3}$ Thin Plates: Optical Microscopy (Sample \#4)}

Using optical microscopy, we were able to easily find 5:3 thin plates everywhere on the $\mathrm{Gd}_{5} \mathrm{Ge}_{4}(010)$ surface. An example is shown in Figure 22. Figure 22(a) was taken before any experiments were performed on the surface and Figure 22(b) was taken after SEM, AES, and SAM experiments were performed. These experiments will be discussed in sections that follow. As we can see from Figure 22, the thin plates lie in two different directions at an $83^{\circ}$ angle when viewed from the (010) direction. This compares well with the angle of $80^{\circ}$ reported in the literature and helps to confirm that we identify these features correctly. The width of the thin plates varies from $0.40 \mu \mathrm{m}$ to $2 \mu \mathrm{m}$. The relative area of the 5:3 thin plates was $2.3 \pm 0.2 \%$ before any other experiments were performed (Figure 22(a)) and $2.1 \pm 0.6 \%$ after other experiments were performed (Figure 22(b)), i.e. there was no change in the area covered by the plates. In other words, the sputtering and annealing processes described below did not change the relative population of the 5:3 phase in the 5:4 matrix.

\subsection{Characterizing $\mathrm{Gd}_{5} \mathrm{Ge}_{3}$ Thin Plates: SEM, AES and SAM (Sample \#4)}

In this set of experiments, we explored whether the 5:3 plates change after different surface treatments. 
After the sample was placed into the SEM/AES/SAM chamber, the first surface treatment was one full cleaning cycle (10 minutes sputtering and 1 hour annealing at 900 K). The SEM image shown in Figure 23 was then acquired. The 5:3 plates are visible. They lie in two different directions at an $84^{\circ}$ angle, consistent with the optical microscopy results (Figure 22). The dotted lines in the figure represent the two different directions of the 5:3 thin plates.

Figure 24(a) is an SEM of a surface region at higher magnification. Note especially the bright line, about $0.3 \mu \mathrm{m}$ wide, that crosses left to right about halfway down the image. This is a 5:3 thin plate, based upon the SAM images in Figure 24(b-c). Figure 24(b) is a Gd map, showing that the bright line in Figure 24(a) is Gd-rich compared with the surrounding 5:4 matrix, while Figure 24(c) is a Ge map showing that the line is Ge-poor. The other marks in Figure 24(a) are probably scratches from polishing or handling.

Semi-quantitative verification of the phase assignments is available from AES. Figure 25 is an SEM image, showing another bright line on the surface. Auger spectra were acquired at the points labeled 1-6, and the compositions from Auger analysis are given in the table below the image. The first three numbered points $(1,2$, and 3$)$ are on the darker matrix and the last three points $(4,5$, and 6$)$ are on the bright line. From the table included in the Figure, the surface compositions at points 1, 2, and 3 are consistent with the bulk compositions of $\mathrm{Gd}$ and $\mathrm{Ge}$ in the $\mathrm{Gd}_{5} \mathrm{Ge}_{4}$ phase. However, the surface compositions at points 4,5 , and 6 do not match the nominal composition of $\mathrm{Gd}_{5} \mathrm{Ge}_{4}(55$ at. $\% \mathrm{Gd}, 45$ at. $\% \mathrm{Ge}$ ). In fact, they are closer to the ideal composition of $\mathrm{Gd}_{5} \mathrm{Ge}_{3}(63$ at. $\% \mathrm{Gd}, 37$ at. $\% \mathrm{Ge})$. 
The next treatment consisted of several $\mathrm{Ar}^{+}$sputtering cycles (without annealing), until AES detected no carbon or oxygen on the surface. The SEM image shown in Figure 26(a) shows the clean surface after this treatment. The dark shadow that crosses left to right, about halfway down the image, is a 5:3 thin plate. This is based upon the Gd map in Figure 26(b), showing Gd-enrichment along the line, and the Ge map in Figure 26(c), showing Ge-depletion along the line. The other linear marks in Figure26(a) are probably scratches from polishing or handling.

Finally, the sample was subjected to six full cleaning cycles (sputtering plus annealing at $900 \mathrm{~K}$ for 30 minutes), and several SEM images were taken after each cycle. Some are shown in Figure 27. Figure 27(a) was taken after the third cleaning cycle, Figure 27(b) after the fourth, Figure 27(c) after the fifth, and Figure 27(d) after the sixth. In these 4 panels, lumps appear, and they increase in density and size with each cleaning cycle. These lumps eventually aggregate along the scratches and also along the 5:3 plates (Figure 27(d)). This assignment rests on Figure 27(f), where the red lines show the features that are probably the 5:3 plates. Many of the marked lines are parallel, and another line lines make an angle of $88^{\circ}$ with the parallel group, making them all likely 5:3 plates. On the other hand, some of the lines decorated by lumps are simply scratches, since they make angles that are far from the angle of $83^{\circ}$ observed in optical microscopy (Section 4.5.1).

AES was performed at five different locations on the $\mathrm{Gd}_{5} \mathrm{Ge}_{4}(010)$ surface after the sixth cleaning cycle. Results are shown in Figure 28. Locations 3, 4, and 5 are on the lumps, while positions 1 and 2 are on the smoother region. The surface compositions of these five different AES locations are shown in the table in Figure 28. The lumps have a 
lower Gd surface composition and correspondingly higher Ge concentration than the 5:4 matrix (which is opposite to the 5:3 phase). Their average composition is 47 at. $\%$ Gd and 53 at. $\%$ Ge. Among the bulk phases listed in Table 1 , the closest match in composition is GdGe. Of course, the area analyzed with AES is not necessarily a single phase. It is interesting, however, that GdGe is the same phase that is the most likely candidate for the checkerboard pattern in STM, seen after annealing Sample \#2 to 1200 K (see Section 5.)

After annealing at a higher annealing temperature, $1150 \mathrm{~K}$ for 30 minutes, more lumps are seen in SEM. This is shown in Fig. 29. AES was performed at four different locations (four different lumps) on the $\mathrm{Gd}_{5} \mathrm{Ge}_{4}(010)$ surface. These points are shown in Fig. 29(c). The surface compositions of the lumps are shown in the table in Fig. 29. The lumps have a lower Gd surface composition and a higher Ge concentration than at the lower annealing temperature of $900 \mathrm{~K}$. Their average composition is now 39 at. \% Gd and 59 at. $\% \mathrm{Ge}$, This composition has the closest match to $\mathrm{Gd}_{3} \mathrm{Ge}_{5}$ when comparing it to the bulk phases listed in Table 1. Regardless of whether the lumps correspond to a single phase, one can conclude that their formation, on this sample, is associated with loss of Gd at the surface at high temperature. As we will see in the following section, however, this phenomenon is not universal among the samples.

\subsection{Characterizing $\mathrm{Gd}_{5} \mathrm{Ge}_{3}$ Thin Plates: SEM (Sample \#2)}

The results described in Section 6.2 suggest that sputter-annealing cycles may cause large changes in surface morphology-specifically, lumps, which form preferentially at surface scratches and at the $\mathrm{Gd}_{5} \mathrm{Ge}_{3}$ phase inclusions. We therefore checked whether lumps were also present on the surface of a sample after it had been 
annealed and used for STM experiments, Sample \#2. Sample \#2 was used for the STM experiments described in Section 4.3.2. It was extensively sputter-annealed, and its treatments included annealing at $1200 \mathrm{~K}$. It was then transferred to the SEM/SAM/AES chamber. SEM images of the sample's surface are shown in Fig. 30. In Fig. 30(a), we begin to see the usual 5:3 thin plates. The black dotted lines in the figure represent the two different directions, as expected. High magnification SEM images are shown in Figs. 30(b) and 30(c). There are no lumps on this surface. Thus, the lumps do not complicate the interpretation of the STM data in Section 4. The reasons why lumps formed on Sample \#4 but not on Sample \#2, under comparable conditions, is not known. One difference is that the base pressure in the SAM/AES chamber, where Sample \#4 was sputtered and annealed, was at least an order of magnitude higher than the base pressure in the STM/XPS chamber, where Sample \#2 was sputtered and annealed. Conceivably, some reaction with background gas or impurity in the sputtering gas triggered growth of the lumps on Sample \#4 but not on Sample \#2.

\subsection{Characterizing $\mathrm{Gd}_{5} \mathrm{Ge}_{3}$ Thin Plates: STM (Sample \#2)}

With STM, we would expect to see two different phases: the $\mathrm{Gd}_{5} \mathrm{Ge}_{4}$ matrix and areas of embedded $\mathrm{Gd}_{5} \mathrm{Ge}_{3}$. However, in STM (as presented in Section 4.2), we did not find two distinct phases. Generally, features were very similar all over the sample, except for differences due to thermal gradients with sample \#2. This might be due to the fact that the $\mathrm{Gd}_{5} \mathrm{Ge}_{3}$ thin plates comprise only $2 \%$ of the surface area (as shown in Section 6.1), so it is statistically unlikely that the STM tip will happen to land on a thin plate. Therefore, 
we looked for evidence of the thin plates with STM over much larger areas, i.e. at lower magnification.

Figure 31 shows different surface areas ranging from $2 \mu \mathrm{m} \times 2 \mu \mathrm{m}$ to $4 \mu \mathrm{m} \times 4$ $\mu \mathrm{m}$, after annealing to $900 \mathrm{~K}$. Large-scale linear features are present. These may be plates or scratches. In Figure 31(a), two parallel lines are shown going across the surface. The lines are $0.9 \mu \mathrm{m}$ apart. If they are boundaries of a thin plate, then its width is $0.9 \mu \mathrm{m}$, which is a plausible value. However, it may also represent a polishing mark or other type of scratch. The same is true of the diagonal lines shown in Figures 31(b-d).

Figure 32(a) shows another region on the terrace where there is a $1.19 \mu \mathrm{m}$-wide linear stripe that cuts roughly horizontally through the figure. This again is a candidate for a thin plate. Figure 32(b) shows a closer view that includes the region above the stripe, and an upper part of the stripe. The terraces inside and outside the stripe are visibly different. In Figure 32(a), several vacancy-pits are present above and below the stripe, while within the stripe, there are no visible pits on terraces. This suggests that the regions may represent two different phases. In addition, bumps and elongated islands appear above and below the stripe, but not within the stripe. Figure 32(c) shows a closer view of part of the upper area and Figure 32(d) shows terraces within the stripe. In Figure 32(c), the elongated islands are aligned along two different directions, making an angle of about $70^{\circ}$. These elongated islands are not typical of the surface. 


\section{Conclusions}

We have characterized the (010) surface of $\mathrm{Gd}_{5} \mathrm{Ge}_{4}$ using STM and XPS. XPS reveals the surface compositions to be within \pm 5 at. $\%$ with its bulk composition, both after sputtering and annealing at various temperatures. With STM, the surface exhibits two main types of terraces which alternate across the surface. Step heights between similar terraces correspond well to the separation between equivalent layers along the $<010>$ direction in the bulk structure, and step heights between dissimilar terraces correspond to the distance between certain dissimilar but dense layers. In addition, two fine structure types appeared on terraces at various annealing temperatures. (1) Diagonal lines after the sample had been annealed to $900 \mathrm{~K}$ and (2) checkerboard pattern after the sample had been annealed to $1200 \mathrm{~K}$. These fine structures do not correlate with the bulk structure, and therefore, we suggest that there is significant surface reconstruction.

In addition, we also characterized the $\mathrm{Gd}_{5} \mathrm{Ge}_{3}$ secondary phase on the $(010)$ surface of $\mathrm{Gd}_{5} \mathrm{Ge}_{4}$ using OM, SEM, AES, SAM, and STM. As expected, thin plates were seen using $\mathrm{OM}$ and $\mathrm{SEM}$ on the $\mathrm{Gd}_{5} \mathrm{Ge}_{4}$ surface. These thin plates were identified as the $\mathrm{Gd}_{5} \mathrm{Ge}_{3}$ secondary phase based on their compositions from AES and SAM. In STM images at low magnification, long stripes can be found on the surface, with widths between $0.9 \mu \mathrm{m}$ and $1.19 \mu \mathrm{m}$. These may be thin plates, or polishing scratches.

\section{Acknowledgments}

This research was supported by the U.S. Department of Energy, Office of Basic Energy Sciences, Division of Materials Sciences and Engineering, under Contract No. DE-AC02-07CH11358. James W. Anderegg, Mark Wallingford, and Holly Walen 
assisted with some of the experiments. D. L. Schlagel expertly grew, oriented, and polished the samples, and performed optical microscopy. Shalabh Gupta and Srinivasa Thimmaiah gave insights into the bulk structure, and assisted in its representation. We thank them all.

\section{$\underline{\text { References }}$}

[1] D. Paudyal, V.K. Pecharsky, K.A. Gschneidner, B.N. Harmon, Physical Review B 75 (2007) 094427.

[2] D. Paudyal, V.K. Pecharsky, K.A. Gschneidner, Journal of Physics-Condensed Matter 20 (2008) 235235.

[3] J.D. Moore, G.K. Perkins, Y. Bugoslavsky, M.K. Chattopadhyay, S.B. Roy, P. Chaddah, V.K. Pecharsky, K.A. Gschneidner, L.F. Cohen, Applied Physics Letters 88 (2006) 072501.

[4] V.K. Pecharsky, J.K.A. Gschneidner, Physical Review Letters 78 (1997) 44944497.

[5] E. Bruck, O. Tegus, D.T.C. Thanh, K.H.J. Buschow, Journal of Magnetism and Magnetic Materials 310 (2007) 2793-2799.

[6] G.S. Smith, A.G. Tharp, W. Johnson, Acta Crystallographica 22 (1967) 940-943.

[7] F. Holtzberg, R.J. Gambino, T.R. McGuire, Journal of Physics and Chemistry of Solids 28 (1967) 2283-2289.

[8] Samples were synthesized at the Materials Preparation Center, Ames Laboratory USDOE, Ames, IA, USA. 
[9] D.L. Schlagel, T.A. Lograsso, A.O. Pecharsky, J.A. Sampaio, Light Metals 2005 (2005) $1177-1180$

1236.

[10] T. Cai, Scanning Tunneling Microscopy Studies of Surface Structures of Icosahedral Al-Cu-Fe Quasicrystals, Iowa State University, Ames, 2001.

[11] See www.CasaXPS.com.

[12] I. Horcas, R. Fernandez, J.M. Gomez-Rodriguez, J. Colchero, J. Gomez-Herrero, A.M. Baro, Review of Scientific Instruments 78 (2007) -.

[13] T.B. Massalski, H. Okamoto, P.R. Subramanian, L. Kacprzak (Eds.), Binary Alloy Phase Diagrams, ASM International, Materials Park, Ohio, 1990.

[14] V.K. Pecharsky, K.A. Gschneidner, Journal of Alloys and Compounds 260 (1997) 98-106.

[15] P. Eckerlin, H. Kandler, GaVO - GeLaS, SpringerMaterials - The LandoltBornstein Database.

[16] P.H. Tobash, D. Lins, S. Bobev, N. Hur, J.D. Thompson, J.L. Sarrao, Inorganic Chemistry 45 (2006) 7286-7294.

[17] H.F. Yang, G.H. Rao, G.Y. Liu, Z.W. Ouyang, W.F. Liu, X.M. Feng, W.G. Chu, J.K. Liang, Journal of Alloys and Compounds 361 (2003) 113-117.

[18] G.S. Smith, Q. Johnson, A.G. Tharp, Acta Crystallographica 22 (1967) 269-272.

[19] A.O. Pecharsky, K.A. Gschneidner, V.K. Pecharsky, C.E. Schindler, Journal of Alloys and Compounds 338 (2002) 126-135.

[20] J. Szade, G. Skorek, A. Winiarski, Journal of Crystal Growth 205 (1999) 289-293. 
[21] O. Ugurlu, L.S. Chumbley, D.L. Schlagel, T.A. Lograsso, A.O. Tsokol, Scripta Materialia 53 (2005) 373-377.

[22] J.S. Meyers, L.S. Chumbley, F. Laabs, A.O. Pecharsky, Scripta Materialia 47 (2002) 509-514.

[23] O. Ugurlu, L.S. Chumbley, D.L. Schlagel, T.A. Lograsso, Acta Materialia 53 (2005) 3525-3533.

[24] L.S. Chumbley, O. Ugurlu, R.W. McCallum, K.W. Dennis, Y. Mudryk, K.A. Gschneidner Jr, V.K. Pecharsky, Acta Materialia 56 (2008) 527-536.

[25] E.I. Gladyshevskii, Journal of Structural Chemistry 5 (1965) 852-853.

[26] N.C. Baenziger, J.J. Hegenbarth, Acta Crystallographica 17 (1964) 620-621.

[27] O. Ugurlu, L.S. Chumbley, D.L. Schlagel, T.A. Lograsso, Acta Materialia 54 (2006) 1211-1219.

[28] Q. Cao, L.S. Chumbley, Z. Qian, Intermetallics 18 1021-1026.

[29] C.J. Jenks, J.W. Burnett, D.W. Delaney, T.A. Lograsso, P.A. Thiel, Applied Surface Science 157 (2000) 23-28. 


\section{$\underline{\text { Figure Captions }}$}

\section{Figure 1}

Typical temperature-power and temperature-time cooling rate after the $\mathrm{Gd}_{5} \mathrm{Ge}_{4}(010)$ had been annealed to (a-b) $900 \mathrm{~K}$ and (c-d) $1200 \mathrm{~K}$. Sample \#1 and Sample \#2. NOTE: Temperature readings are based on power calibration.

\section{Figure 2}

Phase diagram on the Gd-Ge binary alloys. Reprinted with permission of ASM International. All rights reserved. www.asminternational.org.

\section{Figure 3}

Bulk unit cell structure of the $\mathrm{Gd}_{5} \mathrm{Ge}_{4}$ binary alloy, (a) side view and (b) top view. Dimensions are taken from Yang et al. J. Alloys and Comps. 361 (2003), 113. The rectangular box (a) and square box (b) represents the unit cell.

\section{Figure 4}

XPS depth profile of Gd and Ge after the (010) sample was introduced from air to UHV at $300 \mathrm{~K}$. Bulk compositions are shown for reference by the horizontal dash lines. Sample $\# 1$.

\section{Figure 5}

Surface composition as a function of annealing temperature on two photoelectron peaks, Gd $3 d_{5 / 2}$ and Ge $2 p_{1 / 2}$. (a) Sample \#1. (b) Sample \#2. Error bars represent the standard deviation. The error bar on the Ge concentration at $1200 \mathrm{~K}$ in (a) is shifted laterally, to prevent confusing overlap with the Gd error bar The opened squares and diamonds in (b) are Sample \#3.

\section{Figure 6}

XPS depth-profiles after annealing at different temperatures. The surface concentration is shown in at. \% as a function of sputtering time based on two photoelectron peaks. (a) Gd $3 \mathrm{~d}_{5 / 2}$, (b) Ge $2 \mathrm{p}_{1 / 2}$. In (c) and (d) the curves are displaced vertically so they can be shown without overlap. The surface was sputtered for two minute intervals, for ten minutes in total, except for the cure that follows annaeling at $900 \mathrm{~K}$. There the interval was the same but the total duration was 28 minutes. Dotted lines represent the bulk concentrations. All curves represent Sample \#1 except for the $900 \mathrm{~K}$ data, which represent Sample \#2.

\section{Figure 7}

XPS depth-profiles after annealing at different temperatures. The surface concentration is shown in at. $\%$ as a function of sputtering time based on two photoelectron peaks. (a) Gd 
$3 \mathrm{~d}_{5 / 2}$, (b) Ge $2 \mathrm{p}_{1 / 2}$. In (c) and (d) the curves are displaced vertically so they can be shown without overlap. The surface was sputtered for 30 second intervals, for ten minutes in total. Dotted lines represent the bulk concentrations. All curves represent Sample \#3.

\section{Figure 8}

STM images of the $\mathrm{Gd}_{5} \mathrm{Ge}_{4}(010)$ rough surface after annealing at $900 \mathrm{~K}$ and sputtering at room temperature, (a) $500 \mathrm{~nm} \times 500 \mathrm{~nm}, \mathrm{I}=0.5 \mathrm{nA}, \mathrm{V}$-tip $=-1 \mathrm{~V}$, (b) line profile taken from the black arrowhead in (a), (c) $500 \mathrm{~nm} \times 500 \mathrm{~nm}, \mathrm{I}=0.5 \mathrm{nA}$, V-tip $=-1 \mathrm{~V}$, (d) line profile taken from the black arrowhead in (c), (e) $500 \mathrm{~nm} \times 500 \mathrm{~nm}, \mathrm{I}=0.5 \mathrm{nA}, \mathrm{V}$-tip = $1 \mathrm{~V}$, and (f) line profile taken from the black arrowhead in (e). Sample \#1.

\section{Figure 9}

STM images of the $\mathrm{Gd}_{5} \mathrm{Ge}_{4}(010)$ surface after annealing at $900 \mathrm{~K}$ and sputtering at room temperature, (a) $250 \mathrm{~nm} \times 250 \mathrm{~nm}, \mathrm{I}=0.5 \mathrm{nA}, \mathrm{V}$-tip $=-1 \mathrm{~V}$, (b) $100 \mathrm{~nm} \times 100 \mathrm{~nm}, \mathrm{I}=0.5$ $\mathrm{nA}, \mathrm{V}$-tip $=+1 \mathrm{~V}$, (c) line profile corresponding to arrow in panel (b), and (d) $50 \mathrm{~nm} \times 50$ $\mathrm{nm}, \mathrm{I}=0.5 \mathrm{nA}, \mathrm{V}$-tip $=-1 \mathrm{~V}$. Each frame is a magnification of part of the previous image, outlined in the box. Sample \#1.

\section{Figure 10}

STM images of the $\mathrm{Gd}_{5} \mathrm{Ge}_{4}(010)$ surface after annealing at $900 \mathrm{~K}$. (a) $100 \mathrm{~nm} \times 100 \mathrm{~nm}$, $\mathrm{I}=0.5 \mathrm{nA}$, V-tip $=+1 \mathrm{~V}$, (b) $250 \mathrm{~nm} \times 250 \mathrm{~nm}, \mathrm{I}=0.5 \mathrm{nA}, \mathrm{V}$-tip $=+1 \mathrm{~V}$, (c) $100 \mathrm{~nm} \mathrm{x}$ $100 \mathrm{~nm}, \mathrm{I}=0.5 \mathrm{nA}, \mathrm{V}$-tip $=+1 \mathrm{~V}$, and (d) $250 \mathrm{~nm} \times 250 \mathrm{~nm}, \mathrm{I}=0.5 \mathrm{nA}, \mathrm{V}$-tip $=+1 \mathrm{~V}$. Sample \#1.

\section{Figure 11}

STM images at room temperature after the sample were annealed to $1050 \mathrm{~K}$ for 15 minutes. Surface features show (a) bumps on B-terraces and the emergence of A-terraces, (b) the emergence of A-terraces. All STM images are $100 \mathrm{~nm} \times 100 \mathrm{~nm}$ and tunneling conditions are (a) $\mathrm{I}=0.5 \mathrm{nA}, \mathrm{V}$-tip $=+1 \mathrm{~V}$ and (b) $\mathrm{I}=0.5 \mathrm{nA}, \mathrm{V}$-tip $=-1 \mathrm{~V}$. Sample \#1.

\section{Figure 12}

STM images at room temperature after the sample was annealed to $1100 \mathrm{~K}$ for 15 minutes. Surface features show (a) bumps on B-terraces and the emergence of A-terraces; (b) bumps on B-terraces the emergence of A-terraces. STM images and tunneling conditions are (a) $250 \mathrm{~nm} \times 250 \mathrm{~nm}, \mathrm{I}=0.5 \mathrm{nA}, \mathrm{V}$-tip $=-1 \mathrm{~V}$, and (b) $100 \mathrm{~nm} \times 100 \mathrm{~nm}, \mathrm{I}$ $=0.5 \mathrm{nA}$, V-tip $=-1 \mathrm{~V}$. Sample \#1. 


\section{Figure 13}

STM images at room temperature after the sample were annealed to $1150 \mathrm{~K}$ for 15 minutes. Surface features show (a) bumps on B-terraces and the emergence of A-terraces; (b-c) close-up view of the bumps; (d) bumps on B-terraces and the emergence of Aterraces. STM image sizes are as follows: (a) $100 \mathrm{~nm} \times 100 \mathrm{~nm}, \mathrm{I}=0.5 \mathrm{nA}, \mathrm{V}$-tip $=+1 \mathrm{~V}$; (b) $50 \mathrm{~nm} \times 50 \mathrm{~nm}, \mathrm{I}=0.5 \mathrm{nA}, \mathrm{V}$-tip $=+1 \mathrm{~V}$; (c) $50 \mathrm{~nm} \times 50 \mathrm{~nm}, \mathrm{I}=0.5 \mathrm{nA}, \mathrm{V}$-tip $=-1$ V; (d) $100 \mathrm{~nm}$ x $100 \mathrm{~nm}, \mathrm{I}=0.5 \mathrm{nA}$, V-tip = +0.5 V. Sample \#1.

\section{Figure 14}

STM images on the $\mathrm{Gd}_{5} \mathrm{Ge}_{4}$ (010) surface after it had been annealed to $1200 \mathrm{~K}$, (a) 250 $\mathrm{nm} \times 250 \mathrm{~nm}, \mathrm{I}=0.5 \mathrm{nA}$, V-tip $=+1 \mathrm{~V}$ (middle), (b) $100 \mathrm{~nm} \times 100 \mathrm{~nm}, \mathrm{I}=0.5 \mathrm{nA}$, V-tip $=+1 \mathrm{~V}$ (middle), and (c) $100 \mathrm{~nm} \times 100 \mathrm{~nm}, \mathrm{I}=0.5 \mathrm{nA}, \mathrm{V}$-tip $=+1 \mathrm{~V}$ (middle). Sample $\# 1$.

\section{Figure 15}

STM images on the $\mathrm{Gd}_{5} \mathrm{Ge}_{4}$ (010) surface after it had been annealed to $900 \mathrm{~K}$, (a) $500 \mathrm{~nm}$ x $500 \mathrm{~nm}, \mathrm{I}=0.5 \mathrm{nA}, \mathrm{V}$-tip $=+1 \mathrm{~V}$ (middle sample), (b) $250 \mathrm{~nm}$ x $250 \mathrm{~nm}, \mathrm{I}=0.5 \mathrm{nA}$, $\mathrm{V}$-tip $=+1 \mathrm{~V}$ (middle sample), (c) line profile taken from the black arrowhead in (b), (d) $1000 \mathrm{~nm} \times 1000 \mathrm{~nm}, \mathrm{I}=0.5 \mathrm{nA}, \mathrm{V}$-tip = +1 V (right side sample), (e) $500 \mathrm{~nm}$ x $500 \mathrm{~nm}, \mathrm{I}$ $=0.5 \mathrm{nA}, \mathrm{V}$-tip $=+1 \mathrm{~V}$ (right side sample), (f) line profile taken from the black arrowhead in (e), (g) $250 \mathrm{~nm} \times 250 \mathrm{~nm}, \mathrm{I}=0.5 \mathrm{nA}, \mathrm{V}$-tip $=+1 \mathrm{~V}$ (left side sample), (h), $100 \mathrm{~nm} \times 100 \mathrm{~nm}, \mathrm{I}=0.5 \mathrm{nA}$, V-tip = +1 V (left side sample), and (i) line profile taken from the black arrowhead in (h). Circles in (b) and (e) show B-terraces near A-terrace step edges. Sample \#2.

\section{Figure 16}

High magnification STM images of the $\mathrm{Gd}_{5} \mathrm{Ge}_{4}(010)$ surface after it had been annealed at $900 \mathrm{~K}$ for 1 hour which was then slowly cooled down to room temperature, (a) Aterrace fine structure showing diagonal rows, $33 \mathrm{~nm}$ x $31 \mathrm{~nm}, \mathrm{I}=0.5 \mathrm{nA}, \mathrm{V}$-tip $=+1 \mathrm{~V}$, (b) line profile taken from the black arrowhead in (a). Sample \#2. (c) B-terrace fine structure show bumps, $34 \mathrm{~nm} \times 27 \mathrm{~nm}, \mathrm{I}=0.5 \mathrm{nA}, \mathrm{V}$-tip $=+1 \mathrm{~V}$, (d) line profile taken from black arrowhead in (c). The parallel lines in the STM image (a) make an angle of about $28^{\circ}$ with $\vec{c}$. Sample \# 2 .

\section{Figure 17}

STM images on the $\mathrm{Gd}_{5} \mathrm{Ge}_{4}$ (010) surface after it had been annealed to $900 \mathrm{~K}$, (a-f) show the fine structures of A- and B-terraces, where the diagonal rows are on A-terraces and bumps on B-terraces. Rectangular boxes are zoomed-in images. The tunneling conditions are (a) $\mathrm{I}=0.5 \mathrm{nA}, \mathrm{V}$-tip $=+1 \mathrm{~V}$, (b) $\mathrm{I}=0.5 \mathrm{nA}, \mathrm{V}$-tip $=+1 \mathrm{~V}$, (c) $\mathrm{I}=0.5 \mathrm{nA}, \mathrm{V}$-tip $=+1$ 
$\mathrm{V}$, (d) $\mathrm{I}=0.5 \mathrm{nA}, \mathrm{V}$-tip $=+1 \mathrm{~V}$, (e) $\mathrm{I}=0.5 \mathrm{nA}, \mathrm{V}$-tip $=+1 \mathrm{~V}$, and (f) $\mathrm{I}=0.5 \mathrm{nA}, \mathrm{V}$-tip $=$ +1 V. Sample \#2.

\section{Figure 18}

STM images on the $\mathrm{Gd}_{5} \mathrm{Ge}_{4}$ (010) surface after it had been annealed to $1050 \mathrm{~K}$, (a) 1000 $\mathrm{nm} \times 1000 \mathrm{~nm}, \mathrm{I}=0.5 \mathrm{nA}$, V-tip $=-1 \mathrm{~V}$ (middle side), (b) $250 \mathrm{~nm} \times 250 \mathrm{~nm}, \mathrm{I}=0.5 \mathrm{nA}$, $\mathrm{V}$-tip $=+1 \mathrm{~V}$ (middle sample), (c) $1000 \mathrm{~nm} \times 1000 \mathrm{~nm}, \mathrm{I}=0.5 \mathrm{nA}, \mathrm{V}$-tip $=+1 \mathrm{~V}$ (right side sample), (d) $100 \mathrm{~nm} \times 100 \mathrm{~nm}, \mathrm{I}=0.5 \mathrm{nA}, \mathrm{V}$-tip $=+1 \mathrm{~V}$ ( right side sample), (e) $1000 \mathrm{~nm} \times 1000 \mathrm{~nm}, \mathrm{I}=0.5 \mathrm{nA}, \mathrm{V}$-tip $=+1 \mathrm{~V}$ (left side sample), and (f) $250 \mathrm{~nm} \times 250$ $\mathrm{nm}, \mathrm{I}=0.5 \mathrm{nA}, \mathrm{V}$-tip $=+1 \mathrm{~V}$ (left side sample). Sample \#2.

\section{Figure 19}

STM images on the $\mathrm{Gd}_{5} \mathrm{Ge}_{4}$ (010) surface after it had been annealed to $1200 \mathrm{~K}$, (a) 500 $\mathrm{nm} \times 500 \mathrm{~nm}, \mathrm{I}=0.5 \mathrm{nA}, \mathrm{V}$-tip $=-1 \mathrm{~V}$ (middle), (b) $250 \mathrm{~nm} \times 250 \mathrm{~nm}, \mathrm{I}=0.5 \mathrm{nA}$, V-tip $=-1 \mathrm{~V}$ (middle), (c) $1000 \mathrm{~nm} \times 1000 \mathrm{~nm}, \mathrm{I}=0.5 \mathrm{nA}, \mathrm{V}$-tip $=+1 \mathrm{~V}$ (right side), (d) 500 $\mathrm{nm} \times 500 \mathrm{~nm}, \mathrm{I}=0.5 \mathrm{nA}, \mathrm{V}$-tip $=+1 \mathrm{~V}$ (right side), (e) $500 \mathrm{~nm} \times 500 \mathrm{~nm}, \mathrm{I}=0.5 \mathrm{nA}, \mathrm{V}-$ tip $=-1 \mathrm{~V}$ (left side), (f) $250 \mathrm{~nm} \times 250 \mathrm{~nm}$ (left side), I $=0.5 \mathrm{nA}, \mathrm{V}$-tip $=+1 \mathrm{~V}$, (g) contour image showing the vacancy voids on surface in (f), and (h) contour image showing the vacancy voids on surface, $100 \mathrm{~nm} \times 100 \mathrm{~nm}, \mathrm{I}=0.5 \mathrm{nA}$, V-tip $=-1 \mathrm{~V}$ (left side). Sample \#2.

\section{Figure 20}

High magnification STM images of the $\mathrm{Gd}_{5} \mathrm{Ge}_{4}(010)$ surface after it had been annealed at $1200 \mathrm{~K}$ for 15 minutes which was then slowly cooled down to room temperature, (a) $250 \mathrm{~nm} \times 250 \mathrm{~nm}, \mathrm{I}=0.5 \mathrm{nA}, \mathrm{V}$-tip $=-1 \mathrm{~V}$, (b) differentiated image from (a), (c) $30 \mathrm{~nm} \times$ $16 \mathrm{~nm}, \mathrm{I}=0.5 \mathrm{nA}, \mathrm{V}$-tip $=-1 \mathrm{~V}$, (d) line profile from the black arrowhead in (c), and (e) $11.5 \mathrm{~nm} \times 7 \mathrm{~nm}, \mathrm{I}=0.5 \mathrm{nA}, \mathrm{V}$-tip $=-1 \mathrm{~V}$. The checkerboard patches are separated from the diagonal row structure by a ridge, marked by an asterisk $(*)$ in (c) and (d).

\section{Figure 21}

Showing dense planes on the bulk unit cell structure of the $\mathrm{Gd}_{5} \mathrm{Ge}_{4}$ binary alloy. Dimensions are taken from Yang et al. J. Alloys and Comps. 361 (2003), 113.

\section{Figure 22}

Images using optical microscopy (OM) showing 5:3 thin plates on the binary $\mathrm{Gd}_{5} \mathrm{Ge}_{4}$ alloy sample, (a) was taken before any experiments were performed and (b) was taken after. The black dotted lines behind the OM image are shown visually seeing the 5:3 thin plates. Sample \#4. 


\section{Figure 23}

SEM image of the binary $\mathrm{Gd}_{5} \mathrm{Ge}_{4}$ alloy sample that shows 5:3 thin plates after the sample had been annealed to $900 \mathrm{~K}$ for 30 minutes. The black dotted lines behind the SEM image are shown visually seeing the 5:3 thin plates. The 5:3 thin plates lie in two different directions at an $84^{\circ}$ angle. The red marker bar shows a length of $100 \mu \mathrm{m}$. Sample \#4.

\section{Figure 24}

Images of the binary $\mathrm{Gd}_{5} \mathrm{Ge}_{4}$ alloy sample that shows (a) the SEM image, and SAM images of (b) the Gd concentration and (c) the Ge concentration after first cleaning cycle. The red marker bar in (b) is $1 \mu \mathrm{m}$ long, and the scale is the same for all 3 panels. Sample \#4.

\section{Figure 25}

SEM image of the binary $\mathrm{Gd}_{5} \mathrm{Ge}_{4}$ alloy sample. AES was taken on six different locations in the SEM image after the first cleaning cycle. The table shows the surface concentration of $\mathrm{Gd}$ and $\mathrm{Ge}$ at the six different locations. The first three locations are on the 5:4 matrix and the last three locations are on the 5:3 thin plates. Red bar is $1 \mu \mathrm{m}$ long. Sample \#4.

\section{Figure 26}

Images of the Gd5Ge4 (010). (a) SEM image, (b) SAM image of the Gd concentration, and (c) SAM image of the Ge concentration after one cleaning cycle and several sputtering treatments without annealing. Red bar is $2 \mu \mathrm{m}$ long. Sample \#4.

\section{Figure 27}

SEM image of the binary $\mathrm{Gd}_{5} \mathrm{Ge}_{4}$ alloy sample after (a) the third cleaning cycle, (b) the fourth cleaning cycle, (c) the fifth cleaning cycle, (d)-(f) the sixth cleaning cycle. A cleaning cycle represents $\mathrm{Ar}^{+}$sputtering and annealing to $900 \mathrm{~K}$ for 30 minutes. The black dotted lines in (f) serve to visually highlight the 5:3 thin plates. Sample \#4.

\section{Figure 28}

An SEM image of the binary $\mathrm{Gd}_{5} \mathrm{Ge}_{4}$ alloy sample after the sixth cleaning cycle. AES was taken at five different locations in the image. The table shows the surface concentration of $\mathrm{Gd}$ and $\mathrm{Ge}$ at the five different locations. A cleaning cycle represents $\mathrm{Ar}^{+}$sputtering and annealing to $900 \mathrm{~K}$ for 30 minutes. The red bar is $1 \mu \mathrm{m}$ long. Sample \#4. 


\section{Figure 29}

SEM images of the Gd5Ge4 (010) surface after annealing to $1150 \mathrm{~K}$ for 30 minutes. AES was taken at four different locations in (c). The table shows the surface concentration of $\mathrm{Gd}$ and $\mathrm{Ge}$ at the four different locations (four different lump locations). Sample \#4.

\section{Figure 30}

SEM images on the Gd5Ge4 (010) surface showed no lumps on Sample \#2 after it had been annealed and used for STM experiments. The black dotted lines in (a) serve to visually highlight the 5:3 thin plates.

\section{Figure 31}

STM images of a binary $\mathrm{Gd}_{5} \mathrm{Ge}_{4}(010)$ alloy sample that was annealed to $900 \mathrm{~K}$ for one hour and then cooled down to $300 \mathrm{~K}$. The STM images were taken at (a) $3000 \mathrm{~nm} \times 3000$ $\mathrm{nm}, \mathrm{I}=0.5 \mathrm{nA}, \mathrm{V}$-tip $=+1 \mathrm{~V}$ (b) $2000 \mathrm{~nm} \times 2000 \mathrm{~nm}, \mathrm{I}=0.5 \mathrm{nA}, \mathrm{V}$-tip $=+1 \mathrm{~V}$ (c) 4000 $\mathrm{nm} \times 4000 \mathrm{~nm}, \mathrm{I}=0.5 \mathrm{nA}, \mathrm{V}$-tip $=+1 \mathrm{~V}$, and (d) $3000 \mathrm{~nm} \times 3000 \mathrm{~nm}, \mathrm{I}=0.5 \mathrm{nA}, \mathrm{V}$-tip = +0.5 V. Sample \#2.

\section{Figure 32}

STM images of a binary $\mathrm{Gd}_{5} \mathrm{Ge}_{4}(010)$ alloy sample that was annealed to $900 \mathrm{~K}$ for one hour and then cooled down to $300 \mathrm{~K}$. The STM images were taken at (a) $3000 \mathrm{~nm} \times 3000$ $\mathrm{nm}, \mathrm{I}=0.5 \mathrm{nA}, \mathrm{V}$-tip $=+0.5 \mathrm{~V}$, (b) $2000 \mathrm{~nm} \times 2000 \mathrm{~nm}, \mathrm{I}=0.5 \mathrm{nA}, \mathrm{V}$-tip $=+0.5 \mathrm{~V}$, (c) $500 \mathrm{~nm} \times 500 \mathrm{~nm}, \mathrm{I}=0.5 \mathrm{nA}, \mathrm{V}$-tip $=+0.5 \mathrm{~V}$, and (d) $500 \mathrm{~nm} \times 500 \mathrm{~nm}, \mathrm{I}=0.5 \mathrm{nA}$, Vtip $=+1$ V. Sample \#2. 


\section{Table 1}

Structural data for Gd-Ge binary alloys.

\begin{tabular}{|c|c|c|c|}
\hline Phase & Space Group & $\begin{array}{c}\text { Lattice } \\
\text { Parameters }\end{array}$ & Prototype \\
\hline$[13 ; 15] \mathbf{G d}_{5} \mathbf{G e}_{3}$ & Pnma & $\begin{array}{l}\mathrm{a}=\mathrm{b}=0.8546 \mathrm{~nm} \\
\mathrm{c}=0.6410 \mathrm{~nm}\end{array}$ & $\mathrm{Mn}_{5} \mathrm{Si}_{3}$ - hexagonal \\
\hline$[13 ; 15] \mathbf{G d}_{5} \mathbf{G e}_{4}$ & Pnma & $\begin{array}{l}\mathrm{a}=0.769 \mathrm{~nm} \\
\mathrm{~b}=1.475 \mathrm{~nm} \\
\mathrm{c}=0.776 \mathrm{~nm}\end{array}$ & $\begin{array}{l}\mathrm{Sm}_{5} \mathrm{Ge}_{4}- \\
\text { orthorhombic }\end{array}$ \\
\hline$[13 ; 15] G d G e$ & $\mathrm{Cmcm}$ & $\begin{array}{l}\mathrm{a}=0.4175 \mathrm{~nm} \\
\mathrm{~b}=1.061 \mathrm{~nm} \\
\mathrm{c}=0.3960 \mathrm{~nm}\end{array}$ & $\mathrm{CrB}$ - orthorhombic \\
\hline$[13 ; 15] \mathbf{G d}_{2} \mathbf{G e}_{3}$ & $\mathrm{P} 6 / \mathrm{mmm}$ & $\begin{array}{l}\mathrm{a}=\mathrm{b}=0.4077 \mathrm{~nm} \\
\mathrm{c}=1.373 \mathrm{~nm}\end{array}$ & $\mathrm{AlB}_{2}$ - hexagonal \\
\hline$[13 ; 16] \alpha-\mathrm{Gd}_{3} \mathrm{Ge}_{5}$ & I4 1 /amd & $\begin{array}{l}\mathrm{a}=0.58281 \mathrm{~nm} \\
\mathrm{~b}=1.7355 \mathrm{~nm} \\
\mathrm{c}=1.3785 \mathrm{~nm}\end{array}$ & $\begin{array}{l}\alpha \mathrm{Si}_{2} \mathrm{Th}- \\
\text { orthorhombic }\end{array}$ \\
\hline$[13 ; 16] \beta-\mathrm{Gd}_{3} \mathrm{Ge}_{5}$ & Imma & $\begin{array}{l}\mathrm{a}=0.58281 \mathrm{~nm} \\
\mathrm{~b}=1.7355 \mathrm{~nm} \\
\mathrm{c}=1.3785 \mathrm{~nm}\end{array}$ & $\begin{array}{l}\alpha \mathrm{Si}_{2} \mathrm{Th}- \\
\text { orthorhombic }\end{array}$ \\
\hline$[13 ; 15] G_{d G e}$ & I4 1 /amd & $\begin{array}{l}\mathrm{a}=\mathrm{b}=0.412 \mathrm{~nm} \\
\mathrm{c}=1.372 \mathrm{~nm}\end{array}$ & $\alpha \mathrm{Si}_{2} \mathrm{Th}$ - hexagonal \\
\hline
\end{tabular}




\section{Table 2}

Heights of steps between A-A- or B-B-terraces on the $\mathrm{Gd}_{5} \mathrm{Ge}_{4}$ (010) surface after annealing at different temperatures. Values are derived from line profiles of steps in STM images. A total of 835 step heights were analyzed. Numbers in the column headers refer to samples \#1 and \#2. The number of steps analyzed to obtain the values are shown in parentheses.

\begin{tabular}{|c|c|c|c|c|c|c|c|}
\hline \multirow{3}{*}{ Temperature (K) } & \multicolumn{7}{|c|}{ Step Height (nm) } \\
\hline & \multicolumn{2}{|c|}{ Left } & \multicolumn{2}{|c|}{ Middle } & \multicolumn{2}{|c|}{ Right } & \multirow{2}{*}{$\begin{array}{c}\text { Average } \\
\text { (number } \\
\text { analyzed) }\end{array}$} \\
\hline & $\# 1$ & $\# 2$ & $\# 1$ & $\# 2$ & $\# 1$ & $\# 2$ & \\
\hline 300 & - & - & $\begin{array}{c}0.75 \pm \\
0.16 \\
(39)\end{array}$ & - & - & - & $\begin{array}{c}0.75 \pm 0.16 \\
\text { (39) }\end{array}$ \\
\hline 900 & $\begin{array}{c}0.71 \pm \\
0.09 \\
(54)\end{array}$ & $\begin{array}{c}0.75 \pm \\
0.09 \\
(74)\end{array}$ & $\begin{array}{c}0.73 \pm \\
0.10 \\
(51)\end{array}$ & $\begin{array}{c}0.75 \pm \\
0.07 \\
(94)\end{array}$ & - & $\begin{array}{c}0.77 \pm \\
0.08 \\
(83)\end{array}$ & $\begin{array}{c}0.75 \pm 0.09 \\
\quad(356)\end{array}$ \\
\hline 1050 & $\begin{array}{c}0.76 \pm \\
0.05 \\
(83)\end{array}$ & $\begin{array}{c}0.71 \pm \\
0.09 \\
(26)\end{array}$ & $\begin{array}{c}0.76 \pm \\
0.16 \\
(22)\end{array}$ & $\begin{array}{c}0.78 \pm \\
0.07 \\
(18)\end{array}$ & $\begin{array}{c}0.79 \pm \\
0.08 \\
(14)\end{array}$ & $\begin{array}{c}0.77 \pm \\
0.09 \\
(17)\end{array}$ & $\begin{array}{c}0.76 \pm 0.09 \\
\quad(180)\end{array}$ \\
\hline 1100 & $\begin{array}{c}0.75 \pm \\
0.08 \\
(21)\end{array}$ & - & $\begin{array}{c}0.79 \pm \\
0.12 \\
(47)\end{array}$ & - & $\begin{array}{c}0.74 \pm \\
0.08 \\
(21)\end{array}$ & - & $\begin{array}{c}0.77 \pm 0.10 \\
(89)\end{array}$ \\
\hline 1150 & $\begin{array}{c}0.75 \pm \\
0.04 \\
(19) \\
\end{array}$ & - & $\begin{array}{c}0.72 \pm \\
0.07 \\
(18) \\
\end{array}$ & - & $\begin{array}{c}0.74 \pm \\
0.02 \\
(14) \\
\end{array}$ & - & $\begin{array}{c}0.74 \pm 0.05 \\
\quad(51)\end{array}$ \\
\hline 1200 & - & $\begin{array}{c}0.77 \pm \\
0.09 \\
(38)\end{array}$ & $\begin{array}{c}0.74 \pm \\
0.05 \\
(6)\end{array}$ & $\begin{array}{c}0.76 \pm \\
0.07 \\
(36)\end{array}$ & - & $\begin{array}{c}0.76 \pm \\
0.09 \\
(40)\end{array}$ & $\begin{array}{l}0.76 \pm 0.08 \\
\quad(120)\end{array}$ \\
\hline
\end{tabular}


Table 3

Heights of steps between A- and B-terraces on the $\mathrm{Gd}_{5} \mathrm{Ge}_{4}(010)$ surface after annealing at different temperatures. Values are derived from line profiles of steps in STM images. A total of 782 step heights were analyzed.

\begin{tabular}{|c|c|c|c|c|c|c|c|c|}
\hline \multirow{3}{*}{$\begin{array}{l}\text { Temperature } \\
\text { (K) } \\
{ }^{*} \text { Sample } 1 \\
{ }^{\dagger} \text { Sample } 2\end{array}$} & \multicolumn{8}{|c|}{ Step Height (nm) } \\
\hline & \multicolumn{2}{|c|}{ Left } & \multicolumn{2}{|c|}{ Middle } & \multicolumn{2}{|c|}{ Right } & \multicolumn{2}{|c|}{$\begin{array}{c}\text { Average } \\
\text { (number analyzed) }\end{array}$} \\
\hline & Terrace A & Terrace B & Terrace A & Terrace B & Terrace A & Terrace B & Terrace A & Terrace B \\
\hline 900 & $\begin{array}{c}{ }^{\dagger} 0.36 \pm \\
0.08\end{array}$ & $\begin{array}{c}{ }^{\dagger} 0.37 \pm \\
0.07\end{array}$ & $\begin{array}{c}{ }^{\dagger} 0.40 \pm \\
0.06\end{array}$ & $\begin{array}{c}{ }^{\dagger} 0.35 \pm \\
0.07\end{array}$ & $\begin{array}{c}{ }^{\dagger} 0.40 \pm \\
0.05\end{array}$ & $\begin{array}{c}{ }^{\dagger} 0.34 \pm \\
0.07\end{array}$ & $\begin{array}{c}0.39 \pm \\
0.07 \\
(183)\end{array}$ & $\begin{array}{c}0.35 \pm \\
0.07 \\
(183)\end{array}$ \\
\hline 1050 & $\begin{array}{c}{ }^{*} 0.38 \pm \\
0.05 \\
{ }^{\dagger} 0.33 \pm \\
0.07\end{array}$ & $\begin{array}{c}{ }^{*} 0.30 \pm \\
0.07 \\
{ }^{\dagger} 0.44 \pm \\
0.06\end{array}$ & $\begin{array}{c}0.31 \pm \\
0.13 \\
{ }^{\dagger} 0.41 \pm \\
0.06\end{array}$ & $\begin{array}{c}{ }^{*} 0.46 \pm \\
0.12 \\
{ }^{\dagger} 0.37 \pm \\
0.05\end{array}$ & $\begin{array}{c}0.26 \pm \\
0.04 \\
{ }^{*} 0.36 \pm \\
0.04\end{array}$ & $\begin{array}{c}0.44 \pm \\
0.06 \\
+0.39 \pm \\
0.05\end{array}$ & $\begin{array}{c}0.35 \pm \\
0.08 \\
(83)\end{array}$ & $\begin{array}{c}0.40 \pm \\
0.09 \\
(83)\end{array}$ \\
\hline 1100 & $\begin{array}{c}{ }^{*} 0.39 \pm \\
0.07\end{array}$ & $\begin{array}{c}{ }^{*} 0.31 \pm \\
0.05\end{array}$ & $\begin{array}{c}* 0.28 \pm \\
0.08\end{array}$ & $\begin{array}{c}{ }^{*} 0.43 \pm \\
0.10\end{array}$ & $\begin{array}{c}{ }^{*} 0.34 \pm \\
0.07\end{array}$ & $\begin{array}{c}{ }^{*} 0.29 \pm \\
0.06\end{array}$ & $\begin{array}{c}0.32 \pm \\
0.09 \\
(34)\end{array}$ & $\begin{array}{c}0.36 \pm \\
0.10 \\
(34)\end{array}$ \\
\hline 1150 & $\begin{array}{c}{ }^{*} 0.35 \pm \\
0.07\end{array}$ & $\begin{array}{c}{ }^{*} 0.33 \pm \\
0.06\end{array}$ & $\begin{array}{c}* 0.29 \pm \\
0.09\end{array}$ & $\begin{array}{c}{ }^{*} 0.39 \pm \\
0.08\end{array}$ & $\begin{array}{c}{ }^{*} 0.36 \pm \\
0.06\end{array}$ & $\begin{array}{c}* 0.29 \pm \\
0.07\end{array}$ & $\begin{array}{c}0.33 \pm \\
0.08 \\
(48)\end{array}$ & $\begin{array}{c}0.34 \pm \\
0.08 \\
(48)\end{array}$ \\
\hline 1200 & - & - & $\begin{array}{c}0.37 \pm \\
0.13 \\
{ }^{\dagger} 0.36 \pm \\
0.03\end{array}$ & $\begin{array}{c}0.25 \pm \\
0.06 \\
{ }^{\dagger} 0.32 \pm \\
0.06\end{array}$ & $\begin{array}{c}- \\
{ }^{\dagger} 0.37 \pm \\
0.09\end{array}$ & $\begin{array}{c}- \\
{ }^{\dagger} 0.33 \pm \\
0.08\end{array}$ & $\begin{array}{c}0.37 \pm \\
0.09 \\
(43)\end{array}$ & $\begin{array}{c}0.31 \pm \\
0.08 \\
(43)\end{array}$ \\
\hline
\end{tabular}




\section{Table 4}

Bump heights on B terraces on the $\mathrm{Gd}_{5} \mathrm{Ge}_{4}$ (010) surface after annealing at annealing temperatures. Heights were measured from STM line profiles. A total of 317 bump heights were analyzed.

\begin{tabular}{|c|c|c|c|}
\hline \multirow{2}{*}{$\begin{array}{c}\text { Temperature } \\
\text { (K) }\end{array}$} & \multicolumn{3}{|c|}{ Bump Heights (nm) } \\
\hline & Sample 1 & Sample 2 & $\begin{array}{c}\text { Average Height } \\
\text { (nm) } \\
\text { (number analyzed) }\end{array}$ \\
\hline $900 \mathrm{~K}$ & $0.38 \pm 0.09($ middle $)$ & $0.40 \pm 0.05(\mathrm{left})$ & $\begin{array}{c}0.39 \pm 0.07 \\
(58)\end{array}$ \\
\hline $1050 \mathrm{~K}$ & $\begin{array}{c}0.29 \pm 0.05(\text { middle }) \\
0.29 \pm 0.04(\text { left })\end{array}$ & $\begin{array}{c}0.36 \pm 0.05 \text { (middle) } \\
0.36 \pm 0.13 \text { (right) } \\
0.25 \pm 0.05 \text { (left) }\end{array}$ & $\begin{array}{c}0.32 \pm 0.09 \\
(78)\end{array}$ \\
\hline $1100 \mathrm{~K}$ & $\begin{array}{c}0.27 \pm 0.04 \text { (middle) } \\
0.38 \pm 0.07 \text { (right) } \\
0.39 \pm 0.06(\text { left })\end{array}$ & 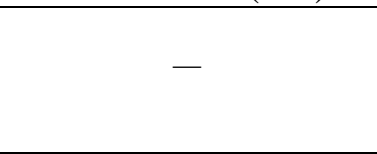 & $\begin{array}{c}0.35 \pm 0.08 \\
(48)\end{array}$ \\
\hline $1150 \mathrm{~K}$ & $\begin{array}{c}0.32 \pm 0.05 \text { (middle) } \\
0.33 \pm 0.08 \text { (right) } \\
0.33 \pm 0.07(\text { left })\end{array}$ & - & $\begin{array}{c}0.33 \pm 0.07 \\
(88)\end{array}$ \\
\hline $1200 \mathrm{~K}$ & $\begin{array}{c}0.35 \pm 0.05 \text { (middle) } \\
0.28 \pm 0.08 \text { (right) } \\
0.29 \pm 0.04 \text { (left) }\end{array}$ & - & $\begin{array}{c}0.31 \pm 0.07 \\
(45)\end{array}$ \\
\hline
\end{tabular}




\section{Table 5}

Average individual bump area on B-terraces on the $\mathrm{Gd}_{5} \mathrm{Ge}_{4}(010)$ surface after annealing at different temperatures. The number of bumps analyzed for each value is given in parentheses. The values were determined by zooming in and flooding the image, which typically contained several bumps. Values of areas obtained by flooding can be sensitive to the flooding level chosen. The entire range of values of bump areas is shown in square brackets.

\begin{tabular}{|c|c|c|c|}
\hline \multirow{2}{*}{ Temperature $(\mathrm{K})$} & \multicolumn{3}{|c|}{ Average Individual Bump Area $\left(\mathrm{nm}^{2}\right)$} \\
\hline & Sample \#1 & Sample \#2 & Average \\
\hline $900 \mathrm{~K}$ & $\begin{array}{c}1.84 \pm 0.59 \\
(17)\end{array}$ & $\begin{array}{c}1.69 \pm 0.52 \\
(14)\end{array}$ & $\begin{array}{c}1.78 \pm 0.56 \\
(31) \\
{[0.32-3.25]}\end{array}$ \\
\hline $1050 \mathrm{~K}$ & $\begin{array}{c}1.81 \pm 0.90 \\
(17)\end{array}$ & $\begin{array}{c}2.18 \pm 1.52 \\
\quad(17)\end{array}$ & $\begin{array}{c}1.99 \pm 1.24 \\
(34) \\
{[0.72-5.59]}\end{array}$ \\
\hline $1100 \mathrm{~K}$ & $\begin{array}{c}2.28 \pm 0.71 \\
(13)\end{array}$ & - & $\begin{array}{c}2.28 \pm 0.71 \\
(13) \\
{[1.02-3.50]}\end{array}$ \\
\hline $1150 \mathrm{~K}$ & $\begin{array}{c}4.84 \pm 2.41 \\
(33)\end{array}$ & - & $\begin{array}{c}4.84 \pm 2.41 \\
(33) \\
{[1.04-12.00]}\end{array}$ \\
\hline $1200 \mathrm{~K}$ & $\begin{array}{c}2.26 \pm 0.72 \\
\quad(18)\end{array}$ & - & $\begin{array}{c}2.26 \pm 0.72 \\
(18) \\
{[1.04-3.96]}\end{array}$ \\
\hline
\end{tabular}




\section{Table 6}

Fractional area covered by bumps on B-terraces on the $\mathrm{Gd}_{5} \mathrm{Ge}_{4}(010)$ surface after annealing at different temperatures. The total area analyzed is given in parentheses, in units of $\mathrm{nm}^{2}$. This number was determined by flooding STM images. Values derived from such an approach can be sensitive to the flooding level that is chosen.

\begin{tabular}{|c|c|c|c|}
\hline \multirow{2}{*}{ Temperature (K) } & \multicolumn{3}{|c|}{ Fractional Bump Area } \\
\cline { 2 - 4 } & Sample \#1 & Sample \#2 & Average \\
\hline \multirow{2}{*}{$900 \mathrm{~K}$} & 0.08 & 0.22 & 0.15 \\
& $(11451.18)$ & $(47786.1)$ & $(59237.28)$ \\
\hline \multirow{2}{*}{$1050 \mathrm{~K}$} & 0.05 & 0.15 & 0.10 \\
& $(69914.93)$ & $(23111.76)$ & $(93026.69)$ \\
\hline \multirow{2}{*}{$1100 \mathrm{~K}$} & 0.08 & - & 0.08 \\
& $(148712.08)$ & - & 0.16 \\
\multirow{2}{*}{$1150 \mathrm{~K}$} & 0.16 & - & $(28025.84)$ \\
\hline \multirow{2}{*}{$1200 \mathrm{~K}$} & $(28025.84)$ & & 0.22 \\
& $(28350.39)$ & $(28350.39)$ \\
\hline
\end{tabular}




\section{Table 7}

Bump density $(\mathrm{N})$ on B-terraces on the $\mathrm{Gd}_{5} \mathrm{Ge}_{4}(010)$ surface after annealing at different temperatures. NOTE: $\mathrm{N}$ is the number of bumps divided by the total image area. The total area analyzed, summed over all images, is shown in parentheses, in units of $\mathrm{nm}^{2}$.

\begin{tabular}{|c|c|c|c|}
\hline \multirow{2}{*}{ Temperature (K) } & \multicolumn{3}{|c|}{ Bump Density (nm } \\
& Sample \#1 & Sample \#2 & Average \\
\cline { 2 - 4 } & 0.04 & 0.10 & 0.08 \\
$(800 \mathrm{~K}$ & $(31346.81)$ & 0.07 & $(39975.2)$ \\
\hline \multirow{2}{*}{$1050 \mathrm{~K}$} & 0.02 & $(8594.4)$ & 0.05 \\
& $(55825.35)$ & - & $(64419.75)$ \\
\hline \multirow{2}{*}{$1100 \mathrm{~K}$} & 0.01 & - & 0.01 \\
& $(37312.98)$ & - & 0.04 \\
\multirow{2}{*}{$1150 \mathrm{~K}$} & 0.04 & - & $(32614.44)$ \\
\hline \multirow{2}{*}{$1200 \mathrm{~K}$} & $(32614.44)$ & 0.06 & $(28021.31)$ \\
\hline
\end{tabular}

\section{Table 8}

Vacancy pit depths on the $\mathrm{Gd}_{5} \mathrm{Ge}_{4}(010)$ surface after annealing at different temperatures. Values are derived from line profiles from STM images. A total of 136 pit heights were analyzed.

\begin{tabular}{|c|c|c|c|}
\hline \multirow{2}{*}{ Temperature (K) } & \multicolumn{3}{|c|}{ Pit Depths (nm) } \\
\hline & Sample 1 & Sample 2 & $\begin{array}{c}\text { Average } \\
\text { (number analyzed) }\end{array}$ \\
\hline $900 \mathrm{~K}$ & - & $\begin{array}{c}0.73 \pm 0.05 \text { (right) } \\
0.79 \pm 0.06 \text { (left) }\end{array}$ & $\begin{array}{c}0.77 \pm 0.06 \\
(33)\end{array}$ \\
\hline $1050 \mathrm{~K}$ & $0.73 \pm 0.03(\mathrm{left})$ & $\begin{array}{c}0.74 \pm 0.09 \text { (middle) } \\
0.80 \pm 0.06 \text { (right) } \\
0.74 \pm 0.15 \text { (left) }\end{array}$ & $\begin{array}{c}0.76 \pm 0.11 \\
(57)\end{array}$ \\
\hline $1150 \mathrm{~K}$ & $\begin{array}{c}0.77 \pm 0.06 \text { (right) } \\
0.82 \pm 0.06 \text { (left) }\end{array}$ & - & $\begin{array}{c}0.81 \pm 0.06 \\
(12)\end{array}$ \\
\hline $1200 \mathrm{~K}$ & - & $\begin{array}{c}0.80 \pm 0.08 \text { (right) } \\
0.76 \pm 0.09 \text { (left) }\end{array}$ & $\begin{array}{c}0.79 \pm 0.09 \\
(34)\end{array}$ \\
\hline
\end{tabular}


Table 9

Progression of surface features observed with STM on samples \#1 and \#2, as a function of annealing temperature.

\begin{tabular}{|l|l|l|}
\hline \multicolumn{1}{|c|}{ History } & \multicolumn{1}{c|}{ Sample \#1 } & \multicolumn{1}{c|}{ Sample \#2 } \\
\hline Thermal gradient? & None detected & $\begin{array}{l}\text { 20 K between coolest (middle) } \\
\text { and hottest (left side) at 900 K }\end{array}$ \\
\hline Surface after 900 K annealing & $\begin{array}{l}\text { Mostly rough, with a few } \\
\text { regions of B-terraces. }\end{array}$ & $\begin{array}{l}\text { Mainly terrace-step } \\
\text { morphology. Cool regions are } \\
\text { mainly A-terraces. Hot side } \\
\text { has A + B mixture, } \\
\text { alternating. }\end{array}$ \\
\hline $1050 \mathrm{~K}$ & Mostly B-terraces. & Mostly B-terraces. \\
\hline $1100 \mathrm{~K}$ & Mostly B-terraces. & n/a \\
\hline $1150 \mathrm{~K}$ & Mostly B-terraces. & $\begin{array}{l}\text { nhackerboard on coolest } \\
\text { region. Pits on hottest region. }\end{array}$ \\
\hline $1200 \mathrm{~K}$ & A+ B mixture, alternating & $\begin{array}{l}\text { A } \rightarrow \text { A+B } \rightarrow \text { B } \rightarrow \text { A }+ \\
\text { checkerboard + pits. }\end{array}$ \\
\hline Summary, $900 \mathrm{~K} \rightarrow 1200 \mathrm{~K}$ & Rough $\rightarrow$ B $\rightarrow$ A+B & \\
\hline
\end{tabular}


(a)
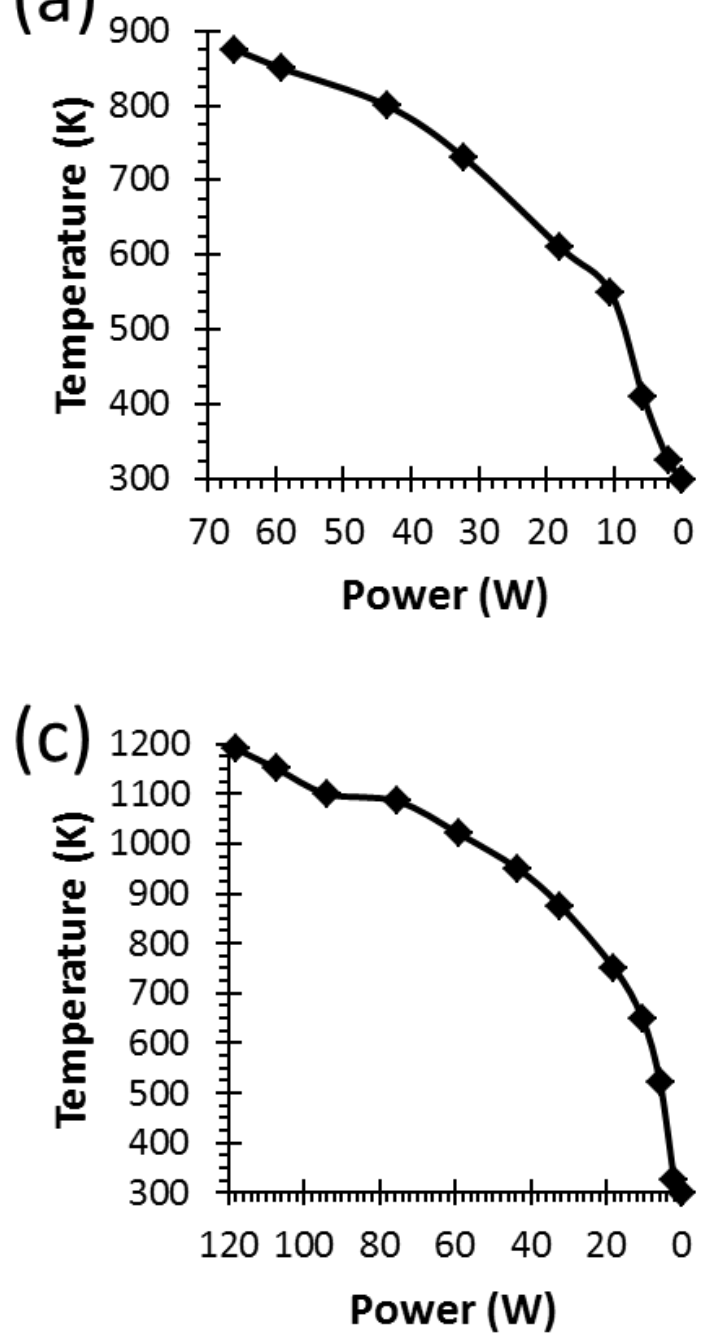

(b)

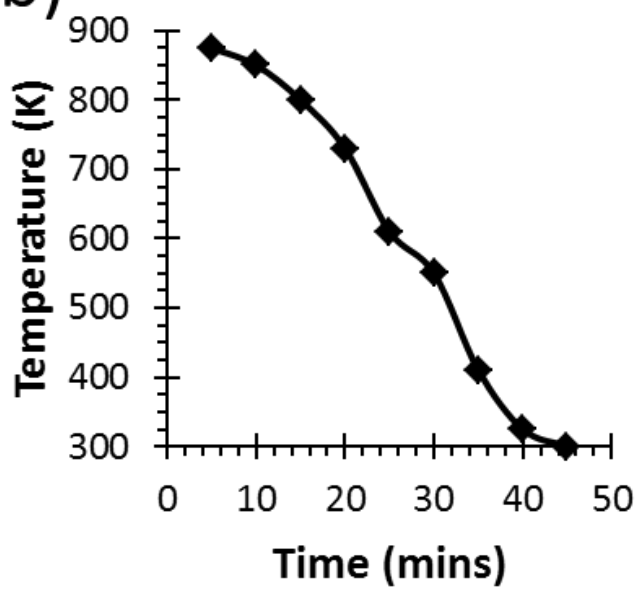

(d) 1200

1100

₹ 1000

ㄴ 900

800

700

을 600

๘ 500

400

300

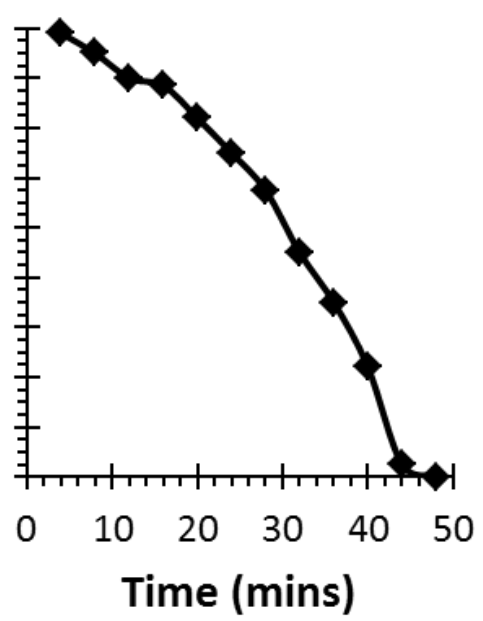

Figure 1 


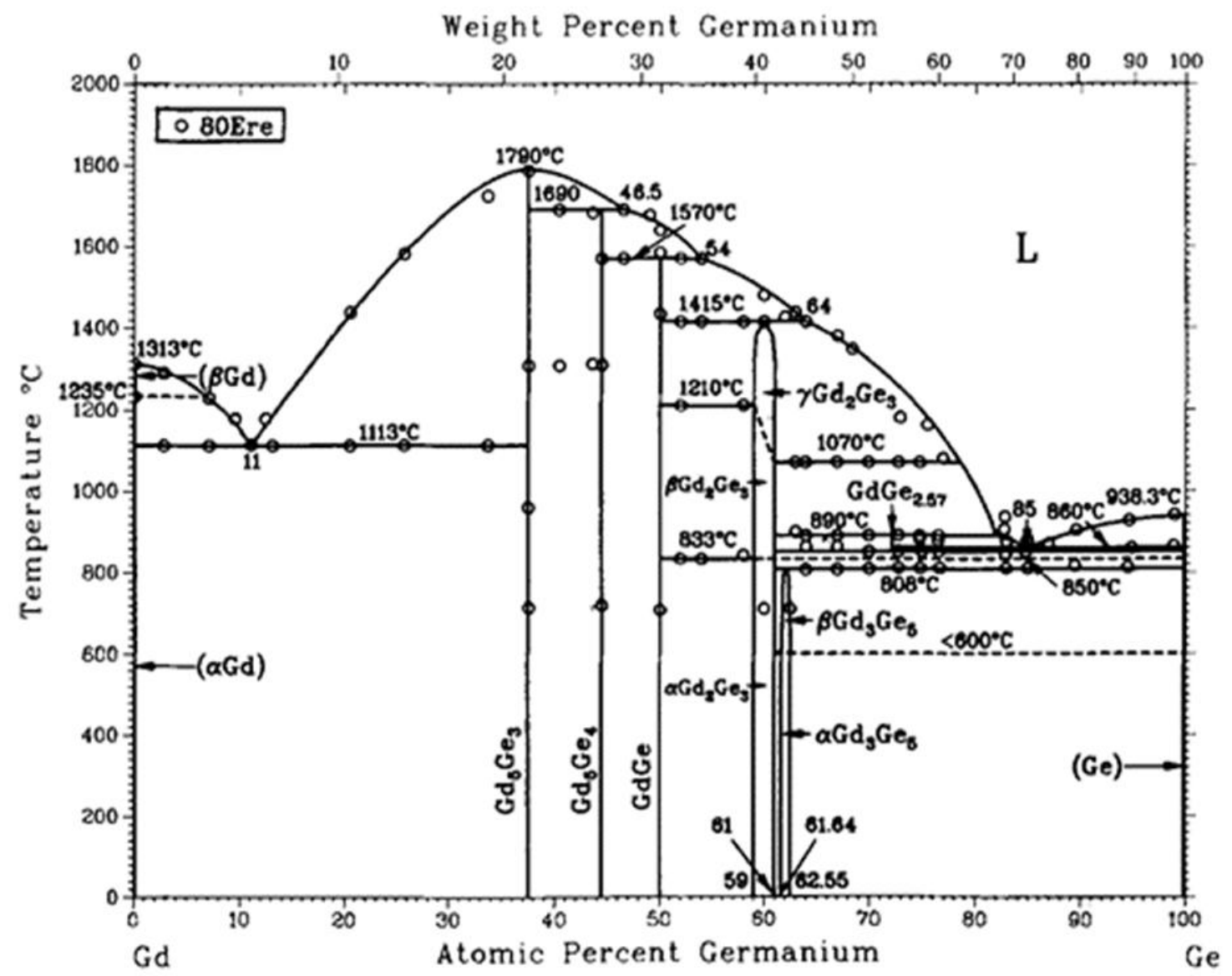

Figure 2 
(a)

\section{$0.403 \mathrm{~nm}$}

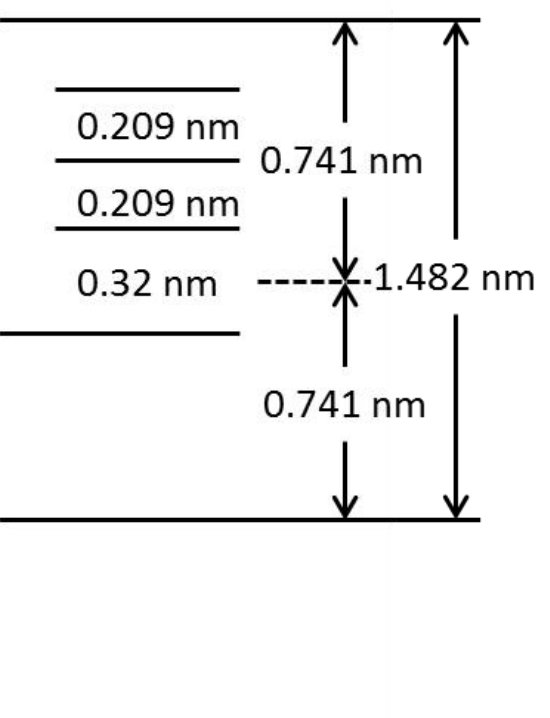

(010)
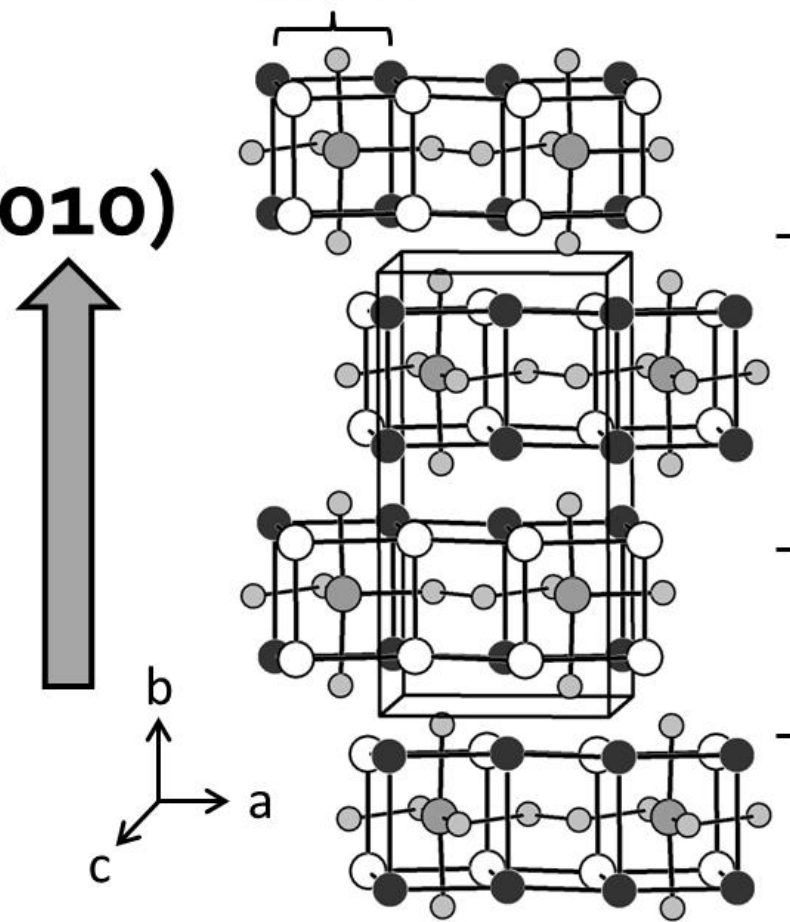

(b)

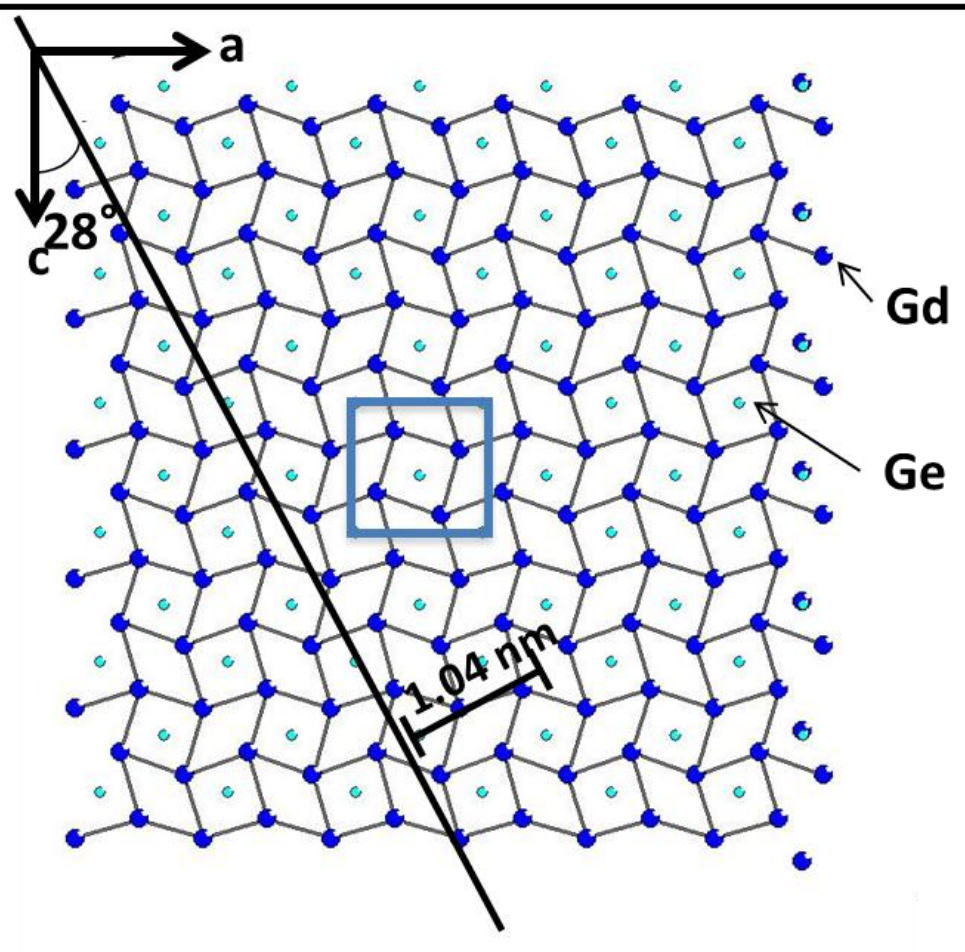

Figure 3 


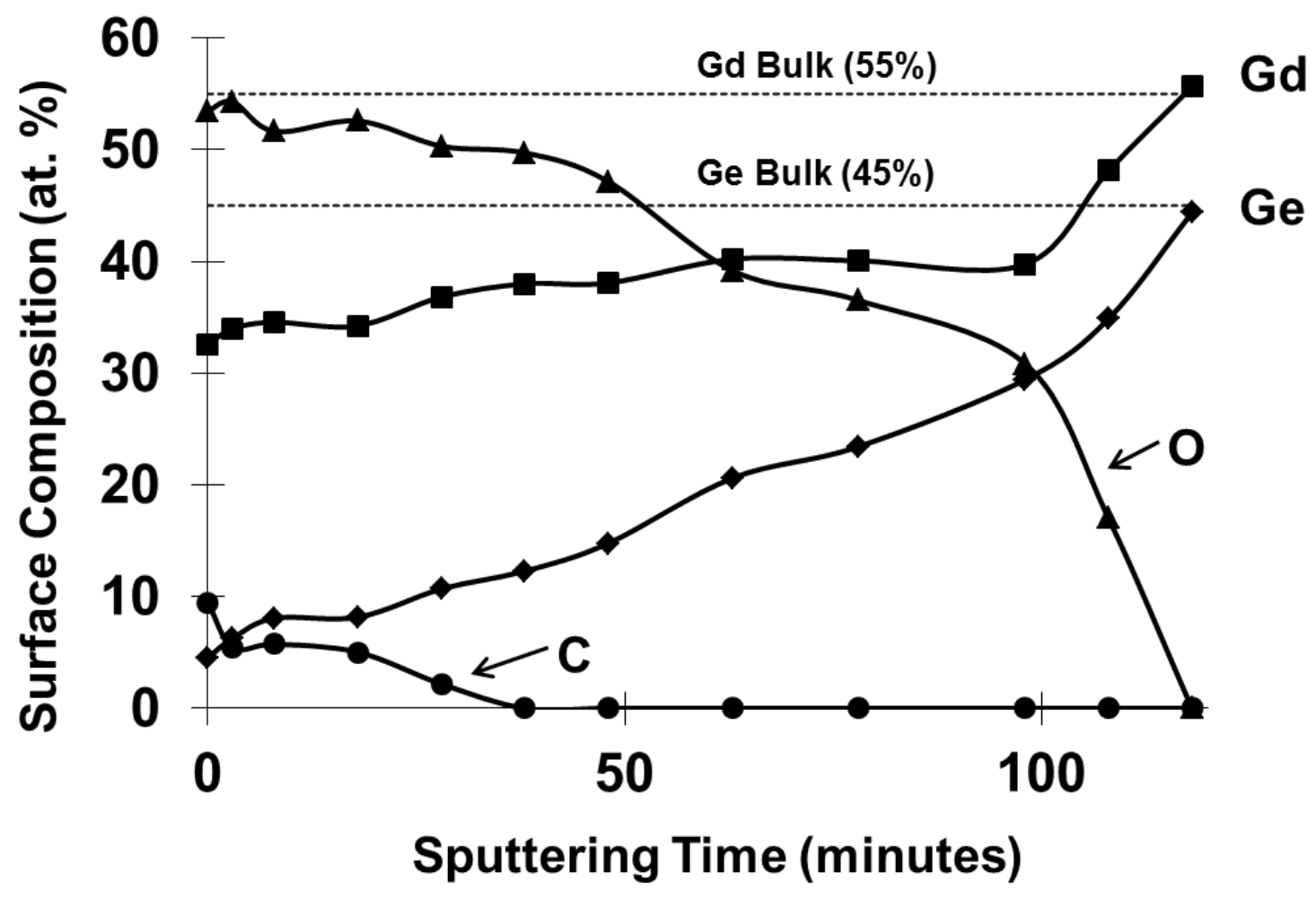

Figure 4 


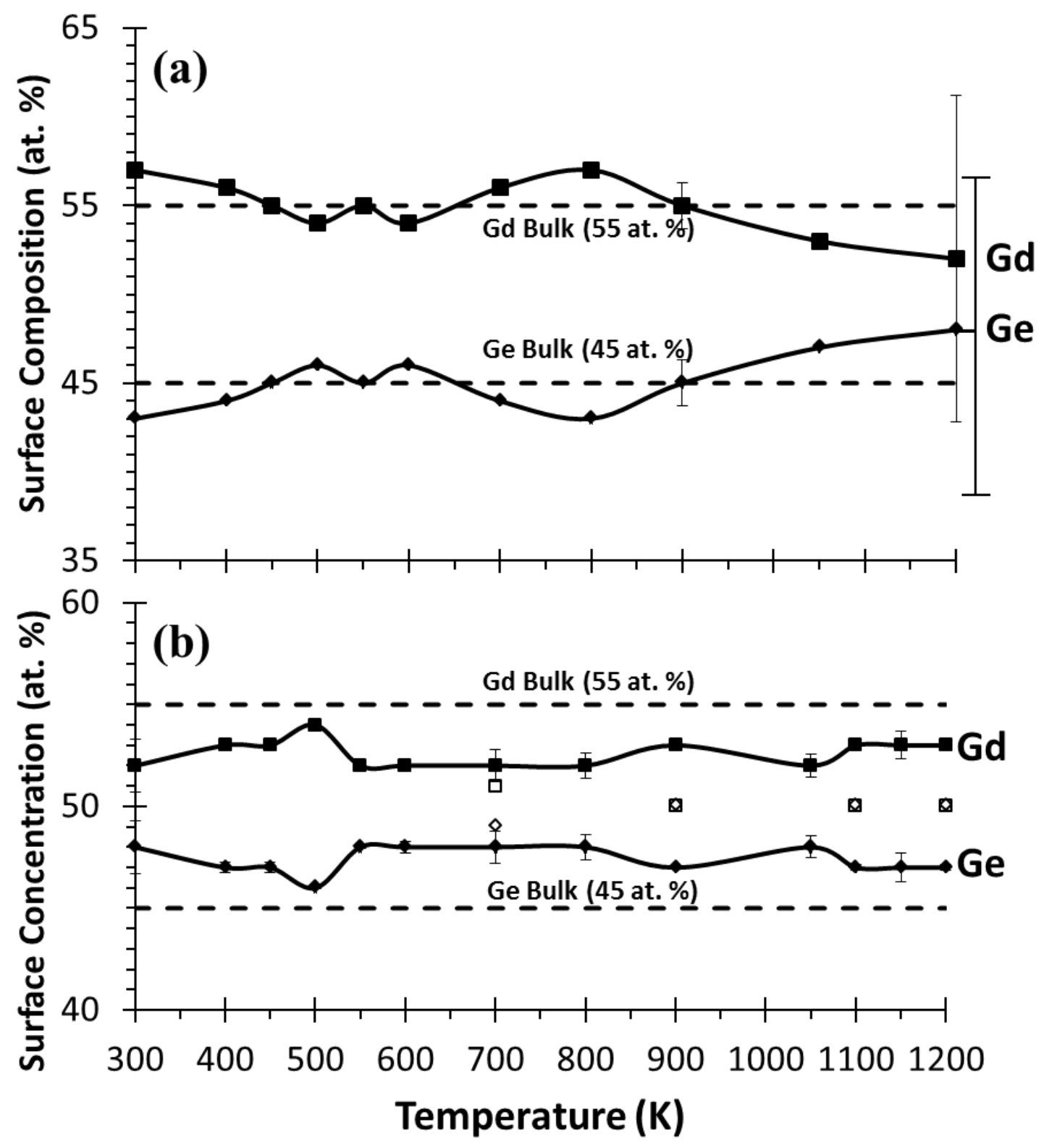

Figure 5 

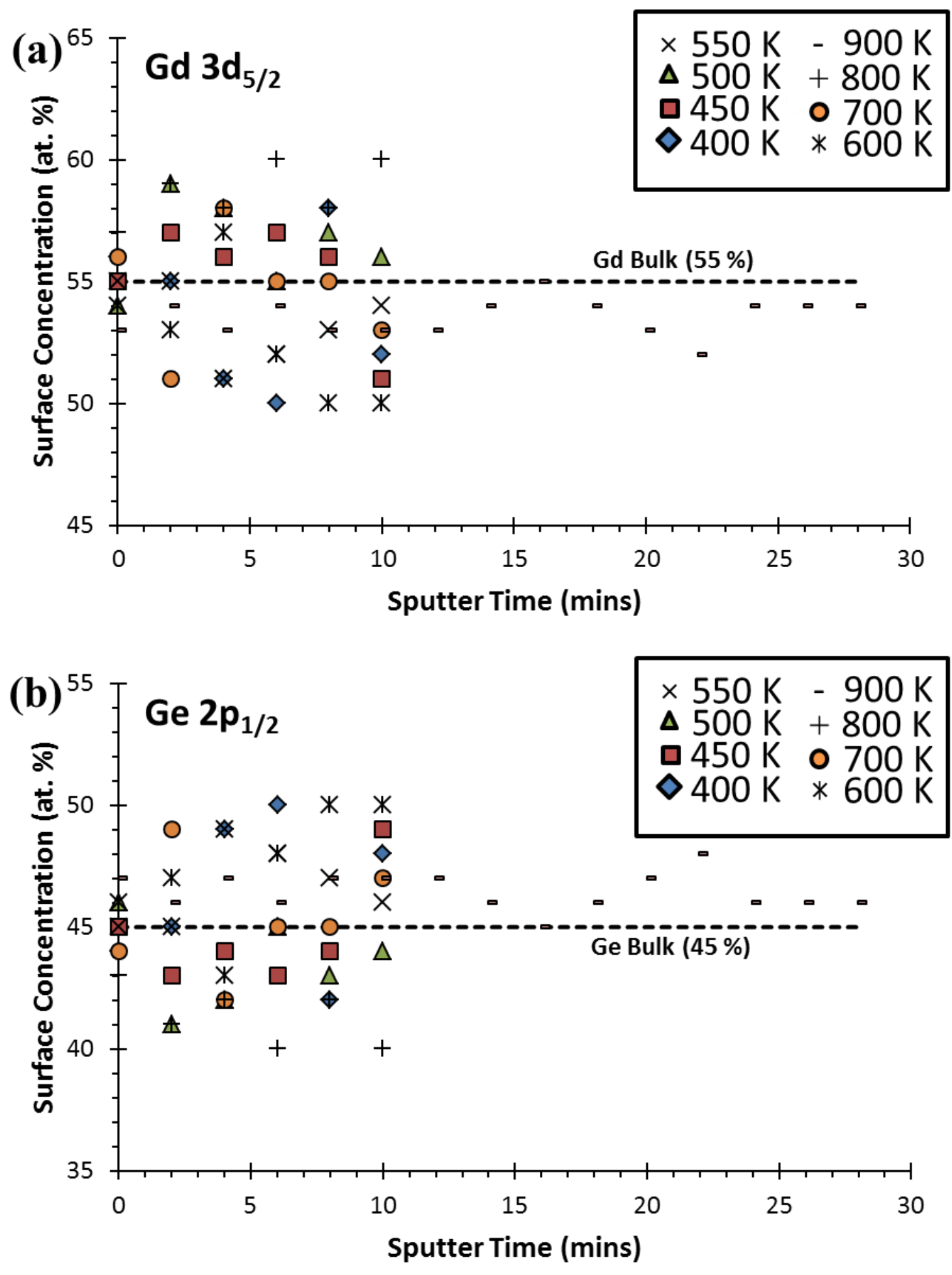

Figure 6 

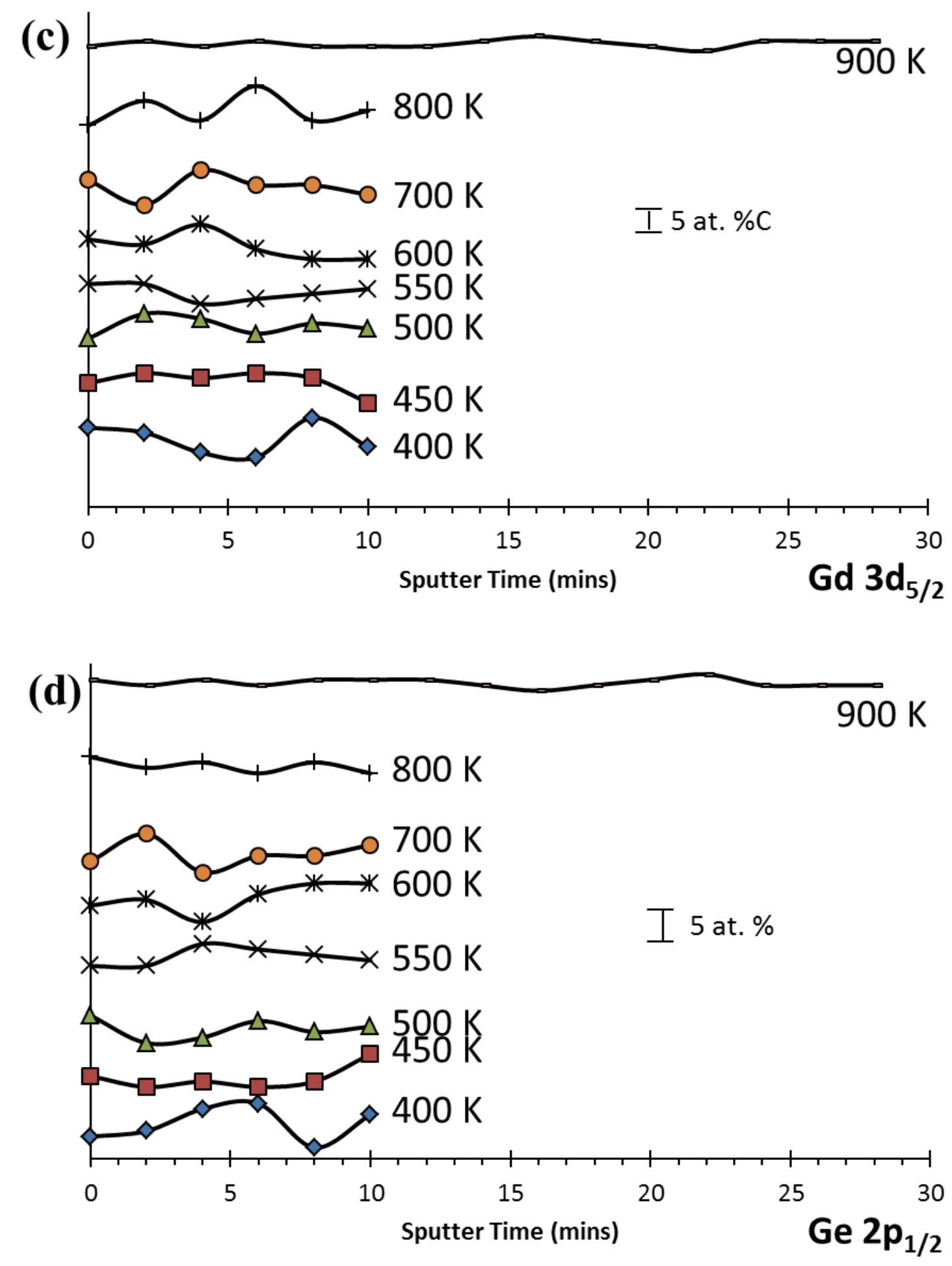

Figure 6 (Continue) 

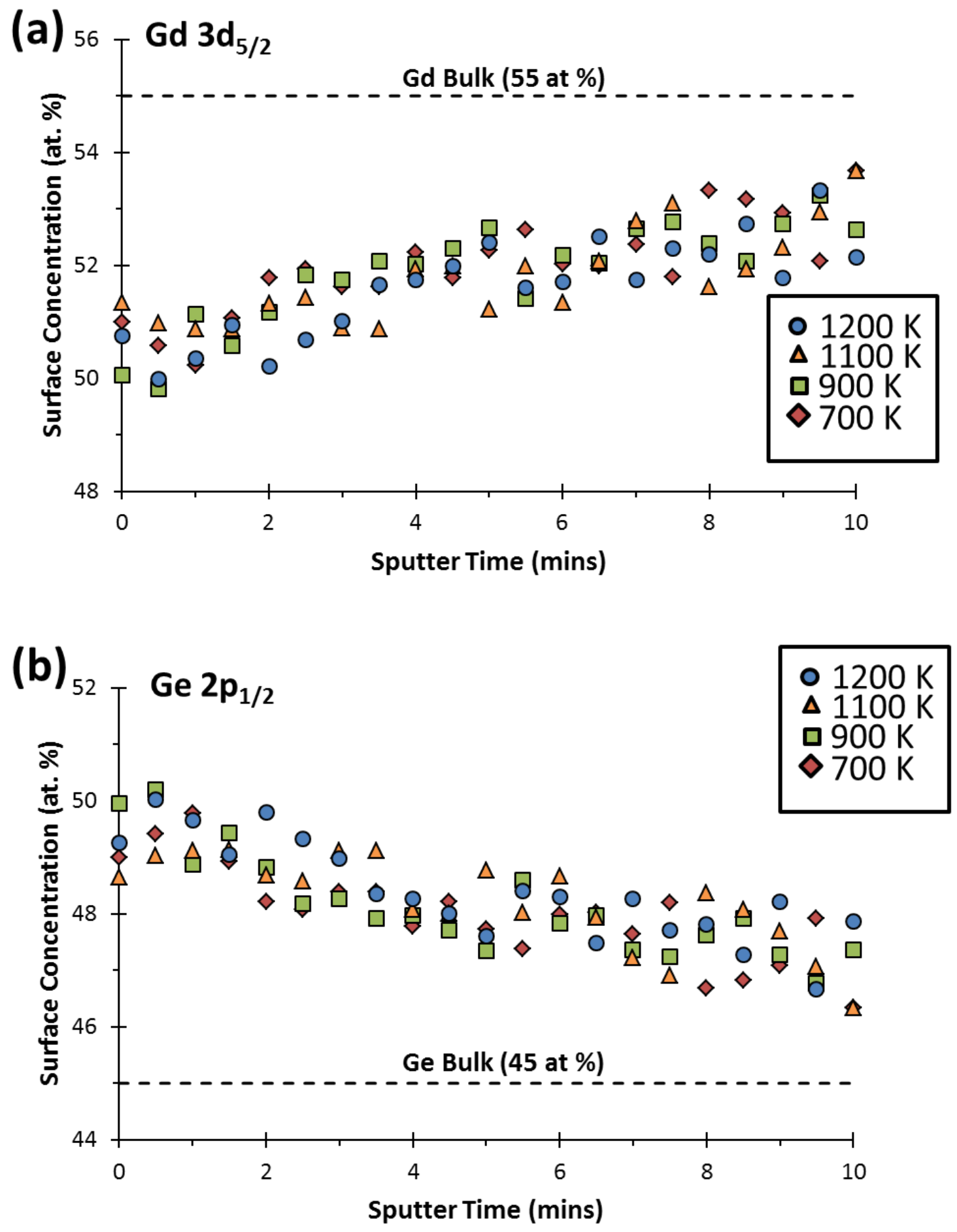

Figure 7 
(c)

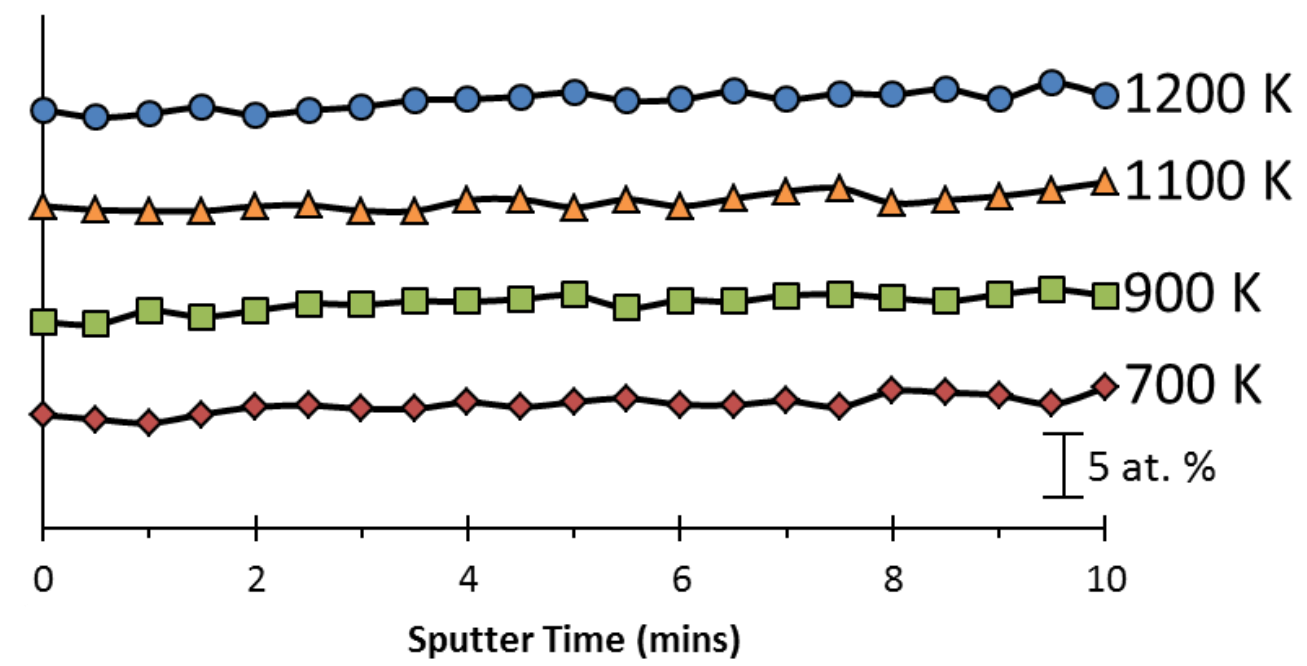

(d)

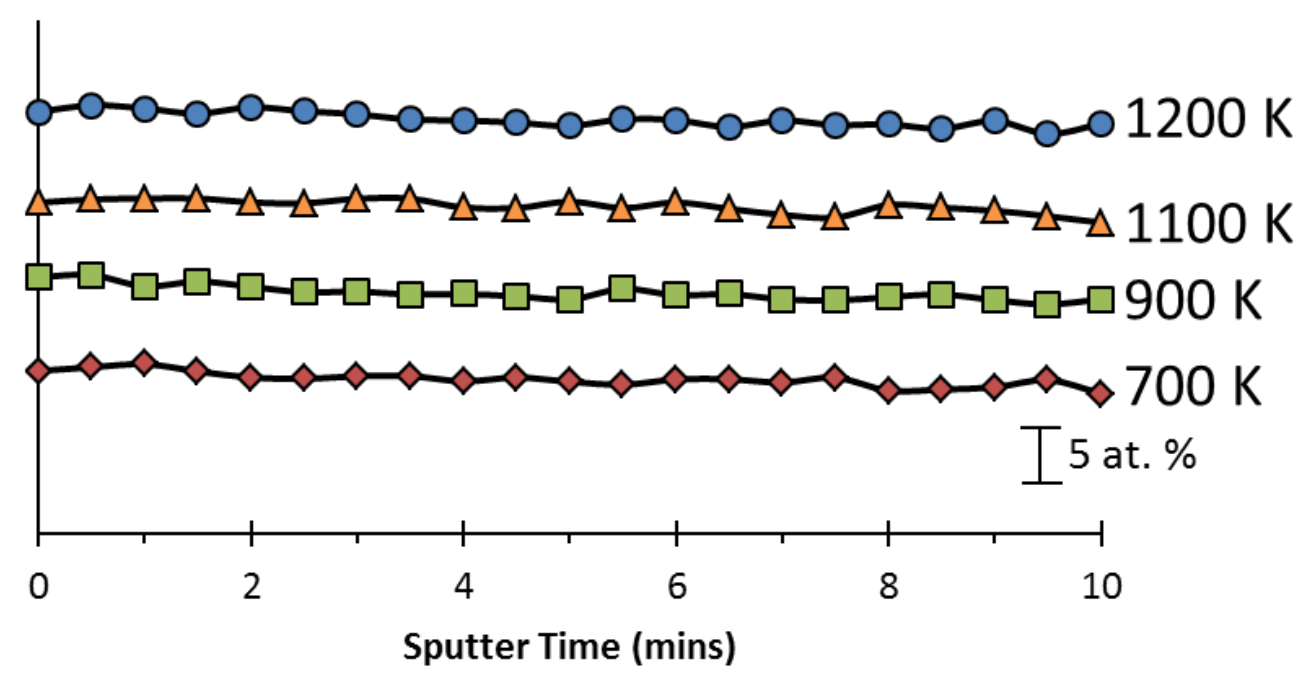

Figure 7 (Continue) 

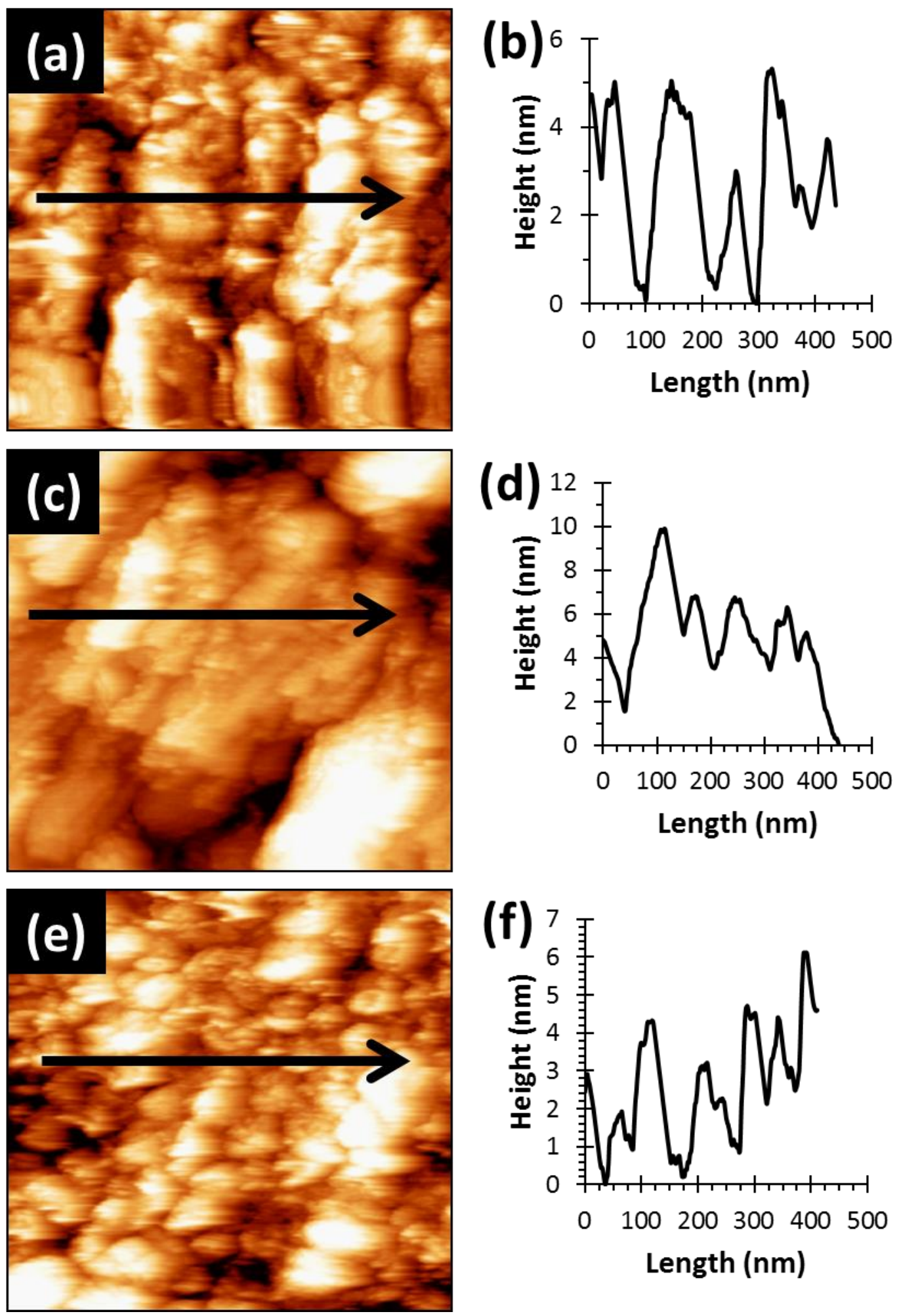

Figure 8 

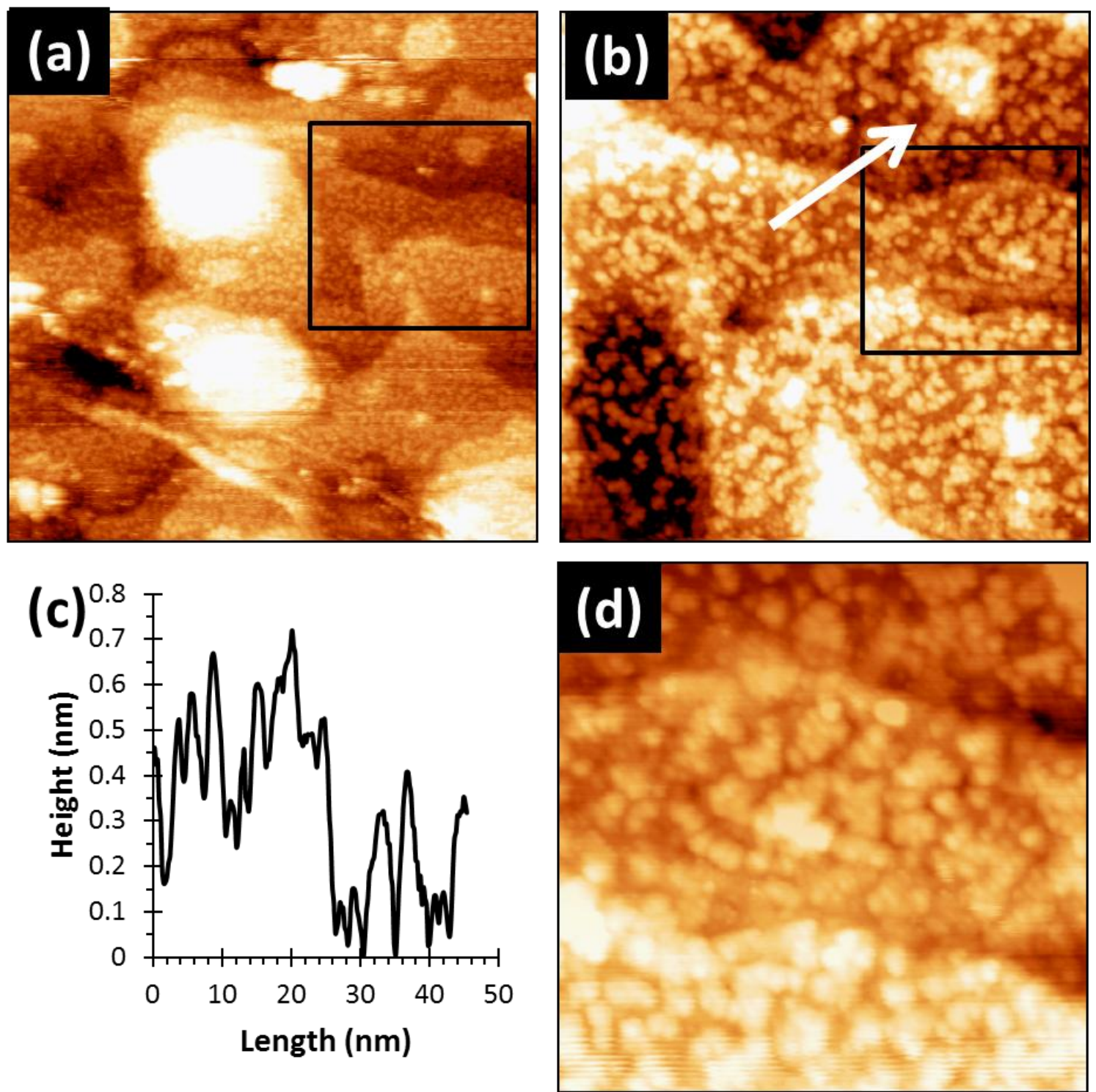

Figure 9 

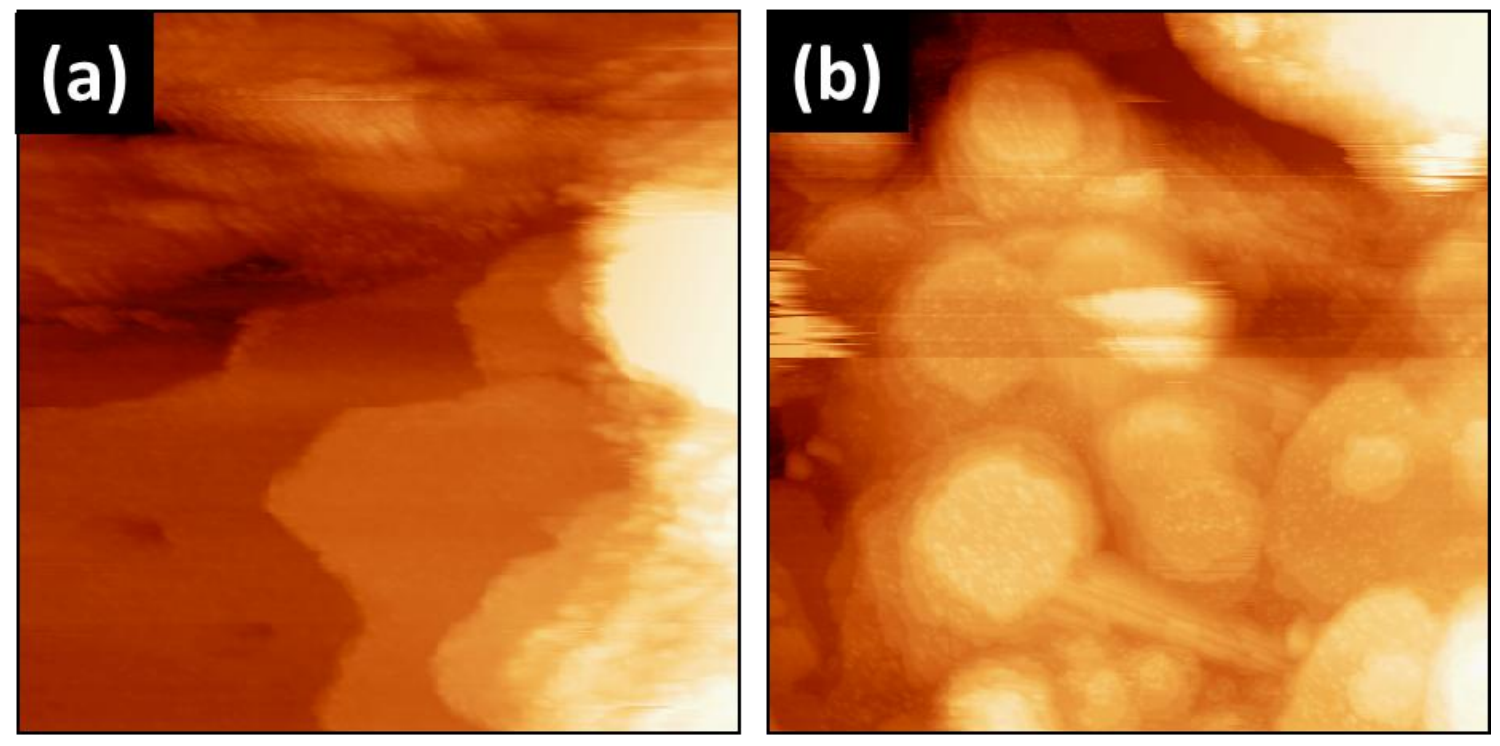

\section{(c)}
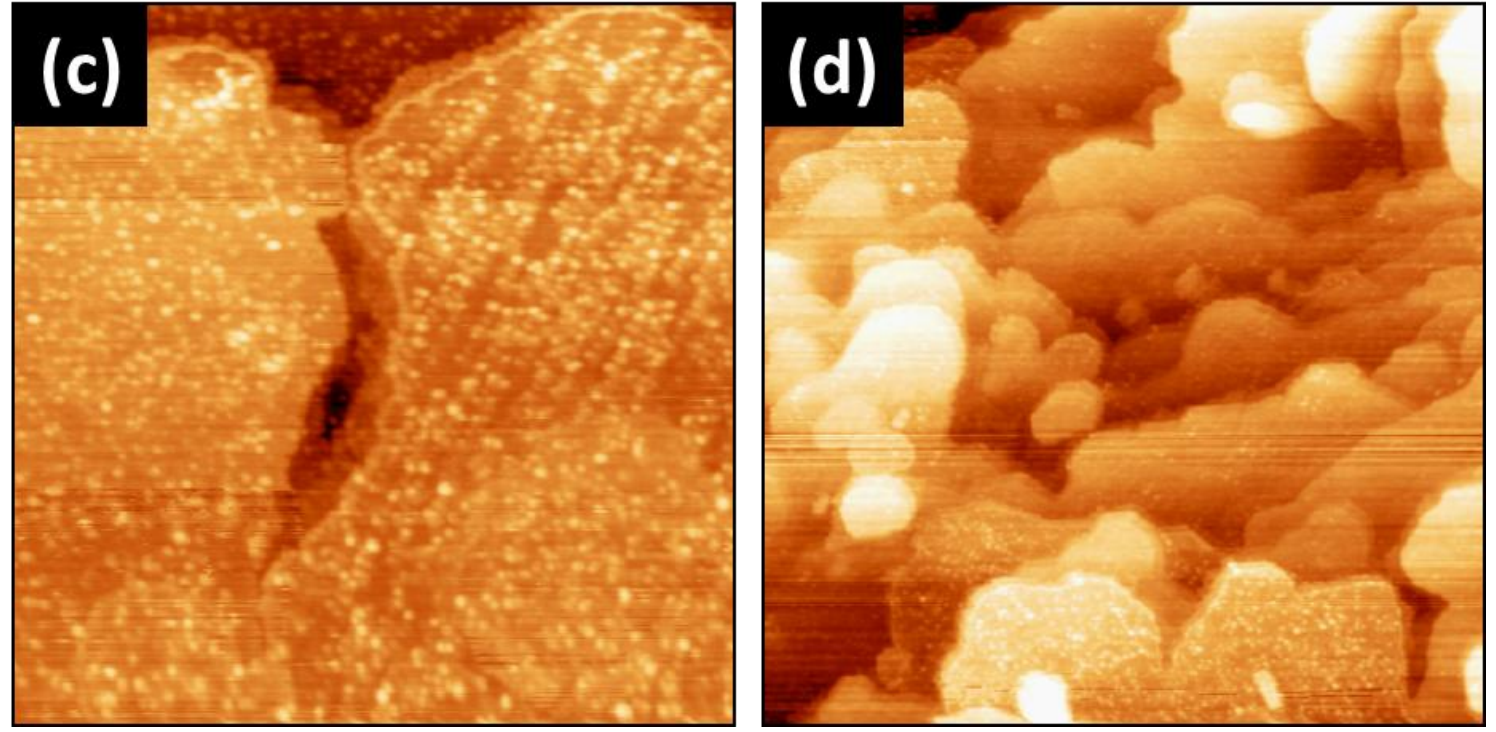

Figure 10 

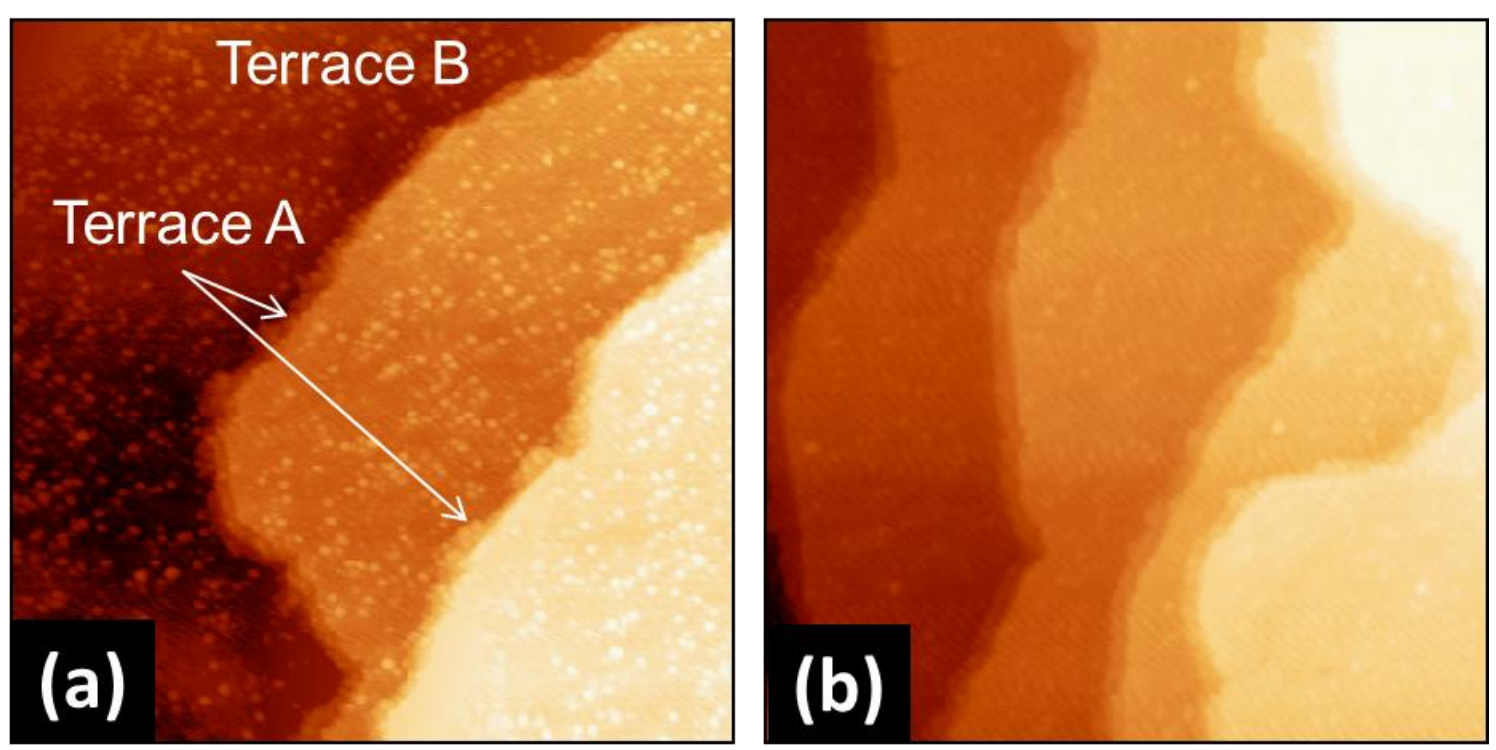

Figure 11 

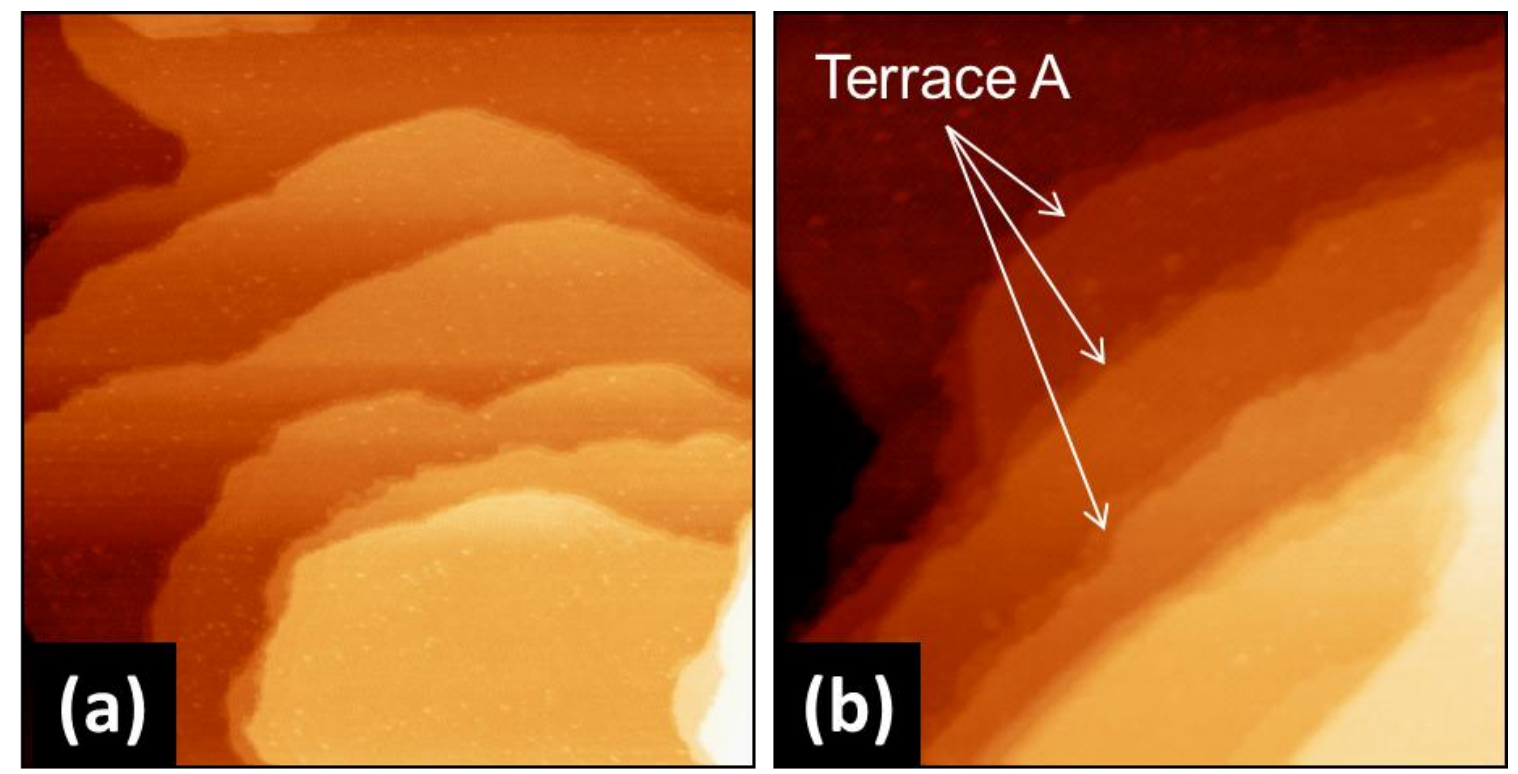

Figure 12 


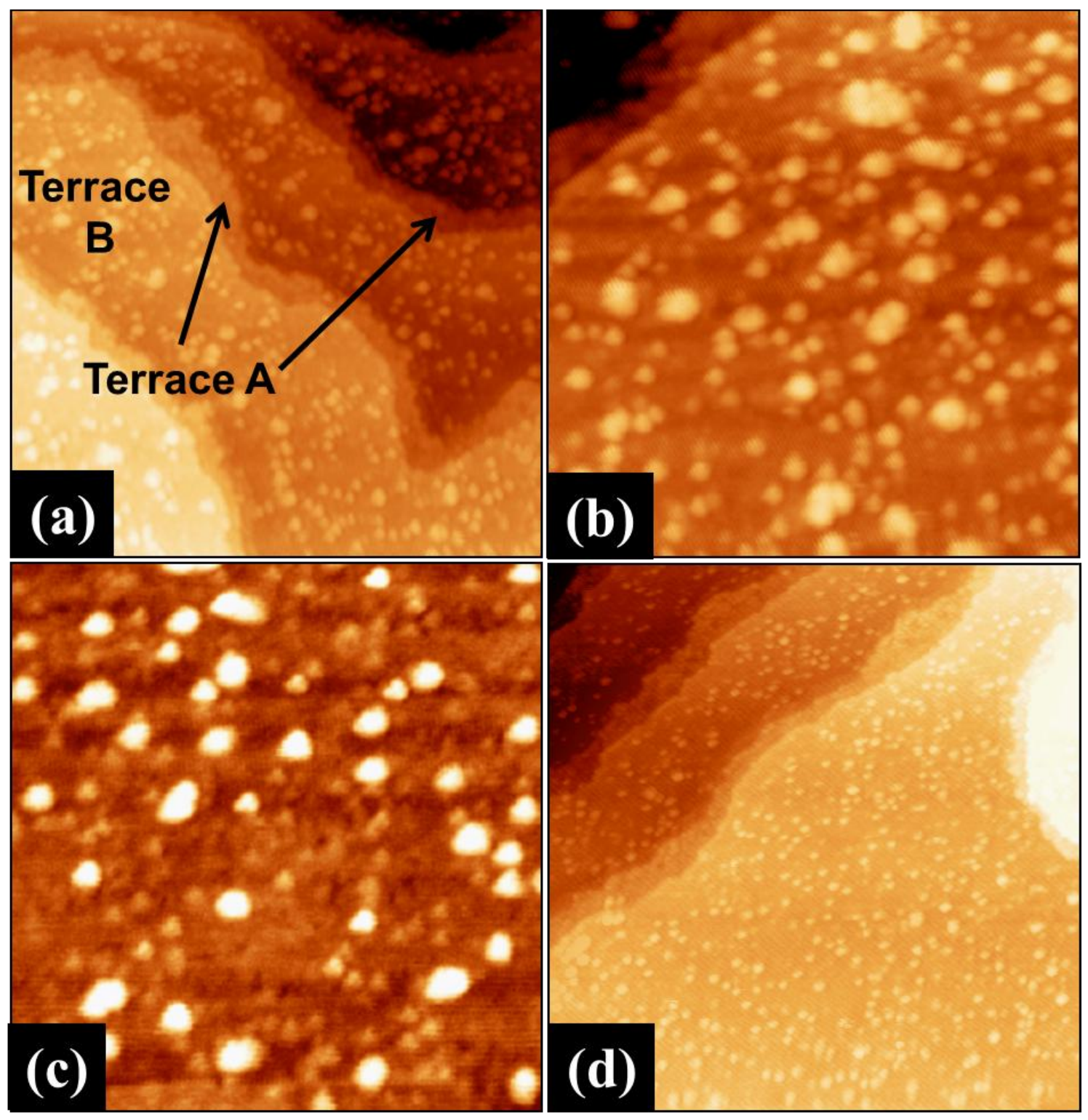

Figure 13 

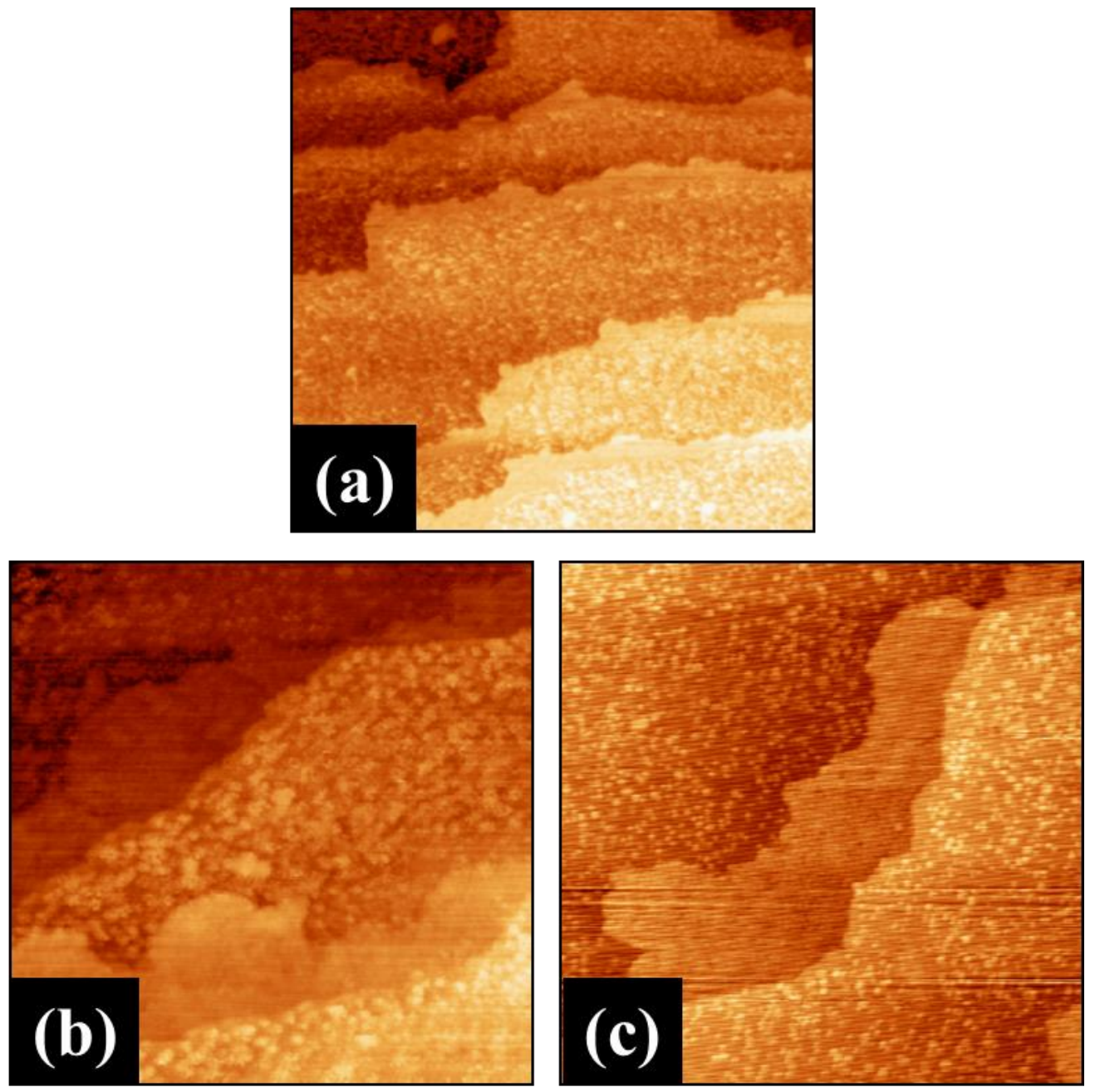

Figure 14 

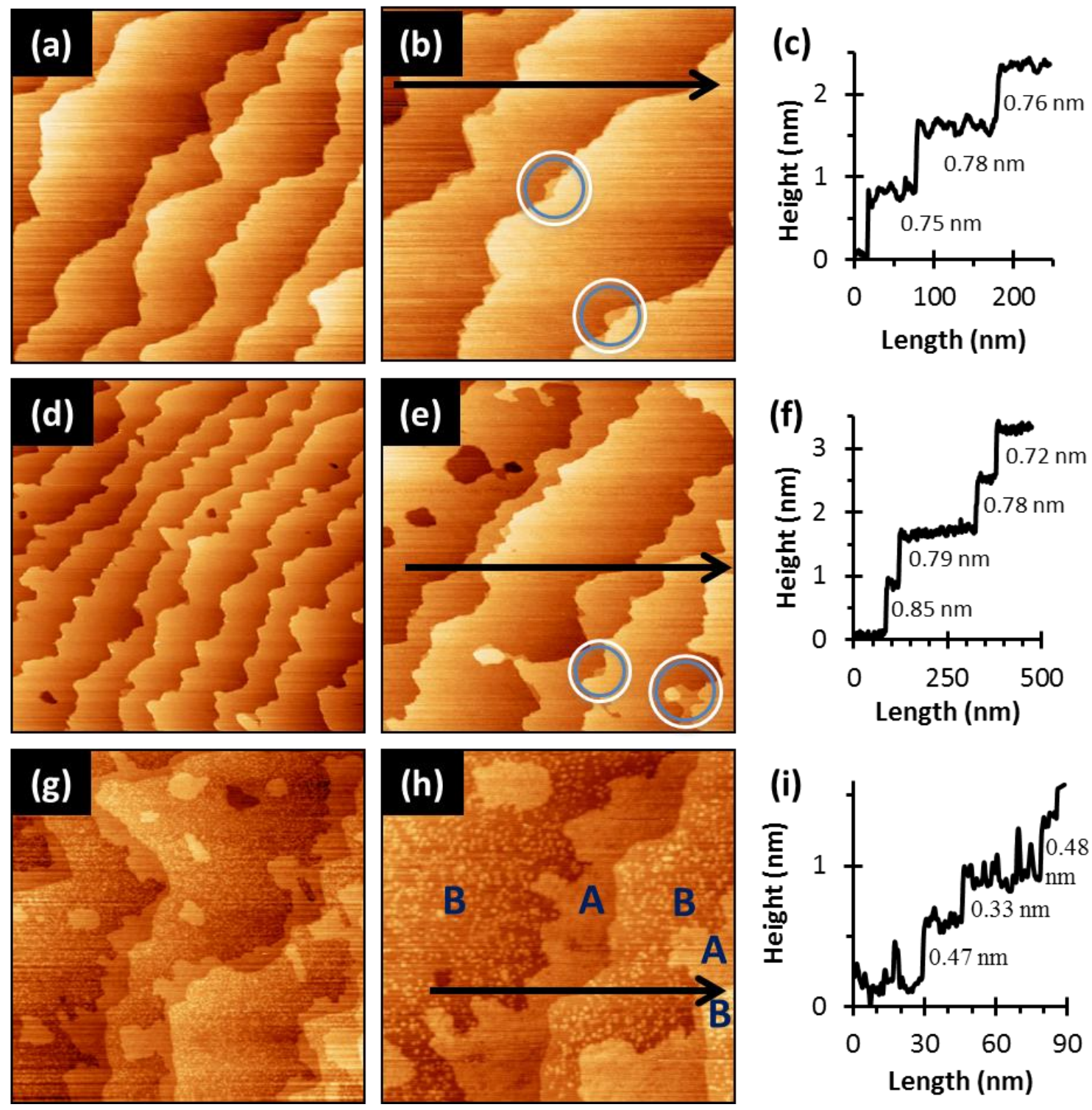

Figure 15 


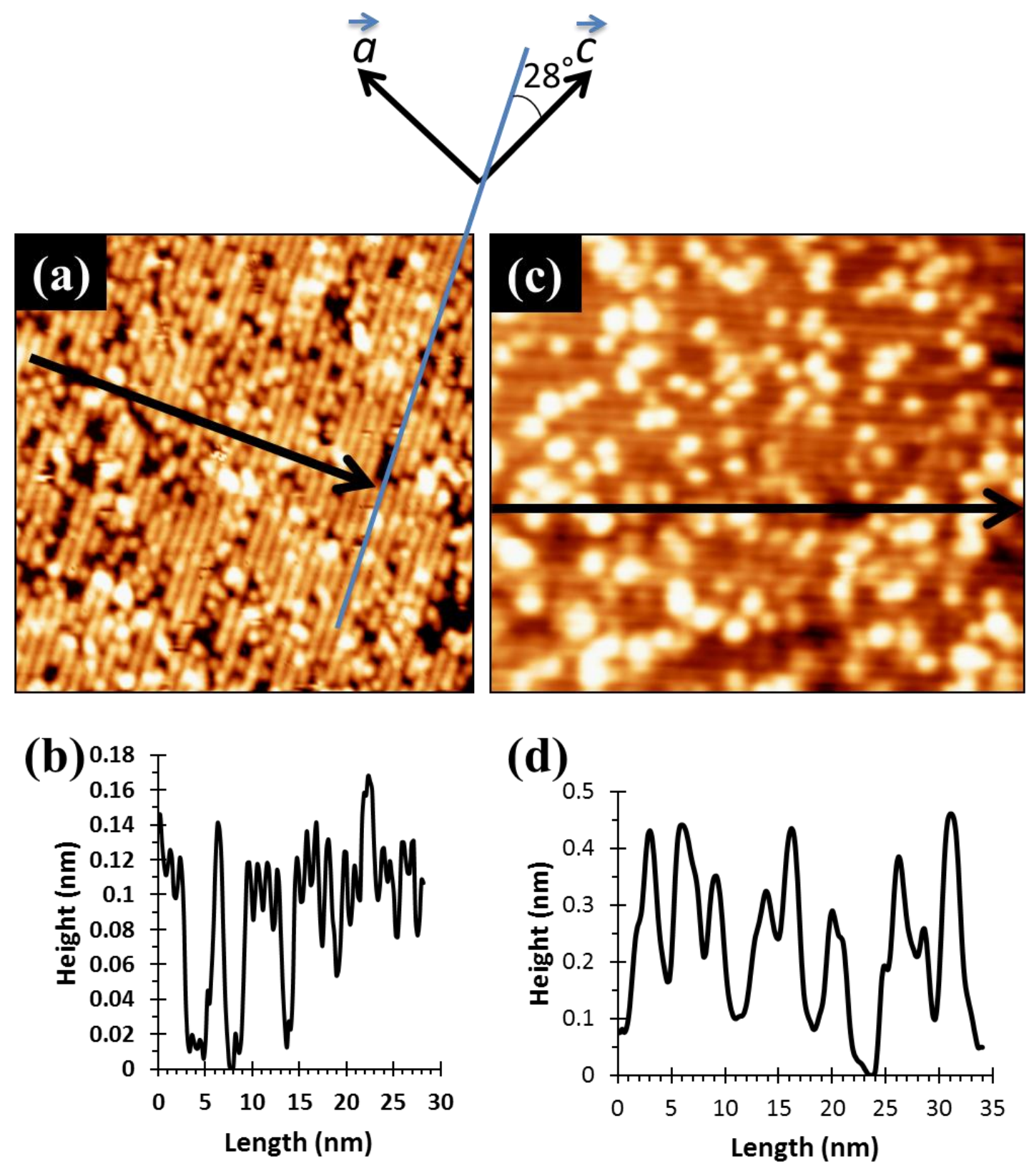

Figure 16 


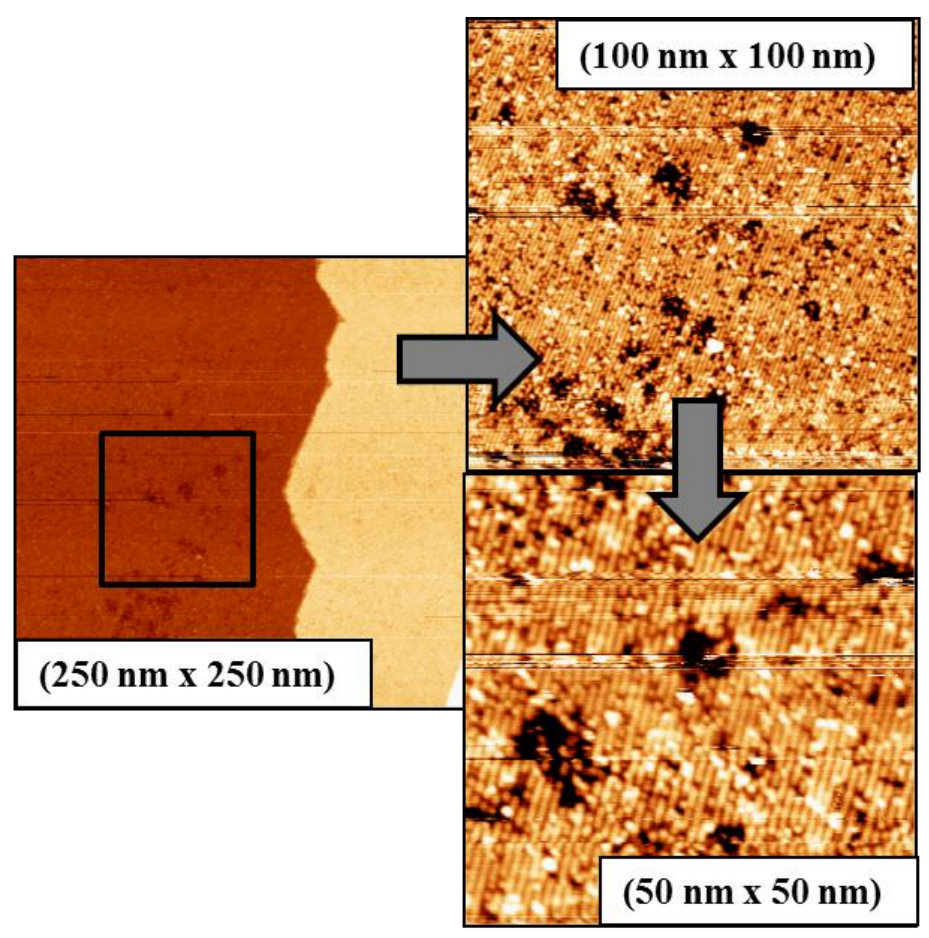

(a)
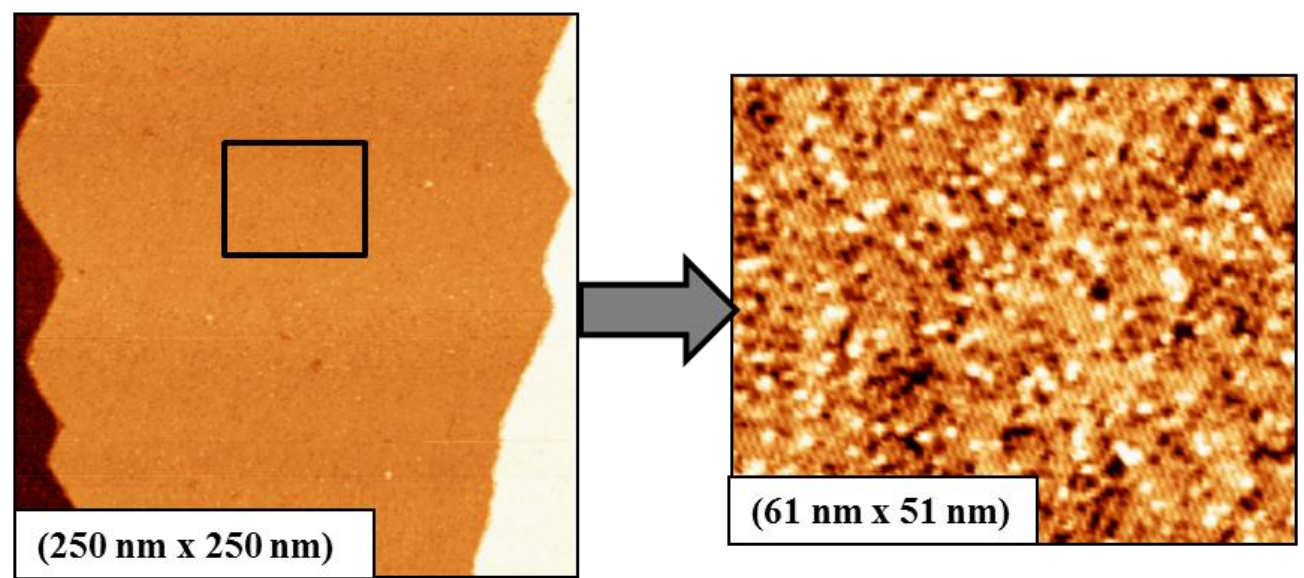

(b)

Figure 17 

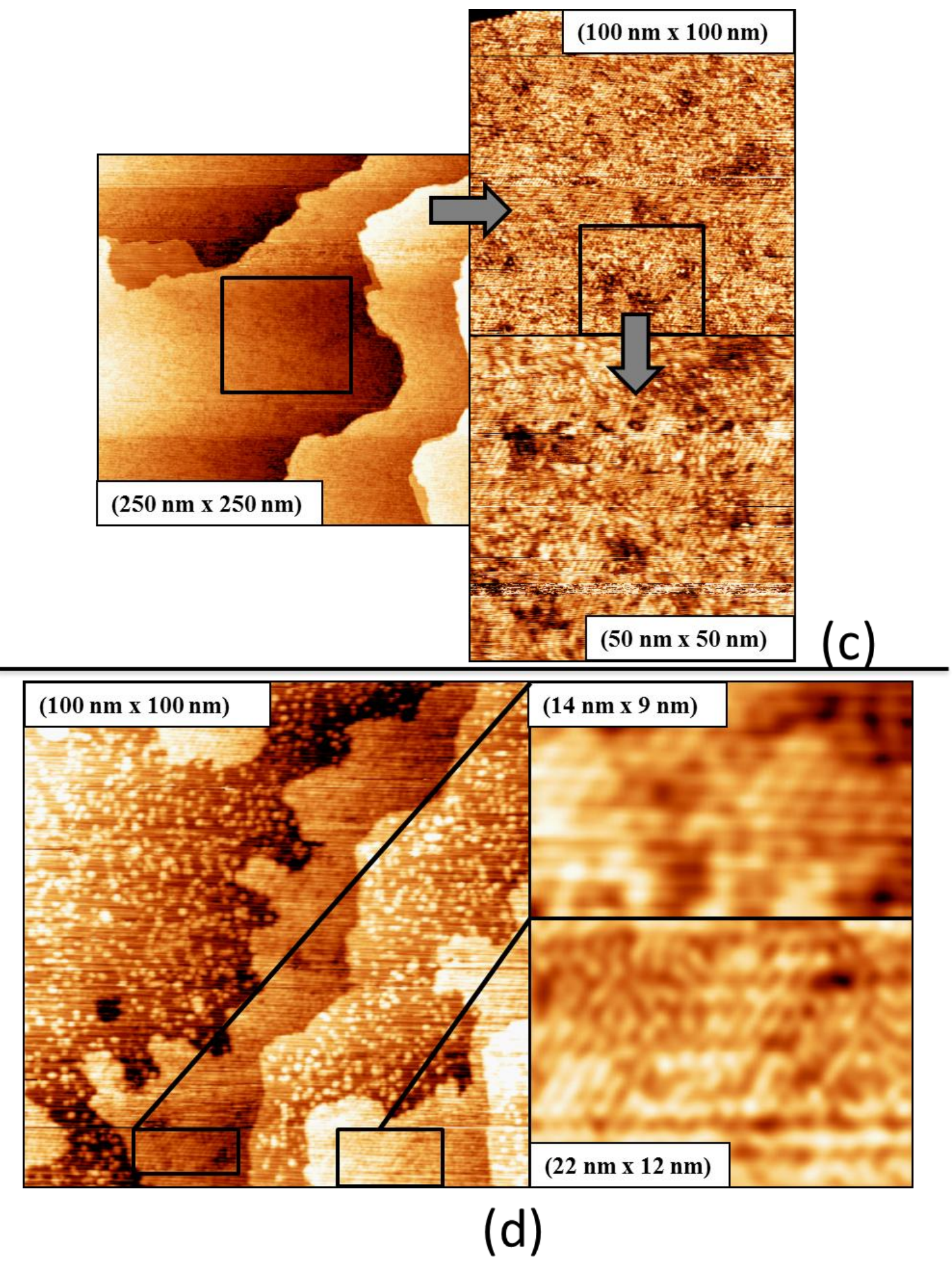

Figure 17 (Continue) 

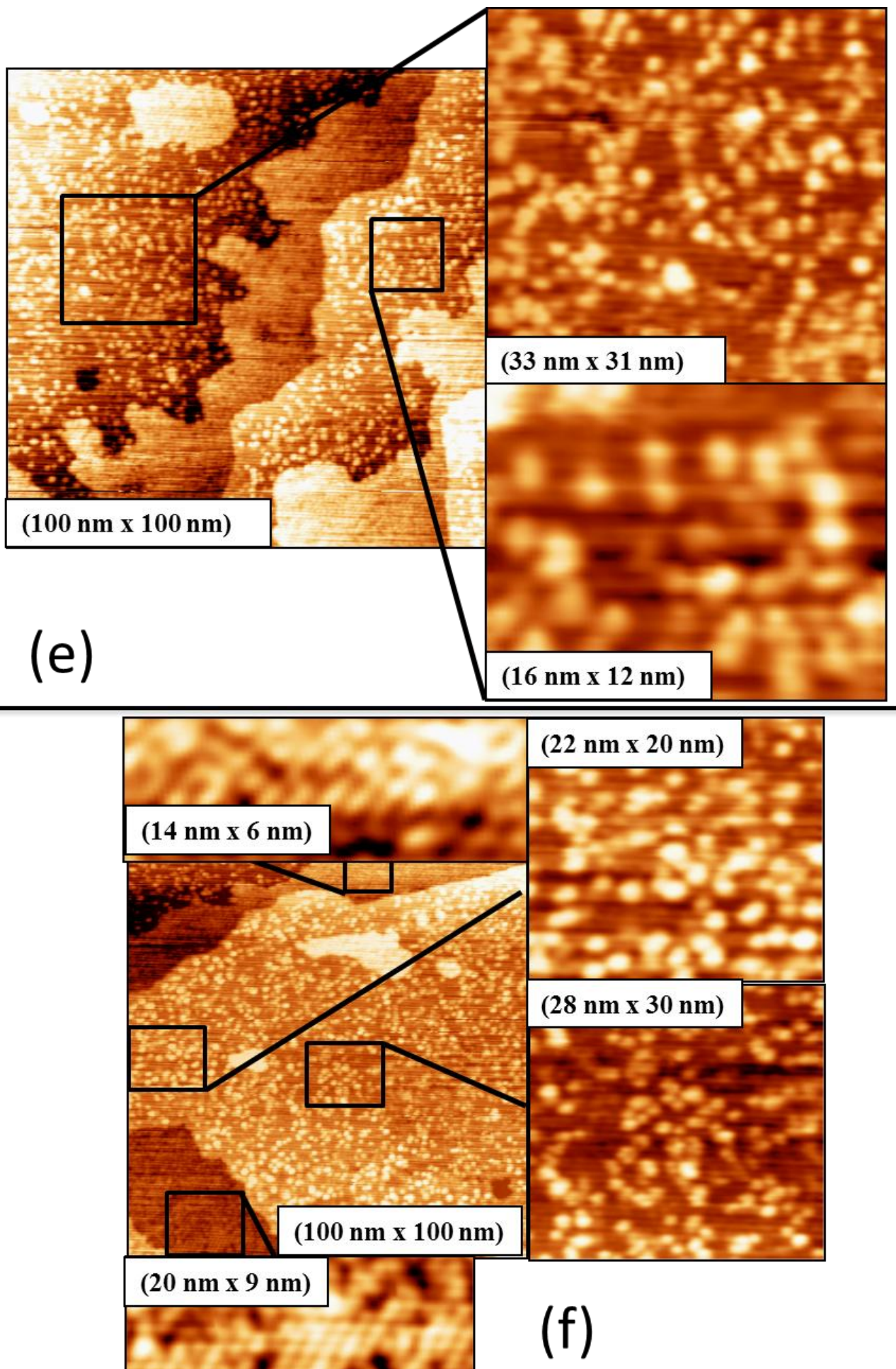

Figure 17 (Continue) 

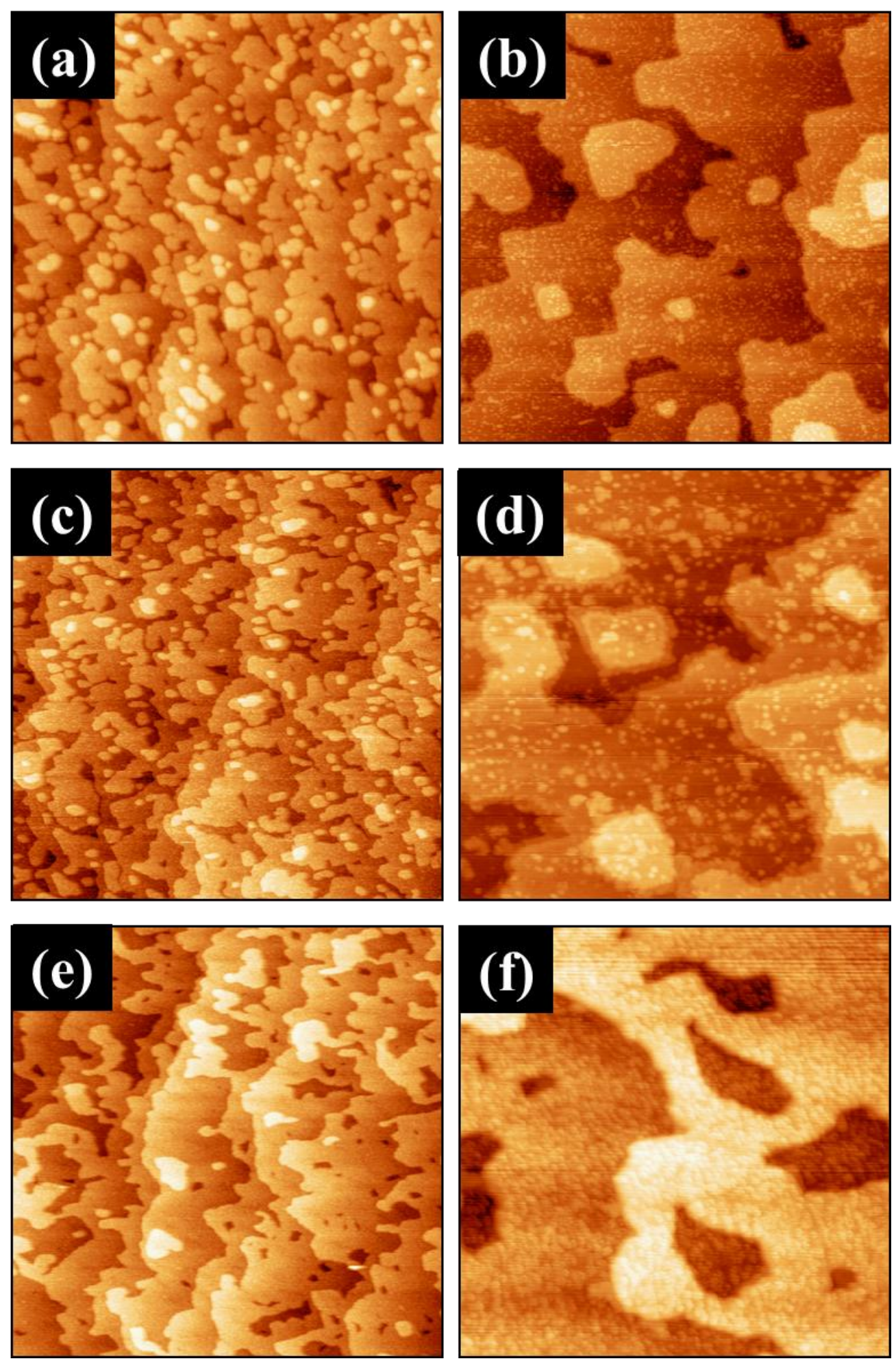

Figure 18 

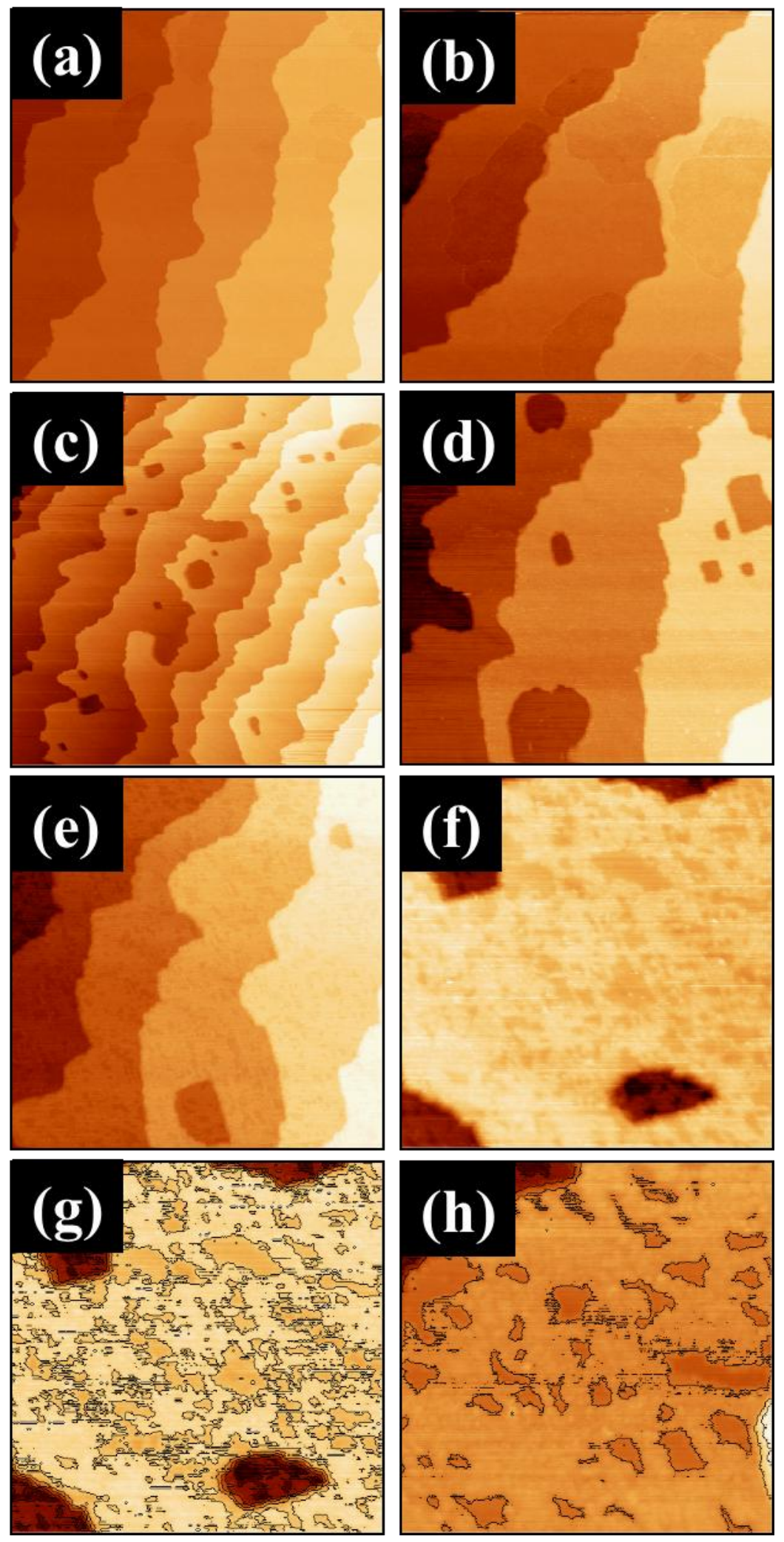

Figure 19 


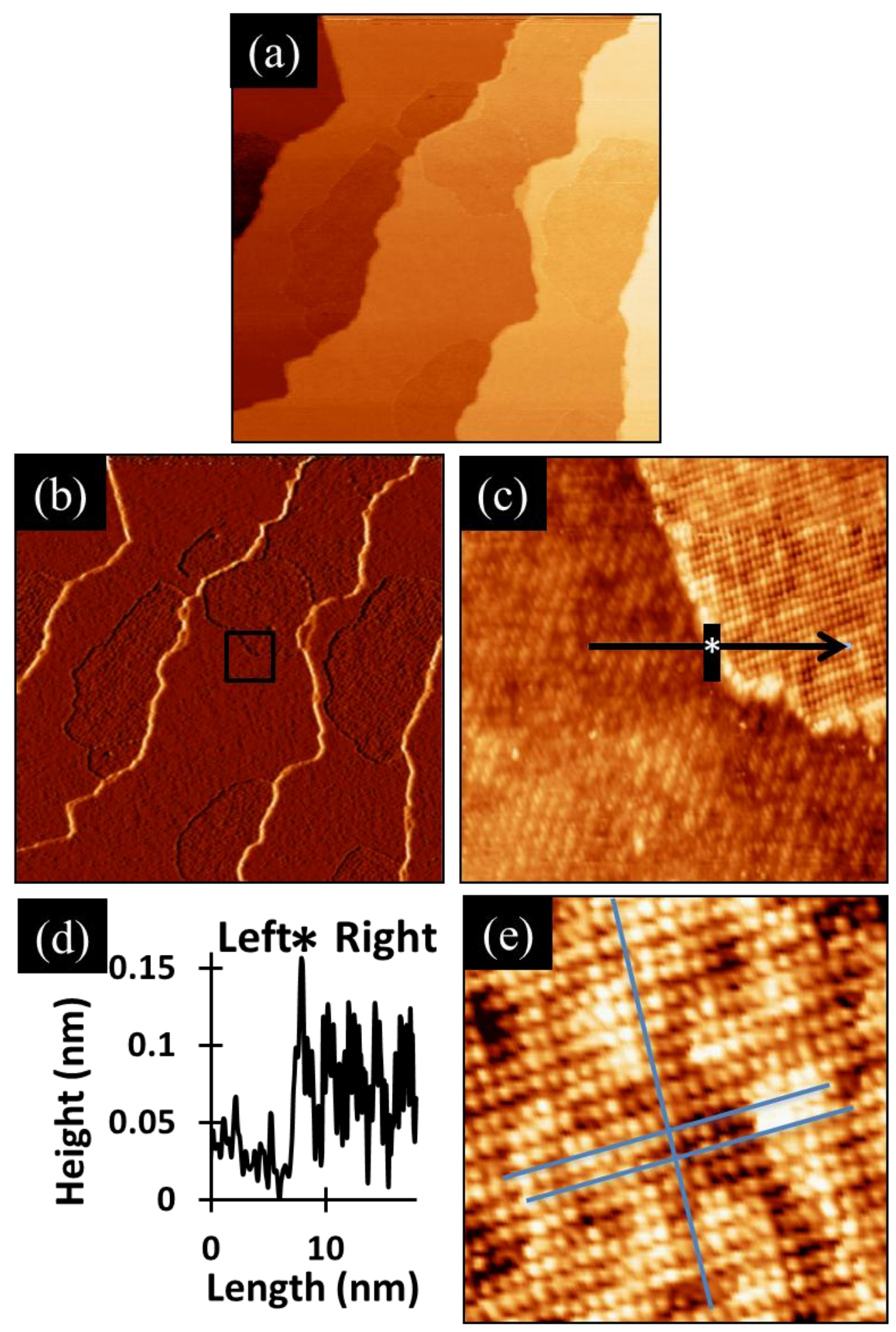

Figure 20 
Ge-pure, sparse plane: $\mathrm{Ge}_{\mathrm{s1}}$

Gd-pure, dense plane: $\mathbf{G d}_{\mathrm{d} 1}$ Ge-Gd, dense plane: $\mathbf{G e}_{-} \mathbf{G d}_{d}$ Gd-pure, dense plane: $\mathbf{G d}_{\mathrm{d} 2}$ Ge-pure, sparse plane: $G_{\mathrm{s} 2}$ Ge-pure, sparse plane: $\mathrm{Ge}_{11}$ Gd-pure, dense plane: $\mathbf{G d}_{\mathrm{d} 1}$
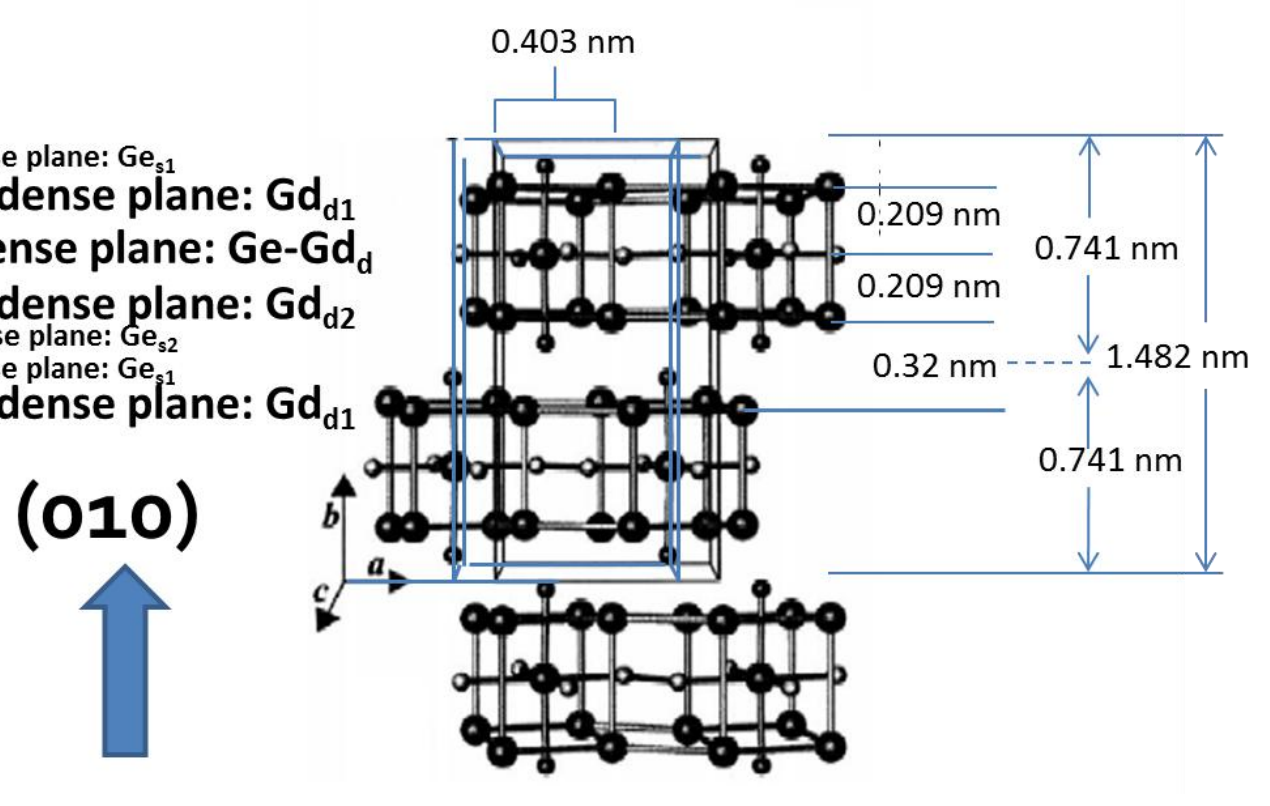

Figure 21 


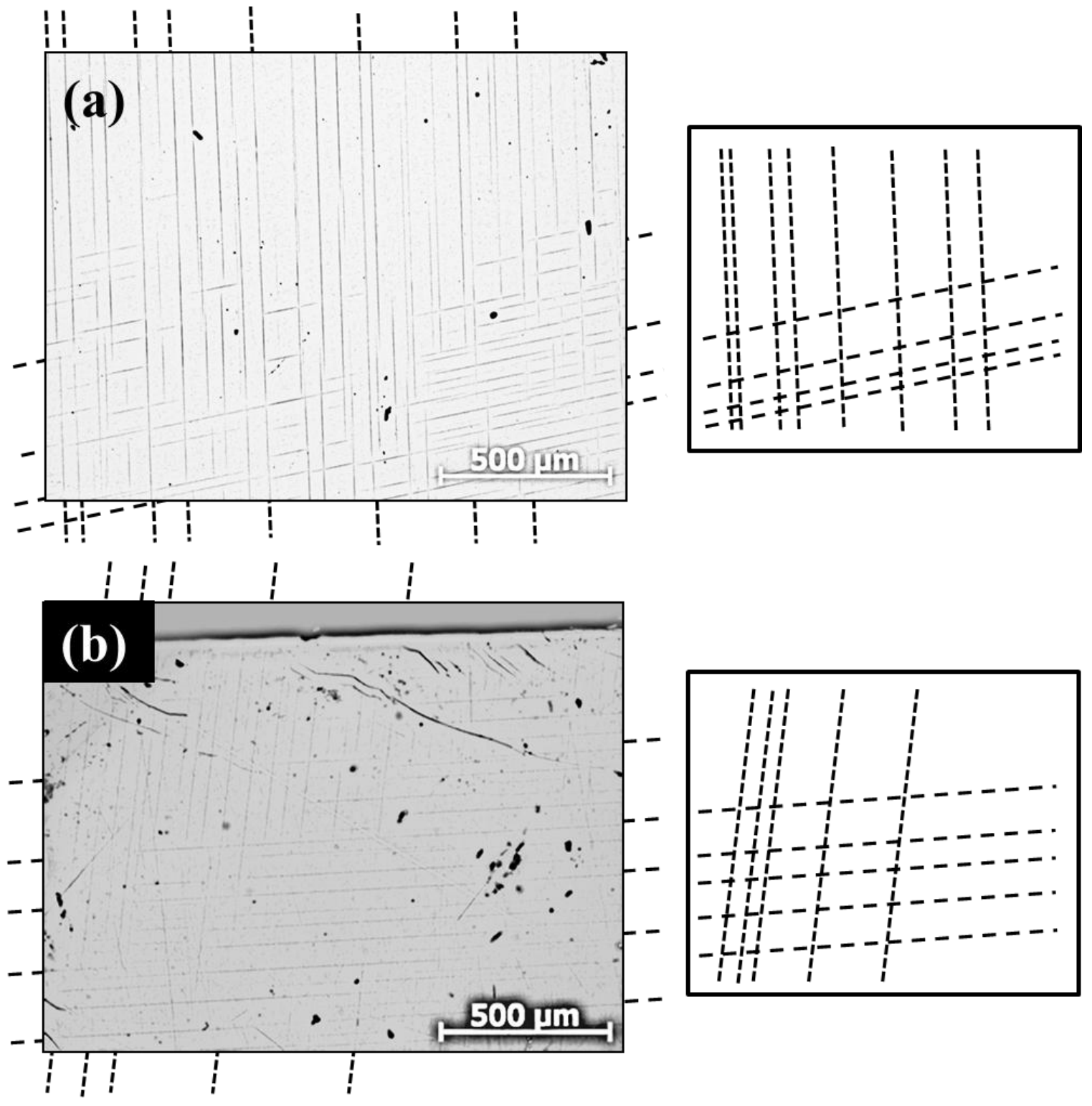

Figure 22 


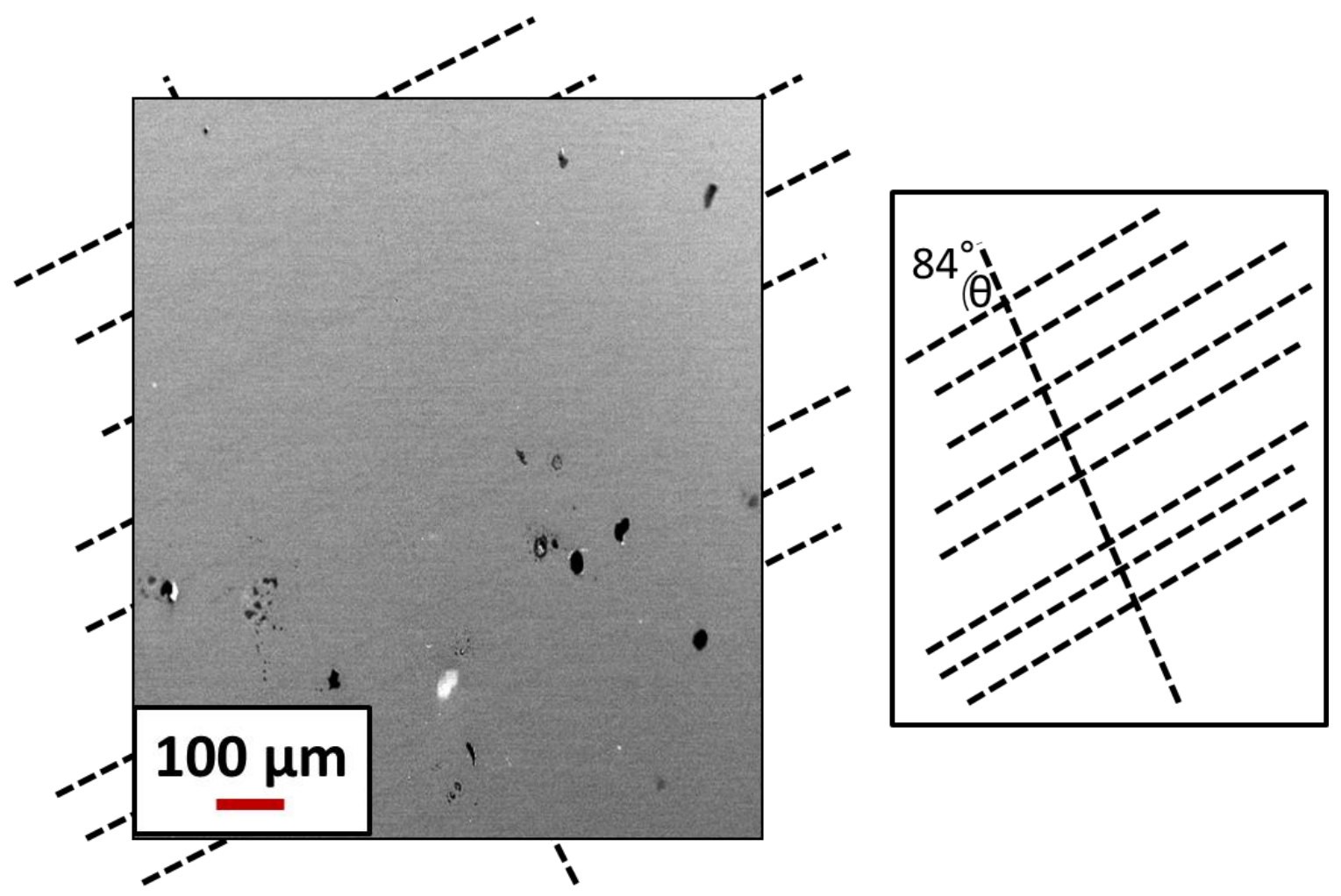

Figure 23 


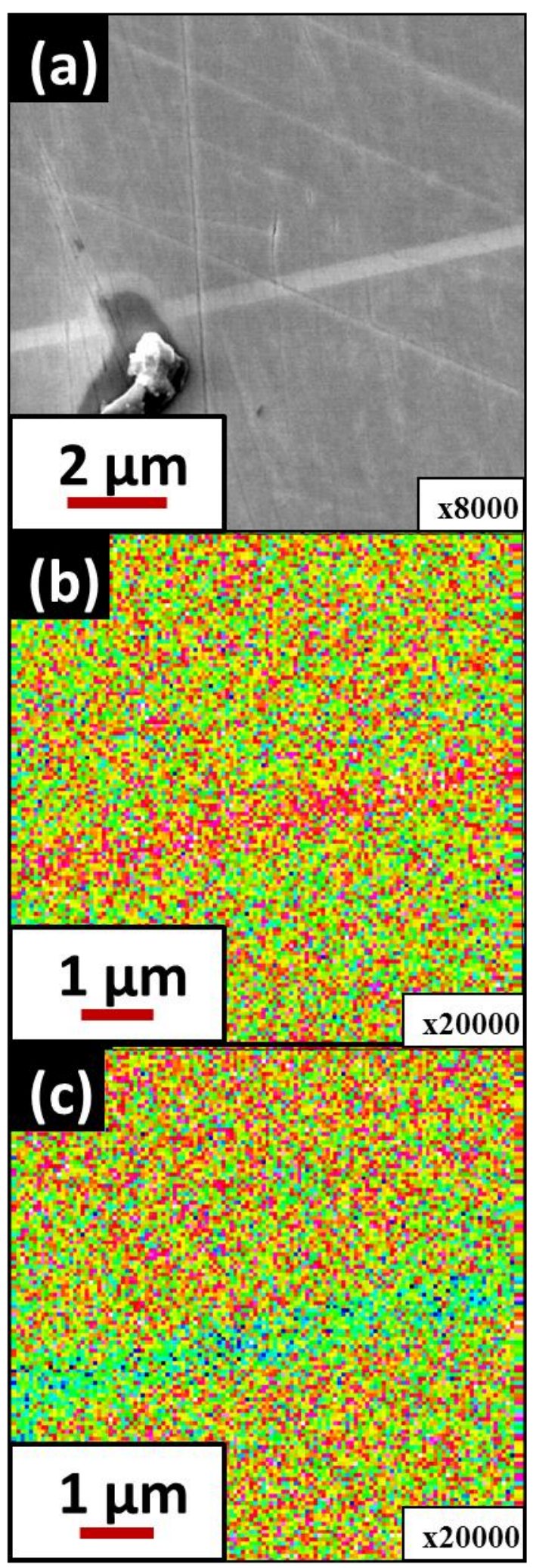

Figure 24 


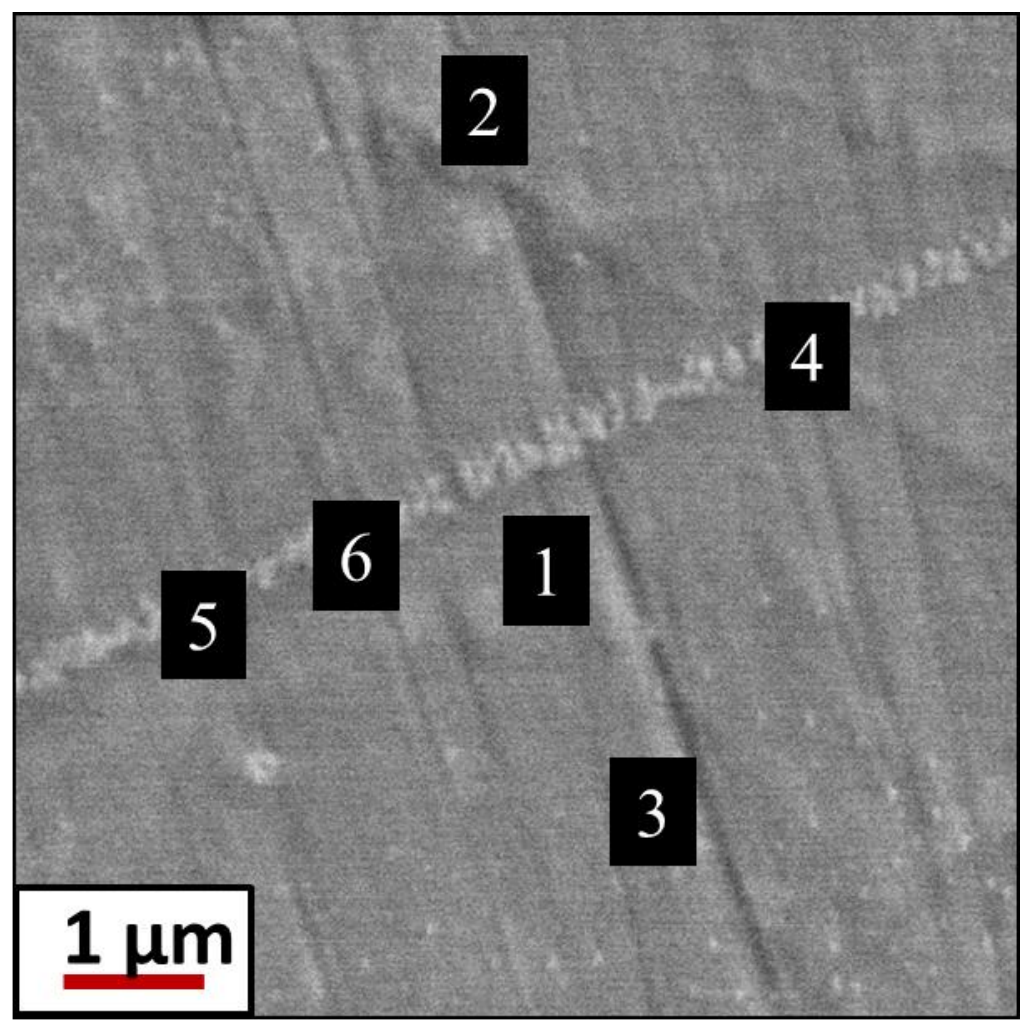

\begin{tabular}{|c|c|c|}
\hline & Gd & Ge \\
\hline 1 & $53 \%$ & $47 \%$ \\
\hline 3 & $52 \%$ & $48 \%$ \\
\hline 4 & $50 \%$ & $50 \%$ \\
\hline 5 & $64 \%$ & $36 \%$ \\
\hline $6^{6}$ & $67 \%$ & $33 \%$ \\
\hline Gd $_{5} \mathbf{G e}_{3}$ & $66 \%$ & $34 \%$ \\
\hline
\end{tabular}

Figure 25 


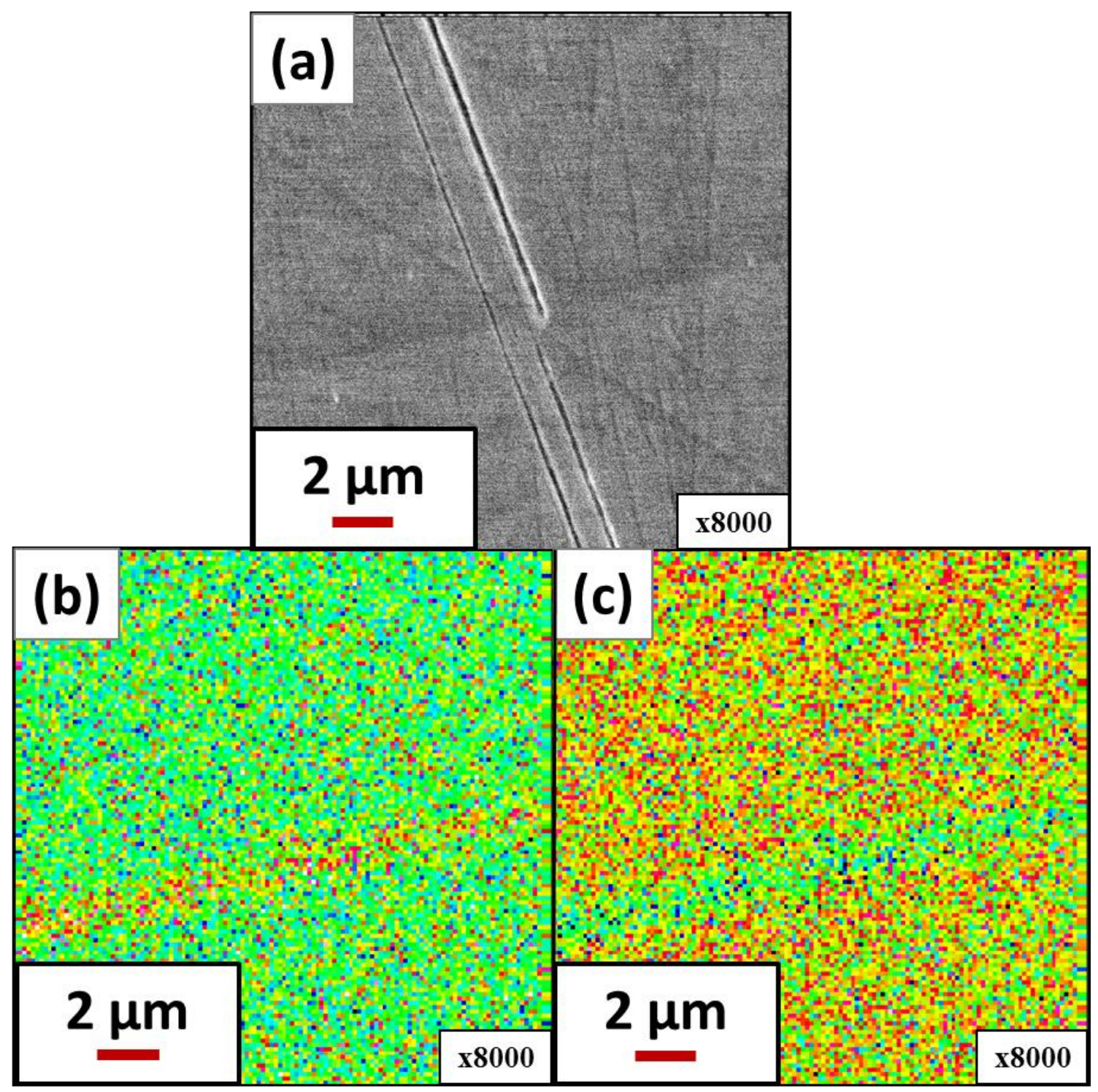

Figure 26 


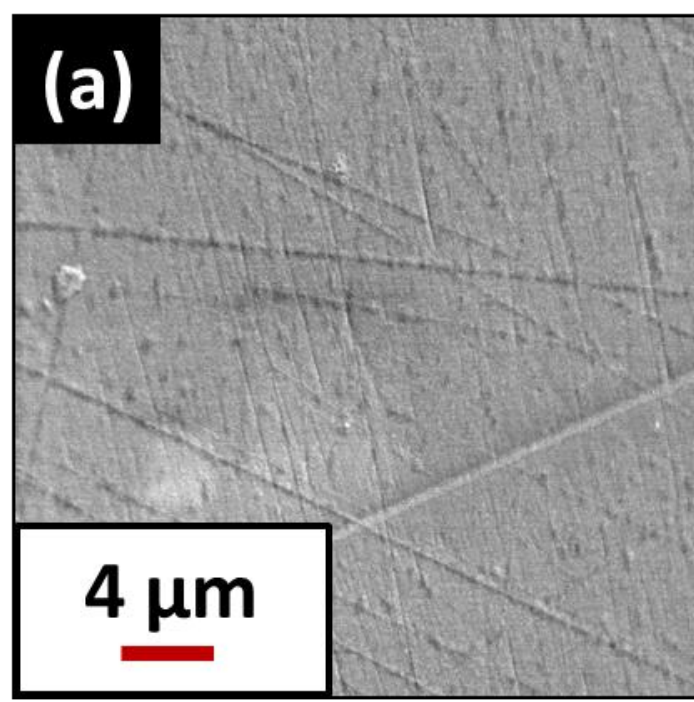

\section{(b)}

$1 \mu \mathrm{m}$
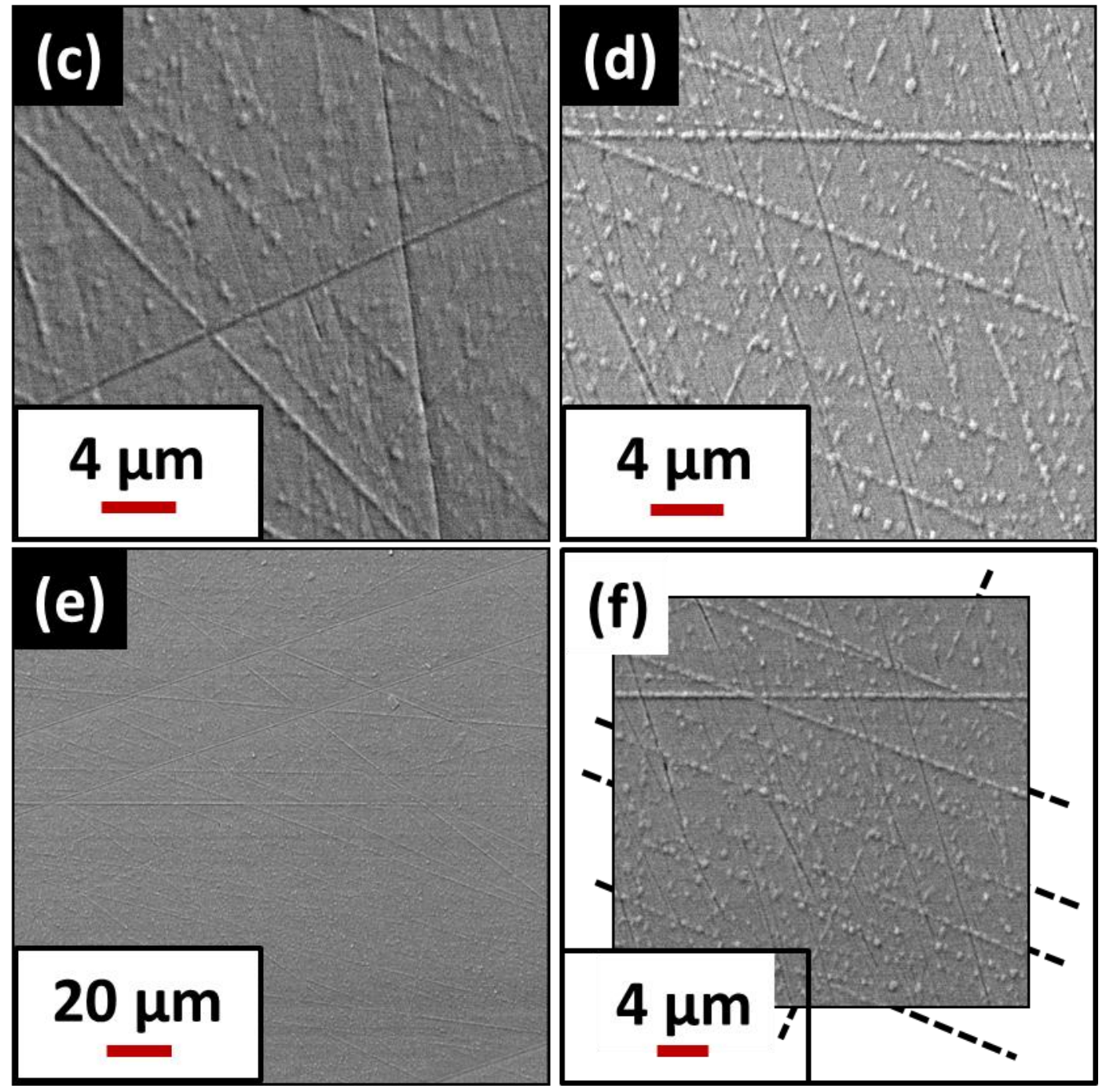

Figure 27 


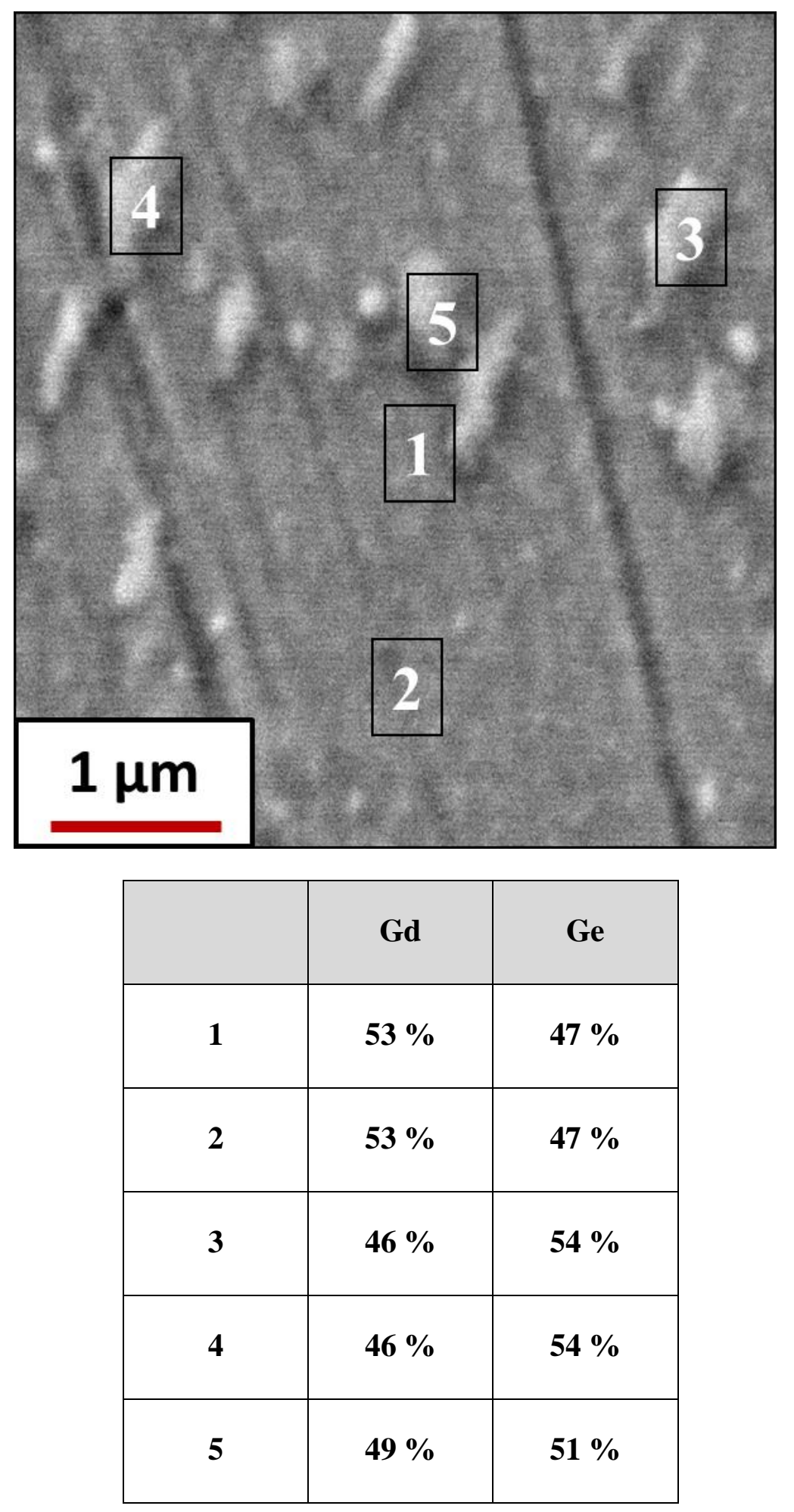

Figure 28 

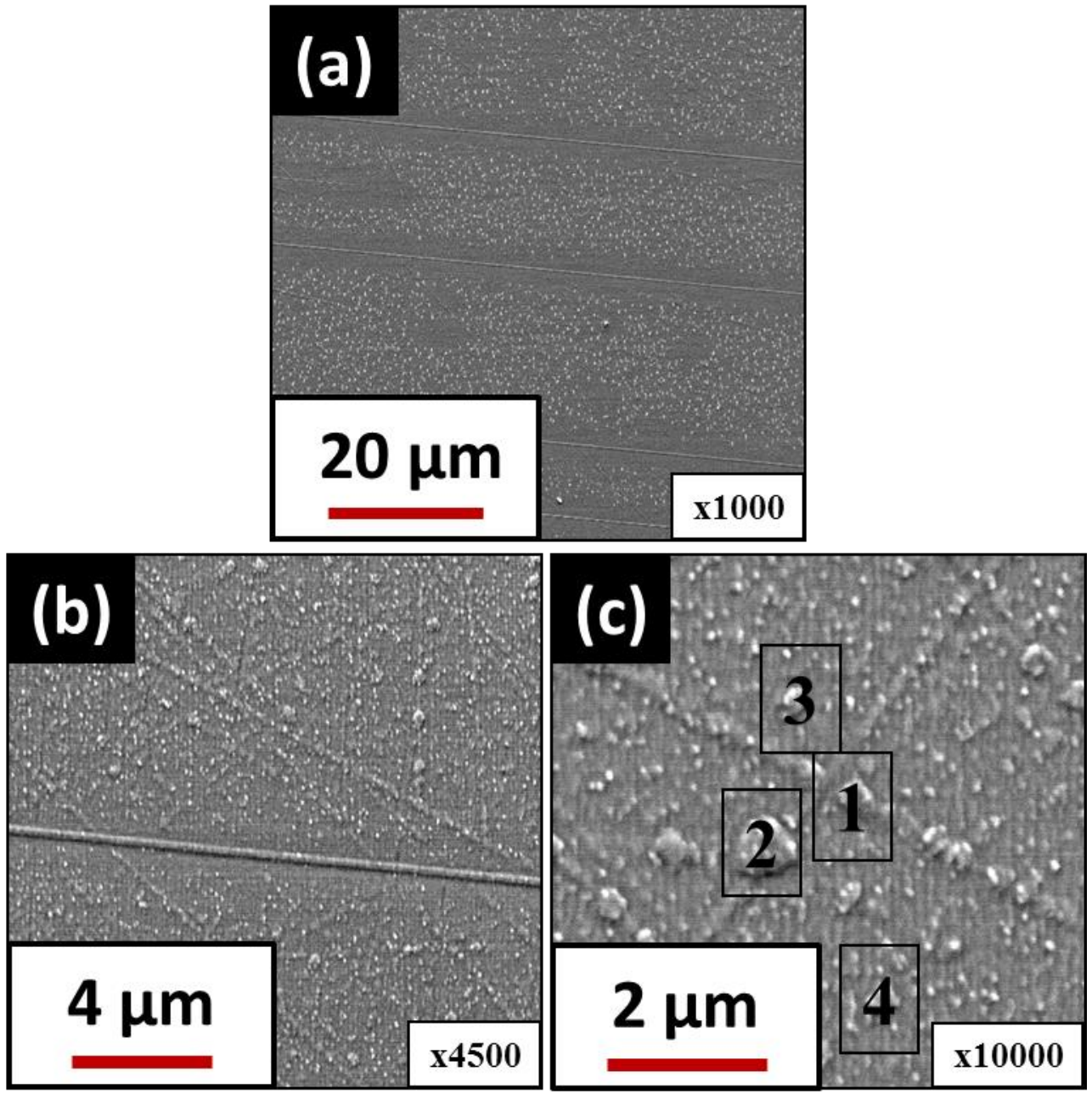

\begin{tabular}{|c|c|c|}
\hline & Gd & Ge \\
\hline 1 & $41 \%$ & $59 \%$ \\
\hline 2 & $34 \%$ & $66 \%$ \\
\hline 3 & $45 \%$ & $55 \%$ \\
\hline 4 & $36 \%$ & $54 \%$ \\
\hline
\end{tabular}

Figure 29 


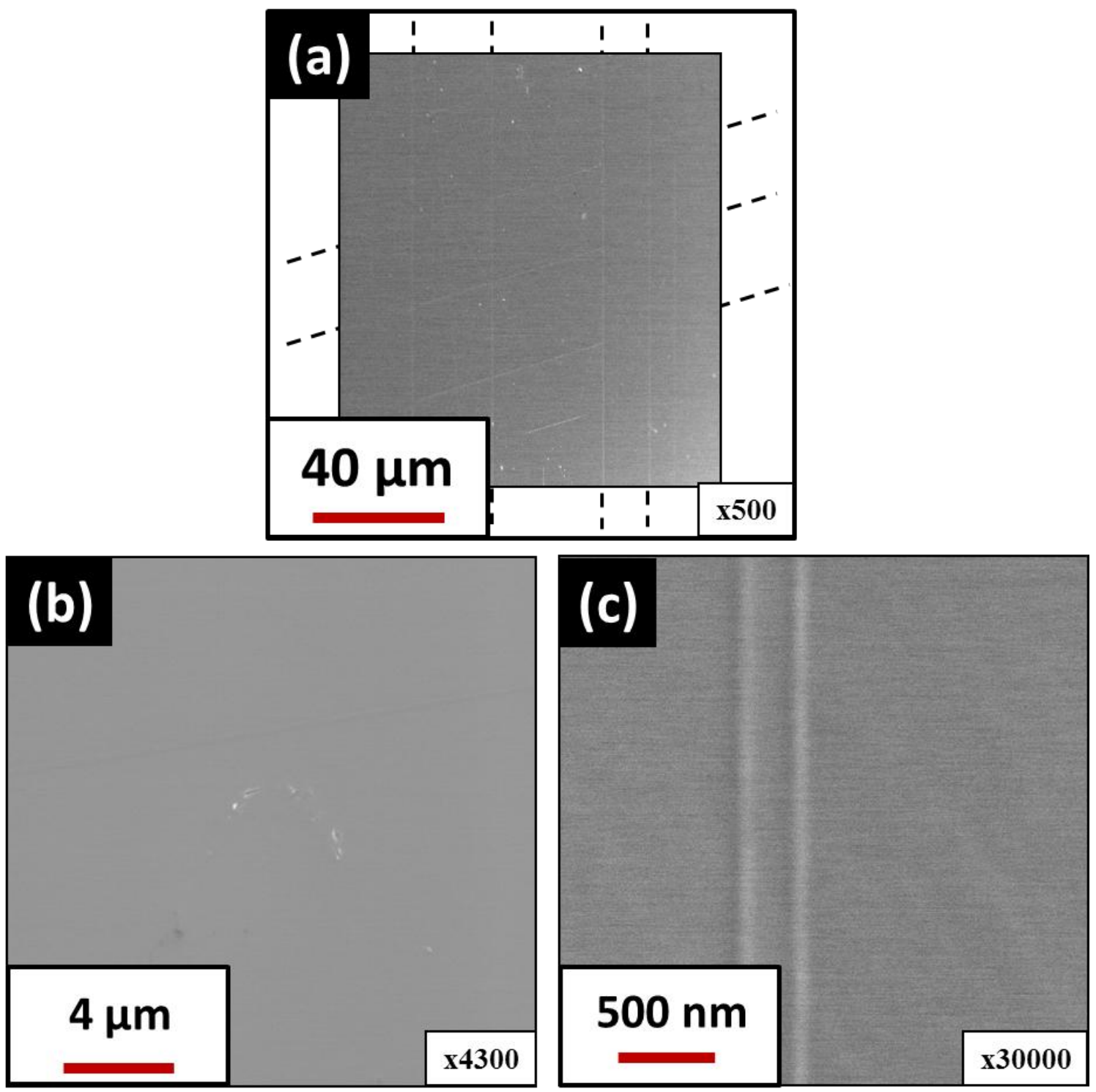

Figure 30 


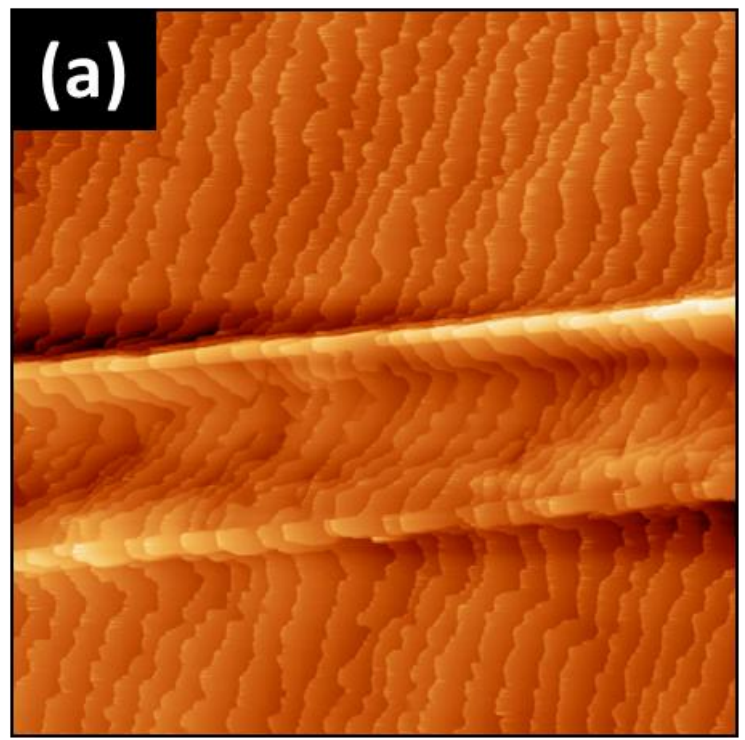

\section{(b)}

\section{(c)}
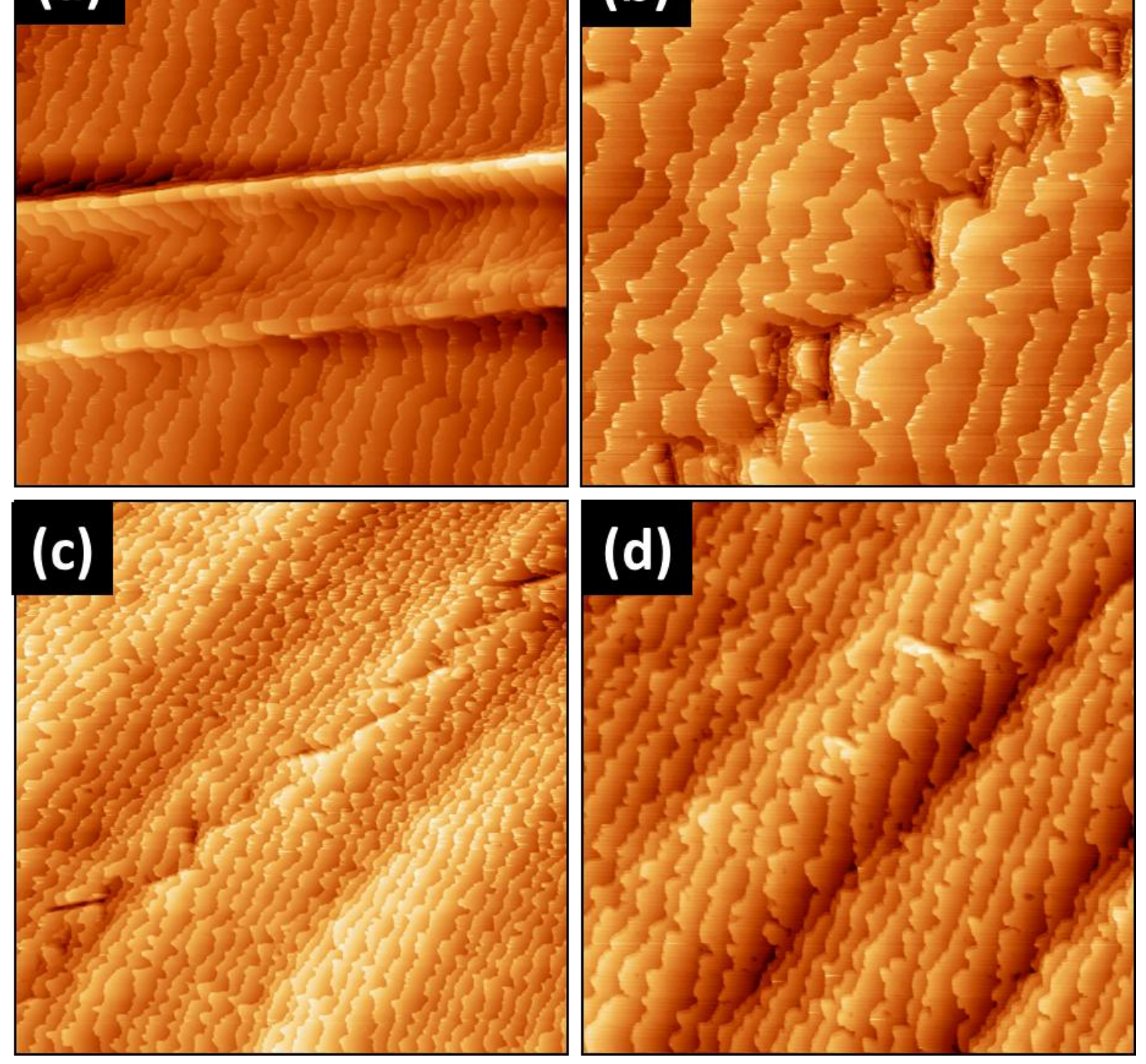

Figure 31 


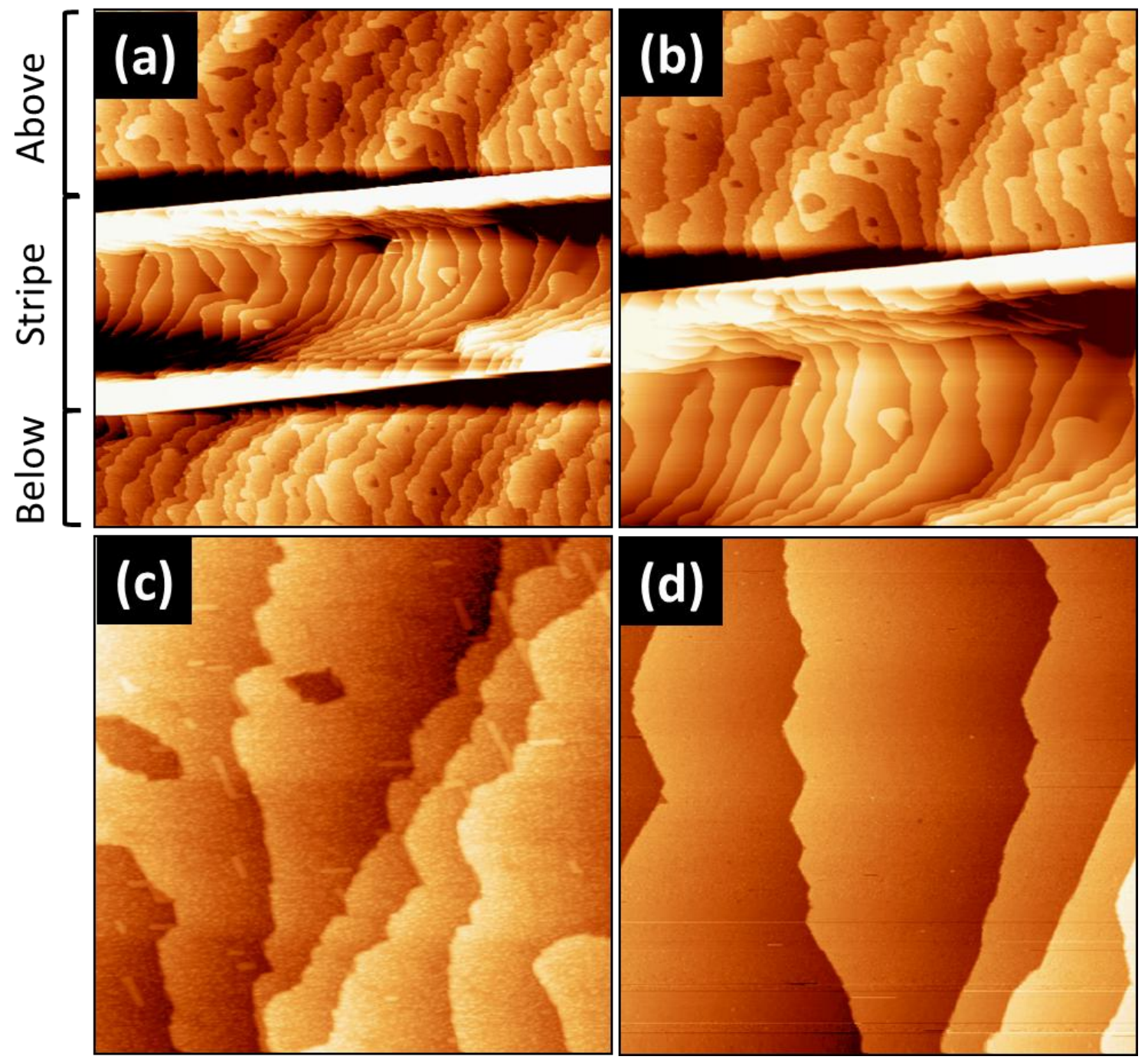

Figure 32 


\section{$\underline{\text { Appendix }}$}

\section{Vapor Pressure of Elemental Gd and Ge}

Vapor pressures of elemental Gd and Ge are shown in Fig. A1 and A2, from five different sources [1-5].

Vapor pressures of the elements are relevant to the study of $\mathrm{Gd}_{5} \mathrm{Ge}_{4}$ for at least two reasons. First, surface energy often scales with the heat of vaporization, and in turn, the heat of vaporization is proportional to the logarithm of the vapor pressure. Hence, determining relative vapor pressures may give an indication of the relative surface energies of $\mathrm{Gd}$ and Ge. In turn, this could provide an indication of whether one would expect a pure Gd termination to be more favorable than a mixed Gd-Ge termination. Second, the vapor pressures of the elements may help to predict which element is most likely to evaporate selectively from $\mathrm{Gd}_{5} \mathrm{Ge}_{4}$ at high temperature. Of course, both of these exercises assume that it is valid to extrapolate from the elements to the inter metallic, which may not be valid. Specifically, chemical potentials of Gd and Ge may be much different in $\mathrm{Gd}_{5} \mathrm{Ge}_{4}$ than in elemental Gd or Ge. However, if the differences between the elements are very large, one might expect the trends to appear also in the intermetallic.

We found five different sources of vapor pressure data that included both $\mathrm{Gd}$ and Ge. Of these, two indicated that the vapor pressure of $\mathrm{Ge}$ is higher than that of $\mathrm{Gd}$, and the others showed the opposite trend. We concluded that the vapor pressures of Gd and Ge are probably close. 


\section{Bumps on B-Terraces}

The bumps on the B-terraces are positioned randomly. This conclusion was based on the work illustrated in Fig. A3 and A4. There, images A3a and A4a show large regions of B-terraces with bumps. Images $\mathrm{A} 3 \mathrm{~b}$ and $\mathrm{A} 4 \mathrm{~b}$ show the same regions after filtering to isolate the bumps. Images A3c and A4c show the fast Fourier Transforms of the filtered images. Images A3d and A4d show the auto correlation of the filtered images. The lack of distinct spots indicates that the bumps are not arranged periodically.

\section{$\underline{\text { References }}$}

[1] D. Stull (Ed.) American Institute of Physics Handbook, McGraw Hill, New York, 1972.

[2] K.J. Lesker, Deposition Techniques: Material names G-L, Kurt J. Lesker Company.

[3] D.R. Lide (Ed.) CRC Handbook of Chemistry and Physics, CRC Press, Boca Raton, Florida, 2003.

[4] R.E. Honig, RCA Review 23 (1962) 567.

[5] L.I. Maissel, R. Glang (Eds.), Handbook of Thin Film Technology, McGraw Hill, Texas, 1970. 


\section{Figure Captions}

\section{Figure A1}

Vapor pressure of elemental Gd and Ge from five different sources. The abbreviations are as follow: (AIP) American Institute of Physics Handbook; (KJL) Kurt J. Lesker; (TFT) Handbook of Thin Film Technology, (CRC) Chemical Rubber Company Handbook of Chemistry and Physics; and (RCA) RCA Review.

\section{Figure A2}

Vapor pressure of elemental Gd and Ge from five different sources (zoomed in). The abbreviations are as follow: (AIP) American Institute of Physics Handbook; (KJL) Kurt J. Lesker; (TFT) Handbook of Thin Film Technology, (CRC) Chemical Rubber Company Handbook of Chemistry and Physics; and (RCA) RCA Review.

\section{Figure A3}

STM images of the bumps on B-terraces on the $\mathrm{Gd}_{5} \mathrm{Ge}_{4}(010)$ surface, (a) raw image, (b) filtered image, (c) fast Fourier Transform, and (d) auto correlation after the sample had been annealed to $1150 \mathrm{~K}$. The filter was set to a minimum height of $0.23 \mathrm{~nm}$. The image area and tunneling conditions are $50 \mathrm{~nm} \times 50 \mathrm{~nm}, \mathrm{I}=0.5 \mathrm{nA}$, V-tip $=-1 \mathrm{~V}$. Sample \#1, right side.

\section{Figure A4}

STM images of the bumps on B-terraces on the $\mathrm{Gd}_{5} \mathrm{Ge}_{4}(010)$ surface, (a) raw image, (b) filtered image, (c) fast Fourier Transform, and (d) auto correlation after the sample had been annealed to $900 \mathrm{~K}$. The filter was set to a minimum height of $0.23 \mathrm{~nm}$. The image area and tunneling conditions are $50 \mathrm{~nm} \times 50 \mathrm{~nm}, \mathrm{I}=0.5 \mathrm{nA}$, V-tip $=+1 \mathrm{~V}$. Sample \#2, left side. 


\section{Table 1}

Vapor pressure of elemental Gd and Ge from five different sources. The abbreviations are as follow: (AIP) American Institute of Physics Handbook; (KJL) Kurt J. Lesker; (TFT) Handbook of Thin Film Technology, (CRC) Chemical Rubber Company Handbook of Chemistry and Physics; and (RCA) RCA Review.

\begin{tabular}{|l|c|c|c|c|c|c|c|c|c|c|}
\hline P (Torr) & $\begin{array}{c}\text { Gd } \\
\text { (AIP) }\end{array}$ & $\begin{array}{c}\text { Ge } \\
\text { (AIP) }\end{array}$ & P (Torr) & $\begin{array}{c}\text { Gd } \\
\text { (TFT) }\end{array}$ & $\begin{array}{c}\text { Ge } \\
\text { (TFT) }\end{array}$ & P(Torr) & $\begin{array}{c}\text { Gd } \\
\text { (CRC.c) }\end{array}$ & $\begin{array}{c}\text { Ge } \\
\text { (CRC.b) }\end{array}$ & P (Torr) & $\begin{array}{c}\text { Gd } \\
\text { (RCA) }\end{array}$ \\
\hline $7.60 \mathrm{E}-08$ & 987 & 851 & $1.00 \mathrm{E}-10$ & 607 & 667 & $7.50 \mathrm{E}-03$ & 1563 & 1371 & $1.00 \mathrm{E}-10$ & 627 \\
\hline $7.60 \mathrm{E}-07$ & 1070 & 926 & $1.00 \mathrm{E}-09$ & 657 & 707 & $7.50 \mathrm{E}-02$ & 1755 & 1541 & $6.00 \mathrm{E}-09$ & 700 \\
\hline $7.60 \mathrm{E}-06$ & 1165 & 1013 & $1.00 \mathrm{E}-08$ & 707 & 757 & $7.50 \mathrm{E}-01$ & 1994 & 1750 & $1.00 \mathrm{E}-08$ & 727 \\
\hline $7.60 \mathrm{E}-05$ & 1270 & 1114 & $1.00 \mathrm{E}-07$ & 762 & 812 & $1.50 \mathrm{E}+00$ & & & $4.50 \mathrm{E}-07$ & 800 \\
\hline $7.60 \mathrm{E}-04$ & 1406 & 1232 & $1.00 \mathrm{E}-06$ & 827 & 877 & $7.50 \mathrm{E}+00$ & 2300 & 2014 & $1.00 \mathrm{E}-05$ & 900 \\
\hline $7.60 \mathrm{E}-03$ & 1564 & 1372 & $1.00 \mathrm{E}-05$ & 897 & 947 & $1.50 \mathrm{E}+01$ & & & $1.00 \mathrm{E}-02$ & 1227 \\
\hline $7.60 \mathrm{E}-02$ & 1757 & 1542 & $1.00 \mathrm{E}-04$ & 977 & 1037 & $3.75 \mathrm{E}+01$ & & & P (Torr) & Ge \\
\hline (RCA)
\end{tabular}




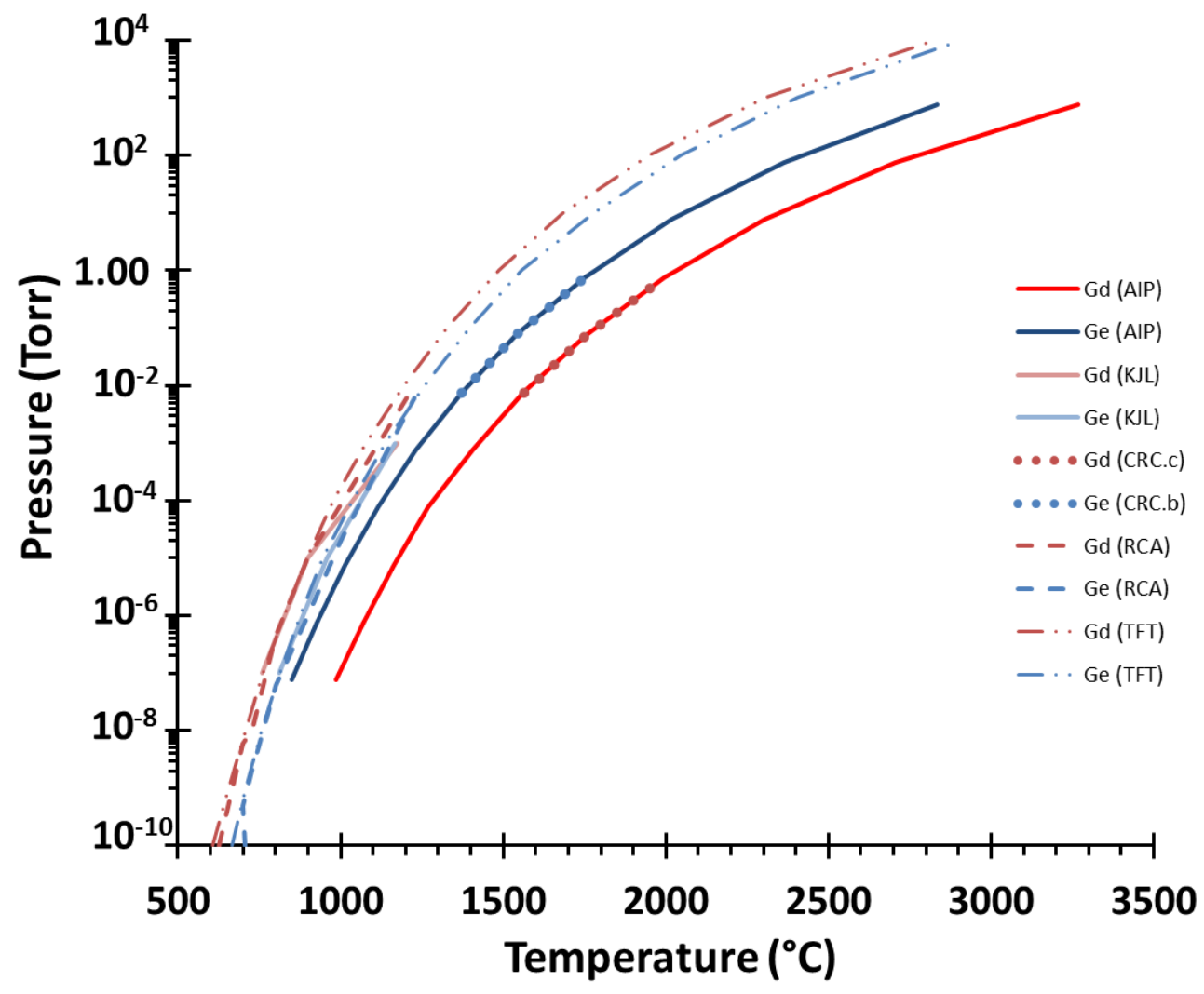

Figure A1 


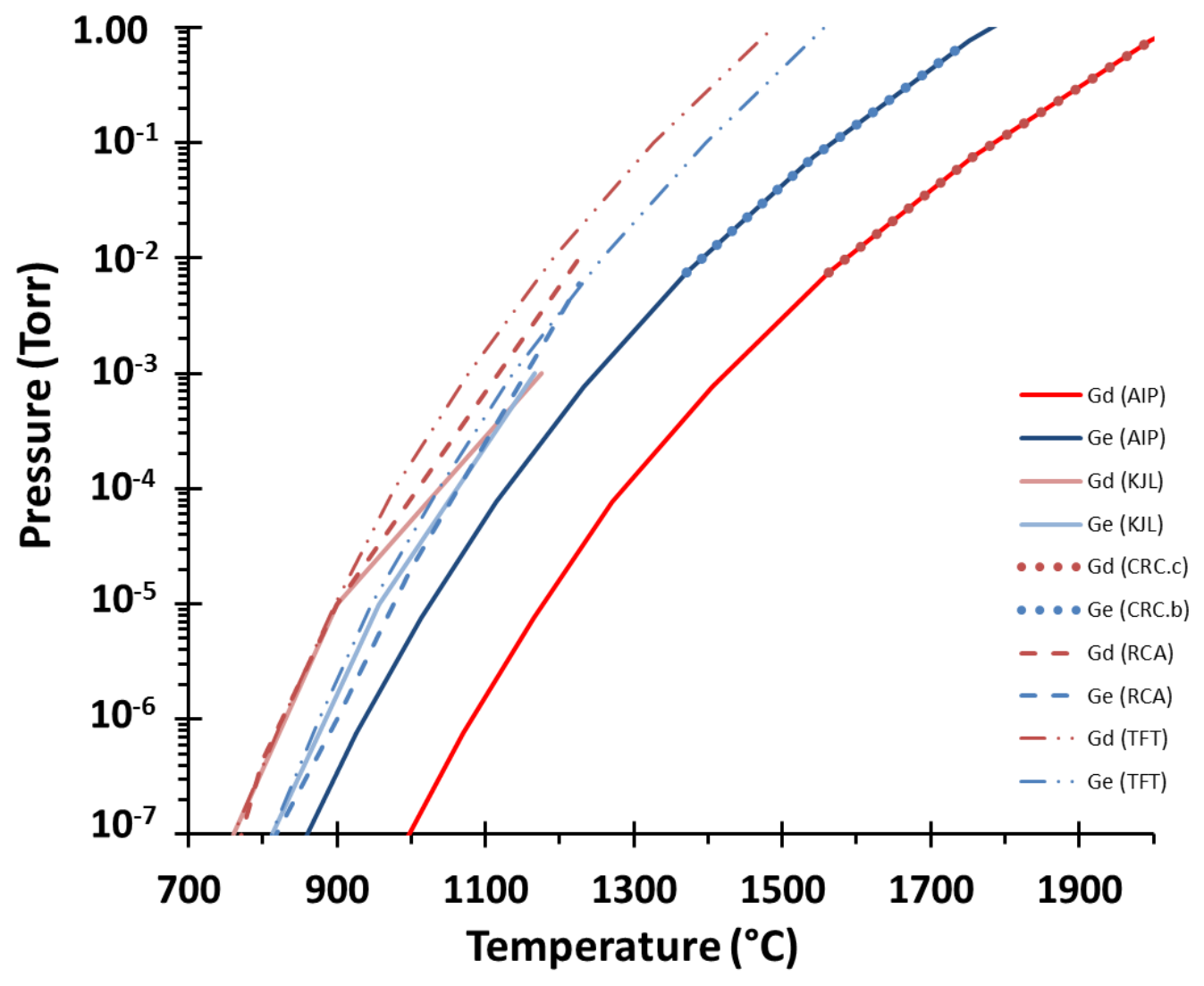

Figure A2 

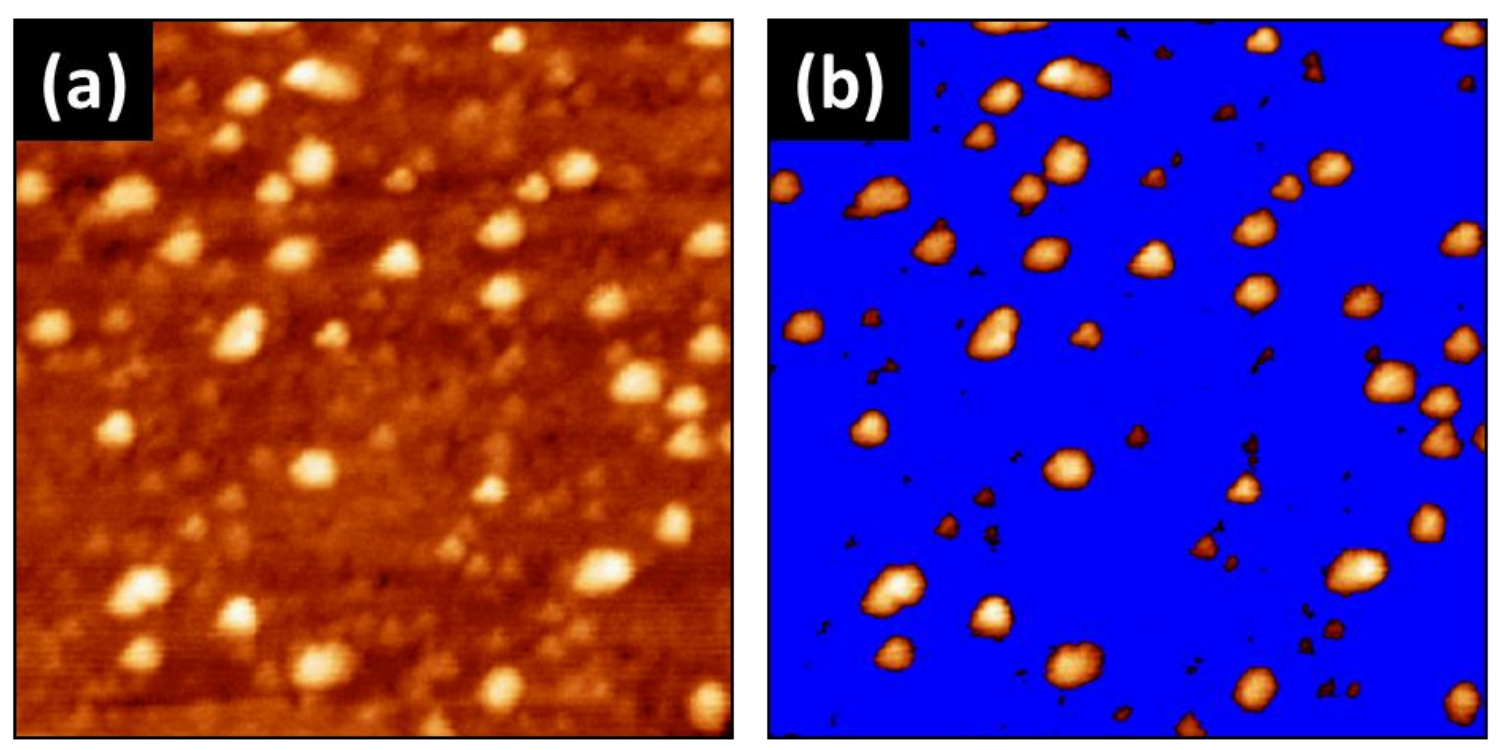

(c)

(d)

Figure A3 

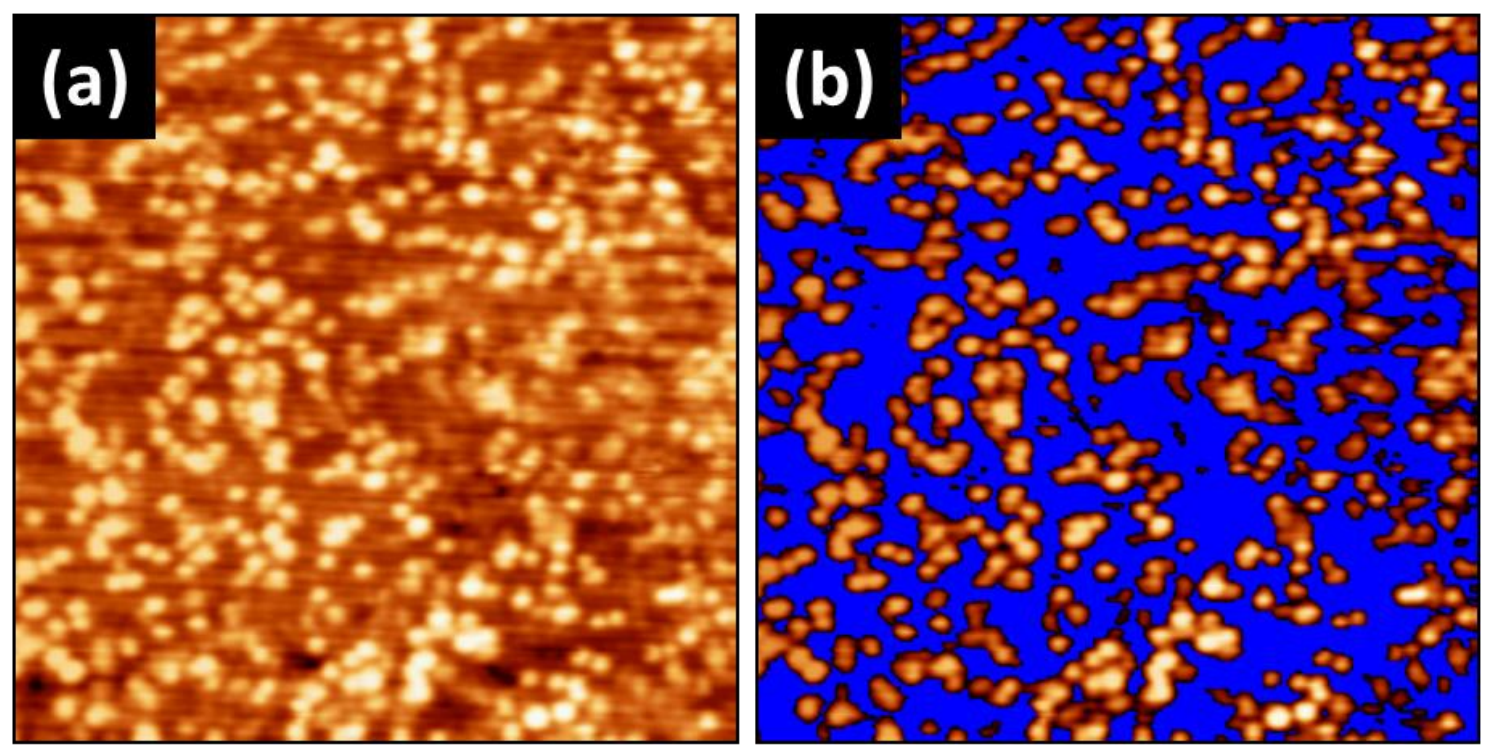

(c)

(d)

$1.0\{1 / \mathrm{nm}\}$

$10 \mathrm{~nm}$

Figure A4 


\title{
CHAPTER 4
}

\section{Preferential Surface Oxidation of $\mathbf{G d}$ in $\mathrm{Gd}_{5} \mathrm{Ge}_{4}{ }^{*}$}

\author{
Chad D. Yuen, ${ }^{\mathrm{a}, \mathrm{b}}$, Gordon J. Miller, ${ }^{\mathrm{a}, \mathrm{b}}$ and Patricia A. Thiel ${ }^{\mathrm{a}, \mathrm{b}, \mathrm{c}}$ \\ ${ }^{a}$ Ames Laboratory, Iowa State University, Ames, Iowa, 50011 \\ ${ }^{\mathrm{b}}$ Department of Chemistry, Iowa State University, Ames, Iowa 50011 \\ ${ }^{c}$ Department of Material Science and Engineering, Iowa State University, Ames, Iowa \\ 50011 \\ "Parts of this chapter was published in "Applied Surface Science, 2012"
}

\begin{abstract}
$\underline{\text { Abstract }}$
Gd oxidizes preferentially at the (010) surface of $\mathrm{Gd}_{5} \mathrm{Ge}_{4}$. This is consistent with thermodynamic data for the bulk oxides. Upon oxidation in vacuum, the gadolinium oxide displaces or covers the Ge. Oxidation is more extensive at $600 \mathrm{~K}$ than at $300 \mathrm{~K}$, because more oxygen is incorporated into the surface and the shift of the Gd binding energy is larger.
\end{abstract}

\section{$\underline{\text { 1. Introduction }}$}

The $\mathrm{Gd}_{5} \mathrm{Si}_{4}$ and $\mathrm{Gd}_{5} \mathrm{Ge}_{4}$ binary systems [1], plus the pseudobinary $\mathrm{Gd}_{5}\left(\mathrm{Si}_{\mathrm{x}} \mathrm{Ge}_{1-\mathrm{x}}\right)_{4}$ [2], were discovered in the 1960 s by Smith et al. and Holtzberg et al., respectively. These systems are of interest because of their magnetic and thermomagnetic properties [3-5]. Giant magnetiocaloric effects were discovered in these systems in 1997 by 
Pecharsky and Gschneidner [6]. This and other properties such as giant magnetoresistance [7], spontaneous generation of voltage [8], metastability [9], and phase separation [10] may lead to new refrigeration and other energy conversion technologies.

Previous work has suggested that small amounts of interstitial oxygen can affect the coupled structural and magnetic phase transition in $\mathrm{Gd}_{5} \mathrm{Si}_{2} \mathrm{Ge}_{2}$ [11]. Presumably, oxygen locks in the relative positions of loosely-coupled, slab-like structural units in this type of compound. It has been postulated that oxygen has this effect because it occupies interstitial sites between the slabs. If this is correct, then oxygen would affect magnetic transition temperature, and would reduce the magnetocaloric effect by eliminating the structural transition that often increases the total entropy change during the coupled magnetostructural transitions. Hence, it is important to understand the effect of oxygen in these systems.

Our primary focus here is on surface oxidation of the $\mathrm{Gd}_{5} \mathrm{Ge}_{4}$ phase. We choose the (010) surface because it is the closest-packed, meaning that it is likely to be the most stable surface. We will show that Gd oxidizes preferentially at this surface and that the oxide covers or displaces Ge.

\section{Materials and methods}

We used a single crystal of $\mathrm{Gd}_{5} \mathrm{Ge}_{4}$, synthesized at the Materials Preparation Center of the Ames Laboratory [12], and cut to expose the (010) surface. X-ray photoelectron spectroscopy (XPS) experiments were performed with an Omicron X-ray source $(\mathrm{Al} K \alpha)$, and an Omicron EA 125 hemispherical electron energy analyzer. The 
XPS source was perpendicular to the sample plate, and the take-off angle (the angle between the entrance axis of the analyzer and the sample surface plane) was $45^{\circ}$. The angular acceptance range was $\pm 8^{\circ}$. The aperture used in the EA 125 analyzer was $6 \mathrm{~mm}$ x $12 \mathrm{~mm}$. The $\mathrm{Gd} 3 \mathrm{~d}_{5 / 2}$ peak, with a binding energy of $1186 \mathrm{eV}$, was chosen for analysis because it was most intense. The Ge $2 \mathrm{p}_{1 / 2}$ peak, at $1248 \mathrm{eV}$, was chosen because it was the most intense peak that did not overlap with a Gd peak. (The Ge $2 \mathrm{p}_{3 / 2}$, which is more commonly used for surface analysis, overlapped with the $\mathrm{Gd} 3 \mathrm{~d}_{3 / 2}$ peak.) XP spectra were analyzed with CasaXPS software [13]. The accuracy in determining binding energies, both for Gd and Ge was $\pm 0.2 \mathrm{eV}$.

\section{$\underline{\text { 3. Results }}$}

After the $\mathrm{Gd}_{5} \mathrm{Ge}_{4}$ sample was initially placed in UHV, its composition was checked with XPS. This revealed carbon and oxygen contaminants. It was then sputtered at $300 \mathrm{~K}$ for several minutes. This process was repeated several times until there was no carbon detectable by XPS, and a small, invariant O 1s peak remained. (The source of the oxygen will be discussed below.) Figure 1 a shows the evolution of the $\operatorname{Gd} 3 \mathrm{~d}_{5 / 2}$ peak, and Fig. $1 b$ shows that of the Ge $2 p_{1 / 2}$ peak, while the air-exposed sample was sputtered. The curves at the top are the contaminated surface, and those at the bottom are the clean surface. First, we consider intensities. The intensity of the Gd peak decreases, and that of the Ge peak increases, as material is removed. Next, we consider the peak positions (binding energies). The vertical dotted lines in Fig. 1 represent the initial (top) and final (bottom) positions of the $\mathrm{Gd}$ and Ge peaks. Initially, the $\mathrm{Gd}$ and Ge peaks are at binding 
energies of $1187.3 \mathrm{eV}$ and $1247.5 \mathrm{eV}$. After 118 minutes of $\mathrm{Ar}^{+}$sputtering, they shift down to $1186.1 \mathrm{eV}$ and $1247.1 \mathrm{eV}$, a change of $-1.2 \mathrm{eV}$ and $-0.4 \mathrm{eV}$, respectively. The downward shift in binding energies can be explained by a transition from a more highly oxidized to a less oxidized surface. Key binding energies are summarized in Table 1.

In a separate set of experiments, the surface was annealed at $900 \mathrm{~K}$ to restore the surface atomic structure after ion bombardment. This did not change the intensity of the small residual oxygen peak at $531.1 \pm 0.4 \mathrm{eV}$, which was present also after ion bombardment without annealing. It is apparent in the top curve of Fig. 2a. Its intensity corresponds to a concentration of $1.4 \pm 0.7$ at $\%$. The constant presence and level of this residual oxygen, independent of sample treatment, suggests that a low level of oxygen is a bulk constituent.

After annealing, the sample was exposed to oxygen by backfilling the UHV chamber with $\mathrm{O}_{2}$ at a pressure of $10^{-7}$ Torr for $1000 \mathrm{~s}$. This equals an exposure of 100 Langmuir (L).

The sample was held at two temperatures, $300 \mathrm{~K}$ and $600 \mathrm{~K}$, during oxygen exposure. The results for $300 \mathrm{~K}$ are shown in Fig. 2, and for $600 \mathrm{~K}$ in Fig. 3. In both figures, top curves represent the initial surface, and bottom curves represent the surface after oxygen exposure. Upon exposure to oxygen, the $\mathrm{O} 1 \mathrm{~s}$ peak increases strongly and its binding energy shifts downward, to $529.8-530.0 \mathrm{eV}$, as shown in Fig. 2a and Fig. 3a. This indicates that oxygen adsorbs in both cases, i.e. the adsorption probability is substantial. 


\section{Discussion}

With regard to the Gd and Ge peak intensities, the oxygen adsorption experiments in Fig. 2-3 show the reverse of the trends during cleaning the air-oxidized surface as in Fig. 1. Adsorption of oxygen causes the Gd intensity to increase (slightly), and the Ge intensity to decrease. In fact, the Ge peak almost disappears after exposure to $100 \mathrm{~L}$ oxygen. It seems that Ge is displaced from the surface, or perhaps preferentially covered by oxygen, as a result of $\mathrm{Gd}$ oxidation.

Second, consider the shift in position of the Gd peak. The peak moves up in binding energy by $0.8 \mathrm{eV}$ at $300 \mathrm{~K}$-from $1186.2 \mathrm{eV}$ to $1187.0 \mathrm{eV}$. Its binding energy also shifts upward, but by a larger amount $(1.3 \mathrm{eV})$ at $600 \mathrm{~K}$-from $1186.2 \mathrm{eV}$ to $1187.5 \mathrm{eV}$. An upward shift in binding energy is typical for a metal when it oxidizes. The larger shift in the binding energy at $600 \mathrm{~K}$ than at $300 \mathrm{~K}$ supports the hypothesis that surface oxidation is enhanced at the higher temperature, correlating with a larger oxygen uptake.

To put the extent of oxidation on a more quantitative basis, we have deconvoluted the $\mathrm{Gd} 3 \mathrm{~d}_{5 / 2}$ peak into a peak representative of the clean surface, and a peak representative of the oxidized state of Gd. This is shown in Fig. 4, where Fig. 4a shows the spectrum of the clean surface, Fig. $4 \mathrm{~b}$ the oxidized surface at $300 \mathrm{~K}$, and Fig. 4c the oxidized surface at $600 \mathrm{~K}$. The position and width of the peak in Fig. 4a are used to fix the low-binding-energy component in the fitted spectra of Fig. 4b and 4c, at $1186.2 \mathrm{eV}$. The spectra in Fig. $4 \mathrm{~b}$ and $4 \mathrm{c}$ are fit well by addition of a second component at higher binding energy, $1189.1 \mathrm{eV}$. Its relative intensity is higher after $600 \mathrm{~K}$ oxidation than after $300 \mathrm{~K}$ oxidation, confirming that oxidation is more extensive at higher temperature. 
It is also informative to compare the absolute XPS peak positions with published values. The stable form of gadolinium oxide is $\mathrm{Gd}_{2} \mathrm{O}_{3}$ [14]. For this oxide, the $\mathrm{Gd} 3 \mathrm{~d}_{5 / 2}$ binding energy is in the range 1187.0-1189.5 eV, according to the literature [15]. Our value for oxidized $\mathrm{Gd}$ is at $1189.1 \mathrm{eV}$, based upon peak-fitting. This is compatible. The energy range for clean elemental $\mathrm{Gd}$ is $1186.0-1186.9 \mathrm{eV}[15 ; 16]$. Based upon peakfitting, our value is $1186.2 \mathrm{eV}$, which is also compatible.

For Ge, the stable form of the bulk oxide is $\mathrm{GeO}_{2}$ [14]. For this oxide, the Ge $2 \mathrm{p}_{1 / 2}$ binding energy is in the range $1250.6-1251.0 \mathrm{eV}[15 ; 17]$. In the air-exposed sample, we find the Ge $2 \mathrm{p}_{1 / 2}$ peak at $1247.5 \mathrm{eV}$. This lies $3.1 \mathrm{eV}$ outside the range expected for $\mathrm{GeO}_{2}$. The measured value of the air-oxidized sample does, however, fall within the range for pure Ge, which is $1247.0-1248.2 \mathrm{eV}$ [15]. After oxidation in vacuum, the Ge $2 p_{1 / 2}$ peak is very small and its position is difficult to determine accurately, but it is still not compatible with $\mathrm{GeO}_{2}$. Taken together, these observations indicate that $\mathrm{Gd}$ oxidizes but Ge does not.

Preferential oxidation of $\mathrm{Gd}$ in $\mathrm{Gd}_{5} \mathrm{Ge}_{4}$ is consistent with the hierarchy of enthalpies of formation of the bulk oxides of Gd and Ge. At room temperature, they are $1819.6 \mathrm{~kJ} / \mathrm{mol}$ for $\mathrm{Gd}_{2} \mathrm{O}_{3}$, and $-551.0 \mathrm{~kJ} / \mathrm{mol}$ for $\mathrm{GeO}_{2}$ [14]. Thus, preferential oxidation of $\mathrm{Gd}$ is thermodynamically-driven.

A similar effect occurs at surfaces of another rare earth alloy, $\mathrm{LaNi}_{5}$ [18]. In this case, as here, the rare earth oxidizes preferentially and the other component is effectively displaced from the surface. This phenomenon is driven by the well-known stability of the rare earth oxides. 


\section{Conclusions}

We have found that Gd undergoes preferential oxidation at the (010) surface of $\mathrm{Gd}_{5} \mathrm{Ge}_{4}$. This is consistent with thermodynamic data for the bulk oxides. Upon oxidation in vacuum, the gadolinium oxide displaces or covers the Ge. Oxidation in vacuum is more extensive at $600 \mathrm{~K}$ than at $300 \mathrm{~K}$, based upon the observation that more oxygen is incorporated into the surface and the shift of the Gd binding energy is larger. A small amount of oxygen (about 1.4 at. \%) is a bulk constituent in this sample.

\section{Acknowledgments}

This work was supported by the Office of Science, Basic Energy Sciences, Materials Sciences and Engineering Division of the U.S. Department of Energy (USDOE). This manuscript has been authorized by Iowa State University of Science and Technology under Contract No. DE-AC02-07CH11358 with the U.S. Department of Energy. We thank Vitalij Pecharsky for a careful reading and useful suggestions.

\section{$\underline{\text { References }}$}

[1] G.S. Smith, A.G. Tharp, W. Johnson, Acta Crystallographica 22 (1967) 940-943.

[2] F. Holtzberg, R.J. Gambino, T.R. McGuire, Journal of Physics and Chemistry of Solids 28 (1967) 2283-2289.

[3] D. Paudyal, V.K. Pecharsky, K.A. Gschneidner, B.N. Harmon, Physical Review B 75 (2007) 094427. 
[4] D. Paudyal, V.K. Pecharsky, K.A. Gschneidner, Journal of Physics-Condensed Matter 20 (2008) 235235.

[5] J.D. Moore, G.K. Perkins, Y. Bugoslavsky, M.K. Chattopadhyay, S.B. Roy, P. Chaddah, V.K. Pecharsky, K.A. Gschneidner, L.F. Cohen, Applied Physics Letters 88 (2006) 072501.

[6] V.K. Pecharsky, J.K.A. Gschneidner, Physical Review Letters 78 (1997) 44944497.

[7] L. Morellon, J. Stankiewicz, B. Garcia-Landa, P.A. Algarabel, M.R. Ibarra, Applied Physics Letters 73 (1998) 3462-3464.

[8] E.M. Levin, V.K. Pecharsky, K.A. Gschneidner, Physical Review B 63 (2001) 174110.

[9] M.K. Chattopadhyay, et al., Physical Review B 70 (2004) 214421.

[10] V.K. Pecharsky, A.P. Holm, K.A. Gschneidner, R. Rink, Physical Review Letters 91 (2003) 197204.

[11] Y. Mozharivskyj, A.O. Pecharsky, V.K. Pecharsky, G.J. Miller, Journal of the American Chemical Society 127 (2005) 317-324.

[12] Samples were synthesized at the Materials Preparation Center, Ames Laboratory USDOE, Ames, IA, USA.

[13] See www.CasaXPS.com.

[14] D.D. Wagman, W.H. Evans, V.B. Parker, R.H. Schumm, I. Halow, S.M. Bailey, K.L. Churney, R.L. Nuttall, The NBS tables of chemical thermodynamic properties: Selected values for inorganic and $\mathrm{C} 1$ and $\mathrm{C} 2$ organic substances in SI units, American Chemical Society and American Institute of Physics, Washington D.C., 1982. 
[15] J.F. Moulder, W.F. Stickle, P.E. Sobol, K.D. Bomben, Handbook of X-ray Photoelectron Spectroscopy: a reference book of standard spectra for identification and interpretation of XPS data, Perkin-Elmer Corporation, Physical Electronics Division, Eden Prairie, Minnesota, 1992.

[16] C.J. Powell, A. Jablonski, NIST Electron Effective-Attenuation-Length Database - Version 1.3, National Institute of Standards and Technology, Gaithersburg, Maryland, 2011.

[17] I. Lucy, J. Beynon, B. Orton, Journal of Materials Science Letters 16 (1997) $1477-1479$.

[18] H.C. Siegmann, L. Schlapbach, C.R. Brundle, Physical Review Letters 40 (1978) 972. 


\section{$\underline{\text { Figure Captions }}$}

\section{Figure 1}

X-ray photoelectron spectra showing (a) Gd $3 \mathrm{~d}_{5 / 2}$ and (b) Ge $2 \mathrm{p}_{1 / 2}$ peaks after exposure to air at $300 \mathrm{~K}$. The top curves represent the air-exposed surface, and bottom curves the clean surface. The dashed lines mark the initial and final peak positions. Curves are displaced vertically to avoid overlap.

\section{Figure 2}

X-ray photoelectron spectra showing (a) O $1 \mathrm{~s}$, (b) $\mathrm{Gd} 3 \mathrm{~d}_{5 / 2}$, and (c) $\mathrm{Ge} 2 \mathrm{p}_{1 / 2}$ peaks after $100 \mathrm{~L}$ of $\mathrm{O}_{2}$ exposure within the UHV chamber at $300 \mathrm{~K}$. Curves are displaced vertically to avoid overlap. The intensity scale is the same for all frames.

\section{Figure 3}

X-ray photoelectron spectra showing (a) O $1 \mathrm{~s}$, (b) $\mathrm{Gd} 3 \mathrm{~d}_{5 / 2}$, and (c) $\mathrm{Ge} 2 \mathrm{p}_{1 / 2}$ peaks after $100 \mathrm{~L} \mathrm{O}_{2}$ within the UHV chamber at $600 \mathrm{~K}$. Curves are displaced vertically to avoid overlap. The intensity scale is the same for all frames.

\section{Figure 4}

Deconvoluted X-ray photoelectron spectra of $\mathrm{Gd} 3 \mathrm{~d}_{5 / 2}$ peak showing the surface (a) after cleaning by ion bombardmant and then annealing to $900 \mathrm{~K}$, (b) after $100 \mathrm{~L} \mathrm{O}_{2}$ exposure at $300 \mathrm{~K}$, and (c) after $100 \mathrm{~L} \mathrm{O}_{2}$ exposure at $600 \mathrm{~K}$. The vertical intensity scale is the same for all frames. 
(a) Gd

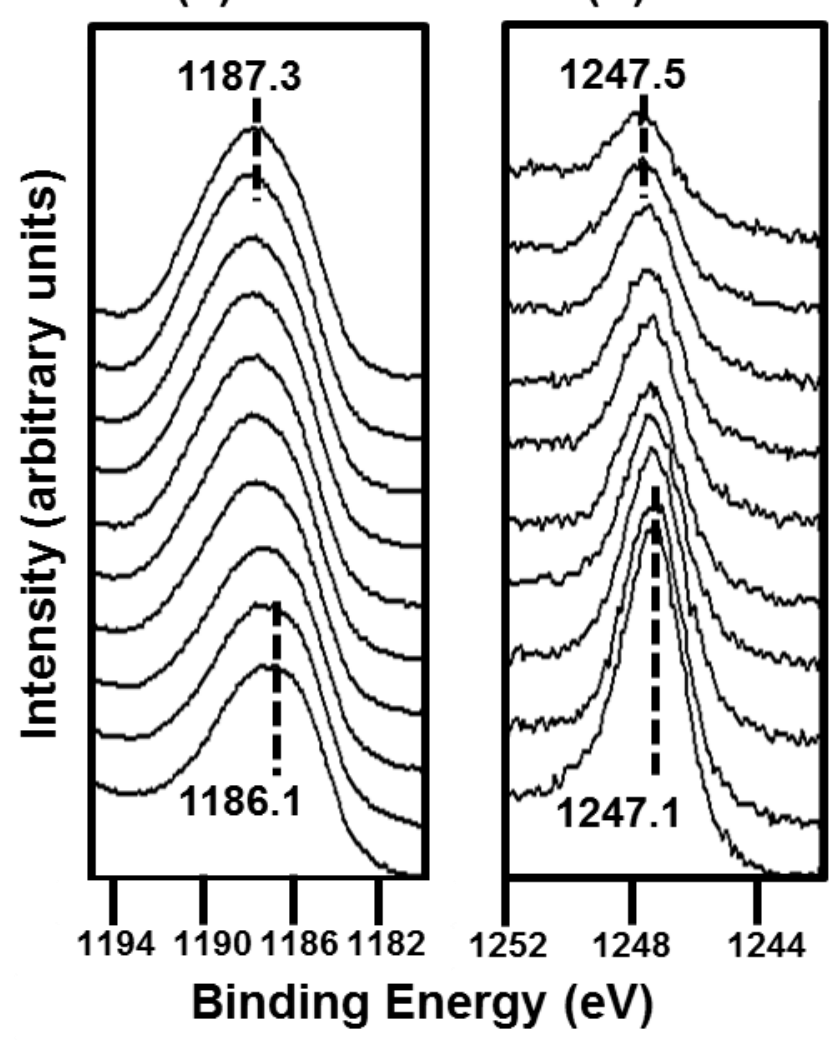

Figure 1 


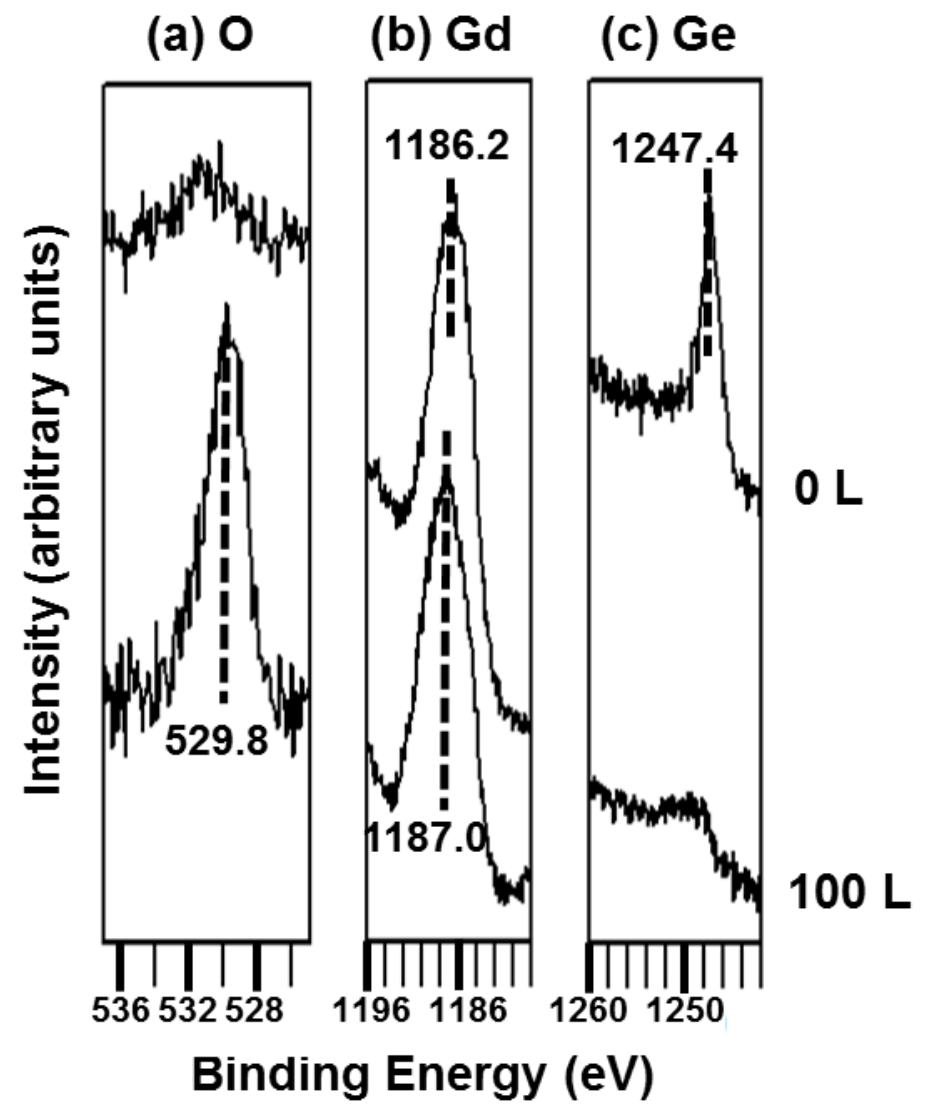

Figure 2 


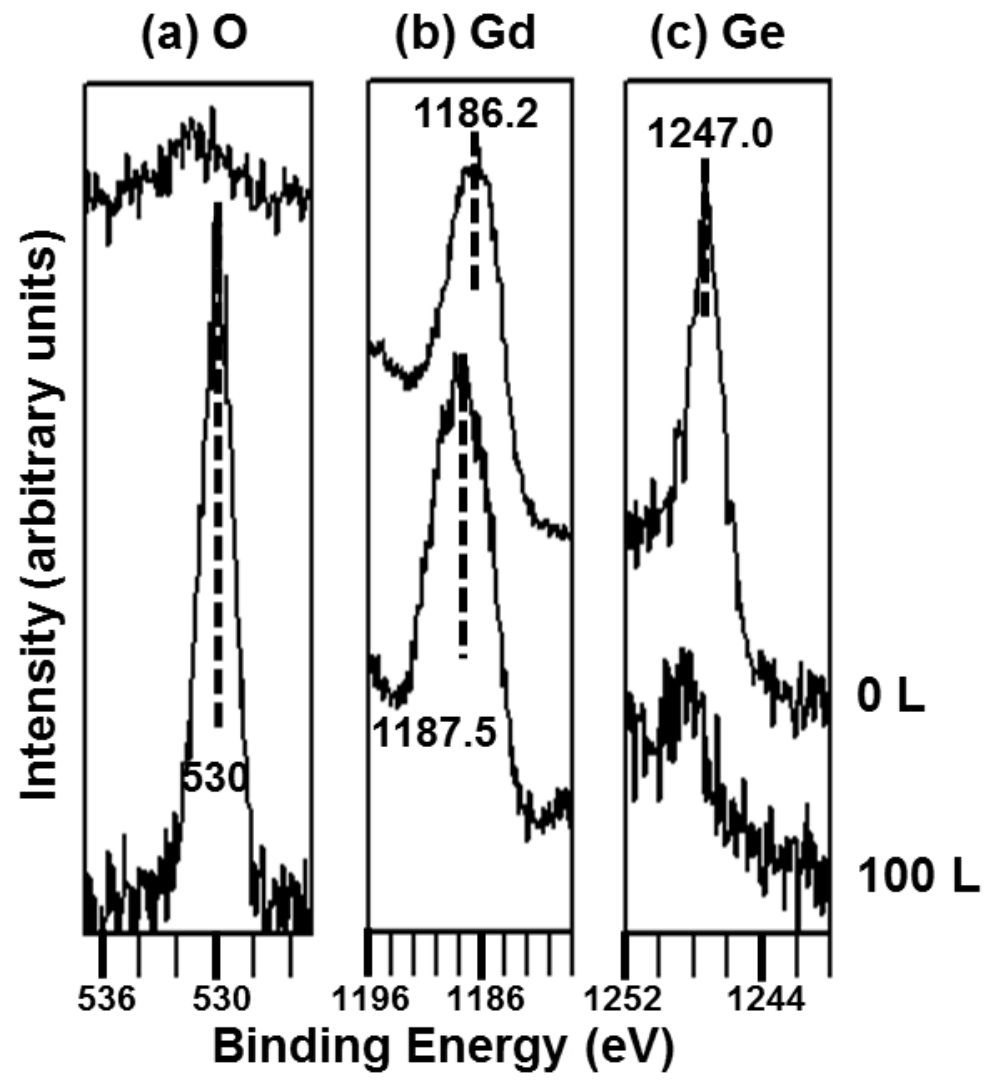

Figure 3 
(a) Clean

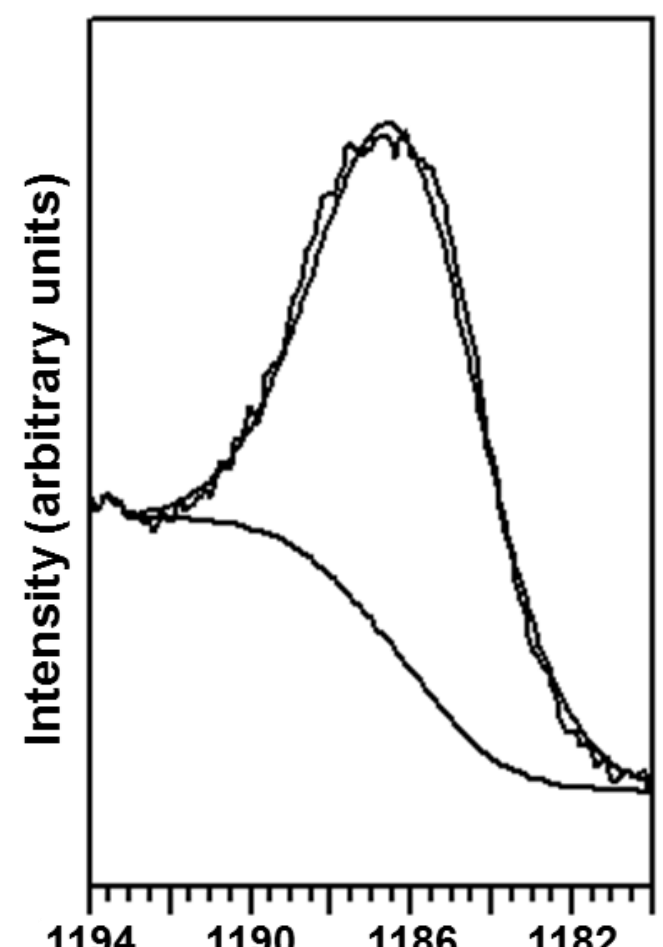

(b) $300 \mathrm{~K}$

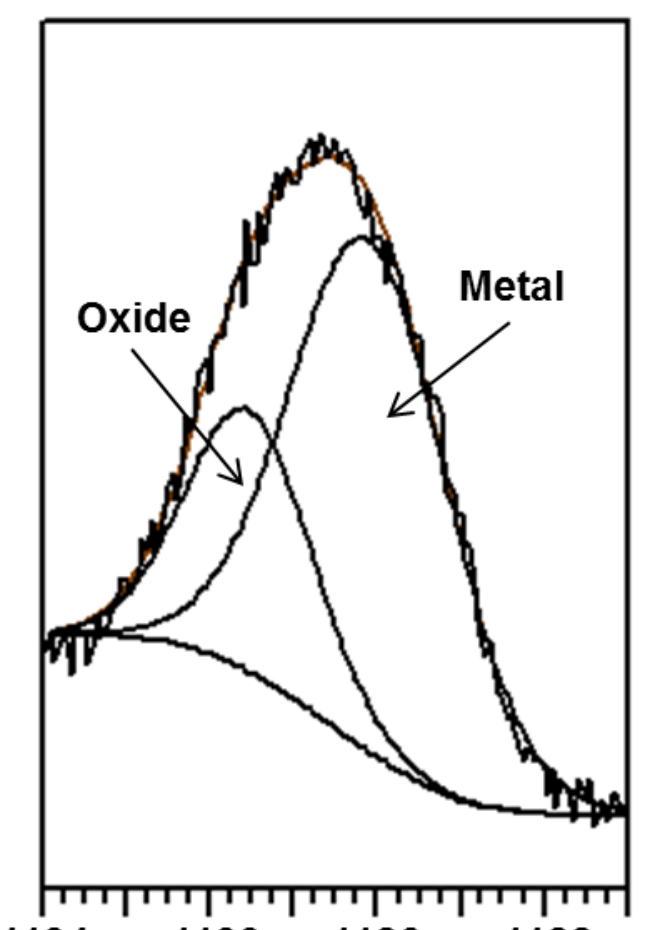

(c) $600 \mathrm{~K}$

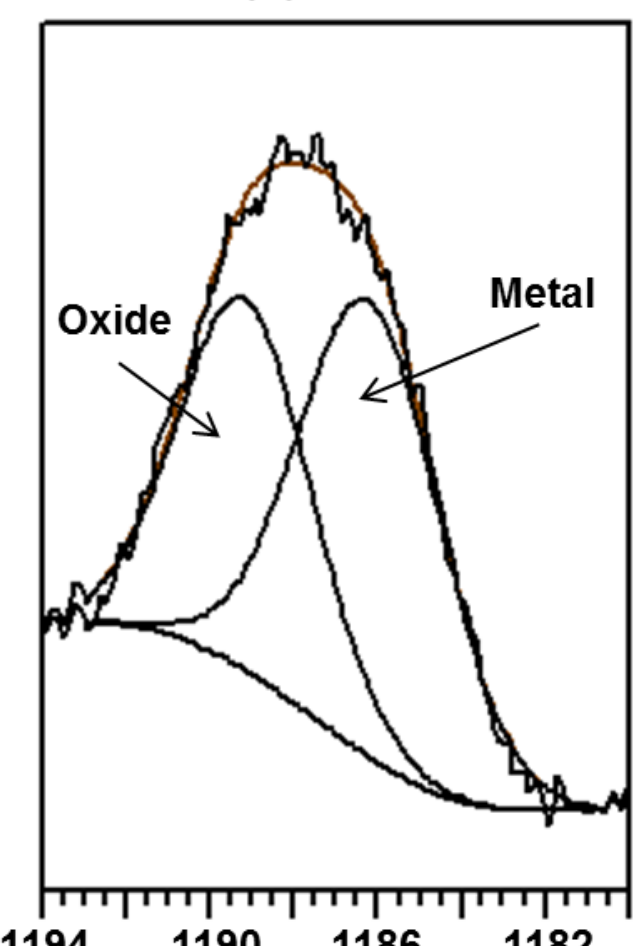

Binding Energy (eV)

Figure 4 


\section{$\underline{\text { Appendix }}$}

Data represented in this chapter thus far, have shown that Gd oxidizes preferentially at the $(010)$ of the $\mathrm{Gd}_{5} \mathrm{Ge}_{4}$ surface. We begin to represent more data to show that Gd oxidizes. Figure A1, shows the deconvolution of the $\mathrm{Gd} 3 \mathrm{~d}_{5 / 2}$ peak of the pure clean metal and the air oxidized Gd.

A sequence of pure oxygen exposures was experimented on the $\mathrm{Gd}_{5} \mathrm{Ge}_{4}(010)$ surface, starting with $0.5 \mathrm{~L}$, followed by $2 \mathrm{~L}, 10 \mathrm{~L}$, and $100 \mathrm{~L}$ at $300 \mathrm{~K}$. XPS was taken in between each oxygen exposure. XP spectra of Ge $2 \mathrm{p}_{1 / 2}$ peak, Gd $3 \mathrm{~d}_{5 / 2}$ peak, and $\mathrm{O} 1 \mathrm{~s}$ peak is shown in Fig. A2a, A2b, and A2c, respectively. We see similar trends such as the Ge peak decreases, almost vanishes after $10 \mathrm{~L}$ of oxygen had been exposed onto the surface. This was consistent when the surface was exposed to straight $100 \mathrm{~L}$ of oxygen at $300 \mathrm{~K}$ and $600 \mathrm{~K}$ as shown in Figs. 2 and 3. However, there are some strange results, such that the intensities of the Gd and O peaks, Figs. A2b-c, decrease as more oxygen has been exposed on the $\mathrm{Gd}_{5} \mathrm{Ge}_{4}$ surface. We would expect an increase an intensities of both peaks as a result of Gd oxidation, similar to Fig. 2-3. This result was due to a broken channeltron in the electron analyzer. Over a period of time, the intensity levels slowly decrease, which leads to error in the results. Thus, Fig. A2 was not used for publication.

With the sequence of pure oxygen exposures on the $\mathrm{Gd}_{5} \mathrm{Ge}_{4}$ surface, a graph of intensities as a function of oxygen exposure of the $\mathrm{Gd} 3 \mathrm{~d}_{5 / 2}$ peak is shown in Fig. A3. In Fig. A3a, shows the trend in intensity levels of the oxide and metal up to $100 \mathrm{~L}$ of oxygen whereas Fig A3b, shows the trend up to $2 \mathrm{~L}$ of oxygen, a close-up view of Fig. A3a. As oxygen was exposed, the Gd oxide intensity increases while the Gd metal intensity 
decreases up to $2 \mathrm{~L}$ of oxygen. Afterwards, both the intensity levels of the oxide and the metal decrease, which resulted from the broken channeltron. We would expect to see the oxide intensity increase up until it reaches saturation while the metal intensity decreases. 


\section{Figure Captions}

\section{Figure A1}

Deconvoluted X-ray photoelectron spectra of $\mathrm{Gd} 3 \mathrm{~d}_{5 / 2}$ peak showing the surface after cleaning by ion bombardmant and then annealing to $900 \mathrm{~K}$, and after air exposure. The vertical intensity scale is the same for all frames.

\section{Figure A2}

X-ray photoelectron spectra showing (a) Ge $2 \mathrm{p}_{1 / 2}$, (b) $\mathrm{Gd} 3 \mathrm{~d}_{5 / 2}$, and (c) $\mathrm{O} 1 \mathrm{~s}$ peaks after a sequence of $\mathrm{O}_{2}$ exposure, starting with $0.5 \mathrm{~L}$, followed by $2 \mathrm{~L}, 10 \mathrm{~L}$, and $100 \mathrm{~L}$ within the UHV chamber at $300 \mathrm{~K}$. XPS was taken in between each $\mathrm{O}_{2}$ exposure. The dashed lines mark the initial and final peak positions. Curves are displaced vertically to avoid overlap.

\section{Figure A3}

Graph of intensities as a function of $\mathrm{O}_{2}$ exposure of the $\mathrm{Gd} 3 \mathrm{~d}_{5 / 2}$ peak. A sequence of $\mathrm{O}_{2}$ exposure, starting with $0.5 \mathrm{~L}$, followed by $2 \mathrm{~L}, 10 \mathrm{~L}$, and $100 \mathrm{~L}$ within the UHV chamber at $300 \mathrm{~K}$. (a) shows the whole sequence, and (b) shows $2 \mathrm{~L}$ of $\mathrm{O}_{2}$, zoomed in from (a). 


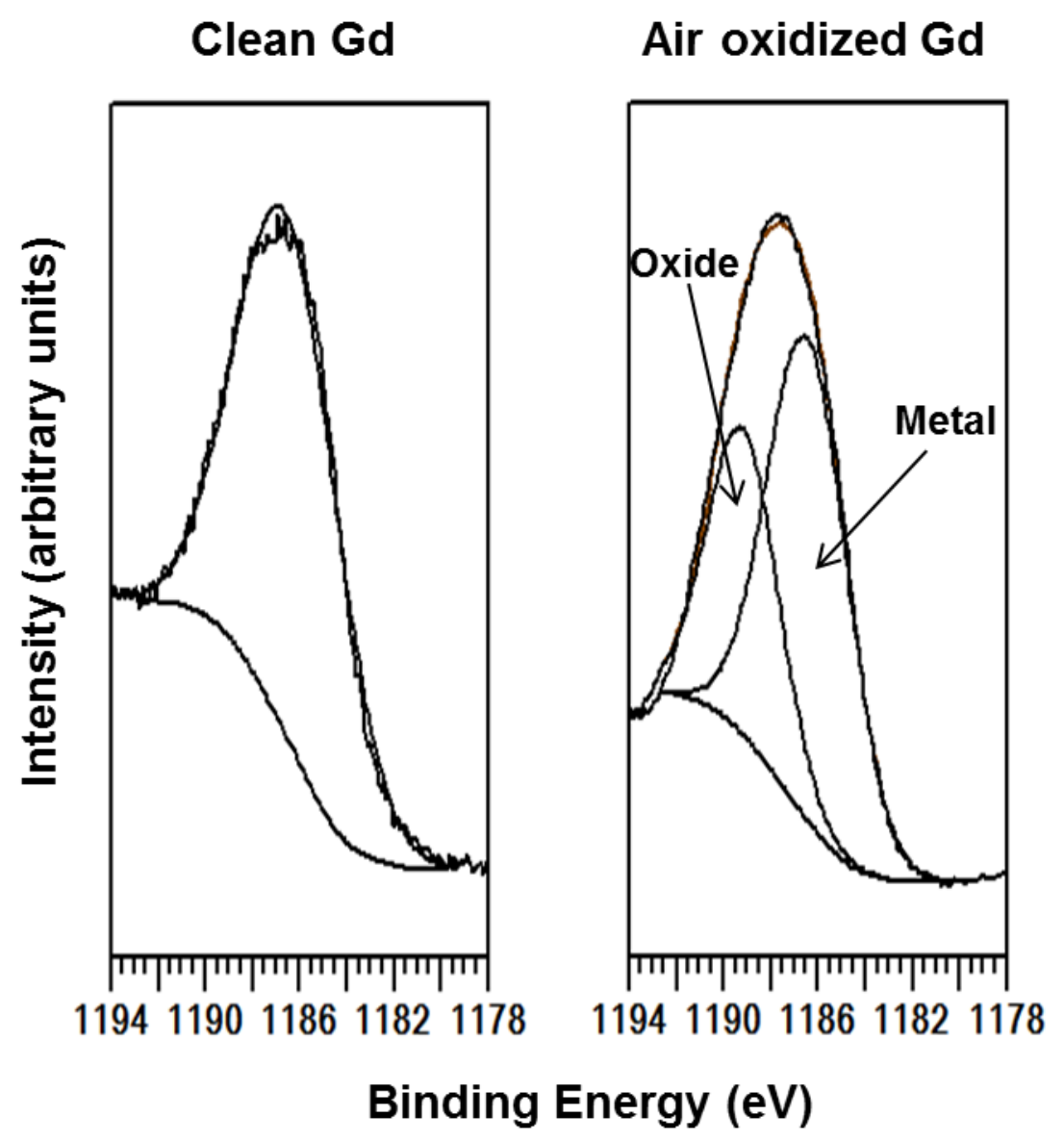

Figure A1 
Ge $2 p_{1 / 2}$

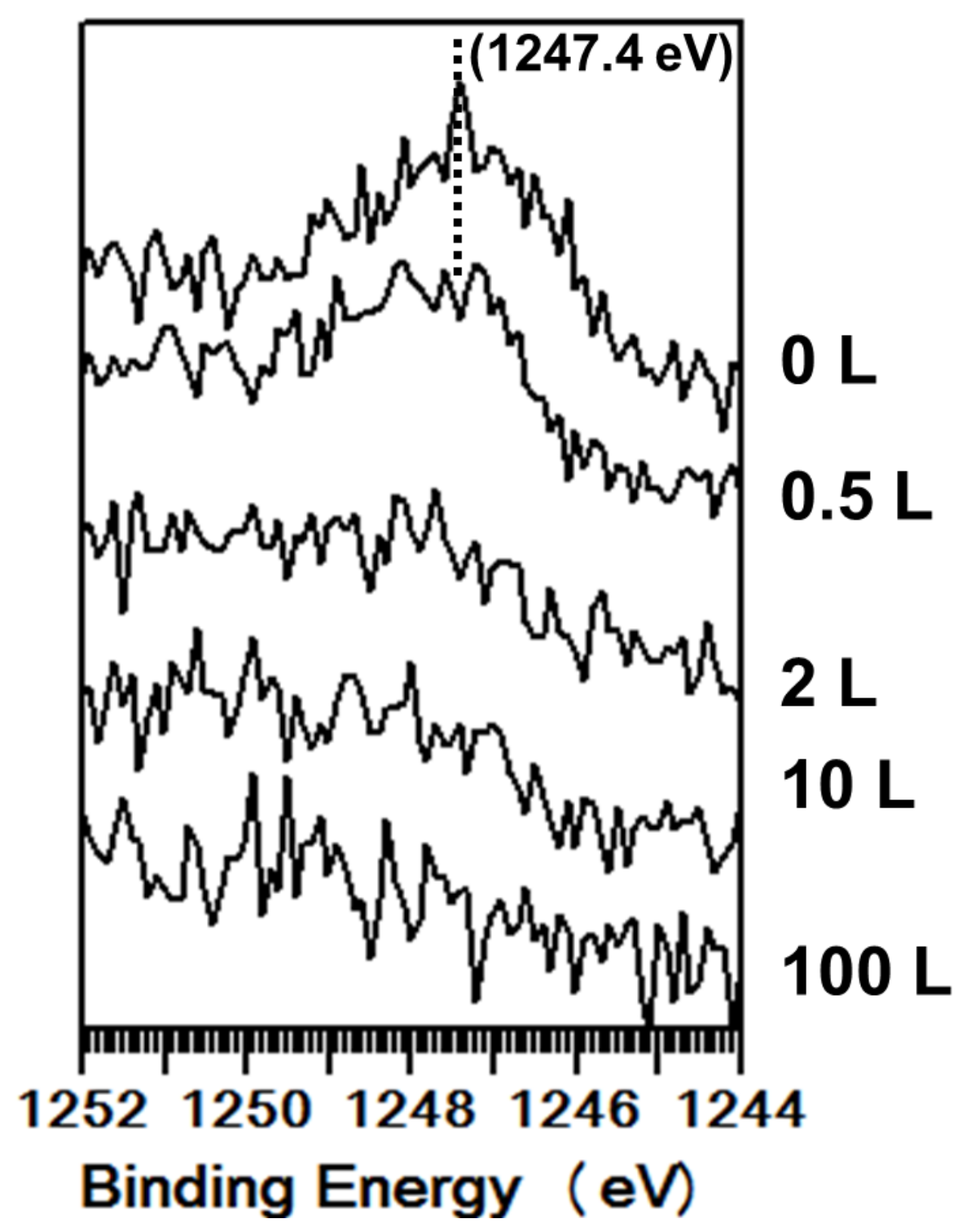

Figure A2a 


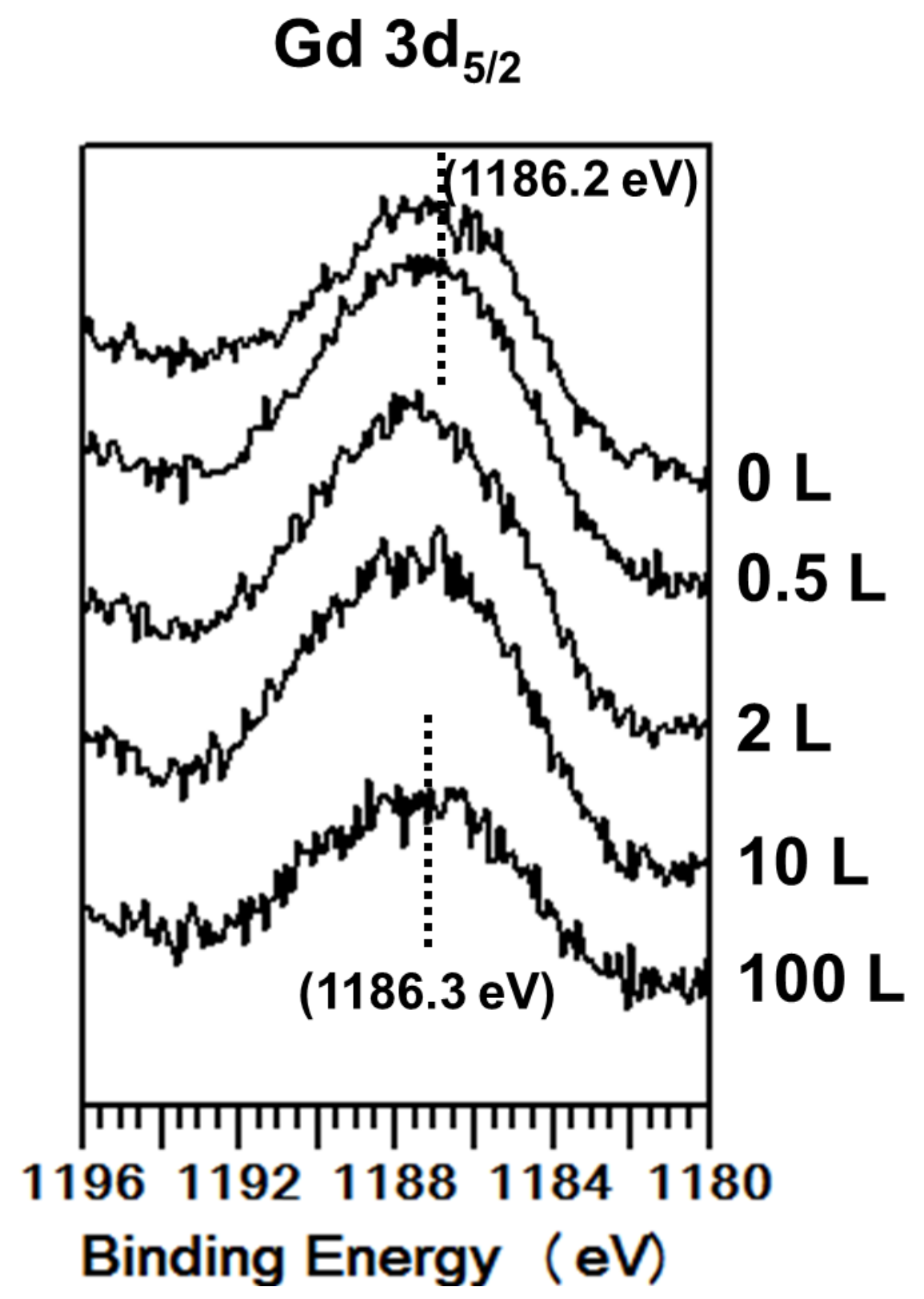

Figure A2b 
$01 \mathrm{~s}$

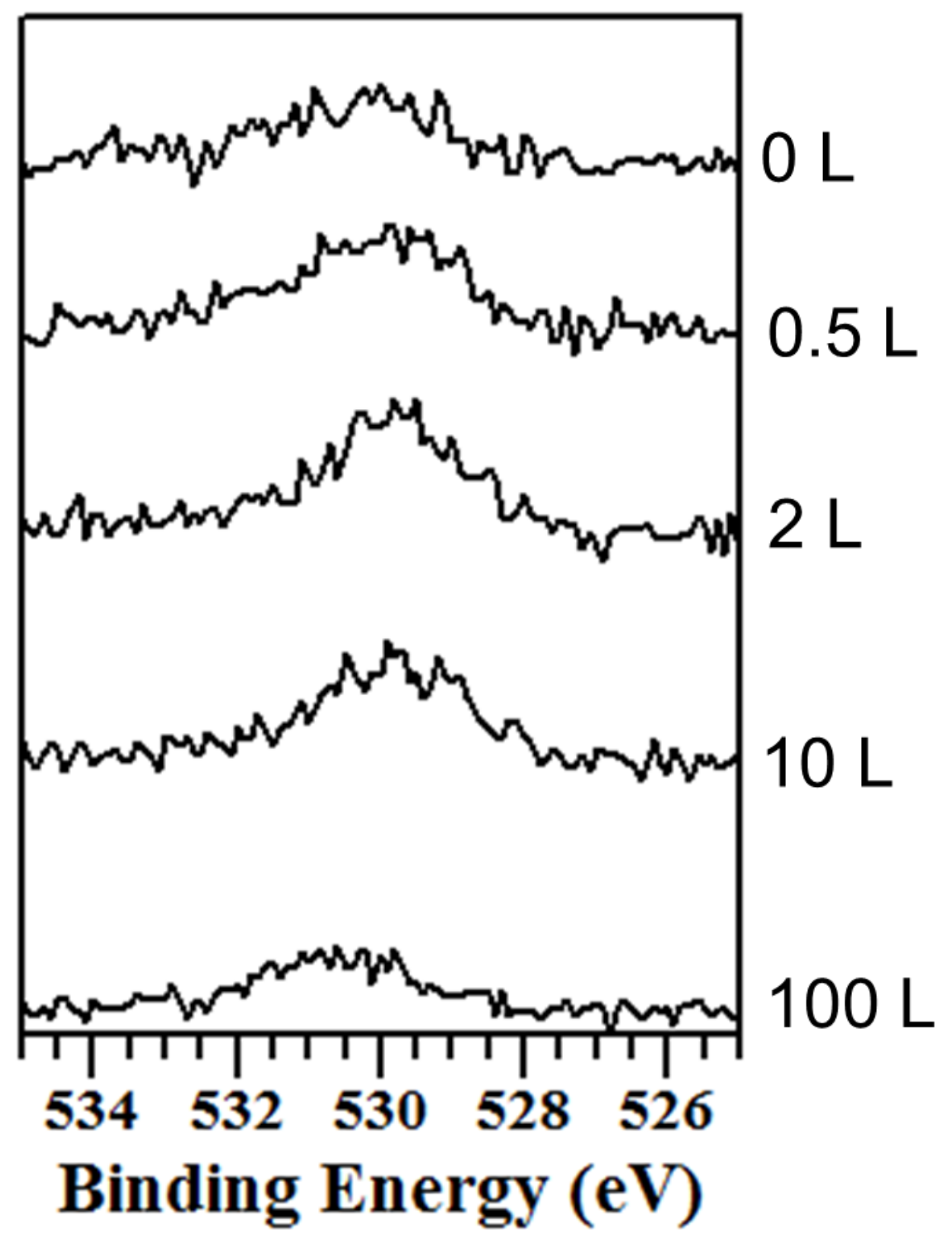

Figure A2c 

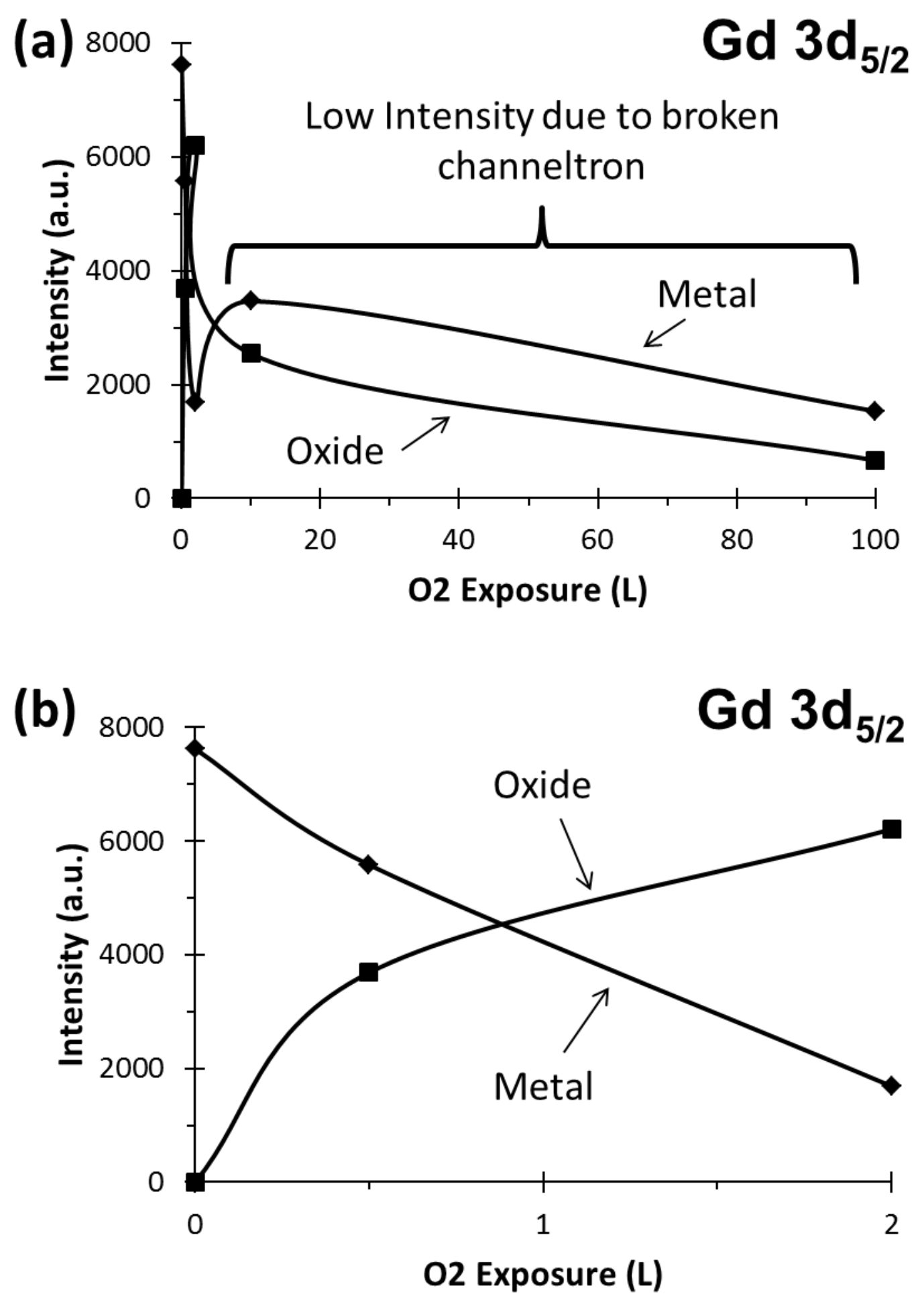

Figure A3 


\title{
CHAPTER 5
}

\section{Interaction of Au with the $\mathrm{NiAl}(110)$ Surface}

\author{
Chad D. Yuen, ${ }^{1,2}$ Thomas Duguet, ${ }^{1,4}$ and Patricia A. Thiel ${ }^{1,2,3}$
}

\footnotetext{
${ }^{1}$ Ames Laboratory, Iowa State University, Ames, Iowa 50011

${ }^{2}$ Department of Chemistry, Iowa State University, Ames, Iowa 50011

${ }^{3}$ Department of Material Science and Engineering, Iowa State University, Ames, Iowa 50011

${ }^{4}$ Present address: CNRS - Centre national de la recherché scientifique, Toulouse area, France
}

\section{Introduction}

Surfaces of the binary intermetallic alloy NiAl have been studied extensively, for several reasons. First, NiAl is a prototype within a family of aluminides known as superalloys. These materials find use in the aerospace and power industries because of their low density (relative to steel), strength, creep resistance, and oxidation resistance at high temperatures $[1 ; 2]$. Second, $\mathrm{NiAl}$ and $\mathrm{Ni}_{3} \mathrm{Al}$ serve as excellent substrates for growth of thin, epitaxial aluminum oxide overlayers [3]. In turn, these oxide overlayers can be used as model catalyst supports [3], and as templates for ordered arrays of metal particles [4; 5]. Finally, nickel is often a major component of ternary (or higher) aluminides with useful properties. One example is $\mathrm{Al}-\mathrm{Ni}-\mathrm{Co}$, which forms the basis for some permanent magnets [6]. 
NiAl adopts a bcc-like, $\mathrm{CsCl}$ structure [7]. Its clean (110) surface, depicted in Fig. 1, has been studied thoroughly, probably because it can be prepared (with relative ease) in a state that is nearly bulk-terminated. The real surface is slightly rippled, with $\mathrm{Al}$ atoms displaced outward by $0.02 \mathrm{~nm}$ relative to the plane of $\mathrm{Ni}$ atoms [8-13]. Defects also are observed on this surface, including a substitutional defect in which a surface Al atom is replaced by $\mathrm{Ni}[14 ; 15]$.

Previously, our group studied the interaction of Ag with this surface [13; 15-18]. We found that Ag grows as islands with a height that corresponds to two atomic layers of fcc(110) Ag. At room temperature, these islands are highly elongated, adopting a needlelike appearance. Our group extensively modeled the growth and evolution of these interesting structures, finding that the two-layer height is stabilized by a quantum size effect, and that the anisotropic shape is a kinetic effect which can be related to the structure of the presumed fcc(110) structure of the epitaxial Ag. Nucleation of the islands is influenced by the NiAl defects, an effect which becomes more pronounced with increasing deposition temperature between 130 and $300 \mathrm{~K}$. Our goal here is to compare the characteristics of Au islands that form on the same NiAl surface. As an interesting aside, it has been reported recently that traces of Au alloyed with NiAl can have a positive effect on the mechanical properties [19].

Like Ag, Au is a noble fcc metal, and its bulk lattice constant nearly equals that of $\mathrm{Ag}(\mathrm{Au}$ is smaller by only $0.25 \%)$. However, one might expect differences between $\mathrm{Ag}$ and Au films on NiAl, since many differences exist between the isolated elements. For instance, the Au low-index surfaces reconstruct, whereas those of Ag do not [20;21]. This difference between $\mathrm{Ag}$ and $\mathrm{Au}$ has been attributed to relativistic effects in $\mathrm{Au}$, at 
least for the (100) surfaces [22]. Another difference, particularly relevant to the present study, is that alloys and intermetallics containing substantial fractions of Au are generally more common than those containing Ag [23].

Previously, our group reported briefly that islands of $\mathrm{Au}$ on $\mathrm{NiAl}(110)$ are only a single layer high and are less elongated than Ag islands, at $300 \mathrm{~K}$ [18]. In this paper, we report a more detailed study of the interaction of $\mathrm{Au}$ with the $\mathrm{NiAl}(110)$ surface, at temperatures of $200 \mathrm{~K}$ to $350 \mathrm{~K}$. We find evidence that $\mathrm{Au}$ intermixes with the NiAl substrate at temperatures slightly above $300 \mathrm{~K}$, based both upon x-ray photoelectron spectroscopy (XPS) and scanning tunneling microscopy (STM).

\section{Experimental Procedures}

A $\mathrm{NiAl}(110)$ single crystal was polished using standard metallographic techniques, with the final abrasive being $0.25 \mu \mathrm{m}$ diamond paste. The sample was then sonicated with acetone and methanol, in sequence. The polished sample was mounted on an Omicron variable-temperature sample plate. The sample was then transferred to an UHV chamber that was equipped with a sputter gun, Omicron X-ray source $(\mathrm{Mg} \mathrm{K} \alpha)$, Omicron EA 125 hemispherical electron energy analyzer, and an Omicron variabletemperature STM. The base pressure of the chamber was below $1 \times 10^{-10}$ mbar. The sample was cleaned by repeated cycles of $\mathrm{Ar}^{+}$sputtering (30 mins, $2 \mathrm{keV}$, and $\mathrm{T}=300 \mathrm{~K}$ ) followed by annealing to $1150 \mathrm{~K}$ for a variety of annealing times from 1.5 hours to 3 hours, until the surface was judged clean by XPS, which detected no contaminants such as oxygen and carbon. 
STM images of the clean surface of NiAl(110), as shown in Fig 2(a), revealed that this sample preparation procedure could yield terraces at least $200 \mathrm{~nm}$ wide. Steps were pinned by impurities that were undetected with XPS.

STM images were processed using WSxM scanning probe microscopy software [24]. A tungsten tip that was electrochemically etched was used to scan the images with a bias range from $-1.5 \mathrm{~V}$ to $+1.5 \mathrm{~V}$ (increments of $0.5 \mathrm{~V}$ ). The tunneling current was set at $0.1 \mathrm{nA}$ and $0.5 \mathrm{nA}$. A single STM image took 2 minutes to acquire.

XPS data were analyzed using CasaXPS software [25]. The XPS source was perpendicular to the sample holder, and the take-off angle (defined as the angle between the entrance axis of the analyzer and the sample surface) was $45^{\circ}$. Spectra were acquired in two ways: an overview or survey energy range from $1000 \mathrm{eV}$ to $-5 \mathrm{eV}$; and over smaller energy ranges. The smaller energy ranges showed the Ni $2 \mathrm{p}_{3 / 2}$ binding energy from $880 \mathrm{eV}$ to $830 \mathrm{eV}$, the $\mathrm{Al} 2 \mathrm{~s}$ binding energy from $130 \mathrm{eV}$ to $100 \mathrm{eV}$, the $\mathrm{Au} 4 \mathrm{f}$ binding energy from $100 \mathrm{eV}$ to $75 \mathrm{eV}$, and the $\mathrm{Ni} 3 \mathrm{p}$ and $\mathrm{Al} 2 \mathrm{p}$ binding energies from 80 $\mathrm{eV}$ to $60 \mathrm{eV}$. The following settings in our XPS were used: analysis size was less than $1.5 \mathrm{~mm}$ in diameter, angular acceptance angle was $\pm 8^{\circ}$, and the aperture size in the EA 125 analyzer was $6 \mathrm{~mm} \times 12 \mathrm{~mm}$.

$\mathrm{Au}$ was deposited on $\mathrm{NiAl}(110)$ from a Mantis Quad-EV-C mini e-beam evaporator. The base pressure during Au deposition was below $3 \times 10^{-10}$ mbar. Au coverage (expressed in units of monolayers, ML) was determined by measuring the fractional surface area of the Au islands, i.e. by flooding the STM image. (If multilayer islands were present, flooding was done in multiple steps and areas were added to obtain total coverage.) From this, the flux was calibrated by taking the ratio of the coverage to 
the $\mathrm{Au}$ deposition time at $300 \mathrm{~K}$. This gave a flux of $0.034 \mathrm{ML} \mathrm{min}^{-1}$. The filament settings were $1.6 \mathrm{~A}$ and $22 \mathrm{~W}$.

Coverage vs. deposition time at $300 \mathrm{~K}$ is shown in Fig 3. For each data point, the error bar represents the standard deviation of all the images acquired in that experiment. The linearity of the data indicates that the flux was constant over deposition times of a few minutes up to a few tens of minutes. Further, the data shown in Fig. 3 were acquired over a period of 3 weeks and 2 different experimental runs, indicating that the Au flux was constant in different experiments.

In some cases, the sample was heated slightly above room temperature. In one case, XPS data were acquired, and in the other case, STM data were acquired. The detailed thermal treatment in each case was as follows. For XPS, the sample was first heated to $325 \mathrm{~K}$ and held at that temperature for 30 minutes. XP spectra were then measured while the sample was held at $325 \mathrm{~K}$, and the measurement itself lasted 48 minutes. The sample was next heated to $350 \mathrm{~K}$, and held at that temperature for 30 minutes. XP spectra were then measured with the sample held at $350 \mathrm{~K}$, and the measurement again lasted 48 minutes. For STM, the sample was slowly heated from 300 $\mathrm{K}$ to $325 \mathrm{~K}$ over a period of 1 hour and 25 minutes. After it reached temperature, STM was performed for a period of 1 hour 6 minutes at $325 \mathrm{~K}$. Next, the sample was slowly heated from $325 \mathrm{~K}$ to $350 \mathrm{~K}$ over a period of 53 minutes, and then STM was performed for a period of 2 hours at $350 \mathrm{~K}$. 


\section{Experimental Results and Discussion}

\subsection{Growth at $200 \mathrm{~K}$ and $300 \mathrm{~K}$}

An STM image following Au deposition at room temperature is shown in Fig 2(b), and it can be compared with the clean surface in Fig. 2(a). Two-dimensional islands exist on terraces and also along step edges. The islands on the terraces are irregular and elongated. Islands on the step edges grow outward from the step.

Figure 4 shows how the islands develop as a function of coverage at $300 \mathrm{~K}$. In this experiment, $\mathrm{Au}$ is deposited sequentially, i.e. the surface is not cleaned between successive Au depositions. Between 0.1 and 0.5 ML, terrace islands are flat and irregular, and they grow laterally with increasing coverage. At $0.54 \mathrm{ML}$, a second layer starts to form, even though the first is far from completion (first-layer islands are clearly separated). The second-layer islands seem more compact and rectangular in shape than the first-layer islands. Their shape changes, however, between 0.8 and 1.3 ML. This can be seen by comparing Fig. 4(f) and Fig. 4(g). In that interval, the first layer coalesces and the second-layer islands grow into irregular shapes that resemble the first-layer islands below $0.5 \mathrm{ML}$.

Island number density is given in Table 1 as a function of coverage through 0.24 ML. Island density is a slowly increasing function of coverage. At $0.24 \mathrm{ML}$, it reaches $0.0013 \mathrm{~nm}^{-2}$. This is about a factor of 25 higher than the island density of Ag on this same surface,[16] indicating that the nucleation kinetics are significantly different than for Ag. The island size distribution is shown in Fig. 5(a). 
The island heights of the first and second layer islands are shown in Table 1. These island heights are determined from pixel height histograms of the STM images. Two examples are shown in Fig. 6, at coverages of 0.24 ML and 0.60 ML. In the histograms, the large peak on the left is the NiAl substrate, and the small peaks on the right are the Au islands. From the histograms, the first-layer height is constant at about $0.25 \mathrm{~nm}$. An exception occurs at the coverage of 0.54 ML, where the first-layer height from the histograms is $0.37 \mathrm{~nm}$. It is not clear whether this single unusual value is real, or an artifact. For comparison, Fig. 7 shows representative island profiles from this experiment. It can be seen that the profiles are consistent with the histograms.

To test for electronic effects in the measured island morphology, a range of tip bias voltages are employed, from $-1.5 \mathrm{~V}$ to $+1.5 \mathrm{~V}$ (in increments of $0.5 \mathrm{~V}$ ). Fig. 8 shows representative STM images at $0.24 \mathrm{ML}$ and $300 \mathrm{~K}$. There are no apparent differences between island morphologies at different voltages. Corresponding values of island heights are shown in Table 2 for deposition at $300 \mathrm{~K}$, and these values also are independent of bias voltage.

At high magnification and at relatively high coverage (large islands), STM shows a fine structure of stripes on the island tops after $\mathrm{Au}$ deposition at $300 \mathrm{~K}$. These stripes are illustrated in Fig. 9 and Fig. 10 (0.60 ML), and Fig. 11 (1.3 ML). There are two domains of stripes, rotated by $\sim 113^{\circ} \pm 5^{\circ}$ from one another. The spacing between the stripes is $1.23 \pm 0.08 \mathrm{~nm}$, based on the line profiles in Fig. 10 and other STM images. Fig. 11 shows that the stripes occur in both the first and second layer islands, but they do not have the same orientation in the second layer as in the first. In the second layer, the stripe 
spacing is $1.16 \pm 0.06 \mathrm{~nm}$, which is the same as the spacing in the first layer within experimental uncertainty.

A single coverage of $\mathrm{Au}, 0.25 \mathrm{ML}$, was also deposited at lower temperature, 200 $\mathrm{K}$. The resultant island heights are about $0.24 \mathrm{~nm}$, effectively identical to the height of $0.25 \mathrm{~nm}$ at $300 \mathrm{~K}$. This value is shown in Table 1 . In addition, the bias conditions do not affect the island heights on the surface. This is shown by the STM images of Fig 12, acquired at different bias conditions. Resultant island heights are shown in Table 2. The $\mathrm{Au}$ islands are elongated, but they seem less irregular in shape than at $300 \mathrm{~K}$. The island density is about an order of magnitude higher, $0.019 \mathrm{~nm}^{-2}$, than at $300 \mathrm{~K}$. The island size distribution is shown in Fig. 5(b); it is somewhat narrower than at $300 \mathrm{~K}$. No stripes are discernible on these islands, but that could be due to the fact that at this temperature the islands are relatively small. At $300 \mathrm{~K}$, the stripes were not visible until the islands were much larger.

\subsection{Thermal Treatments above $300 \mathrm{~K}$}

XPS data indicate that the surface changes when the sample is heated above room temperature. Figures 13-16 show the $\mathrm{Ni} 2 \mathrm{p}_{3 / 2}, \mathrm{Al} 2 \mathrm{~s}, \mathrm{Au} 4 \mathrm{f}_{7 / 2,5 / 2}, \mathrm{Ni} 3 \mathrm{p}$, and $\mathrm{Al} 2 \mathrm{p}$ peaks after the sample is prepared by deposition of $0.21 \mathrm{ML}$ at $300 \mathrm{~K}$, then heated to $325 \mathrm{~K}$ and $350 \mathrm{~K}$. (The exact thermal program is described in Section 2.) In all cases, the peaks shift to higher binding energies between 300 and $325 \mathrm{~K}$, by increments of 0.5 to $0.8 \mathrm{eV}$. Changes are smaller ( 0.0 to $0.3 \mathrm{eV}$ ) and not systematic between 325 and $350 \mathrm{~K}$. The peak positions, together with binding energy ranges for the elemental metals [26], are given in Table 3. 
One explanation for the peak shifts between 300 and $325 \mathrm{~K}$ is surface alloying or exchange. This interpretation is supported by an analysis of the relative peak areas. Peak areas are proportional to the depth-weighted density of atoms of a given element. We calculated ratios of $\mathrm{Ni} / \mathrm{Au}$ intensities, as well as ratios of $\mathrm{Al} / \mathrm{Au}$ intensities, and the results are shown in Table 4. Heating causes these ratios to increase by small amounts, ranging from $2 \%$ to $10 \%$. Within the scatter, the effect seems to be about the same for $\mathrm{Ni}$ and for Al. Since Au is presumably the topmost scatterer after deposition at $300 \mathrm{~K}$, alloying at higher temperature would cause these ratios to increase. As Table 4 shows, an increase is indeed observed with increasing temperature, indicating that both $\mathrm{Ni}$ and $\mathrm{Al}$ probably exchange with $\mathrm{Au}$ at the surface.

STM data also suggest that the surface changes when it is heated above room temperature. In one experiment, 0.21 ML of Au was deposited at $300 \mathrm{~K}$, after which the surface was heated to slightly higher temperatures. Images were then acquired at the elevated temperature. (The exact thermal treatment is described in Section 2.) Fig. 17 shows the resultant STM images at $325 \mathrm{~K}$. In this case, it turns out that the experimental parameter of tip bias is crucial. When the bias magnitude is low, $0.5 \mathrm{eV}$, all the $\mathrm{Au}$ islands are similar. As the bias magnitude increases to $1.0 \mathrm{~V}$ and then $1.5 \mathrm{~V}$, some $\mathrm{Au}$ islands become brighter than others, indicating different effective heights. The brighter islands are effectively $\sim 0.1 \mathrm{~nm}$ higher than the dark islands. This is illustrated by the height histograms and line profiles in Fig. 18 and Fig. 19, which show two distinct peaks corresponding to the Au islands. We interpret this to mean that at $325 \mathrm{~K}$, some islandsperhaps the bright ones - are more affected than others by exchange with the $\mathrm{NiAl}(110)$ substrate. 
As the surface is heated to $350 \mathrm{~K}$, the islands return to a single effective height that falls in the range $0.25 \mathrm{~nm}-0.27 \mathrm{~nm}$, independent of bias conditions (see Table 2). This is shown by the STM images in Fig 20, and by the histograms and line profiles in Fig. 21 and Fig. 22, where there is only a single peak corresponding to Au islands. We interpret this to mean that the alloying or exchange process is completed at $350 \mathrm{~K}$. In addition to their heights, the shapes of these 'alloyed' islands are very similar to the original ones at $300 \mathrm{~K}$. Compare, for instance, Fig. 20 with Fig. 8. Finally, the island coverage is invariant during the alloying process, remaining constant at $0.21 \mathrm{ML}$ between 300 and $350 \mathrm{~K}$. Hence, the exchange process disrupts neither the island shape nor the island area, in this temperature range. It changes the island heights, but only temporarily.

Stripes like those shown in Fig. 9 through Fig. 11 cannot be discerned after heating to 325 or $350 \mathrm{~K}$, but it is not clear whether the stripes actually disappear or whether the resolution is simply poorer (or noise higher) in the STM images above 300 K.

\section{Discussion}

\subsection{Growth at $200 \mathrm{~K}$ and $300 \mathrm{~K}$}

Island Heights. Growth of $\mathrm{Au}$ islands at $200 \mathrm{~K}$ and $300 \mathrm{~K}$ produces islands with heights of $0.24-0.25 \mathrm{~nm}$, and this height is bias-independent in both cases. The value of the height indicates that islands are one atom thick. (For instance, [111] and [110] interplanar spacings in bulk $\mathrm{Au}$ are $0.236 \mathrm{~nm}$ and $0.289 \mathrm{~nm}$, respectively.) By comparison, $\mathrm{Ag} / \mathrm{NiAl}(110)$ formed first-layer islands that were $0.32 \mathrm{~nm}$ high, compatible 
with a bilayer of fcc(110) metal. The difference in island heights is one indication that growth is much different for $\mathrm{Au}$ than for $\mathrm{Ag}$.

Island Densities. For a fixed coverage of 0.24-0.25 ML and fixed flux of 0.034 $\mathrm{ML} / \mathrm{min}$ (as presented in Sec. 2), the Au islands are much smaller and denser at $200 \mathrm{~K}$ than at $300 \mathrm{~K}$. The island densities are 0.019 and 0.0013 , respectively. This trend is in agreement with expectation for homogeneous nucleation, where lower temperature suppresses atomic diffusion and enhances the probability for nucleation of new islands, relative to the probability for attachment to existing islands.

Comparison with $\mathrm{Ag} / \mathrm{NiAl}(110)$ is interesting here as well. At $300 \mathrm{~K}$, the island density for $\mathrm{Au} / \mathrm{NiAl}(110)$ is much higher than it is for $\mathrm{Ag} / \mathrm{NiAl}(110)$. The island density in the latter case was thought to be suppressed strongly by preferential Ag adsorption at defect sites in the $\mathrm{NiAl}(110)$ substrate, specifically, at sites where a Ni replaced an $\mathrm{Al}$ atom [15]. Density functional theory (DFT) showed that Ag atoms bond more strongly at such sites, by $0.21 \mathrm{eV}$, relative to the next-most-favorable adsorption sites on the surface [15]. These defect sites thus serve as points of preferential nucleation, and they lead to lower island density than would be obtained with pure homogeneous nucleation. The effect was thought to increase with increasing temperature because diffusion lengths increased, making the defect sites more accessible to Ag atoms. The fact that the island density is about an order of magnitude higher for $\mathrm{Au} / \mathrm{NiAl}(110)$ under comparable conditions suggests that the defect sites are less important for Au. It would be interesting to test this with DFT.

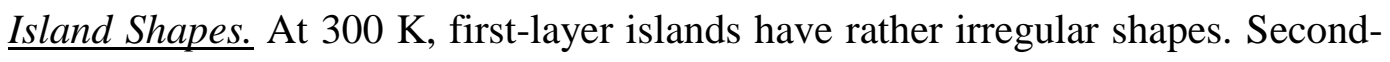
layer islands, which appear at $0.54 \mathrm{ML}$, are more rectangular and compact. As coverage 
increases they become quite elongated. This is particularly evident at 0.8 ML [see Fig. 4(g)]. However, at higher coverage they return to a rather irregular shape, as shown in Fig. 4(h). The reasons for these transitions in shape are not clear. The elongated, compact shape shown by the second-layer islands between 0.6 and $0.8 \mathrm{ML}$ is what one might expect naturally for an fcc(110) island, since it reflects the anisotropy of the fcc(110) structure. (Almond-shaped islands have been predicted and observed for $\mathrm{Au}$ on $\mathrm{Au}(110)$, but this shape is due to the missing-row reconstruction [27]). Further studies are needed to clarify the origin of the island shapes for $\mathrm{Au} / \mathrm{NiAl}(110)$.

Fine Structure. At $300 \mathrm{~K}$ and at coverages of $0.6 \mathrm{ML}$ or above, the islands show a chevron-like arrangement of stripes that are separated by about $1.2 \mathrm{~nm}$. Domains of stripes are rotated by about $113^{\circ} \pm 5^{\circ}$ within the first layer. Domains of stripes also appear in second-layer islands, but these are not parallel to first-layer stripes.

Similar stripes were observed for $\mathrm{Ag} / \mathrm{NiAl}(110)$, where they were attributed to a rumpling of the Ag layer that provided strain relief [13]. Only one domain was observed, presumably because the islands were highly anisotropic and served to orient the ripples. One can speculate that the cause of the stripes for $\mathrm{Au} / \mathrm{NiAl}(110)$ may be similar.

\subsection{Thermal effects above $300 \mathrm{~K}$}

Ours is the first study of the stability of Au deposited on a NiAl surface at or near room temperature. We propose that surface exchange occurs slightly above room temperature. This stands in contrast to the bulk system. The solubility of Au in bulk $\mathrm{NiAl}$ is very low, only 0.3 at. \% [19]. At higher concentrations, $\mathrm{Au}$ reacts to form $\mathrm{AuAl}_{2}$, but this occurs well above room temperature [19]. 
On the other hand, at surfaces, $\mathrm{Au}$ intermixes readily with $\mathrm{Al}$ or $\mathrm{Ni}$ alone. Examples include Al/Au(111) [28], $\mathrm{Au} / \mathrm{Ni}(110)$ [29], $\mathrm{Au} / \mathrm{Ni}(111)$ [30], Ni/Au(110) [31], and $\mathrm{Ni} / \mathrm{Au}(111)$ [32]. In each case, surface intermixing occurs even at $300 \mathrm{~K}$. It should be noted that $\mathrm{Au}$ and $\mathrm{Ni}$ are bulk-immiscible, illustrating the principle that a surface alloy can form even when a bulk alloy cannot. We propose that this principle applies in the present situation, since $\mathrm{Au}$ is nearly-insoluble in bulk NiAl.

To our knowledge, the only prior study of Au deposited on a substrate containing both $\mathrm{Al}$ and Ni was that of Shimoda et al. [33], who studied submonolayer Au coverages on the decagonal Al-Ni-Co quasicrystal, using XPS and reflection-high energy electron diffraction. They found that, upon deposition at $300 \mathrm{~K}$, Au mixed preferentially with Al to form an Al-Au alloy. When annealed to 350-400 K, this alloy became more welldefined, both structurally and chemically, and could be identified as $\mathrm{AuAl}_{2}$.

Our data do not serve to identify the exact nature of the exchange or alloying reaction of $\mathrm{Au}$ on $\mathrm{NiAl}(110)$ at $325-350 \mathrm{~K}$. The signatures of the change are shifts in the XPS peaks, and (transient) changes in the effective island heights. The XPS area ratios suggest that the reaction affects and involves both $\mathrm{Ni}$ and $\mathrm{Al}$, which is not compatible with exclusive formation of $\mathrm{AuAl}_{2}$. It is somewhat surprising that the change occurs without significantly perturbing the island areas or shapes.

Our data show that this reaction certainly proceeds above $300 \mathrm{~K}$. We cannot rule out the possibility that it occurs partially already at lower temperatures and, indeed, one might expect that this would be the case. On the other hand, the island heights and biasdependences at $200 \mathrm{~K}$ and $300 \mathrm{~K}$ are similar and thus provide no evidence of thermallyactivated changes in this temperature interval. More extensive investigations of the 
temperature-dependence would be necessary to determine the exact thermal evolution of this system, particularly the conditions under which surface exchange or alloying begins.

\section{Conclusions}

When $\mathrm{Au}$ is deposited on the $\mathrm{NiAl}(110)$ surface, islands form that are one atom high. After deposition of $0.24 \mathrm{ML}$ at $200 \mathrm{~K}$, islands are small and their number density is about an order of magnitude higher than after deposition at $300 \mathrm{~K}$. At $300 \mathrm{~K}$, first-layer islands adopt larger, more irregular shapes. As coverage increases, second-layer islands appear and over a limited coverage range, they show compact rectangular shapes. At or above 0.6 ML and at $300 \mathrm{~K}$, all island tops exhibit domains of stripes. Upon heating slightly above room temperature, there is evidence of intermixing, from both XPS and STM. More extensive studies are needed to understand these observations.

\section{Acknowledgements}

This work was supported by the Office of Science, Basic Energy Sciences, Materials Sciences and Engineering Division of the US Department of Energy (USDOE). This manuscript has been authorized by Iowa State University of Science and Technology under Contract No. DE-AC02-07CH11358 with the US Department of Energy. 


\section{$\underline{\text { References }}$}

[1] S.C. Deevi, V.K. Sikka, Intermetallics 4 (1996) 357-375.

[2] C.T. Liu, J. Stringer, J.N. Mundy, L.L. Horton, P. Angelini, Intermetallics 5 (2997) 579-596.

[3] N. Nilius, A. Cörper, G. Bozdech, N. Ernst, H.-J. Freund, Prog. Surf. Sci. 67 (2001) 99-121.

[4] S. Degen, C. Becker, K. Wandelt, Far. Disc. 125 (2004) 343-356.

[5] S. Gritschneder, C. Becker, K. Wandelt, M. Reichling, J. Am. Chem. Soc. (2007) 4925-4928.

[6] J.E. Gould, Proc. IEE 125 (1978) 1137-1150.

[7] S.C. Lui, J.W. Davenport, E.W. Plummer, D.M. Zehner, G.W. Fernando, Physical Review B 42 (1990) 1582-1597.

[8] M.H. Kang, E.J. Mele, Physical Review B 36 (1987) 7371-7377.

[9] H.L. Davis, J.R. Noonan, Phys. Rev. Lett. 54 (1985) 566-569.

[10] S.M. Yalisove, W.R. Graham, Surf. Sci. 183 (1987) 556-564.

[11] X. Torrelles, F. Wendler, O. Bikondoa, H. Isern, W. Moritz, G.R. Castro, Surf. Sci. 487 (2001) 97-106.

[12] J. Hong, Phy. Rev. B 73 (2006) 092413.

[13] B. Ünal, F. Qin, Y. Han, D.J. Liu, D. Jing, A.R. Layson, C. Jenks, J.W. Evans, P.A. Thiel, Phys. Rev B 76 (2007) 195410.

[14] Z. Song, J.I. Pascual, H. Conrad, K. Horn, H.-P. Rust, Appl. Phys. A: Mat. Sci. Processing 72 (2001) S159-S162. 
[15] Y. Han, B. Ünal, D. Jing, F. Qin, C.J. Jenks, D.-J. Liu, P.A. Thiel, J.W. Evans, Phys. Rev B 81 (2010) 115462.

[16] Y. Han, B. Ünal, F. Qin, D. Jing, C. Jenks, D.-J. Liu, P.A. Thiel, J.W. Evans, Phys. Rev. Lett 100 (2008) 116105.

[17] J.W. Evans, Y. Han, B. Ünal, M. Li, K.J. Caspersen, D. Jing, A.R. Layson, C.R. Stoldt, T. Duguet, P.A. Thiel, AIP Conference Proceedings 1270 (2010) 26-44.

[18] T. Duguet, Y. Han, C. Yuen, D. Jing, B. Ünal, J.W. Evans, P.A. Thiel, Proc. Nat. Acad. Sci. 108 (2011) 989-994.

[19] L. Sheng, W. Zhang, J. Guo, F. Yang, Y. Liang, H. Ye, Intermetallics 18 (2010) $740-744$.

[20] G.A. Somorjai, Y. Li, Introduction to Surface Chemistry and Catalysis, John Wiley \& Sons, Inc., Hoboken, NJ, 2010.

[21] P.A. Thiel, P.J. Estrup, in: A.T. Hubbard (Ed.), The Handbook of Surface Imaging and Visualization, CRC Press, Boca Raton, Florida, 1995, p. 407.

[22] N. Takeuchi, C.T. Chan, K.M. Ho, Phys. Rev. Lett. 63 (1989) 1273-1276.

[23] T.B. Massalski, H. Okamoto, P.R. Subramanian, L. Kacprzak (Eds.), Binary Alloy Phase Diagrams, ASM International, 1990.

[24] I. Horcas, R. Fernandez, J.M. Gomez-Rodriguez, J. Colchero, J. Gomez-Herrero, A.M. Baro, Review of Scientific Instruments 78 (2007) -.

[25] See www.CasaXPS.com.

[26] J.F. Moulder, W.F. Stickle, P.E. Sobol, K.D. Bomben, Handbook of X-ray Photoelectron Spectroscopy, Perkin-Elmer Corporation, Physical Electronics Division, Eden Prairie, Minnesota, 1992. 
[27] M.J. Rost, R. van Gastel, J.W.M. Frenken, Phys. Rev. Lett 84 (2000) 1966-1969.

[28] B. Fischer, J.V. Barth, A. Fricke, L. Nedelmann, K. Kern, Surface Science 389 (1997) 366-374.

[29] L.P. Nielsen, F. Besenbacher, I. Stensgaard, E. Laegsgaard, C. Engdahl, P. Stoltze, K.W. Jacobsen, J.K. Norskov, Physical Review Letters 71 (1993) 754-757.

[30] J. Jacobsen, L. Pleth Nielsen, F. Besenbacher, I. Stensgaard, E. Lægsgaard, T.

Rasmussen, K.W. Jacobsen, J.K. Nørskov, Physical Review Letters 75 (1995) 489.

[31] M.B. Hugenschmidt, A. Hitzke, R.J. Behm, Physical Review Letters 76 (1996) 2535.

[32] W.G. Cullen, P.N. First, Surf. Sci. 420 (1999) 53-64.

[33] M. Shimoda, T.J. Sato, A.P. Tsai, J.Q. Guo, Phys. Rev. B: Condens. Matter Mater. Phys. 62 (2000) 11288-11291.

[34] N. Ohtsu, A. Nomura, T. Shishido, Surf. Sci. Spectra 17 (2010) 68-75. 


\section{Figure Caption}

\section{Figure 1}

Bulk structure of NiAl (110), (a) top view and (b) side view. The black rectangle box in (a) represents the unit cell.

\section{Figure 2}

STM images. (a) clean surface of $\mathrm{NiAl}(110)$, taken at $250 \mathrm{~nm}$ x $250 \mathrm{~nm}, \mathrm{I}=0.5 \mathrm{nA}$, V-tip $=-1 \mathrm{~V}$; (b) $0.24 \mathrm{ML}$ deposition of $\mathrm{Au}$ on $\mathrm{NiAl}(110)$ at $300 \mathrm{~K}$, taken at $500 \mathrm{~nm} \times 500 \mathrm{~nm}$, $\mathrm{I}=0.5 \mathrm{nA}, \mathrm{V}$-tip $=-1 \mathrm{~V}$.

\section{Figure 3}

All the data points represent experiments in which Au was deposited at $300 \mathrm{~K}$, without heating, except for the point labeled "Fig. 7", in which Au was deposited at $200 \mathrm{~K}$. Each point is labeled with the name of a figure that represents this experiment. The point itself and its error bars are usually based upon more images than just the figure (not all images are shown as figures in this paper). The straight line is a linear least-squares fit, for which the regression parameter is 0.935 . The least-squares fit for a line is shown in the figure and has been taken into account for the uncertainty in the measurement.

\section{Figure 4}

STM images of given $\mathrm{Au}$ deposition times on $\mathrm{NiAl}(110)$ with a coverage of (a) $0.10 \mathrm{ML}$, (b) $0.16 \mathrm{ML}$, (c) $0.24 \mathrm{ML}$, (d) $0.54 \mathrm{ML}$, (e) $0.54 \mathrm{ML}$, (f) $0.60 \mathrm{ML}$, (g) $0.83 \mathrm{ML}$, and (h) 1.3 ML. STM image size and tunneling conditions are (a) $250 \mathrm{~nm} \times 250 \mathrm{~nm}, \mathrm{I}=0.5 \mathrm{nA}$, V-tip = -1 V; (b) $250 \mathrm{~nm} \times 250 \mathrm{~nm}, \mathrm{I}=0.5 \mathrm{nA}$, V-tip = -1 V; (c) $250 \mathrm{~nm} \times 250 \mathrm{~nm}, \mathrm{I}=$ $0.5 \mathrm{nA}, \mathrm{V}$-tip = +1 V; (d) $250 \mathrm{~nm} \times 250 \mathrm{~nm}, \mathrm{I}=0.5 \mathrm{nA}, \mathrm{V}$-tip = -1 V; (e) $100 \mathrm{~nm} \times 100$ $\mathrm{nm}, \mathrm{I}=0.5 \mathrm{nA}$, V-tip = -1 V; (f) $200 \mathrm{~nm} \times 200 \mathrm{~nm}, \mathrm{I}=0.5 \mathrm{nA}$, V-tip = -1 V; (g) $150 \mathrm{~nm}$ x $150 \mathrm{~nm}, \mathrm{I}=0.1 \mathrm{nA}, \mathrm{V}$-tip = +1 V; and (h) $100 \mathrm{~nm}$ x $80 \mathrm{~nm}, \mathrm{I}=0.1 \mathrm{nA}, \mathrm{V}$-tip = +1 V.

\section{Figure 5}

Island size distribution at $0.24 \mathrm{ML}$ coverage where $\mathrm{S}=$ island size and $\langle\mathrm{S}\rangle=$ mean island size, (a) $300 \mathrm{~K}$ and (b) $200 \mathrm{~K}$.

\section{Figure 6}

STM images and height histograms at different Au coverages, (a) $100 \mathrm{~nm} \times 100 \mathrm{~nm}, \mathrm{I}=$ $0.5 \mathrm{nA}$, V-tip = -1 V, with a coverage of $0.24 \mathrm{ML}$ of Au; (b) height histogram of (a); (c) $100 \mathrm{~nm} \times 100 \mathrm{~nm}, \mathrm{I}=0.1 \mathrm{nA}, \mathrm{V}$-tip $=+1 \mathrm{~V}$ with a coverage of $0.60 \mathrm{ML}$ of $\mathrm{Au}$; (d) height histogram of (c).

\section{Figure 7}

STM images and line profiles at different Au coverages at $300 \mathrm{~K}$. Tunneling conditions at coverages from $0.1 \mathrm{ML}$ to $0.60 \mathrm{ML}$ are $\mathrm{I}=0.50 \mathrm{nA}$ and $\mathrm{V}$-tip $=-1 \mathrm{~V}$ and coverages from $0.83 \mathrm{ML}$ to $1.3 \mathrm{ML}$ are $\mathrm{I}=0.1 \mathrm{nA}$ and $\mathrm{V}$-tip $=+1 \mathrm{~V}$. 


\section{Figure 8}

$\mathrm{Au} / \mathrm{NiAl}(110)$ at $300 \mathrm{~K}$ with different bias conditions. Coverage of $0.24 \mathrm{ML}$ of $\mathrm{Au}$ was deposited at $300 \mathrm{~K}$. All of these STM images are $\mathrm{I}=0.5 \mathrm{nA}$ and $100 \mathrm{~nm} \times 100 \mathrm{~nm}$ with a V-tip of (a) $-0.5 \mathrm{~V}$, (b) $-1.0 \mathrm{~V}$, (c) $-1.5 \mathrm{~V}$, (d) $+0.5 \mathrm{~V}$, (e) $+1.0 \mathrm{~V}$, and (f) $+1.5 \mathrm{~V}$.

\section{Figure 9}

STM image of $\mathrm{Au}$ on $\mathrm{NiAl}(110)$ at $300 \mathrm{~K}$ at a coverage of $0.60 \mathrm{ML}$. STM images are (a) $100 \mathrm{~nm} \times 100 \mathrm{~nm}$, (b) $22 \mathrm{~nm}$ x $22 \mathrm{~nm}$, (c) $22 \mathrm{~nm}$ x $22 \mathrm{~nm}$, (d) $30 \mathrm{~nm}$ x $30 \mathrm{~nm}$, (e) $22 \mathrm{~nm}$ x $22 \mathrm{~nm}$, and (f) $100 \mathrm{~nm} \times 100 \mathrm{~nm}$. The tunneling conditions are I = $0.5 \mathrm{nA}$ and V-tip = $1 \mathrm{~V}$.

\section{Figure 10}

Stripes in the Au island on $\mathrm{NiAl}(110)$ at $300 \mathrm{~K}$, (a) STM image by $11 \mathrm{~nm} \times 6 \mathrm{~nm}$, (b) line profile from (a) taken by the black arrowhead, (c) STM image by $7 \mathrm{~nm}$ x $5 \mathrm{~nm}$, (d) line profile from (c) taken by the black arrowhead, (e) derivative STM image by $11 \mathrm{~nm}$ x 11 $\mathrm{nm}$, (f) line profile from (e) taken by the white arrowhead, (g) derivative STM image by $10 \mathrm{~nm} \times 8 \mathrm{~nm}$, and (h) line profile from (g) taken by the black arrowhead. Coverage of $0.60 \mathrm{ML}$ of $\mathrm{Au}$.

\section{Figure 11}

STM image of 1.3 ML Au coverage on $\mathrm{NiAl}(110)$ at $300 \mathrm{~K}$ with dimensions of, (a) is 100 $\mathrm{nm} \times 81 \mathrm{~nm}$, (b) $11 \mathrm{~nm} \times 12 \mathrm{~nm}$ (1 $1^{\text {st }}$ layer), (c) $15 \mathrm{~nm} \times 13 \mathrm{~nm}$ (1 ${ }^{\text {st }}$ layer $),(d) 11 \mathrm{~nm} \times 16$ $\mathrm{nm}\left(2^{\text {nd }}\right.$ layer $),\left(\right.$ e) $22 \mathrm{~nm} \times 17 \mathrm{~nm}\left(1^{\text {st }}\right.$ and $2^{\text {nd }}$ layers $)$, and (f) $15 \mathrm{~nm} \mathrm{x} 11 \mathrm{~nm}$ ( $1^{\text {st }}$ layer $)$.

\section{Figure 12}

$\mathrm{Au} / \mathrm{NiAl}(110)$ at $200 \mathrm{~K}$ with different bias conditions. Coverage of $0.25 \mathrm{ML}$ of $\mathrm{Au}$ was deposited at $200 \mathrm{~K}$. All of these STM images are I $=0.5 \mathrm{nA}$ and $100 \mathrm{~nm} \times 100 \mathrm{~nm}$ with a V-tip of (a) $-0.5 \mathrm{~V}$, (b) $-1.0 \mathrm{~V}$, (c) $-1.5 \mathrm{~V}$, (d) $+0.5 \mathrm{~V}$, (e) $+1.0 \mathrm{~V}$, and (f) $+1.5 \mathrm{~V}$.

\section{Figure 13}

XPS Ni 2p $p_{3 / 2}$ binding energy range from 880 to $830 \mathrm{eV}$ at given temperatures. Deposited $\mathrm{Au}$ at $300 \mathrm{~K}$ and then annealed to $325 \mathrm{~K}$ and $350 \mathrm{~K}$.

\section{Figure 14}

XPS Al 2s binding energy range from 130 to $100 \mathrm{eV}$ at given temperatures. Deposited $\mathrm{Au}$ at $300 \mathrm{~K}$ and then annealed to $325 \mathrm{~K}$ and $350 \mathrm{~K}$.

\section{Figure 15}

XPS $\mathrm{Au} 4 \mathrm{f}_{7 / 2}, 5 / 2$ binding energy range from 100 to $75 \mathrm{eV}$ at given temperatures. Deposited $\mathrm{Au}$ at $300 \mathrm{~K}$ and then annealed to $325 \mathrm{~K}$ and $350 \mathrm{~K}$.

\section{Figure 16}

XPS Ni $3 p$ and $\mathrm{Al} 2 \mathrm{p}$ binding energy range from 80 to $60 \mathrm{eV}$ at given temperatures. Deposited $\mathrm{Au}$ at $300 \mathrm{~K}$ and then annealed to $325 \mathrm{~K}$ and $350 \mathrm{~K}$. 
Figure 17

$\mathrm{Au} / \mathrm{NiAl}(110)$ at $325 \mathrm{~K}$ with different bias conditions. Coverage of $0.24 \mathrm{ML}$ of Au was deposited at $300 \mathrm{~K}$ and was then annealed at $325 \mathrm{~K}$. Different island height is shown at high biases as indicated by dark and light contrast. All of these STM images are I $=0.5$ $\mathrm{nA}$ and are zoomed-in $(250 \mathrm{~nm} \times 140 \mathrm{~nm})$ from $250 \mathrm{~nm} \times 250 \mathrm{~nm}$ with a V-tip of (a) -0.5 $\mathrm{V},(\mathrm{b})+0.5 \mathrm{~V}$, (c) $-1.0 \mathrm{~V},(\mathrm{~d})+1.0 \mathrm{~V}$, (e) $-1.5 \mathrm{~V}$, and (f) $+1.5 \mathrm{~V}$.

\section{Figure 18}

Height histograms which were taken from the STM images in Fig. 8 at $325 \mathrm{~K}$. The tunneling conditions are $\mathrm{I}=0.5 \mathrm{nA}$ and a V-tip of (a) $-0.5 \mathrm{~V}$, (b) $+0.5 \mathrm{~V}$, (c) $-1.0 \mathrm{~V}$, (d) $+1.0 \mathrm{~V},(\mathrm{e})-1.5 \mathrm{~V}$, and (f) $+1.5 \mathrm{~V}$.

\section{Figure 19}

STM images with corresponding line profiles of $\mathrm{Au}$ on $\mathrm{NiAl}(110)$ at $325 \mathrm{~K}$. The tunneling conditions are $\mathrm{I}=0.5 \mathrm{nA}$ and $\mathrm{V}$-tip $=-1 \mathrm{~V}$.

\section{Figure 20}

$\mathrm{Au} / \mathrm{NiAl}(110)$ at $350 \mathrm{~K}$ with different bias conditions. Coverage of $0.24 \mathrm{ML}$ of $\mathrm{Au}$ was deposited at $300 \mathrm{~K}$ and was then annealed at $350 \mathrm{~K}$. All of these STM images are I $=0.5$ $\mathrm{nA}$ and are $100 \mathrm{~nm} \times 100 \mathrm{~nm}$ with a V-tip of (a) $-0.5 \mathrm{~V}$, (b) $+0.5 \mathrm{~V}$, (c) $-1.0 \mathrm{~V}$, (d) +1.0 $\mathrm{V},(\mathrm{e})-1.5 \mathrm{~V}$ and (f) $+1.5 \mathrm{~V}$.

\section{Figure 21}

Height histograms which were taken from the STM images in Fig. 10 at $350 \mathrm{~K}$. The tunneling conditions are $\mathrm{I}=0.5 \mathrm{nA}$ and a V-tip of (a) $-0.5 \mathrm{~V}$, (b) $+0.5 \mathrm{~V}$, (c) $-1.0 \mathrm{~V}$, (d) $+1.0 \mathrm{~V}$, (e) $-1.5 \mathrm{~V}$, and (f) $+1.5 \mathrm{~V}$.

\section{Figure 22}

STM images with corresponding line profiles of $\mathrm{Au}$ on $\mathrm{NiAl}(110)$ at $350 \mathrm{~K}$. The tunneling conditions are $\mathrm{I}=0.500 \mathrm{nA}$ and V-tip $=-1 \mathrm{~V}$. 


\section{Table 1}

Island heights and island densities after deposition of various coverages of $\mathrm{Au}$ at $300 \mathrm{~K}$. $\mathrm{Au}$ was deposited on $\mathrm{NiAl}(110)$ at $300 \mathrm{~K}$. The tunneling conditions were $0.1 \mathrm{nA}$ and 0.5 $\mathrm{nA}$ with a bias voltage between $-1.5 \mathrm{~V}$ and $+1.5 \mathrm{~V}$.

\begin{tabular}{|c|c|c|c|c|}
\hline $\begin{array}{c}\text { Au Coverage } \\
(\mathbf{M L})\end{array}$ & $\begin{array}{c}\text { Au Deposition } \\
\text { Time (min) }\end{array}$ & $\begin{array}{c}\mathbf{1}^{\text {st }} \text { Layer } \\
\text { Height }(\mathbf{n m})\end{array}$ & $\begin{array}{c}\mathbf{2}^{\text {nd }} \text { Layer } \\
\text { Height }(\mathbf{n m})\end{array}$ & $\begin{array}{c}\text { Island Density } \\
\left.\mathbf{( n m}^{\mathbf{- 2}}\right)\end{array}$ \\
\hline 0.10 & 2 & $0.25 \pm 0.01$ & - & 0.0006 \\
\hline 0.16 & 4 & $0.25 \pm 0.01$ & - & 0.0008 \\
\hline 0.24 & 8 & $0.24 \pm 0.02$ & - & 0.0013 \\
\hline 0.54 & 16 & $0.37 \pm 0.02$ & $0.25 \pm 0.01$ & \\
\hline 0.60 & 16.5 & $0.26 \pm 0.02$ & $0.21 \pm 0.02$ & \\
\hline 0.83 & 24.5 & $0.27 \pm 0.01$ & $0.24 \pm 0.01$ & \\
\hline 1.3 & 40.5 & $0.25 \pm 0.03$ & $0.24 \pm 0.01$ & \\
\hline
\end{tabular}

\section{Table 2}

Island heights, determined from pixel height histograms, at different bias voltages and different temperatures. The Au coverage is constant at $0.24 \mathrm{ML}$. The temperatures of 200 $\mathrm{K}$ and $300 \mathrm{~K}$ are deposition temperatures, while $325 \mathrm{~K}$ and $350 \mathrm{~K}$ are annealing temperatures. Details of the thermal program are given in Section 2.

\begin{tabular}{|l|l|l|l|l|l|l|}
\hline \multirow{2}{*}{ Temp (K) } & \multicolumn{7}{|c|}{ Island Height (nm) } \\
\cline { 2 - 7 } & $\mathbf{- 1 . 5} \mathbf{~ V}$ & $\mathbf{- 1 . 0 ~ V}$ & $\mathbf{- 0 . 5} \mathbf{~ V}$ & $\mathbf{+ 0 . 5 ~ V}$ & $\mathbf{+ 1 . 0 ~ V}$ & $\mathbf{+ 1 . 5 ~ V}$ \\
\hline 200 & 0.25 & 0.23 & 0.25 & 0.24 & 0.25 & 0.25 \\
\hline 300 & 0.23 & 0.23 & 0.23 & 0.23 & 0.24 & 0.25 \\
\hline 325 & 0.26 & 0.27 & 0.37 & 0.43 & 0.29 & 0.23 \\
& 0.33 & 0.33 & & & 0.40 & 0.39 \\
\hline 350 & 0.25 & 0.25 & 0.25 & 0.26 & 0.25 & 0.27 \\
\hline
\end{tabular}




\section{Table 3}

Peak positions in XPS after different thermal treatments. The sample was initially prepared by depositing $0.24 \mathrm{ML} \mathrm{Au}$ at $300 \mathrm{~K}$. After XPS at $300 \mathrm{~K}$, it was heated to the higher temperatures as indicated. Details of the thermal program are given in Section 2. Peak positions of references are given in the bottom 3 rows.

\begin{tabular}{|l|c|c|c|c|c|c|}
\hline \multirow{2}{*}{ Temp (K) } & \multicolumn{7}{|c|}{ Experimental Peak position (eV) } \\
\cline { 2 - 8 } & Ni 2p $\mathbf{3 / 2}$ & Al 2s & $\begin{array}{l}\text { Au } \\
\mathbf{4 f}_{\mathbf{7 / 2}}\end{array}$ & $\begin{array}{l}\text { Au } \\
\mathbf{4 f}_{\mathbf{5} / \mathbf{2}}\end{array}$ & Ni 3p & Al 2p \\
\hline 300 & 852.6 & 117.1 & 83.3 & 87.3 & 66.3 & 72.0 \\
\hline 325 & 853.3 & 117.9 & 84.1 & 87.9 & 66.8 & 72.8 \\
\hline 350 & 853.3 & 117.6 & 84.1 & 88.0 & 66.8 & 72.5 \\
\hline $\begin{array}{l}\text { Clean NiAl(110) - this } \\
\text { work }\end{array}$ & - & - & - & - & 66.5 & 72.0 \\
\hline $\begin{array}{l}\text { Fractured, polycrystalline } \\
\text { NiAl [34] }\end{array}$ & 853.2 & - & - & - & - & 72.8 \\
\hline Elemental metals [26] & $852.5-$ & $117.1-$ & $82.8-$ & $86.3-$ & $66.1-$ & $72.5-$ \\
& 852.9 & 118.0 & 83.9 & 87.7 & 66.9 & 73.0 \\
\hline
\end{tabular}




\section{Table 4}

Integrated intensity ratios in XPS after different thermal treatments. In cases where $\mathrm{Au}$ was present, the coverage was $0.24 \mathrm{ML}$ and it was deposited at $300 \mathrm{~K}$. After XPS at 300 $\mathrm{K}$, it was heated to the higher temperatures. Details of the thermal program are given in Section 2. The clean $\mathrm{NiAl}(110)$ spectrum was measured in a different run, one day before the Au deposition experiments.

\begin{tabular}{|c|c|c|c|c|c|c|}
\hline \multirow[b]{2}{*}{ Surface } & \multicolumn{6}{|c|}{ Intensity Ratios } \\
\hline & $\begin{array}{l}\left(\mathrm{Ni} 2 \mathrm{p}_{3 / 2}\right) \\
:(\mathrm{Au} \\
\left.4 \mathbf{f}_{5 / 2+7 / 2}\right)\end{array}$ & $\begin{array}{l}(\mathrm{Ni} 3 p): \\
(\mathrm{Au} \\
\left.4 \mathbf{f}_{5 / 2+7 / 2}\right)\end{array}$ & 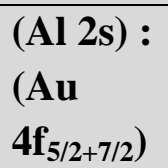 & 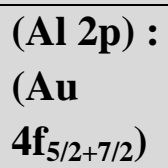 & $\begin{array}{l}\left(\mathrm{Ni} 2 \mathrm{p}_{3 / 2}\right) \\
:(\mathrm{Al} 2 \mathrm{~s})\end{array}$ & $\begin{array}{l}\text { (Ni 3p): } \\
(\text { Al 2p) }\end{array}$ \\
\hline $\begin{array}{l}\text { Clean } \\
\operatorname{NiAl}(110)\end{array}$ & - & - & - & - & - & 2.24 \\
\hline $\begin{array}{l}\text { With } \mathrm{Au}, \\
300 \mathrm{~K}\end{array}$ & 2.94 & 0.274 & 0.172 & 0.098 & 17.04 & 2.81 \\
\hline $\begin{array}{l}\text { With } \mathrm{Au} \text {, } \\
325 \mathrm{~K}\end{array}$ & 3.09 & 0.289 & 0.174 & 0.107 & 17.78 & 2.70 \\
\hline $\begin{array}{l}\text { With Au, } \\
350 \mathrm{~K}\end{array}$ & 3.23 & 0.282 & 0.176 & 0.103 & 18.38 & 2.73 \\
\hline $\begin{array}{l}\text { Relative } \\
\text { Change } \\
\text { between } \\
300 \mathrm{~K} \text { and } \\
350 \mathrm{~K} \text { with } \\
\mathrm{Au}\end{array}$ & $+10 \%$ & $+3 \%$ & $+2 \%$ & $+5 \%$ & $+8 \%$ & $-3 \%$ \\
\hline
\end{tabular}



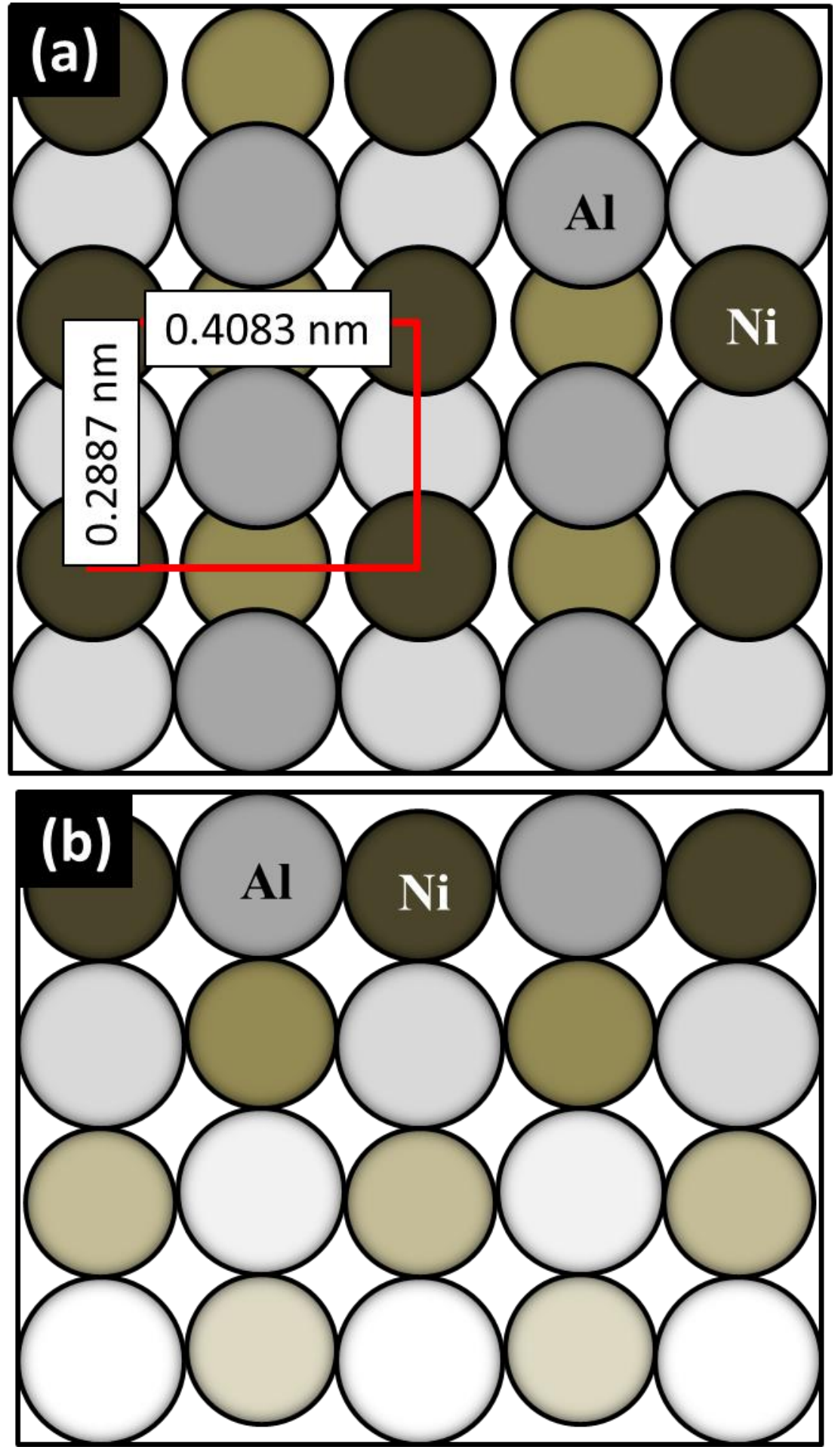

Figure 1 

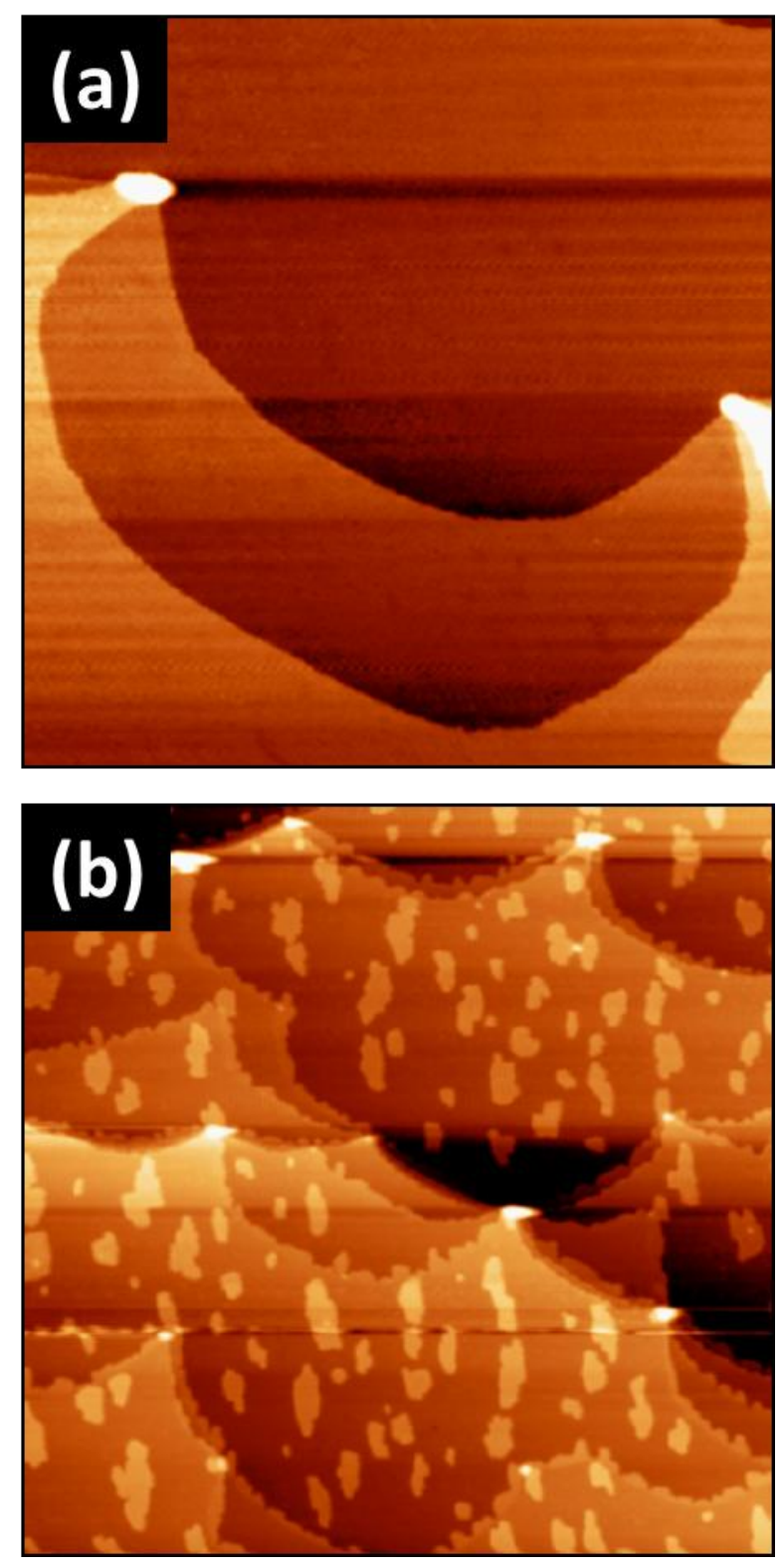

Figure 2 


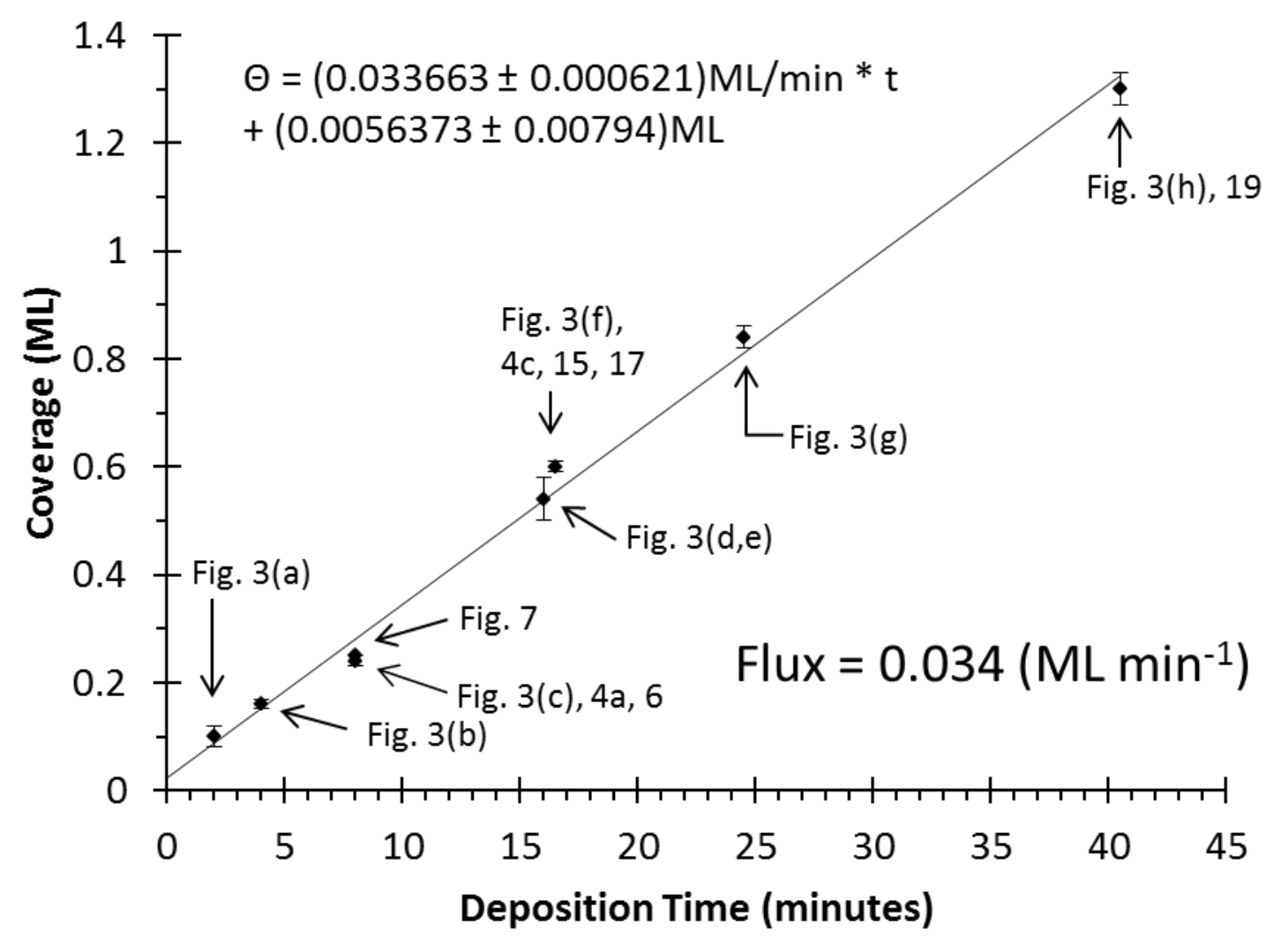

Figure 3 

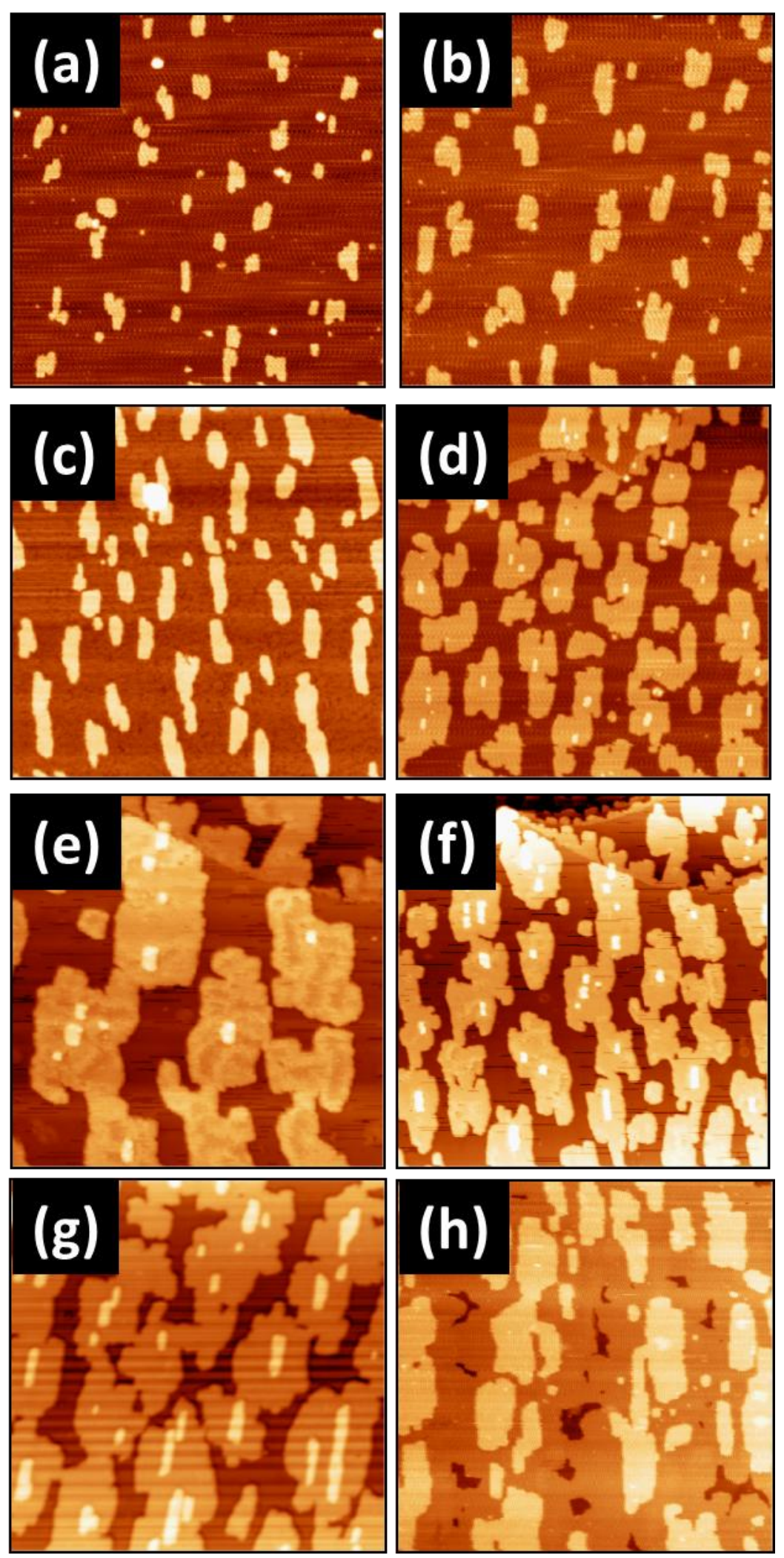

Figure 4 


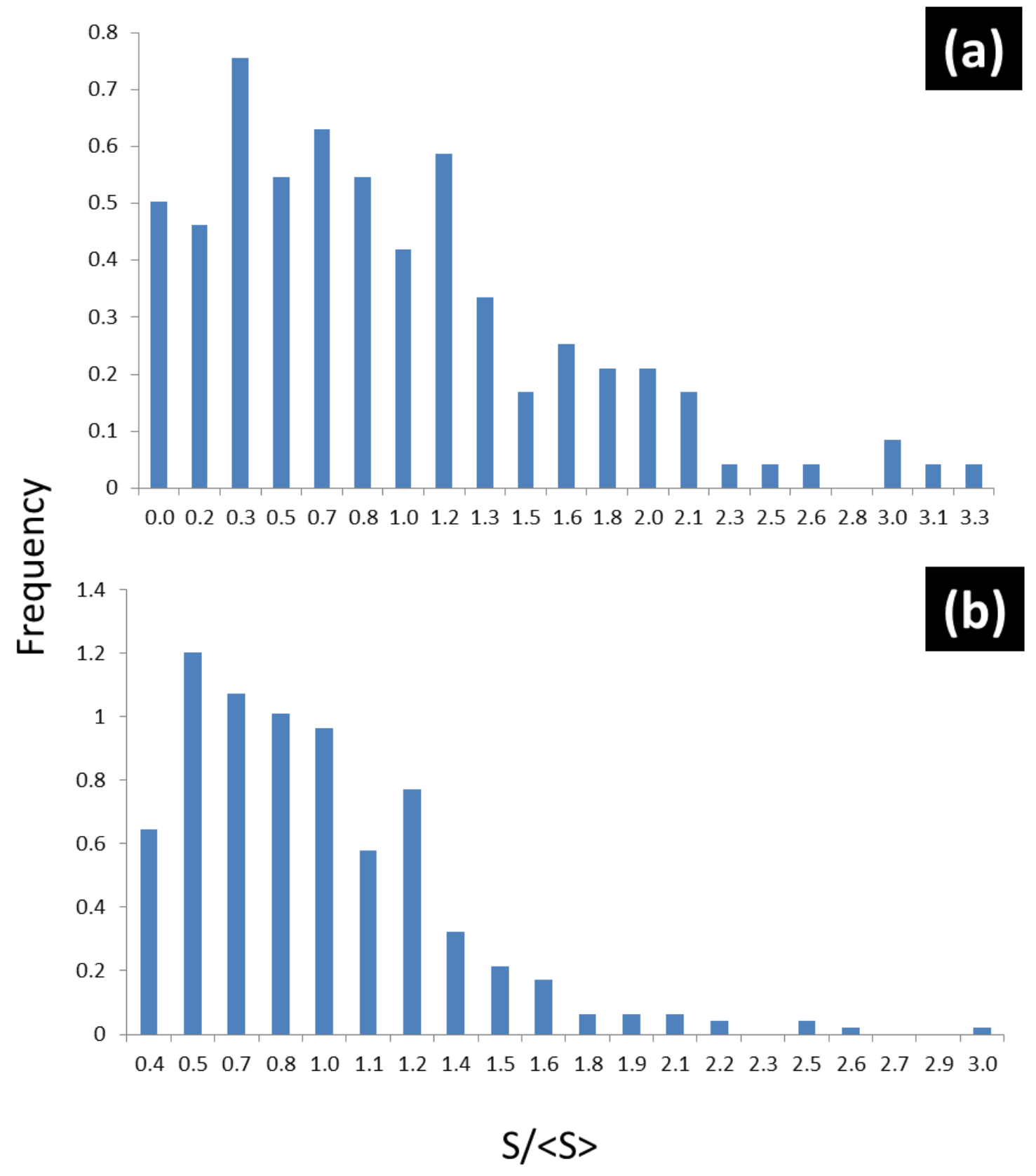

Figure 5 

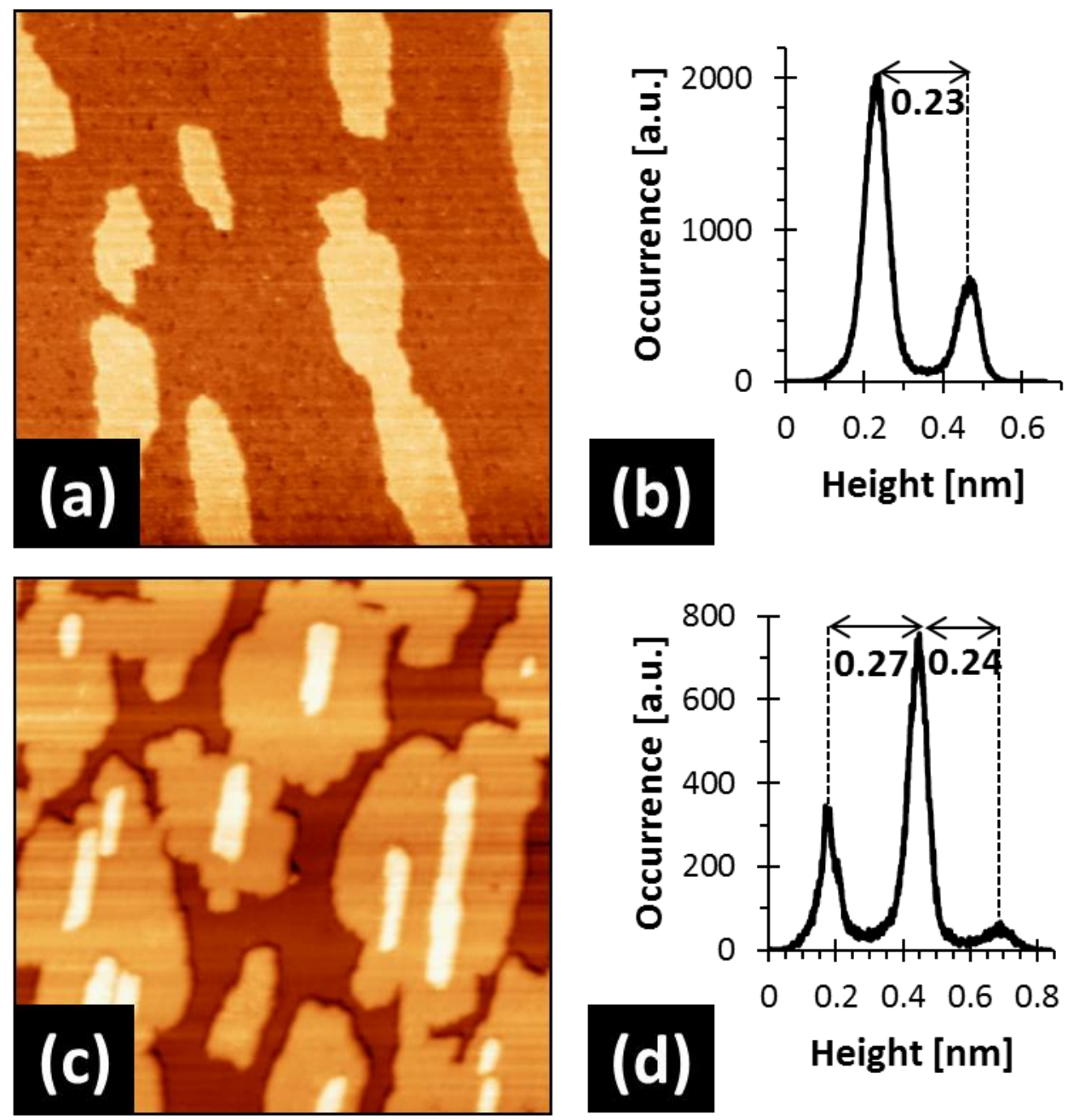

Figure 6 

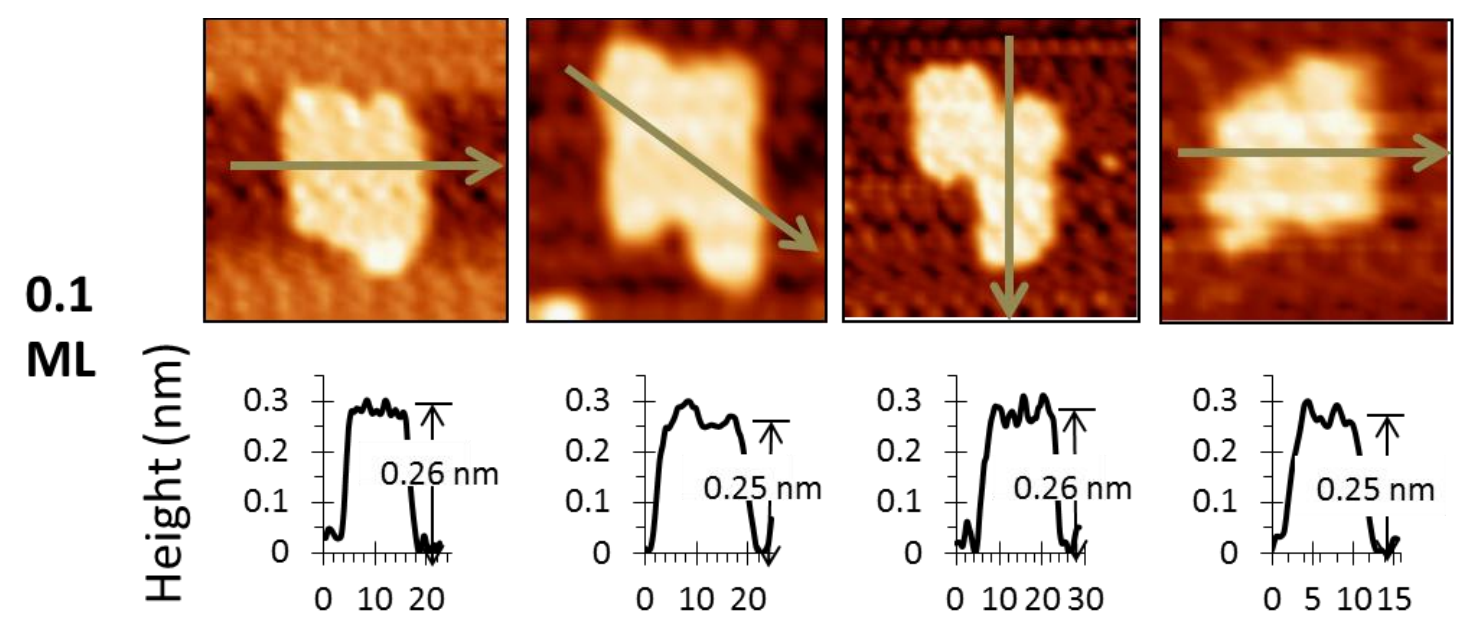

Length ( $\mathrm{nm}$ )

0.16
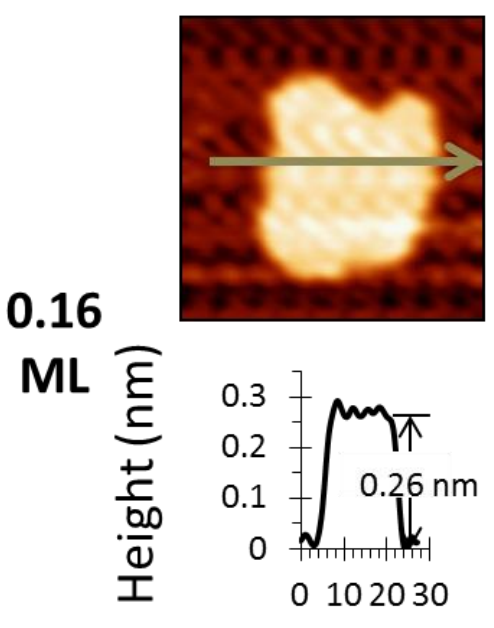
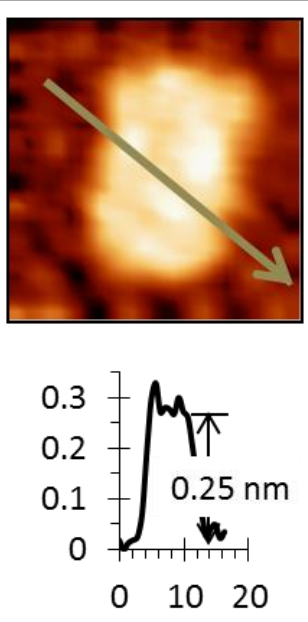
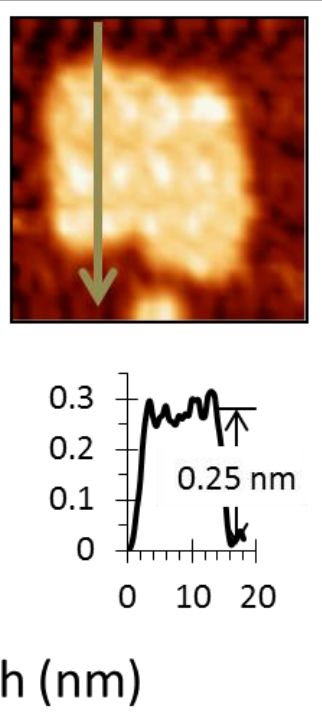
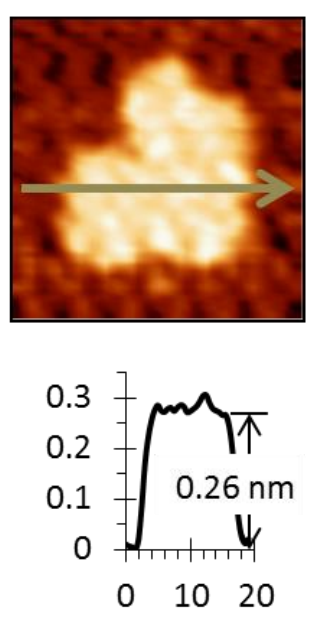

Length $(\mathrm{nm})$

Figure 7 
0.24
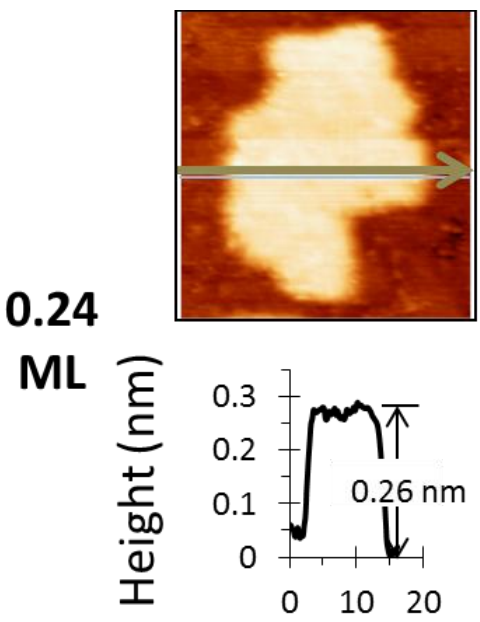
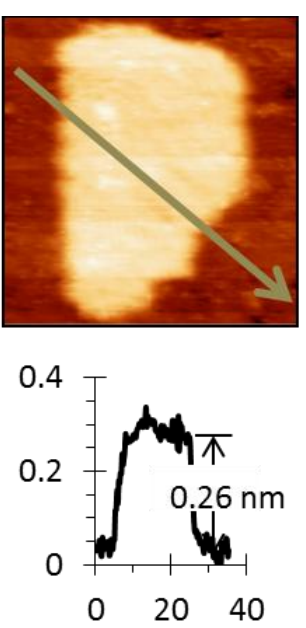
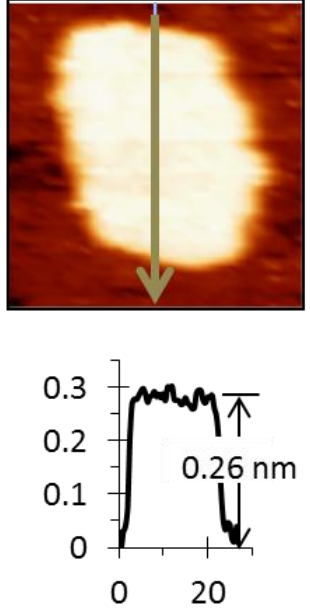
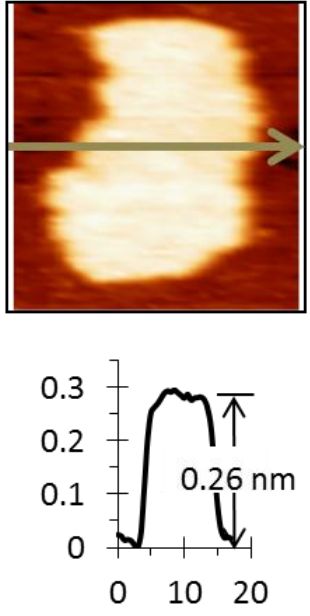

Length (nm)

0.54
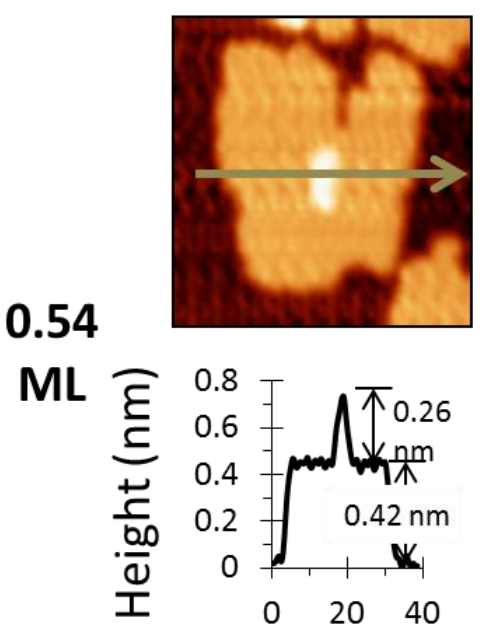
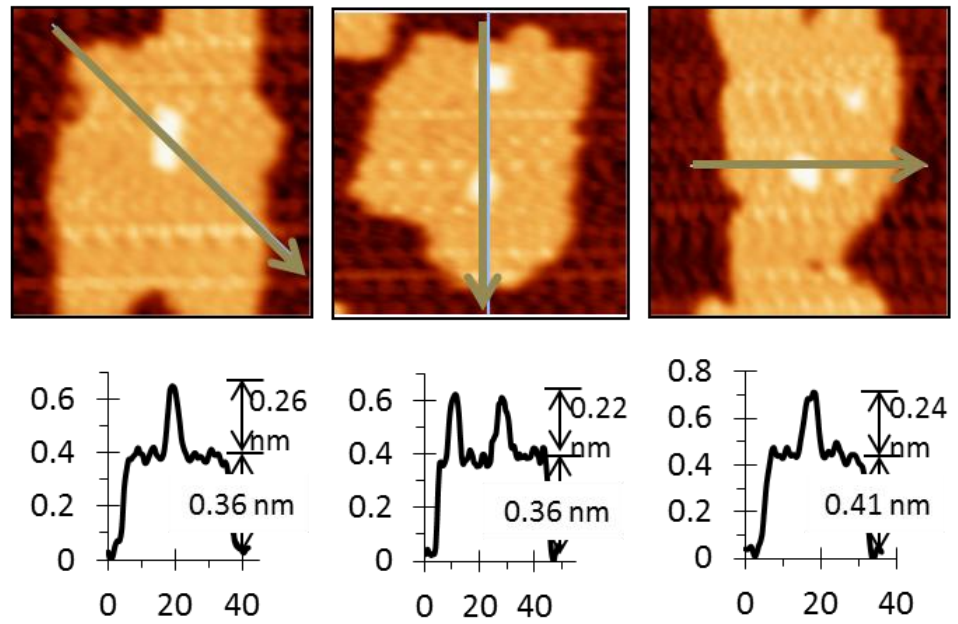

Length ( $\mathrm{nm}$ )

Figure 7 (Continue) 

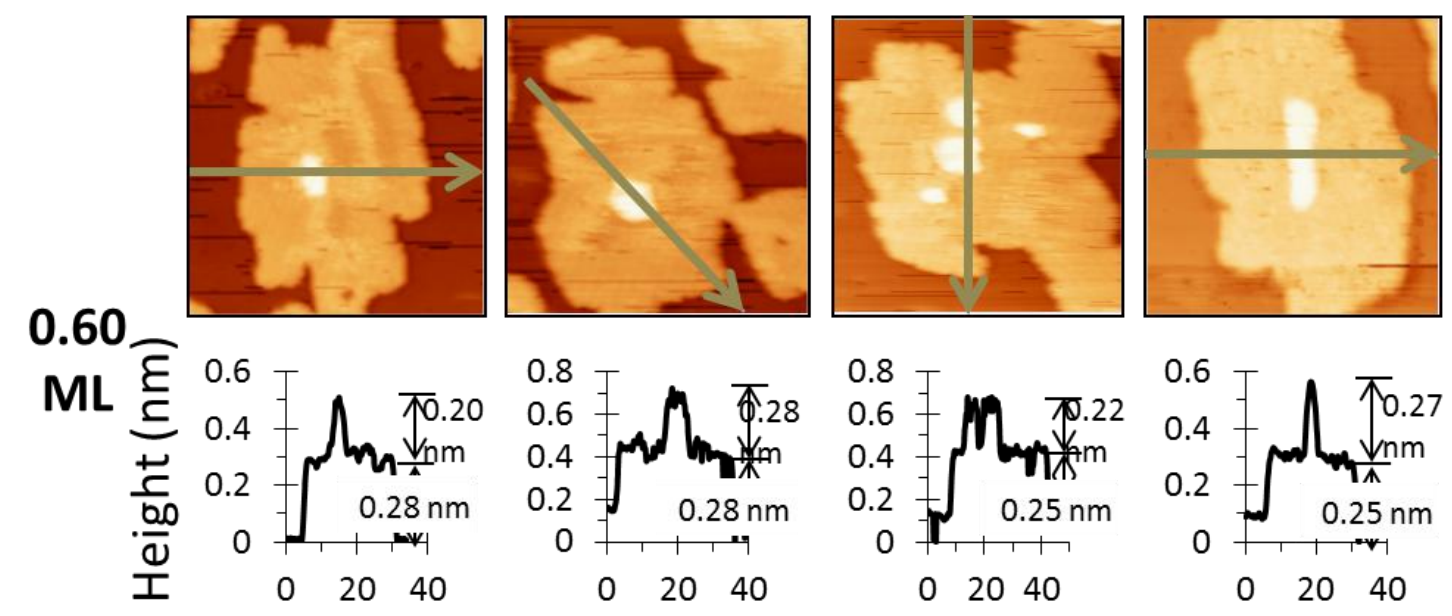

Length ( $\mathrm{nm}$ )
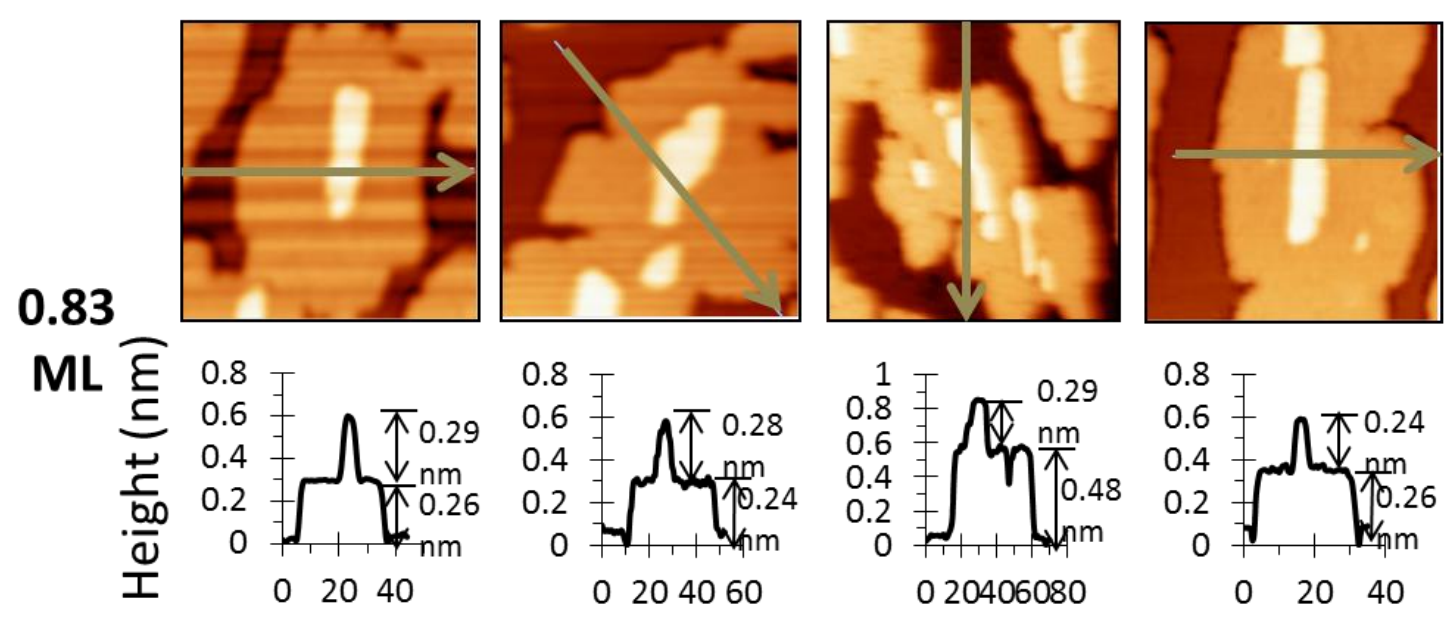

Length $(\mathrm{nm})$

Figure 7 (Continue) 

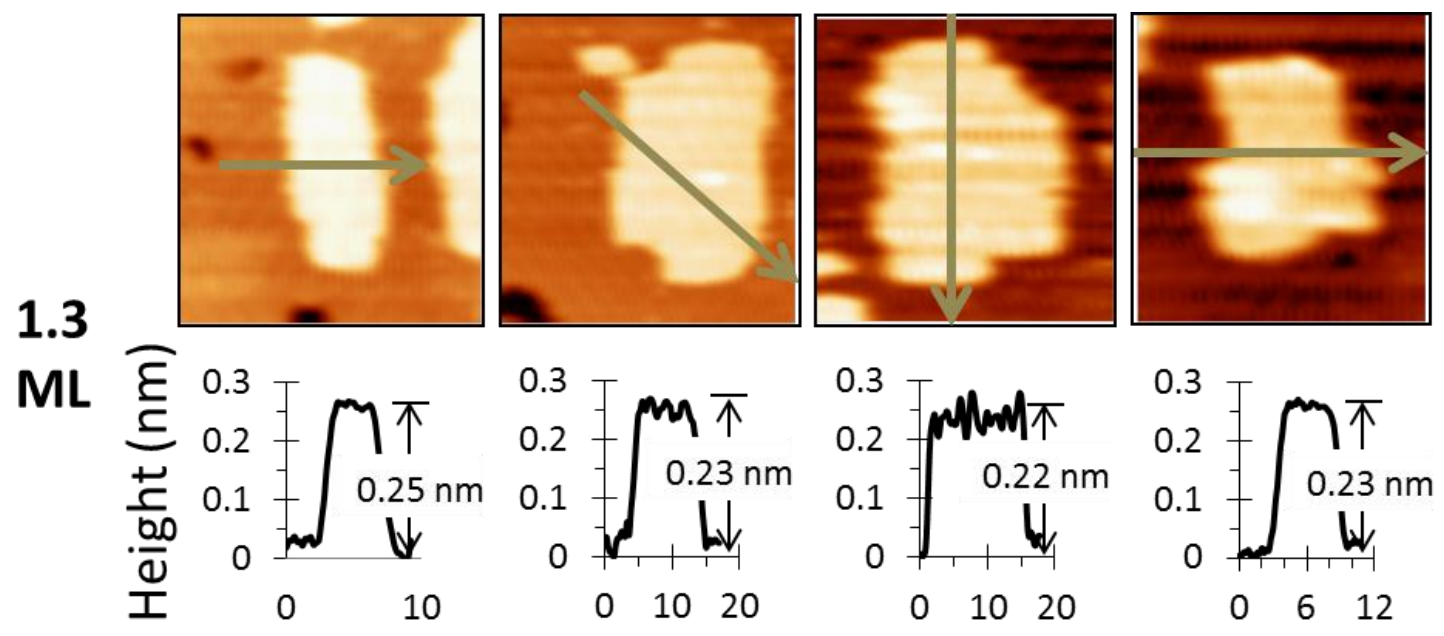

Length ( $\mathrm{nm}$ )

Figure 7 (Continue) 

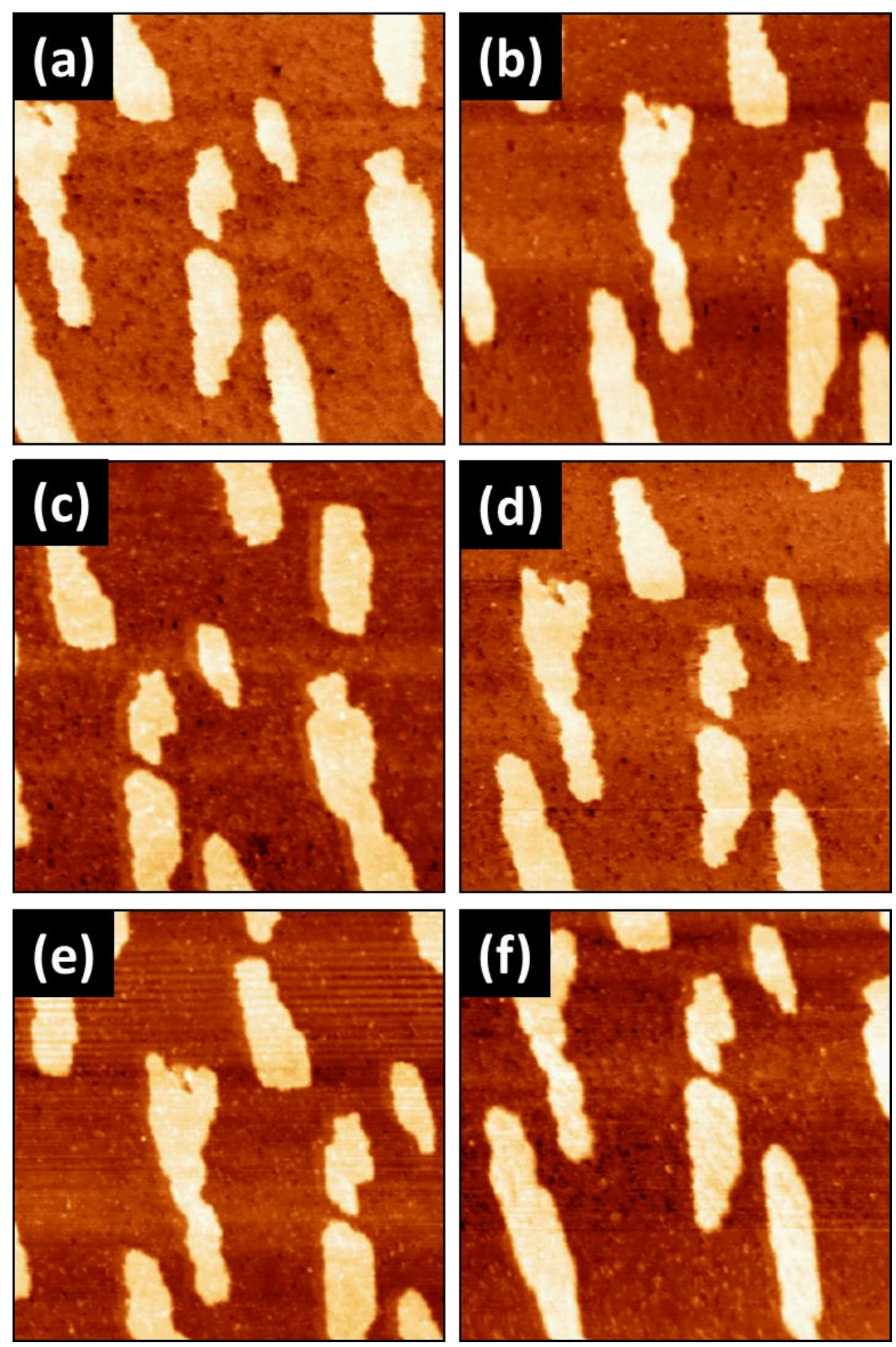

Figure 8 

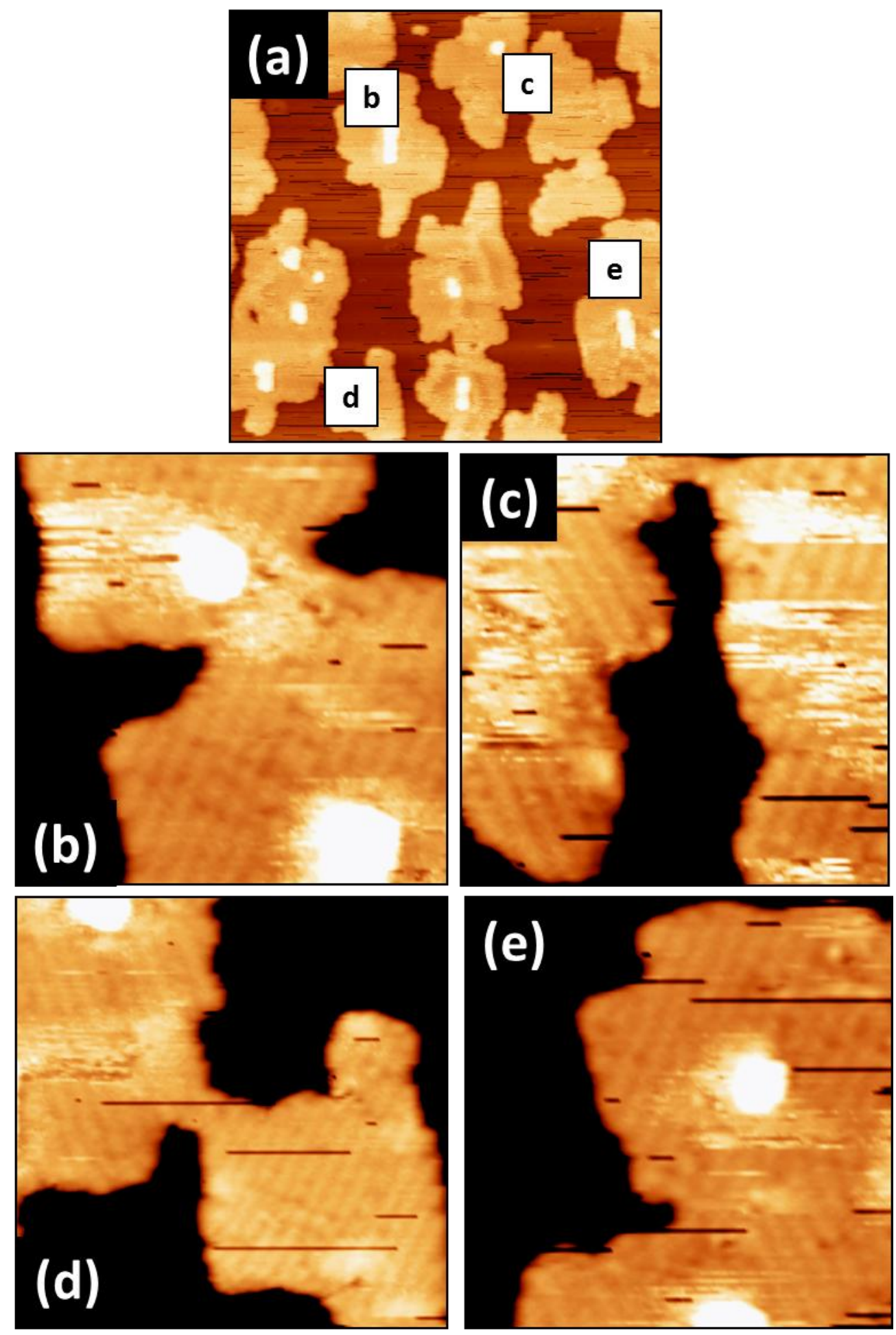

Figure 9 


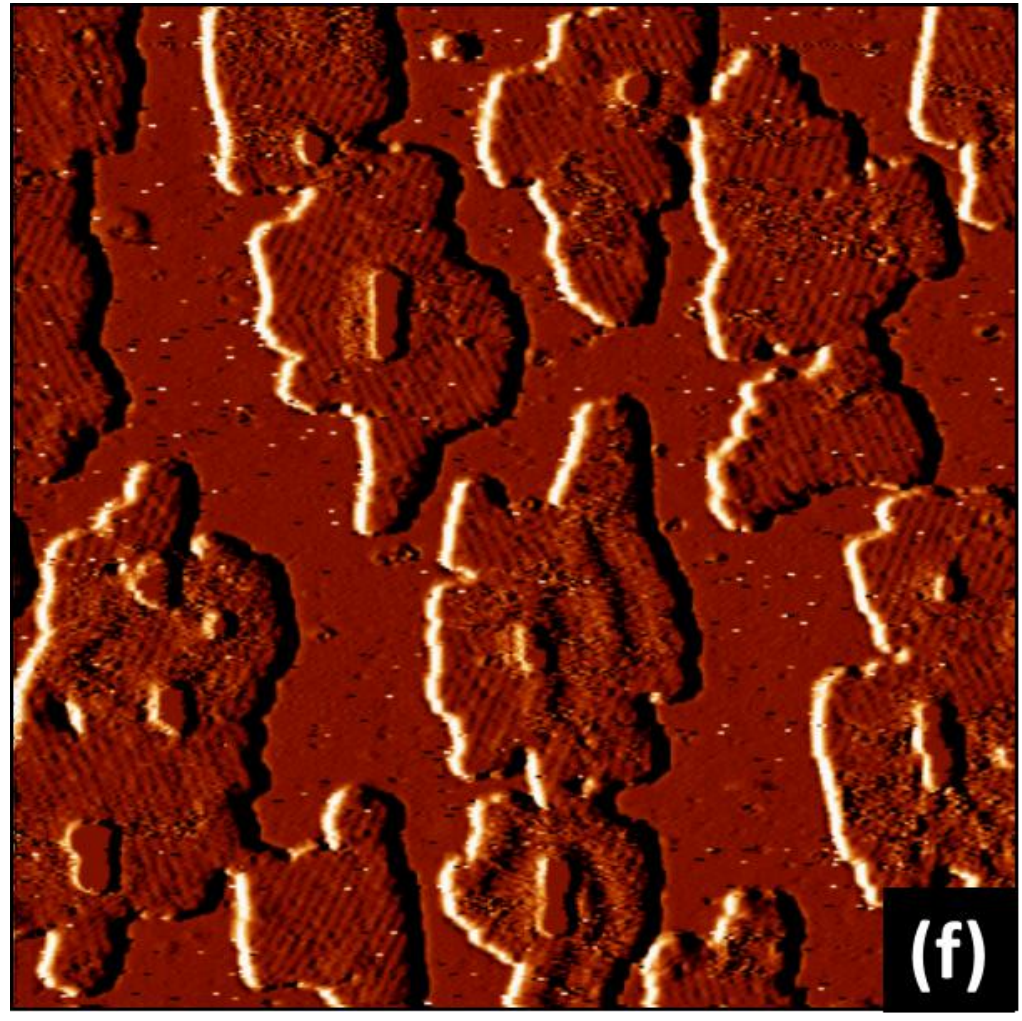

Figure 9 (Continue) 

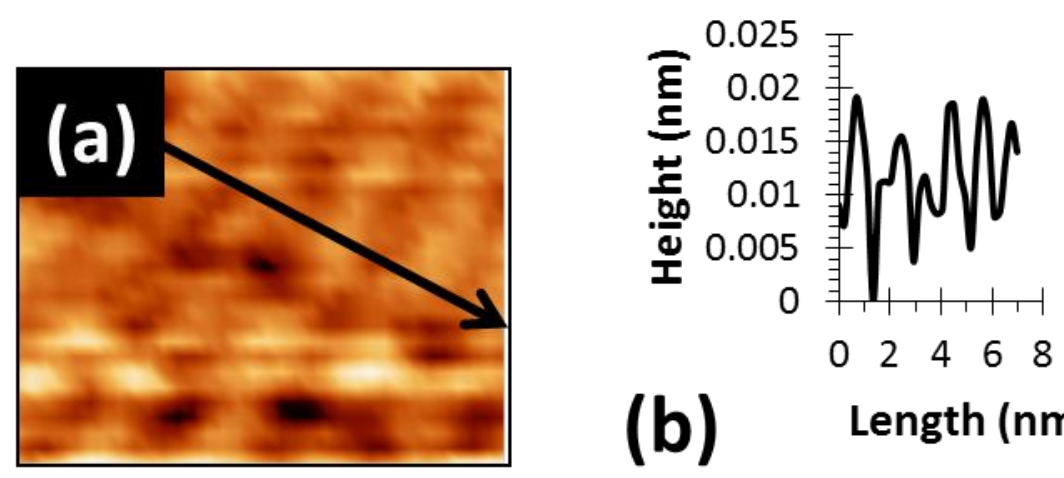

(b) Length $(\mathrm{nm})$
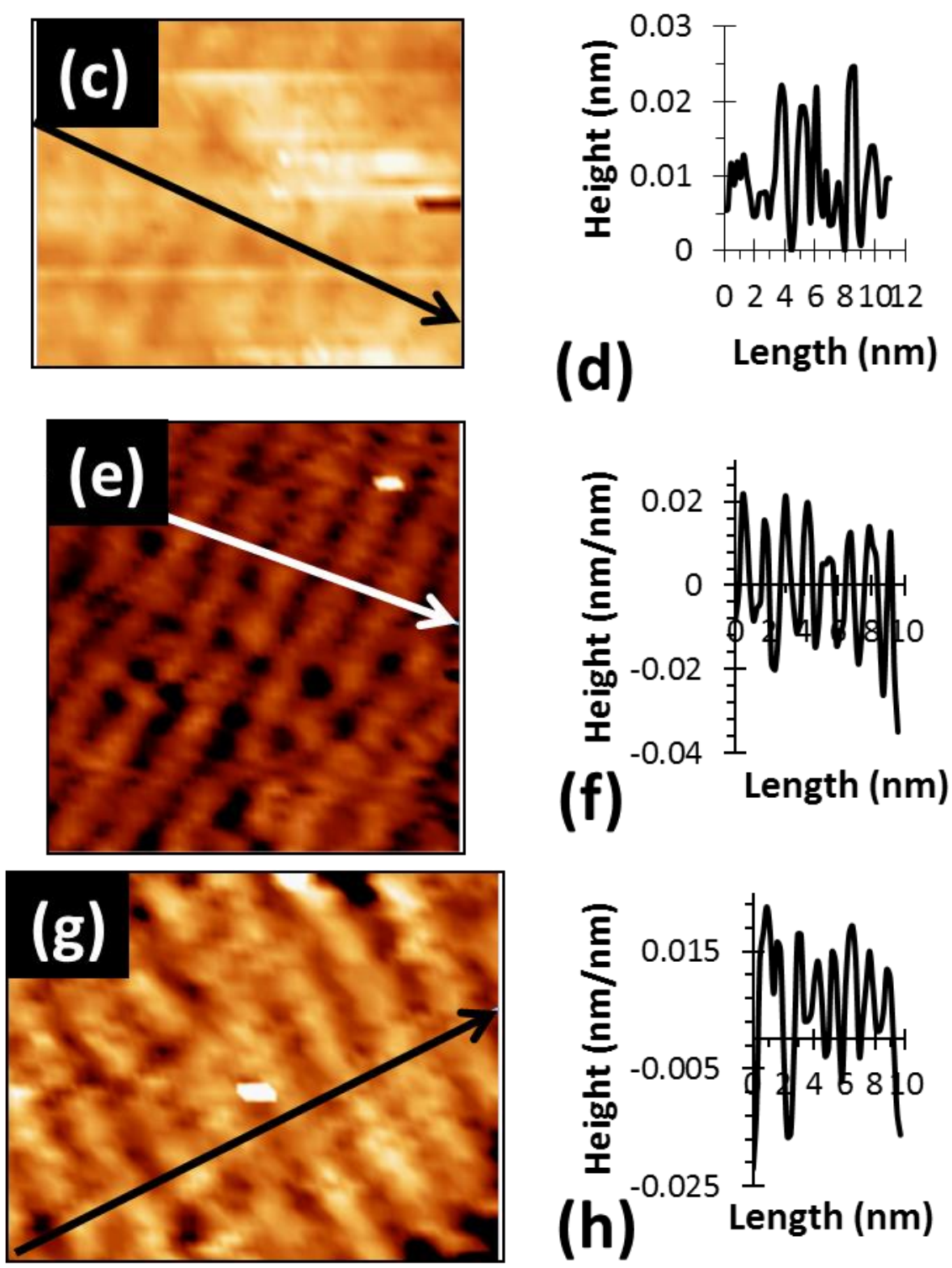

Figure 10 


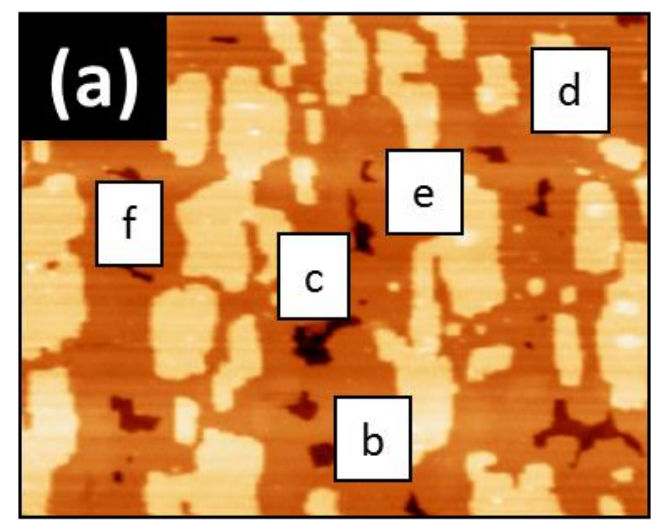

\section{(b)}

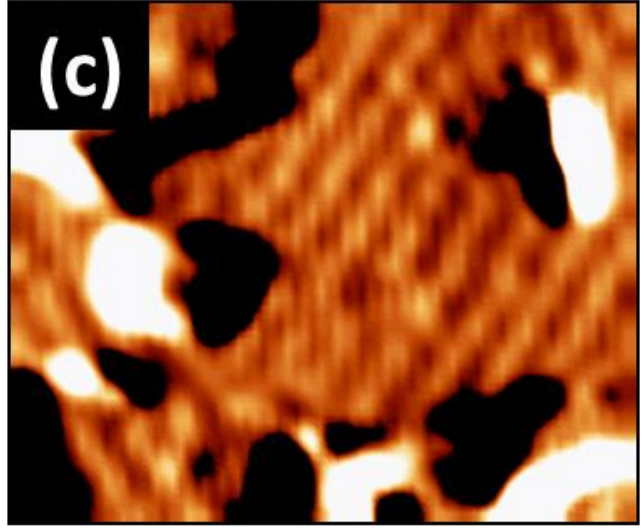
更

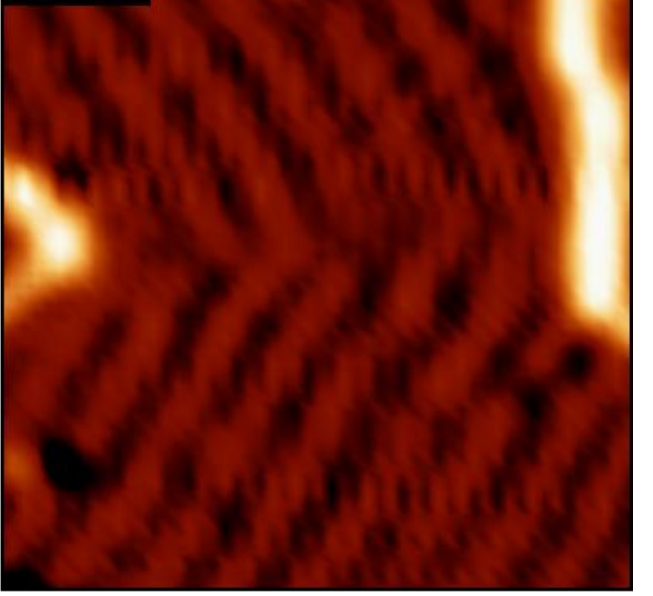

(d)
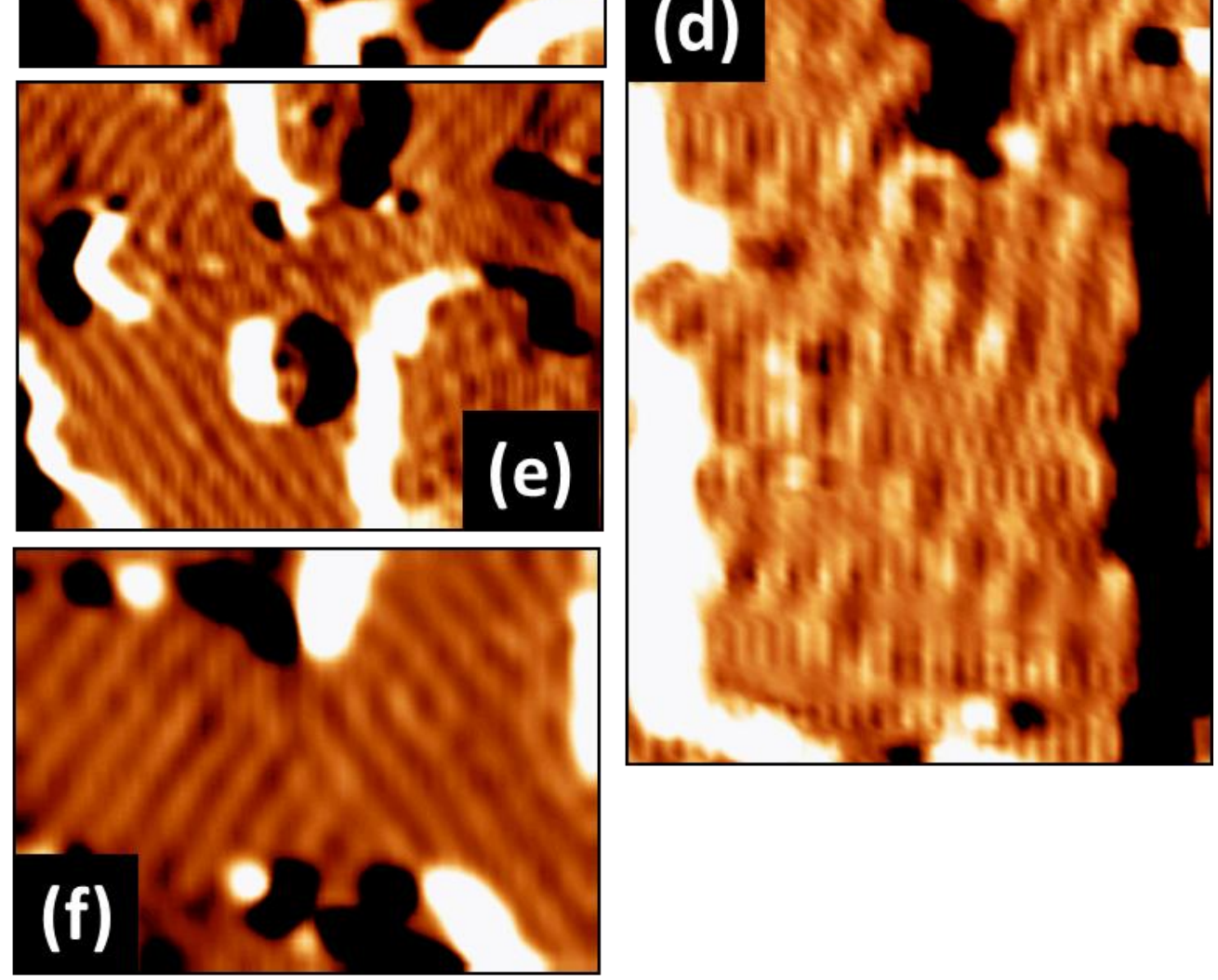

Figure 11 


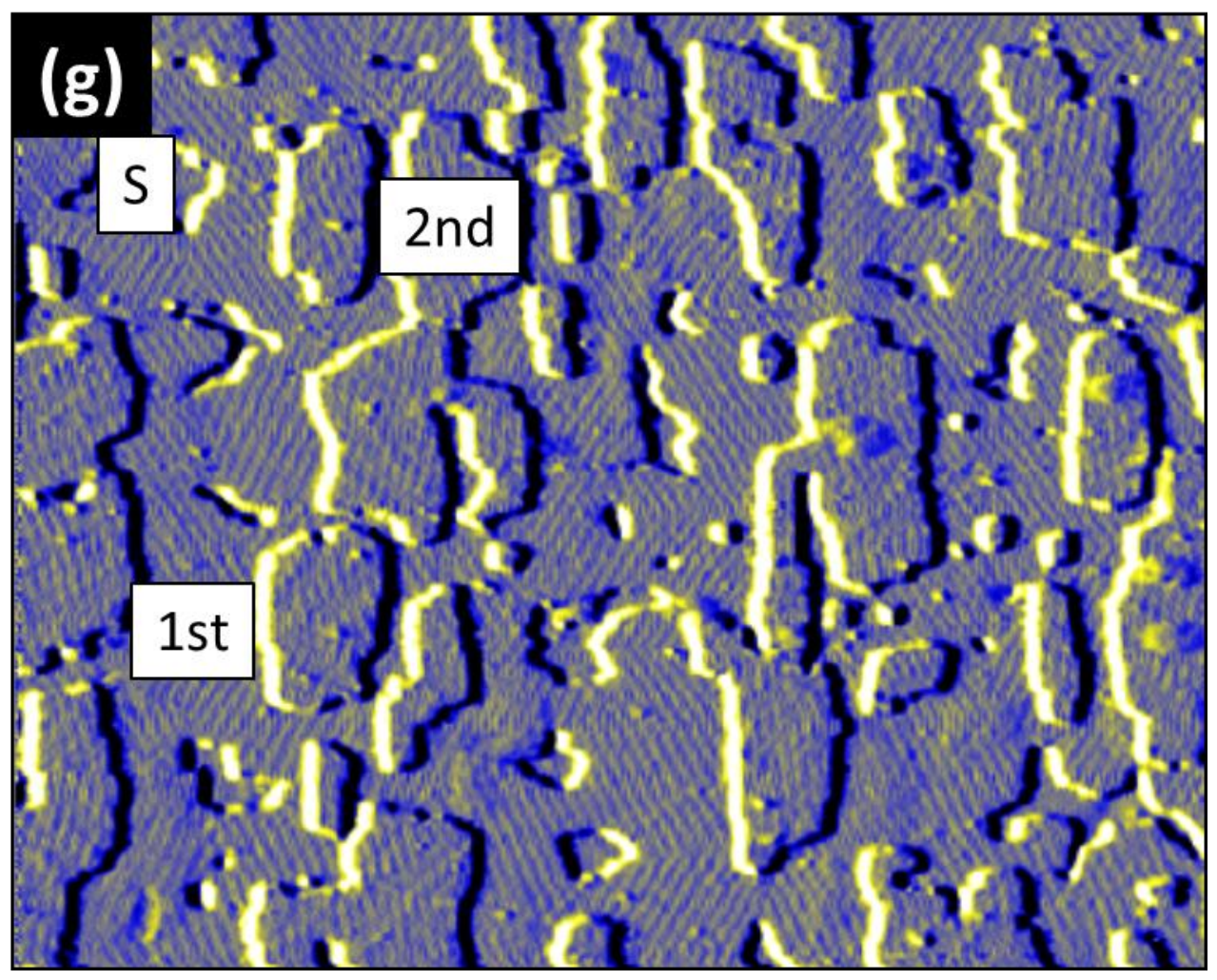

Figure 11 (Continue) 

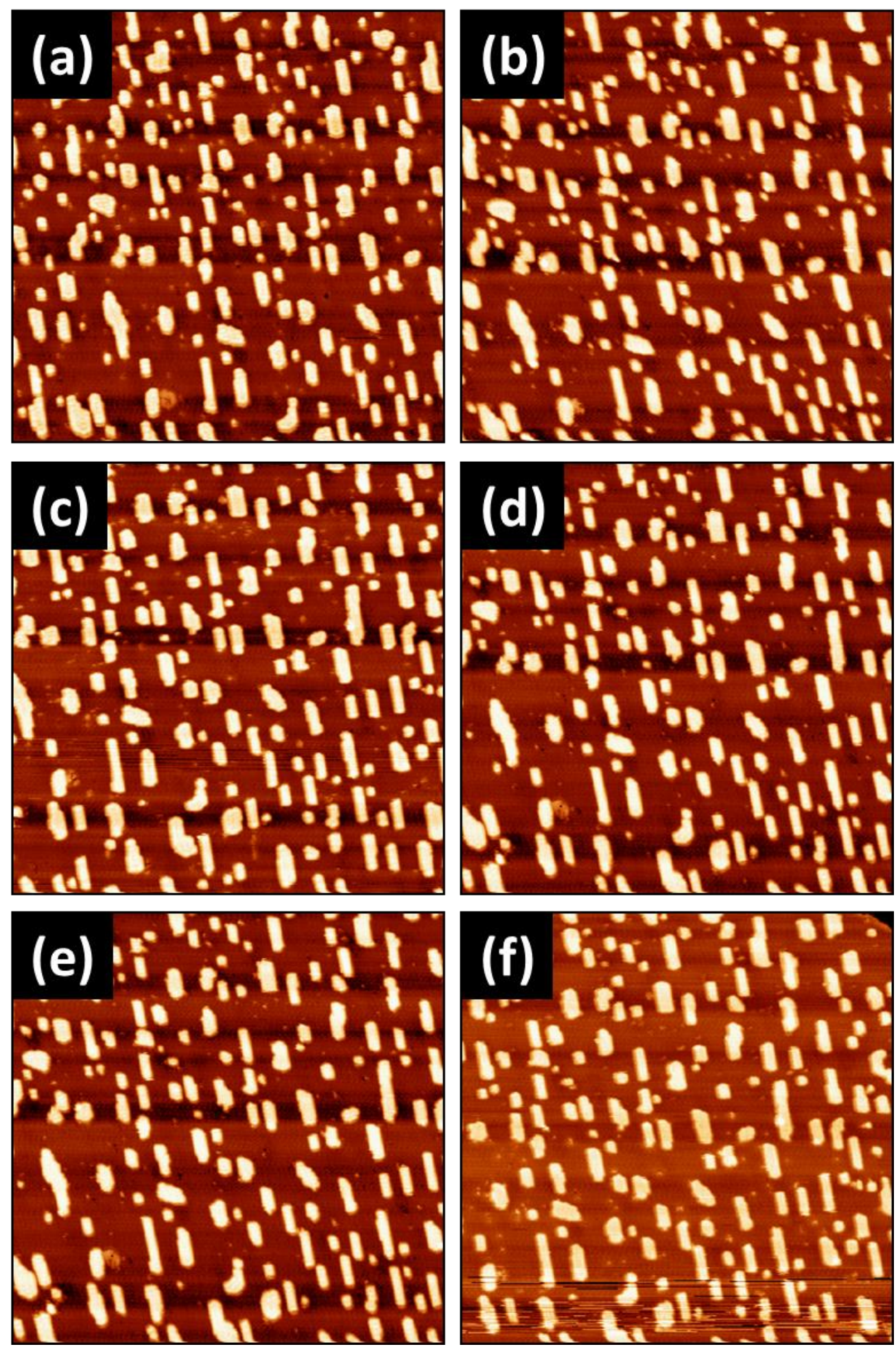

Figure 12 


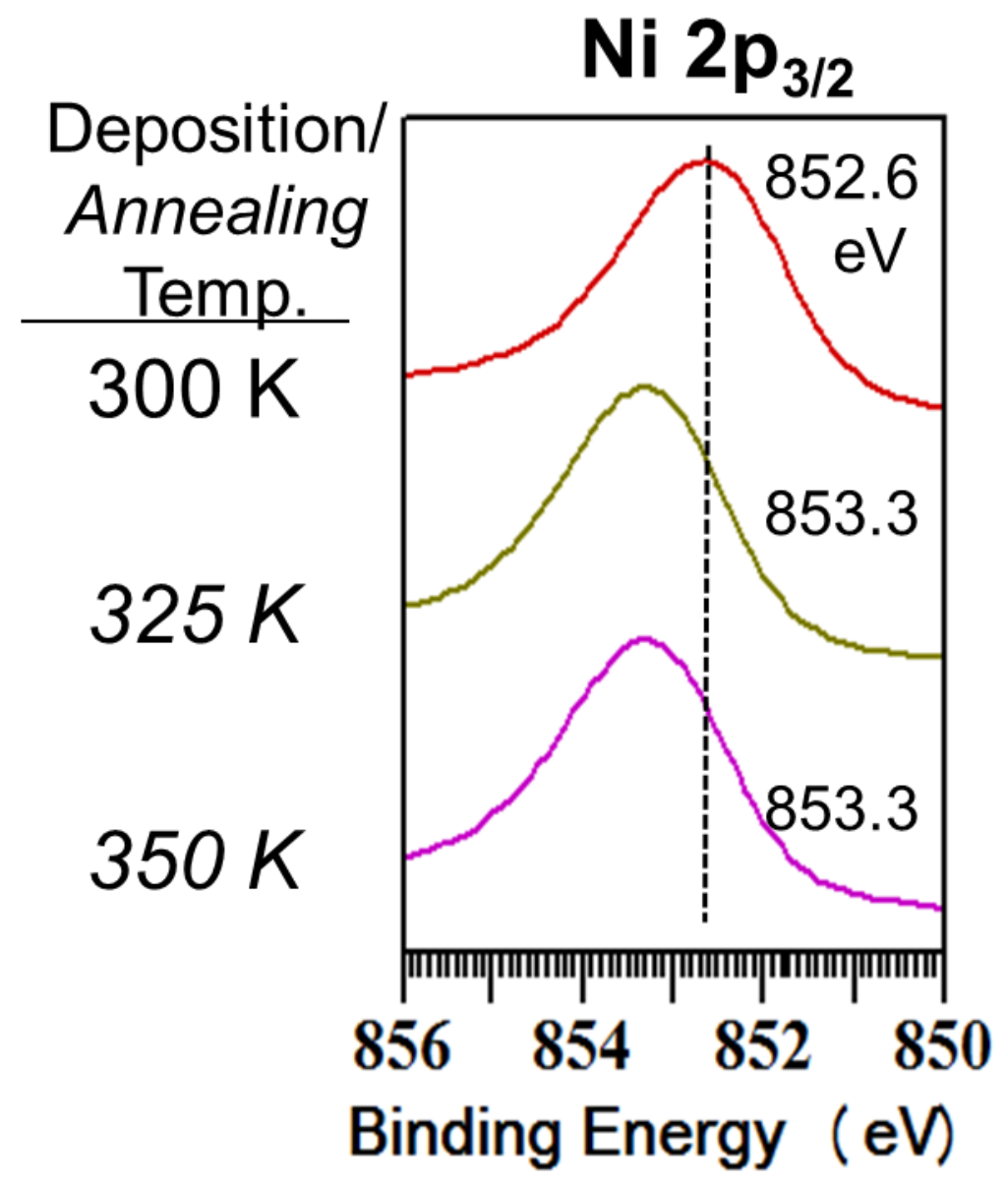

Figure 13 


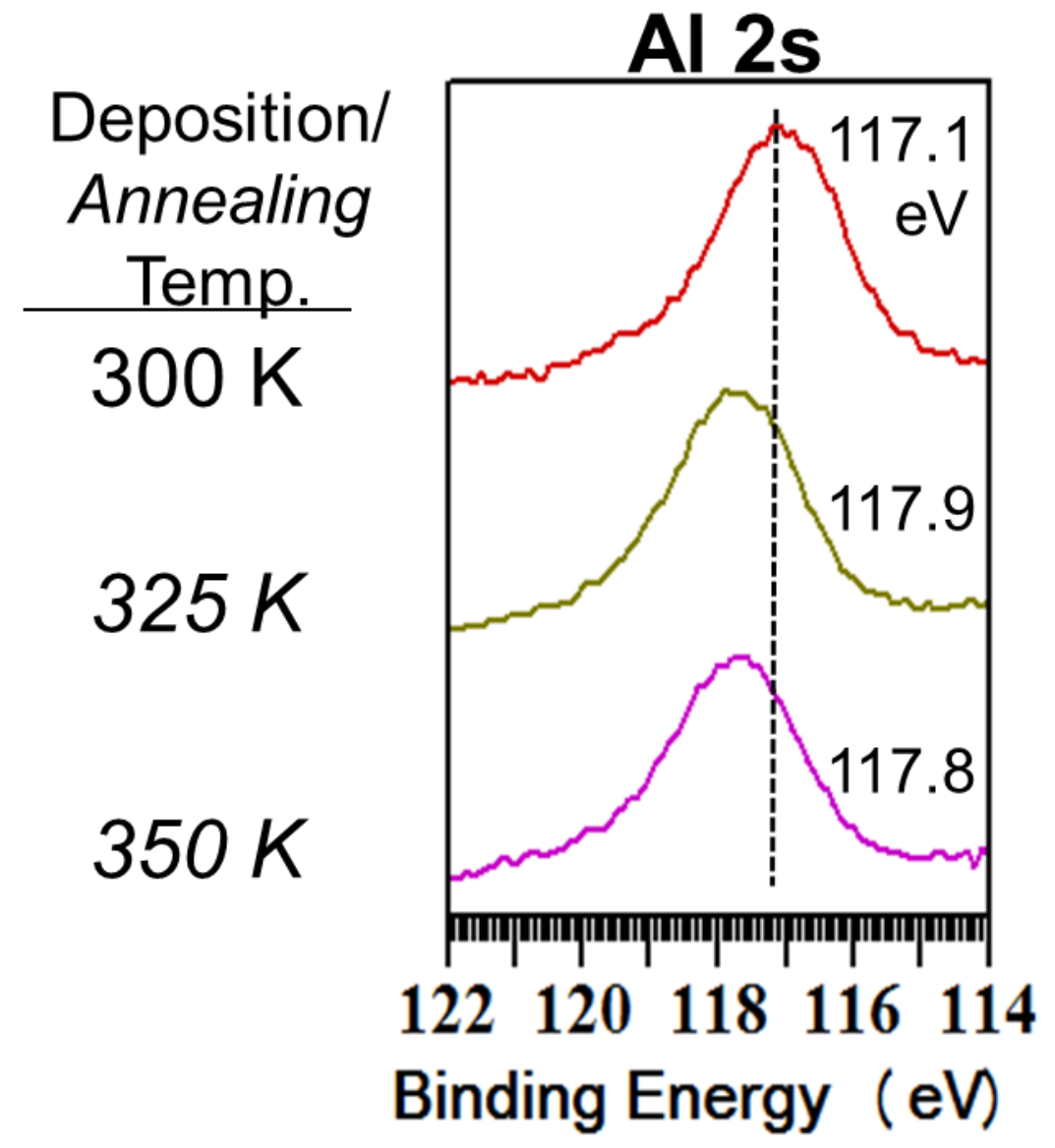

Figure 14 


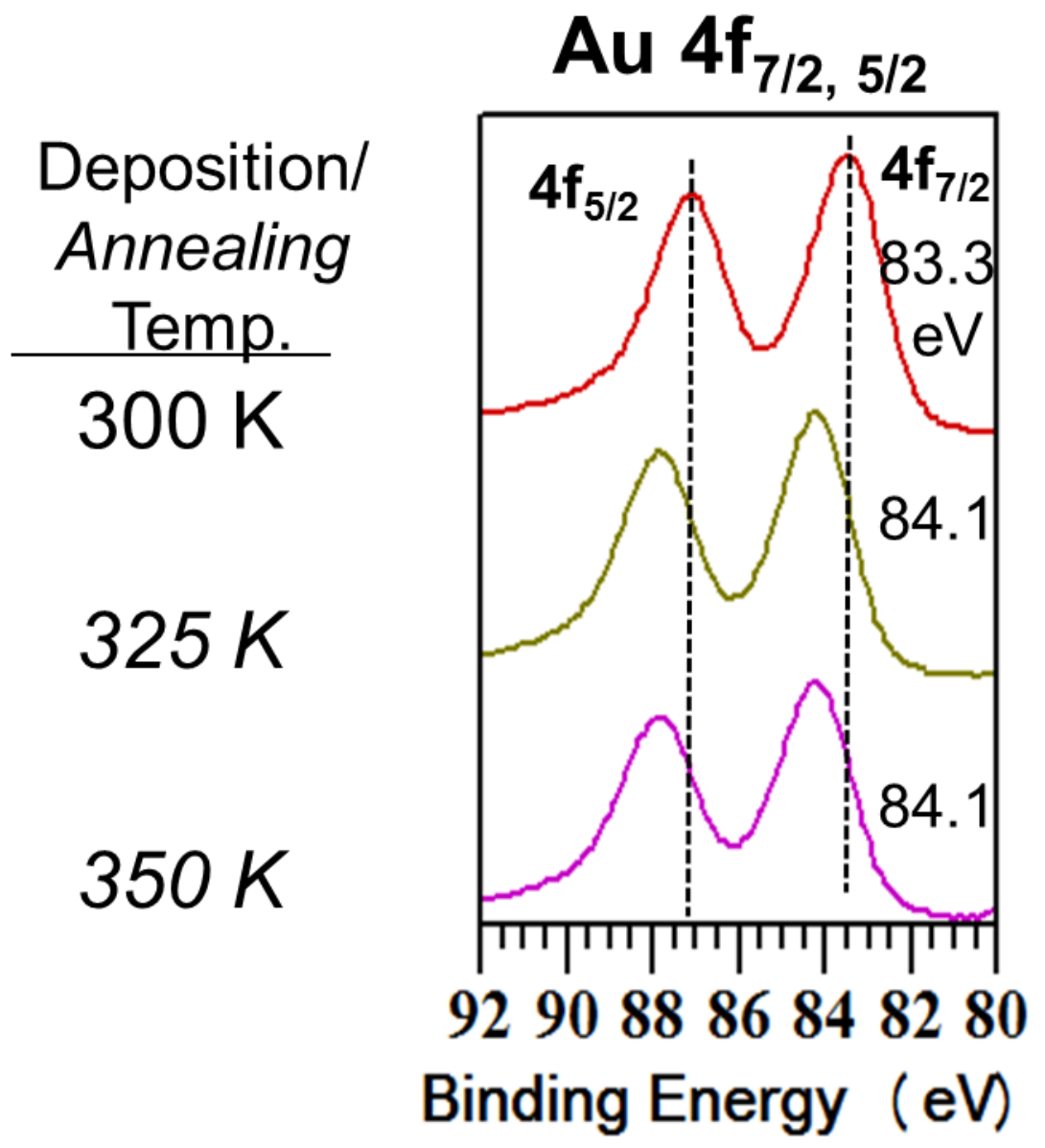

Figure 15 


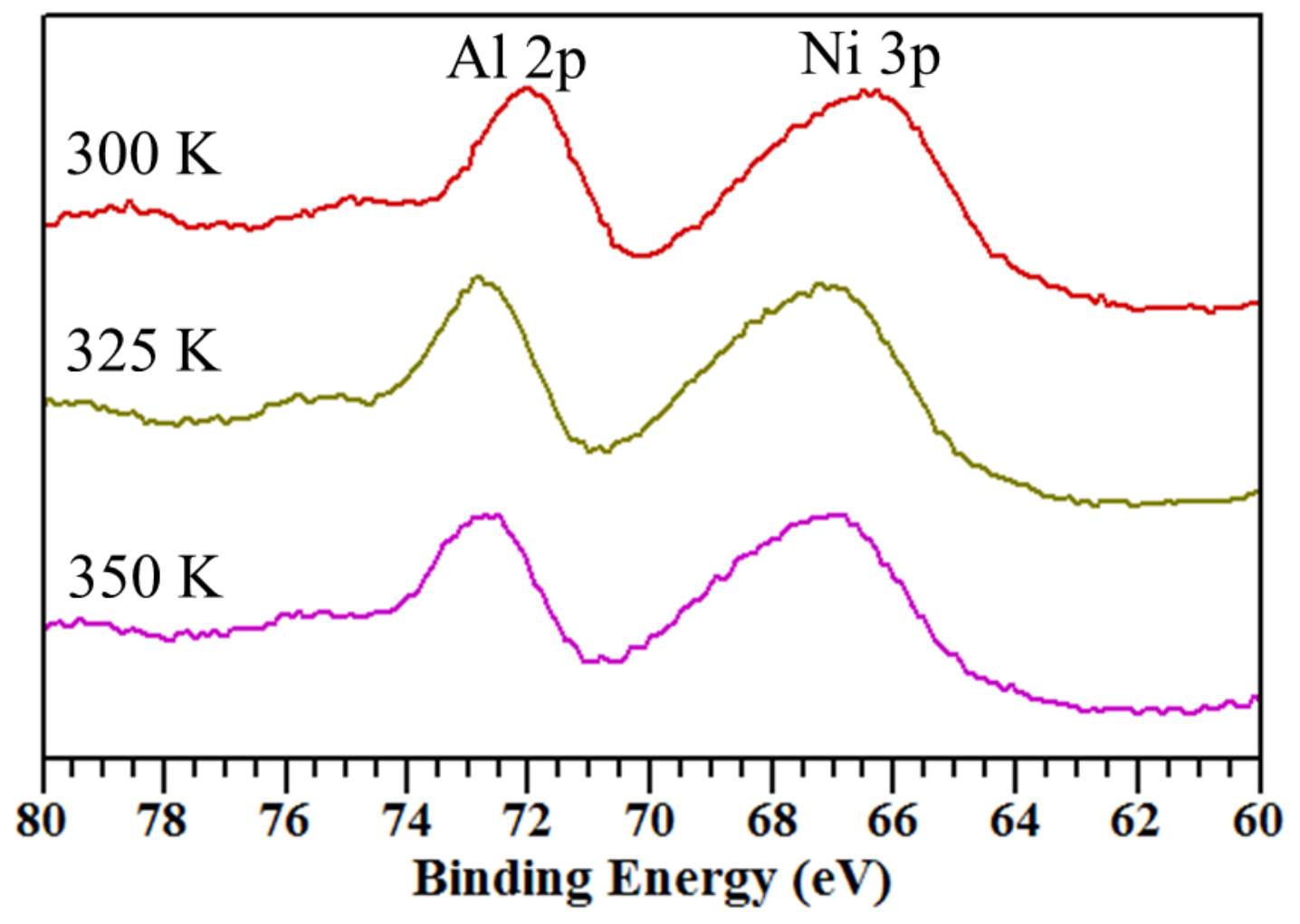

Figure 16 

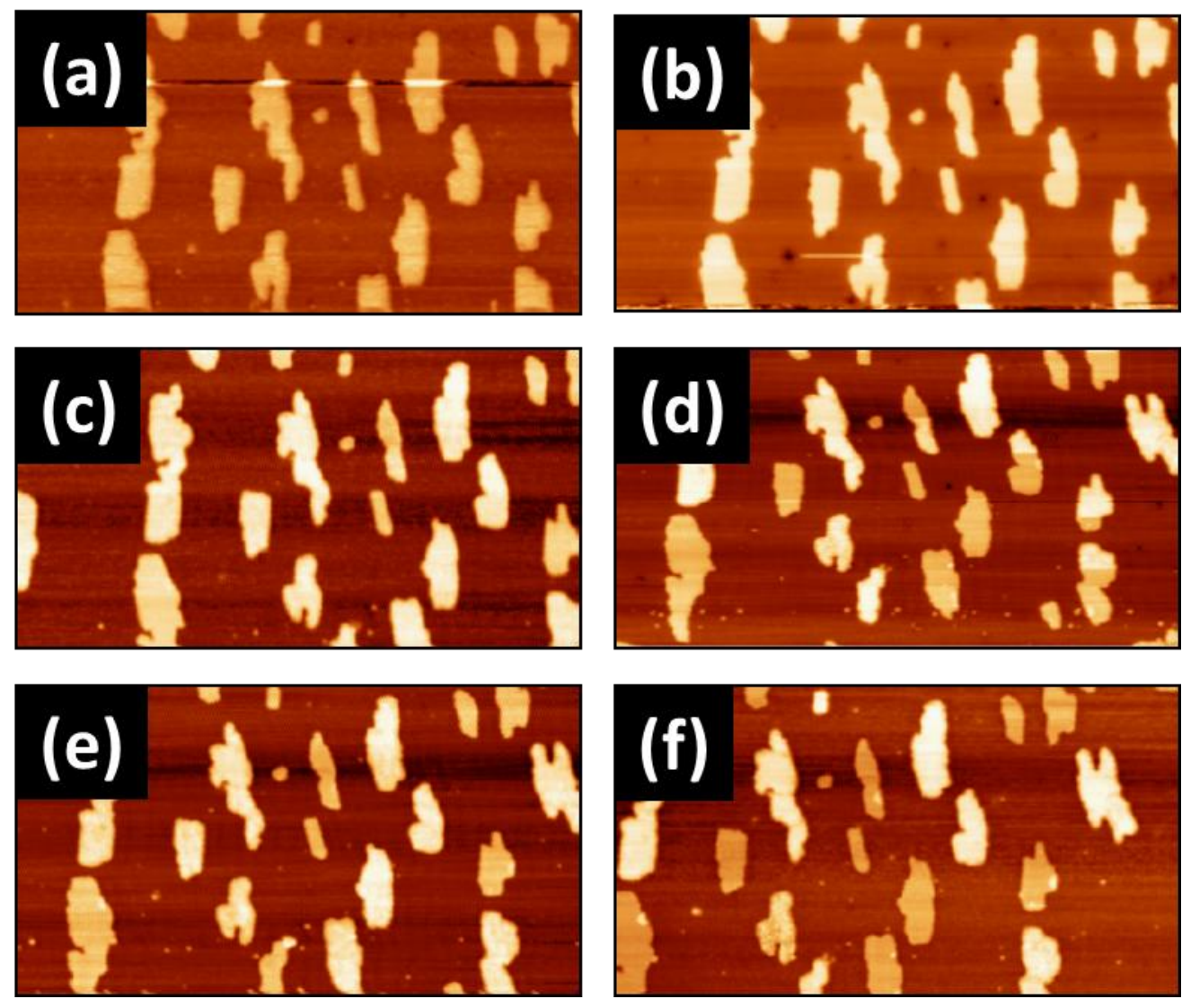

Figure 17 

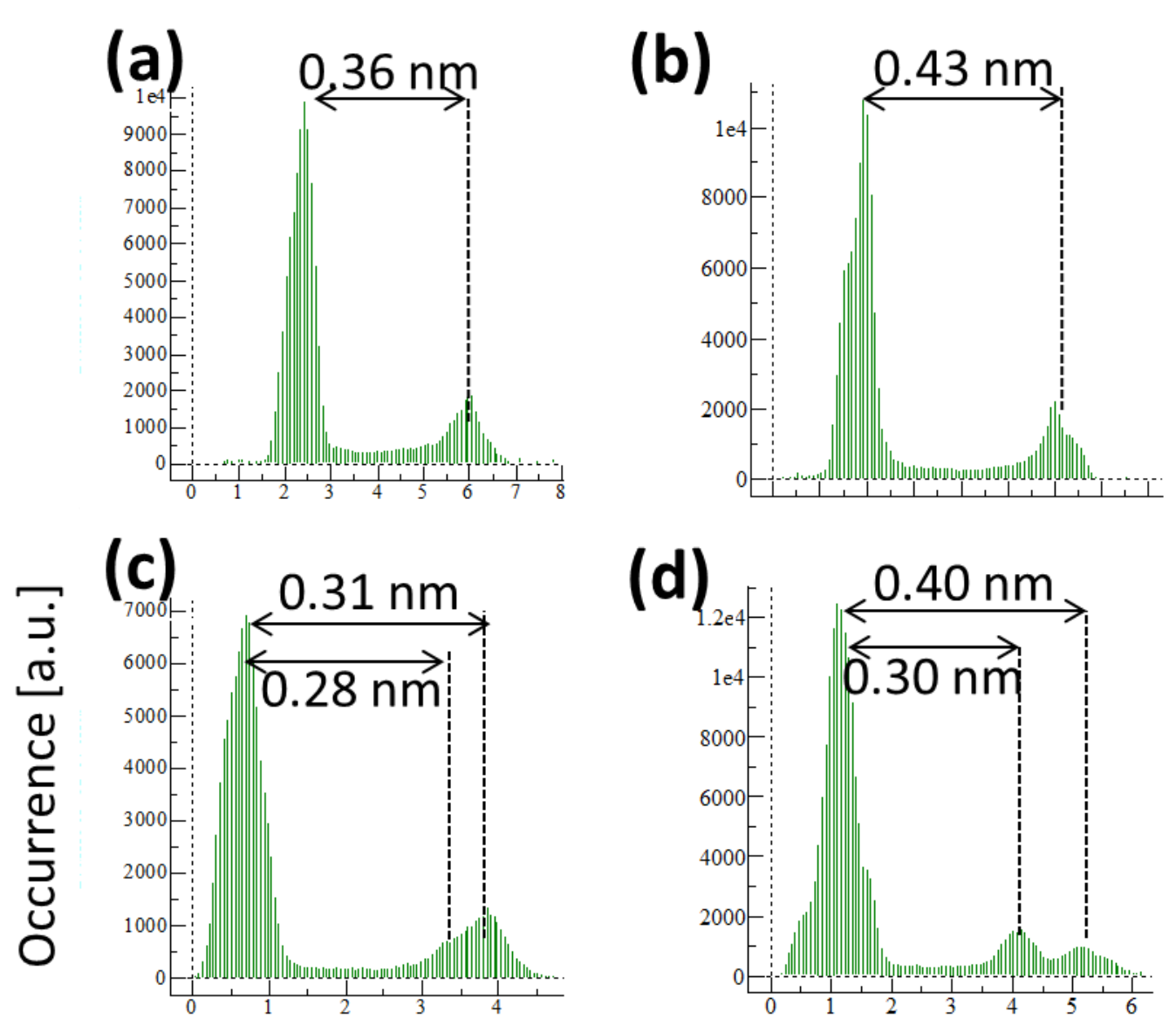

(d)
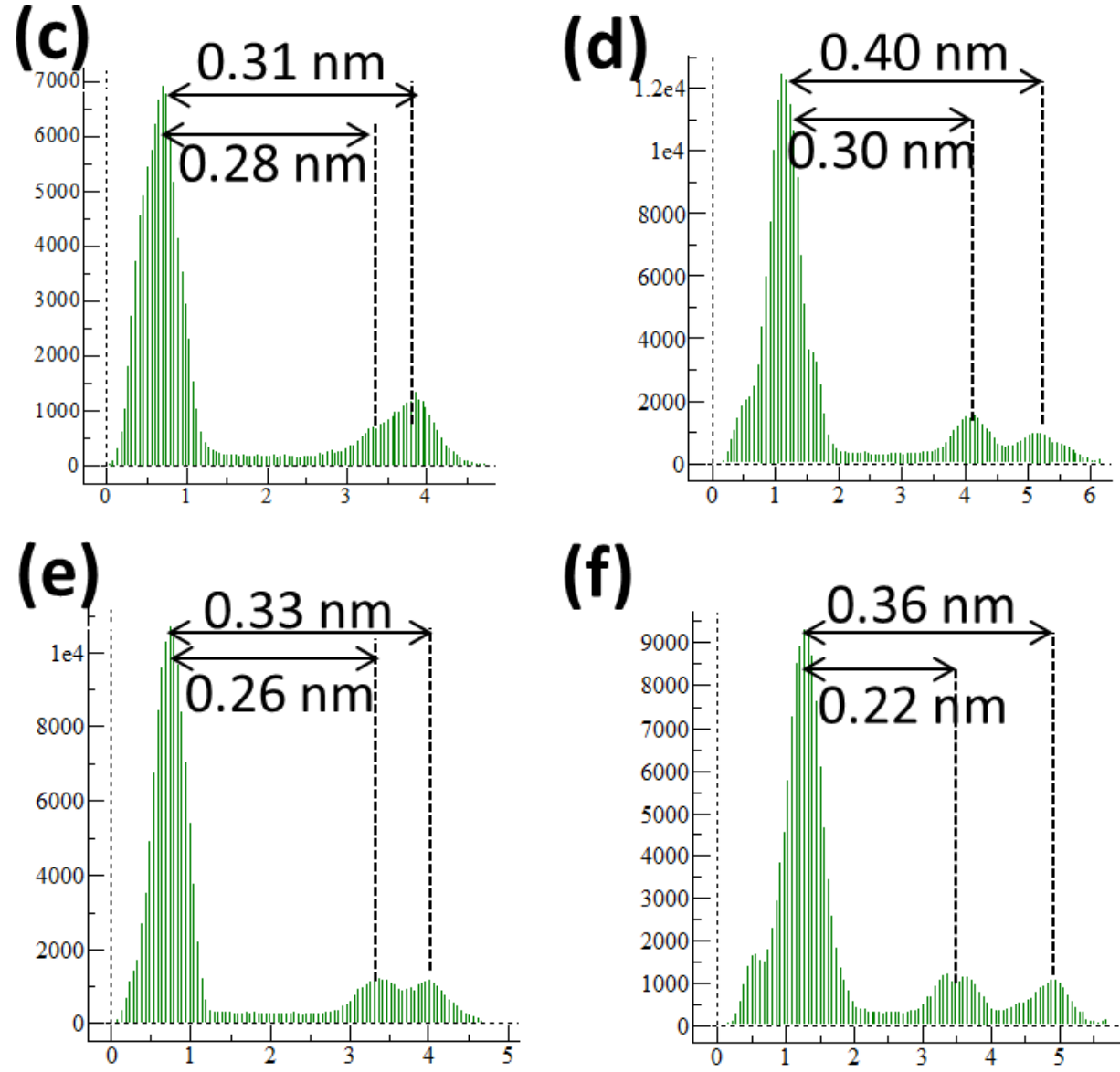

(f)

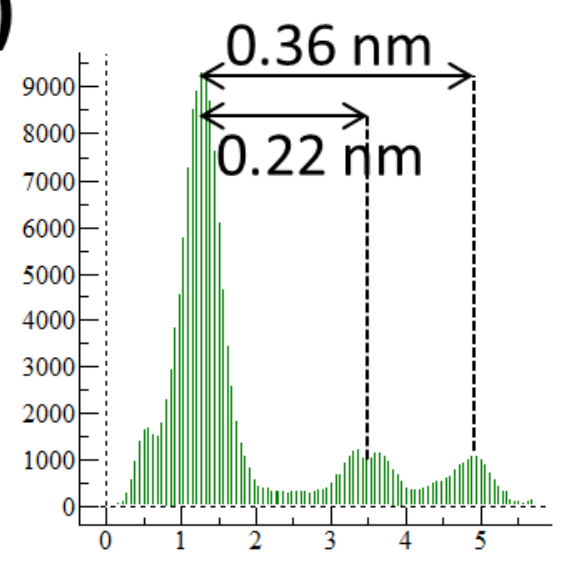

\section{Height [nm]}

Figure 18 


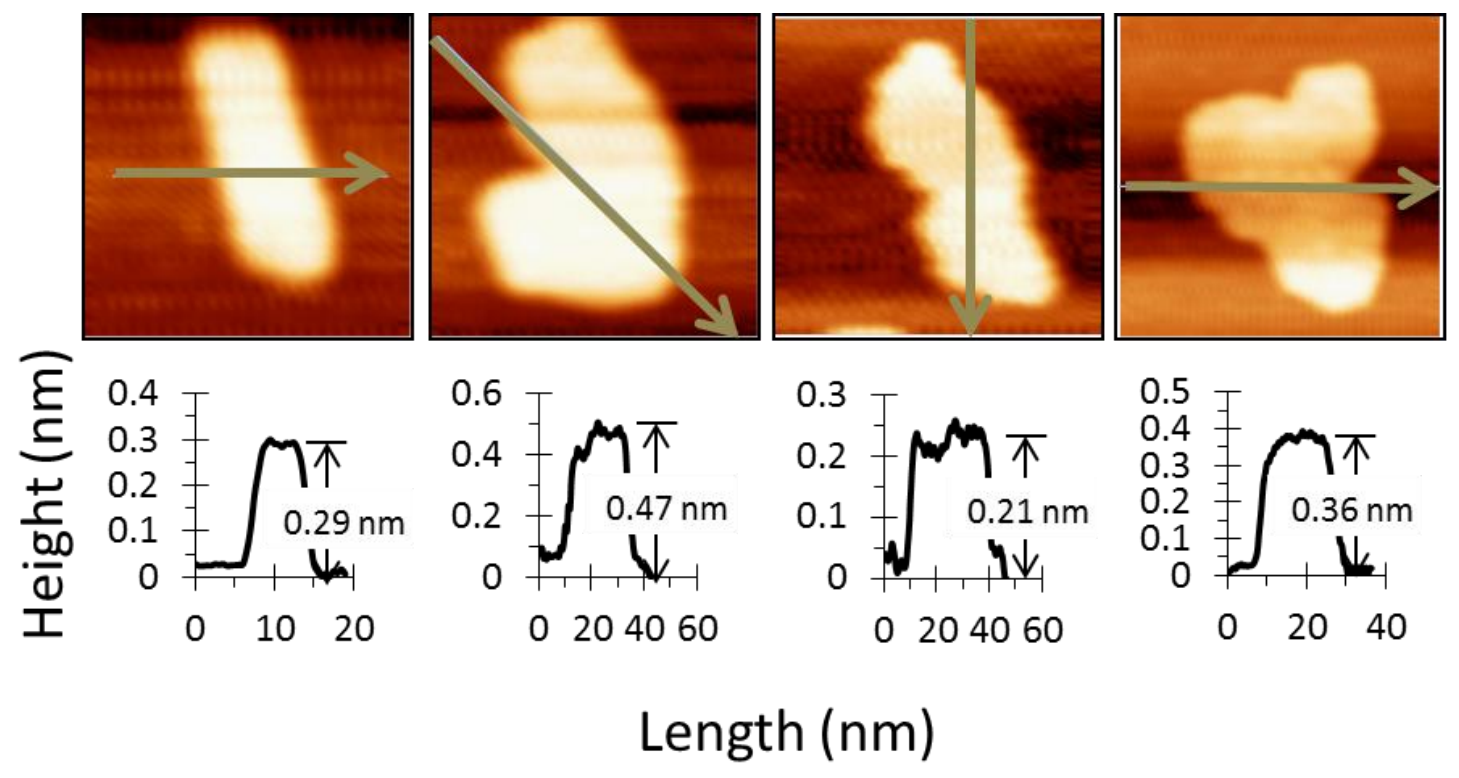

Figure 19 

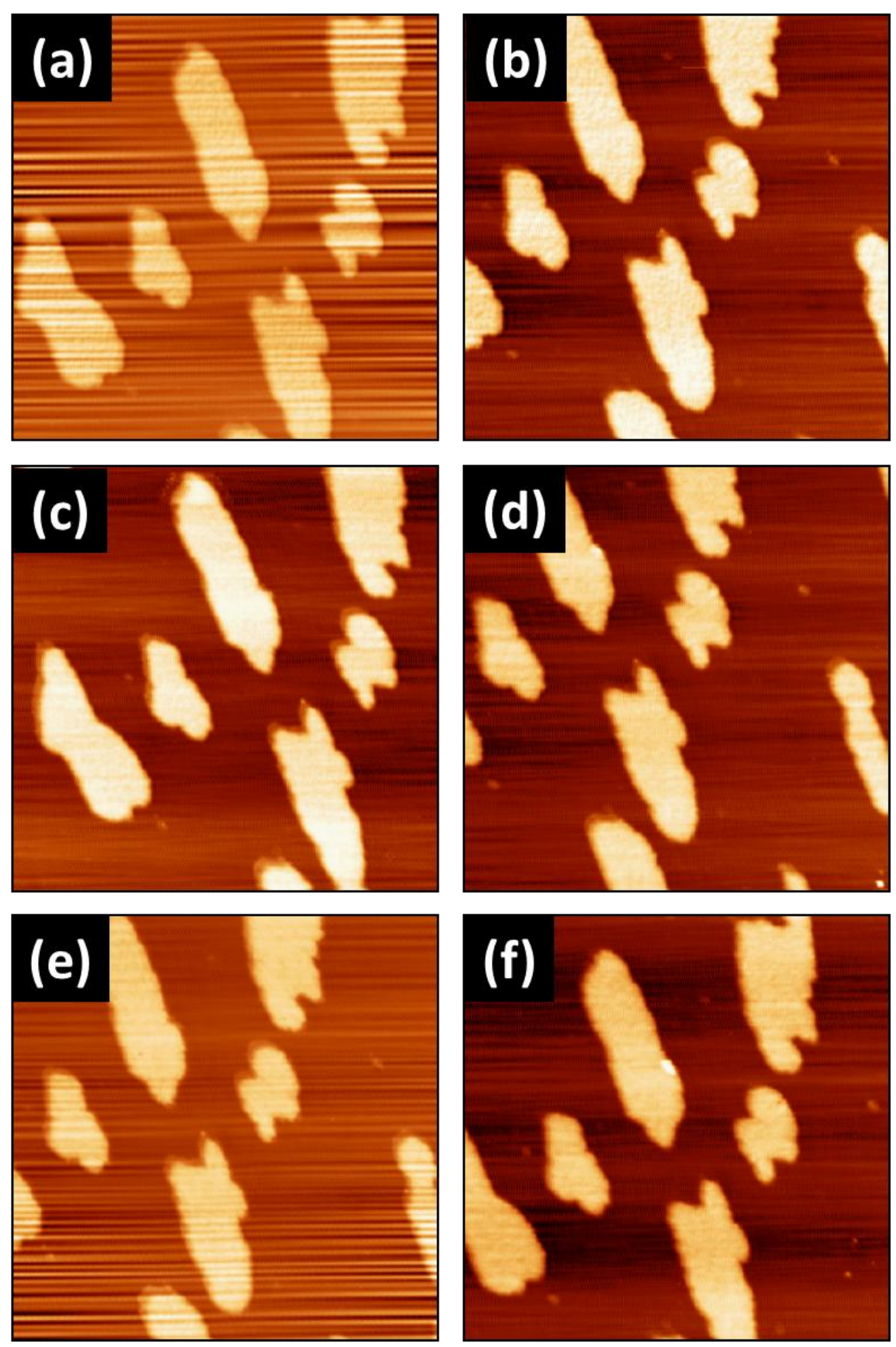

Figure 20 

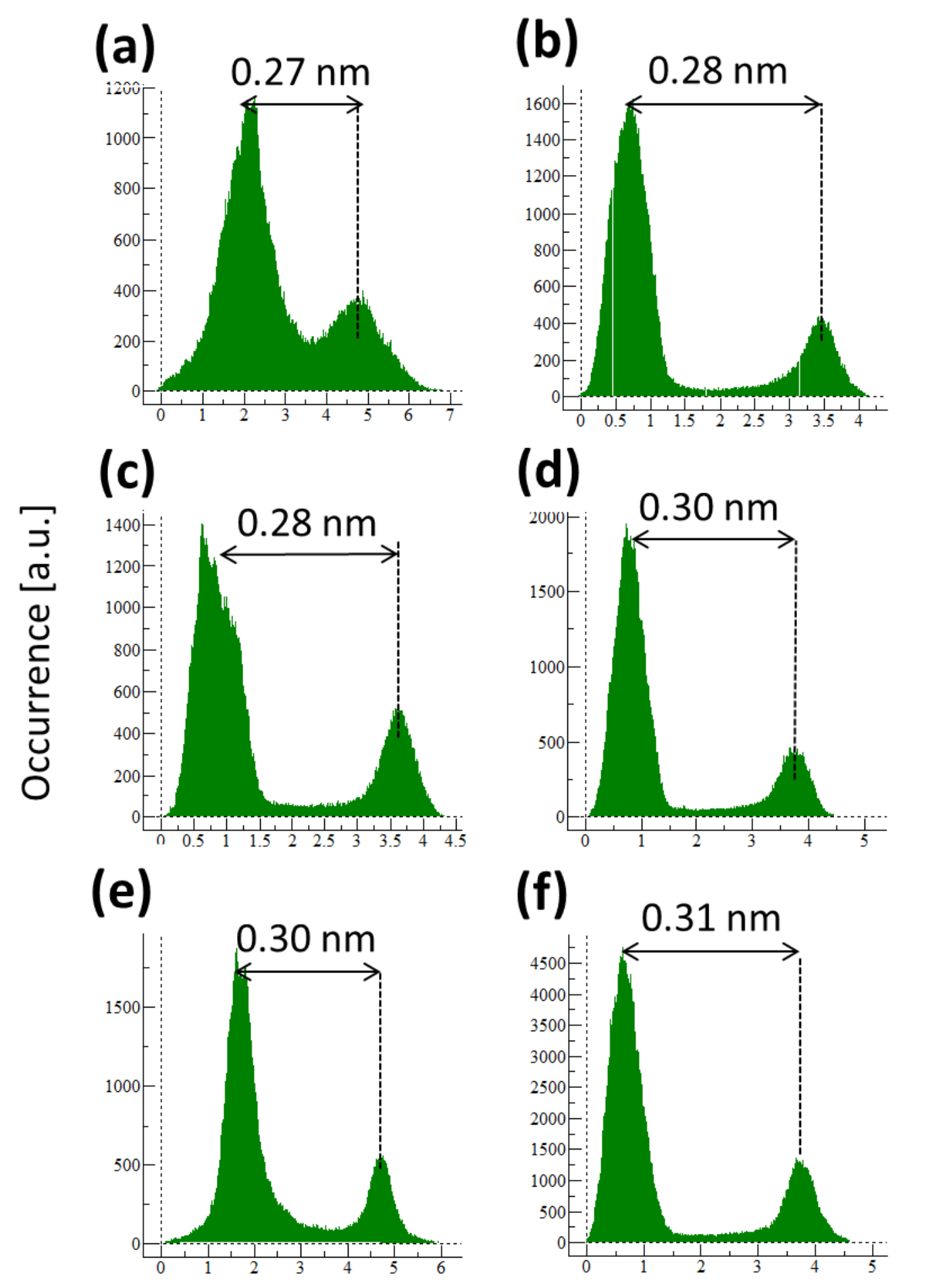

\section{Height [nm]}

Figure 21 

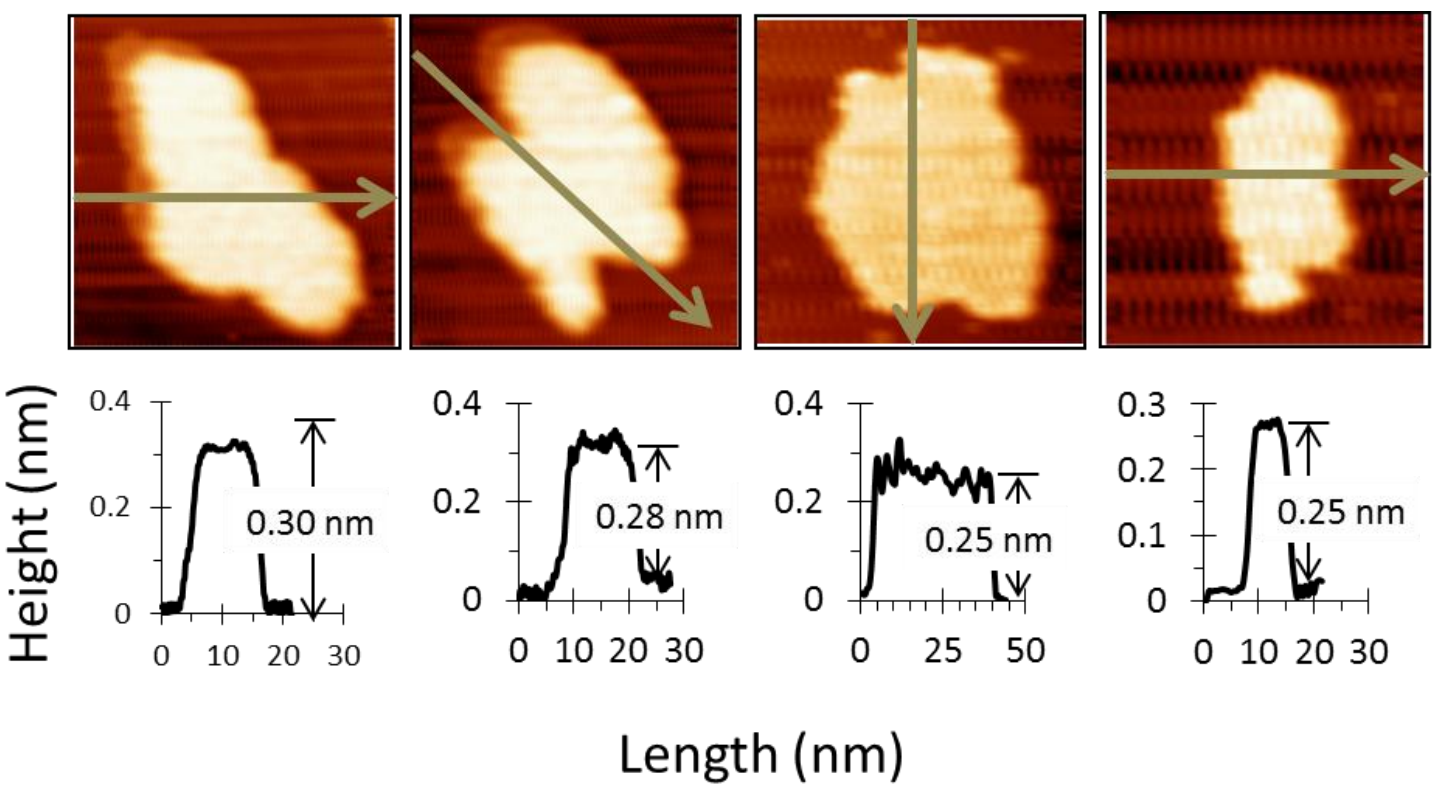

Length $(\mathrm{nm})$

Figure 22 


\title{
CHAPTER 6
}

\section{A Comparison of the Ag and Au Structures on NiAl(110) using XPD and STM}

\author{
Chad D. Yuen, ${ }^{1,2}$ Roland Widmer, ${ }^{4}$ Oliver Gröning, ${ }^{4}$ and Patricia A. Thiel ${ }^{1,2,3}$ \\ ${ }^{1}$ Ames Laboratory, Iowa State University, Ames, Iowa 50011 \\ ${ }^{2}$ Department of Chemistry, Iowa State University, Ames, Iowa 50011 \\ ${ }^{3}$ Department of Material Science and Engineering, Iowa State University, Ames, Iowa \\ 50011 \\ ${ }^{4}$ EMPA Materials Science and Technology, Ueberlandstrasse 129, CH-8600 Duebendorf, \\ Switzerland
}

\section{Introduction}

In Chapter 4, we introduced studies of $\mathrm{Au}$ and $\mathrm{Ag}$ overlayers on $\mathrm{NiAl}(110)$, reviewed some of our past work, and presented new results for $\mathrm{Au} / \mathrm{NiAl}(110)$ using STM and XPS. In this Chapter, we present a study of both systems in which the primary technique is X-ray photoelectron diffraction (XPD), which is a powerful technique for determining short-range atomic structure. Because this technique is not available in our laboratory, we established a collaboration with the group of Dr. Roland Widmer at EMPA in Switzerland. He and his co-workers are experts in this method and they have a well-equipped laboratory for XPD studies of surfaces.

X-ray photoelectron diffraction is similar to XPS in the sense that X-rays incident on the sample cause ejection of core electrons (these are the so-called photoelectrons). The difference is that in XPS, the object of analysis is the energy distribution of the photoelectrons within a narrow range of emission angles. In XPD, the object of analysis 
is the spatial distribution of the photoelectrons within a narrow window of kinetic energies, corresponding to electron emission from a specific element. The spatial distribution is inhomogeneous because the photoelectrons emitted from a single nucleus can be scattered by neighboring nuclei. When the emitted photoelectron interferes constructively with components of scattered photoelectron, diffraction conditions are met. As a result, emission from the surface is not isotropic. If the sample is single-crystal, then the emission pattern reflects local arrangements of scatterers of specific atomic identity. More details about the technique, and examples of its use in surface science, are given in a review by Woodruff and Bradshaw [1].

Our goal is to study and compare the first few monolayers of $\mathrm{Ag}$ and $\mathrm{Au}$ on $\mathrm{NiAl}$ (110) using XPD. Certain candidate structures were identified in past work from our group. We use single scattering cluster (SSC) calculations to generate model XPD patterns expected from these candidate structures of $\mathrm{Ag}$ and $\mathrm{Au}$ on $\mathrm{NiAl}(110)$, and we compare these models to our XPD results. In addition, the XPD experiments are supplemented by some XPS, STM, and low-energy electron diffraction (LEED) experiments that were performed concurrently in Dr. Widmer's laboratory.

\section{$\underline{\text { 2. Experimental Details }}$}

The XPS/XPD, STM, and LEED experiments were carried out in an Omicron ESCA ultra-high vacuum (UHV) chamber. This chamber consisted of two parts: a preparation chamber and an analysis chamber. The preparation chamber was equipped with a sputter plasma gun, room temperature STM/AFM, and rear-view LEED optics. 
The analysis chamber was equipped with a VSW 125 HR electron analyzer, and an x-ray source ( $\mathrm{Al} \mathrm{K} \alpha$ ). The $\mathrm{X}$-ray source was perpendicular to the sample plate. The base pressures of the preparation chamber and the analysis chamber were below $1 \times 10^{-9} \mathrm{mbar}$ and $1 \times 10^{-10} \mathrm{mbar}$, respectively.

The $\operatorname{NiAl}(110)$ was cleaned via $\mathrm{Ar}^{+}$sputtering and annealing. For sputtering, the plasma source was operated at pressures of $6 \times 10^{-6} \mathrm{mbar}$ to $8 \times 10^{-6} \mathrm{mbar}$. The emission current was $5 \mathrm{~mA}$ and the accelerating voltage was $1 \mathrm{kV}$. The sputtering time was 5 to 15 minutes. The sample was heated via an electron beam. For annealing, the sample was held for 1 to 3 hours at $1200 \mathrm{~K}$.

$\mathrm{Ag}$ and $\mathrm{Au}$ were deposited from a homemade two-pocket multi-evaporator, one for $\mathrm{Ag}$ and one for $\mathrm{Au}$. Each pocket contained a W filament that had been formed into a spiral. The ends of the $\mathrm{W}$ wire were connected to copper feedthroughs. Ag or Au wires were placed into the middle of the spiral $\mathrm{W}$ filament. The evaporator was heated resistively.

All metal depositions were performed with the sample at room temperature. Between each deposition, the sample was cleaned by sputtering and annealing. In other words, no sequential depositions were performed.

In most cases, metal coverages were determined by flooding the STM images. In the case of $\mathrm{Ag}$, islands often were attached to $\mathrm{NiAl}$ step edges, so the entire image could not be flooded. Instead, we zoomed in on individual islands and measured their areas. The fractional surface area covered by metal islands was reported in units of bilayers (BL). (Note that a unit of $1 \mathrm{BL}$ here is chosen to be consistent with the units used in Ref. [2], and also with some of the structural models. In describing the experimental data, it 
has the same meaning as the unit of monolayer used in other chapters, i.e., fractional surface coverage.) In one case (noted in the text), coverage was determined by comparing integrated XPS peak intensities.

In XPS and XPD, we used the photoelectron peaks of the $\mathrm{Ni} 3 \mathrm{p}_{3 / 2}, \mathrm{Al} 2 \mathrm{~s}_{1 / 2}, \mathrm{Ag}$ $3 \mathrm{~d}_{5 / 2}$, and $\mathrm{Au} 4 \mathrm{f}_{7 / 2}$ because they were most intense. XPS data were acquired by taking a survey spectrum from $0 \mathrm{eV}$ to $1210 \mathrm{eV}$, followed by closer examination of individual peaks in narrower energy ranges: $\mathrm{Ni} 3 \mathrm{p}_{3 / 2}$ at $60 \mathrm{eV}-72 \mathrm{eV} ; \mathrm{Al} 2 \mathrm{~s}_{1 / 2}$ at $110 \mathrm{eV}-125 \mathrm{eV}$; $\operatorname{Ag~} 3 \mathrm{~d}_{5 / 2}$ at $362 \mathrm{eV}-378 \mathrm{eV}$; and $\mathrm{Au} 4 \mathrm{f}_{7 / 2}$ at $75 \mathrm{eV}-95 \mathrm{eV}$. XPD data were measured by collecting core-level photoelectron intensities over a dense grid of polar emission angles $(\theta)$ from grazing emission $\left(90^{\circ}\right)$ to normal emission $\left(0^{\circ}\right)$, and over the full $360^{\circ}$ azimuthal angle $(\varphi)$ range.

In the XPD patterns reported in this paper, the grazing emission intensities (displayed near the edges of the outer ring) represent photoelectrons emitted nearly parallel to the surface plane. Intensities near the center of the ring represent photoelectrons emitted along the surface normal. The photoelectron intensity was displayed in a linear black-and-white scale where white corresponded to maximum intensity.

All experimental data were acquired while the sample was at room temperature. 


\section{Experimental Results: Ag on NiAl(110)}

3.1 STM, XPD, and LEED for Ag on NiAl(110)

After the surface was introduced from air, we performed cleaning cycles as described in Section 2, and checked with STM to determine when a step-terrace structure began to emerge. This structure became visible after about 12 cleaning cycles. Representative STM images of the clean surface are shown in Fig. 1. Terraces are about $100 \mathrm{~nm}$ wide.

At this point, we began to deposit Ag. STM images and XPD patterns for different Ag coverages are shown in Fig. 2. The STM images in Fig. AGXPD were all acquired before the XPD measurements. In STM, long rectangular islands of Ag can be identified on the surface. They grow outward from step edges. These features are quite similar to those reported by Ünal et al. [2].

In Fig. 2(a), the Ag coverage is $0.65 \pm 0.03$ BL. No Ag XPD pattern is seen, as shown in Fig. 2(b). It is likely that this coverage of $\mathrm{Ag}$ is insufficient to generate a $\mathrm{Ag}$ XPD pattern.

At a slightly higher coverage, $0.77 \pm 0.09 \mathrm{BL}$ of $\mathrm{Ag}$, an almond-shaped XPD pattern begins to emerge, as shown in Fig. 2(d). It is even clearer at higher coverage, 1.2 $\pm 0.1 \mathrm{BL}$ total coverage, as shown in Fig. 2(e). Though the XPD pattern is stronger, it does not appear to contain any different features. Note especially that there are several strong features near normal emission.

LEED patterns were also recorded right after the 1.2 BL deposition. These are shown in Fig. 3, for incident electron energies from $60 \mathrm{eV}$ to $200 \mathrm{eV}$. The patterns in Fig. 
3 have rectangular symmetry as would be expected for both $\operatorname{Ag}(110)$ and $\mathrm{NiAl}(110)$. These results are consistent with the LEED results of Jing et al. for $\mathrm{Ag}$ on $\mathrm{NiAl}(110)$, which showed no change in the symmetry or number of diffraction spots in the diffraction pattern when low coverages of $\mathrm{Ag}$ were deposited on $\mathrm{NiAl}(110)$ [3].

Lastly, we deposited 5 BL of Ag. (In this case, the coverage was determined by comparing the integrated XPS Ag $3 \mathrm{~d}_{5 / 2}$ peak with that from $1.2 \mathrm{BL}$, where coverage had been established via STM.) The XPD pattern is shown in Fig. 2(g). Although weaker than at 1.2 BL, it shows the same features as the Ag XPD patterns in Fig. 2(d) and 2(f) at lower Ag coverages. No STM images or LEED patterns are available at this coverage of Ag.

Additional information from STM is available. In one experiment, we measured STM both before and after XPD, to see if XPD had any effect on the surface. Fig. 4(a) shows an STM image before XPD, at $0.65 \mathrm{BL}$ of $\mathrm{Ag}$. This image is taken from the same experiment as in Fig. 2(a). Fig. 4(b) shows a line profile across a Ag island, corresponding to the black arrowhead in Fig. 4(a). Based on the line profile, the island height is $0.34 \mathrm{~nm}$, in agreement with the prior results [2].

An STM image of this same surface after XPD is shown in Fig. 4(c), where one can see small pits on the $\mathrm{Ag}$ islands. In addition, there are many protrusions or bumps on the substrate. Fig. 4(d) shows a line profile across a Ag island, corresponding to the black arrowhead in Fig. 4(c). The island height is now $0.38 \mathrm{~nm}$. Overall, it appears that the Ag islands remain intact but suffer minor damage from XPD. It is well known that techniques such as XPS often produce low levels of surface contamination that are 
detectable in STM, so the changes between Fig. 4(a) and Fig. 4(c) are likely due to contamination.

In addition, STM can provide information on the fine structure in the islands at high magnification. For that purpose, high-magnification STM images were also taken in the same experiment as in Fig. 2(a), at a coverage of 0.65 BL. These images are shown in Fig. 5. There are diagonal stripes or rows across the Ag islands. In Fig. 5(e), there are two types of distances between rows which are labeled DL (long) and DS (short). These two distances alternate. DL and DS have values of $1.30 \pm 0.10 \mathrm{~nm}$ and $0.60 \pm 0.07 \mathrm{~nm}$, respectively. The total distance (D), which combines DL and DS, is $1.95 \pm 0.06 \mathrm{~nm}$. These results are not too different from those of Ünal et al., [2; 4] where DL, DS, and D were $1.2 \mathrm{~nm}, 0.8 \mathrm{~nm}$, and $2.0 \mathrm{~nm}$, respectively, and the lengths also alternated.

\subsection{Comparing SSC Models with XPD Patterns for Ag on NiAl(110)}

Our collaborators, Dr. Yong Han and Prof. Jim Evans, earlier found a number of possible stable structures for $\mathrm{Ag}$ on $\mathrm{NiAl}(110)$ that are reasonbly close in energy, based on Density Functional Theory (DFT). The seven SSC models and there real structures are shown in Fig. 6 and Fig. 7, respectively. We will call these seven the 1BL, 2BL, and 3BL fcc (110) structures, the (2x1) rippled structure, the square - hex structure, the $(3 \times 1)$ rippled structure, and the square - square - hex structure. More information on these structures can be found in Ref. [5]. SSC calculations were done on these structures and the results are shown in Fig. 6.

It is noteworthy that some of the SSC models do not have any spots in the center of the pattern, corresponding to near-normal emission. For example, in Fig. 6, the SSC 
models in (a), (d), (e), (f), and (g) do not have any spots in the center of the pattern. This is due to the fact that the models are only $1 \mathrm{BL}$ coverage of $\mathrm{Ag}$ on the substrate. Photoelectrons which escape at grazing emission angles are more surface-sensitive than those which escape near normal angles, because in grazing emission the path length through the surface layer is longer. Hence, normal emission tends to build up as the thickness of the metal film increases.

By comparing the SSC models with the experimental XPD results, we can quickly see differences. None of the SSC models that contain a single layer or single bilayer(110) structure, (2x1) rippled structure, square - hex structure, $(3 \times 1)$ rippled structure, and the square - square - hex - match the experimental XPD results (see Fig. 6 and Fig. 2). The reason that these SSC models do not match well with the XPD pattern is that in the experimental data, there are spots near the center of the experimental pattern. In the SSC models mentioned above, there are no spots near the center of the pattern. Hence, the SSC 1 BL models and the XPD result do not match.

However, there are spots in the center of the SSC model pattern of the $2 \mathrm{BL}$ and 3 BL Ag (110) structures. Furthermore, the almond shape of the most intense spots in each model matches the general shape of the experimental pattern. Figure 8 shows the SSC model of the $1 \mathrm{BL} \operatorname{Ag}(110)$ structure (in green) overlaid on top of the experimental XPD pattern (in gray). We can see that certain spots in the SSC model do not overlap well with the measured XPD pattern and vice versa. Therefore, the $1 \mathrm{BL} \operatorname{Ag}(110)$ structure does not match our Ag XPD pattern. However, it is possible that small changes in the lattice constant of the model would bring the SSC model pattern in closer alignment with the experimental pattern. We see similar results with the $2 \mathrm{BL}$ and the $3 \mathrm{BL} \mathrm{Ag}(110)$ 
structure. These SSC models are overlaid on top of the experimental XPD pattern which is shown in Fig. 9 and Fig. 10, respectively. Again, we can see that certain spots in the SSC model (green overlay) do not overlap with spots in the measured XPD pattern (in gray) and vice versa. Again, it is possible that small changes in the lattice constant of the model would bring these spots into better alignment.

In conclusion, the measured XPD patterns do not match any of the structure models for $\mathrm{Ag}$ on $\mathrm{NiAl}(110)$. Further work is needed to establish the atomic structure of these metal islands.

\section{Experimental Results: Au on $\mathrm{NiAl}(110)$}

\subsection{STM, XPD, and LEED for Au on NiAl(110)}

No STM images are available for Au deposition. LEED results show a rectangular arrangement of diffraction spots, similar to the 1.2 BL Ag coverage The LEED images are shown in Fig. 11 ranging from $60 \mathrm{eV}$ to $200 \mathrm{eV}$. After LEED, we then started XPD. The XPD results for Au showed no pattern. This is shown in Fig. 12(a). However, XPS showed Au photoelectron peaks, indicating there was Au on the surface (see Fig. 12(b)). Therefore, we concluded that there was not enough Au on the surface to generate an XPD pattern for Au. More experiments need to be performed.

\subsection{SSC Models}

DFT suggests four possible structures of $\mathrm{Au}$ on $\mathrm{NiAl}(110)$, which are the square hex structure variations 1 and 2, and the square -hex - hex structure variations 1 and 2 . More information on these structures can be found in Ref. [5]. SSC calculations were 
done on these structures and are shown in Fig. 13 and there real structures are shown in Fig. 14.

\section{Conclusions}

The goal of this work was to measure XPD patterns for both Ag and Au on $\mathrm{NiAl}(110)$. In the case of $\mathrm{Ag}$, a clear almond-shaped pattern was recorded for the $\mathrm{Ag}$ $3 \mathrm{~d}_{5 / 2}$ peak, over a range of $\mathrm{Ag}$ coverages from $0.6 \mathrm{BL}$ to $5 \mathrm{BL}$. STM and LEED were performed concurrently, and those results were consistent with prior experimental results for this system. In STM, the existence of long, rectangular islands growing outward from $\mathrm{NiAl}$ step edges, the heights of the Ag islands, and the existence of fine ripples on island tops, were all comparable to previous results[2]. Possible structures of $\mathrm{Ag}$ and $\mathrm{Au}$ had been determined by our colleagues, using DFT. These candidate structures served as the basis for SSC calculations of model XPD patterns. For Ag on NiAl(110), seven model patterns were generated. None of them matched well with the experimental XPD patterns of $\mathrm{Ag}$, although it is possible that small changes in the lattice parameters of the structure model would result in better agreement. Only one attempt was made to deposit Au on NiAl. The results showed no XPD pattern for $\mathrm{Au}$, probably indicating insufficient coverage of $\mathrm{Au}$.

\section{$\underline{\text { Acknowledgements }}$}

This work was supported by the Office of Science, Basic Energy Sciences, Materials Sciences and Engineering Division of the US Department of Energy (USDOE). 
This manuscript has been authorized by Iowa State University of Science and Technology under Contract No. DE-AC02-07CH11358 with the US Department of Energy. We are indebted to the group of Dr. Roland Widmer at EMPA Materials Science and Technology, Switzerland for allowing us to collaborate by letting use their XPD system and expertise.

\section{$\underline{\text { References }}$}

[1] D.P. Woodruff, A.M. Bradhsaw, Rep. Prog. Phys. 57 (1994) 1029-1080.

[2] B. Unal, F. Qin, Y. Han, D.-J. Liu, D. Jing, A.R. Layson, C.J. Jenks, J.W. Evans, P.A. Thiel, Physical Review B 76 (2007) 195410.

[3] D. Jing, Metal thin film growth on multimetallic surfaces from quaternary metallic glass to binary crystal, Iowa State University, Ames, 2010.

[4] Y. Han, B. Unal, D. Jing, F. Qin, C.J. Jenks, D.-J. Liu, P.A. Thiel, J.W. Evans, Physical Review B 81 (2010) 115462.

[5] T. Duguet, Y. Han, C. Yuen, D. Jing, B. Unal, J.W. Evans, P.A. Thiel, Proceedings of the National Academy of Sciences 108 (2011) 989-994. 


\section{$\underline{\text { Figure Captions }}$}

\section{Figure 1}

STM image of the clean NiAl (110) at $300 \mathrm{~K}$. The STM parameters are (a) $50 \mathrm{~nm} \times 50$ $\mathrm{nm}, \mathrm{I}=0.50 \mathrm{nA}, \mathrm{V}$-tip $=-1 \mathrm{~V},(\mathrm{~b}), 100 \mathrm{~nm} \times 100 \mathrm{~nm}, \mathrm{I}=0.5 \mathrm{nA}, \mathrm{V}$-tip $=+2 \mathrm{~V}$, and (c) $100 \mathrm{~nm} \times 100 \mathrm{~nm}, \mathrm{I}=0.50 \mathrm{nA}$, V-tip $=-1 \mathrm{~V}$.

\section{Figure 2}

STM images (color) and XPD patterns (gray) of $\mathrm{Ag}$ on NiAl(110) at $300 \mathrm{~K}$ (a-b) $250 \mathrm{~nm}$ x $250 \mathrm{~nm}(0.65 \mathrm{BL}),(\mathrm{c}-\mathrm{d}) 250 \mathrm{~nm}$ x $250 \mathrm{~nm}(0.77 \mathrm{BL}),(\mathrm{e}-\mathrm{f}) 150 \mathrm{~nm}$ x $150 \mathrm{~nm}(1.2 \mathrm{BL})$, and $(\mathrm{g}) 5 \mathrm{BL}$. The tunneling conditions for all STM images are $\mathrm{I}=0.5 \mathrm{nA}$ and V-tip $=+2$ $\mathrm{V}$.

\section{Figure 3}

LEED images after 1.2 BL of Ag deposition and STM, but before XPD at $300 \mathrm{~K}$, (a) 60 $\mathrm{eV}$, (b) $80 \mathrm{eV}$, (c) $100 \mathrm{eV}$, (d) $150 \mathrm{eV}$, and (e) $200 \mathrm{eV}$.

\section{Figure 4}

STM images of $0.65 \mathrm{BL} \mathrm{Ag}$ on $\mathrm{NiAl}(110)$ at $300 \mathrm{~K}$, (a) before XPD, $150 \mathrm{~nm} \times 150 \mathrm{~nm}$, (b) line profile from the black arrowhead in (a), (c) after XPD, $150 \mathrm{~nm}$ x $150 \mathrm{~nm}$, (d) line profile from the black arrowhead in (c). The tunneling conditions for all the STM images are $\mathrm{I}=0.5 \mathrm{nA}$ and $\mathrm{V}$-tip $=+2 \mathrm{~V}$.

\section{Figure 5}

High magnification STM images of the Ag islands on NiAl(110) at $300 \mathrm{~K}$, (a) $40 \mathrm{~nm}$ x 40 $\mathrm{nm}$, (b) $40 \mathrm{~nm} \times 40 \mathrm{~nm}$, (c) FFT filter $11 \mathrm{~nm}$ x $11 \mathrm{~nm}$, (d) line profile taken by black arrowhead in (c), (e) $13 \mathrm{~nm} \times 13 \mathrm{~nm}$, and (f) line profile taken by the black arrowhead in (e). The coverage is $0.65 \mathrm{BL} \mathrm{Ag}$. The tunneling conditions for all STM images are $\mathrm{I}=0.5$ $\mathrm{nA}$ and $\mathrm{V}$-tip $=+2 \mathrm{~V}$.

\section{Figure 6}

SSC calculations of the seven possible structures of $\mathrm{Ag}$ on $\mathrm{NiAl}(110)$, (a) $1 \mathrm{BL}$ fcc (110) structure, (b) 2 BL fcc (110) structure, (c) 3 BL fcc (110) structure, (d) (2x1) rippled structure, (e) square - hex structure, (f) (3x1) rippled structure, and (g) square - square hex structure.

\section{Figure 7}

Real Structure models of $\mathrm{Ag} / \mathrm{NiAl}(110)$, (a) $1 \mathrm{BL}$ fcc (110) structure, (b) $2 \mathrm{BL}$ fcc (110) structure, (c) $3 \mathrm{BL}$ fcc (110) structure, (d) (2x1) rippled structure, (e) square - hex structure, (f) $(3 \times 1)$ rippled structure, and (g) square - square - hex structure. The purple circles represent the silver atoms, the red circles represent the aluminum atoms, and the green circles represent the nickel atoms. The purple outlined in the top view images represent a silver atom on top of either the aluminum or nickel atom. 


\section{Figure 8}

Comparing experimental XPD pattern with SSC model, (a) Experimental XPD pattern of 1.2 BL Ag, (b) SSC model of 1 BL fcc (110) structure, (c) SSC 1 BL fcc (110) structure overlaid on top of experimental XPD 1.2 BL pattern. The green model represents the SSC calculations and the gray model represents the experimental XPD pattern. The experimental XPD pattern (gray) was rotated $14^{\circ}$ in order to overlap with the SSC model.

\section{Figure 9}

Comparing experimental XPD pattern with SSC model, (a) Experimental XPD pattern of 1.2 BL Ag, (b) SSC model of 2 BL fcc (110) structure, (c) SSC 2 BL fcc (110) structure overlaid on top of the experimental XPD 1.2 BL pattern. The green model represents the SSC calculations and the gray model represents the experimental XPD pattern. The experimental XPD pattern (gray) was rotated $14^{\circ}$ in order to overlap with the SSC model.

\section{Figure 10}

Comparing experimental XPD pattern with SSC model, (a) Experimental XPD pattern of 1.2 BL Ag, (b) SSC model of 3 BL fcc (110) structure, (c) SSC 3 BL fcc (110) structure overlaid on top of the experimental XPD 1.2 BL pattern. The green model represents the SSC calculations and the gray model represents the experimental XPD pattern. The experimental XPD pattern (gray) was rotated $14^{\circ}$ in order to overlap with the SSC model.

\section{Figure 11}

LEED images after Au deposition and STM, but before XPD at $300 \mathrm{~K}$, (a) $60 \mathrm{eV}$, (b) 80 $\mathrm{eV}$, (c) $100 \mathrm{eV}$, (d) $150 \mathrm{eV}$, and (e) $200 \mathrm{eV}$.

\section{Figure 12}

$\mathrm{Au}$ on $\mathrm{NiAl}(110)$ at $300 \mathrm{~K}$, (a) XPD pattern of $\mathrm{Au} 4 \mathrm{f}_{7 / 2}$, and (b) survey XP spectrum.

\section{Figure 13}

SSC calculations of the four possible structures of Au on NiAl(110), (a) Square - hex (Structure 1), (b) Square - hex (Structure 2), (c) Square - hex - hex (Structure 1), and (d) Square - hex - hex (Structure 2).

\section{Figure 14}

Real Structure models of $\mathrm{Au} / \mathrm{NiAl}(110)$, (a) Square - hex structure (version 1), (b) Square - hex structure (version 2), (c) Square - hex - hex structure (version 1), and (d) Square - hex - hex structure (version 2). The purple circles represent the gold atoms, the red circles represent the aluminum atoms, and the yellow circles represent the nickel atoms. The purple outlined in the top view images represent a gold atom on top of either the aluminum or nickel atom. 


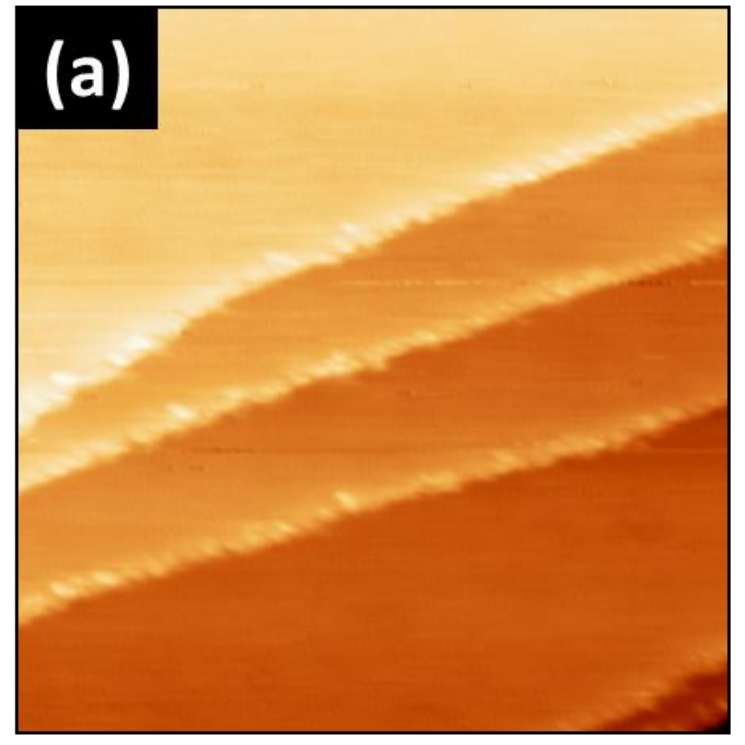

\section{(b)}

(c)

Figure 1 

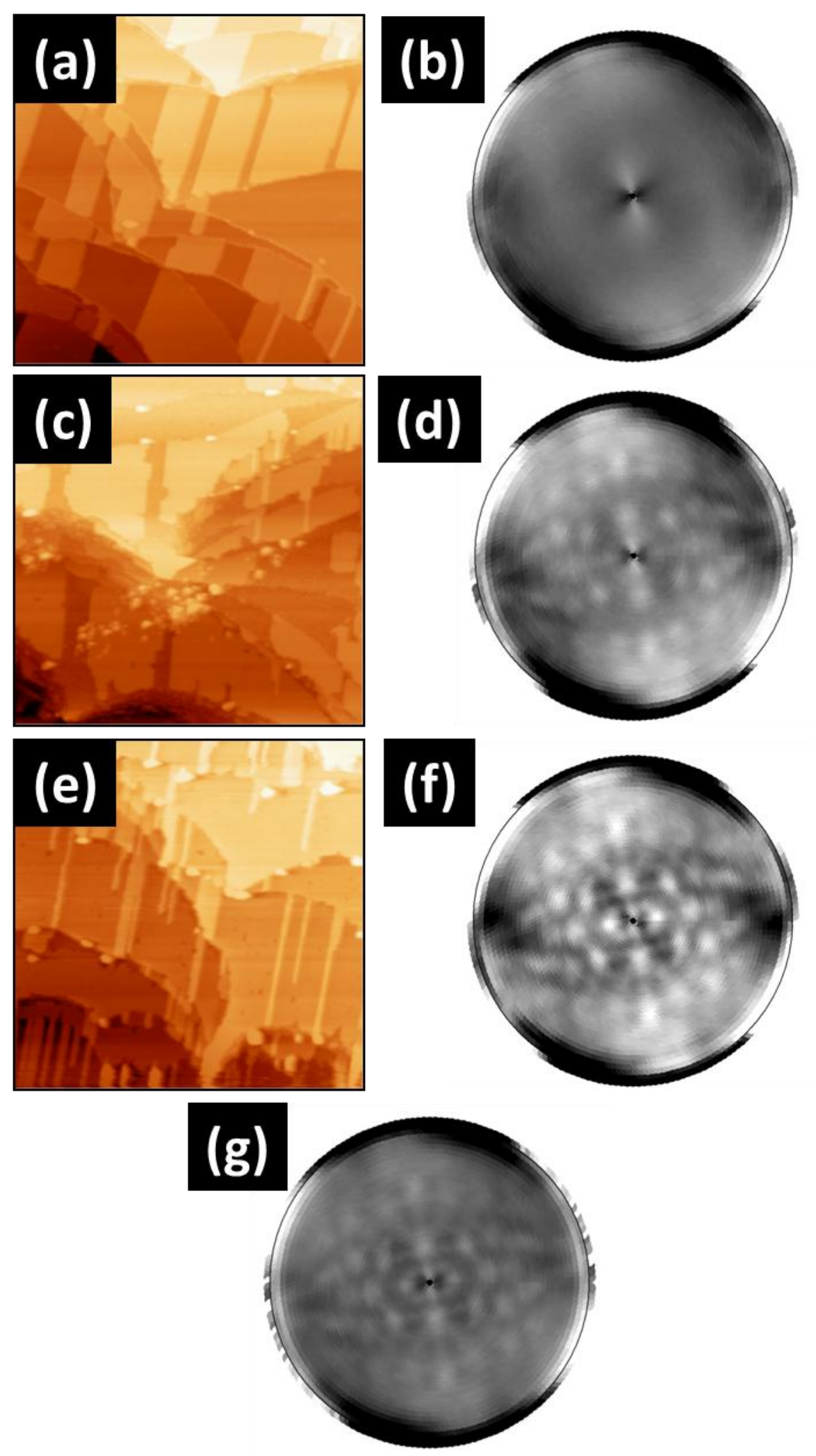

Figure 2 

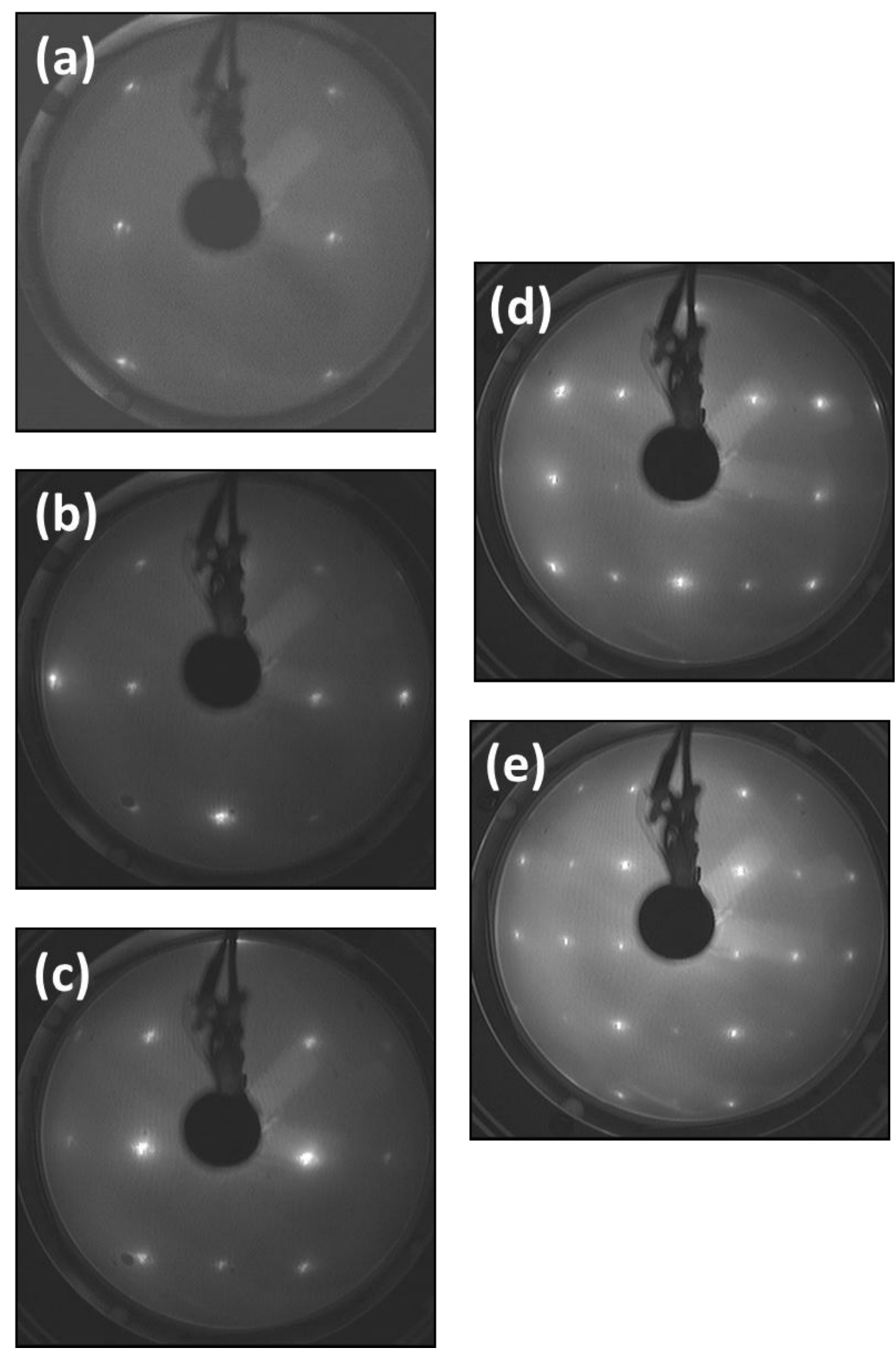

Figure 3 

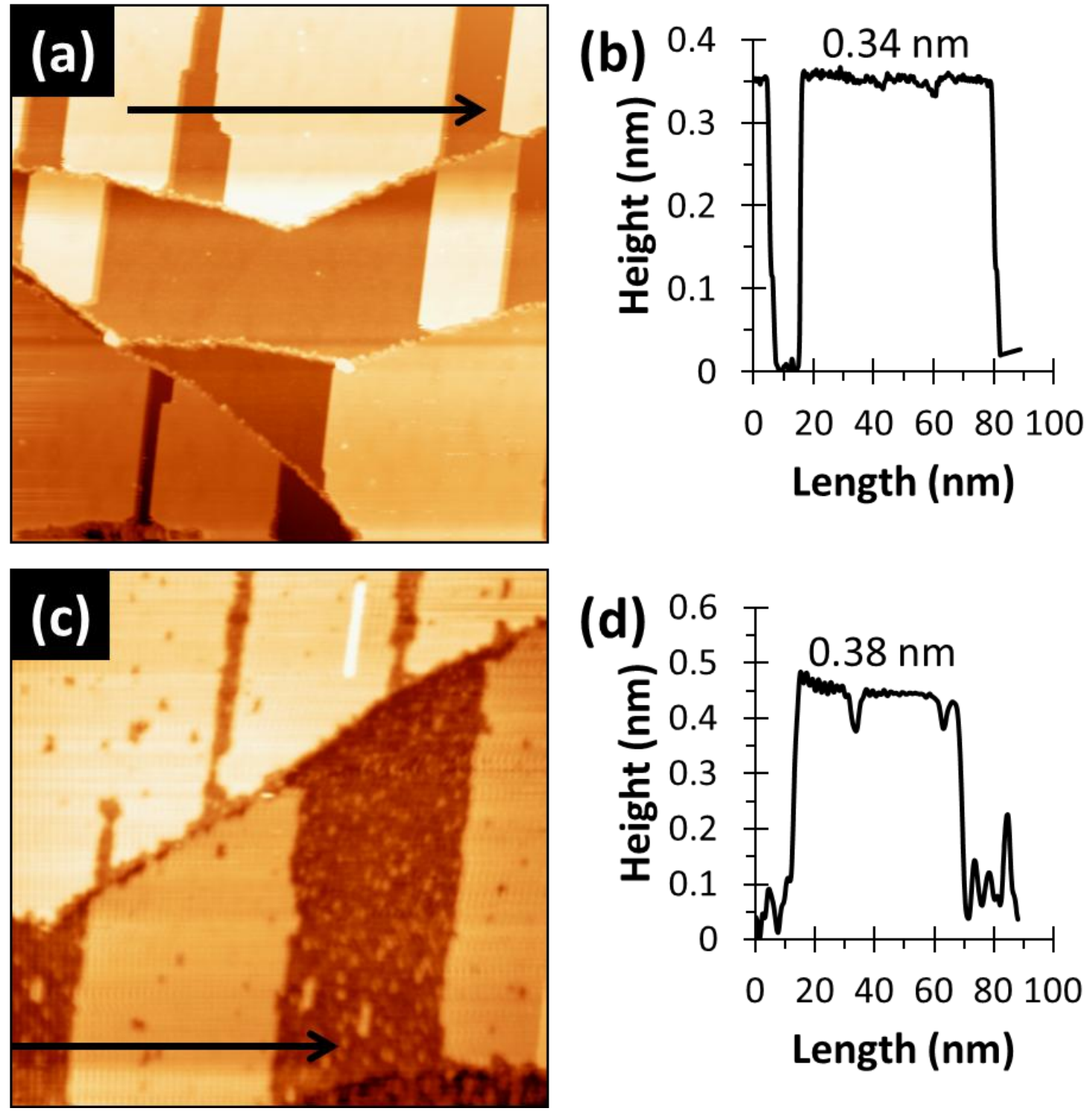

Figure 4 

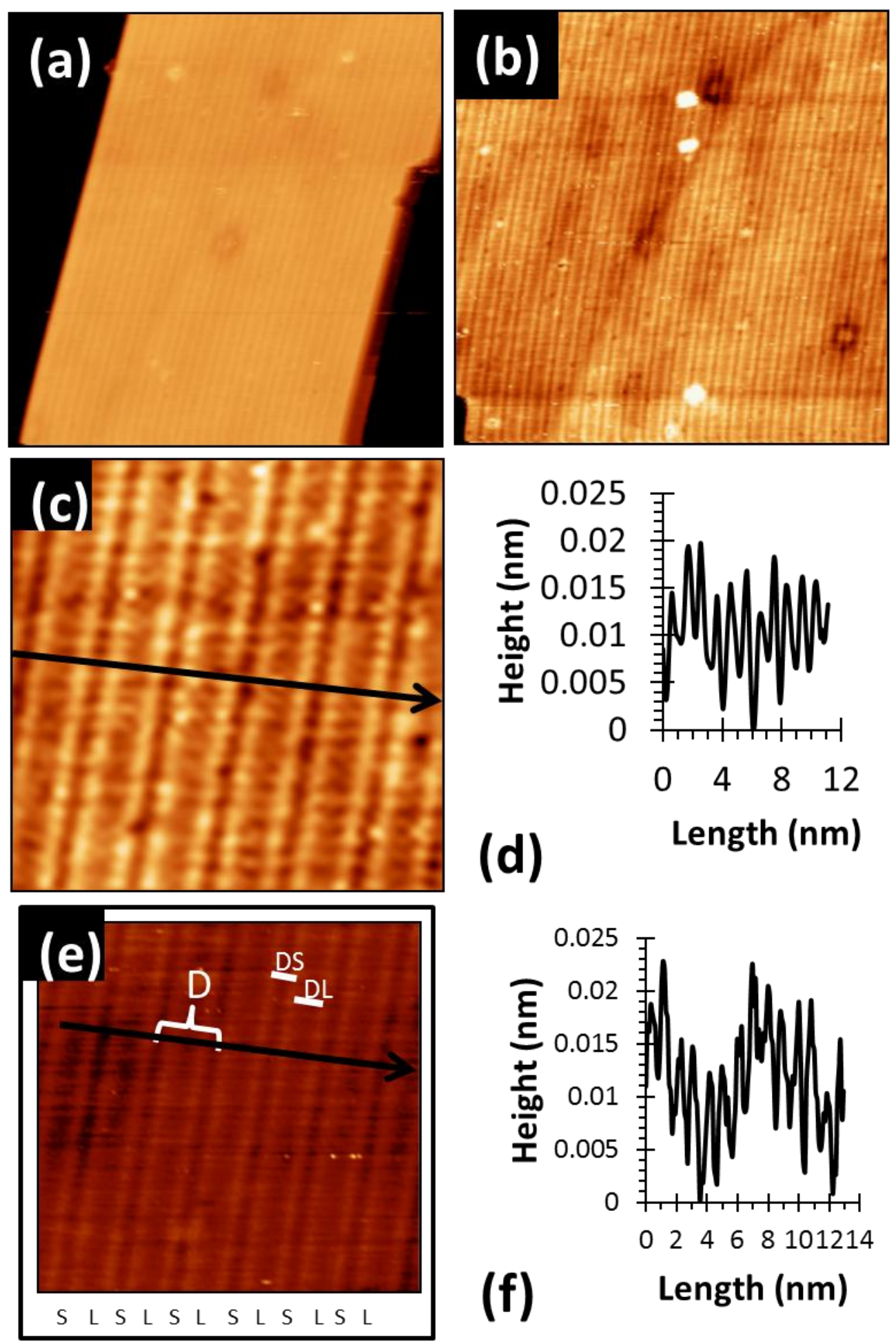

Figure 5 

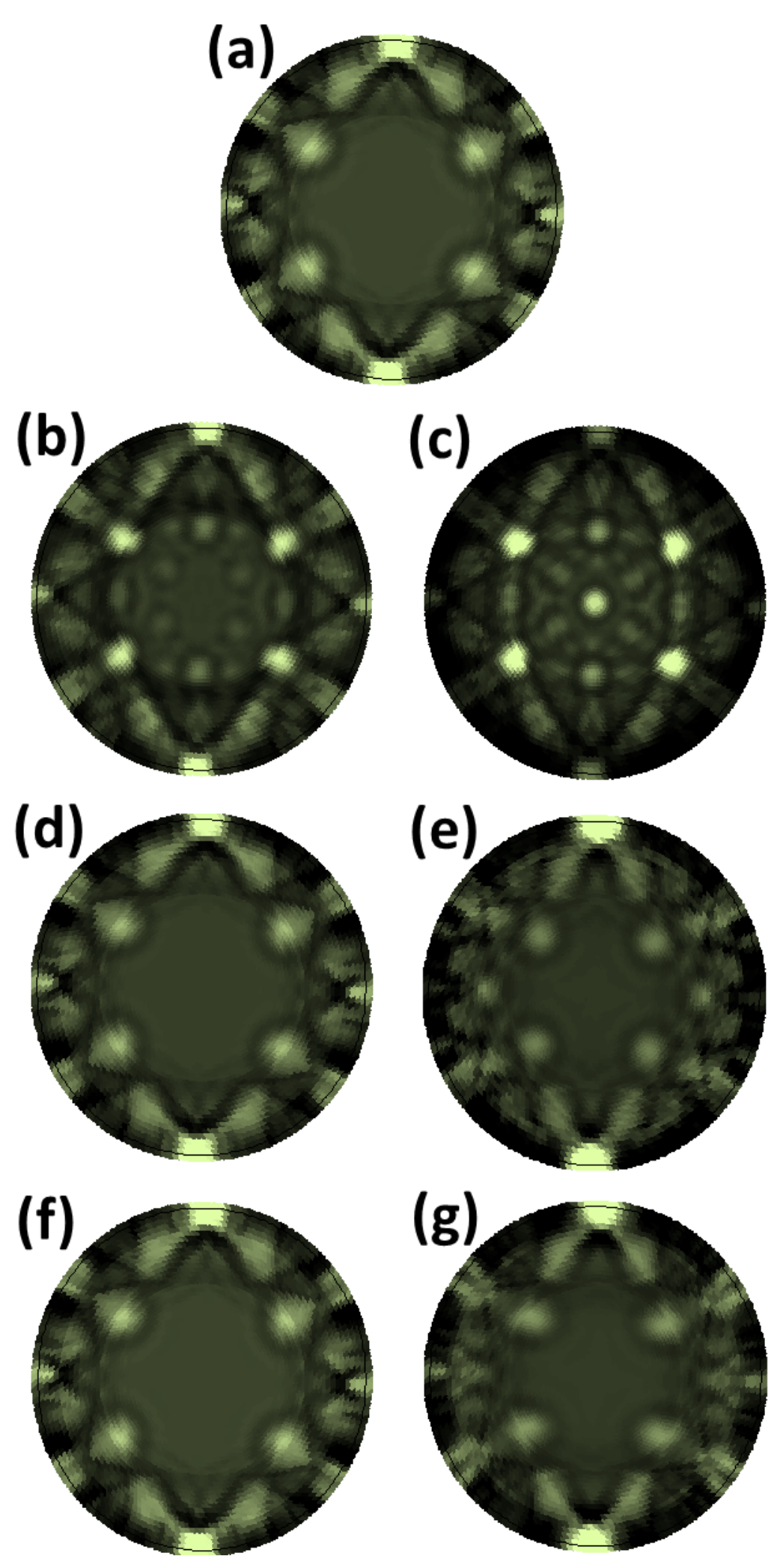

Figure 6 


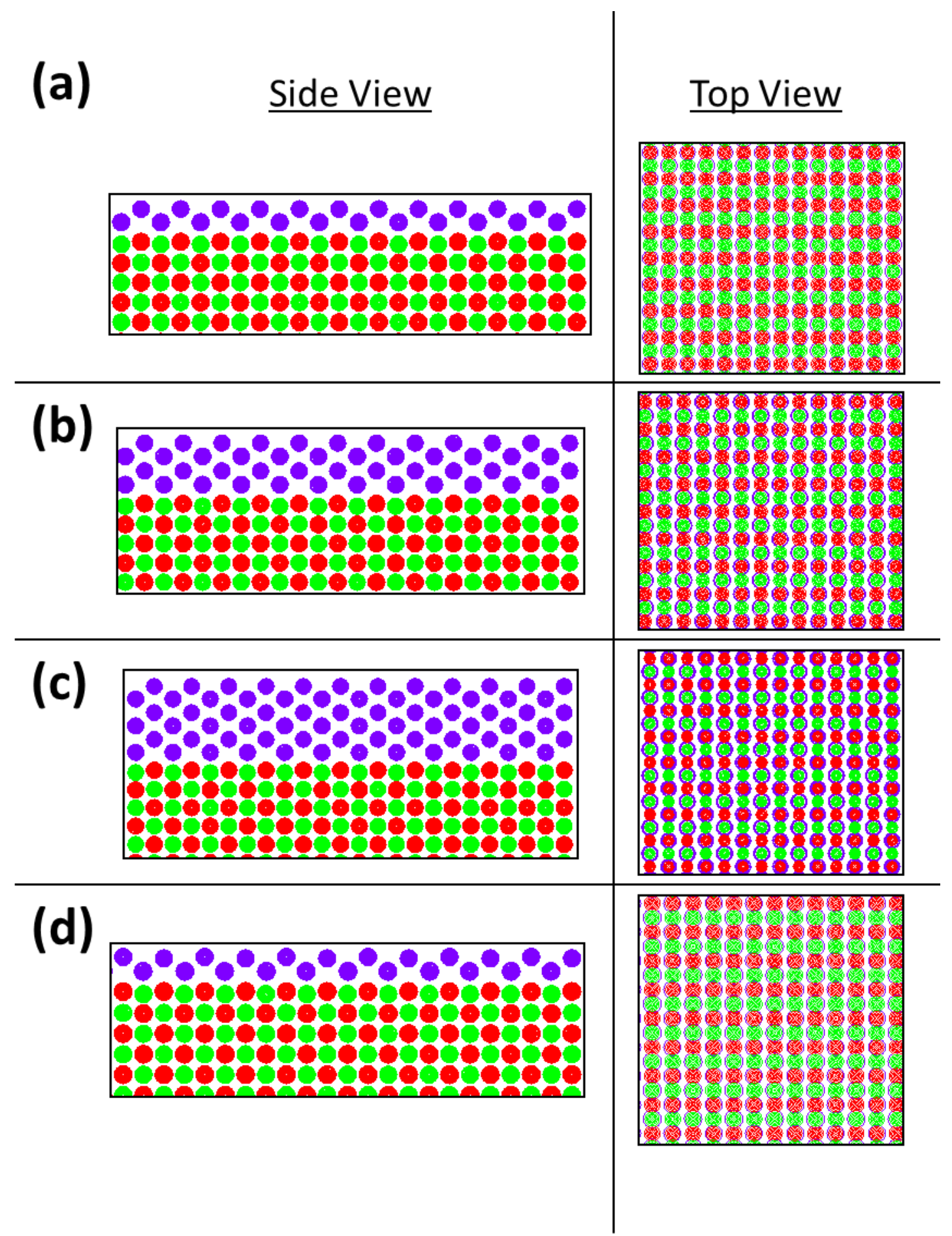

Figure 7 


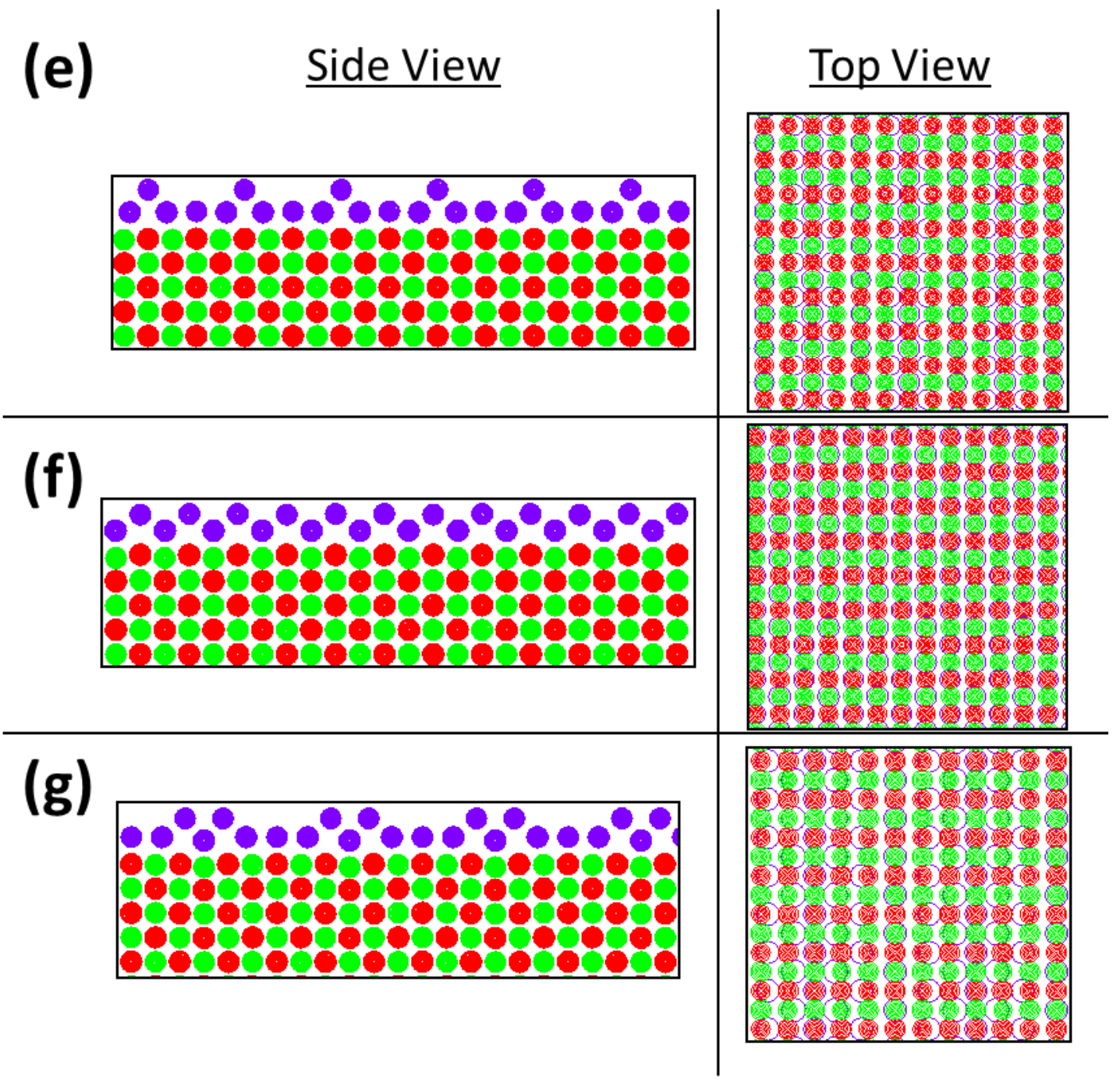

Figure 7 (Continue) 

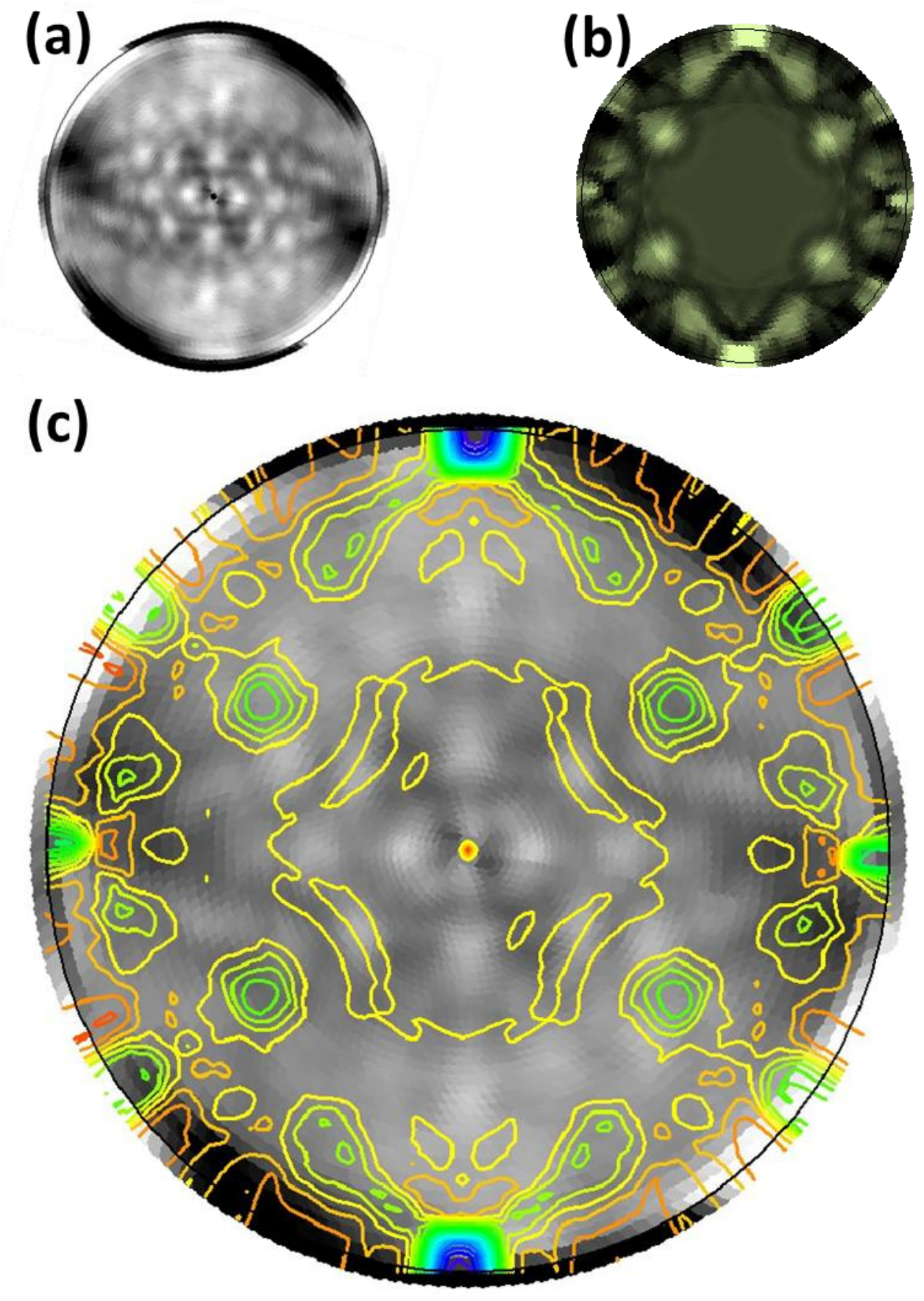

Figure 8 

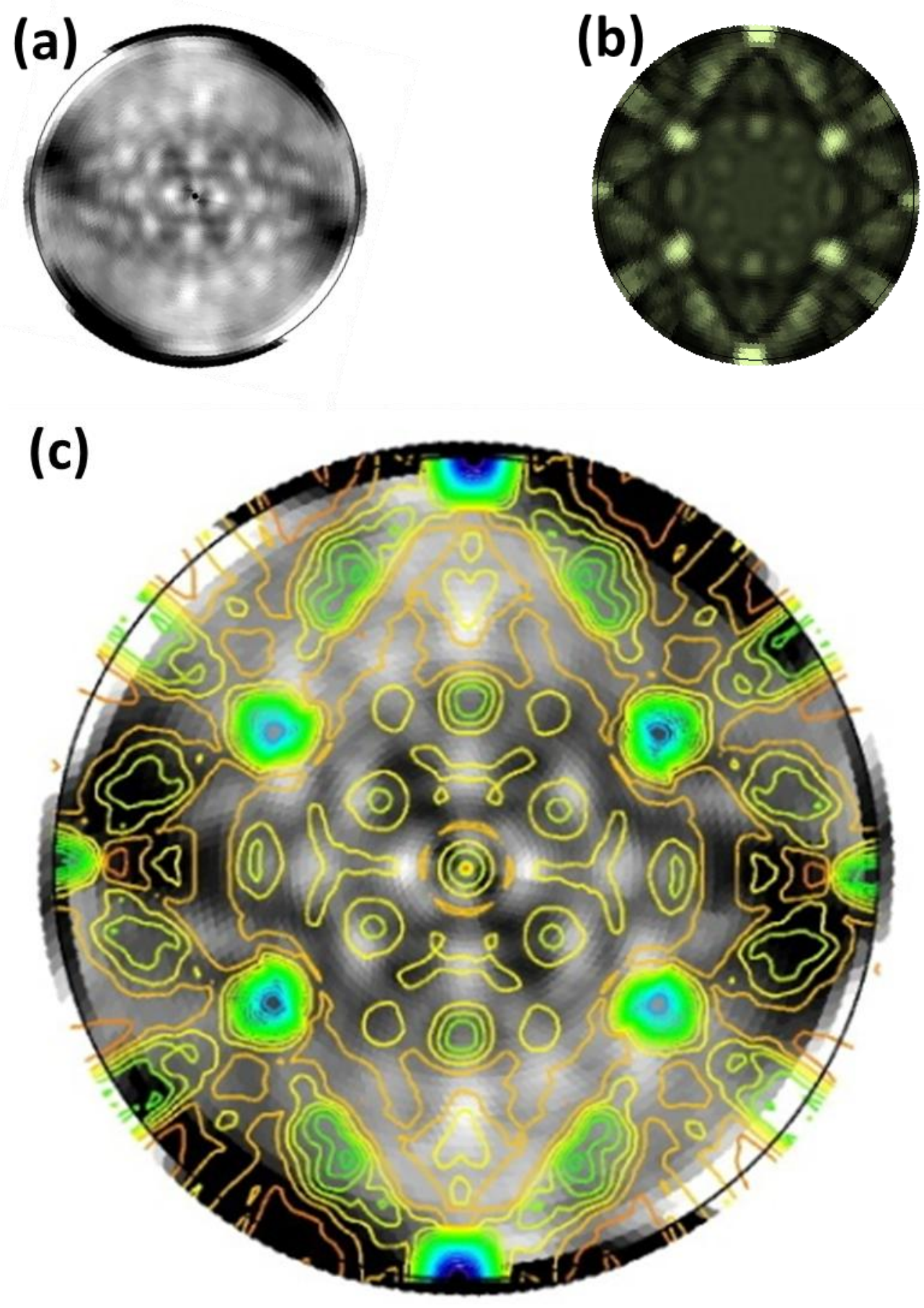

Figure 9 

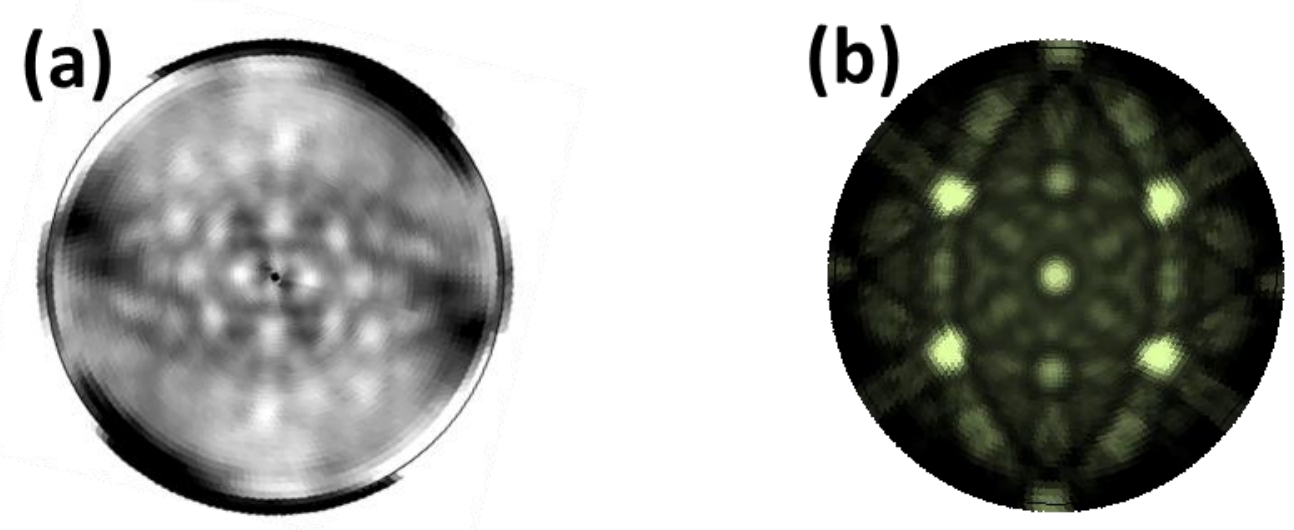

(c)

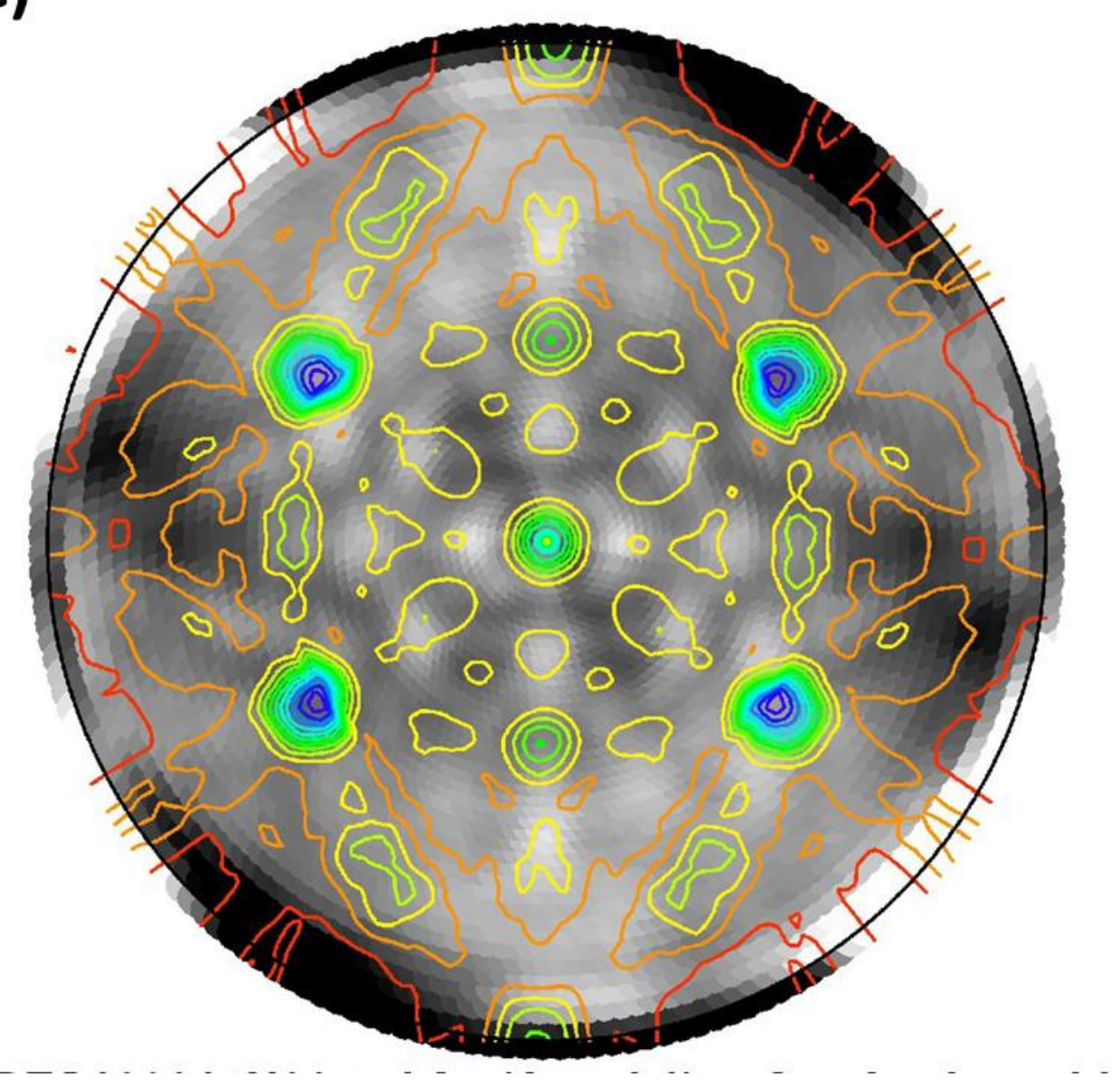

Figure 10 

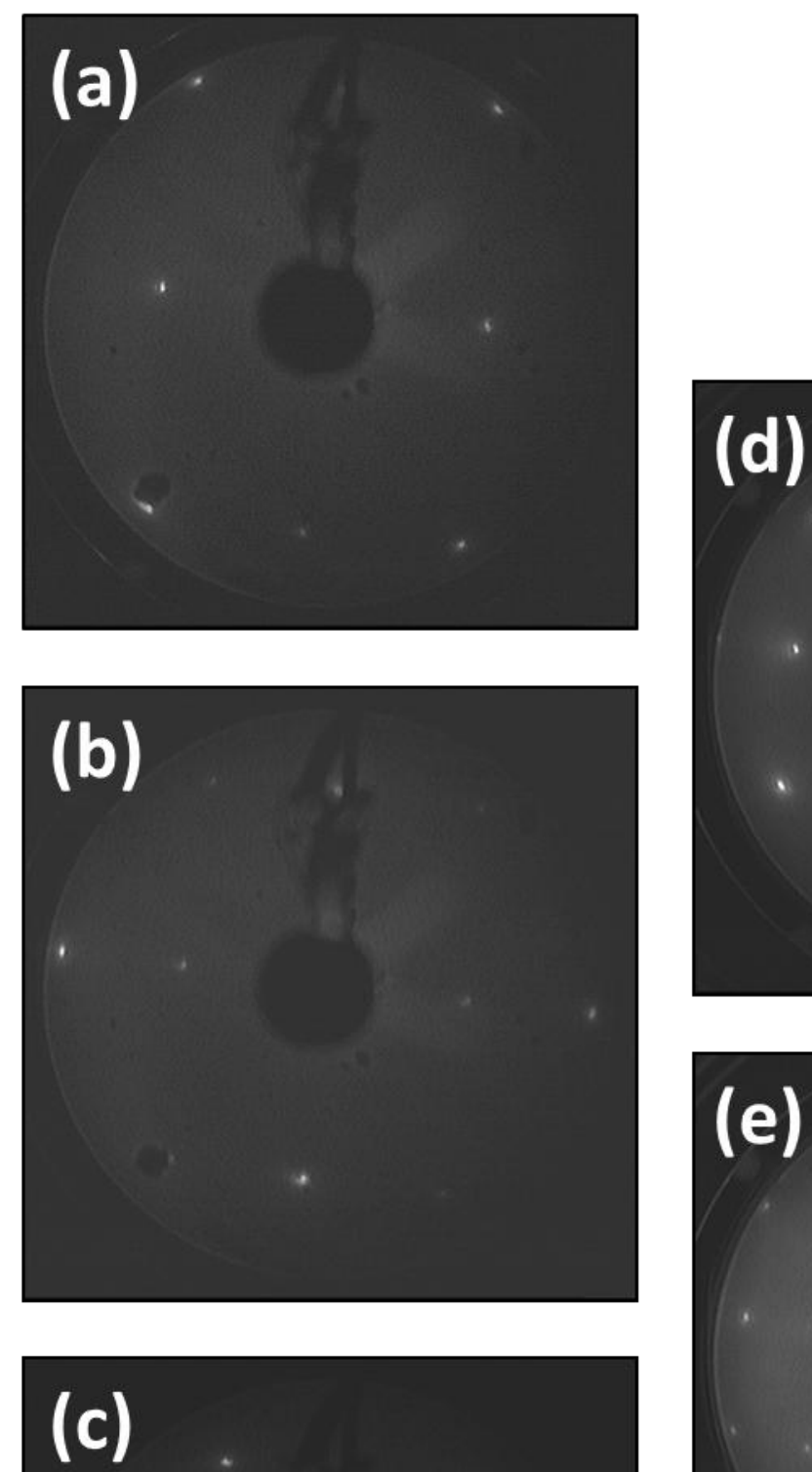

Figure 11 


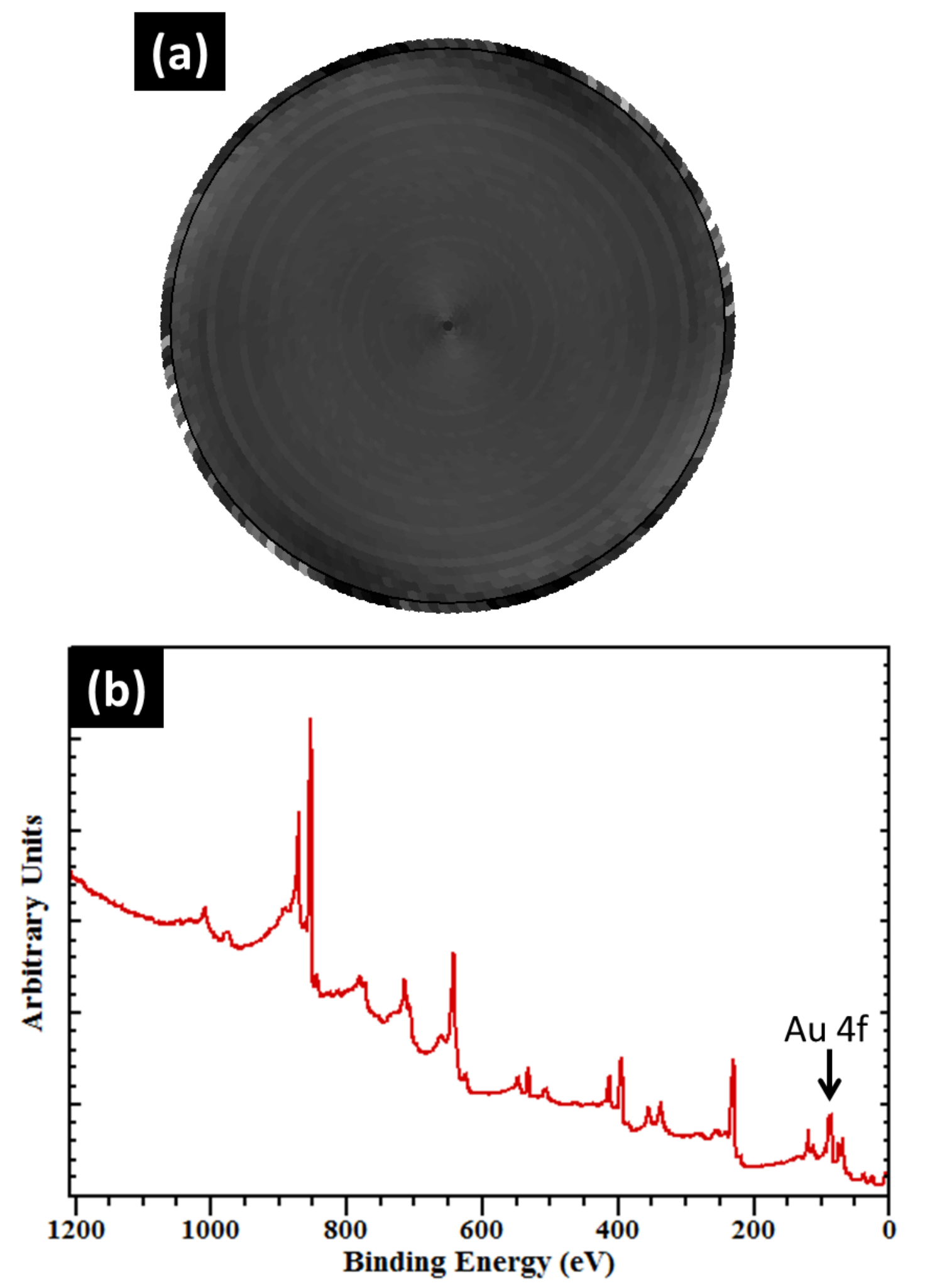

Figure 12 

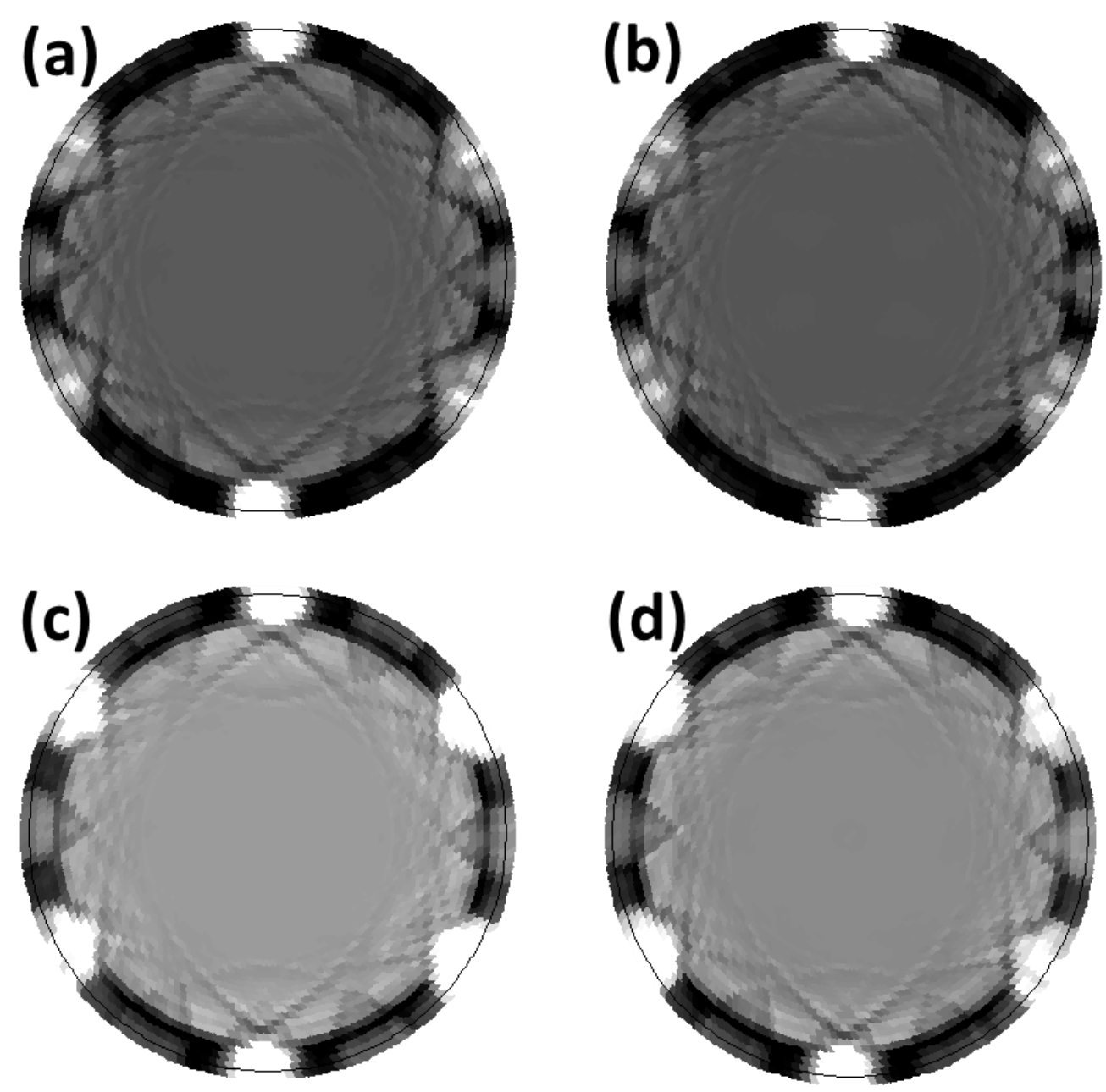

Figure 13 

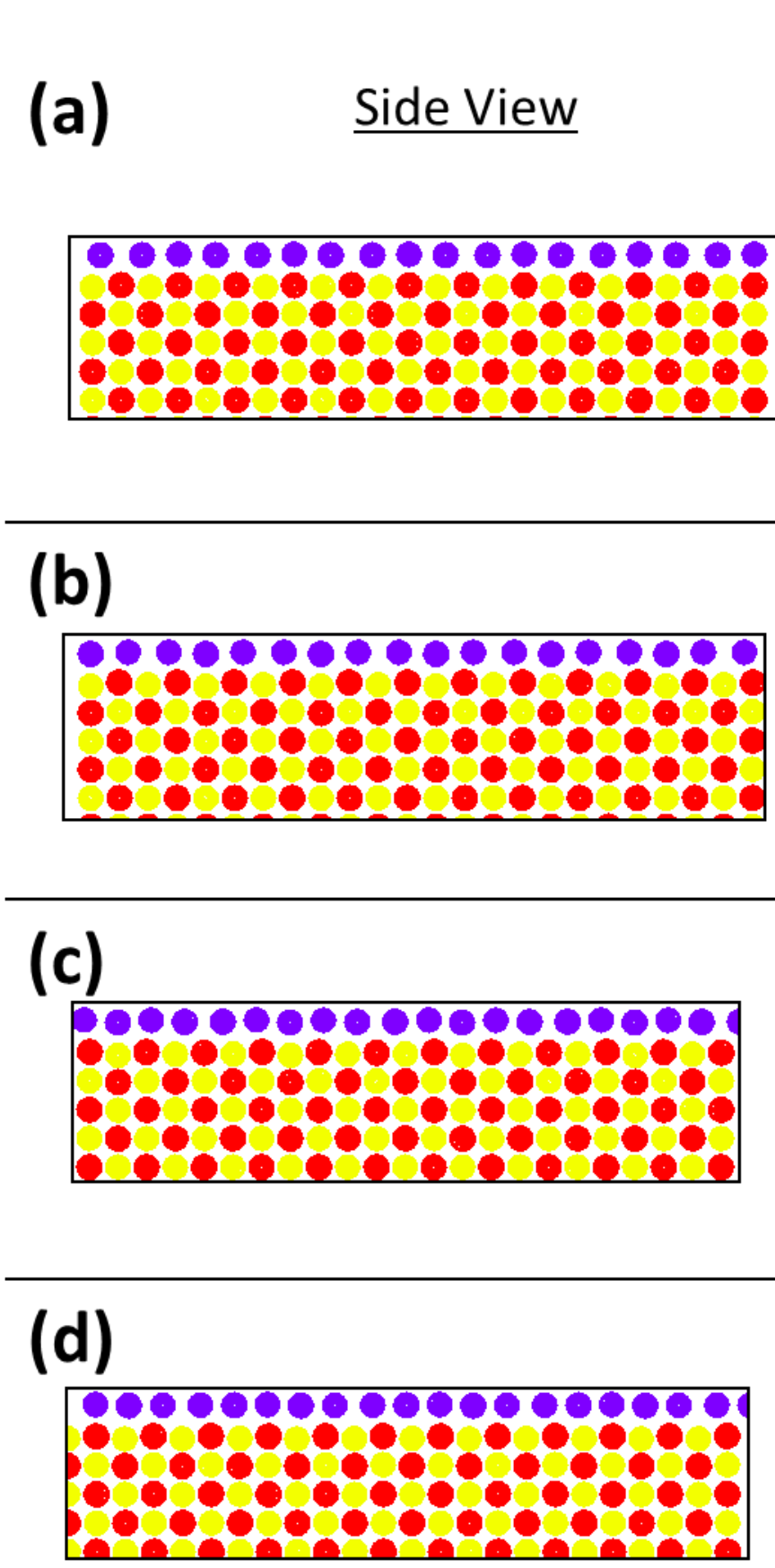

Figure 14 


\section{APPENDIX A. Using CasaXPS Software}

\section{File Formats}

CasaXPS software only works on VAMAS file formats. Any formats with (*.aes) or (*.xps) does not work with this software (NOTE: The EIS software on the Omicron chamber in 225 Spedding can convert (*.aes) and (*.xps) formats into VAMAS formats). The procedure is as follows:

1) Save original data file (*.aes) or (*.xps) in the EIS program.

2) Once saved, go to File, export as, and then click on VAMAS.

Fortunately, you can convert some non-VAMAS formats into a VAMAS format. Listed below are the non-VAMAS formats that can be converted to VAMAS.

- SpecsLab I Files (*.exp)

- SuperESCA Files (*_allx)

- Kratos Files (*.kal)

- PHI MultiPak Files (*.spe), (*.pro), (*.ang)

- Scienta ASCII Files (*.sci)

- DS800 Files (*.mpa)

- Eclipse Files (*.dts), (*.dti)

- PCSurf Files (*.sp0)

- SSI Files (*.mrs), (*.dpr)

- PHI ASCII Files (*.asc)

- RBD ASCII Files (*.txt)

- Bristol Files (*.seq)

- Kore Files (*.1st)

- PSU Files (*.xyt)

- (*.npl) 


\section{Toolbar Information}

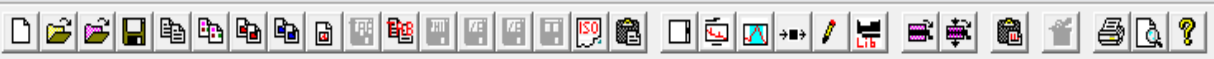

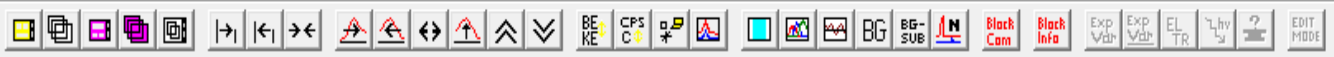

\section{$\mid \rightarrow_{1}$}

Zoom In

The zoom-in icon zooms-in on your selected region of your spectrum.

1. Drag the mouse and select the region you want to zoom-in on your spectrum.

2. Click on the "Zoom-In" $\mid \rightarrow_{\mid}$icon.

$|+|$

Zoom Out

The zoom-out icon brings back your original spectrum from your zoomed in region.

\section{$\rightarrow \in$}

Reset

The reset icon brings back your original spectrum from either zooming-in or zoomingout.

\section{Q1)}

Quantification Parameters

The quantification parameter icon allows you to create regions as well as calculating the atomic percent concentration, area, peak plus and peak minus values, etc. 


\section{$+\square$}

\section{Spectrum Processing}

The spectrum processing icon allows you to smooth, differentiate, and other types of data processing on your spectrum.

1. Click on the "Spectrum Processing" $+\div \div$ icon.

2. A new window should appear depicted below.

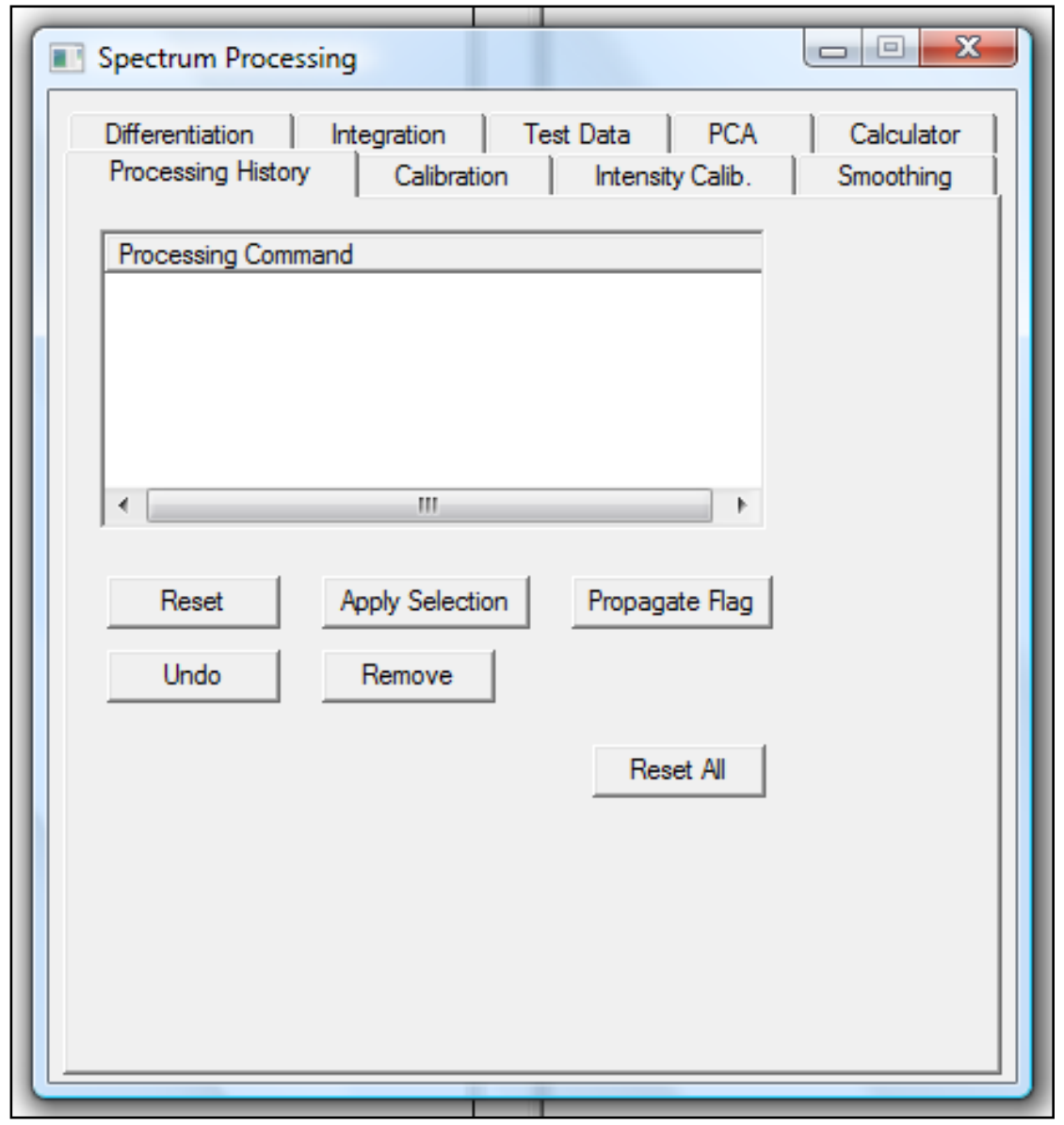

3. The "Processing History" tab tells you what you have processed from beginning to end. You can undo or reset any type of processing command that you have made.

4. The "Smoothing" tab allows you to smooth the spectrum. In the method section, there are four choices for smoothing, which are: SG Quadratic, SG Quartic, SG Linear, and Gaussian. The default is set to SG Quadratic. The smoothing width 
section allows you to control the smoothness on your spectrum. The default value is set at 5. Once you have picked your preference on method and smoothing values, click on "Apply". Below is an example on how the spectrum should look like after smoothing.

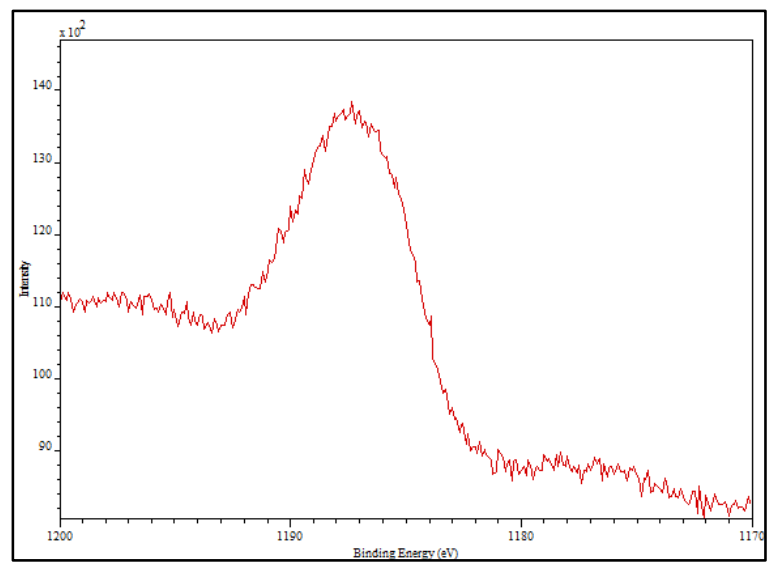

\section{Original Spectrum}

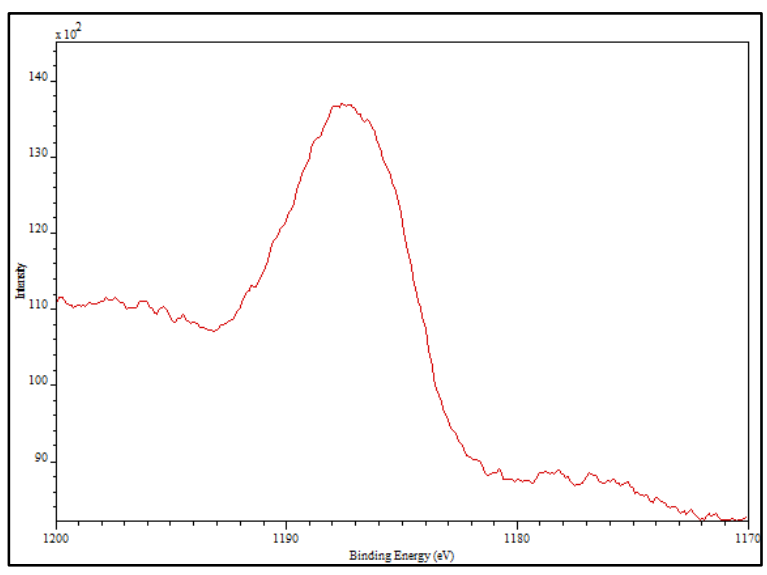

\section{Smooth Spectrum}

5. The "Differentiation" tab can take first derivatives on your spectrum. In the method section, there are two choices which are: SG Quadratic and SG Quartic. The default set is to SG Quadratic. The smoothing width section allows you to control the smoothness on your spectrum. The default value is set at 5. Once you have picked your preference on method and smoothing values, click on "Apply". Below is an example of how the spectrum would look like after the spectrum has been differentiated. 


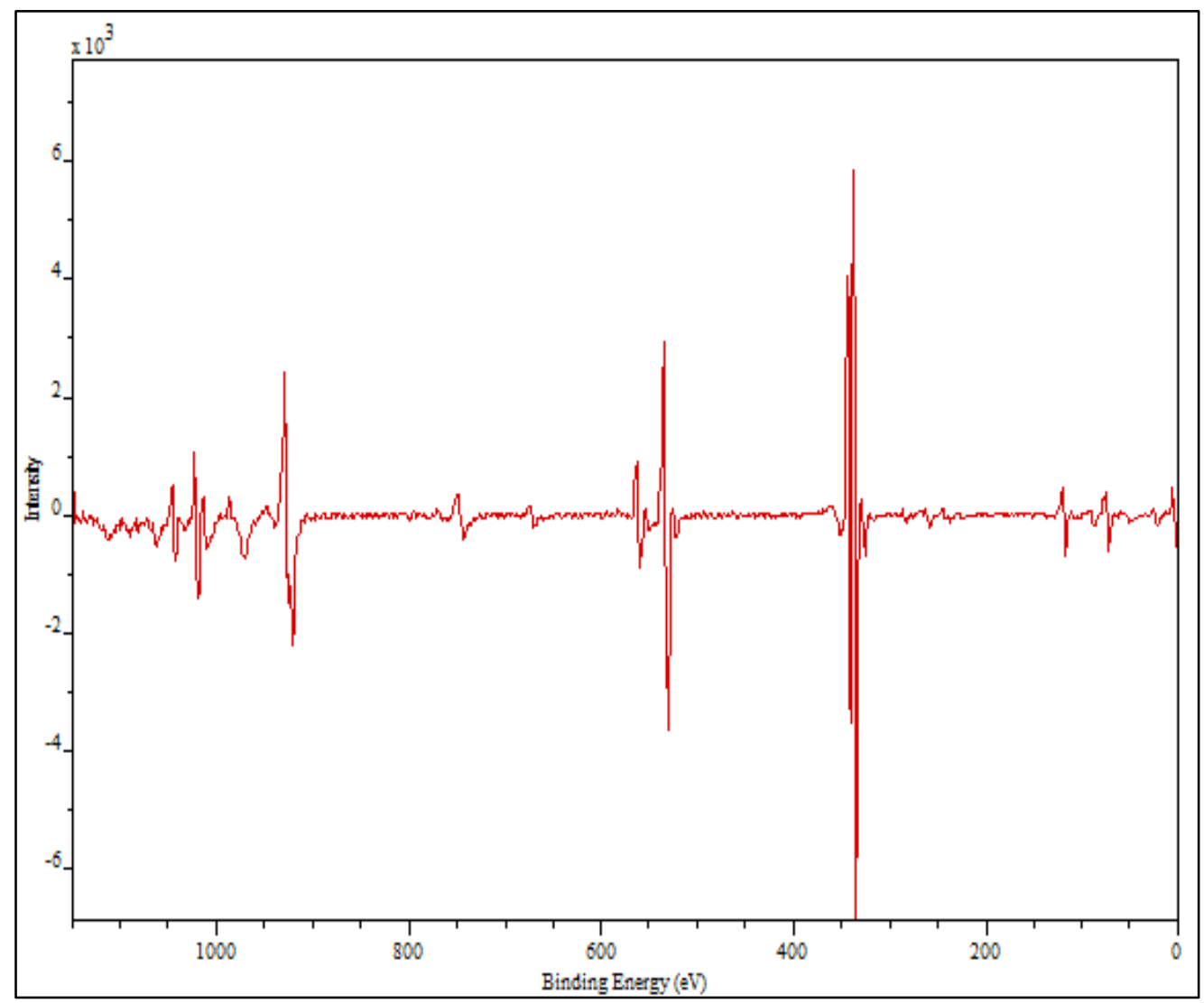

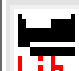
Elemental Library

Elemental library icon allows you to easily create regions in XPS or AES analysis (See section IV. Creating Regions B for procedures). In addition, the library icon gives you relative sensitivity factors (RSF) for individual cross sections by doing XPS analysis. However, the elemental library does NOT give any relative sensitivity factors for AES analysis. Therefore, use the RSF values in the AES handbook for analysis. 


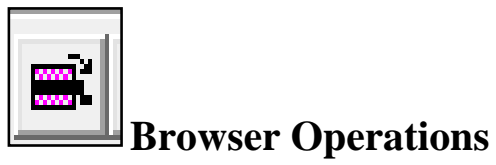

The browser operation allows you to spectrum process and editing your regions on all highlighted files at once. In other words, it can smooth, creates regions, take derivatives, and many more things to all the highlighted spectra at once.

1. Do spectrum processing (See section II. Toolbar information under spectrum processing for procedure) and/or creating regions (See section III. Creating Regions A or IV. Creating Regions B for procedure) in one of the highlight files.

2. Then highlight all the files you want to have the same process done in step 1 as shown below.

\begin{tabular}{|l|l|l|}
\hline None & None & \\
\hline 0 & None & \\
0 & None & \\
0 & None & \\
0 & None \\
& \\
\hline
\end{tabular}

3. Click on the "Browser Operations" icon.

4. A new window should appear depicted below. 


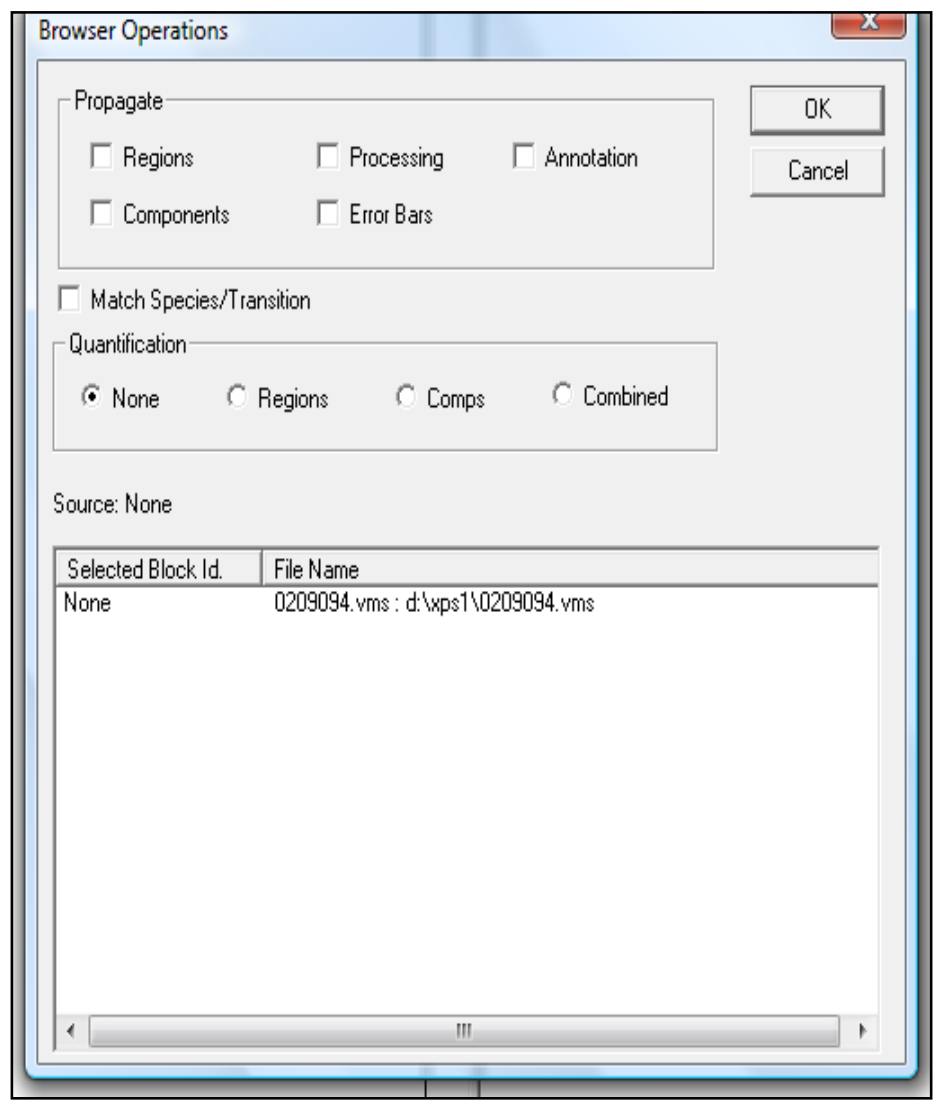

5. Check the "Regions" and "Processing" box.

6. Click the "OK" button.

Insert Many

Insert many icon allows you to insert your individual peak spectra's into one spectrum.

1. Highlight the selected files on the right column. Example below. 


\begin{tabular}{|l|l|}
\hline None & None \\
\hline 0 & None \\
\hline 0 & None \\
\hline 0 & None \\
\hline 0 & None \\
\hline
\end{tabular}

2. Click on the "Insert Many" icon.

3. Below is an example of what the spectrum would look like.

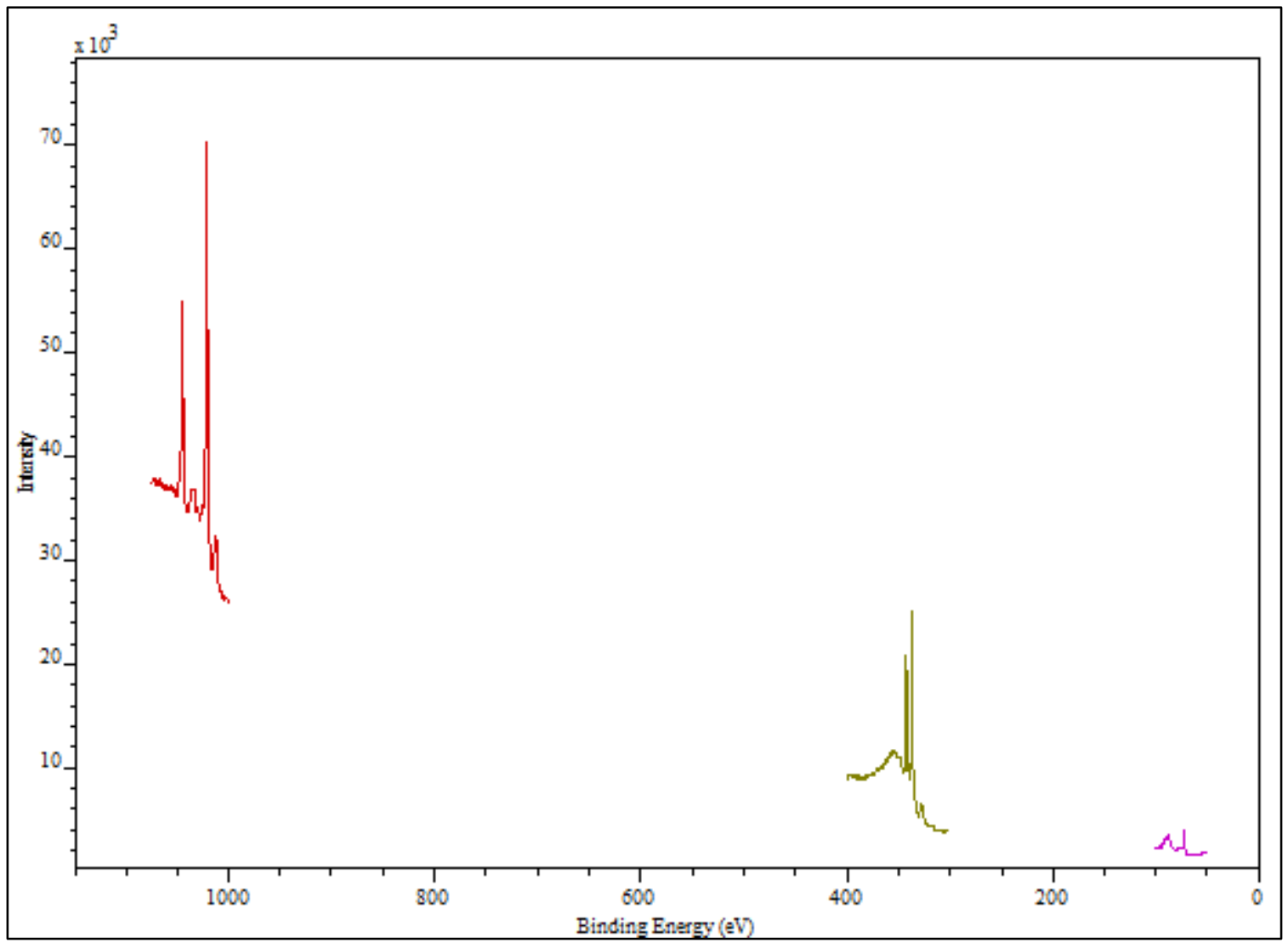




\section{局 \\ Overlaying}

The overlaying icon allows you to overlay your overview spectra or individual spectra into one graph. (NOTE: This is a great tool to do accurate quantitative analysis by making sure the start and end energy ranges are the same on every spectrum).

1. Highlight the selected files on the right column. Example below.

\begin{tabular}{|c|c|}
\hline $1=1$ & \\
\hline Data Set & None \\
\hline 0 & None \\
\hline 1 & None \\
\hline 2 & None \\
\hline 3 & None \\
\hline 4 & None \\
\hline 5 & None \\
\hline 6 & None \\
\hline
\end{tabular}

2. Click on graph to activate the toolbar.

3. Click on the "Overlaying" icon.

4. Below is an example of what the spectrum would look like. 

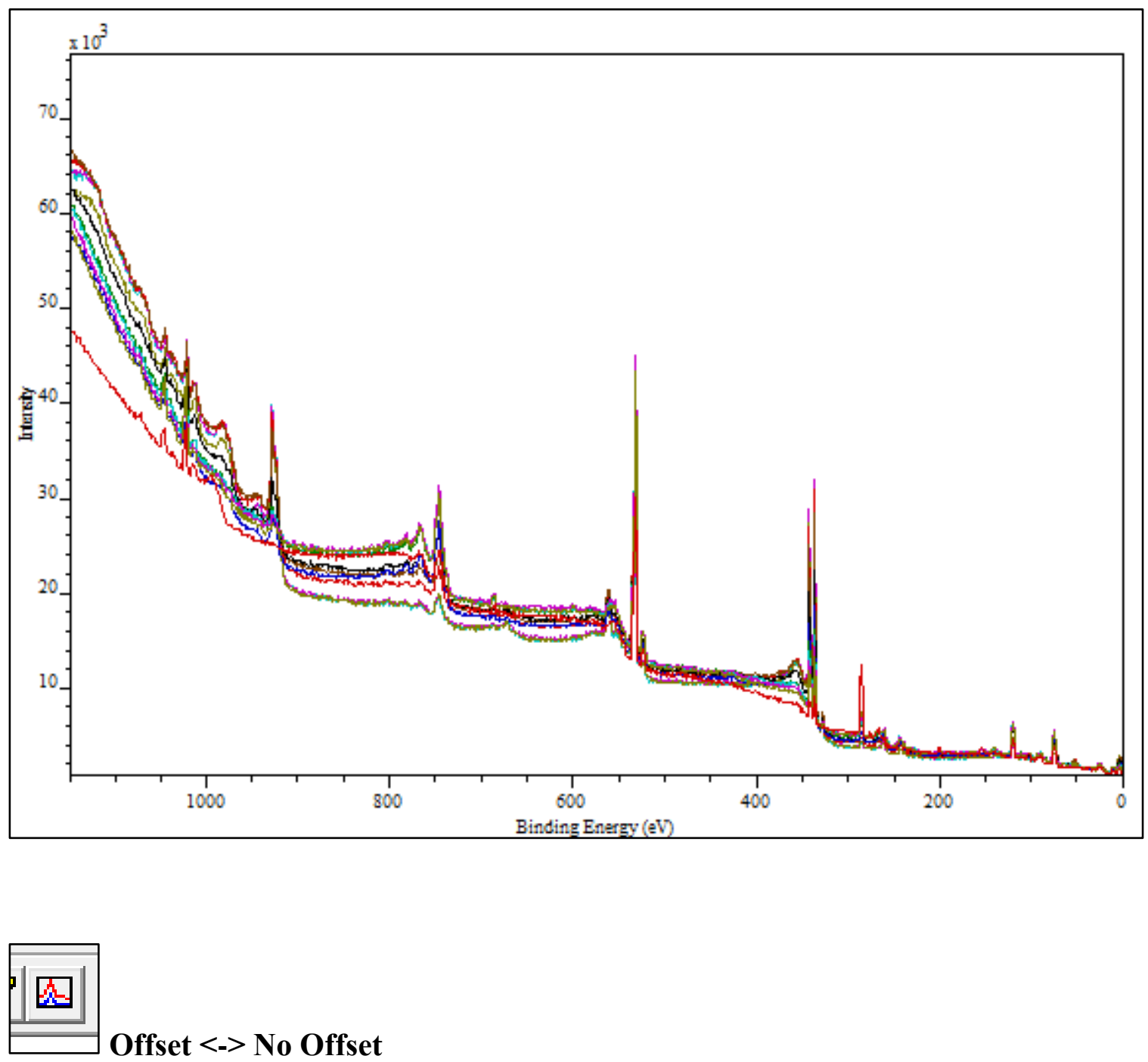

The Offset <-> No Offset icon allows you to offset your overlaid spectra.

1. Highlight the selected files on the right column. See example below.

\begin{tabular}{|c|c|}
\hline \multicolumn{2}{|c|}{ Em -1 - = } \\
\hline Data Set & None \\
\hline 0 & None \\
\hline 1 & None \\
\hline 2 & None \\
\hline 3 & None \\
\hline 4 & None \\
\hline 5 & None \\
\hline 6 & None \\
\hline
\end{tabular}

2. Click on graph to activate the toolbar. 
3. Click on the "Overlaying"

4. Click on the "Offset $<->$ No Offset" icon.

5. Below is an example of what the spectrum would look like. There are multiple options to choose from, just continue to click on the "Offset $<_{-}>$No Offset" icon until you find the one you want. The left graph is going from bottom to top and the right graph is going from top to bottom. (NOTE: the red line is your first spectrum).
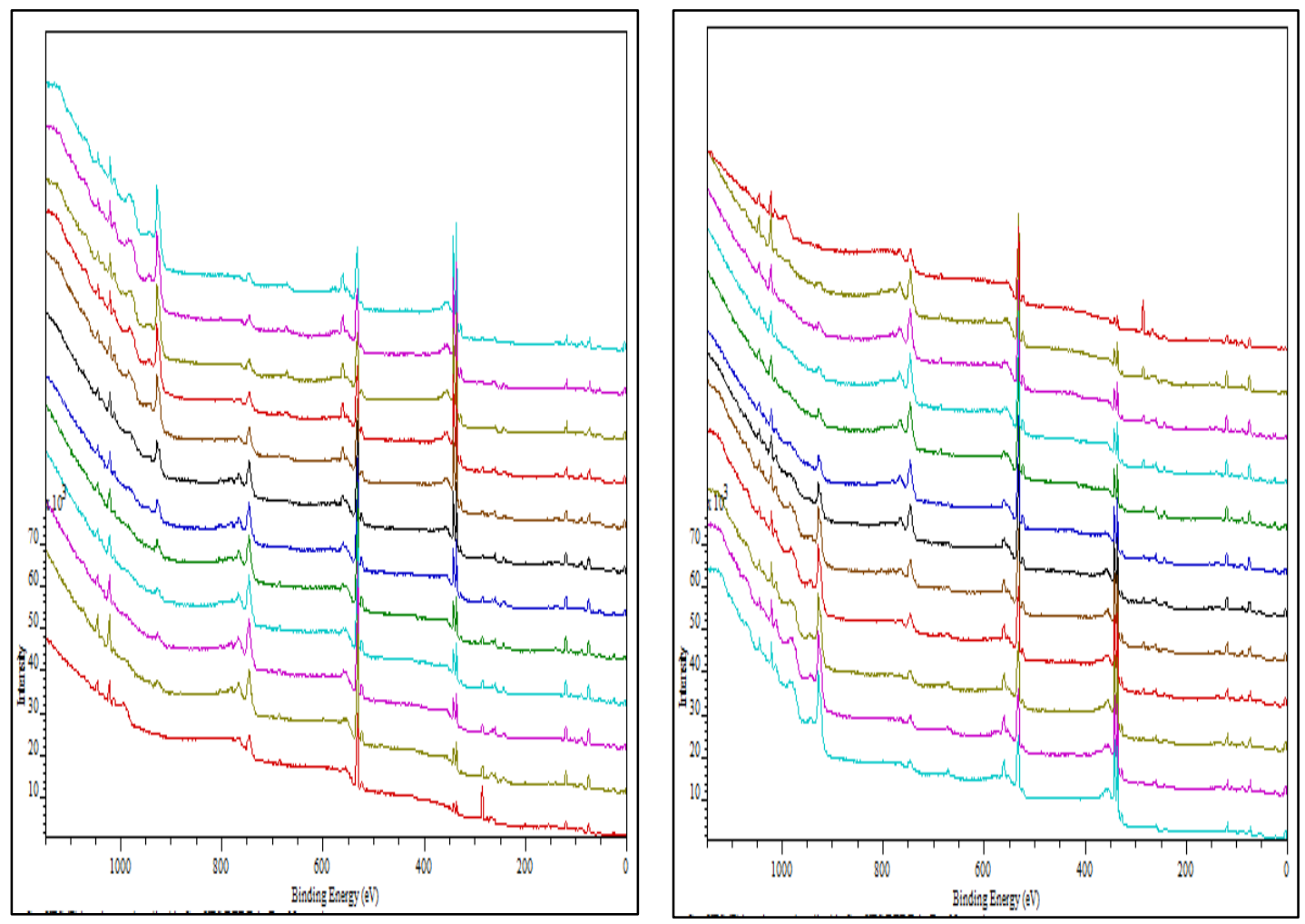


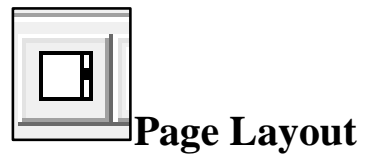

The page layout icon allows you to change the size of the graph.

1. Highlight the selected files on the right column. See example below.

\begin{tabular}{|l|l|}
\hline \hline Data Set & None \\
\hline 0 & None \\
\hline 1 & None \\
2 & None \\
3 & None \\
4 & None \\
5 & None \\
6 & None \\
\hline
\end{tabular}

2. Click on graph to activate the toolbar.

3. Click on the "Page layout"

4. A "page layout" window would appear as depicted below. Play around with the settings until you are satisfied. 

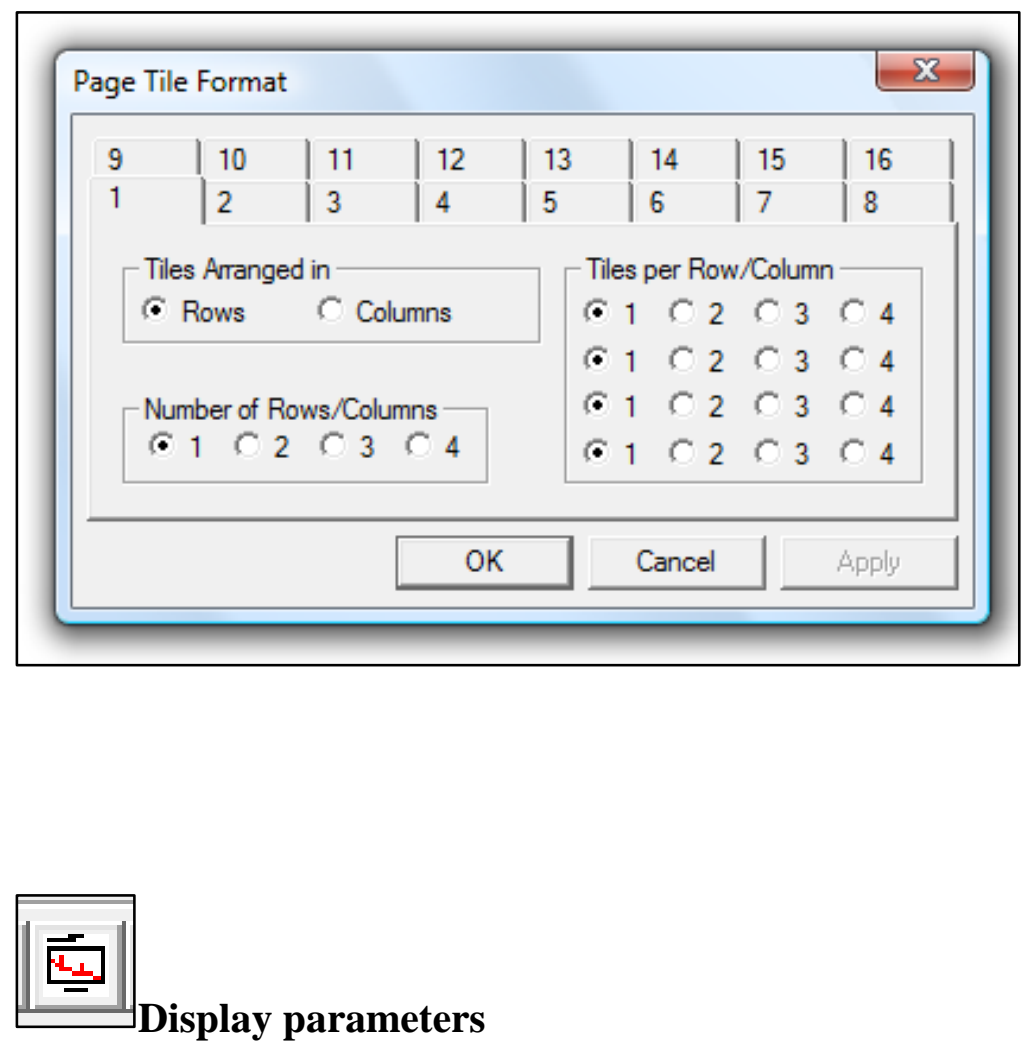

The display parameters icon allows you to "dress up" the graph. In other words, it makes it look professional for publications and presentations.

1. Highlight the selected files on the right column. See example below.

\begin{tabular}{|c|c|}
\hline \multicolumn{2}{|c|}{${ }^{m+1}=1$} \\
\hline Data Set & None \\
\hline 0 & None \\
\hline 1 & None \\
\hline 2 & None \\
\hline 3 & None \\
\hline 4 & None \\
\hline 5 & None \\
\hline 6 & None \\
\hline
\end{tabular}

2. Click on the graph to activate the toolbar. 
3. Click on the "Display Parameters"

4. A display parameters window would appear as depicted below. Play around with the settings until you are satisfied.

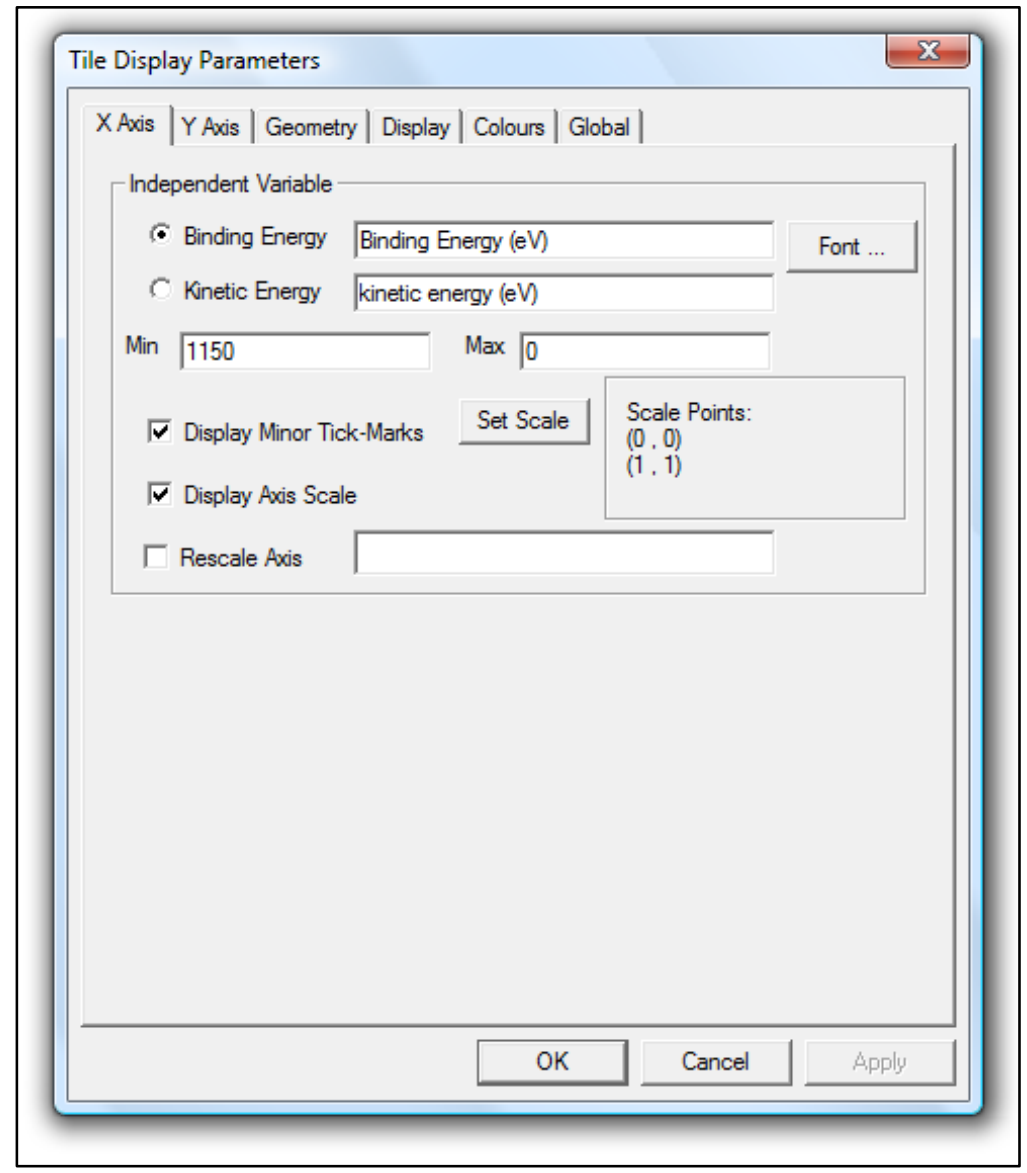

a) $\mathrm{X}$-axis tab allows you to change the font and size of the $\mathrm{X}$-axis label, choosing binding energy or kinetic energy $x$-axis labels, change the minimum and maximum energies of your spectrum, etc. 
b) Y-axis tab allows you to change the font and size of the $y$-axis label, can change display y-axis parameters, can normalize your overlaid or offset spectrums, etc.

c) Geometry tab allows you to change your spectrum graph from 2D to 3D.

d) Display parameters allow you to display what you want or do not want on your graph. For instance, you can change the line width of the spectrum, change the axes font and size, etc.

e) Colours tab alloys you to change the color lines in your spectra and such. In order to go from color to all black, please follow these next few steps below.

i) Click "Spectra". A "color" window would appear as depicted below. Depending on how many spectra are in your graph, the colors would start off with red, then olive, pink, light blue, green, dark blue, black, brown, would then repeat that cycle again (see custom colors in the figure below). [Note: the first spectrum is depicted in red, the second spectrum is depicted in olive, and so forth.] 


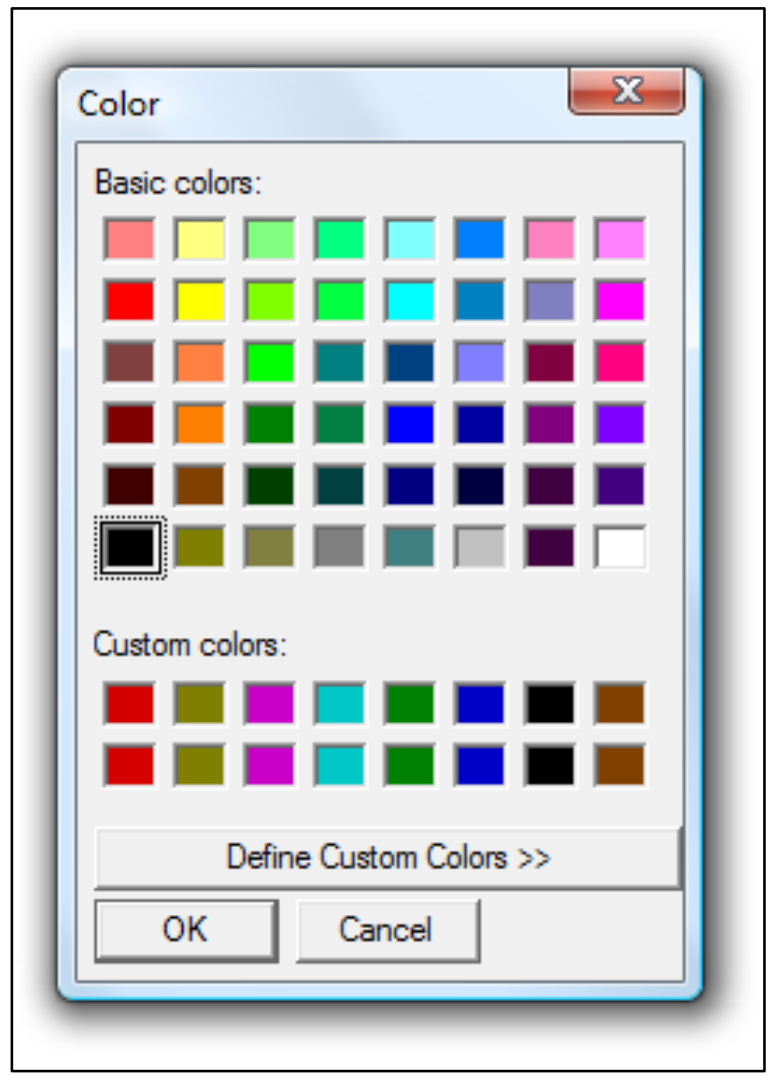

ii) In order to change these colors, click on the color you want to change in the custom colors section. Then, click "Define Custom Colors $>>$ ". The "color" window would now look like this.

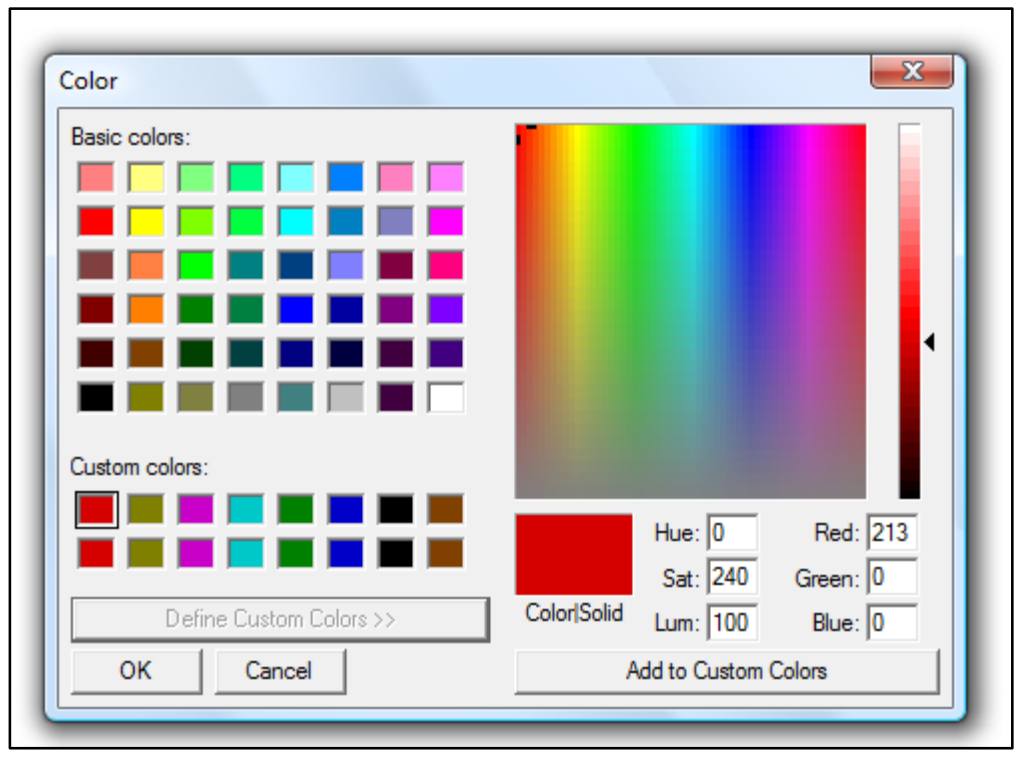


iii) To go from red to black, drag the black arrow on the right side of the window down to black and click "Add to Custom Colors". Then click "Ok". Repeat steps ii) and iii) if desired. 


\section{Creating Regions A (Long Method)}

1. Click on one of the files on the right column to work on.

2. Click on the spectrum to activate the toolbar.

3. Click on the "Quantification Parameter" icon.

4. A "quantification parameter" window should pop up.

5. Click on the "Create" button at the bottom left of the window.

6. Type in the name of your region and press enter.

7. If this is an AES data, fill in the relative sensitivity factor in the "RSF" section. (NOTE: RSF is not given in AES analysis. You will need to plug in values from the "Handbook of Auger Electron Spectroscopy". Make sure you multiply the sensitivity factor with the scale factor and type that into the "RSF" section). See "Handbook of Auger Electron Spectroscopy" for the surface concentration equation.

8. On the spectrum, a blue shade color appears with gray columns at the ends. This is your start and end energy ranges. Use the mouse to drag the gray columns to where you want to start and end your energy range. The blue highlighted range is your energy range being analyzed.

9. If you are doing XPS analysis, type in "Shirley" in BG type. If you are doing AES analysis, type in "Linear" in BG type.

10. You have then created your region. This is shown by annotation on the top left of the spectrum. To add more regions, repeat steps 5 through 9 again. 


\section{Creating Regions B (Short Method)}

1. Click on one of the files on the right column to work on.

2. Click on the spectrum to activate the toolbar.

3. Click on the "Elemental Library" icon.

4. Can either go to the "Element Table" tab (XPS analysis) or "Periodic Table" tab (XPS or AES analysis).

A. Under the "Element Table" tab, scroll down until you have reached your desired cross section. Click "create regions". Keep doing this process until you got all the regions desired. (NOTE: If not all regions were created, meaning the annotation does not appear on the top left of the spectrum, you would then have to do the long method. See section III. Creating Regions A for procedures.)

B. Under the "Periodic Table" tab, click on all the elements that you want to create regions on. Click on the "create regions" button when finished. (NOTE: If not all regions were created, meaning the annotation does not appear on the top left of the spectrum, you would then have to do the long method. See section III. Creating Regions A for procedures.)

5. If all the regions are created by step $4 \mathrm{a}$ or $4 \mathrm{~b}$, then close the "elemental library" window.

6. Click on the "Quantification Parameter" icon.

7. Make sure name, RSF, and start/end energy ranges are correct (NOTE: RSF is not given in AES analysis. Need to plug in values from the "Handbook of Auger Electron Spectroscopy". Make sure you multiply the sensitivity factor with the scale factor and type that into "RSF").

8. You have then created your region. This is shown by annotation on the top left of the spectrum. 


\section{Finding Atomic Percent Concentration for AES Analysis (Survey Spectra)}

1. Click on one of the files to work on.

2. Click on the spectrum to activate the toolbar.

3. Click on the "Spectrum Processing"

4. Click on the "Smoothing" tab to smooth your spectrum. (See II. Toolbar Information under Spectrum Processing for procedure)

5. Click on the "Differentiation" tab to take the first derivative on your spectrum. (See II. Toolbar Information under Spectrum Processing for procedure)

6. Close the "Spectrum Processing" window.

7. Need to create regions. (See III. Creating Regions A or IV. Creating Regions B for procedure)

8. In the "Quantification Parameter" window, click on "Report Spec" tab.

9. Click "Regions" in the Custom Report section. A list of all of your regions should appear in the second "white box" region where it says "Names and Formulas".

10. Click "Height Report".

11. A new window would appear. It will give you your atomic per concentration as well as counts per second (CPS) for that file.

12. If you have more than one file and need to analyze the same regions, please see II. Toolbar Information under Browser operations for procedure. 


\section{Finding Atomic Percent Concentration for AES Analysis (Individual Peak Spectra)}

** Unfortunately, CasaXPS cannot calculate atomic percent concentrations for individual peak spectra. However, it can calculate maximum peak heights (peak plus) and minimum peak heights (peak minus). You can use this information to calculate the atomic percent concentration manually.

1. Follow Steps 1 through 8 and/or 12 under section V. Finding Atomic Percent Concentration for AES Analysis (Overview Spectrum) for procedures.

2. Click "Regions" in the "Standard Report" section.

3. A new window will appear. It shows the name, position, FWHM, raw area, area/(T*MFP), area/(RSF*T*MFP), library RSF, peak plus, peak minus, total RSF, and atomic percent concentration.

4. Record the peak plus and peak minus values to find the atomic percent concentrations. 


\section{Finding Atomic Percent Concentration for XPS Analysis (Survey Spectra)}

1. Click on one of the files to work on.

2. Click on the spectrum to activate the toolbar.

3. Need to create regions (See III. Creating Regions A or IV. Creating Regions B for procedure)

4. In the "Quantification parameter" window, click on "Report Spec" tab.

5. Click "Regions" in the Custom Report section. A list of all of your regions should appear in the second "white box" region where it says "Names and Formulas".

6. Click "Area Report".

7. A new window would appear. It will give you your atomic percent concentration as well as counts per second (CPS) for that file.

8. If you have more than one file and need to analyze the same regions, please see II. Toolbar Information under Browser operations for procedure. 


\section{Finding Atomic Percent Concentration for XPS Analysis (Individual Peak Spectra)}

** Unfortunately, CasaXPS cannot calculate atomic percent concentrations for individual peak spectra. However, it can calculate area of the peak. You can use this information to calculate the atomic percent concentration manually.

1. Follow steps 1 to 4 and/or 8 under section VII. Finding Atomic Percent Concentration for XPS Analysis (Overview Spectra).

2. Click "Regions" in the "Standard Report" section.

3. A new window will appear. It shows the name, position, FWHM, raw area, area/(T*MFP), area/(RSF*T*MFP), library RSF, peak plus, peak minus, total RSF, and atomic percent concentration.

4. Record the raw area values to find the atomic percent concentration.

5. Below is an example on calculating the atomic percent concentration manually on Excel. This procedure also is illustrated on the next page.

a. Record the area values from step \#4 into Excel.

b. Record the RSF of the individual cross section from the "Elemental Library"

$$
\text { icon Lit. }
$$

c. Take the area and divided by the RSF of the individual cross section.

d. Make a third column and sum the individual cross section.

e. Atomic percent concentration is taking one of the (area/RSF) divided by the sum and multiplying by 100 . 


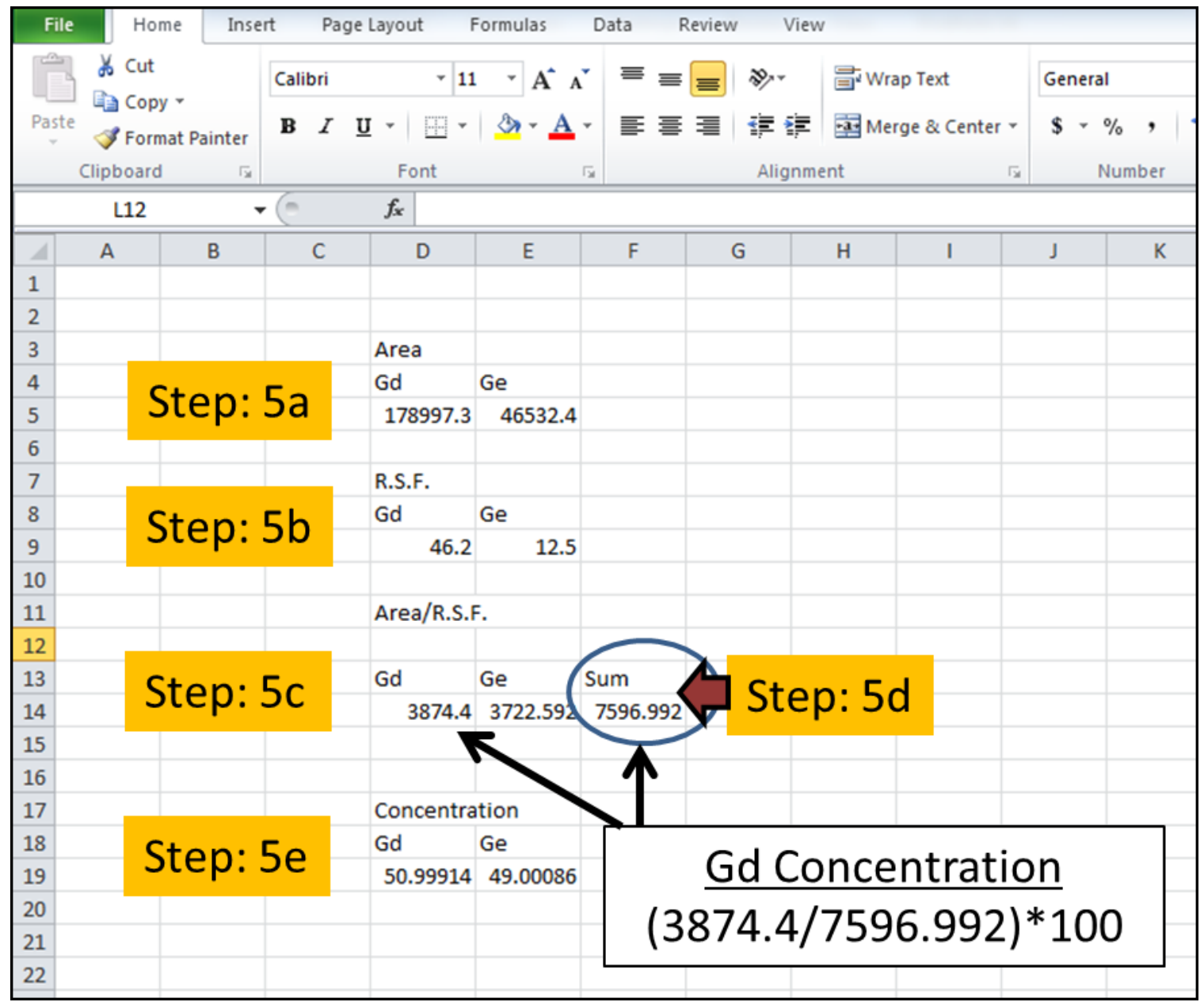




\section{Deconvoluting Peaks}

1. Open a file that contains your standard peaks. [i.e. a spectrum of a clean surface]

2. Click on the spectrum to activate the toolbar.

3. Follow steps 1-5 in Section III. Creating Regions A (Long Method).

4. With the "Quantification Parameter" icon opened, select your binding energy ranges by moving the grey vertical bar in the spectrum. [NOTE: The blue highlighted area is your energy range as illustrated below].

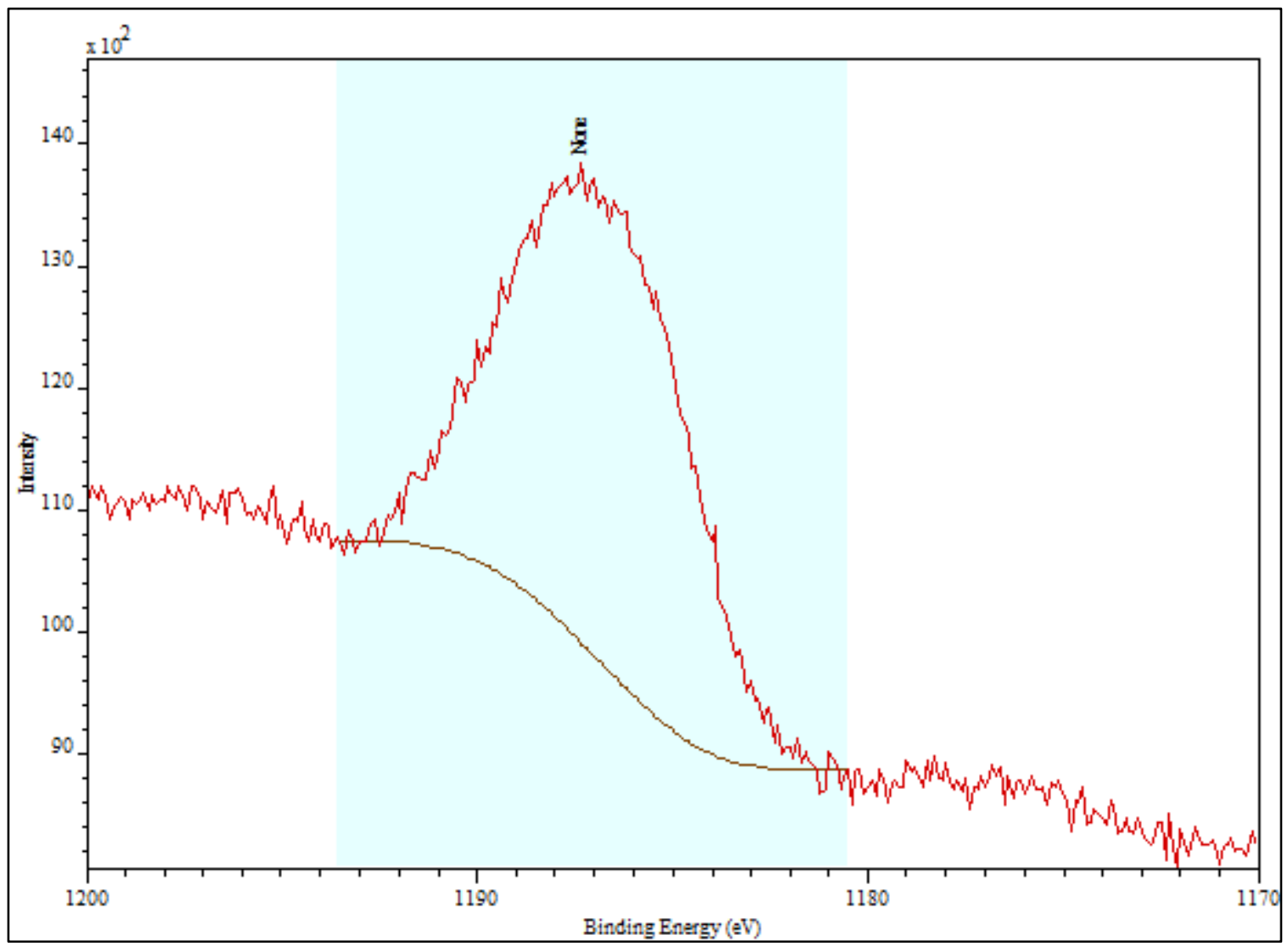

5. In the "Quantification Parameter" window, make sure the BG (Background) Type is set to "Shirley". If not, type it in and click "enter" to set it. A Shirley background is defined by the area underneath the curve minus from the background spectrum. It should look like an upside S-shape as shown in the figure above (See illustration in Step \#4). 
6. In the "Quantification Parameters" window, click on the "Components" tab.

7. Click the "Create" button.

8. A pink Gaussian curve-fit line will appear in your spectrum as depicted below. As best as you can, play around with the "Line Shape" number [i.e. GL(25)] in order to make the Gaussian line fit in your desired peak. See below. GL stands for Gaussian and Lorentzian and the number represents the percentage amount of either Gaussian or Lorentzian.

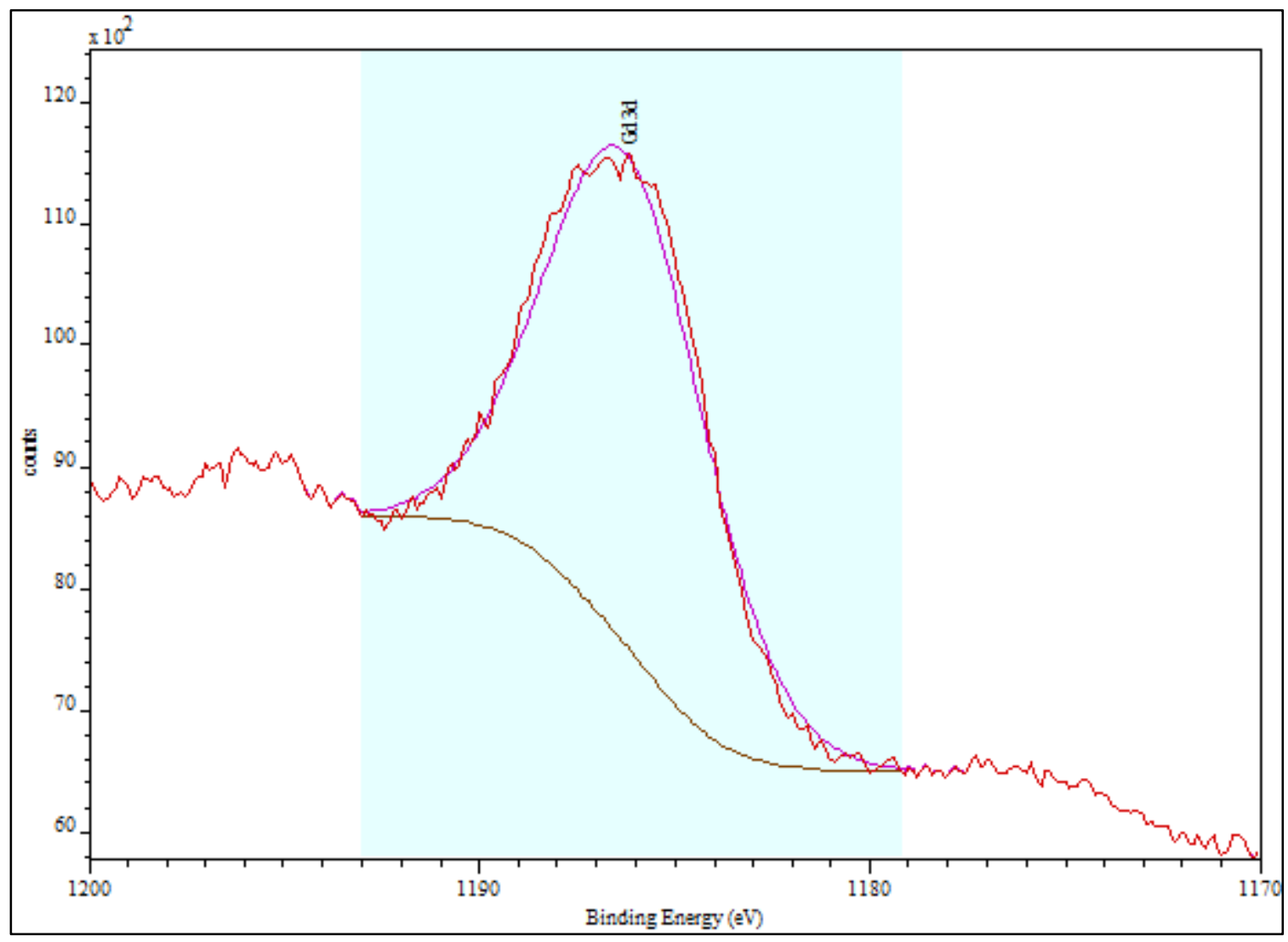

9. Once fitted, record the peak position and fwhm (full width at half maximum).

10. Then, open a file that contains your experimental peaks. [i.e. a spectrum of an oxidized surface]

11. Repeat steps \#2 - 7. Make sure the binding energy ranges are constant as with your standard peak in step \#4.

12. After you had created a component, a pink Gaussian curve-fit line will appear in your spectrum. Type in your standard peak position and fwhm that you had recorded in Step \#9 into your component. 
13. Once the new peak positions and fwhm have been recorded into your component, you then need to constrain it. Under "Pos. Constr." and "fwhm Constr.", either change the minimum or maximum or both so that the position and the fwhm are fixed. The position and fwhm should now turn the color pink.

14. Create a second component.

15. A blue Gaussian curve fit will appear as depicted below. Since, you had restrained the pure metal onto the oxidized peak, your blue Gaussian line is designated as the oxide metal and the pink Gaussian line is designated as the pure metal.

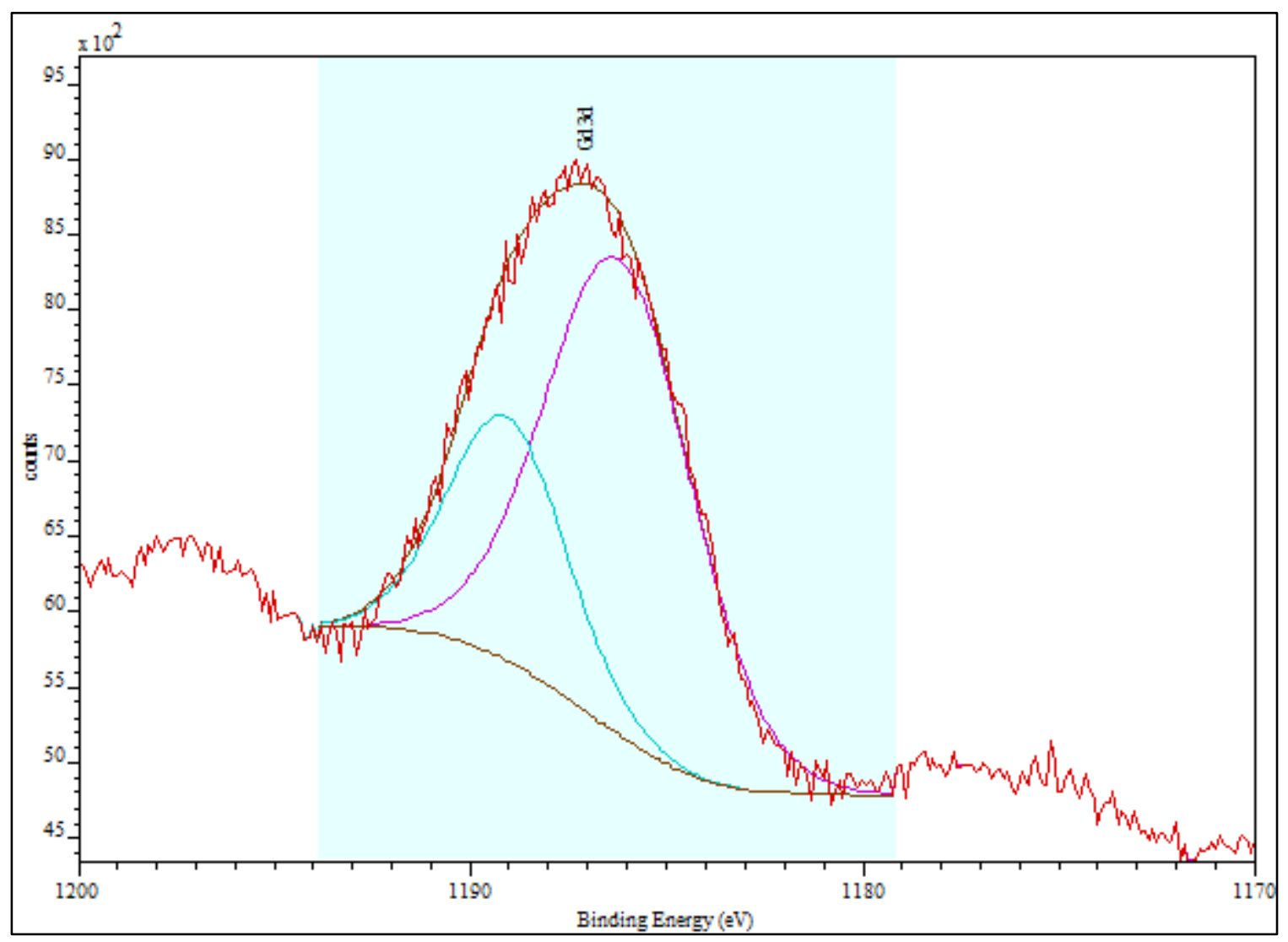


16. Below is an example of deconvoluting the $\mathrm{Gd}$ oxide peak in $\mathrm{Gd}_{5} \mathrm{Ge}_{4}$.

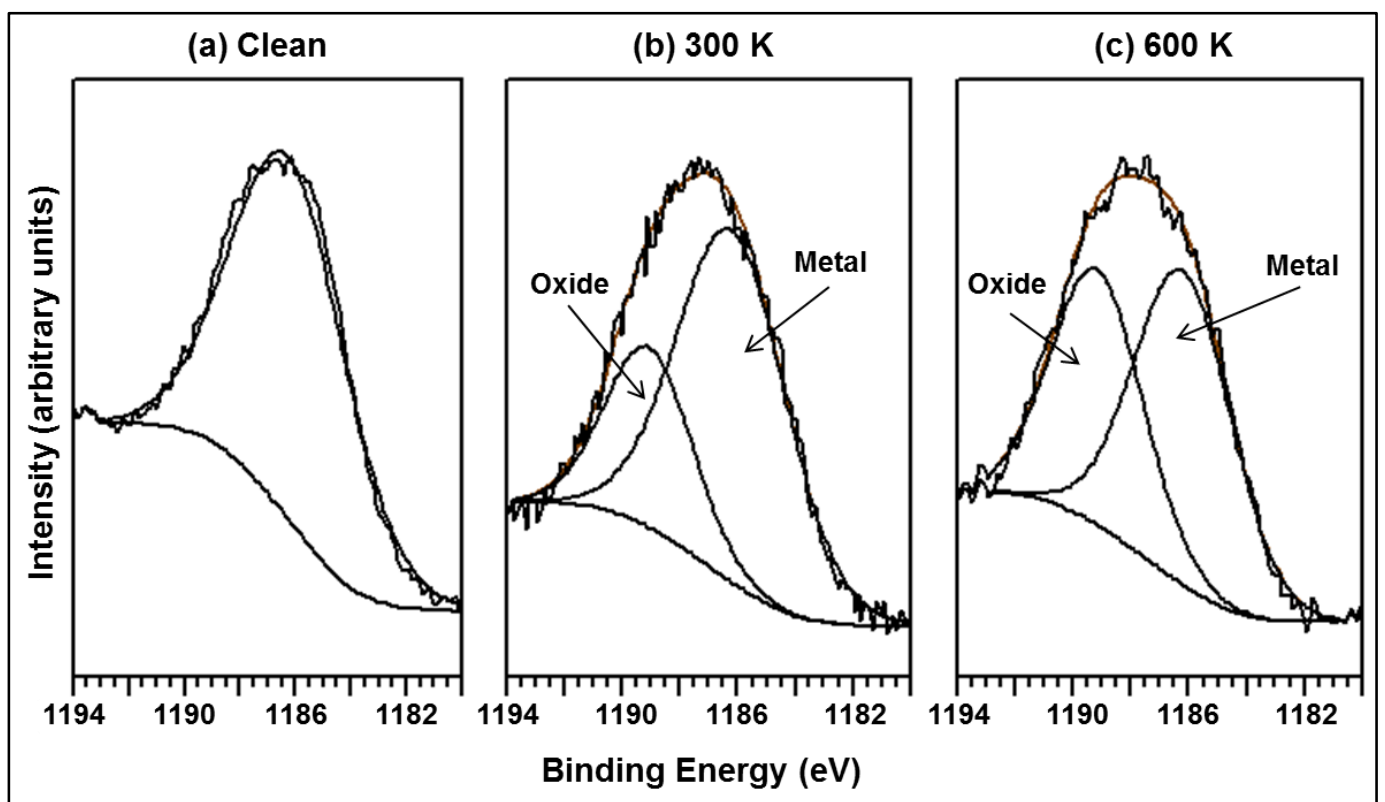

Fig.4 


\section{APPENDIX B. Experimental Database}

\section{Table Captions}

1. 2f Al-Pd-Zn Approximant

2. $10 \mathrm{f} \mathrm{Al}-\mathrm{Pd}-\mathrm{Zn}$ Approximant

3. $\mathrm{Gd}_{5} \mathrm{Ge}_{4}(010)$

a. Omicron Chamber (224 Spedding), performed by Chad Yuen

b. AES/SEM Chamber (137 Wilhelm), performed by Jim Anderegg

\begin{tabular}{|c|c|c|}
\hline Sample \# & Table \# & Date \\
\hline MPC hmd-1-73 & 3A & $10 / 23 / 2010-12 / 12 / 2010$ \\
\hline \multirow{2}{*}{ MPC-dls-7-68-2 } & 3A & $4 / 21 / 2011-5 / 18 / 2011$ \\
& 3B & $7 / 4 / 2012$ \\
\hline MPC dlw-1-97 & 3A & $4 / 25 / 2012-6 / 28 / 2012$ \\
\hline \multirow{2}{*}{ MPC dlw-1-1 } & 3B & $\begin{array}{c}6 / 14 / 2011-8 / 6 / 2012(\text { except on } \\
7 / 4 / 2012)\end{array}$ \\
\hline
\end{tabular}

4. Au on NiAl (110)

5. Ag on NiAl (110) and Au on NiAl (110) [Switzerland]

6. $\mathrm{O}_{2}$ on $\mathrm{Ag}$ on oxidized $\mathrm{NiAl}$ (110) and Ag on oxidized NiAl (110) 
Table 1

\begin{tabular}{|c|c|c|c|c|c|c|}
\hline \multicolumn{7}{|c|}{ 2f AlPdZn Data List } \\
\hline Date & $\begin{array}{l}\text { Images / } \\
\text { Spectrum }\end{array}$ & Instr. & Purpose & Lab \#, Page \# & File Name & Notes \\
\hline $1 / 21 / 2009$ & overview & AES & Finding a good position & Bk 1, pg 42 & 121090 & $\begin{array}{l}\text { Overview Spectrum: The whole scan } \\
\text { range. }\end{array}$ \\
\hline $1 / 22 / 2009$ & overview & AES & $\begin{array}{l}\text { Cleaning sample (sputtering } \\
\text { only) }\end{array}$ & Bk 1, pg 42 & $\begin{array}{l}122090 \text { to } \\
122092\end{array}$ & $\mathrm{O}$ and $\mathrm{C}$ were decreasing. \\
\hline $1 / 23 / 2009$ & overview & AES & $\begin{array}{l}\text { Cleaning sample (sputtering } \\
\text { only) }\end{array}$ & Bk 1, pg 46 & $\begin{array}{l}123090 \text { to } \\
123092\end{array}$ & Shows $\mathrm{O}$ and $\mathrm{C}$. \\
\hline \multirow{2}{*}{$1 / 24 / 2009$} & overview & AES & $\begin{array}{l}\text { Cleaning sample (sputtering } \\
\text { only) }\end{array}$ & Bk 1, pg 48 & 124090 & Shows $\mathrm{O}$ and $\mathrm{C}$. \\
\hline & overview & XPS & Finding a good position & Bk 1, pg 51 & 124090 & $\begin{array}{l}\text { Found } \mathrm{Ni} \text { and Fe. It turns out the sample } \\
\text { plate was Stainless steal and not Ta. }\end{array}$ \\
\hline \multirow[t]{2}{*}{$1 / 25 / 2009$} & overview & AES & $\begin{array}{l}\text { Cleaning sample (sputtering } \\
\text { only) }\end{array}$ & Bk 1, pg 51 & $\begin{array}{l}125090 \text { to } \\
125091\end{array}$ & \\
\hline & overview & XPS & Finding a good position & $\mathrm{Bk} 1, \operatorname{pg} 53$ & 125090 & \\
\hline \multirow{2}{*}{$1 / 26 / 2009$} & overview & \multirow{2}{*}{ XPS } & $\begin{array}{l}\text { Using a Ag sample to help } \\
\text { place correct position on } \\
\text { AlPdZn }\end{array}$ & Bk 1, pg 54 & 126090 & Showed huge Ag intensity peaks. \\
\hline & overview & & $\begin{array}{l}\text { Using the Ag sample position } \\
\text { for the AlPdZn }\end{array}$ & Bk 1, pg 55 & $\begin{array}{l}126091 \text { to } \\
126093\end{array}$ & $\begin{array}{l}\text { File Name } 126092 \text { showed the best } \\
\text { position. }\end{array}$ \\
\hline \multirow{2}{*}{$1 / 27 / 2009$} & overview & AES & $\begin{array}{l}\text { Cleaning sample (sputtering } \\
\text { only) }\end{array}$ & Bk 1, pg 56 & $\begin{array}{l}127090 \text { to } \\
127091\end{array}$ & Identifying peaks. \\
\hline & overview & XPS & Still searching a good position & Bk 1, pg 57 & $\begin{array}{l}127090 \text { to } \\
127093\end{array}$ & $\begin{array}{l}\text { Still file name } 126092 \text { had the best } \\
\text { position. }\end{array}$ \\
\hline
\end{tabular}


Table 1 (Continue)

\begin{tabular}{|c|c|c|c|c|c|c|}
\hline Date & $\begin{array}{l}\text { Images / } \\
\text { Spectrum }\end{array}$ & Instr. & Purpose & Lab \#, Page \# & File Name & Notes \\
\hline \multirow{3}{*}{$1 / 28 / 2009$} & overview & XPS & $\begin{array}{l}\text { Playing with the CRR and Mag. } \\
\text { to get good intensities }\end{array}$ & Bk 1, pg 59 & $\begin{array}{l}128090 \text { to } \\
128096\end{array}$ & $\begin{array}{l}\text { The best intensities was making the CRR } \\
=7 \text { and the Mag = Medium. }\end{array}$ \\
\hline & M1-M13 & \multirow{2}{*}{ STM } & $\begin{array}{l}\text { Scanning on Site A (left grain } \\
\text { from the fracture) on a sputtered } \\
\text { surface }\end{array}$ & Bk 1, pg 60 & \multirow{2}{*}{12809} & $\begin{array}{l}\text { Surface was rough, lots of white circles } \\
\text { (maybe oxidation), step bunching } \\
\text { (maybe). }\end{array}$ \\
\hline & M14-M20 & & $\begin{array}{l}\text { Scanning on Site B (right grain } \\
\text { from the fracture) on a sputtered } \\
\text { surface }\end{array}$ & Bk 1, pg 60 & & $\begin{array}{l}\text { Same as Site A, but appears to be } \\
\text { smoother. }\end{array}$ \\
\hline $1 / 29 / 2009$ & overview & AES & Finding a good position & Bk 1, pg 61 & $\begin{array}{l}129090 \text { to } \\
129096\end{array}$ & $\begin{array}{l}\text { File Name } 129094 \text { was the best for } \\
\text { Frame Mode. }\end{array}$ \\
\hline $1 / 30 / 2009$ & overview & XPS & $\begin{array}{l}\text { Testing to see which cathode: } \mathrm{Al} \\
\text { or Mg produces best intensities }\end{array}$ & Bk 1, pg 63 & $\begin{array}{l}130090 \text { to } \\
130092\end{array}$ & Mg Cathode produces the best intensities. \\
\hline \multirow{4}{*}{$2 / 3 / 2009$} & overview & AES & Taken after sputtering & Bk 1, pg 65 & 203090 & \\
\hline & overview & XPS & Taken after sputtering & Bk 1, pg 65 & 203090 & \\
\hline & overview & AES & $\begin{array}{l}\text { After sputtering again and } \\
\text { annealing at } 0.4 \mathrm{~A}\end{array}$ & Bk 1, pg 66 & 203091 & \\
\hline & overview & XPS & $\begin{array}{l}\text { After sputtering again and } \\
\text { annealing at } 0.4 \mathrm{~A}\end{array}$ & Bk 1, pg 66 & 203091 & \\
\hline
\end{tabular}


Table 1 (Continue)

\begin{tabular}{|c|c|c|c|c|c|c|}
\hline Date & $\begin{array}{l}\text { Images / } \\
\text { Spectrum }\end{array}$ & Instr. & Purpose & Lab \#, Page \# & $\begin{array}{l}\text { File } \\
\text { Name }\end{array}$ & Notes \\
\hline \multirow{9}{*}{$2 / 4 / 2009$} & overview & AES & $\begin{array}{l}\text { After sputtering (starting the } \\
\text { concentration vs time expt) }\end{array}$ & Bk 1, pg 67 & $\begin{array}{l}204090 \text { to } \\
204091\end{array}$ & $\begin{array}{l}\text { Spot Mode shows a higher intensity than } \\
\text { frame mode and also changed my position } \\
\text { to file name } 204090 \text {. }\end{array}$ \\
\hline & overview & XPS & $\begin{array}{l}\text { After sputtering (starting the } \\
\text { concentration vs time expt) }\end{array}$ & Bk 1, pg 67 & 204090 & \\
\hline & overview & XPS & $\begin{array}{l}\text { After annealing at } 0.4 \mathrm{~A} \text { for } 30 \\
\text { minutes }\end{array}$ & Bk 1, pg 68 & 204091 & $\begin{array}{l}\text { Pd decreases, } \mathrm{Zn} \text { increases (note: } \mathrm{O} 1 \mathrm{~s} \\
\text { peak overlapse one of the } \mathrm{Pd} \text { peaks). }\end{array}$ \\
\hline & overview & AES & After annealing at $0.4 \mathrm{~A}$ for 1 hour & Bk 1, pg 68 & 204093 & Pd decreases, $\mathrm{Zn}$ increases. \\
\hline & overview & XPS & After annealing at $0.4 \mathrm{~A}$ for 1 hour & Bk 1, pg 68 & 204092 & Pd decreases, $\mathrm{Zn}$ increases. \\
\hline & overview & AES & $\begin{array}{l}\text { After annealing at } 0.4 \mathrm{~A} \text { for } 1.5 \\
\text { hours }\end{array}$ & Bk 1, pg 69 & 204094 & $\mathrm{Zn}$ increases, hard to find $\mathrm{Al}$ peak. \\
\hline & overview & XPS & $\begin{array}{l}\text { After annealing at } 0.4 \mathrm{~A} \text { for } 1.5 \\
\text { hours }\end{array}$ & Bk 1, pg 69 & 204093 & $\begin{array}{l}\text { Zn increases, little oxygen (note: oxygen } \\
\text { auger peak). }\end{array}$ \\
\hline & overview & AES & $\begin{array}{l}\text { After annealing at } 0.4 \text { A for } 2 \\
\text { hours (expt. Finished) }\end{array}$ & Bk 1, pg 70 & 204095 & Saw Pd and $\mathrm{Zn}$ peaks. \\
\hline & overview & XPS & $\begin{array}{l}\text { After annealing at } 0.4 \text { A for } 2 \\
\text { hours (expt. Finished) }\end{array}$ & Bk 1, pg 70 & 204094 & Little Pd peak, huge Zn peak. \\
\hline
\end{tabular}


Table 1 (Continue)

\begin{tabular}{|c|c|c|c|c|c|c|}
\hline Date & $\begin{array}{l}\text { Images / } \\
\text { Spectrum }\end{array}$ & Instr. & Purpose & Lab \#, Page \# & $\begin{array}{l}\text { File } \\
\text { Name }\end{array}$ & Notes \\
\hline \multirow{12}{*}{$2 / 5 / 2009$} & overview & AES & $\begin{array}{l}\text { After sputtering (starting } \\
\text { concentration vs temp expt) }\end{array}$ & Bk 1, pg 70 & $\begin{array}{l}205090 \text { to } \\
205091\end{array}$ & $\begin{array}{l}\text { File } 205091 \text { showed better signal by } \\
\text { changing angle on the manipulator. }\end{array}$ \\
\hline & overview & XPS & $\begin{array}{l}\text { After sputtering (starting } \\
\text { concentration vs temp expt) }\end{array}$ & Bk 1, pg 71 & 205090 & \\
\hline & overview & AES & $\begin{array}{l}\text { After annealing at } 0.2 \mathrm{~A} \text { for } 2 \\
\text { hours }\end{array}$ & Bk 1, pg 71 & 205092 & No change compared to after sputtering. \\
\hline & overview & XPS & $\begin{array}{l}\text { After annealing at } 0.2 \mathrm{~A} \text { for } 2 \\
\text { hours }\end{array}$ & Bk 1, pg 71 & 205091 & No change compared to after sputtering. \\
\hline & overview & AES & After sputtering & Bk 1, pg 72 & 205093 & \\
\hline & overview & XPS & After sputtering & Bk 1, pg 72 & 205092 & \\
\hline & overview & AES & $\begin{array}{l}\text { After annealing at } 0.3 \mathrm{~A} \text { for } 2 \\
\text { hours }\end{array}$ & Bk 1, pg 73 & 205094 & Pd decreases, $\mathrm{Zn}$ increases. \\
\hline & overview & XPS & $\begin{array}{l}\text { After annealing at } 0.3 \mathrm{~A} \text { for } 2 \\
\text { hours }\end{array}$ & Bk 1, pg 73 & 205093 & $\mathrm{Zn}, \mathrm{Ni}, \mathrm{Fe}, \mathrm{Pd}$, and $\mathrm{O}$. \\
\hline & overview & AES & After sputtering & Bk 1, pg 73 & 205095 & \\
\hline & overview & XPS & After sputtering & Bk 1, pg 74 & 205094 & \\
\hline & overview & AES & $\begin{array}{l}\text { After annealing at } 0.4 \mathrm{~A} \text { for } 2 \\
\text { hours }\end{array}$ & Bk 1, pg 74 & 205096 & $\begin{array}{l}\text { Pd decreases, } \mathrm{Zn} \text { increases, possibly see } \mathrm{Al} \\
\text { peak. }\end{array}$ \\
\hline & overview & XPS & $\begin{array}{l}\text { After annealing at } 0.4 \mathrm{~A} \text { for } 2 \\
\text { hours }\end{array}$ & Bk 1, pg 74 & 205095 & Pd decreases, $\mathrm{Zn}$ increases, and oxygen. \\
\hline
\end{tabular}


Table 1 (Continue)

\begin{tabular}{|c|c|c|c|c|c|c|}
\hline Date & $\begin{array}{l}\text { Images / } \\
\text { Spectrum }\end{array}$ & Instr. & Purpose & Lab \#, Page \# & $\begin{array}{l}\text { File } \\
\text { Name }\end{array}$ & Notes \\
\hline \multirow{6}{*}{$2 / 6 / 2009$} & overview & AES & $\begin{array}{l}\text { After sputtering (continue expt } \\
\text { from } 2 / 5 / 09 \text { ) }\end{array}$ & Bk 1, pg 75 & 206090 & \\
\hline & overview & XPS & $\begin{array}{l}\text { After sputtering (continue expt } \\
\text { from } 2 / 5 / 09 \text { ) }\end{array}$ & Bk 1, pg 75 & 206090 & \\
\hline & overview & AES & $\begin{array}{l}\text { After annealing at } 0.5 \text { A for } 2 \\
\text { hours (expt finished) }\end{array}$ & Bk 1, pg 76 & 206091 & See Pd and Zn peaks. \\
\hline & overview & XPS & $\begin{array}{l}\text { After annealing at } 0.5 \text { A for } 2 \\
\text { hours (expt finished) }\end{array}$ & Bk 1, pg 76 & 206091 & $\mathrm{Zn}, \mathrm{Ni}, \mathrm{Fe}$, little Pd. \\
\hline & M1-M13 & STM & Site A (right grain from fracture) & Bk 1, pg 77 & \multirow{2}{*}{20609} & See maybe step bunching, rough surface. \\
\hline & M14-M21 & STM & Site B (left grain from fracture) & Bk 1, pg 77 & & $\begin{array}{l}\text { Rougher than Site A, same surface } \\
\text { morphology as in Site A. }\end{array}$ \\
\hline \multirow{2}{*}{ 2/7/2009 } & overview & AES & $\begin{array}{l}\text { Replaced sample plate and finding } \\
\text { good position }\end{array}$ & Bk 1, pg 77 & $\begin{array}{l}207090 \text { to } \\
207092\end{array}$ & $\begin{array}{l}\text { Used Ta plate instead of stainless steal } \\
\text { plate. File } 207092 \text { had best intensity. }\end{array}$ \\
\hline & overview & XPS & $\begin{array}{l}\text { Replaced sample plate and finding } \\
\text { good position }\end{array}$ & Bk 1, pg 78 & $\begin{array}{l}207090 \text { to } \\
207093\end{array}$ & $\begin{array}{l}\text { Used Ta plate instead of stainless steal } \\
\text { plate. File } 207093 \text { had best intensity. }\end{array}$ \\
\hline
\end{tabular}


Table 1 (Continue)

\begin{tabular}{|c|c|c|c|c|c|c|}
\hline Date & $\begin{array}{l}\text { Images / } \\
\text { Spectrum }\end{array}$ & Instr. & Purpose & Lab \#, Page \# & $\begin{array}{l}\text { File } \\
\text { Name }\end{array}$ & Notes \\
\hline \multirow{13}{*}{ 2/8/2009 } & overview & AES & Starting Depth-Profiling Expt & $\mathrm{Bk} 1, \operatorname{pg} 78$ & 208090 & No sputtering (found $\mathrm{O}$ and $\mathrm{C}$ ). \\
\hline & overview & XPS & Starting Depth-Profiling Expt & Bk 1, pg 79 & 208090 & No sputtering (found $\mathrm{O}$ and $\mathrm{C}$ ). \\
\hline & overview & AES & After 5 minutes of sputtering & Bk 1, pg 79 & 208091 & O peak decreases, no $\mathrm{C}$ peak. \\
\hline & overview & XPS & After 5 minutes of sputtering & Bk 1, pg 79 & 208091 & $\mathrm{O}$ and $\mathrm{C}$ peak decreasing. \\
\hline & overview & AES & $\begin{array}{l}\text { After } 5 \text { minutes of sputtering (10 } \\
\text { mins total) }\end{array}$ & $\mathrm{Bk} 1, \mathrm{pg} 80$ & 208092 & O peak decreases. \\
\hline & overview & XPS & $\begin{array}{l}\text { After } 5 \text { minutes of sputtering ( } 10 \\
\text { mins total) }\end{array}$ & Bk 1, pg 80 & 208092 & $\mathrm{O}$ and $\mathrm{C}$ peak decreasing. \\
\hline & overview & AES & $\begin{array}{l}\text { After } 5 \text { minutes of sputtering ( } 15 \\
\text { mins total) }\end{array}$ & Bk 1, pg 81 & 208093 & O peak decreases. \\
\hline & overview & XPS & $\begin{array}{l}\text { After } 5 \text { minutes of sputtering ( } 15 \\
\text { mins total) }\end{array}$ & Bk 1, pg 81 & 208093 & $\mathrm{O}$ and $\mathrm{C}$ peak decreasing. \\
\hline & overview & AES & $\begin{array}{l}\text { After } 5 \text { minutes of sputtering ( } 20 \\
\text { mins total) }\end{array}$ & Bk 1, pg 81 & 208094 & Hard to tell if there was O peak or not. \\
\hline & overview & XPS & $\begin{array}{l}\text { After } 5 \text { minutes of sputtering ( } 20 \\
\text { mins total) }\end{array}$ & $\mathrm{Bk} 1, \operatorname{pg} 82$ & 208094 & $\begin{array}{l}\text { Shows } \mathrm{O} \text { and } \mathrm{C} \text { peaks, } \mathrm{Pd} \text { increases, } \mathrm{Al} \\
\text { and } \mathrm{Zn} \text { starts to decrease. }\end{array}$ \\
\hline & overview & AES & $\begin{array}{l}\text { After } 10 \text { minutes of sputtering ( } 30 \\
\text { mins total) }\end{array}$ & Bk 1, pg 82 & 208095 & Show Al, Pd, and $\mathrm{Zn}$ peaks. \\
\hline & overview & XPS & $\begin{array}{l}\text { After } 10 \text { minutes of sputtering ( } 30 \\
\text { mins total) }\end{array}$ & Bk 1, pg 82 & 208095 & Show $\mathrm{Al}, \mathrm{Pd}, \mathrm{Zn}, \mathrm{Ta}$, alittle $\mathrm{C}$ and $\mathrm{O}$ peaks. \\
\hline & overview & AES & $\begin{array}{l}\text { After } 10 \text { minutes of sputtering ( } 40 \\
\text { mins total) [finish expt] }\end{array}$ & Bk 1, pg 82 & 208096 & Show $\mathrm{Al}, \mathrm{Pd}$, and $\mathrm{Zn}$ peaks. \\
\hline
\end{tabular}


Table 1 (Continue)

\begin{tabular}{|c|c|c|c|c|c|c|}
\hline Date & $\begin{array}{l}\text { Images / } \\
\text { Spectrum }\end{array}$ & Instr. & Purpose & Lab \#, Page \# & $\begin{array}{c}\text { File } \\
\text { Name }\end{array}$ & Notes \\
\hline $2 / 8 / 2009$ & overview & XPS & $\begin{array}{l}\text { After } 10 \text { minutes of sputtering } \\
\text { (40 mins total) [finish expt] }\end{array}$ & Bk 1, pg 83 & 208096 & $\begin{array}{l}\text { Show } \mathrm{Al}, \mathrm{Pd}, \mathrm{Zn}, \mathrm{Ta} \text {, alittle } \mathrm{C} \text { and } \mathrm{O} \text { peaks } \\
\text { (could not get rid of } \mathrm{C} \text { and } \mathrm{O} \text { ). }\end{array}$ \\
\hline \multirow{6}{*}{ 2/9/2009 } & $\begin{array}{l}\text { overview, } \mathrm{Zn} \\
\text { (low energy), } \\
\mathrm{Pd}, \mathrm{Al} \text { and } \mathrm{Zn} \\
\text { (high energy) }\end{array}$ & AES & $\begin{array}{l}\text { After Sputtering } \\
\text { (concentration vs time expt) }\end{array}$ & Bk 1, pg 84 & 209090 & $\begin{array}{l}\text { Did an overview spectrum followed by } \\
\text { individual peak range spectrums. }\end{array}$ \\
\hline & $\begin{array}{l}\text { overview, } \mathrm{Zn} \text {, } \\
\mathrm{Pd} \text {, and } \mathrm{Al}\end{array}$ & XPS & $\begin{array}{l}\text { After Sputtering } \\
\text { (concentration vs time expt) }\end{array}$ & Bk 1, pg 84 & 209090 & $\begin{array}{l}\text { Did an overview spectrum followed by } \\
\text { individual peak range spectrums. }\end{array}$ \\
\hline & $\begin{array}{l}\text { overview, } \mathrm{Zn} \\
\text { (low energy), } \\
\mathrm{Pd}, \mathrm{Al} \text { and } \mathrm{Zn} \\
\text { (high energy) }\end{array}$ & AES & $\begin{array}{l}\text { After annealing at } 0.4 \mathrm{~A} \text { for } 30 \\
\text { minutes }\end{array}$ & Bk 1, pg 85 & 209091 & Pd decreases, $\mathrm{Zn}$ increases. \\
\hline & $\begin{array}{l}\text { overview, } \mathrm{Zn} \text {, } \\
\mathrm{Pd} \text {, and } \mathrm{Al}\end{array}$ & XPS & $\begin{array}{l}\text { After annealing at } 0.4 \mathrm{~A} \text { for } 30 \\
\text { minutes }\end{array}$ & Bk 1, pg 85 & 209091 & Pd decreases, $\mathrm{Zn}$ increases. \\
\hline & $\begin{array}{l}\text { overview, } \mathrm{Zn} \\
\text { (low energy), } \\
\mathrm{Pd}, \mathrm{Al} \text { and } \mathrm{Zn} \\
\text { (high energy) }\end{array}$ & AES & $\begin{array}{l}\text { After annealing at } 0.4 \mathrm{~A} \text { for } 1 \\
\text { hour }\end{array}$ & Bk 1, pg 85 & 209092 & Pd decreases, $\mathrm{Zn}$ increases. \\
\hline & $\begin{array}{l}\text { overview, } \mathrm{Zn} \text {, } \\
\mathrm{Pd} \text {, and } \mathrm{Al}\end{array}$ & XPS & $\begin{array}{l}\text { After annealing at } 0.4 \mathrm{~A} \text { for } 1 \\
\text { hour }\end{array}$ & Bk 1, pg 86 & 209092 & $\mathrm{Pd}$ and $\mathrm{Al}$ decreases, $\mathrm{Zn}$ increases. \\
\hline
\end{tabular}


Table 1 (Continue)

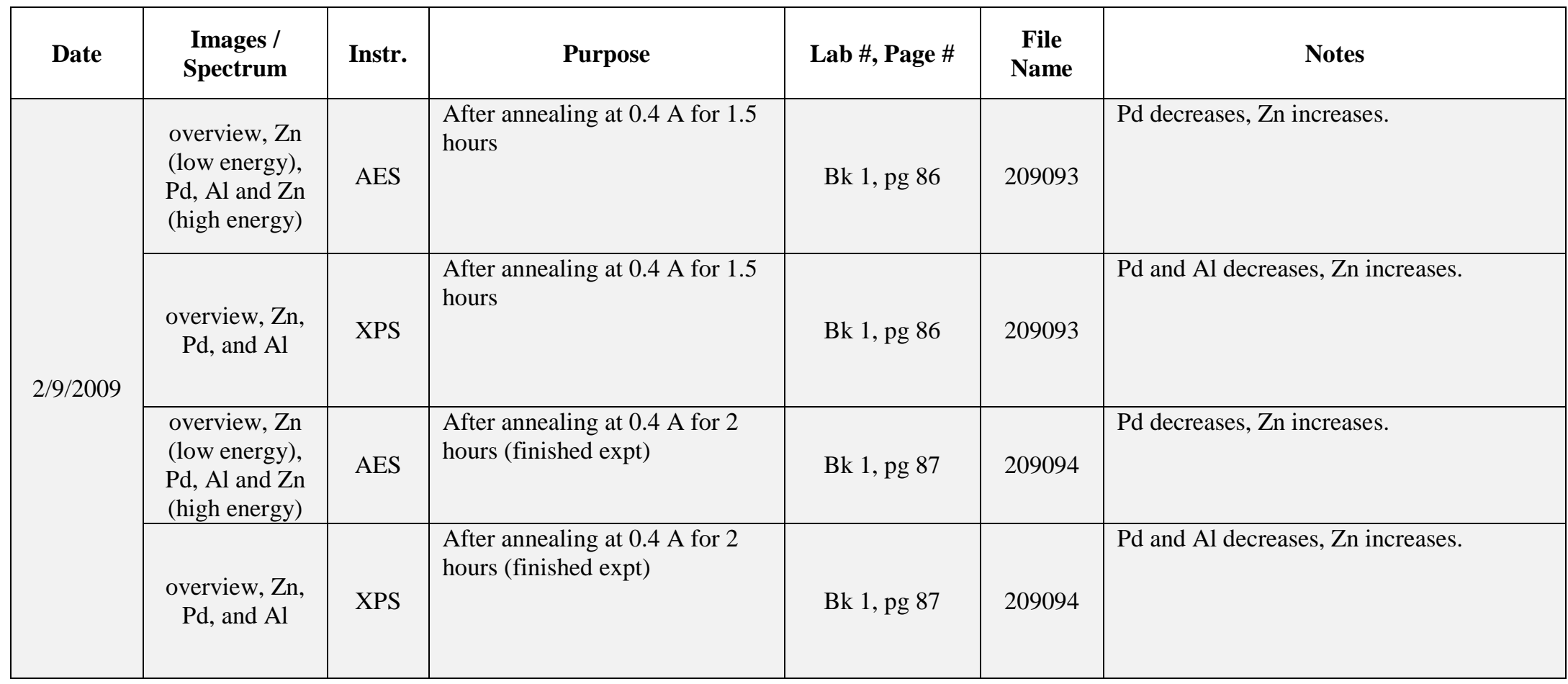


Table 1 (Continue)

\begin{tabular}{|c|c|c|c|c|c|c|}
\hline Date & $\begin{array}{l}\text { Images / } \\
\text { Spectrum }\end{array}$ & Instr. & Purpose & Lab \#, Page \# & File Name & Notes \\
\hline \multirow{4}{*}{$2 / 11 / 2009$} & $\begin{array}{l}\text { overview, } \mathrm{Zn} \\
\text { (low energy), } \\
\mathrm{Pd}, \mathrm{Al} \text { and } \mathrm{Zn} \\
\text { (high energy) }\end{array}$ & AES & $\begin{array}{l}\text { After sputtering (concentration vs } \\
\text { temperature expt) }\end{array}$ & Bk 1, pg 88 & 211090 & \\
\hline & $\begin{array}{l}\text { overview, } \mathrm{Zn} \text {, } \\
\mathrm{Pd} \text {, and } \mathrm{Al}\end{array}$ & XPS & $\begin{array}{l}\text { After sputtering (concentration vs } \\
\text { temperature expt) }\end{array}$ & Bk 1, pg 88 & 211090 & \\
\hline & $\begin{array}{l}\text { overview, } \mathrm{Zn} \\
\text { (low energy), } \\
\mathrm{Pd}, \mathrm{Al} \text { and } \mathrm{Zn} \\
\text { (high energy) }\end{array}$ & AES & $\begin{array}{l}\text { After annealing at } 0.2 \mathrm{~A} \text { for } 2 \\
\text { hours }\end{array}$ & Bk 1, pg 89 & 211091 & $\begin{array}{l}\text { No change compared to after } \\
\text { sputtering. }\end{array}$ \\
\hline & $\begin{array}{l}\text { overview, } \mathrm{Zn} \text {, } \\
\mathrm{Pd} \text {, and } \mathrm{Al}\end{array}$ & XPS & $\begin{array}{l}\text { After annealing at } 0.2 \mathrm{~A} \text { for } 2 \\
\text { hours }\end{array}$ & Bk 1, pg 89 & 211091 & $\begin{array}{l}\text { No change compared to after } \\
\text { sputtering. }\end{array}$ \\
\hline
\end{tabular}


Table 1 (Continue)

\begin{tabular}{|c|c|c|c|c|c|c|}
\hline Date & Images / Spectrum & Instr. & Purpose & Lab \#, Page \# & $\begin{array}{l}\text { File } \\
\text { Name }\end{array}$ & Notes \\
\hline \multirow{4}{*}{ 2/12/2009 } & $\begin{array}{l}\text { overview, } \mathrm{Zn} \text { (low } \\
\text { energy), Pd, Al and } \\
\text { Zn (high energy) }\end{array}$ & AES & $\begin{array}{l}\text { After sputtering (continue expt } \\
\text { from } 2 / 11 / 09 \text { ) }\end{array}$ & Bk 1, pg 89 & 212090 & \\
\hline & $\begin{array}{l}\text { overview, } \mathrm{Zn}, \mathrm{Pd}, \\
\quad \text { and } \mathrm{Al}\end{array}$ & XPS & $\begin{array}{l}\text { After sputtering (continue expt } \\
\text { from } 2 / 11 / 09 \text { ) }\end{array}$ & Bk 1, pg 90 & 212090 & \\
\hline & $\begin{array}{l}\text { overview, } \mathrm{Zn} \text { (low } \\
\text { energy), Pd, Al and } \\
\mathrm{Zn} \text { (high energy) }\end{array}$ & AES & $\begin{array}{l}\text { After annealing at } 0.3 \mathrm{~A} \text { for } 2 \\
\text { hours }\end{array}$ & Bk 1, pg 90 & 212091 & Pd starts to decrease. \\
\hline & $\begin{array}{l}\text { overview, } \mathrm{Zn}, \mathrm{Pd} \\
\quad \text { and } \mathrm{Al}\end{array}$ & XPS & $\begin{array}{l}\text { After annealing at } 0.3 \mathrm{~A} \text { for } 2 \\
\text { hours }\end{array}$ & Bk 1, pg 90 & 212091 & Zn starts to increase. \\
\hline \multirow{3}{*}{ 2/13/2009 } & $\begin{array}{l}\text { overview, } \mathrm{Zn} \text { (low } \\
\text { energy), Pd, Al and } \\
\mathrm{Zn} \text { (high energy) }\end{array}$ & AES & $\begin{array}{l}\text { After sputtering (continue expt } \\
\text { from } 2 / 11 / 09 \text { ) }\end{array}$ & Bk 1, pg 91 & 213090 & \\
\hline & $\begin{array}{l}\text { overview, } \mathrm{Zn}, \mathrm{Pd} \\
\quad \text { and } \mathrm{Al}\end{array}$ & XPS & $\begin{array}{l}\text { After sputtering (continue expt } \\
\text { from } 2 / 11 / 09 \text { ) }\end{array}$ & Bk 1, pg 91 & 213090 & \\
\hline & $\begin{array}{l}\text { overview, } \mathrm{Zn} \text { (low } \\
\text { energy), Pd, Al and } \\
\mathrm{Zn} \text { (high energy) }\end{array}$ & AES & $\begin{array}{l}\text { After annealing at } 0.4 \mathrm{~A} \text { for } 2 \\
\text { hours }\end{array}$ & Bk 1, pg 92 & 213091 & Pd decreases and $\mathrm{Zn}$ increases. \\
\hline
\end{tabular}


Table 1 (Continue)

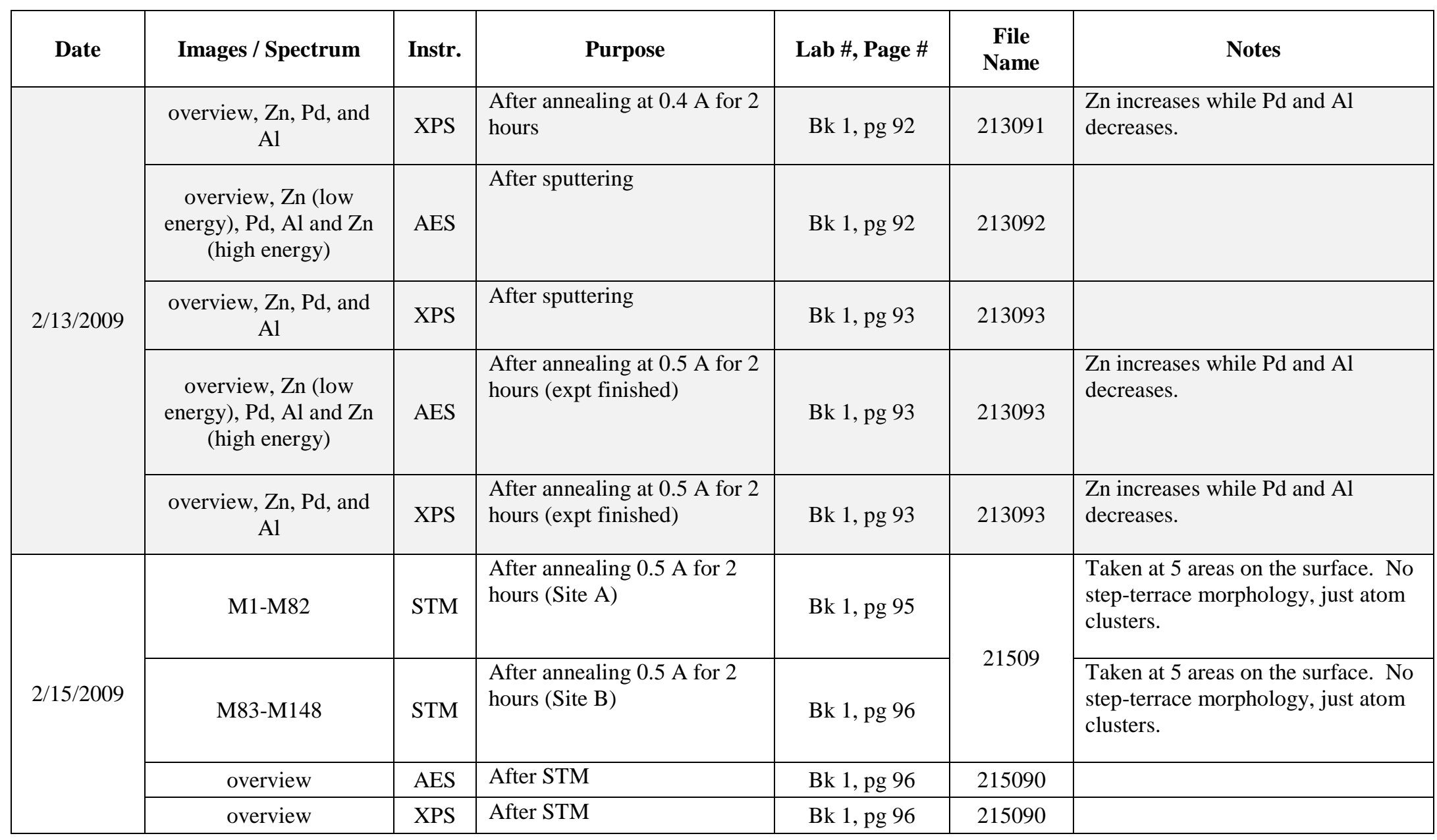


Table 1 (Continue)

\begin{tabular}{|c|c|c|c|c|c|c|}
\hline Date & $\begin{array}{l}\text { Images / } \\
\text { Spectrum }\end{array}$ & Instr. & Purpose & Lab \#, Page \# & $\begin{array}{c}\text { File } \\
\text { Name }\end{array}$ & Notes \\
\hline \multirow{6}{*}{$2 / 16 / 2009$} & M1-M39 & STM & $\begin{array}{l}\text { After sputtering and annealing } \\
\text { at } 0.3 \text { A for } 2 \text { hours (Site A) } \\
\text { [Temp-Independ Expt] }\end{array}$ & Bk 1, pg 97 & \multirow{6}{*}{21609} & $\begin{array}{l}\text { No step-terrace morphology, just atom } \\
\text { clusters. }\end{array}$ \\
\hline & M40-M78 & STM & $\begin{array}{l}\text { After sputtering and annealing } \\
\text { at } 0.3 \text { A for } 2 \text { hours (Site A) } \\
\text { [Temp-Independ Expt] }\end{array}$ & Bk 1, pg 97 & & $\begin{array}{l}\text { No step-terrace morphology, just atom } \\
\text { clusters. }\end{array}$ \\
\hline & M79-M91 & STM & $\begin{array}{l}\text { After annealing at } 0.3 \mathrm{~A} \text { for } 1 \\
\text { hour (Site B) }\end{array}$ & Bk 1, pg 98 & & No change in surface structure. \\
\hline & M92-M103 & STM & $\begin{array}{l}\text { After annealing at } 0.3 \mathrm{~A} \text { for } 1 \\
\text { hour (Site A) }\end{array}$ & Bk 1, pg 98 & & No change in surface structure. \\
\hline & M104-M129 & STM & $\begin{array}{l}\text { After annealing at } 0.3 \text { A for } \\
2.75 \text { hours (Site A) [Finished } \\
\text { Expt] }\end{array}$ & Bk 1, pg 98 & & No change in surface structure. \\
\hline & M130-M155 & STM & $\begin{array}{l}\text { After annealing at } 0.3 \text { A for } \\
2.75 \text { hours (Site B) [Finished } \\
\text { Expt] }\end{array}$ & Bk 1, pg 98 & & No change in surface structure. \\
\hline
\end{tabular}


Table 1 (Continue)

\begin{tabular}{|c|c|c|c|c|c|c|}
\hline Date & $\begin{array}{l}\text { Images / } \\
\text { Spectrum }\end{array}$ & Instr. & Purpose & Lab \#, Page \# & $\begin{array}{c}\text { File } \\
\text { Name }\end{array}$ & Notes \\
\hline \multirow{8}{*}{$2 / 17 / 2009$} & overview & AES & After sputtering for $20 \mathrm{mins}$ & Bk 1, pg 99 & 217090 & Just cleaning the surface. \\
\hline & overview & XPS & After sputtering for $20 \mathrm{mins}$ & Bk 1, pg 99 & 217090 & Just cleaning the surface. \\
\hline & overview & AES & $\begin{array}{l}\text { After sputtering } 10 \text { mins (total }= \\
30 \text { mins) }\end{array}$ & Bk 1,pg 100 & 217091 & \\
\hline & overview & XPS & $\begin{array}{l}\text { After sputtering } 10 \text { mins (total }= \\
30 \text { mins) }\end{array}$ & Bk 1,pg 100 & 217091 & \\
\hline & overview & AES & $\begin{array}{l}\text { After sputtering } 10 \text { mins (total }= \\
40 \text { mins) }\end{array}$ & Bk 1,pg 100 & 217092 & \\
\hline & overview & XPS & $\begin{array}{l}\text { After sputtering } 10 \text { mins (total }= \\
40 \text { mins) }\end{array}$ & Bk 1,pg 101 & 217092 & \\
\hline & overview & AES & $\begin{array}{l}\text { After sputtering } 10 \text { mins (total = } \\
50 \text { mins) }\end{array}$ & Bk 1,pg 101 & 217093 & $\begin{array}{l}\text { Found out AES was not surface sensitive } \\
\text { compared to XPS. All AES images were } \\
\text { weird. }\end{array}$ \\
\hline & overview & XPS & $\begin{array}{l}\text { After sputtering } 10 \text { mins (total }= \\
50 \text { mins) }\end{array}$ & Bk 1, pg 101 & 217093 & \\
\hline
\end{tabular}


Table 1 (Continue)

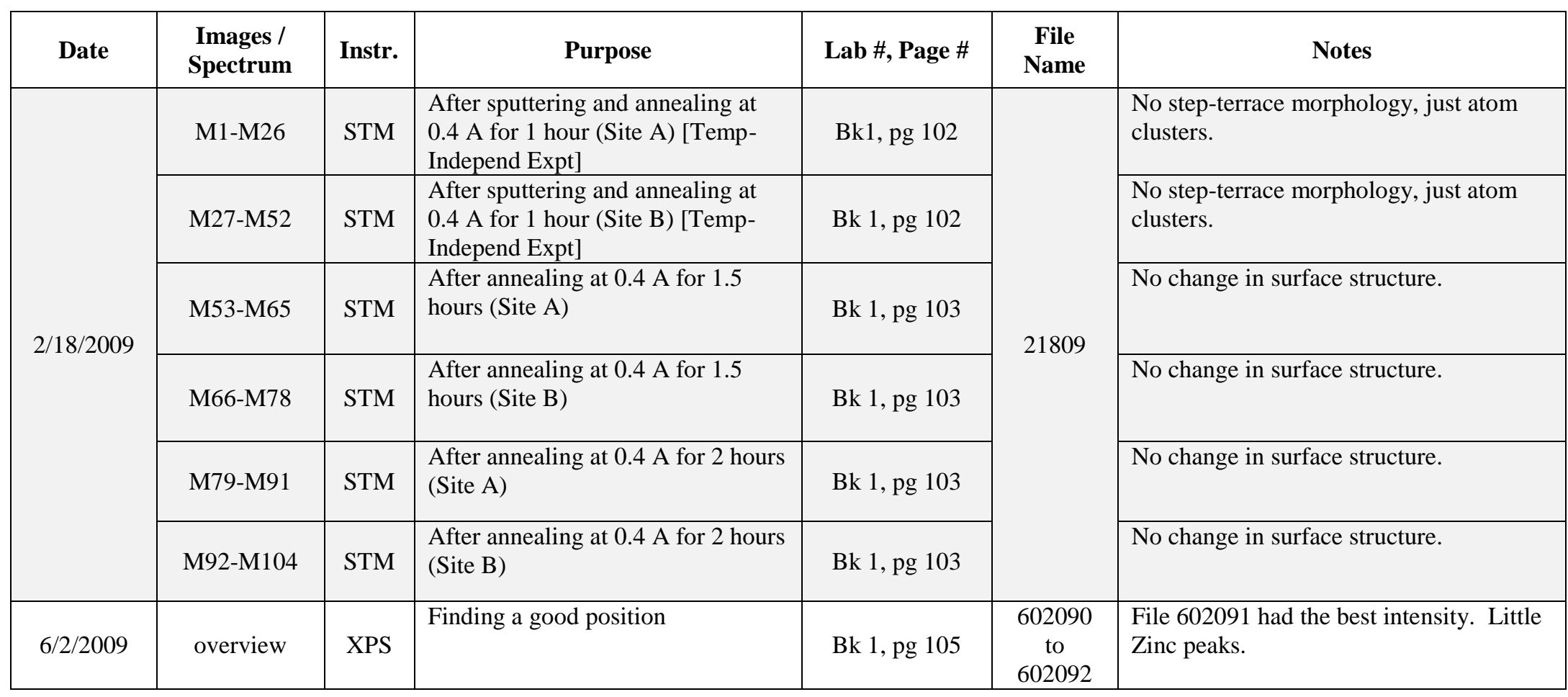


Table 1 (Continue)

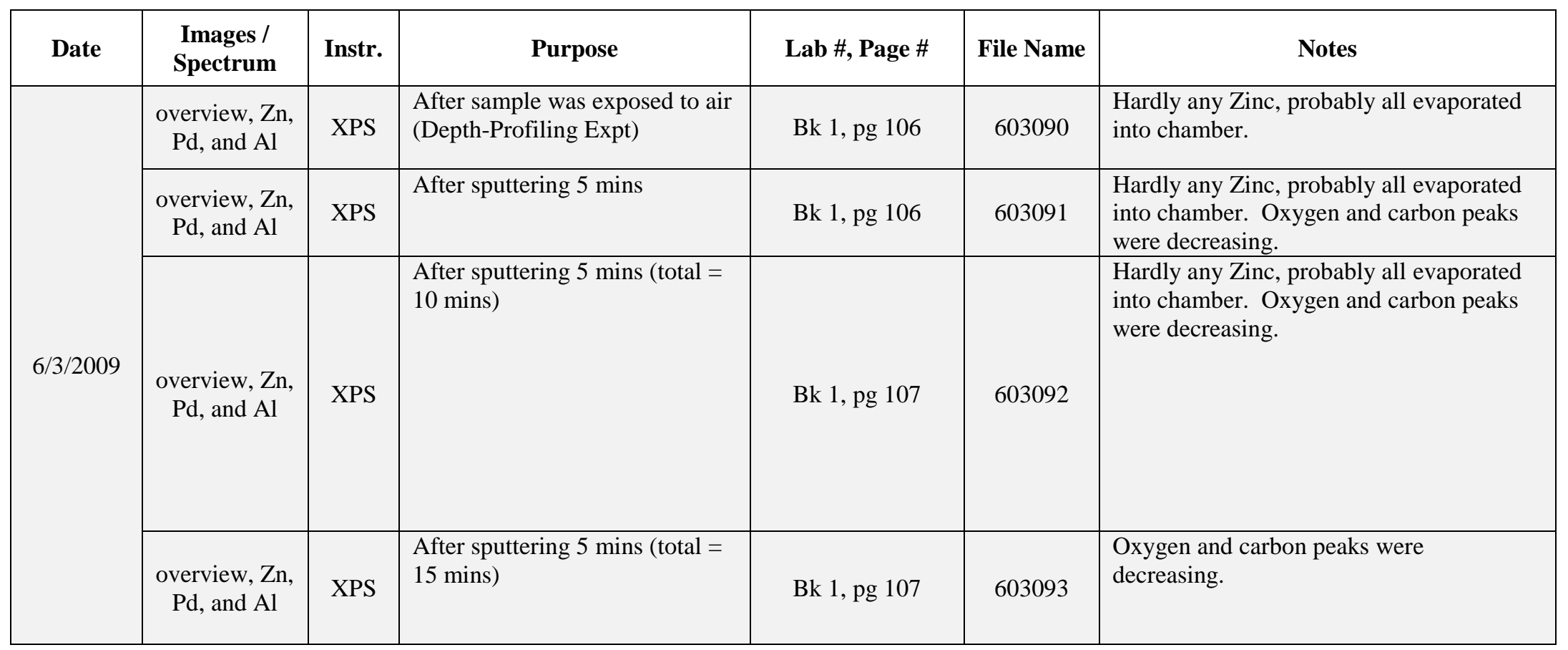


Table 1 (Continue)

\begin{tabular}{|c|c|c|c|c|c|c|}
\hline Date & $\begin{array}{l}\text { Images / } \\
\text { Spectrum }\end{array}$ & Instr. & Purpose & Lab \#, Page \# & $\begin{array}{l}\text { File } \\
\text { Name }\end{array}$ & Notes \\
\hline \multirow{5}{*}{$6 / 3 / 2009$} & $\begin{array}{l}\text { overview, } \mathrm{Zn} \text {, } \\
\mathrm{Pd} \text {, and } \mathrm{Al}\end{array}$ & XPS & $\begin{array}{l}\text { After sputtering } 5 \text { mins (total }=20 \\
\text { mins) }\end{array}$ & Bk 1,pg 108 & 603094 & $\begin{array}{l}\text { Oxygen and carbon peaks were } \\
\text { decreasing. }\end{array}$ \\
\hline & $\begin{array}{l}\text { overview, } \mathrm{Zn} \text {, } \\
\mathrm{Pd} \text {, and } \mathrm{Al}\end{array}$ & XPS & $\begin{array}{l}\text { After sputtering } 10 \text { mins (total = } \\
30 \text { mins) }\end{array}$ & Bk 1,pg 108 & 603095 & $\begin{array}{l}\text { Oxygen and carbon peaks were } \\
\text { decreasing. }\end{array}$ \\
\hline & $\begin{array}{l}\text { overview, } \mathrm{Zn} \text {, } \\
\mathrm{Pd} \text {, and } \mathrm{Al}\end{array}$ & XPS & $\begin{array}{l}\text { After sputtering } 10 \text { mins }(\text { total }= \\
40 \text { mins) }\end{array}$ & Bk 1, pg 109 & 603096 & $\begin{array}{l}\text { Oxygen and carbon peaks were } \\
\text { decreasing. }\end{array}$ \\
\hline & $\begin{array}{l}\text { overview, } \mathrm{Zn} \text {, } \\
\mathrm{Pd} \text {, and } \mathrm{Al}\end{array}$ & XPS & $\begin{array}{l}\text { After sputtering } 10 \mathrm{mins} \text { (total = } \\
50 \text { mins) [Finshed Expt] }\end{array}$ & Bk 1,pg 109 & 603097 & No zinc peak. \\
\hline & $\begin{array}{l}\text { overview, } \mathrm{Zn} \text {, } \\
\mathrm{Pd} \text {, and } \mathrm{Al}\end{array}$ & XPS & $\begin{array}{l}\text { After sputtering } 10 \text { mins (total }= \\
60 \text { mins) [Finished Expt] }\end{array}$ & Bk 1,pg 110 & 603908 & No zinc peak. \\
\hline \multirow{4}{*}{$6 / 4 / 2009$} & $\begin{array}{l}\text { overview, } \mathrm{Zn} \text {, } \\
\mathrm{Pd} \text {, and } \mathrm{Al}\end{array}$ & XPS & $\begin{array}{l}\text { After sputtering (temp-depend } \\
\text { expt) }\end{array}$ & $\mathrm{Bk} 1, \operatorname{pg} 111$ & 604090 & \\
\hline & $\begin{array}{l}\text { overview, } \mathrm{Zn} \text {, } \\
\mathrm{Pd} \text {, and } \mathrm{Al}\end{array}$ & XPS & $\begin{array}{l}\text { After annealing at } 0.2 \mathrm{~A} \text { for } 2 \\
\text { hours }\end{array}$ & $\mathrm{Bk} 1, \operatorname{pg} 112$ & 604091 & No change in concentration. \\
\hline & $\begin{array}{l}\text { overview, } \mathrm{Zn} \text {, } \\
\mathrm{Pd} \text {, and } \mathrm{Al}\end{array}$ & XPS & After sputtering & $\mathrm{Bk} 1, \operatorname{pg} 112$ & 604092 & \\
\hline & $\begin{array}{l}\text { overview, } \mathrm{Zn} \text {, } \\
\mathrm{Pd} \text {, and } \mathrm{Al}\end{array}$ & XPS & $\begin{array}{l}\text { After annealing at } 0.3 \mathrm{~A} \text { for } 2 \\
\text { hours (finished expt) }\end{array}$ & Bk 1,pg 113 & 604093 & $\begin{array}{l}\text { Zinc did not increase intensity. I } \\
\text { think it all evaporated into chamber. }\end{array}$ \\
\hline
\end{tabular}


Table 2

\begin{tabular}{|c|c|c|c|c|c|c|}
\hline \multicolumn{7}{|c|}{ 10f AlPdZn Data List } \\
\hline Date & $\begin{array}{l}\text { Images / } \\
\text { Spectrum }\end{array}$ & Instr. & Purpose & Lab \#, Page \# & $\begin{array}{l}\text { File } \\
\text { Name }\end{array}$ & Notes \\
\hline $6 / 6 / 2009$ & $\begin{array}{l}\text { overview, } \mathrm{Zn} \text {, } \\
\mathrm{Pd} \text {, and } \mathrm{Al}\end{array}$ & XPS & Finding a good position & Bk 1, pg 115 & $\begin{array}{c}606090 \text { to } \\
606091\end{array}$ & File 606090 had the best intensity. \\
\hline \multirow{7}{*}{$6 / 7 / 2009$} & $\begin{array}{l}\text { overview, } \mathrm{Zn} \text {, } \\
\mathrm{Pd} \text {, and } \mathrm{Al}\end{array}$ & XPS & $\begin{array}{l}\text { After exposure from air (Depth } \\
\text { Profiling Expt) }\end{array}$ & Bk 1,pg 116 & 607090 & Lots of oxygen and carbon. \\
\hline & $\begin{array}{l}\text { overview, } \mathrm{Zn} \text {, } \\
\mathrm{Pd} \text {, and } \mathrm{Al}\end{array}$ & XPS & After sputtering for 6 mins & Bk 1, pg 116 & 607091 & Carbon starts to decrease. \\
\hline & $\begin{array}{l}\text { overview, } \mathrm{Zn} \text {, } \\
\mathrm{Pd} \text {, and } \mathrm{Al}\end{array}$ & XPS & $\begin{array}{l}\text { After sputtering for } 6 \text { mins (total } \\
=12 \text { mins) }\end{array}$ & Bk 1, pg 117 & 607092 & Carbon decreases, oxygen increases. \\
\hline & $\begin{array}{l}\text { overview, } \mathrm{Zn} \text {, } \\
\mathrm{Pd} \text {, and } \mathrm{Al}\end{array}$ & XPS & $\begin{array}{l}\text { After sputtering for } 6 \text { mins (total } \\
=18 \text { mins) }\end{array}$ & $\mathrm{Bk} 1, \operatorname{pg} 118$ & 607093 & Carbon and oxygen decreases. \\
\hline & $\begin{array}{l}\text { overview, } \mathrm{Zn} \text {, } \\
\mathrm{Pd} \text {, and } \mathrm{Al}\end{array}$ & XPS & $\begin{array}{l}\text { After sputtering for } 6 \text { mins (total } \\
=24 \text { mins) }\end{array}$ & Bk 1, pg 118 & 607094 & Carbon and oxygen decreases. \\
\hline & $\begin{array}{l}\text { overview, } \mathrm{Zn}, \\
\mathrm{Pd} \text {, and } \mathrm{Al}\end{array}$ & XPS & $\begin{array}{l}\text { After sputtering for } 15 \mathrm{mins} \\
\text { (total = } 39 \mathrm{mins} \text { ) }\end{array}$ & Bk 1, pg 119 & 607095 & Carbon and oxygen decreases. \\
\hline & $\begin{array}{l}\text { overview, } \mathrm{Zn} \text {, } \\
\mathrm{Pd} \text {, and } \mathrm{Al}\end{array}$ & XPS & $\begin{array}{l}\text { After sputtering for } 15 \mathrm{mins} \\
\text { (total = } 54 \text { mins) }\end{array}$ & Bk 1, pg 120 & 607096 & Carbon and oxygen decreases. \\
\hline
\end{tabular}


Table 2 (Continue)

\begin{tabular}{|c|c|c|c|c|c|c|}
\hline Date & $\begin{array}{l}\text { Images / } \\
\text { Spectrum }\end{array}$ & Instr. & Purpose & Lab \#, Page \# & File Name & Notes \\
\hline \multirow{5}{*}{$6 / 7 / 2009$} & $\begin{array}{l}\text { overview, } \mathrm{Zn} \text {, } \\
\mathrm{Pd} \text {, and } \mathrm{Al}\end{array}$ & XPS & $\begin{array}{l}\text { After sputtering for } 30 \mathrm{mins} \\
\text { (total = } 84 \mathrm{mins} \text { ) }\end{array}$ & Bk 1,pg 120 & 607097 & Carbon and oxygen decreases. \\
\hline & $\begin{array}{l}\text { overview, } \mathrm{Zn} \text {, } \\
\mathrm{Pd} \text {, and } \mathrm{Al}\end{array}$ & XPS & $\begin{array}{l}\text { After sputtering for } 30 \mathrm{mins} \\
\text { (total }=114 \text { mins) }\end{array}$ & Bk 1,pg 121 & 607098 & Oxygen decreases, carbon is gone. \\
\hline & $\begin{array}{l}\text { overview, } \mathrm{Zn} \text {, } \\
\mathrm{Pd} \text {, and } \mathrm{Al}\end{array}$ & XPS & $\begin{array}{l}\text { Afer sputtering for } 30 \text { mins (total } \\
=144 \text { mins) }\end{array}$ & Bk 1,pg 122 & 607099 & Oxygen decreases. \\
\hline & $\begin{array}{l}\text { overview, } \mathrm{Zn} \text {, } \\
\mathrm{Pd} \text {, and } \mathrm{Al}\end{array}$ & XPS & $\begin{array}{l}\text { After sputtering for } 30 \text { mins } \\
\text { (total }=174 \text { mins) [finished expt] }\end{array}$ & Bk 1, pg 122 & 6070991 & Oxygen decreases. \\
\hline & $\begin{array}{l}\text { overview, } \mathrm{Zn} \text {, } \\
\mathrm{Pd} \text {, and } \mathrm{Al}\end{array}$ & XPS & $\begin{array}{l}\text { After sputtering for } 30 \text { mins } \\
\text { (total = } 204 \text { mins) [finished expt] }\end{array}$ & Bk 1, pg 123 & 6070992 & $\begin{array}{l}\text { Little oxygen auger peak. Looked at } \\
\text { Dapeng's and Baris's XPS spectras, it also } \\
\text { shows a little oxygen auger peak. }\end{array}$ \\
\hline
\end{tabular}


Table 2 (Continue)

\begin{tabular}{|c|c|c|c|c|c|c|}
\hline Date & $\begin{array}{l}\text { Images / } \\
\text { Spectrum }\end{array}$ & Instr. & Purpose & Lab \#, Page \# & File Name & Notes \\
\hline \multirow{5}{*}{$6 / 8 / 2009$} & $\begin{array}{l}\text { overview, } \mathrm{Zn} \text {, } \\
\mathrm{Pd} \text {, and } \mathrm{Al}\end{array}$ & XPS & After sputtering & Bk 1, pg 124 & 608090 & \\
\hline & $\begin{array}{l}\text { overview, } \mathrm{Zn} \text {, } \\
\mathrm{Pd} \text {, and } \mathrm{Al}\end{array}$ & XPS & $\begin{array}{l}\text { After annealing at } 0.2 \mathrm{~A} \text { for } \\
2 \text { hours }\end{array}$ & Bk 1,pg 125 & 608091 & \\
\hline & $\begin{array}{l}\text { overview, } \mathrm{Zn} \text {, } \\
\mathrm{Pd} \text {, and } \mathrm{Al}\end{array}$ & XPS & After sputtering & Bk 1,pg 126 & $\begin{array}{l}608092 \text { to } \\
608096\end{array}$ & Finding good position. \\
\hline & $\begin{array}{l}\text { overview, } \mathrm{Zn} \text {, } \\
\mathrm{Pd} \text {, and } \mathrm{Al}\end{array}$ & XPS & After sputtering & Bk 1,pg 127 & $\begin{array}{l}608097 \text { to } \\
608098\end{array}$ & File 608095 had best intensity. \\
\hline & overview & AES & After sputtering & Bk 1, pg 127 & $\begin{array}{l}608090 \text { to } \\
608091\end{array}$ & $\begin{array}{l}\text { AES spectras were still weird. Should Pd } \\
\text { had more intensity than } \mathrm{Al} \text { and Zn. Not } \\
\text { using AES. }\end{array}$ \\
\hline \multirow{6}{*}{$6 / 9 / 2009$} & $\begin{array}{l}\text { overview, } \mathrm{Zn} \text {, } \\
\mathrm{Pd} \text {, and } \mathrm{Al}\end{array}$ & XPS & $\begin{array}{l}\text { After sputtering (temp- } \\
\text { depend expt) }\end{array}$ & Bk 1, pg 129 & 609090 & \\
\hline & $\begin{array}{l}\text { overview, } \mathrm{Zn} \text {, } \\
\mathrm{Pd} \text {, and } \mathrm{Al}\end{array}$ & XPS & $\begin{array}{l}\text { After annealing at } 0.2 \mathrm{~A} \text { for } \\
2 \text { hours }\end{array}$ & Bk 1, pg 130 & 609091 & $\begin{array}{l}\text { Not much change in surface composition } \\
\text { from } 609090 .\end{array}$ \\
\hline & $\begin{array}{l}\text { overview, } \mathrm{Zn} \text {, } \\
\mathrm{Pd} \text {, and } \mathrm{Al}\end{array}$ & XPS & After sputtering & Bk 1,pg 130 & 609092 & \\
\hline & $\begin{array}{l}\text { overview, } \mathrm{Zn} \text {, } \\
\mathrm{Pd} \text {, and } \mathrm{Al}\end{array}$ & XPS & $\begin{array}{l}\text { After annealing at } 0.3 \mathrm{~A} \text { for } \\
2 \text { hours }\end{array}$ & $\mathrm{Bk} 1, \operatorname{pg} 131$ & 609093 & $\begin{array}{l}\mathrm{Zn} \text { starts to increase and Pd starts to } \\
\text { decrease. }\end{array}$ \\
\hline & $\begin{array}{l}\text { overview, } \mathrm{Zn} \text {, } \\
\mathrm{Pd} \text {, and } \mathrm{Al}\end{array}$ & XPS & After sputtering & Bk 1, pg 132 & 609094 & \\
\hline & $\begin{array}{l}\text { overview, } \mathrm{Zn} \text {, } \\
\mathrm{Pd} \text {, and } \mathrm{Al}\end{array}$ & XPS & $\begin{array}{l}\text { After annealing at } 0.4 \mathrm{~A} \text { for } \\
2 \text { hours }\end{array}$ & Bk 1, pg 132 & 609095 & $\mathrm{Zn}$ increase while $\mathrm{Pd}$ and $\mathrm{Al}$ decreases. \\
\hline
\end{tabular}


Table 2 (Continue)

\begin{tabular}{|c|c|c|c|c|c|c|}
\hline Date & $\begin{array}{l}\text { Images / } \\
\text { Spectrum }\end{array}$ & Instr. & Purpose & Lab \#, Page \# & $\begin{array}{l}\text { File } \\
\text { Name }\end{array}$ & Notes \\
\hline \multirow{2}{*}{$6 / 10 / 2009$} & $\begin{array}{l}\text { overview, } \mathrm{Zn} \text {, } \\
\mathrm{Pd} \text {, and } \mathrm{Al}\end{array}$ & XPS & $\begin{array}{l}\text { After sputtering (continuing } \\
\text { temp-depend expt) }\end{array}$ & Bk 1,pg 133 & 610090 & \\
\hline & $\begin{array}{l}\text { overview, } \mathrm{Zn} \text {, } \\
\mathrm{Pd} \text {, and } \mathrm{Al}\end{array}$ & XPS & $\begin{array}{l}\text { After annealing at } 0.5 \mathrm{~A} \text { for } 2 \\
\text { hours (finished expt) }\end{array}$ & Bk 1,pg 134 & 610091 & $\mathrm{Zn}$ increase while $\mathrm{Pd}$ and $\mathrm{Al}$ decreases. \\
\hline \multirow{4}{*}{$6 / 11 / 2009$} & $\begin{array}{l}\text { overview, } \mathrm{Zn} \text {, } \\
\mathrm{Pd} \text {, and } \mathrm{Al}\end{array}$ & XPS & $\begin{array}{l}\text { After sputtering (temp-independ } \\
\text { expt) }\end{array}$ & Bk 1,pg 135 & 611090 & \\
\hline & $\begin{array}{l}\text { overview, } \mathrm{Zn} \text {, } \\
\mathrm{Pd} \text {, and } \mathrm{Al}\end{array}$ & XPS & $\begin{array}{l}\text { After annealing at } 0.4 \mathrm{~A} \text { for } 30 \\
\text { mins }\end{array}$ & Bk 1, pg 136 & 611091 & Zn increase while $\mathrm{Pd}$ and $\mathrm{Al}$ decreases. \\
\hline & $\begin{array}{l}\text { overview, } \mathrm{Zn} \text {, } \\
\mathrm{Pd} \text {, and } \mathrm{Al}\end{array}$ & XPS & $\begin{array}{l}\text { After annealing at } 0.4 \mathrm{~A} \text { for } 30 \\
\text { mins (total }=1 \text { hour) }\end{array}$ & Bk 1,pg 137 & 611092 & $\mathrm{Zn}$ increase while $\mathrm{Pd}$ and $\mathrm{Al}$ decreases. \\
\hline & $\begin{array}{l}\text { overview, } \mathrm{Zn} \text {, } \\
\mathrm{Pd} \text {, and } \mathrm{Al}\end{array}$ & XPS & $\begin{array}{l}\text { After annealing at } 0.4 \mathrm{~A} \text { for } 30 \\
\text { mins (total }=2 \text { hours) [finished } \\
\text { expt] }\end{array}$ & Bk 1, pg 138 & 611094 & Zn increase while $\mathrm{Pd}$ and $\mathrm{Al}$ decreases. \\
\hline \multirow{2}{*}{$6 / 12 / 2009$} & $\begin{array}{l}\text { overview, } \mathrm{Zn} \text {, } \\
\mathrm{Pd} \text {, and } \mathrm{Al}\end{array}$ & XPS & $\begin{array}{l}\text { After sputtering (part of temp- } \\
\text { depend expt) }\end{array}$ & Bk 1,pg 139 & 612090 & \\
\hline & $\begin{array}{l}\text { overview, } \mathrm{Zn} \text {, } \\
\mathrm{Pd} \text {, and } \mathrm{Al}\end{array}$ & XPS & $\begin{array}{l}\text { After annealing at } 0.6 \mathrm{~A} \text { for } 10 \\
\text { mins }\end{array}$ & Bk 1, pg 140 & 612091 & $\begin{array}{l}\mathrm{Zn} \text { is really high while } \mathrm{Pd} \text { and } \mathrm{Al} \text { are } \\
\text { small. }\end{array}$ \\
\hline
\end{tabular}


Table 2 (Continue)

\begin{tabular}{|c|c|c|c|c|c|c|}
\hline Date & $\begin{array}{l}\text { Images / } \\
\text { Spectrum }\end{array}$ & Instr. & Purpose & Lab \#, Page \# & $\begin{array}{l}\text { File } \\
\text { Name }\end{array}$ & Notes \\
\hline \multirow[b]{2}{*}{$6 / 15 / 2009$} & M1-M44 & STM & $\begin{array}{l}\text { After sputtering and annealing at } \\
0.4 \text { A for } 15 \text { mins (single grain) }\end{array}$ & Bk 1, pg 142 & \multirow[b]{2}{*}{61509} & $\begin{array}{l}\text { No step-terrace morphology. Lots of } \\
\text { atom clusters. }\end{array}$ \\
\hline & M45-M84 & STM & $\begin{array}{l}\text { After sputtering and annealing at } \\
0.4 \text { A for } 15 \text { mins (poly grain) }\end{array}$ & Bk 1, pg 142 & & $\begin{array}{l}\text { No step-terrace morphology. Lots of } \\
\text { atom clusters. Cannot tell any difference } \\
\text { between the single grain and the poly } \\
\text { grain areas. }\end{array}$ \\
\hline \multirow{3}{*}{$6 / 16 / 2009$} & M1-M41 & STM & $\begin{array}{l}\text { After sputtering and annealing at } \\
0.5 \text { A for } 15 \text { mins (single grain) }\end{array}$ & Bk 1, pg 145 & \multirow{3}{*}{61609} & $\begin{array}{l}\text { No step-terrace morphology. Lots of } \\
\text { atom clusters. }\end{array}$ \\
\hline & M42-M82 & STM & $\begin{array}{l}\text { After sputtering and annealing at } \\
0.5 \text { A for } 15 \text { mins (poly grain) }\end{array}$ & Bk 1, pg 145 & & $\begin{array}{l}\text { No step-terrace morphology. Lots of } \\
\text { atom clusters. Cannot tell any difference } \\
\text { between the single grain and the poly } \\
\text { grain areas. }\end{array}$ \\
\hline & M83-M94 & STM & $\begin{array}{l}\text { After sputtering and annealing at } \\
0.5 \text { A for } 15 \text { mins (different poly } \\
\text { grain region) }\end{array}$ & Bk 1, pg 145 & & $\begin{array}{l}\text { No step-terrace morphology. Lots of } \\
\text { atom clusters. Cannot tell any difference } \\
\text { between the single grain and the poly } \\
\text { grain areas. }\end{array}$ \\
\hline \multirow[b]{2}{*}{$6 / 17 / 2009$} & M1-M37 & STM & $\begin{array}{l}\text { After sputtering and annealing at } \\
0.6 \text { A for } 15 \text { mins (single grain) }\end{array}$ & Bk 1, pg 147 & \multirow[b]{2}{*}{61709} & $\begin{array}{l}\text { No step-terrace morphology. Lots of } \\
\text { atom clusters. It appears to be a lot } \\
\text { rougher than at lower temperatures. }\end{array}$ \\
\hline & M38-M68 & STM & $\begin{array}{l}\text { After sputtering and annealint at } \\
0.6 \text { A for } 15 \text { mins (poly grain) }\end{array}$ & Bk 1,pg 147 & & $\begin{array}{l}\text { No step-terrace morphology. Lots of } \\
\text { atom clusters. It appears to be a lot } \\
\text { rougher than at lower temperatures. } \\
\text { Cannot tell any difference between the } \\
\text { single grain and the poly grain areas. }\end{array}$ \\
\hline
\end{tabular}


Table 2 (Continue)

\begin{tabular}{|c|c|c|c|c|c|c|}
\hline Date & $\begin{array}{l}\text { Images / } \\
\text { Spectrum }\end{array}$ & Instr. & Purpose & Lab \#, Page \# & $\begin{array}{l}\text { File } \\
\text { Name }\end{array}$ & Notes \\
\hline \multirow{4}{*}{$6 / 24 / 2009$} & overview & XPS & After sputtering $30 \mathrm{mins}$ & Bk 1, pg 154 & $\begin{array}{l}\text { Did not } \\
\text { save }\end{array}$ & $\begin{array}{l}\text { Intensities were too low, due to oxide } \\
\text { layer. }\end{array}$ \\
\hline & overview & XPS & $\begin{array}{l}\text { After sputtering } 30 \text { mins } \\
\text { (total }=1 \text { hour) }\end{array}$ & Bk 1,pg 154 & 624090 & $\begin{array}{l}\text { Lots of oxygen and carbon. Surface is } \\
\text { getting better. }\end{array}$ \\
\hline & overview & XPS & $\begin{array}{l}\text { After sputtering } 30 \mathrm{mins} \\
\text { (total }=1.5 \text { hour) }\end{array}$ & $\mathrm{Bk} 1, \operatorname{pg} 155$ & 624091 & $\begin{array}{l}\text { No carbon, still oxygen auger peak, but } \\
\text { decreased a lot. }\end{array}$ \\
\hline & $\begin{array}{l}\text { overview, } \mathrm{Zn} \text {, } \\
\mathrm{Pd} \text {, and } \mathrm{Al}\end{array}$ & XPS & $\begin{array}{l}\text { After sputtering } 30 \text { mins } \\
\text { (total }=2 \text { hours) }\end{array}$ & Bk 1,pg 156 & 624092 & Have that little oxygen auger peak. \\
\hline \multirow{2}{*}{$6 / 25 / 2009$} & overview & XPS & After sputtering & Bk 2, pg 1 & 625090 & Cleaning sample. \\
\hline & overview & XPS & $\begin{array}{l}\text { After annealing at } 0.4 \mathrm{~A} \text { for } \\
20 \text { mins }\end{array}$ & $\mathrm{Bk} 2, \operatorname{pg} 1$ & 625091 & Cleaning sample. \\
\hline
\end{tabular}


Table 2 (Continue)

\begin{tabular}{|c|c|c|c|c|c|c|}
\hline Date & $\begin{array}{l}\text { Images / } \\
\text { Spectrum }\end{array}$ & Instr. & Purpose & Lab \#, Page \# & $\begin{array}{c}\text { File } \\
\text { Name }\end{array}$ & Notes \\
\hline \multirow{7}{*}{$6 / 26 / 2009$} & $\begin{array}{l}\text { overview, } \\
\mathrm{Zn}, \mathrm{O}, \mathrm{Pd} \text {, } \\
\text { and } \mathrm{Al}\end{array}$ & XPS & $\begin{array}{l}\text { After sputtering and annealing at } \\
0.4 \text { A for } 20 \text { mins (oxidation expt) }\end{array}$ & $\mathrm{Bk} 2, \operatorname{pg} 4$ & $\begin{array}{c}6260901 \\
\text { to } \\
6260905\end{array}$ & \\
\hline & $\begin{array}{c}\text { overview, } \\
\mathrm{Zn}, \mathrm{O}, \mathrm{Pd}, \\
\text { and } \mathrm{Al}\end{array}$ & XPS & After $0.2 \mathrm{~L}$ of oxygen & $\mathrm{Bk} 2, \operatorname{pg} 4$ & 6260906 & \\
\hline & $\begin{array}{c}\text { overview, } \\
\mathrm{Zn}, \mathrm{O}, \mathrm{Pd}, \\
\text { and } \mathrm{Al}\end{array}$ & XPS & After $0.8 \mathrm{~L}$ of oxygen $($ total $=1 \mathrm{~L})$ & $\mathrm{Bk} 2, \operatorname{pg} 4$ & 6260907 & \\
\hline & $\begin{array}{c}\text { overview, } \\
\mathrm{Zn}, \mathrm{O}, \mathrm{Pd}, \\
\text { and } \mathrm{Al}\end{array}$ & XPS & After $9 \mathrm{~L}$ of oxygen $($ total $=10 \mathrm{~L})$ & $\mathrm{Bk} 2, \operatorname{pg} 4$ & 6260908 & \\
\hline & $\begin{array}{c}\text { overview, } \\
\mathrm{Zn}, \mathrm{O}, \mathrm{Pd}, \\
\text { and } \mathrm{Al}\end{array}$ & XPS & $\begin{array}{l}\text { After } 90 \mathrm{~L} \text { of oxygen }(\text { total }=100 \\
\mathrm{L})\end{array}$ & $\mathrm{Bk} 2, \operatorname{pg} 4$ & 6260909 & \\
\hline & $\begin{array}{l}\text { overview, } \\
\mathrm{Zn}, \mathrm{O}, \mathrm{Pd}, \\
\text { and } \mathrm{Al}\end{array}$ & XPS & $\begin{array}{l}\text { After Annealing at } 0.3 \mathrm{~A} \text { for } 20 \\
\text { mins }\end{array}$ & $\mathrm{Bk} 2, \operatorname{pg} 4$ & 6260910 & \\
\hline & $\begin{array}{c}\text { overview, } \\
\mathrm{Zn}, \mathrm{O}, \mathrm{Pd}, \\
\text { and } \mathrm{Al}\end{array}$ & XPS & $\begin{array}{l}\text { After } 200 \text { L of oxygen (total }= \\
300 \mathrm{~L}) \text { [finished expt] }\end{array}$ & $\mathrm{Bk} 2, \operatorname{pg} 4$ & 6260911 & \\
\hline
\end{tabular}


Table 3A

\begin{tabular}{|c|c|c|c|c|c|c|}
\hline \multicolumn{7}{|c|}{$\mathrm{Gd}_{5} \mathrm{Ge}_{4}(010)$ Data List } \\
\hline Date & $\begin{array}{l}\text { Images / } \\
\text { Spectrum }\end{array}$ & Instr. & Purpose & Lab \#, Page \# & File Name & Notes \\
\hline \multirow{5}{*}{$10 / 27 / 2010$} & $\begin{array}{l}\text { overview, Ge, } \\
\text { Ge and } \mathrm{Gd}, \mathrm{Gd}, \\
\mathrm{O} \text {, and } \mathrm{C}\end{array}$ & XPS & $\begin{array}{l}\text { After exposure from Air } \\
\text { (Depth Profiling Experiment) }\end{array}$ & $\mathrm{Bk} 3, \mathrm{pg} 7$ & 10271001 & $\begin{array}{l}\text { Initial composition after sample was } \\
\text { exposed to air. Lots of carbon and } \\
\text { oxygen. }\end{array}$ \\
\hline & $\begin{array}{l}\text { overview, Ge, } \\
\text { Ge and } \mathrm{Gd}, \mathrm{Gd}, \\
\mathrm{O} \text {, and } \mathrm{C}\end{array}$ & XPS & After 3 minutes of sputtering & $\mathrm{Bk} 3, \mathrm{pg} 7$ & 10271002 & $\begin{array}{l}\text { Carbon decreased, oxygen increased } \\
\text { slightly. }\end{array}$ \\
\hline & $\begin{array}{l}\text { overview, Ge, } \\
\text { Ge and } \mathrm{Gd}, \mathrm{Gd} \text {, } \\
\mathrm{O} \text {, and } \mathrm{C}\end{array}$ & XPS & $\begin{array}{l}\text { After } 5 \text { minutes of sputtering } \\
\text { (total }=8 \text { mins) }\end{array}$ & Bk 3, pg 8 & 10271003 & $\begin{array}{l}\text { Carbon decreased, oxygen } \\
\text { decreased. }\end{array}$ \\
\hline & $\begin{array}{l}\text { overview, Ge, } \\
\text { Ge and } \mathrm{Gd}, \mathrm{Gd}, \\
\mathrm{O} \text {, and } \mathrm{C}\end{array}$ & XPS & $\begin{array}{l}\text { After } 10 \text { minutes of sputtering } \\
\text { (total }=18 \text { mins) }\end{array}$ & Bk $3, \operatorname{pg} 8$ & 10271004 & $\begin{array}{l}\text { Carbon decreased, oxygen } \\
\text { decreased. }\end{array}$ \\
\hline & $\begin{array}{l}\text { overview, Ge, } \\
\text { Ge and } \mathrm{Gd}, \mathrm{Gd} \text {, } \\
\mathrm{O} \text {, and } \mathrm{C}\end{array}$ & XPS & $\begin{array}{l}\text { After } 10 \text { minutes of sputtering } \\
\text { (total }=28 \text { mins) }\end{array}$ & Bk 3, pg 8 & 10271005 & $\begin{array}{l}\text { Alittle amount of Carbon, oxygen } \\
\text { decreasing. }\end{array}$ \\
\hline
\end{tabular}


Table 3A (Continue)

\begin{tabular}{|c|c|c|c|c|c|c|}
\hline Date & $\begin{array}{l}\text { Images / } \\
\text { Spectrum }\end{array}$ & Instr. & Purpose & Lab \#, Page \# & File Name & Notes \\
\hline \multirow{5}{*}{$10 / 27 / 2010$} & $\begin{array}{c}\text { overview, Ge, } \\
\text { Ge and } \mathrm{Gd}, \mathrm{Gd} \text {, } \\
\mathrm{O} \text {, and } \mathrm{C}\end{array}$ & XPS & $\begin{array}{l}\text { After } 10 \text { minutes of sputtering } \\
\text { (total }=38 \text { mins) }\end{array}$ & $\mathrm{Bk} 3, \operatorname{pg} 9$ & 10271006 & No or very little $C$, oxygen decreasing. \\
\hline & $\begin{array}{c}\text { overview, Ge, } \\
\text { Ge and } \mathrm{Gd}, \mathrm{Gd} \text {, } \\
\mathrm{O} \text {, and } \mathrm{C}\end{array}$ & XPS & $\begin{array}{l}\text { After } 10 \text { minutes of sputtering } \\
\text { (total }=48 \text { mins) }\end{array}$ & $\mathrm{Bk} 3, \operatorname{pg} 9$ & 10271007 & Oxygen decreasing. \\
\hline & $\begin{array}{c}\text { overview, Ge, } \\
\text { Ge and } \mathrm{Gd}, \mathrm{Gd} \text {, } \\
\mathrm{O} \text {, and } \mathrm{C}\end{array}$ & XPS & $\begin{array}{l}\text { After } 15 \text { minutes of sputtering } \\
\text { (total }=63 \text { mins) }\end{array}$ & $\mathrm{Bk} 3, \operatorname{pg} 9$ & 10271008 & Huge decrease in Oxygen. \\
\hline & $\begin{array}{c}\text { overview, Ge, } \\
\text { Ge and } \mathrm{Gd}, \mathrm{Gd} \text {, } \\
\mathrm{O} \text {, and } \mathrm{C}\end{array}$ & XPS & $\begin{array}{l}\text { After } 15 \text { minutes of sputtering } \\
\text { (total }=78 \text { mins) }\end{array}$ & $\mathrm{Bk} 3$, pg 10 & 10271009 & Oxygen decreasing. \\
\hline & $\begin{array}{l}\text { overview, Ge, } \\
\text { Ge and } \mathrm{Gd}, \mathrm{Gd} \text {, } \\
\text { and } \mathrm{O}\end{array}$ & XPS & $\begin{array}{l}\text { After } 20 \text { minutes of sputtering } \\
\text { (total = } 98 \text { mins) }\end{array}$ & $\mathrm{Bk} 3$, pg 10 & 10271010 & oxygen decreasing. \\
\hline
\end{tabular}


Table 3A (Continue)

\begin{tabular}{|c|c|c|c|c|c|c|}
\hline Date & $\begin{array}{l}\text { Images / } \\
\text { Spectrum }\end{array}$ & Instr. & Purpose & Lab \#, Page \# & File Name & Notes \\
\hline \multirow{6}{*}{$10 / 28 / 2010$} & $\begin{array}{l}\text { overview, } \\
\text { Ge, Gd, and } \\
\text { O }\end{array}$ & XPS & $\begin{array}{l}\text { After } 20 \text { minutes of sputtering } \\
\text { (total }=118 \text { mins) [End Depth } \\
\text { Profiling Experiment] }\end{array}$ & Bk 3, pg 11 & 10281001 & $\begin{array}{l}\text { Still have very little Oxygen, cannot get } \\
\text { rid of it. No preferential sputtering of } \\
\text { either Ge or Gd. }\end{array}$ \\
\hline & $\begin{array}{l}\text { overview, } \\
\text { Ge, and Gd }\end{array}$ & XPS & $\begin{array}{l}\text { After annealing at } 400 \mathrm{~K} \text { for } 30 \\
\text { mins }\end{array}$ & Bk 3,pg 11 & 10281002 & Start Depth Profiling Experiment. \\
\hline & $\begin{array}{l}\text { overview, } \\
\text { Ge, and Gd }\end{array}$ & XPS & After 2 minutes of sputtering & $\mathrm{Bk} 3, \mathrm{pg} 12$ & 10281003 & oxygen decreasing. \\
\hline & $\begin{array}{l}\text { overview, } \\
\text { Ge, and } \mathrm{Gd}\end{array}$ & XPS & $\begin{array}{l}\text { After } 2 \text { minutes of sputtering } \\
\text { (total }=4 \text { mins) }\end{array}$ & Bk 3, pg 12 & 10281004 & \\
\hline & $\begin{array}{l}\text { overview, } \\
\text { Ge, and Gd }\end{array}$ & XPS & $\begin{array}{l}\text { After } 2 \text { minutes of sputtering } \\
\text { (total }=6 \text { mins) }\end{array}$ & Bk 3, pg 12 & 10281005 & \\
\hline & $\begin{array}{l}\text { overview, } \\
\text { Ge, and Gd }\end{array}$ & XPS & $\begin{array}{l}\text { After } 2 \text { minutes of sputtering } \\
\text { (total }=8 \text { mins) }\end{array}$ & Bk 3, pg 13 & 10281006 & \\
\hline
\end{tabular}


Table 3A (Continue)

\begin{tabular}{|c|c|c|c|c|c|c|}
\hline Date & $\begin{array}{l}\text { Images / } \\
\text { Spectrum }\end{array}$ & Instr. & Purpose & Lab \#, Page \# & File Name & Notes \\
\hline \multirow{7}{*}{$10 / 28 / 2010$} & $\begin{array}{l}\text { overview, } \\
\text { Ge, and Gd }\end{array}$ & XPS & $\begin{array}{l}\text { After } 2 \text { minutes of sputtering } \\
\text { (total }=10 \text { mins) }\end{array}$ & Bk 3, pg 13 & 10281007 & $\begin{array}{l}\text { End Depth Profiling Experiment. No } \\
\text { preferential sputtering of either Ge or Gd. }\end{array}$ \\
\hline & $\begin{array}{l}\text { overview, } \\
\text { Ge, and Gd }\end{array}$ & XPS & $\begin{array}{l}\text { After annealing at } 450 \mathrm{~K} \text { for } 30 \\
\text { mins }\end{array}$ & $\mathrm{Bk} 3$, pg 13 & 10281008 & Start Depth Profiling Experiment. \\
\hline & $\begin{array}{l}\text { overview, } \\
\text { Ge, and Gd }\end{array}$ & XPS & After 2 minutes of sputtering & Bk 3, pg 14 & 10281009 & \\
\hline & $\begin{array}{l}\text { overview, } \\
\text { Ge, and Gd }\end{array}$ & XPS & $\begin{array}{l}\text { After } 2 \text { minutes of sputtering } \\
\text { (total }=4 \text { mins) }\end{array}$ & Bk 3, pg 14 & 10281010 & \\
\hline & $\begin{array}{l}\text { overview, } \\
\text { Ge, and Gd }\end{array}$ & XPS & $\begin{array}{l}\text { After } 2 \text { minutes of sputtering } \\
\text { (total }=6 \text { mins) }\end{array}$ & Bk 3, pg 14 & 10281011 & \\
\hline & $\begin{array}{l}\text { overview, } \\
\text { Ge, and Gd }\end{array}$ & XPS & $\begin{array}{l}\text { After } 2 \text { minutes of sputtering } \\
\text { (total }=8 \text { mins) }\end{array}$ & $\mathrm{Bk} 3, \mathrm{pg} 14$ & 10281012 & \\
\hline & $\begin{array}{l}\text { overview, } \\
\text { Ge, and Gd }\end{array}$ & XPS & $\begin{array}{l}\text { After } 2 \text { minutes of sputtering } \\
\text { (total }=10 \text { mins) }\end{array}$ & $\mathrm{Bk} 3, \mathrm{pg} 15$ & 10281013 & $\begin{array}{l}\text { End Depth Profiling Experiment. No } \\
\text { preferential sputtering of either Ge or Gd. }\end{array}$ \\
\hline
\end{tabular}


Table 3A (Continue)

\begin{tabular}{|c|c|c|c|c|c|c|}
\hline Date & $\begin{array}{l}\text { Images / } \\
\text { Spectrum }\end{array}$ & Instr. & Purpose & Lab \#, Page \# & File Name & Notes \\
\hline \multirow{6}{*}{$10 / 29 / 2010$} & $\begin{array}{l}\text { overview, } \\
\mathrm{Ge} \text {, and } \mathrm{Gd}\end{array}$ & XPS & $\begin{array}{l}\text { After annealing at } 500 \mathrm{~K} \text { for } 30 \\
\text { mins }\end{array}$ & Bk 3, pg 15 & 10291001 & Start Depth Profiling Experiment. \\
\hline & $\begin{array}{l}\text { overview, } \\
\text { Ge, and Gd }\end{array}$ & XPS & After 2 minutes of sputtering & Bk 3, pg 15 & 10291002 & \\
\hline & $\begin{array}{l}\text { overview, } \\
\mathrm{Ge}, \text { and } \mathrm{Gd}\end{array}$ & XPS & $\begin{array}{l}\text { After } 2 \text { minutes of sputtering } \\
\text { (total }=4 \text { mins) }\end{array}$ & Bk 3, pg 16 & 10291003 & \\
\hline & $\begin{array}{l}\text { overview, } \\
\mathrm{Ge} \text {, and } \mathrm{Gd}\end{array}$ & XPS & $\begin{array}{l}\text { After } 2 \text { minutes of sputtering } \\
\text { (total }=6 \text { mins) }\end{array}$ & Bk 3, pg 16 & 10291004 & \\
\hline & $\begin{array}{l}\text { overview, } \\
\mathrm{Ge} \text {, and Gd }\end{array}$ & XPS & $\begin{array}{l}\text { After } 2 \text { minutes of sputtering } \\
\text { (total }=8 \text { mins) }\end{array}$ & Bk 3,pg 16 & 10291005 & \\
\hline & $\begin{array}{l}\text { overview, } \\
\text { Ge, and Gd }\end{array}$ & XPS & $\begin{array}{l}\text { After } 2 \text { minutes of sputtering } \\
\text { (total }=10 \text { mins) }\end{array}$ & Bk 3,pg 17 & 10291006 & $\begin{array}{l}\text { End Depth Profiling Experiment. No } \\
\text { preferential sputtering of either Ge or Gd. }\end{array}$ \\
\hline
\end{tabular}


Table 3A (Continue)

\begin{tabular}{|c|c|c|c|c|c|c|}
\hline Date & $\begin{array}{l}\text { Images / } \\
\text { Spectrum }\end{array}$ & Instr. & Purpose & Lab \#, Page \# & File Name & Notes \\
\hline \multirow{12}{*}{$11 / 1 / 2010$} & $\begin{array}{l}\text { overview, } \\
\text { Ge, and Gd }\end{array}$ & XPS & $\begin{array}{l}\text { After annealing at } 550 \mathrm{~K} \text { for } 30 \\
\text { mins }\end{array}$ & Bk 3, pg 17 & 11011001 & Start Depth Profiling Experiment. \\
\hline & $\begin{array}{l}\text { overview, } \\
\mathrm{Ge} \text {, and } \mathrm{Gd}\end{array}$ & XPS & After 2 minutes of sputtering & Bk 3, pg 17 & 11011002 & \\
\hline & $\begin{array}{l}\text { overview, } \\
\mathrm{Ge} \text {, and } \mathrm{Gd}\end{array}$ & XPS & $\begin{array}{l}\text { After } 2 \text { minutes of sputtering (total } \\
=4 \text { mins) }\end{array}$ & $\mathrm{Bk} 3, \operatorname{pg} 18$ & 11011003 & \\
\hline & $\begin{array}{l}\text { overview, } \\
\text { Ge, and Gd }\end{array}$ & XPS & $\begin{array}{l}\text { After } 2 \text { minutes of sputtering (total } \\
=6 \text { mins) }\end{array}$ & $\mathrm{Bk} 3, \operatorname{pg} 18$ & 11011004 & \\
\hline & $\begin{array}{l}\text { overview, } \\
\text { Ge, and Gd }\end{array}$ & XPS & $\begin{array}{l}\text { After } 2 \text { minutes of sputtering (total } \\
=8 \text { mins) }\end{array}$ & Bk 3,pg 18 & 11011005 & \\
\hline & $\begin{array}{l}\text { overview, } \\
\text { Ge, and Gd }\end{array}$ & XPS & $\begin{array}{l}\text { After } 2 \text { minutes of sputtering (total } \\
=10 \text { mins) }\end{array}$ & $\mathrm{Bk} 3, \operatorname{pg} 19$ & 11011006 & $\begin{array}{l}\text { End Depth Profiling Experiment. No } \\
\text { preferential sputtering of either Ge or } \\
\text { Gd. }\end{array}$ \\
\hline & $\begin{array}{l}\text { overview, } \\
\text { Ge, and Gd }\end{array}$ & XPS & $\begin{array}{l}\text { After annealing at } 600 \mathrm{~K} \text { for } 30 \\
\text { mins }\end{array}$ & $\mathrm{Bk} 3$, pg 19 & 11011007 & Start Depth Profiling Experiment. \\
\hline & $\begin{array}{l}\text { overview, } \\
\text { Ge, and Gd }\end{array}$ & XPS & After 2 minutes of sputtering & Bk 3, pg 19 & 11011008 & \\
\hline & $\begin{array}{l}\text { overview, } \\
\text { Ge, and Gd }\end{array}$ & XPS & $\begin{array}{l}\text { After } 2 \text { minutes of sputtering (total } \\
=4 \text { mins) }\end{array}$ & $\mathrm{Bk} 3, \operatorname{pg} 19$ & 11011009 & \\
\hline & $\begin{array}{l}\text { overview, } \\
\text { Ge, and Gd }\end{array}$ & XPS & $\begin{array}{l}\text { After } 2 \text { minutes of sputtering (total } \\
=6 \text { mins) }\end{array}$ & $\mathrm{Bk} 3, \mathrm{pg} 20$ & 11011010 & \\
\hline & $\begin{array}{l}\text { overview, } \\
\text { Ge, and Gd }\end{array}$ & XPS & $\begin{array}{l}\text { After } 2 \text { minutes of sputtering (total } \\
=8 \text { mins) }\end{array}$ & Bk 3, pg 20 & 11011011 & \\
\hline & $\begin{array}{l}\text { overview, } \\
\text { Ge, and Gd }\end{array}$ & XPS & $\begin{array}{l}\text { After } 2 \text { minutes of sputtering (total } \\
=10 \text { mins) }\end{array}$ & Bk 3, pg 20 & 11011012 & $\begin{array}{l}\text { End Depth Profiling Experiment. No } \\
\text { preferential sputtering of either Ge or } \\
\text { Gd. }\end{array}$ \\
\hline
\end{tabular}


Table 3A (Continue)

\begin{tabular}{|c|c|c|c|c|c|c|}
\hline Date & $\begin{array}{l}\text { Images / } \\
\text { Spectrum }\end{array}$ & Instr. & Purpose & Lab \#, Page \# & File Name & Notes \\
\hline \multirow{6}{*}{$11 / 2 / 2010$} & $\begin{array}{l}\text { overview, } \\
\text { Ge, and Gd }\end{array}$ & XPS & $\begin{array}{l}\text { After annealing at } 700 \mathrm{~K} \text { for } 30 \\
\text { mins }\end{array}$ & $\mathrm{Bk} 3, \operatorname{pg} 21$ & 11021001 & Start Depth Profiling Experiment. \\
\hline & $\begin{array}{l}\text { overview, } \\
\text { Ge, and Gd }\end{array}$ & XPS & After 2 minutes of sputtering & $\mathrm{Bk} 3$, pg 21 & 11021002 & \\
\hline & $\begin{array}{l}\text { overview, } \\
\text { Ge, and Gd }\end{array}$ & XPS & $\begin{array}{l}\text { After } 2 \text { minutes of sputtering (total } \\
=4 \text { mins) }\end{array}$ & $\mathrm{Bk} 3, \operatorname{pg} 21$ & 11021003 & \\
\hline & $\begin{array}{l}\text { overview, } \\
\text { Ge, and Gd }\end{array}$ & XPS & $\begin{array}{l}\text { After } 2 \text { minutes of sputtering (total } \\
=6 \text { mins) }\end{array}$ & $\mathrm{Bk} 3, \operatorname{pg} 22$ & 11021004 & \\
\hline & $\begin{array}{l}\text { overview, } \\
\text { Ge, and Gd }\end{array}$ & XPS & $\begin{array}{l}\text { After } 2 \text { minutes of sputtering (total } \\
=8 \text { mins) }\end{array}$ & Bk 3, pg 22 & 11021005 & \\
\hline & $\begin{array}{l}\text { overview, } \\
\text { Ge, and Gd }\end{array}$ & XPS & $\begin{array}{l}\text { After } 2 \text { minutes of sputtering (total } \\
=10 \text { mins) }\end{array}$ & $\mathrm{Bk} 3, \operatorname{pg} 22$ & 11021006 & $\begin{array}{l}\text { End Depth Profiling Experiment. No } \\
\text { preferential sputtering of either Ge or Gd. }\end{array}$ \\
\hline \multirow{6}{*}{$11 / 9 / 2010$} & $\begin{array}{l}\text { overview, } \\
\text { Ge, and Gd }\end{array}$ & XPS & $\begin{array}{l}\text { After annealing at } 800 \mathrm{~K} \text { for } 30 \\
\text { mins }\end{array}$ & $\mathrm{Bk} 3, \operatorname{pg} 28$ & 11091001 & Start Depth Profiling Experiment. \\
\hline & $\begin{array}{l}\text { overview, } \\
\text { Ge, and Gd }\end{array}$ & XPS & After 2 minutes of sputtering & $\mathrm{Bk} 3$, pg 28 & 11091002 & \\
\hline & $\begin{array}{l}\text { overview, } \\
\text { Ge, and Gd }\end{array}$ & XPS & $\begin{array}{l}\text { After } 2 \text { minutes of sputtering (total } \\
=4 \text { mins) }\end{array}$ & $\mathrm{Bk} 3, \operatorname{pg} 28$ & 11091003 & \\
\hline & $\begin{array}{l}\text { overview, } \\
\mathrm{Ge} \text {, and } \mathrm{Gd}\end{array}$ & XPS & $\begin{array}{l}\text { After } 2 \text { minutes of sputtering (total } \\
=6 \text { mins) }\end{array}$ & Bk 3, pg 29 & 11091004 & \\
\hline & $\begin{array}{l}\text { overview, } \\
\text { Ge, and Gd }\end{array}$ & XPS & $\begin{array}{l}\text { After } 2 \text { minutes of sputtering (total } \\
=8 \text { mins) }\end{array}$ & Bk 3, pg 29 & 11091005 & \\
\hline & $\begin{array}{l}\text { overview, } \\
\text { Ge, and Gd }\end{array}$ & XPS & $\begin{array}{l}\text { After } 2 \text { minutes of sputtering (total } \\
=10 \text { mins) }\end{array}$ & Bk 3, pg 29 & 11091006 & $\begin{array}{l}\text { End Depth Profiling Experiment. No } \\
\text { preferential sputtering of either Ge or Gd. }\end{array}$ \\
\hline
\end{tabular}


Table 3A (Continue)

\begin{tabular}{|c|c|c|c|c|c|c|}
\hline Date & $\begin{array}{l}\text { Images / } \\
\text { Spectrum }\end{array}$ & Instr. & Purpose & Lab \#, Page \# & File Name & Notes \\
\hline \multirow{9}{*}{$11 / 11 / 2010$} & $\begin{array}{l}\text { overview, } \\
\text { Ge, and Gd }\end{array}$ & XPS & $\begin{array}{l}\text { After annealing at } 900 \mathrm{~K} \text { for } 30 \\
\text { mins }\end{array}$ & Bk 3, pg 29 & 11111001 & Start Depth Profiling Experiment. \\
\hline & $\begin{array}{l}\text { overview, } \\
\text { Ge, and Gd }\end{array}$ & XPS & After 2 minutes of sputtering & $\mathrm{Bk} 3, \mathrm{pg} 32$ & 11111002 & $\begin{array}{l}\text { XPS signal is decreasing! Something } \\
\text { wrong with Channeltron(?) }\end{array}$ \\
\hline & $\begin{array}{l}\text { overview, } \\
\text { Ge, and Gd }\end{array}$ & XPS & $\begin{array}{l}\text { After } 2 \text { minutes of sputtering } \\
\text { (total }=4 \text { mins) }\end{array}$ & $\mathrm{Bk} 3, \operatorname{pg} 32$ & 11111003 & \\
\hline & $\begin{array}{l}\text { overview, } \\
\text { Ge, and Gd }\end{array}$ & XPS & $\begin{array}{l}\text { After } 2 \text { minutes of sputtering } \\
\text { (total }=6 \text { mins) }\end{array}$ & Bk 3, pg 32 & 11111004 & \\
\hline & $\begin{array}{l}\text { overview, } \\
\text { Ge, and Gd }\end{array}$ & XPS & $\begin{array}{l}\text { After } 2 \text { minutes of sputtering } \\
\text { (total }=8 \text { mins) }\end{array}$ & Bk 3, pg 33 & 11111005 & \\
\hline & $\begin{array}{l}\text { overview, } \\
\text { Ge, and Gd }\end{array}$ & XPS & $\begin{array}{l}\text { After } 2 \text { minutes of sputtering } \\
\text { (total }=10 \text { mins })\end{array}$ & Bk 3, pg 33 & 11111006 & \\
\hline & $\begin{array}{l}\text { overview, } \\
\text { Ge, and Gd }\end{array}$ & XPS & $\begin{array}{l}\text { After } 2 \text { minutes of sputtering } \\
\text { (total }=12 \text { mins) }\end{array}$ & $\mathrm{Bk} 3, \operatorname{pg} 33$ & 11111007 & \\
\hline & $\begin{array}{l}\text { overview, } \\
\text { Ge, and Gd }\end{array}$ & XPS & $\begin{array}{l}\text { After } 2 \text { minutes of sputtering } \\
\text { (total }=14 \text { mins) }\end{array}$ & Bk 3, pg 33 & 11111008 & \\
\hline & $\begin{array}{l}\text { overview, } \\
\text { Ge, and Gd }\end{array}$ & XPS & $\begin{array}{l}\text { After } 2 \text { minutes of sputtering } \\
\text { (total }=16 \text { mins) }\end{array}$ & Bk 3, pg 34 & 11111009 & $\begin{array}{l}\text { Low Signal! Probably from the } \\
\text { channeltron. }\end{array}$ \\
\hline
\end{tabular}


Table 3A (Continue)

\begin{tabular}{|c|c|c|c|c|c|c|}
\hline Date & $\begin{array}{l}\text { Images / } \\
\text { Spectrum }\end{array}$ & Instr. & Purpose & Lab \#, Page \# & File Name & Notes \\
\hline \multirow{5}{*}{$11 / 12 / 2010$} & $\begin{array}{l}\text { overview, } \\
\text { Ge, and Gd }\end{array}$ & XPS & $\begin{array}{l}\text { After } 2 \text { minutes of sputtering } \\
\text { (total }=18 \text { mins) }\end{array}$ & Bk 3, pg 34 & $\begin{array}{l}11121001 \\
11121002\end{array}$ & $\begin{array}{l}\text { Low Signal! Probably from the } \\
\text { channeltron. }\end{array}$ \\
\hline & $\begin{array}{l}\text { overview, } \\
\text { Ge, and Gd }\end{array}$ & XPS & $\begin{array}{l}\text { After } 2 \text { minutes of sputtering } \\
\text { (total }=20 \text { mins) }\end{array}$ & Bk 3, pg 35 & 11121003 & $\begin{array}{l}\text { Low Signal! Probably from the } \\
\text { channeltron. }\end{array}$ \\
\hline & $\begin{array}{l}\text { overview, } \\
\text { Ge, and Gd }\end{array}$ & XPS & $\begin{array}{l}\text { After } 2 \text { minutes of sputtering } \\
\text { (total }=22 \text { mins) }\end{array}$ & Bk 3, pg 35 & 11121004 & $\begin{array}{l}\text { Low Signal! Probably from the } \\
\text { channeltron. }\end{array}$ \\
\hline & $\begin{array}{l}\text { overview, } \\
\text { Ge, and Gd }\end{array}$ & XPS & $\begin{array}{l}\text { After } 2 \text { minutes of sputtering } \\
\text { (total }=24 \text { mins) }\end{array}$ & Bk 3, pg 35 & 11121005 & $\begin{array}{l}\text { Low Signal! Probably from the } \\
\text { channeltron. }\end{array}$ \\
\hline & $\begin{array}{l}\text { overview, } \\
\text { Ge, and Gd }\end{array}$ & XPS & $\begin{array}{l}\text { After } 2 \text { minutes of sputtering } \\
\text { (total }=26 \text { mins) }\end{array}$ & Bk 3, pg 35 & 11121006 & $\begin{array}{l}\text { End Depth Profiling Experiment. No } \\
\text { preferential sputtering of either Ge or Gd. } \\
\text { Low Signal! Probably from the } \\
\text { channeltron. }\end{array}$ \\
\hline \multirow{5}{*}{$11 / 16 / 2010$} & M1 - M48 & STM & $\begin{array}{l}\text { After sputtering, room } \\
\text { temperature }=300 \mathrm{~K}\end{array}$ & Bk 3, pg 37 & \multirow{5}{*}{$11 / 16 / 2010$} & $\begin{array}{l}\text { Middle of sample: see step-terrace } \\
\text { morphology, protrusions on terraces } \\
\text { caused by sputter damaged. }\end{array}$ \\
\hline & M49 - M73 & STM & $\begin{array}{l}\text { After sputtering, room } \\
\text { temperature }=300 \mathrm{~K}\end{array}$ & Bk 3, pg 37 & & $\begin{array}{l}\text { Upper left corner of sample: see small } \\
\text { step-terrace features. }\end{array}$ \\
\hline & M74 - M86 & STM & $\begin{array}{l}\text { After sputtering, room } \\
\text { temperature }=300 \mathrm{~K}\end{array}$ & Bk 3, pg 37 & & $\begin{array}{l}\text { Upper right corner of sample: very rough } \\
\text { surface, small step-terrace features. }\end{array}$ \\
\hline & M87 - M107 & STM & $\begin{array}{l}\text { After sputtering, room } \\
\text { temperature }=300 \mathrm{~K}\end{array}$ & Bk 3, pg 37 & & $\begin{array}{l}\text { Lower right corner of sample: very rough } \\
\text { surface, small step-terrace features. }\end{array}$ \\
\hline & M108 - M123 & STM & $\begin{array}{l}\text { After sputtering, room } \\
\text { temperature }=300 \mathrm{~K}\end{array}$ & Bk 3, pg 38 & & $\begin{array}{l}\text { Lower left corner of sample: very rough } \\
\text { surface, small step-terrace features. }\end{array}$ \\
\hline
\end{tabular}


Table 3A (Continue)

\begin{tabular}{|c|c|c|c|c|c|c|}
\hline Date & $\begin{array}{l}\text { Images / } \\
\text { Spectrum }\end{array}$ & Instr. & Purpose & Lab \#, Page \# & File Name & Notes \\
\hline \multirow{3}{*}{$11 / 20 / 2010$} & M1 - M27 & STM & $\begin{array}{l}\text { After sputtering for } 5 \text { mins and } \\
\text { annealing at } 900 \mathrm{~K} \text { for } 2 \text { hours }\end{array}$ & Bk 3, pg 40 & \multirow{3}{*}{$11 / 20 / 2010$} & $\begin{array}{l}\text { Middle of sample: rough surface, signs of } \\
\text { step-terrace morphology on almost every } \\
\text { image. }\end{array}$ \\
\hline & M28 - M41 & STM & $\begin{array}{l}\text { After sputtering for } 5 \text { mins and } \\
\text { annealing at } 900 \mathrm{~K} \text { for } 2 \text { hours }\end{array}$ & $\mathrm{Bk} 3, \mathrm{pg} 40$ & & $\begin{array}{l}\text { Right of sample: step-terrace morphology, } \\
\text { same features as in middle of sample. }\end{array}$ \\
\hline & M42 - M57 & STM & $\begin{array}{l}\text { After sputtering for } 5 \text { mins and } \\
\text { annealing at } 900 \mathrm{~K} \text { for } 2 \text { hours }\end{array}$ & $\mathrm{Bk} 3, \mathrm{pg} 40$ & & $\begin{array}{l}\text { Left of sample: rough surface compared to } \\
\text { middle of sample. Step-terrace } \\
\text { morphology, same features as in middle of } \\
\text { sample. }\end{array}$ \\
\hline \multirow{3}{*}{$11 / 24 / 2010$} & M1 - M7 & STM & $\begin{array}{l}\text { After sputtering for } 15 \text { mins and } \\
\text { annealing at } 900 \mathrm{~K} \text { for } 2 \text { hours }\end{array}$ & $\mathrm{Bk} 3, \operatorname{pg} 43$ & \multirow{3}{*}{$11 / 24 / 2010$} & $\begin{array}{l}\text { Middle of sample: Huge improvement in } \\
\text { step-terrace features. }\end{array}$ \\
\hline & M8 - M11 & STM & $\begin{array}{l}\text { After sputtering for } 15 \text { mins and } \\
\text { annealing at } 900 \mathrm{~K} \text { for } 2 \text { hours }\end{array}$ & $\mathrm{Bk} 3, \operatorname{pg} 43$ & & $\begin{array}{l}\text { Right of sample: surface looks worse than } \\
\text { previous STM run. Surface is rough. }\end{array}$ \\
\hline & M12 - M32 & STM & $\begin{array}{l}\text { After sputtering for } 15 \text { mins and } \\
\text { annealing at } 900 \mathrm{~K} \text { for } 2 \text { hours }\end{array}$ & Bk 3, pg 43 & & $\begin{array}{l}\text { Left of sample: see a smooth area of step- } \\
\text { terrace features. }\end{array}$ \\
\hline \multirow{3}{*}{$11 / 29 / 2010$} & M1 - M22 & STM & $\begin{array}{l}\text { After annealing at } 1050 \mathrm{~K} \text { for } 15 \\
\text { mins }\end{array}$ & Bk 3, pg 47 & \multirow{3}{*}{$11 / 29 / 2010$} & Middle of sample: lots of terraces. \\
\hline & M23 - M33 & STM & $\begin{array}{l}\text { After annealing at } 1050 \mathrm{~K} \text { for } 15 \\
\text { mins }\end{array}$ & Bk 3, pg 47 & & $\begin{array}{l}\text { Right of sample: lots of small terracces. } \\
\text { More rough surface compared to middle of } \\
\text { sample. }\end{array}$ \\
\hline & M34 - M70 & STM & $\begin{array}{l}\text { After annealing at } 1050 \mathrm{~K} \text { for } 15 \\
\text { mins }\end{array}$ & Bk 3, pg 47 & & $\begin{array}{l}\text { Left of sample: terraces are bigger and } \\
\text { much smoother than middle and right side } \\
\text { of sample. }\end{array}$ \\
\hline
\end{tabular}


Table 3A (Continue)

\begin{tabular}{|c|c|c|c|c|c|c|}
\hline Date & $\begin{array}{l}\text { Images / } \\
\text { Spectrum }\end{array}$ & Instr. & Purpose & Lab \#, Page \# & File Name & Notes \\
\hline \multirow{3}{*}{$12 / 2 / 2010$} & M1 - M26 & STM & $\begin{array}{l}\text { After annealing at } 1100 \\
\mathrm{~K} \text { for } 15 \text { mins }\end{array}$ & Bk 3, pg 51 & \multirow{3}{*}{$12 / 2 / 2010$} & $\begin{array}{l}\text { Middle of sample: a new terrace starts to emerge } \\
\text { "label as Terrace B" (looks like double step effect). } \\
\text { See circle bumps or islands on terrace. }\end{array}$ \\
\hline & M27 - M45 & STM & $\begin{array}{l}\text { After annealing at } 1100 \\
\mathrm{~K} \text { for } 15 \text { mins }\end{array}$ & Bk 3, pg 51 & & $\begin{array}{l}\text { Right of sample: same features as in the middle of } \\
\text { the sample. }\end{array}$ \\
\hline & M46 - M70 & STM & $\begin{array}{l}\text { After annealing at } 1100 \\
\mathrm{~K} \text { for } 15 \text { mins }\end{array}$ & $\mathrm{Bk} 3, \operatorname{pg} 51$ & & $\begin{array}{l}\text { Left of sample: big terraces. Same features as in the } \\
\text { middle of the sample. }\end{array}$ \\
\hline \multirow{3}{*}{$12 / 4 / 2010$} & M1 - M23 & STM & $\begin{array}{l}\text { After annealing at } 1150 \\
\mathrm{~K} \text { for } 15 \text { mins }\end{array}$ & Bk 3, pg 54 & $12 / 4 / 2010$ & $\begin{array}{l}\text { Middle of sample: "Terrace B" is alittle more } \\
\text { noticeable. Bumps or islands are on the main terrace } \\
\text { "labeled as Terrace A". }\end{array}$ \\
\hline & M24 - M47 & STM & $\begin{array}{l}\text { After annealing at } 1150 \\
\mathrm{~K} \text { for } 15 \text { mins }\end{array}$ & Bk 3, pg 55 & & $\begin{array}{l}\text { Right of sample: same features as in the middle of } \\
\text { the sample. }\end{array}$ \\
\hline & M48 - M97 & STM & $\begin{array}{l}\text { After annealing at } 1150 \\
\mathrm{~K} \text { for } 15 \text { mins }\end{array}$ & Bk 3, pg 55 & & $\begin{array}{l}\text { Left of sample: same features as in the middle of the } \\
\text { sample. }\end{array}$ \\
\hline \multirow{3}{*}{$12 / 6 / 2010$} & M1 - M25 & STM & $\begin{array}{l}\text { After annealing at } 1200 \\
\mathrm{~K} \text { for } 15 \text { mins }\end{array}$ & $\mathrm{Bk} 3$, pg 58 & \multirow{3}{*}{$12 / 6 / 2010$} & $\begin{array}{l}\text { Middle of sample: can see the difference between } \\
\text { terrace A and terrace B. Terrace B has no islands or } \\
\text { bumps while terrace A does. The islands or bumps } \\
\text { changed shape from circles to squares. Noisy! }\end{array}$ \\
\hline & M26 - M30 & STM & $\begin{array}{l}\text { After annealing at } 1200 \\
\mathrm{~K} \text { for } 15 \text { mins }\end{array}$ & Bk 3, pg 58 & & $\begin{array}{l}\text { Right of sample: same features as in the middle of } \\
\text { the sample. Noisy! }\end{array}$ \\
\hline & M31 - M33 & STM & $\begin{array}{l}\text { After annealing at } 1200 \\
\mathrm{~K} \text { for } 15 \text { mins }\end{array}$ & $\mathrm{Bk} 3, \operatorname{pg} 58$ & & $\begin{array}{l}\text { Left of sample: same features as in the middle of the } \\
\text { sample. Really noisy! }\end{array}$ \\
\hline
\end{tabular}


Table 3A (Continue)

\begin{tabular}{|c|c|c|c|c|c|c|}
\hline Date & $\begin{array}{l}\text { Images / } \\
\text { Spectrum }\end{array}$ & Instr. & Purpose & Lab \#, Page \# & File Name & Notes \\
\hline \multirow{3}{*}{$12 / 8 / 2010$} & M1 - M27 & STM & $\begin{array}{l}\text { After annealing at } 1100 \mathrm{~K} \text { for } 15 \\
\text { mins }\end{array}$ & Bk 3, pg 60 & \multirow{3}{*}{$12 / 8 / 2010$} & $\begin{array}{l}\text { Middle of sample: see terrace features. } \\
\text { Still have bumps or islands on surface as } \\
\text { well as terrace B. Similar features } \\
\text { compared with STM images at } 12 / 2 / 2010 \text {. }\end{array}$ \\
\hline & M28 - M36 & STM & $\begin{array}{l}\text { After annealing at } 1100 \mathrm{~K} \text { for } 15 \\
\text { mins }\end{array}$ & $\mathrm{Bk} 3, \operatorname{pg} 60$ & & $\begin{array}{l}\text { Right of sample: step bunching, lots of } \\
\text { bumps or islands on terraces. Terrace B } \\
\text { also visible. }\end{array}$ \\
\hline & M37 - M52 & STM & $\begin{array}{l}\text { After annealing at } 1100 \mathrm{~K} \text { for } 15 \\
\text { mins }\end{array}$ & Bk 3, pg 61 & & $\begin{array}{l}\text { Left of sample: same features as in middle } \\
\text { right of sample. }\end{array}$ \\
\hline \multirow{3}{*}{$12 / 10 / 2010$} & M1 - M33 & STM & $\begin{array}{l}\text { After annealing at } 1050 \mathrm{~K} \text { for } 15 \\
\text { mins }\end{array}$ & Bk 3, pg 63 & \multirow{3}{*}{$12 / 10 / 2010$} & $\begin{array}{l}\text { Middle of sample: see terraces, islands or } \\
\text { bumps on terraces, and terrace B. }\end{array}$ \\
\hline & M34 - M48 & STM & $\begin{array}{l}\text { After annealing at } 1050 \mathrm{~K} \text { for } 15 \\
\text { mins }\end{array}$ & Bk 3, pg 64 & & $\begin{array}{l}\text { Right of sample: same features as in } \\
\text { middle of surface. }\end{array}$ \\
\hline & M49 - M56 & STM & $\begin{array}{l}\text { After annealing at } 1050 \mathrm{~K} \text { for } 15 \\
\text { mins }\end{array}$ & Bk 3, pg 64 & & $\begin{array}{l}\text { Left of sample: same features as in middle } \\
\text { of sample. }\end{array}$ \\
\hline \multirow{2}{*}{$12 / 11 / 2010$} & $\begin{array}{l}\text { overview, } \\
\text { Ge, Gd, and } \\
\text { O }\end{array}$ & XPS & Clean surface at $300 \mathrm{~K}$ & $\mathrm{Bk} 3, \operatorname{pg} 64$ & \multirow{2}{*}{12111001} & Beginning of Oxidation experiment. \\
\hline & $\begin{array}{l}\text { overview, } \\
\text { Ge, Gd, and } \\
\text { O }\end{array}$ & XPS & $\begin{array}{l}\text { After } 100 \mathrm{~L} \text { oxygen exposure at } \\
300 \mathrm{~K}\end{array}$ & $\mathrm{Bk} 3, \operatorname{pg} 65$ & & $\begin{array}{l}\text { Done at } 300 \mathrm{~K} \text {, exposed for } 16 \text { mins and } \\
40 \text { secs at } 1.3 \mathrm{E}-7 \text { mbar. End of Oxidation } \\
\text { experiment. }\end{array}$ \\
\hline
\end{tabular}


Table 3A (Continue)

\begin{tabular}{|c|c|c|c|c|c|c|}
\hline Date & $\begin{array}{l}\text { Images / } \\
\text { Spectrum }\end{array}$ & Instr. & Purpose & Lab \#, Page \# & File Name & Notes \\
\hline \multirow{4}{*}{$12 / 12 / 2010$} & $\begin{array}{l}\text { overview, Ge, } \\
\text { Gd, and } \mathrm{O}\end{array}$ & XPS & Clean surface at $300 \mathrm{~K}$ & $\mathrm{Bk} 3, \mathrm{pg} 66$ & 12121001 & Beginning of Oxidation experiment. \\
\hline & $\begin{array}{l}\text { overview, Ge, } \\
\text { Gd, and } \mathrm{O}\end{array}$ & XPS & Clean surface at $600 \mathrm{~K}$ & Bk 3, pg 67 & 12121002 & $\begin{array}{l}\text { Small peak intensities compared to room } \\
\text { temperature at } 12121001 .\end{array}$ \\
\hline & $\begin{array}{l}\text { overview, Ge, } \\
\text { Gd, and } \mathrm{O}\end{array}$ & XPS & $\begin{array}{l}\text { After } 100 \mathrm{~L} \text { oxygen exposure } \\
\text { at } 600 \mathrm{~K}\end{array}$ & Bk 3, pg 67 & 12121003 & $\begin{array}{l}\text { Done at } 600 \mathrm{~K} \text {, exposed for } 16 \text { mins and } 40 \\
\text { secs at } 1.3 \mathrm{E}-7 \text { mbar. Did not see any peaks. } \\
\text { Very little peak of oxygen. Probably from the } \\
\text { electronics. }\end{array}$ \\
\hline & $\begin{array}{l}\text { overview, Ge, } \\
\text { Gd, and } \mathrm{O}\end{array}$ & XPS & $\begin{array}{l}\text { After cool down to room } \\
\text { temperature }=300 \mathrm{~K}\end{array}$ & Bk 3, pg 67 & 12121004 & $\begin{array}{l}\text { See peaks. Running XPS at } 600 \mathrm{~K} \text { was the } \\
\text { problem. End of Oxidation experiment. }\end{array}$ \\
\hline \multirow{5}{*}{$12 / 12 / 2010$} & $\begin{array}{l}\text { overview, Ge, } \\
\text { Gd, and } \mathrm{O}\end{array}$ & XPS & Clean surface at $300 \mathrm{~K}$ & $\mathrm{Bk} 3, \mathrm{pg} 69$ & 12131002 & Beginning of Oxidation experiment. \\
\hline & $\begin{array}{l}\text { overview, Ge, } \\
\text { Gd, and } \mathrm{O}\end{array}$ & XPS & After $0.5 \mathrm{~L}$ oxygen exposure & Bk 3, pg 69 & 12131003 & $\begin{array}{l}\text { Done at } 300 \mathrm{~K} \text {, exposed for } 50 \text { secs at } 1.3 \mathrm{E}-8 \\
\text { mbar. }\end{array}$ \\
\hline & $\begin{array}{l}\text { overview, Ge, } \\
\text { Gd, and } \mathrm{O}\end{array}$ & XPS & $\begin{array}{l}\text { After } 1.5 \mathrm{~L} \text { oxygen exposure } \\
\text { (total exposure }=2 \mathrm{~L} \text { ) }\end{array}$ & Bk 3, pg 70 & 12131004 & $\begin{array}{l}\text { Done at } 300 \mathrm{~K} \text {, exposed for } 2 \text { mins } 30 \text { secs at } \\
1.3 \mathrm{E}-8 \text { mbar. }\end{array}$ \\
\hline & $\begin{array}{l}\text { overview, Ge, } \\
\text { Gd, and } \mathrm{O}\end{array}$ & XPS & $\begin{array}{l}\text { After } 8 \mathrm{~L} \text { oxygen exposure } \\
\text { (total exposure }=10 \mathrm{~L} \text { ) }\end{array}$ & Bk 3, pg 70 & 12131005 & $\begin{array}{l}\text { Done at } 300 \mathrm{~K} \text {, exposed for } 2 \text { mins } 40 \text { secs at } \\
6.5 \mathrm{E}-8 \text { mbar. }\end{array}$ \\
\hline & $\begin{array}{l}\text { overview, Ge, } \\
\text { Gd, and O }\end{array}$ & XPS & $\begin{array}{l}\text { After } 90 \mathrm{~L} \text { oxygen exposure } \\
\text { (total exposure }=100 \mathrm{~L} \text { ) }\end{array}$ & $\mathrm{Bk} 3, \operatorname{pg} 70$ & 12131006 & $\begin{array}{l}\text { Done at } 300 \mathrm{~K} \text {, exposed for } 15 \text { mins at } 1.3 \mathrm{E}-7 \\
\text { mbar. End of Oxidation experiment. }\end{array}$ \\
\hline
\end{tabular}


Table 3A (Continue)

\begin{tabular}{|c|c|c|c|c|c|c|}
\hline Date & $\begin{array}{l}\text { Images / } \\
\text { Spectrum }\end{array}$ & Instr. & Purpose & Lab \#, Page \# & File Name & Notes \\
\hline \multirow{8}{*}{$4 / 21 / 2011$} & $\begin{array}{l}\text { overview, Ge, } \\
\text { Gd, O, and C }\end{array}$ & XPS & $\begin{array}{l}\text { After annealing at } 900 \mathrm{~K} \text { for } 30 \\
\text { mins }\end{array}$ & Bk 3, pg 88 & 4211101 & Start Depth Profiling Experiment. \\
\hline & $\begin{array}{l}\text { overview, Ge, } \\
\text { Gd, O, and C }\end{array}$ & XPS & After 2 minutes of sputtering & Bk 3, pg 89 & 4211102 & \\
\hline & $\begin{array}{l}\text { overview, Ge, } \\
\text { Gd, O, and C }\end{array}$ & XPS & $\begin{array}{l}\text { After } 2 \text { minutes of sputtering (total } \\
=4 \text { mins) }\end{array}$ & Bk 3, pg 89 & 4211103 & \\
\hline & $\begin{array}{l}\text { overview, Ge, } \\
\text { Gd, O, and C }\end{array}$ & XPS & $\begin{array}{l}\text { After } 2 \text { minutes of sputtering (total } \\
=6 \text { mins) }\end{array}$ & Bk 3, pg 89 & 4211104 & \\
\hline & $\begin{array}{l}\text { overview, Ge, } \\
\text { Gd, O, and C }\end{array}$ & XPS & $\begin{array}{l}\text { After } 2 \text { minutes of sputtering (total } \\
=8 \text { mins) }\end{array}$ & Bk 3, pg 90 & 4211105 & \\
\hline & $\begin{array}{l}\text { overview, Ge, } \\
\text { Gd, O, and C }\end{array}$ & XPS & $\begin{array}{l}\text { After } 2 \text { minutes of sputtering (total } \\
=10 \text { mins) }\end{array}$ & Bk 3, pg 90 & 4211106 & \\
\hline & $\begin{array}{l}\text { overview, Ge, } \\
\text { Gd, O, and C }\end{array}$ & XPS & $\begin{array}{l}\text { After } 2 \text { minutes of sputtering (total } \\
=12 \text { mins) }\end{array}$ & Bk 3, pg 90 & 4211107 & \\
\hline & $\begin{array}{l}\text { overview, Ge, } \\
\mathrm{Gd}, \mathrm{O} \text {, and } \mathrm{C}\end{array}$ & XPS & $\begin{array}{l}\text { After } 2 \text { minutes of sputtering (total } \\
=14 \text { mins) }\end{array}$ & Bk 3, pg 91 & 4211108 & \\
\hline
\end{tabular}


Table 3A (Continue)

\begin{tabular}{|c|c|c|c|c|c|c|}
\hline Date & $\begin{array}{l}\text { Images / } \\
\text { Spectrum }\end{array}$ & Instr. & Purpose & Lab \#, Page \# & File Name & Notes \\
\hline \multirow{7}{*}{$4 / 22 / 2011$} & $\begin{array}{l}\text { overview, } \\
\text { Ge, and Gd }\end{array}$ & XPS & $\begin{array}{l}\text { After } 2 \text { minutes of sputtering } \\
\text { (total }=16 \text { mins) }\end{array}$ & Bk 3, pg 91 & 4221102 & $\begin{array}{l}\text { Bad connection between XPS and } \\
\text { computer on File } 04221101 \text {. Had to repeat } \\
\text { XPS. }\end{array}$ \\
\hline & $\begin{array}{l}\text { overview, } \\
\text { Ge, and Gd }\end{array}$ & XPS & $\begin{array}{l}\text { After } 2 \text { minutes of sputtering } \\
\text { (total }=18 \text { mins) }\end{array}$ & Bk 3, pg 92 & 4221103 & \\
\hline & $\begin{array}{l}\text { overview, } \\
\text { Ge, and Gd }\end{array}$ & XPS & $\begin{array}{l}\text { After } 2 \text { minutes of sputtering } \\
\text { (total }=20 \text { mins) }\end{array}$ & Bk 3, pg 92 & 4221104 & \\
\hline & $\begin{array}{l}\text { overview, } \\
\text { Ge, and Gd }\end{array}$ & XPS & $\begin{array}{l}\text { After } 2 \text { minutes of sputtering } \\
\text { (total }=22 \text { mins) }\end{array}$ & Bk 3, pg 92 & 4221105 & \\
\hline & $\begin{array}{l}\text { overview, } \\
\text { Ge, and Gd }\end{array}$ & XPS & $\begin{array}{l}\text { After } 2 \text { minutes of sputtering } \\
\text { (total }=24 \text { mins) }\end{array}$ & Bk 3, pg 93 & 4221106 & \\
\hline & $\begin{array}{l}\text { overview, } \\
\text { Ge, and Gd }\end{array}$ & XPS & $\begin{array}{l}\text { After } 2 \text { minutes of sputtering } \\
\text { (total }=26 \text { mins) }\end{array}$ & Bk 3, pg 93 & 4221107 & \\
\hline & $\begin{array}{l}\text { overview, } \\
\text { Ge, and Gd }\end{array}$ & XPS & $\begin{array}{l}\text { After } 2 \text { minutes of sputtering } \\
\text { (total }=28 \text { mins) }\end{array}$ & Bk 3, pg 93 & 4221108 & $\begin{array}{l}\text { End Depth-Profiling experiment. No } \\
\text { preferential sputtering of either Ge or Gd. }\end{array}$ \\
\hline \multirow{3}{*}{$4 / 24 / 2011$} & M1 - M30 & STM & After annealng 1 hour at $900 \mathrm{~K}$ & Bk 3, pg 94 & \multirow{3}{*}{$4 / 24 / 2011$} & $\begin{array}{l}\text { Middle of sample: see terraces and the } \\
\text { emergence of Terrace B. }\end{array}$ \\
\hline & M31 - M48 & STM & After annealing 1 hour at $900 \mathrm{~K}$ & Bk 3, pg 95 & & $\begin{array}{l}\text { Right of sample: see terraces, vacancy-pits, } \\
\text { emergence of Terrace } \mathrm{B} \text {, and high } \\
\text { resolution images. }\end{array}$ \\
\hline & M49 - M67 & STM & After annealing 1 hour at $900 \mathrm{~K}$ & Bk 3, pg 95 & & $\begin{array}{l}\text { Left of sample: see terraces, emergence of } \\
\text { Terrace B, and high resolution images. }\end{array}$ \\
\hline
\end{tabular}


Table 3A (Continue)

\begin{tabular}{|c|c|c|c|c|c|c|}
\hline Date & $\begin{array}{l}\text { Images / } \\
\text { Spectrum }\end{array}$ & Instr. & Purpose & Lab \#, Page \# & $\begin{array}{l}\text { File } \\
\text { Name }\end{array}$ & Notes \\
\hline \multirow{3}{*}{$4 / 25 / 2011$} & M1 - M38 & STM & $\begin{array}{l}\text { After annealing } 1 \text { hour at } \\
900 \mathrm{~K}\end{array}$ & Bk 3, pg 96 & \multirow{3}{*}{$4 / 25 / 2011$} & $\begin{array}{l}\text { Middle of sample: see terraces, emergence of } \\
\text { Terrace B, and high resolution images. }\end{array}$ \\
\hline & M39 - M66 & STM & $\begin{array}{l}\text { After annealing } 1 \text { hour at } \\
900 \mathrm{~K}\end{array}$ & Bk 3, pg 96 & & $\begin{array}{l}\text { Right of sample: see terraces, vacancy-pits, } \\
\text { emergence of Terrace B, and high resolution } \\
\text { images. }\end{array}$ \\
\hline & M67 - M94 & STM & $\begin{array}{l}\text { After annealing } 1 \text { hour at } \\
900 \mathrm{~K}\end{array}$ & Bk 3, pg 97 & & $\begin{array}{l}\text { Left of sample: see terraces, vacancy-pits, bumps } \\
\text { on terraces, and the emergence of Terrace B. }\end{array}$ \\
\hline \multirow{4}{*}{$4 / 27 / 2011$} & M1 - M26 & STM & $\begin{array}{l}\text { After annealing } 1 \text { hour at } \\
900 \mathrm{~K}\end{array}$ & Bk 3, pg 98 & \multirow{4}{*}{$4 / 27 / 2011$} & $\begin{array}{l}\text { Middle of sample: see terraces, vacancy-pits, } \\
\text { emergence of Terrace B, and high resolution } \\
\text { images. }\end{array}$ \\
\hline & M27- M46 & STM & $\begin{array}{l}\text { After annealing } 1 \text { hour at } \\
900 \mathrm{~K}\end{array}$ & Bk 3, pg 99 & & $\begin{array}{l}\text { Right of sample: see terraces, vacancy-pits, } \\
\text { emergence of Terrace } B \text {, and high resolution } \\
\text { images. }\end{array}$ \\
\hline & M47- M54 & STM & $\begin{array}{l}\text { After annealing } 1 \text { hour at } \\
900 \mathrm{~K}\end{array}$ & Bk 3, pg 99 & & $\begin{array}{l}\text { Left of sample: see terraces, lots of vacancy-pits, } \\
\text { and bumps (very similar to the } 1150 \mathrm{~K} \text { data from } \\
\text { previous sample). }\end{array}$ \\
\hline & M55 - M76 & STM & $\begin{array}{l}\text { After annealing } 1 \text { hour at } \\
900 \mathrm{~K}\end{array}$ & Bk 3, pg 99 & & $\begin{array}{l}\text { Between left and middle of sample: see terraces, } \\
\text { vacancy-pits, and emergence of Terrace B. }\end{array}$ \\
\hline \multirow{3}{*}{$4 / 29 / 2011$} & M1 - M28 & STM & $\begin{array}{l}\text { After annealing } 1 \text { hour at } \\
900 \mathrm{~K}\end{array}$ & Bk 3, pg 100 & \multirow{3}{*}{$4 / 29 / 2011$} & $\begin{array}{l}\text { Middle of sample: see terraces, emergence of } \\
\text { Terrace B, and high resolution images. }\end{array}$ \\
\hline & M29 - M51 & STM & $\begin{array}{l}\text { After annealing } 1 \text { hour at } \\
900 \mathrm{~K}\end{array}$ & Bk 3,pg 101 & & $\begin{array}{l}\text { Right of sample: see terraces, vacancy-pits, } \\
\text { emergence of Terrace B, and high resolution } \\
\text { images. }\end{array}$ \\
\hline & M52 - M88 & STM & $\begin{array}{l}\text { After annealing } 1 \text { hour at } \\
900 \mathrm{~K}\end{array}$ & Bk 3,pg 101 & & $\begin{array}{l}\text { Left of sample: see terraces, vacancy-pits, bumps } \\
\text { on terraces, and the emergence of Terrace B. Also } \\
\text { see different grain boundaries at large image } \\
\text { scales. }\end{array}$ \\
\hline
\end{tabular}


Table 3A (Continue)

\begin{tabular}{|c|c|c|c|c|c|c|}
\hline Date & $\begin{array}{l}\text { Images / } \\
\text { Spectrum }\end{array}$ & Instr. & Purpose & Lab \#, Page \# & File Name & Notes \\
\hline \multirow{7}{*}{$5 / 6 / 2011$} & $\begin{array}{l}\text { overview, } \\
\text { Ge, and Gd }\end{array}$ & XPS & After annealing $900 \mathrm{~K}$ for $30 \mathrm{mins}$ & Bk 3, pg 106 & 2011-05-06-01 & Start Depth Profiling Experiment. \\
\hline & $\begin{array}{l}\text { overview, } \\
\text { Ge, and Gd }\end{array}$ & XPS & After 15 secs of sputtering & Bk 3, pg 107 & 2011-05-06-02 & \\
\hline & $\begin{array}{l}\text { overview, } \\
\text { Ge, and Gd }\end{array}$ & XPS & $\begin{array}{l}\text { After } 15 \text { secs of sputtering (total = } \\
30 \text { secs) }\end{array}$ & Bk 3, pg 107 & 2011-05-06-03 & \\
\hline & $\begin{array}{l}\text { overview, } \\
\mathrm{Ge} \text {, and } \mathrm{Gd}\end{array}$ & XPS & $\begin{array}{l}\text { After } 15 \text { secs of sputtering (total = } \\
45 \text { secs) }\end{array}$ & Bk 3, pg 107 & 2011-05-06-04 & \\
\hline & $\begin{array}{l}\text { overview, } \\
\text { Ge, and Gd }\end{array}$ & XPS & $\begin{array}{l}\text { After } 15 \text { secs of sputtering }(\text { total }= \\
60 \text { secs) }\end{array}$ & Bk 3, pg 107 & 2011-05-06-05 & \\
\hline & $\begin{array}{l}\text { overview, } \\
\mathrm{Ge} \text {, and } \mathrm{Gd}\end{array}$ & XPS & $\begin{array}{l}\text { After } 15 \text { secs of sputtering (total = } \\
75 \text { secs) }\end{array}$ & Bk 3, pg 108 & 2011-05-06-06 & \\
\hline & $\begin{array}{l}\text { overview, } \\
\text { Ge, and Gd }\end{array}$ & XPS & $\begin{array}{l}\text { After } 15 \text { secs of sputtering (total = } \\
90 \text { secs) }\end{array}$ & Bk 3,pg 108 & 2011-05-06-07 & \\
\hline
\end{tabular}


Table 3A (Continue)

\begin{tabular}{|c|c|c|c|c|c|c|}
\hline Date & $\begin{array}{c}\text { Images / } \\
\text { Spectrum }\end{array}$ & Instr. & Purpose & Lab \#, Page \# & File Name & Notes \\
\hline \multirow{6}{*}{$5 / 6 / 2011$} & $\begin{array}{l}\text { overview, } \\
\text { Ge, and Gd }\end{array}$ & XPS & After 15 secs of sputtering (total $=105 \mathrm{secs}$ ) & Bk 3, pg 108 & 2011-05-06-08 & \\
\hline & $\begin{array}{l}\text { overview, } \\
\text { Ge, and Gd }\end{array}$ & XPS & After 15 secs of sputtering (total $=120 \mathrm{secs}$ ) & Bk 3, pg 109 & 2011-05-06-09 & \\
\hline & $\begin{array}{l}\text { overview, } \\
\text { Ge, and Gd }\end{array}$ & XPS & After 15 secs of sputtering (total $=135 \mathrm{secs})$ & Bk 3, pg 109 & 2011-05-06-10 & \\
\hline & $\begin{array}{l}\text { overview, } \\
\text { Ge, and Gd }\end{array}$ & XPS & After 15 secs of sputtering (total $=150$ secs) & Bk 3, pg 109 & 2011-05-06-11 & \\
\hline & $\begin{array}{l}\text { overview, } \\
\text { Ge, and Gd }\end{array}$ & XPS & After 15 secs of sputtering (total $=165$ secs) & Bk 3, pg 109 & 2011-05-06-12 & \\
\hline & $\begin{array}{l}\text { overview, } \\
\text { Ge, and Gd }\end{array}$ & XPS & After 15 secs of sputtering (total $=180 \mathrm{secs})$ & Bk 3, pg 110 & $2011-05-06-13$ & \\
\hline \multirow{4}{*}{$5 / 7 / 2011$} & $\begin{array}{l}\text { overview, } \\
\text { Ge, and Gd }\end{array}$ & XPS & After 15 secs of sputtering (total $=195$ secs) & Bk 3,pg 110 & 2011-05-07-01 & \\
\hline & $\begin{array}{l}\text { overview, } \\
\text { Ge, and Gd }\end{array}$ & XPS & After 15 secs of sputtering (total $=210 \mathrm{secs}$ ) & $\mathrm{Bk} 3, \operatorname{pg} 110$ & $2011-05-07-02$ & \\
\hline & $\begin{array}{l}\text { overview, } \\
\text { Ge, and Gd }\end{array}$ & XPS & After 15 secs of sputtering (total $=225$ secs $)$ & $\mathrm{Bk} 3, \operatorname{pg} 111$ & $2011-05-07-03$ & \\
\hline & $\begin{array}{l}\text { overview, } \\
\text { Ge, and Gd }\end{array}$ & XPS & After 15 secs of sputtering (total $=240$ secs $)$ & Bk 3, pg 111 & 2011-05-07-04 & \\
\hline
\end{tabular}


Table 3A (Continue)

\begin{tabular}{|c|c|c|c|c|c|c|}
\hline Date & $\begin{array}{l}\text { Images / } \\
\text { Spectrum }\end{array}$ & Instr. & Purpose & Lab \#, Page \# & File Name & Notes \\
\hline \multirow{3}{*}{$5 / 9 / 2011$} & M1 - M36 & STM & $\begin{array}{l}\text { After annealing at } 1200 \mathrm{~K} \\
\text { for } 15 \text { mins }\end{array}$ & Bk 3, pg 113 & \multirow{3}{*}{$5 / 9 / 2011$} & $\begin{array}{l}\text { Middle of sample: see terraces, high resolution } \\
\text { images, and faint outline areas near step } \\
\text { edges. }\end{array}$ \\
\hline & M37 - M65 & STM & $\begin{array}{l}\text { After annealing at } 1200 \mathrm{~K} \\
\text { for } 15 \text { mins }\end{array}$ & Bk 3,pg 113 & & $\begin{array}{l}\text { Right of sample: see terraces, vacancy-pits, } \\
\text { emergence of Terrace B, and high resolution } \\
\text { images. }\end{array}$ \\
\hline & M66 - M88 & STM & $\begin{array}{l}\text { After annealing at } 1200 \mathrm{~K} \\
\text { for } 15 \text { mins }\end{array}$ & Bk 3, pg 113 & & $\begin{array}{l}\text { Left of sample: see terraces, vacancy-pits, and } \\
\text { vacancy-voids. }\end{array}$ \\
\hline \multirow{6}{*}{$5 / 11 / 2011$} & M1 - M18 & STM & After 1 minute of sputtering & Bk 3,pg 116 & \multirow{3}{*}{$\begin{array}{l}2011-05-11- \\
01\end{array}$} & $\begin{array}{l}\text { Middle of sample: see terraces, outline blobs } \\
\text { near step edges, and lots of small pits on } \\
\text { terraces. }\end{array}$ \\
\hline & M19 - M32 & STM & After 1 minute of sputtering & Bk 3,pg 116 & & $\begin{array}{l}\text { Right of sample: see terraces, vacancy-pits, } \\
\text { bumps on terraces, and high resolution } \\
\text { images. }\end{array}$ \\
\hline & M33 - M41 & STM & After 1 minute of sputtering & $\mathrm{Bk} 3, \mathrm{pg} 116$ & & $\begin{array}{l}\text { Left of sample: see terraces, vacancy-pits, } \\
\text { vacancy-voids, and step edges seemed to be } \\
\text { more choppy. }\end{array}$ \\
\hline & M1 - M29 & STM & $\begin{array}{l}\text { After annealing at } 900 \mathrm{~K} \text { for } \\
15 \mathrm{mins}\end{array}$ & Bk 3,pg 116 & \multirow{3}{*}{$\begin{array}{l}2011-05-11- \\
02\end{array}$} & $\begin{array}{l}\text { Middle of sample: see terraces, outline blobs } \\
\text { near step edges, and high resolution images } \\
\text { indicating two structures. }\end{array}$ \\
\hline & M30 - M47 & STM & $\begin{array}{l}\text { After annealing at } 900 \mathrm{~K} \text { for } \\
15 \mathrm{mins}\end{array}$ & Bk 3,pg 117 & & $\begin{array}{l}\text { Right of sample: see terraces, vacancy-pits, } \\
\text { tooth shape step edges, bumps on terraces, and } \\
\text { high resolution images. }\end{array}$ \\
\hline & M48 - M65 & STM & $\begin{array}{l}\text { After annealing at } 900 \mathrm{~K} \text { for } \\
15 \text { mins }\end{array}$ & Bk 3,pg 117 & & $\begin{array}{l}\text { Left of sample: see terraces, vacancy-pits, } \\
\text { vacancy-voids, and high resolution images. }\end{array}$ \\
\hline
\end{tabular}


Table 3A (Continue)

\begin{tabular}{|c|c|c|c|c|c|c|}
\hline Date & $\begin{array}{l}\text { Images / } \\
\text { Spectrum }\end{array}$ & Instr. & Purpose & Lab \#, Page \# & File Name & Notes \\
\hline \multirow{4}{*}{$5 / 13 / 2011$} & M1 - M6 & STM & $\begin{array}{l}\text { After annealing at } 1050 \mathrm{~K} \text { for } 15 \\
\text { mins }\end{array}$ & $\mathrm{Bk} 3$, pg 120 & \multirow{4}{*}{$5 / 13 / 2011$} & $\begin{array}{l}\text { Middle of sample: see terraces, vacancy- } \\
\text { pits, and lots of rough areas. }\end{array}$ \\
\hline & M7 - M27 & STM & $\begin{array}{l}\text { After annealing at } 1050 \mathrm{~K} \text { for } 15 \\
\text { mins }\end{array}$ & $\mathrm{Bk} 3, \operatorname{pg} 120$ & & $\begin{array}{l}\text { Middle of sample (different area): see } \\
\text { terraces and vacancy-voids. }\end{array}$ \\
\hline & M28 - M54 & STM & $\begin{array}{l}\text { After annealing at } 1050 \mathrm{~K} \text { for } 15 \\
\text { mins }\end{array}$ & Bk 3, pg 120 & & $\begin{array}{l}\text { Right of sample: see terraces, vacancy- } \\
\text { pits, bumps on terraces, and weird step } \\
\text { edge shapes. }\end{array}$ \\
\hline & M55 - M69 & STM & $\begin{array}{l}\text { After annealing at } 1050 \mathrm{~K} \text { for } 15 \\
\text { mins }\end{array}$ & $\mathrm{Bk} 3$, pg 120 & & $\begin{array}{l}\text { Left of sample: see terraces, vacancy-pits, } \\
\text { and lots of depressions on terraces. }\end{array}$ \\
\hline \multirow{3}{*}{$5 / 17 / 2011$} & M1 - M31 & STM & $\begin{array}{l}\text { After annealing at } 1050 \mathrm{~K} \text { for } 15 \\
\text { mins }\end{array}$ & Bk 3, pg 124 & $5 / 17 / 2011$ & $\begin{array}{l}\text { Middle of sample: see terraces, cury step } \\
\text { edges, bumps on terraces, and an expanded } \\
\text { Terrace B. }\end{array}$ \\
\hline & M32 - M55 & STM & $\begin{array}{l}\text { After annealing at } 1050 \mathrm{~K} \text { for } 15 \\
\text { mins }\end{array}$ & Bk 3,pg 125 & & $\begin{array}{l}\text { Right of sample: see terraces, similar to } \\
\text { middle of sample. }\end{array}$ \\
\hline & M56 - M74 & STM & $\begin{array}{l}\text { After annealing at } 1050 \mathrm{~K} \text { for } 15 \\
\text { mins }\end{array}$ & $\mathrm{Bk} 3$, pg 125 & & $\begin{array}{l}\text { Left of sample: see terraces, vacancy-pits, } \\
\text { bumps on terraces, and an expanded } \\
\text { Terrace B. }\end{array}$ \\
\hline \multirow{2}{*}{$5 / 18 / 2011$} & $\begin{array}{l}\text { overview, } \\
\text { Ge, and Gd }\end{array}$ & XPS & After sputtering for $15 \mathrm{mins}$ & Bk 3, pg 126 & $\begin{array}{l}2011-05-18- \\
02\end{array}$ & $\begin{array}{l}\text { Small take-off angle with respect to } \\
\text { analyzer }\left(20^{\circ}\right) \text { - more surface sensitive. }\end{array}$ \\
\hline & $\begin{array}{l}\text { overview, } \\
\text { Ge, and Gd }\end{array}$ & XPS & $\begin{array}{l}\text { After annealing at } 900 \mathrm{~K} \text { for } 15 \\
\text { mins }\end{array}$ & Bk 3, pg 126 & $\begin{array}{l}2011-05-18- \\
03\end{array}$ & $\begin{array}{l}\text { Small take-off angle with respect to } \\
\text { analyzer }\left(20^{\circ}\right) \text { - more surface sensitive. }\end{array}$ \\
\hline
\end{tabular}


Table 3A (Continue)

\begin{tabular}{|c|c|c|c|c|c|c|}
\hline Date & Images / Spectrum & Instr. & Purpose & Lab \#, Page \# & File Name & Notes \\
\hline \multirow{3}{*}{$4 / 25 / 2012$} & $\begin{array}{c}\text { overview, Ge, Gd, and } \\
\text { O }\end{array}$ & XPS & After sputtering for 15 mins & Bk 3,pg 139 & $2012-04-25-02$ & Surface concentration at $300 \mathrm{~K}$ \\
\hline & $\begin{array}{l}\text { overview, } \mathrm{Ge}, \mathrm{Gd} \text {, and } \\
\mathrm{O}\end{array}$ & XPS & After sputtering for 15 mins & Bk 3, pg 139 & $2012-04-25-03$ & Surface concentration at $300 \mathrm{~K}$ \\
\hline & overview, Ge, and Gd & XPS & $\begin{array}{l}\text { After annealing to } 400 \mathrm{~K} \text { for } 30 \\
\text { mins }\end{array}$ & $\mathrm{Bk} 3, \mathrm{pg} 140$ & $2012-04-25-06$ & Surface concentration at $400 \mathrm{~K}$ \\
\hline \multirow{5}{*}{$4 / 26 / 2012$} & overview, Ge, and Gd & XPS & $\begin{array}{l}\text { After annealing to } 400 \mathrm{~K} \text { for } 30 \\
\text { mins }\end{array}$ & Bk 3, pg 141 & 2012-04-26-01 & Surface concentration at $400 \mathrm{~K}$ \\
\hline & overview, Ge, and Gd & XPS & $\begin{array}{l}\text { After annealing to } 450 \mathrm{~K} \text { for } 30 \\
\text { mins }\end{array}$ & Bk 3, pg 141 & 2012-04-26-02 & Surface concentration at $450 \mathrm{~K}$ \\
\hline & overview, Ge, and Gd & XPS & $\begin{array}{l}\text { After annealing to } 450 \mathrm{~K} \text { for } 30 \\
\text { mins }\end{array}$ & Bk 3, pg 142 & 2012-04-26-03 & Surface concentration at $450 \mathrm{~K}$ \\
\hline & overview, Ge, and Gd & XPS & $\begin{array}{l}\text { After annealing to } 500 \mathrm{~K} \text { for } 30 \\
\text { mins }\end{array}$ & Bk 3, pg 142 & 2012-04-26-04 & Surface concentration at $500 \mathrm{~K}$ \\
\hline & overview, Ge, and Gd & XPS & $\begin{array}{l}\text { After annealing to } 500 \mathrm{~K} \text { for } 30 \\
\text { mins }\end{array}$ & Bk 3, pg 142 & 2012-04-26-05 & Surface concentration at $500 \mathrm{~K}$ \\
\hline \multirow{4}{*}{$4 / 27 / 2012$} & overview, Ge, and Gd & XPS & $\begin{array}{l}\text { After annealing to } 550 \mathrm{~K} \text { for } 30 \\
\text { mins }\end{array}$ & $\mathrm{Bk} 3, \operatorname{pg} 143$ & 2012-04-27-01 & Surface concentration at $550 \mathrm{~K}$ \\
\hline & overview, Ge, and Gd & XPS & $\begin{array}{l}\text { After annealing to } 550 \mathrm{~K} \text { for } 30 \\
\text { mins }\end{array}$ & Bk 3, pg 144 & 2012-04-27-02 & Surface concentration at $550 \mathrm{~K}$ \\
\hline & overview, Ge, and Gd & XPS & $\begin{array}{l}\text { After annealing to } 600 \mathrm{~K} \text { for } 30 \\
\text { mins }\end{array}$ & Bk 3, pg 144 & 2012-04-27-03 & Surface concentration at $600 \mathrm{~K}$ \\
\hline & overview, $\mathrm{Ge}$, and $\mathrm{Gd}$ & XPS & $\begin{array}{l}\text { After annealing to } 600 \mathrm{~K} \text { for } 30 \\
\text { mins }\end{array}$ & Bk 3, pg 145 & 2012-04-27-04 & Surface concentration at $600 \mathrm{~K}$ \\
\hline
\end{tabular}


Table 3A (Continue)

\begin{tabular}{|c|c|c|c|c|c|c|}
\hline Date & Images / Spectrum & Instr. & Purpose & Lab \#, Page \# & File Name & Notes \\
\hline \multirow{2}{*}{$4 / 28 / 2012$} & overview, $\mathrm{Ge}$, and $\mathrm{Gd}$ & XPS & $\begin{array}{l}\text { After annealing to } 700 \mathrm{~K} \text { for } 30 \\
\text { mins }\end{array}$ & $\mathrm{Bk} 3, \operatorname{pg} 145$ & 2012-04-28-01 & Surface concentration at $700 \mathrm{~K}$ \\
\hline & overview, $\mathrm{Ge}$, and $\mathrm{Gd}$ & XPS & $\begin{array}{l}\text { After annealing to } 700 \mathrm{~K} \text { for } 30 \\
\text { mins }\end{array}$ & Bk 3, pg 146 & 2012-04-28-02 & Surface concentration at $700 \mathrm{~K}$ \\
\hline \multirow{2}{*}{$4 / 29 / 2012$} & overview, $\mathrm{Ge}$, and $\mathrm{Gd}$ & XPS & $\begin{array}{l}\text { After annealing to } 800 \mathrm{~K} \text { for } 30 \\
\text { mins }\end{array}$ & $\mathrm{Bk} 3, \mathrm{pg} 146$ & 2012-04-29-01 & Surface concentration at $800 \mathrm{~K}$ \\
\hline & overview, $\mathrm{Ge}$, and $\mathrm{Gd}$ & XPS & $\begin{array}{l}\text { After annealing to } 800 \mathrm{~K} \text { for } 30 \\
\text { mins }\end{array}$ & Bk 3, pg 147 & 2012-04-29-02 & Surface concentration at $800 \mathrm{~K}$ \\
\hline \multirow{2}{*}{$4 / 30 / 2012$} & overview, Ge, and Gd & XPS & $\begin{array}{l}\text { After annealing to } 900 \mathrm{~K} \text { for } 30 \\
\text { mins }\end{array}$ & Bk 3, pg 147 & 2012-04-30-01 & Surface concentration at $900 \mathrm{~K}$ \\
\hline & overview, Ge, and Gd & XPS & $\begin{array}{l}\text { After annealing to } 900 \mathrm{~K} \text { for } 30 \\
\text { mins }\end{array}$ & Bk 3, pg 148 & 2012-04-30-02 & Surface concentration at $900 \mathrm{~K}$ \\
\hline \multirow{5}{*}{$5 / 1 / 2012$} & overview, $\mathrm{Ge}$, and $\mathrm{Gd}$ & XPS & $\begin{array}{l}\text { After annealing to } 1050 \mathrm{~K} \text { for } 30 \\
\text { mins }\end{array}$ & $\mathrm{Bk} 3, \operatorname{pg} 148$ & 2012-05-01-01 & $\begin{array}{l}\text { Surface concentration at } 1050 \\
\mathrm{~K}\end{array}$ \\
\hline & overview, $\mathrm{Ge}$, and $\mathrm{Gd}$ & XPS & $\begin{array}{l}\text { After annealing to } 1050 \mathrm{~K} \text { for } 30 \\
\text { mins }\end{array}$ & Bk 3, pg 149 & 2012-05-01-02 & $\begin{array}{l}\text { Surface concentration at } 1050 \\
\mathrm{~K}\end{array}$ \\
\hline & overview, $\mathrm{Ge}$, and $\mathrm{Gd}$ & XPS & $\begin{array}{l}\text { After annealing to } 1100 \mathrm{~K} \text { for } 30 \\
\text { mins }\end{array}$ & Bk 3, pg 149 & 2012-05-01-03 & $\begin{array}{l}\text { Surface concentration at } 1100 \\
\mathrm{~K}\end{array}$ \\
\hline & overview, $\mathrm{Ge}$, and $\mathrm{Gd}$ & XPS & $\begin{array}{l}\text { After annealing to } 1100 \mathrm{~K} \text { for } 30 \\
\text { mins }\end{array}$ & Bk 3, pg 149 & 2012-05-01-04 & $\begin{array}{l}\text { Surface concentration at } 1100 \\
\mathrm{~K}\end{array}$ \\
\hline & overview, $\mathrm{Ge}$, and $\mathrm{Gd}$ & XPS & $\begin{array}{l}\text { After annealing to } 1150 \mathrm{~K} \text { for } 30 \\
\text { mins }\end{array}$ & $\mathrm{Bk} 3, \operatorname{pg} 150$ & 2012-05-01-06 & $\begin{array}{l}\text { Surface concentration at } 1150 \\
\mathrm{~K}\end{array}$ \\
\hline $5 / 2 / 2012$ & overview, Ge, and Gd & XPS & $\begin{array}{l}\text { After annealing to } 1150 \mathrm{~K} \text { for } 30 \\
\text { mins }\end{array}$ & $\mathrm{Bk} 3, \operatorname{pg} 150$ & 2012-05-02-01 & $\begin{array}{l}\text { Surface concentration at } 1150 \\
\mathrm{~K}\end{array}$ \\
\hline \multirow{2}{*}{$5 / 3 / 2012$} & overview, $\mathrm{Ge}$, and $\mathrm{Gd}$ & XPS & $\begin{array}{l}\text { After annealing to } 1200 \mathrm{~K} \text { for } 30 \\
\text { mins }\end{array}$ & $\mathrm{Bk} 3, \operatorname{pg} 153$ & 2012-05-03-01 & $\begin{array}{l}\text { Surface concentration at } 1200 \\
\mathrm{~K}\end{array}$ \\
\hline & overview, $\mathrm{Ge}$, and $\mathrm{Gd}$ & XPS & $\begin{array}{l}\text { After annealing to } 1200 \mathrm{~K} \text { for } 30 \\
\text { mins }\end{array}$ & Bk 3, pg 153 & $2012-05-03-02$ & $\begin{array}{l}\text { Surface concentration at } 1200 \\
\mathrm{~K}\end{array}$ \\
\hline
\end{tabular}


Table 3A (Continue)

\begin{tabular}{|c|c|c|c|c|c|c|}
\hline Date & $\begin{array}{l}\text { Images / } \\
\text { Spectrum }\end{array}$ & Instr. & Purpose & Lab \#, Page \# & File Name & Notes \\
\hline \multirow{10}{*}{$6 / 25 / 2012$} & $\begin{array}{l}\text { overview, } \\
\text { Ge, and Gd }\end{array}$ & XPS & After annealing to $700 \mathrm{~K}$ for $30 \mathrm{mins}$ & Bk 4,pg 101 & 2012-06-25-01 & $\begin{array}{l}\text { Beginning of Depth Profiling } \\
\text { Experiment at } 700 \mathrm{~K}\end{array}$ \\
\hline & $\begin{array}{l}\text { overview, } \\
\text { Ge, and Gd }\end{array}$ & XPS & After sputtering for $30 \mathrm{secs}$ & Bk 4,pg 102 & $2012-06-25-02$ & \\
\hline & $\begin{array}{l}\text { overview, } \\
\mathrm{Ge} \text {, and } \mathrm{Gd}\end{array}$ & XPS & $\begin{array}{l}\text { After sputtering for } 30 \text { secs (total }=1 \\
\text { min) }\end{array}$ & Bk 4,pg 102 & $2012-06-25-03$ & \\
\hline & $\begin{array}{l}\text { overview, } \\
\text { Ge, and Gd }\end{array}$ & XPS & $\begin{array}{l}\text { After sputtering for } 30 \mathrm{secs}(\text { total }= \\
1.5 \text { mins })\end{array}$ & Bk 4,pg 102 & $2012-06-25-04$ & \\
\hline & $\begin{array}{l}\text { overview, } \\
\text { Ge, and Gd }\end{array}$ & XPS & $\begin{array}{l}\text { After sputtering for } 30 \mathrm{secs} \text { (total }=2 \\
\text { mins) }\end{array}$ & Bk 4,pg 102 & $2012-06-25-05$ & \\
\hline & $\begin{array}{l}\text { overview, } \\
\text { Ge, and Gd }\end{array}$ & XPS & $\begin{array}{l}\text { After sputtering for } 30 \mathrm{secs}(\text { total }= \\
2.5 \text { mins) }\end{array}$ & Bk 4,pg 102 & $2012-06-25-06$ & \\
\hline & $\begin{array}{l}\text { overview, } \\
\mathrm{Ge} \text {, and } \mathrm{Gd}\end{array}$ & XPS & $\begin{array}{l}\text { After sputtering for } 30 \operatorname{secs} \text { (total }=3 \\
\text { mins) }\end{array}$ & Bk 4,pg 103 & $2012-06-25-07$ & \\
\hline & $\begin{array}{l}\text { overview, } \\
\text { Ge, and Gd }\end{array}$ & XPS & $\begin{array}{l}\text { After sputtering for } 30 \mathrm{secs}(\text { total }= \\
3.5 \text { mins) }\end{array}$ & Bk 4,pg 103 & $2012-06-25-08$ & \\
\hline & $\begin{array}{l}\text { overview, } \\
\mathrm{Ge} \text {, and Gd }\end{array}$ & XPS & $\begin{array}{l}\text { After sputtering for } 30 \mathrm{secs} \text { (total }=4 \\
\text { mins) }\end{array}$ & Bk 4, pg 103 & 2012-06-25-09 & \\
\hline & $\begin{array}{l}\text { overview, } \\
\text { Ge, and Gd }\end{array}$ & XPS & $\begin{array}{l}\text { After sputtering for } 30 \mathrm{secs}(\text { total }= \\
4.5 \text { mins) }\end{array}$ & Bk 4,pg 103 & $2012-06-25-10$ & \\
\hline
\end{tabular}


Table 3A (Continue)

\begin{tabular}{|c|c|c|c|c|c|c|}
\hline Date & $\begin{array}{l}\text { Images / } \\
\text { Spectrum }\end{array}$ & Instr. & Purpose & Lab \#, Page \# & File Name & Notes \\
\hline \multirow{11}{*}{$6 / 25 / 2012$} & $\begin{array}{l}\text { overview, } \\
\text { Ge, and Gd }\end{array}$ & XPS & $\begin{array}{l}\text { After sputtering for } 30 \mathrm{secs}(\text { total }= \\
5 \text { mins) }\end{array}$ & $\mathrm{Bk} 4, \operatorname{pg} 103$ & $\begin{array}{l}2012-06-25- \\
11\end{array}$ & \\
\hline & $\begin{array}{l}\text { overview, } \\
\text { Ge, and Gd }\end{array}$ & XPS & $\begin{array}{l}\text { After sputtering for } 30 \mathrm{secs}(\text { total }= \\
5.5 \text { mins) }\end{array}$ & $\mathrm{Bk} 4, \operatorname{pg} 103$ & $\begin{array}{l}2012-06-25- \\
12\end{array}$ & \\
\hline & $\begin{array}{l}\text { overview, } \\
\mathrm{Ge} \text {, and } \mathrm{Gd}\end{array}$ & XPS & $\begin{array}{l}\text { After sputtering for } 30 \text { secs }(\text { total }= \\
6 \text { mins) }\end{array}$ & Bk 4, pg 104 & $\begin{array}{l}2012-06-25- \\
13\end{array}$ & \\
\hline & $\begin{array}{l}\text { overview, } \\
\text { Ge, and Gd }\end{array}$ & XPS & $\begin{array}{l}\text { After sputtering for } 30 \mathrm{secs}(\text { total }= \\
6.5 \text { mins) }\end{array}$ & Bk 4,pg 104 & $\begin{array}{l}2012-06-25- \\
14\end{array}$ & \\
\hline & $\begin{array}{l}\text { overview, } \\
\text { Ge, and Gd }\end{array}$ & XPS & $\begin{array}{l}\text { After sputtering for } 30 \text { secs }(\text { total }= \\
7 \text { mins) }\end{array}$ & Bk 4,pg 104 & $\begin{array}{l}2012-06-25- \\
15\end{array}$ & \\
\hline & $\begin{array}{l}\text { overview, } \\
\text { Ge, and Gd }\end{array}$ & XPS & $\begin{array}{l}\text { After sputtering for } 30 \text { secs }(\text { total }= \\
7.5 \text { mins) }\end{array}$ & $\mathrm{Bk} 4, \operatorname{pg} 104$ & $\begin{array}{l}2012-06-25- \\
16\end{array}$ & \\
\hline & $\begin{array}{l}\text { overview, } \\
\mathrm{Ge} \text {, and } \mathrm{Gd}\end{array}$ & XPS & $\begin{array}{l}\text { After sputtering for } 30 \mathrm{secs} \text { (total }= \\
8 \text { mins) }\end{array}$ & Bk 4,pg 104 & $\begin{array}{l}2012-06-25- \\
17\end{array}$ & \\
\hline & $\begin{array}{l}\text { overview, } \\
\text { Ge, and Gd }\end{array}$ & XPS & $\begin{array}{l}\text { After sputtering for } 30 \mathrm{secs}(\text { total }= \\
8.5 \text { mins) }\end{array}$ & Bk 4,pg 104 & $\begin{array}{l}2012-06-25- \\
18\end{array}$ & \\
\hline & $\begin{array}{l}\text { overview, } \\
\mathrm{Ge} \text {, and } \mathrm{Gd}\end{array}$ & XPS & $\begin{array}{l}\text { After sputtering for } 30 \text { secs }(\text { total }= \\
9 \text { mins) }\end{array}$ & $\mathrm{Bk} 4$, pg 105 & $\begin{array}{l}2012-06-25- \\
19\end{array}$ & \\
\hline & $\begin{array}{l}\text { overview, } \\
\text { Ge, and Gd }\end{array}$ & XPS & $\begin{array}{l}\text { After sputtering for } 30 \mathrm{secs}(\text { total }= \\
9.5 \text { mins) }\end{array}$ & $\mathrm{Bk} 4, \operatorname{pg} 105$ & $\begin{array}{l}2012-06-25- \\
20\end{array}$ & \\
\hline & $\begin{array}{l}\text { overview, } \\
\text { Ge, and Gd }\end{array}$ & XPS & $\begin{array}{l}\text { After sputtering for } 30 \mathrm{secs}(\text { total }= \\
10 \text { mins })\end{array}$ & $\mathrm{Bk} 4, \operatorname{pg} 105$ & $\begin{array}{l}2012-06-25- \\
21\end{array}$ & $\begin{array}{l}\text { End of Depth Profiling Experiment at } \\
700 \mathrm{~K}\end{array}$ \\
\hline
\end{tabular}


Table 3A (Continue)

\begin{tabular}{|c|c|c|c|c|c|c|}
\hline Date & $\begin{array}{l}\text { Images / } \\
\text { Spectrum }\end{array}$ & Instr. & Purpose & Lab \#, Page \# & File Name & Notes \\
\hline \multirow{10}{*}{$6 / 26 / 2012$} & $\begin{array}{l}\text { overview, } \\
\mathrm{Ge} \text {, and } \mathrm{Gd}\end{array}$ & XPS & $\begin{array}{l}\text { After annealing to } 900 \mathrm{~K} \text { for } 30 \\
\text { mins }\end{array}$ & Bk 4,pg 105 & 2012-06-26-01 & $\begin{array}{l}\text { Beginning of Depth Profiling } \\
\text { Experiment at } 900 \mathrm{~K}\end{array}$ \\
\hline & $\begin{array}{l}\text { overview, } \\
\text { Ge, and Gd }\end{array}$ & XPS & After sputtering for $30 \mathrm{secs}$ & Bk 4,pg 106 & 2012-06-26-02 & \\
\hline & $\begin{array}{l}\text { overview, } \\
\mathrm{Ge} \text {, and } \mathrm{Gd}\end{array}$ & XPS & $\begin{array}{l}\text { After sputtering for } 30 \mathrm{secs}(\text { total }= \\
1 \mathrm{~min})\end{array}$ & Bk 4,pg 106 & 2012-06-26-03 & \\
\hline & $\begin{array}{l}\text { overview, } \\
\text { Ge, and Gd }\end{array}$ & XPS & $\begin{array}{l}\text { After sputtering for } 30 \mathrm{secs}(\text { total }= \\
1.5 \text { mins) }\end{array}$ & Bk 4,pg 106 & 2012-06-26-04 & \\
\hline & $\begin{array}{l}\text { overview, } \\
\text { Ge, and } \mathrm{Gd}\end{array}$ & XPS & $\begin{array}{l}\text { After sputtering for } 30 \mathrm{secs} \text { (total = } \\
2 \text { mins) }\end{array}$ & Bk 4,pg 106 & 2012-06-26-05 & \\
\hline & $\begin{array}{l}\text { overview, } \\
\text { Ge, and Gd }\end{array}$ & XPS & $\begin{array}{l}\text { After sputtering for } 30 \mathrm{secs}(\text { total }= \\
2.5 \text { mins) }\end{array}$ & Bk 4,pg 106 & 2012-06-26-06 & \\
\hline & $\begin{array}{l}\text { overview, } \\
\mathrm{Ge} \text {, and } \mathrm{Gd}\end{array}$ & XPS & $\begin{array}{l}\text { After sputtering for } 30 \mathrm{secs} \text { (total }= \\
3 \text { mins) }\end{array}$ & $\mathrm{Bk} 4, \operatorname{pg} 107$ & 2012-06-26-07 & \\
\hline & $\begin{array}{l}\text { overview, } \\
\mathrm{Ge} \text {, and } \mathrm{Gd}\end{array}$ & XPS & $\begin{array}{l}\text { After sputtering for } 30 \mathrm{secs} \text { (total = } \\
3.5 \text { mins) }\end{array}$ & Bk 4,pg 107 & 2012-06-26-08 & \\
\hline & $\begin{array}{l}\text { overview, } \\
\text { Ge, and Gd }\end{array}$ & XPS & $\begin{array}{l}\text { After sputtering for } 30 \mathrm{secs} \text { (total = } \\
4 \text { mins) }\end{array}$ & Bk 4, pg 107 & 2012-06-26-09 & \\
\hline & $\begin{array}{l}\text { overview, } \\
\text { Ge, and Gd }\end{array}$ & XPS & $\begin{array}{l}\text { After sputtering for } 30 \mathrm{secs}(\text { total }= \\
4.5 \text { mins) }\end{array}$ & Bk 4,pg 107 & $2012-06-26-10$ & \\
\hline
\end{tabular}


Table 3A (Continue)

\begin{tabular}{|c|c|c|c|c|c|c|}
\hline Date & $\begin{array}{l}\text { Images / } \\
\text { Spectrum }\end{array}$ & Instr. & Purpose & Lab \#, Page \# & File Name & Notes \\
\hline \multirow{11}{*}{$6 / 26 / 2012$} & $\begin{array}{l}\text { overview, } \\
\text { Ge, and Gd }\end{array}$ & XPS & $\begin{array}{l}\text { After sputtering for } 30 \mathrm{secs} \text { (total }= \\
5 \text { mins) }\end{array}$ & Bk 4, pg 107 & $\begin{array}{l}\text { 2012-06-26- } \\
11\end{array}$ & \\
\hline & $\begin{array}{l}\text { overview, } \\
\text { Ge, and Gd }\end{array}$ & XPS & $\begin{array}{l}\text { After sputtering for } 30 \mathrm{secs}(\text { total }= \\
5.5 \text { mins) }\end{array}$ & Bk 4, pg 107 & $\begin{array}{l}2012-06-26- \\
12\end{array}$ & \\
\hline & $\begin{array}{l}\text { overview, } \\
\mathrm{Ge} \text {, and } \mathrm{Gd}\end{array}$ & XPS & $\begin{array}{l}\text { After sputtering for } 30 \text { secs }(\text { total }= \\
6 \text { mins) }\end{array}$ & Bk 4,pg 108 & $\begin{array}{l}2012-06-26- \\
13\end{array}$ & \\
\hline & $\begin{array}{l}\text { overview, } \\
\text { Ge, and Gd }\end{array}$ & XPS & $\begin{array}{l}\text { After sputtering for } 30 \mathrm{secs}(\text { total }= \\
6.5 \text { mins) }\end{array}$ & Bk 4,pg 108 & $\begin{array}{l}\text { 2012-06-26- } \\
14\end{array}$ & \\
\hline & $\begin{array}{l}\text { overview, } \\
\text { Ge, and Gd }\end{array}$ & XPS & $\begin{array}{l}\text { After sputtering for } 30 \text { secs }(\text { total }= \\
7 \text { mins) }\end{array}$ & Bk 4,pg 108 & $\begin{array}{l}2012-06-26- \\
15\end{array}$ & \\
\hline & $\begin{array}{l}\text { overview, } \\
\text { Ge, and Gd }\end{array}$ & XPS & $\begin{array}{l}\text { After sputtering for } 30 \text { secs }(\text { total }= \\
7.5 \text { mins) }\end{array}$ & $\mathrm{Bk} 4$, pg 108 & $\begin{array}{l}2012-06-26- \\
16\end{array}$ & \\
\hline & $\begin{array}{l}\text { overview, } \\
\mathrm{Ge} \text {, and } \mathrm{Gd}\end{array}$ & XPS & $\begin{array}{l}\text { After sputtering for } 30 \mathrm{secs}(\text { total }= \\
8 \text { mins) }\end{array}$ & Bk 4,pg 108 & $\begin{array}{l}2012-06-26- \\
17\end{array}$ & \\
\hline & $\begin{array}{l}\text { overview, } \\
\text { Ge, and Gd }\end{array}$ & XPS & $\begin{array}{l}\text { After sputtering for } 30 \mathrm{secs}(\text { total }= \\
8.5 \text { mins) }\end{array}$ & Bk 4,pg 108 & $\begin{array}{l}2012-06-26- \\
18\end{array}$ & \\
\hline & $\begin{array}{l}\text { overview, } \\
\mathrm{Ge} \text {, and } \mathrm{Gd}\end{array}$ & XPS & $\begin{array}{l}\text { After sputtering for } 30 \text { secs }(\text { total }= \\
9 \text { mins) }\end{array}$ & Bk 4, pg 109 & $\begin{array}{l}2012-06-26- \\
19\end{array}$ & \\
\hline & $\begin{array}{l}\text { overview, } \\
\text { Ge, and Gd }\end{array}$ & XPS & $\begin{array}{l}\text { After sputtering for } 30 \mathrm{secs}(\text { total }= \\
9.5 \text { mins) }\end{array}$ & Bk 4,pg 109 & $\begin{array}{l}2012-06-26- \\
20\end{array}$ & \\
\hline & $\begin{array}{l}\text { overview, } \\
\text { Ge, and Gd }\end{array}$ & XPS & $\begin{array}{l}\text { After sputtering for } 30 \mathrm{secs}(\text { total }= \\
10 \text { mins })\end{array}$ & $\mathrm{Bk} 4, \operatorname{pg} 109$ & $\begin{array}{l}2012-06-26- \\
21\end{array}$ & $\begin{array}{l}\text { End of Depth Profiling Experiment at } \\
900 \mathrm{~K}\end{array}$ \\
\hline
\end{tabular}


Table 3A (Continue)

\begin{tabular}{|c|c|c|c|c|c|c|}
\hline Date & $\begin{array}{l}\text { Images / } \\
\text { Spectrum }\end{array}$ & Instr. & Purpose & Lab \#, Page \# & File Name & Notes \\
\hline \multirow{10}{*}{$6 / 27 / 2012$} & $\begin{array}{l}\text { overview, } \\
\text { Ge, and Gd }\end{array}$ & XPS & $\begin{array}{l}\text { After annealing to } 900 \mathrm{~K} \text { for } 30 \\
\text { mins }\end{array}$ & Bk 4,pg 109 & 2012-06-27-01 & $\begin{array}{l}\text { Beginning of Depth Profiling } \\
\text { Experiment at } 1100 \mathrm{~K}\end{array}$ \\
\hline & $\begin{array}{l}\text { overview, } \\
\text { Ge, and Gd }\end{array}$ & XPS & After sputtering for $30 \mathrm{secs}$ & Bk 4,pg 110 & 2012-06-27-02 & \\
\hline & $\begin{array}{l}\text { overview, } \\
\mathrm{Ge} \text {, and } \mathrm{Gd}\end{array}$ & XPS & $\begin{array}{l}\text { After sputtering for } 30 \mathrm{secs}(\text { total }= \\
1 \mathrm{~min})\end{array}$ & Bk 4,pg 110 & 2012-06-27-03 & \\
\hline & $\begin{array}{l}\text { overview, } \\
\mathrm{Ge} \text {, and } \mathrm{Gd}\end{array}$ & XPS & $\begin{array}{l}\text { After sputtering for } 30 \mathrm{secs}(\text { total }= \\
1.5 \text { mins) }\end{array}$ & Bk 4,pg 110 & 2012-06-27-04 & \\
\hline & $\begin{array}{l}\text { overview, } \\
\text { Ge, and Gd }\end{array}$ & XPS & $\begin{array}{l}\text { After sputtering for } 30 \operatorname{secs}(\text { total }= \\
2 \text { mins) }\end{array}$ & Bk 4,pg 110 & 2012-06-27-05 & \\
\hline & $\begin{array}{l}\text { overview, } \\
\text { Ge, and Gd }\end{array}$ & XPS & $\begin{array}{l}\text { After sputtering for } 30 \mathrm{secs} \text { (total }= \\
2.5 \text { mins) }\end{array}$ & $\mathrm{Bk} 4, \operatorname{pg} 110$ & $2012-06-27-06$ & \\
\hline & $\begin{array}{l}\text { overview, } \\
\mathrm{Ge} \text {, and } \mathrm{Gd}\end{array}$ & XPS & $\begin{array}{l}\text { After sputtering for } 30 \mathrm{secs} \text { (total = } \\
3 \text { mins) }\end{array}$ & Bk 4,pg 110 & 2012-06-27-07 & \\
\hline & $\begin{array}{l}\text { overview, } \\
\text { Ge, and Gd }\end{array}$ & XPS & $\begin{array}{l}\text { After sputtering for } 30 \mathrm{secs}(\text { total }= \\
3.5 \text { mins) }\end{array}$ & Bk 4,pg 111 & 2012-06-27-08 & \\
\hline & $\begin{array}{l}\text { overview, } \\
\mathrm{Ge} \text {, and Gd }\end{array}$ & XPS & $\begin{array}{l}\text { After sputtering for } 30 \operatorname{secs}(\text { total }= \\
4 \text { mins) }\end{array}$ & Bk 4,pg 111 & 2012-06-27-09 & \\
\hline & $\begin{array}{l}\text { overview, } \\
\text { Ge, and Gd }\end{array}$ & XPS & $\begin{array}{l}\text { After sputtering for } 30 \mathrm{secs}(\text { total }= \\
4.5 \text { mins) }\end{array}$ & Bk 4,pg 111 & 2012-06-27-10 & \\
\hline
\end{tabular}


Table 3A (Continue)

\begin{tabular}{|c|c|c|c|c|c|c|}
\hline Date & $\begin{array}{l}\text { Images / } \\
\text { Spectrum }\end{array}$ & Instr. & Purpose & Lab \#, Page \# & File Name & Notes \\
\hline \multirow{11}{*}{$6 / 27 / 2012$} & $\begin{array}{l}\text { overview, } \\
\text { Ge, and Gd }\end{array}$ & XPS & $\begin{array}{l}\text { After sputtering for } 30 \mathrm{secs}(\text { total }= \\
5 \text { mins) }\end{array}$ & $\mathrm{Bk} 4, \operatorname{pg} 111$ & 2012-06-27-11 & \\
\hline & $\begin{array}{l}\text { overview, } \\
\text { Ge, and Gd }\end{array}$ & XPS & $\begin{array}{l}\text { After sputtering for } 30 \mathrm{secs}(\text { total }= \\
5.5 \text { mins) }\end{array}$ & $\mathrm{Bk} 4, \operatorname{pg} 111$ & $2012-06-27-12$ & \\
\hline & $\begin{array}{l}\text { overview, } \\
\text { Ge, and Gd }\end{array}$ & XPS & $\begin{array}{l}\text { After sputtering for } 30 \mathrm{secs}(\text { total }= \\
6 \text { mins) }\end{array}$ & Bk 4,pg 111 & $2012-06-27-13$ & \\
\hline & $\begin{array}{l}\text { overview, } \\
\text { Ge, and Gd }\end{array}$ & XPS & $\begin{array}{l}\text { After sputtering for } 30 \mathrm{secs}(\text { total }= \\
6.5 \text { mins) }\end{array}$ & $\mathrm{Bk} 4, \operatorname{pg} 111$ & 2012-06-27-14 & \\
\hline & $\begin{array}{l}\text { overview, } \\
\text { Ge, and Gd }\end{array}$ & XPS & $\begin{array}{l}\text { After sputtering for } 30 \mathrm{secs}(\text { total }= \\
7 \text { mins) }\end{array}$ & $\mathrm{Bk} 4$, pg 112 & $2012-06-27-15$ & \\
\hline & $\begin{array}{l}\text { overview, } \\
\text { Ge, and Gd }\end{array}$ & XPS & $\begin{array}{l}\text { After sputtering for } 30 \mathrm{secs}(\text { total }= \\
7.5 \text { mins) }\end{array}$ & $\mathrm{Bk} 4, \operatorname{pg} 112$ & $2012-06-27-16$ & \\
\hline & $\begin{array}{l}\text { overview, } \\
\text { Ge, and Gd }\end{array}$ & XPS & $\begin{array}{l}\text { After sputtering for } 30 \mathrm{secs} \text { (total }= \\
8 \text { mins) }\end{array}$ & $\mathrm{Bk} 4, \operatorname{pg} 112$ & 2012-06-27-17 & \\
\hline & $\begin{array}{l}\text { overview, } \\
\text { Ge, and Gd }\end{array}$ & XPS & $\begin{array}{l}\text { After sputtering for } 30 \mathrm{secs}(\text { total }= \\
8.5 \text { mins) }\end{array}$ & $\mathrm{Bk} 4, \operatorname{pg} 112$ & $2012-06-27-18$ & \\
\hline & $\begin{array}{l}\text { overview, } \\
\mathrm{Ge} \text {, and } \mathrm{Gd}\end{array}$ & XPS & $\begin{array}{l}\text { After sputtering for } 30 \mathrm{secs}(\text { total }= \\
9 \text { mins) }\end{array}$ & $\mathrm{Bk} 4, \operatorname{pg} 112$ & 2012-06-27-19 & \\
\hline & $\begin{array}{l}\text { overview, } \\
\text { Ge, and Gd }\end{array}$ & XPS & $\begin{array}{l}\text { After sputtering for } 30 \mathrm{secs}(\text { total }= \\
9.5 \text { mins) }\end{array}$ & $\mathrm{Bk} 4, \operatorname{pg} 112$ & $2012-06-27-20$ & \\
\hline & $\begin{array}{l}\text { overview, } \\
\mathrm{Ge} \text {, and } \mathrm{Gd}\end{array}$ & XPS & $\begin{array}{l}\text { After sputtering for } 30 \mathrm{secs}(\text { total }= \\
10 \text { mins) }\end{array}$ & $\mathrm{Bk} 4, \operatorname{pg} 112$ & $2012-06-27-21$ & $\begin{array}{l}\text { End of Depth Profiling Experiment } \\
\text { at } 1100 \mathrm{~K}\end{array}$ \\
\hline
\end{tabular}


Table 3A (Continue)

\begin{tabular}{|c|c|c|c|c|c|c|}
\hline Date & $\begin{array}{l}\text { Images / } \\
\text { Spectrum }\end{array}$ & Instr. & Purpose & Lab \#, Page \# & File Name & Notes \\
\hline \multirow{11}{*}{$6 / 28 / 2012$} & $\begin{array}{l}\text { overview, } \\
\text { Ge, and Gd }\end{array}$ & XPS & $\begin{array}{l}\text { After annealing to } 900 \mathrm{~K} \text { for } 30 \\
\text { mins }\end{array}$ & Bk 4,pg 113 & 2012-06-28-01 & $\begin{array}{l}\text { Beginning of Depth Profiling } \\
\text { Experiment at } 1200 \mathrm{~K}\end{array}$ \\
\hline & $\begin{array}{l}\text { overview, } \\
\text { Ge, and Gd }\end{array}$ & XPS & After sputtering for $30 \mathrm{secs}$ & $\mathrm{Bk} 4$, pg 113 & 2012-06-28-02 & \\
\hline & $\begin{array}{l}\text { overview, } \\
\mathrm{Ge} \text {, and } \mathrm{Gd}\end{array}$ & XPS & $\begin{array}{l}\text { After sputtering for } 30 \mathrm{secs}(\text { total }= \\
1 \mathrm{~min})\end{array}$ & $\mathrm{Bk} 4, \operatorname{pg} 113$ & $2012-06-28-03$ & \\
\hline & $\begin{array}{l}\text { overview, } \\
\text { Ge, and Gd }\end{array}$ & XPS & $\begin{array}{l}\text { After sputtering for } 30 \mathrm{secs} \text { (total = } \\
1.5 \text { mins) }\end{array}$ & Bk 4,pg 113 & 2012-06-28-04 & \\
\hline & $\begin{array}{l}\text { overview, } \\
\text { Ge, and Gd }\end{array}$ & XPS & $\begin{array}{l}\text { After sputtering for } 30 \mathrm{secs}(\text { total }= \\
2 \text { mins) }\end{array}$ & Bk 4, pg 114 & 2012-06-28-05 & \\
\hline & $\begin{array}{l}\text { overview, } \\
\text { Ge, and Gd }\end{array}$ & XPS & $\begin{array}{l}\text { After sputtering for } 30 \mathrm{secs}(\text { total }= \\
2.5 \text { mins) }\end{array}$ & $\mathrm{Bk} 4$, pg 114 & 2012-06-28-06 & \\
\hline & $\begin{array}{l}\text { overview, } \\
\mathrm{Ge} \text {, and } \mathrm{Gd}\end{array}$ & XPS & $\begin{array}{l}\text { After sputtering for } 30 \mathrm{secs} \text { (total = } \\
3 \text { mins) }\end{array}$ & $\mathrm{Bk} 4, \operatorname{pg} 114$ & 2012-06-28-07 & \\
\hline & $\begin{array}{l}\text { overview, } \\
\text { Ge, and Gd }\end{array}$ & XPS & $\begin{array}{l}\text { After sputtering for } 30 \mathrm{secs}(\text { total }= \\
3.5 \text { mins) }\end{array}$ & $\mathrm{Bk} 4, \operatorname{pg} 114$ & 2012-06-28-08 & \\
\hline & $\begin{array}{l}\text { overview, } \\
\mathrm{Ge} \text {, and } \mathrm{Gd}\end{array}$ & XPS & $\begin{array}{l}\text { After sputtering for } 30 \mathrm{secs} \text { (total }= \\
4 \text { mins) }\end{array}$ & $\mathrm{Bk} 4, \operatorname{pg} 114$ & 2012-06-28-09 & \\
\hline & $\begin{array}{l}\text { overview, } \\
\text { Ge, and Gd }\end{array}$ & XPS & $\begin{array}{l}\text { After sputtering for } 30 \mathrm{secs}(\text { total }= \\
4.5 \text { mins) }\end{array}$ & $\mathrm{Bk} 4$, pg 114 & $2012-06-28-10$ & \\
\hline & $\begin{array}{l}\text { overview, } \\
\text { Ge, and Gd }\end{array}$ & XPS & $\begin{array}{l}\text { After sputtering for } 30 \mathrm{secs}(\text { total }= \\
5 \text { mins) }\end{array}$ & Bk 4,pg 114 & 2012-06-28-11 & \\
\hline
\end{tabular}


Table 3A (Continue)

\begin{tabular}{|c|c|c|c|c|c|c|}
\hline Date & $\begin{array}{l}\text { Images / } \\
\text { Spectrum }\end{array}$ & Instr. & Purpose & Lab \#, Page \# & File Name & Notes \\
\hline \multirow{10}{*}{$6 / 28 / 2012$} & $\begin{array}{l}\text { overview, } \\
\text { Ge, and Gd }\end{array}$ & XPS & $\begin{array}{l}\text { After sputtering for } 30 \mathrm{secs}(\text { total }= \\
5.5 \text { mins) }\end{array}$ & Bk 4,pg 115 & $2012-06-28-12$ & \\
\hline & $\begin{array}{l}\text { overview, } \\
\text { Ge, and Gd }\end{array}$ & XPS & $\begin{array}{l}\text { After sputtering for } 30 \text { secs }(\text { total }= \\
6 \text { mins) }\end{array}$ & Bk 4,pg 115 & $2012-06-28-13$ & \\
\hline & $\begin{array}{l}\text { overview, } \\
\mathrm{Ge} \text {, and } \mathrm{Gd}\end{array}$ & XPS & $\begin{array}{l}\text { After sputtering for } 30 \mathrm{secs}(\text { total }= \\
6.5 \text { mins) }\end{array}$ & $\mathrm{Bk} 4, \operatorname{pg} 115$ & $2012-06-28-14$ & \\
\hline & $\begin{array}{l}\text { overview, } \\
\text { Ge, and Gd }\end{array}$ & XPS & $\begin{array}{l}\text { After sputtering for } 30 \mathrm{secs} \text { (total = } \\
7 \text { mins) }\end{array}$ & Bk 4,pg 115 & $2012-06-28-15$ & \\
\hline & $\begin{array}{l}\text { overview, } \\
\text { Ge, and Gd }\end{array}$ & XPS & $\begin{array}{l}\text { After sputtering for } 30 \mathrm{secs}(\text { total }= \\
7.5 \text { mins) }\end{array}$ & $\mathrm{Bk} 4, \operatorname{pg} 115$ & $2012-06-28-16$ & \\
\hline & $\begin{array}{l}\text { overview, } \\
\mathrm{Ge} \text {, and } \mathrm{Gd}\end{array}$ & XPS & $\begin{array}{l}\text { After sputtering for } 30 \mathrm{secs} \text { (total = } \\
8 \text { mins) }\end{array}$ & Bk 4,pg 115 & 2012-06-28-17 & \\
\hline & $\begin{array}{l}\text { overview, } \\
\mathrm{Ge} \text {, and } \mathrm{Gd}\end{array}$ & XPS & $\begin{array}{l}\text { After sputtering for } 30 \mathrm{secs}(\text { total }= \\
8.5 \text { mins) }\end{array}$ & Bk 4,pg 115 & 2012-06-28-18 & \\
\hline & $\begin{array}{l}\text { overview, } \\
\text { Ge, and Gd }\end{array}$ & XPS & $\begin{array}{l}\text { After sputtering for } 30 \mathrm{secs}(\text { total }= \\
9 \text { mins) }\end{array}$ & $\mathrm{Bk} 4, \operatorname{pg} 116$ & 2012-06-28-19 & \\
\hline & $\begin{array}{l}\text { overview, } \\
\text { Ge, and Gd }\end{array}$ & XPS & $\begin{array}{l}\text { After sputtering for } 30 \mathrm{secs}(\text { total }= \\
9.5 \text { mins) }\end{array}$ & $\mathrm{Bk} 4, \operatorname{pg} 116$ & $2012-06-28-20$ & \\
\hline & $\begin{array}{l}\text { overview, } \\
\text { Ge, and Gd }\end{array}$ & XPS & $\begin{array}{l}\text { After sputtering for } 30 \mathrm{secs}(\text { total }= \\
10 \text { mins) }\end{array}$ & $\mathrm{Bk} 4, \operatorname{pg} 116$ & $2012-06-28-21$ & $\begin{array}{l}\text { End of Depth Profiling Experiment } \\
\text { at } 1200 \mathrm{~K}\end{array}$ \\
\hline
\end{tabular}


Table 3B

\begin{tabular}{|c|c|c|c|c|c|}
\hline \multicolumn{6}{|c|}{$\mathrm{Gd}_{5} \mathrm{Ge}_{4}(010)$ Data List } \\
\hline Date & Instr. & Purpose & $\begin{array}{l}\text { Folder } \\
\text { Name }\end{array}$ & File Name & Notes \\
\hline \multirow[t]{3}{*}{$\begin{array}{l}6 / 14 / 2011- \\
6 / 15 / 2011\end{array}$} & SEM & $\begin{array}{l}\text { Identifying the } 5: 3 \text { thin plates } \\
\text { on the Gd5Ge4 (010) surface }\end{array}$ & \multirow[t]{3}{*}{ jun1411 } & $\begin{array}{c}7-68-2 a, 7-68-2 b, 7-68-2 c, 7-68- \\
2 d, 7-68-2001,7-68-2003,7-68- \\
2004,7-68-2006,7-68-2008,7- \\
68-2011,7-68-2013,7-68-2014, \\
7-68-2015,7-68-2018,7-68- \\
2019,7-68-2021,7-68-2023,7- \\
68-2026,7-682 a, 7-682 b 001,7- \\
682 b 003,7-682 b 006,7- \\
682 b 008,7-682 b 009,7- \\
682 b 010,7-682 b 011\end{array}$ & $\begin{array}{l}\text { SEM images of the } 5: 3 \text { thin } \\
\text { plates on the } 5: 4 \text { surface. }\end{array}$ \\
\hline & SAM & $\begin{array}{l}\text { Identifying the } 5: 3 \text { thin plates } \\
\text { on the Gd5Ge4 (010) surface }\end{array}$ & & $\begin{array}{c}\text { 7-68-2e, 7-68-2010_01, 7-68- } \\
\text { 2010_02, 7-68-2010y, 7-68- } \\
\text { 2010z, 7-68-2012_01, 7-68- } \\
\text { 2012_02, 7-682b005_01, 7- } \\
\text { 682b005_02, 7-682b005z }\end{array}$ & $\begin{array}{l}\text { Gd-rich (red line) and Ge- } \\
\text { poor (blue line) on the } 5: 3 \\
\text { thin plate. }\end{array}$ \\
\hline & AES & $\begin{array}{l}\text { Identifying the } 5: 3 \text { thin plates } \\
\text { on the Gd5Ge4 (010) surface }\end{array}$ & & All *.npl files & $\begin{array}{l}\text { The } 5: 3 \text { thin plates show the } \\
\text { surface concentration to be } \\
\text { Gd5Ge3. }\end{array}$ \\
\hline
\end{tabular}


Table 3B (Continue)

\begin{tabular}{|c|c|c|c|c|c|}
\hline Date & Instr. & Purpose & $\begin{array}{l}\text { Folder } \\
\text { Name }\end{array}$ & File Name & Notes \\
\hline \multirow{3}{*}{$\begin{array}{l}8 / 2 / 2011- \\
8 / 4 / 2011\end{array}$} & SEM & $\begin{array}{l}\text { What surface looks like after } \\
\text { several cleaning cycles (Ar } \\
\text { sputtering and } 30 \text { minute } \\
\text { anneals at } 900 \mathrm{~K} \text { ) }\end{array}$ & \multirow{3}{*}{ aug11 } & $\begin{array}{l}\text { All *.tiff files, except a } \\
\text { few for SAM }\end{array}$ & $\begin{array}{l}\text { Lumps appeared on surface after a } \\
\text { few cleaning cycles. }\end{array}$ \\
\hline & SAM & $\begin{array}{l}\text { What surface looks like after } \\
\text { several cleaning cycles (Ar } \\
\text { sputtering and } 30 \text { minute } \\
\text { anneals at } 900 \mathrm{~K} \text { ) }\end{array}$ & & $\begin{array}{c}\text { 7-682d026_01, 7- } \\
\text { 682d026_02, 7- } \\
\text { 682d026i, 7-682ddaug }\end{array}$ & $\begin{array}{l}\text { Did not show any surface } \\
\text { concentration contrast between the } \\
\text { lumps and the surface. }\end{array}$ \\
\hline & AES & $\begin{array}{l}\text { What surface looks like after } \\
\text { several cleaning cycles (Ar } \\
\text { sputtering and } 30 \text { minute } \\
\text { anneals at } 900 \mathrm{~K} \text { ) }\end{array}$ & & All *.npl files & $\begin{array}{l}\text { Showed the lumps to be Ge-rich and } \\
\text { Gd-poor. Close to Gd3Ge5. }\end{array}$ \\
\hline \multirow{2}{*}{$7 / 4 / 2012$} & SEM & $\begin{array}{l}\text { Do we see lumps on sample \# } \\
\text { dls-7-68-2? }\end{array}$ & \multirow{2}{*}{ dls-7-68-2 } & All *.tiff files & No lumps on surface. \\
\hline & AES & $\begin{array}{l}\text { Do we see lumps on sample \# } \\
\text { dls-7-68-2? }\end{array}$ & & All *.npl files & $\begin{array}{l}\text { The } 5: 3 \text { thin plates show the surface } \\
\text { concentration to be } \mathrm{Gd} 5 \mathrm{Ge} 3 \text {. }\end{array}$ \\
\hline \multirow{2}{*}{$8 / 2 / 2012$} & SEM & $\begin{array}{l}\text { What surface looks like after } \\
\text { one cleaning cycle (Ar } \\
\text { sputtering and } 30 \text { minute } \\
\text { anneals at } 1200 \mathrm{~K} \text { ) }\end{array}$ & \multirow{2}{*}{ aug0212 } & All *.tiff files & More lumps appeared on surface. \\
\hline & AES & $\begin{array}{l}\text { What surface looks like after } \\
\text { one cleaning cycle (Ar } \\
\text { sputtering and } 30 \text { minute } \\
\text { anneals at } 1200 \mathrm{~K} \text { ) }\end{array}$ & & All *.npl files & $\begin{array}{l}\text { Showed the lumps to be Ge-rich and } \\
\text { Gd-poor. Close to Gd3Ge5. }\end{array}$ \\
\hline
\end{tabular}


Table 3B (Continue)

\begin{tabular}{|c|c|c|c|c|c|}
\hline Date & Instr. & Purpose & $\begin{array}{l}\text { Folder } \\
\text { Name }\end{array}$ & File Name & Notes \\
\hline \multirow{2}{*}{$8 / 3 / 2012$} & SEM & $\begin{array}{l}\text { What surface looks like after } \\
\text { several cleaning cycles (Ar } \\
\text { sputtering and } 30 \text { minute } \\
\text { anneals at } 1200 \mathrm{~K} \text { ) }\end{array}$ & \multirow{2}{*}{ aug0312 } & All *.tiff files & More lumps appeared on surface. \\
\hline & AES & $\begin{array}{l}\text { What surface looks like after } \\
\text { several cleaning cycles (Ar } \\
\text { sputtering and } 30 \text { minute } \\
\text { anneals at } 1200 \mathrm{~K} \text { ) }\end{array}$ & & All *.npl files & $\begin{array}{l}\text { Showed the lumps to be Ge-rich and } \\
\text { Gd-poor. Close to Gd3Ge5. }\end{array}$ \\
\hline \multirow[b]{2}{*}{$8 / 6 / 2012$} & SEM & More cleaning cycles at $1200 \mathrm{~K}$ & \multirow[b]{2}{*}{ aug0612 } & All *.tiff files & More lumps appeared on surface. \\
\hline & AES & More cleaning cycles at $1200 \mathrm{~K}$ & & All *.npl files & $\begin{array}{l}\text { Showed the lumps to be Ge-rich and } \\
\text { Gd-poor. Close to Gd3Ge5. }\end{array}$ \\
\hline
\end{tabular}


Table 4

\begin{tabular}{|c|c|c|c|c|c|c|c|}
\hline \multicolumn{8}{|c|}{ Au on NiAl(110) Data List } \\
\hline Date & $\begin{array}{c}\text { Images / } \\
\text { Spectrum }\end{array}$ & Instr. & Purpose & $\begin{array}{l}\text { Au Coverage } \\
\text { (Total Time) }\end{array}$ & Bk \#, Page \# & $\begin{array}{l}\text { File } \\
\text { Name }\end{array}$ & Notes \\
\hline \multirow{9}{*}{$11 / 13 / 2009$} & M1 - M11 & STM & $\begin{array}{l}\text { Clean } \mathrm{NiAl}(110) \\
\text { surface }\end{array}$ & 0 & Bk 2, pg 23 & \multirow{5}{*}{111309} & See big terraces and lots of pinning sites \\
\hline & M12 - M20 & STM & $\mathrm{Au} / \mathrm{NiAl}(110)$ at $300 \mathrm{~K}$ & $\begin{array}{l}0.10 \mathrm{ML} \\
(2 \mathrm{mins})\end{array}$ & Bk 2, pg 24 & & $\begin{array}{l}\text { Elongated islands, use 4-way Mantis } \\
\text { evaporator (filament }=1.60 \mathrm{~A} \text {, Power }= \\
22 \mathrm{~W} \text { ) }\end{array}$ \\
\hline & M21 - M25 & STM & $\begin{array}{l}\text { Continuing } \mathrm{Au} \\
\text { deposition at } 300 \mathrm{~K}\end{array}$ & $\begin{array}{r}0.16 \mathrm{ML} \\
(4 \mathrm{mins})\end{array}$ & Bk 2, pg 25 & & $\begin{array}{l}\text { Big elongated islands on terraces, see } \\
\text { Au on step edges. The step edges are } \\
\text { more of a scalloped pattern. }\end{array}$ \\
\hline & M26 - M30 & STM & $\begin{array}{l}\text { Continuing } \mathrm{Au} \\
\text { deposition at } 300 \mathrm{~K}\end{array}$ & $\begin{array}{l}0.54 \mathrm{ML} \\
\text { (16 mins) }\end{array}$ & Bk 2, pg 25 & & $\begin{array}{l}\text { 2nd Au adlayer started to form, 1st } \\
\text { adlayer not complete, step edges are } \\
\text { decorated. }\end{array}$ \\
\hline & M31 - M34 & STM & $\begin{array}{l}\text { Continuing } \mathrm{Au} \\
\text { deposition at } 300 \mathrm{~K}\end{array}$ & (22 mins) & Bk 2, pg 25 & & Cannot get coverage, no good images. \\
\hline & overview & XPS & $\mathrm{Au} / \mathrm{NiAl}(110)$ at $300 \mathrm{~K}$ & (22 mins) & Bk 2, pg 25 & \multirow{4}{*}{11130901} & $\begin{array}{l}1000 \mathrm{eV} \text { to }-5 \mathrm{eV} \text { (Steps }-0.5 \mathrm{eV}, 1 \\
\text { Sweep) }\end{array}$ \\
\hline & $\mathrm{Au} 4 \mathrm{f}_{7 / 2,5 / 2}$ & XPS & $\mathrm{Au} / \mathrm{NiAl}(110)$ at $300 \mathrm{~K}$ & (22 mins) & Bk 2, pg 25 & & $\begin{array}{l}100 \mathrm{eV} \text { to } 75 \mathrm{eV} \text { (Steps }-0.1 \mathrm{eV}, 3 \\
\text { Sweeps) }\end{array}$ \\
\hline & $\mathrm{Ni} 3 \mathrm{p}$ & XPS & $\mathrm{Au} / \mathrm{NiAl}(110)$ at $300 \mathrm{~K}$ & (22 mins) & Bk 2, pg 25 & & $\begin{array}{l}80 \mathrm{eV} \text { to } 60 \mathrm{eV} \text { (Steps }-0.1 \mathrm{eV}, 3 \\
\text { Sweeps) }\end{array}$ \\
\hline & $\mathrm{Al} 2 \mathrm{p}$ & XPS & $\mathrm{Au} / \mathrm{NiAl}(110)$ at $300 \mathrm{~K}$ & (22 mins) & Bk 2, pg 25 & & $\begin{array}{l}80 \mathrm{eV} \text { to } 60 \mathrm{eV} \text { (Steps }-0.1 \mathrm{eV}, 3 \\
\text { Sweeps) }\end{array}$ \\
\hline
\end{tabular}


Table 4 (Continue)

\begin{tabular}{|c|c|c|c|c|c|c|c|}
\hline Date & $\begin{array}{c}\text { Images / } \\
\text { Spectrum }\end{array}$ & Instr. & Purpose & $\begin{array}{l}\text { Au Coverage } \\
\text { (Total Time) }\end{array}$ & Bk \#, Page \# & $\begin{array}{c}\text { File } \\
\text { Name }\end{array}$ & Notes \\
\hline \multirow{5}{*}{$11 / 19 / 2009$} & M1 - M6 & STM & $\begin{array}{l}\text { Clean NiAl(110) } \\
\text { surface }\end{array}$ & 0 & Bk 2, pg 39 & \multirow{5}{*}{111909} & $\begin{array}{l}\text { Still have pinning sites, but better than } \\
\text { before. }\end{array}$ \\
\hline & M7 - M33 & STM & $\begin{array}{l}\mathrm{Au} / \mathrm{NiAl}(110) \text { at } 300 \\
\mathrm{~K}\end{array}$ & $\begin{array}{l}0.24 \mathrm{ML} \\
(8 \mathrm{mins})\end{array}$ & $\mathrm{Bk} 2, \operatorname{pg} 40$ & & $\begin{array}{l}\text { Au elongated islands on terraces, } \\
\text { decorated step edges, possible Au } \\
\text { reconstruction happening. }\end{array}$ \\
\hline & M34 - M50 & STM & $\begin{array}{l}\text { Continuing } \mathrm{Au} \\
\text { deposition at } 300 \mathrm{~K}\end{array}$ & $\begin{array}{c}0.60 \mathrm{ML} \\
\text { (16.5 mins) }\end{array}$ & $\mathrm{Bk} 2, \operatorname{pg} 41$ & & $\begin{array}{l}\text { See possible Au reconstruction at } \\
\text { different orientations on the islands. }\end{array}$ \\
\hline & M51 - M56 & STM & $\begin{array}{l}\text { Continuing } \mathrm{Au} \\
\text { deposition at } 300 \mathrm{~K}\end{array}$ & $\begin{array}{l}0.83 \mathrm{ML} \\
\text { (24.5 mins) }\end{array}$ & Bk 2, pg 41 & & $\begin{array}{l}\text { See no change compared to previous } \\
\text { deposition, } 2 \text { nd Au islands are more } \\
\text { elongated while the } 1 \text { st Au islands are } \\
\text { more irregular shaped. }\end{array}$ \\
\hline & M57 - M74 & STM & $\begin{array}{l}\text { Continuing } \mathrm{Au} \\
\text { deposition at } 300 \mathrm{~K}\end{array}$ & $\begin{array}{c}1.3 \mathrm{ML} \\
\text { (40.5 mins) }\end{array}$ & Bk 2, pg 41 & & $\begin{array}{l}\text { 1st adlayer is almost complete, } 2 \text { nd } \\
\text { adlayer is bigger - not as elongated as } \\
\text { before, see possible Au reconstruction } \\
\text { on both adlayers. }\end{array}$ \\
\hline
\end{tabular}


Table 4 (Continue)

\begin{tabular}{|c|c|c|c|c|c|c|c|}
\hline Date & $\begin{array}{l}\text { Images / } \\
\text { Spectrum }\end{array}$ & Instr. & Purpose & $\begin{array}{l}\text { Au Coverage } \\
\text { (Total Time) }\end{array}$ & Bk \#, Page \# & File Name & Notes \\
\hline \multirow{4}{*}{$11 / 20 / 2009$} & overview & XPS & $\mathrm{Au} / \mathrm{NiAl}(110)$ at $300 \mathrm{~K}$ & $\begin{array}{c}1.3 \mathrm{ML} \\
(40.5 \mathrm{mins})\end{array}$ & Bk 2, pg 42 & \multirow{4}{*}{11200901} & $\begin{array}{l}1000 \mathrm{eV} \text { to }-5 \mathrm{eV} \text { (Steps }-0.5 \mathrm{eV}, 1 \\
\text { Sweep) }\end{array}$ \\
\hline & $\mathrm{Au} 4 \mathrm{f}_{7 / 2,5 / 2}$ & XPS & $\mathrm{Au} / \mathrm{NiAl}(110)$ at $300 \mathrm{~K}$ & $\begin{array}{c}1.3 \mathrm{ML} \\
(40.5 \mathrm{mins})\end{array}$ & Bk 2, pg 42 & & $\begin{array}{l}100 \mathrm{eV} \text { to } 75 \mathrm{eV} \text { (Steps }-0.1 \mathrm{eV}, 3 \\
\text { Sweeps) }\end{array}$ \\
\hline & Ni 3p & XPS & $\mathrm{Au} / \mathrm{NiAl}(110)$ at $300 \mathrm{~K}$ & $\begin{array}{c}1.3 \mathrm{ML} \\
\text { (40.5 mins) }\end{array}$ & Bk 2, pg 42 & & $\begin{array}{l}80 \mathrm{eV} \text { to } 60 \mathrm{eV} \text { (Steps }-0.1 \mathrm{eV}, 3 \\
\text { Sweeps) }\end{array}$ \\
\hline & Al 2p & XPS & $\mathrm{Au} / \mathrm{NiAl}(110)$ at $300 \mathrm{~K}$ & $\begin{array}{c}1.3 \mathrm{ML} \\
(40.5 \mathrm{mins})\end{array}$ & Bk 2, pg 42 & & $\begin{array}{l}80 \mathrm{eV} \text { to } 60 \mathrm{eV} \text { (Steps }-0.1 \mathrm{eV}, 3 \\
\text { Sweeps) }\end{array}$ \\
\hline \multirow{7}{*}{$11 / 23 / 2009$} & M1 - M9 & STM & $\begin{array}{l}\text { Clean NiAl(110) } \\
\text { surface }\end{array}$ & 0 & Bk 2, pg 49 & \multirow{7}{*}{112309} & $\begin{array}{l}\text { Clean surface, still see pinning sites, } \\
\text { terraces are not huge as before but } \\
\text { still good for experiment. }\end{array}$ \\
\hline & M10 - M17 & STM & $\mathrm{Au} / \mathrm{NiAl}(110)$ at $300 \mathrm{~K}$ & $\begin{array}{l}0.24 \mathrm{ML} \\
(8 \mathrm{mins})\end{array}$ & Bk 2, pg 49 & & \\
\hline & M18 - M48 & STM & $\begin{array}{l}\text { Increasing temperature } \\
\text { to } 325 \mathrm{~K}\end{array}$ & $\begin{array}{l}0.24 \mathrm{ML} \\
(8 \mathrm{mins})\end{array}$ & Bk 2, pg 49 & & \\
\hline & M49 - M75 & STM & $\begin{array}{l}\text { Holding temperature at } \\
325 \mathrm{~K}\end{array}$ & $\begin{array}{l}0.24 \mathrm{ML} \\
(8 \mathrm{mins})\end{array}$ & Bk 2, pg 49 & & $\begin{array}{l}\text { See different Au island heights at } \\
\text { different bias conditions - indicating } \\
\text { surface intermixing and surface } \\
\text { alloying. }\end{array}$ \\
\hline & M76 - M79 & STM & $\begin{array}{l}\text { Increasing temperature } \\
\text { to } 350 \mathrm{~K}\end{array}$ & $\begin{array}{l}0.24 \mathrm{ML} \\
(8 \mathrm{mins})\end{array}$ & Bk 2, pg 50 & & \\
\hline & M80 - M115 & STM & $\begin{array}{l}\text { Holding temperature at } \\
350 \mathrm{~K}\end{array}$ & $\begin{array}{l}0.24 \mathrm{ML} \\
(8 \mathrm{mins})\end{array}$ & Bk 2, pg 50 & & $\begin{array}{l}\text { Constant Au island heights at } \\
\text { different bias conditions - Au has } \\
\text { already alloyed on the surface. }\end{array}$ \\
\hline & M116 - M118 & STM & $\begin{array}{l}\text { Decreasing temperature } \\
\text { to } 300 \mathrm{~K}\end{array}$ & $\begin{array}{l}0.24 \mathrm{ML} \\
(8 \mathrm{mins})\end{array}$ & Bk 2, pg 50 & & \\
\hline
\end{tabular}


Table 4 (Continue)

\begin{tabular}{|c|c|c|c|c|c|c|c|}
\hline Date & $\begin{array}{l}\text { Images / } \\
\text { Spectrum }\end{array}$ & Instr. & Purpose & $\begin{array}{l}\text { Au Coverage } \\
\text { (Total Time) }\end{array}$ & Bk \#, Page \# & File Name & Notes \\
\hline \multirow{4}{*}{$11 / 24 / 2009$} & overview & XPS & $\mathrm{Au} / \mathrm{NiAl}(110)$ at $300 \mathrm{~K}$ & $\begin{array}{l}0.24 \mathrm{ML} \\
(8 \mathrm{mins})\end{array}$ & Bk 2,pg 51 & \multirow{4}{*}{11240901} & $\begin{array}{l}1000 \mathrm{eV} \text { to }-5 \mathrm{eV} \text { (Steps }-0.5 \mathrm{eV}, 1 \\
\text { Sweep) }\end{array}$ \\
\hline & $\mathrm{Au} 4 \mathrm{f}_{7 / 2,5 / 2}$ & XPS & $\mathrm{Au} / \mathrm{NiAl}(110)$ at $300 \mathrm{~K}$ & $\begin{array}{l}0.24 \mathrm{ML} \\
(8 \mathrm{mins})\end{array}$ & Bk 2,pg 51 & & $\begin{array}{l}100 \mathrm{eV} \text { to } 75 \mathrm{eV} \text { (Steps }-0.1 \mathrm{eV}, 3 \\
\text { Sweeps) }\end{array}$ \\
\hline & Ni 3p & XPS & $\mathrm{Au} / \mathrm{NiAl}(110)$ at $300 \mathrm{~K}$ & $\begin{array}{l}0.24 \mathrm{ML} \\
(8 \mathrm{mins})\end{array}$ & Bk 2, pg 51 & & $\begin{array}{l}80 \mathrm{eV} \text { to } 60 \mathrm{eV} \text { (Steps }-0.1 \mathrm{eV}, 3 \\
\text { Sweeps) }\end{array}$ \\
\hline & Al 2p & XPS & $\mathrm{Au} / \mathrm{NiAl}(110)$ at $300 \mathrm{~K}$ & $\begin{array}{l}0.24 \mathrm{ML} \\
(8 \mathrm{mins})\end{array}$ & Bk 2,pg 51 & & $\begin{array}{l}80 \mathrm{eV} \text { to } 60 \mathrm{eV} \text { (Steps }-0.1 \mathrm{eV}, 3 \\
\text { Sweeps) }\end{array}$ \\
\hline \multirow[b]{3}{*}{$11 / 30 / 2009$} & M1 & STM & Clean $\mathrm{NiAl}(110)$ surface & 0 & Bk 2, pg 61 & \multirow[b]{3}{*}{113009} & Still have some pinning sites. \\
\hline & M2 & STM & $\begin{array}{l}\text { Clean } \mathrm{NiAl}(110) \text { surface } \\
\text { at } 200 \mathrm{~K}\end{array}$ & 0 & Bk 2, pg 61 & & \\
\hline & M3 - M40 & STM & $\mathrm{Au} / \mathrm{NiAl}(110)$ at $200 \mathrm{~K}$ & $\begin{array}{l}0.24 \mathrm{ML} \\
(8 \mathrm{mins})\end{array}$ & $\begin{array}{c}\mathrm{Bk} 2, \operatorname{pg} 61- \\
62\end{array}$ & & $\begin{array}{l}\text { Island density increased compared } \\
\text { to } 300 \mathrm{~K} \text {, islands are more elongated } \\
\text { compared to } 300 \mathrm{~K} \text { data. }\end{array}$ \\
\hline \multirow{4}{*}{$12 / 1 / 2009$} & overview & XPS & $\mathrm{Au} / \mathrm{NiAl}(110)$ at $300 \mathrm{~K}$ & $\begin{array}{l}0.24 \mathrm{ML} \\
(8 \mathrm{mins})\end{array}$ & $\mathrm{Bk} 2$, pg 62 & \multirow{4}{*}{12010901} & $\begin{array}{l}1000 \mathrm{eV} \text { to }-5 \mathrm{eV} \text { (Steps }-0.5 \mathrm{eV}, 1 \\
\text { Sweep) }\end{array}$ \\
\hline & $\mathrm{Au} 4 \mathrm{f}_{7 / 2,5 / 2}$ & XPS & $\mathrm{Au} / \mathrm{NiAl}(110)$ at $300 \mathrm{~K}$ & $\begin{array}{l}0.24 \mathrm{ML} \\
(8 \mathrm{mins})\end{array}$ & Bk 2, pg 62 & & $\begin{array}{l}100 \mathrm{eV} \text { to } 75 \mathrm{eV} \text { (Steps }-0.1 \mathrm{eV}, 3 \\
\text { Sweeps) }\end{array}$ \\
\hline & $\mathrm{Ni} 3 p$ & XPS & $\mathrm{Au} / \mathrm{NiAl}(110)$ at $300 \mathrm{~K}$ & $\begin{array}{l}0.24 \mathrm{ML} \\
(8 \mathrm{mins})\end{array}$ & Bk 2, pg 62 & & $\begin{array}{l}80 \mathrm{eV} \text { to } 60 \mathrm{eV} \text { (Steps }-0.1 \mathrm{eV}, 3 \\
\text { Sweeps) }\end{array}$ \\
\hline & $\mathrm{Al} 2 \mathrm{p}$ & XPS & $\mathrm{Au} / \mathrm{NiAl}(110)$ at $300 \mathrm{~K}$ & $\begin{array}{l}0.24 \mathrm{ML} \\
(8 \mathrm{mins})\end{array}$ & $\mathrm{Bk} 2, \operatorname{pg} 62$ & & $\begin{array}{l}80 \mathrm{eV} \text { to } 60 \mathrm{eV} \text { (Steps }-0.1 \mathrm{eV}, 3 \\
\text { Sweeps) }\end{array}$ \\
\hline
\end{tabular}


Table 4 (Continue)

\begin{tabular}{|c|c|c|c|c|c|c|c|}
\hline Date & $\begin{array}{c}\text { Images / } \\
\text { Spectrum }\end{array}$ & Instr. & Purpose & $\begin{array}{l}\text { Au Coverage } \\
\text { (Total Time) }\end{array}$ & Bk \#, Page \# & $\begin{array}{l}\text { File } \\
\text { Name }\end{array}$ & Notes \\
\hline \multirow{9}{*}{$12 / 4 / 2009$} & overview & XPS & $\mathrm{Au} / \mathrm{NiAl}(110)$ at $300 \mathrm{~K}$ & $\begin{array}{c}0.54 \mathrm{ML} \\
(16 \mathrm{mins})\end{array}$ & Bk 2, pg 70 & \multirow{6}{*}{12040901} & $\begin{array}{l}1000 \mathrm{eV} \text { to }-5 \mathrm{eV} \text { (Steps }-0.5 \mathrm{eV}, 1 \\
\text { Sweep) }\end{array}$ \\
\hline & $\mathrm{Ni} 2 \mathrm{p}$ & XPS & $\mathrm{Au} / \mathrm{NiAl}(110)$ at $300 \mathrm{~K}$ & $\begin{array}{c}0.54 \mathrm{ML} \\
(16 \mathrm{mins})\end{array}$ & $\mathrm{Bk} 2, \mathrm{pg} 70$ & & $\begin{array}{l}880 \mathrm{eV} \text { to } 830 \mathrm{eV} \text { (Steps }-0.1 \mathrm{eV}, 10 \\
\text { Sweeps) }\end{array}$ \\
\hline & $\mathrm{Al} 2 \mathrm{~s}$ & XPS & $\mathrm{Au} / \mathrm{NiAl}(110)$ at $300 \mathrm{~K}$ & $\begin{array}{c}0.54 \mathrm{ML} \\
(16 \mathrm{mins})\end{array}$ & Bk 2, pg 70 & & $\begin{array}{l}130 \mathrm{eV} \text { to } 100 \mathrm{eV} \text { (Steps }-0.1 \mathrm{eV}, 10 \\
\text { Sweeps) }\end{array}$ \\
\hline & $\mathrm{Au} 4 \mathrm{f} 7 / 2,5 / 2$ & XPS & $\mathrm{Au} / \mathrm{NiAl}(110)$ at $300 \mathrm{~K}$ & $\begin{array}{c}0.54 \mathrm{ML} \\
(16 \text { mins })\end{array}$ & Bk 2, pg 70 & & $\begin{array}{l}100 \mathrm{eV} \text { to } 75 \mathrm{eV} \text { (Steps }-0.1 \mathrm{eV}, 10 \\
\text { Sweeps) }\end{array}$ \\
\hline & Ni 3p & XPS & $\mathrm{Au} / \mathrm{NiAl}(110)$ at $300 \mathrm{~K}$ & $\begin{array}{c}0.54 \mathrm{ML} \\
(16 \mathrm{mins})\end{array}$ & Bk 2, pg 70 & & $\begin{array}{l}80 \mathrm{eV} \text { to } 60 \mathrm{eV} \text { (Steps }-0.1 \mathrm{eV}, 10 \\
\text { Sweeps) }\end{array}$ \\
\hline & $\mathrm{Al} 2 \mathrm{p}$ & XPS & $\mathrm{Au} / \mathrm{NiAl}(110)$ at $300 \mathrm{~K}$ & $\begin{array}{c}0.54 \mathrm{ML} \\
(16 \mathrm{mins})\end{array}$ & Bk 2, pg 70 & & $\begin{array}{l}80 \mathrm{eV} \text { t0 } 60 \mathrm{eV} \text { (Steps }-0.1 \mathrm{eV}, 10 \\
\text { Sweeps) }\end{array}$ \\
\hline & overview & XPS & $\begin{array}{l}\text { Increased temperature to } \\
325 \mathrm{~K} \text { and hold for XPS }\end{array}$ & $\begin{array}{c}0.54 \mathrm{ML} \\
(16 \mathrm{mins})\end{array}$ & Bk 2, pg 71 & \multirow{3}{*}{12040902} & $\begin{array}{l}1000 \mathrm{eV} \text { to }-5 \mathrm{eV} \text { (Steps }-0.5 \mathrm{eV}, 1 \\
\text { Sweep) }\end{array}$ \\
\hline & Ni $2 p$ & XPS & $\begin{array}{l}\text { Increased temperature to } \\
325 \mathrm{~K} \text { and hold for XPS }\end{array}$ & $\begin{array}{l}0.54 \mathrm{ML} \\
(16 \mathrm{mins})\end{array}$ & Bk 2, pg 71 & & $\begin{array}{l}\text { See shift, indicating surface } \\
\text { intermixing and surface alloying. }\end{array}$ \\
\hline & $\mathrm{Al} 2 \mathrm{~s}$ & XPS & $\begin{array}{l}\text { Increased temperature to } \\
325 \mathrm{~K} \text { and hold for XPS }\end{array}$ & $\begin{array}{c}0.54 \mathrm{ML} \\
(16 \mathrm{mins})\end{array}$ & Bk 2, pg 71 & & $\begin{array}{l}\text { See shift, indicating surface } \\
\text { intermixing and surface alloying. }\end{array}$ \\
\hline
\end{tabular}


Table 4 (Continue)

\begin{tabular}{|c|c|c|c|c|c|c|c|}
\hline Date & $\begin{array}{l}\text { Images / } \\
\text { Spectrum }\end{array}$ & Instr. & Purpose & $\begin{array}{l}\text { Au Coverage } \\
\text { (Total Time) }\end{array}$ & Bk \#, Page \# & $\begin{array}{l}\text { File } \\
\text { Name }\end{array}$ & Notes \\
\hline \multirow{9}{*}{$12 / 4 / 2009$} & $\mathrm{Au} 4 \mathrm{f}_{7 / 2,5 / 2}$ & XPS & $\begin{array}{l}\text { Increased temperature to } 325 \\
\mathrm{~K} \text { and hold for XPS }\end{array}$ & $\begin{array}{l}0.54 \mathrm{ML} \\
(16 \mathrm{mins})\end{array}$ & Bk 2, pg 71 & \multirow{3}{*}{12040902} & $\begin{array}{l}\text { See shift, indicating surface } \\
\text { intermixing and surface alloying. }\end{array}$ \\
\hline & Ni 3p & XPS & $\begin{array}{l}\text { Increased temperature to } 325 \\
\mathrm{~K} \text { and hold for XPS }\end{array}$ & $\begin{array}{l}0.54 \mathrm{ML} \\
(16 \mathrm{mins})\end{array}$ & Bk 2, pg 71 & & $\begin{array}{l}\text { See shift, indicating surface } \\
\text { intermixing and surface alloying. }\end{array}$ \\
\hline & $\mathrm{Al} 2 \mathrm{p}$ & XPS & $\begin{array}{l}\text { Increased temperature to } 325 \\
\mathrm{~K} \text { and hold for XPS }\end{array}$ & $\begin{array}{l}0.54 \mathrm{ML} \\
(16 \mathrm{mins})\end{array}$ & Bk 2, pg 71 & & $\begin{array}{l}\text { See shift, indicating surface } \\
\text { intermixing and surface alloying. }\end{array}$ \\
\hline & overview & XPS & $\begin{array}{l}\text { Increased temperature to } 350 \\
\mathrm{~K} \text { and hold for XPS }\end{array}$ & $\begin{array}{c}0.54 \mathrm{ML} \\
(16 \mathrm{mins})\end{array}$ & $\mathrm{Bk} 2$, pg 71 & \multirow{6}{*}{12040903} & Little shift change. \\
\hline & Ni $2 p$ & XPS & $\begin{array}{l}\text { Increased temperature to } 350 \\
\mathrm{~K} \text { and hold for XPS }\end{array}$ & $\begin{array}{c}0.54 \mathrm{ML} \\
(16 \mathrm{mins})\end{array}$ & $\mathrm{Bk} 2$, pg 71 & & Little shift change. \\
\hline & $\mathrm{Al} 2 \mathrm{~s}$ & XPS & $\begin{array}{l}\text { Increased temperature to } 350 \\
\mathrm{~K} \text { and hold for XPS }\end{array}$ & $\begin{array}{c}0.54 \mathrm{ML} \\
(16 \mathrm{mins})\end{array}$ & $\mathrm{Bk} 2$, pg 71 & & Little shift change. \\
\hline & $\mathrm{Au} 4 \mathrm{f} 7 / 2,5 / 2$ & XPS & $\begin{array}{l}\text { Increased temperature to } 350 \\
\mathrm{~K} \text { and hold for XPS }\end{array}$ & $\begin{array}{c}0.54 \mathrm{ML} \\
(16 \mathrm{mins})\end{array}$ & Bk 2, pg 71 & & Little shift change. \\
\hline & Ni 3p & XPS & $\begin{array}{l}\text { Increased temperature to } 350 \\
\mathrm{~K} \text { and hold for XPS }\end{array}$ & $\begin{array}{c}0.54 \mathrm{ML} \\
(16 \mathrm{mins})\end{array}$ & $\mathrm{Bk} 2, \mathrm{pg} 71$ & & Little shift change. \\
\hline & $\mathrm{Al} 2 \mathrm{p}$ & XPS & $\begin{array}{l}\text { Increased temperature to } 350 \\
\mathrm{~K} \text { and hold for XPS }\end{array}$ & $\begin{array}{l}0.54 \mathrm{ML} \\
(16 \mathrm{mins})\end{array}$ & $\mathrm{Bk} 2$, pg 71 & & Little shift change. \\
\hline
\end{tabular}


Table 4 (Continue)

\begin{tabular}{|c|c|c|c|c|c|c|c|}
\hline Date & $\begin{array}{l}\text { Images / } \\
\text { Spectrum }\end{array}$ & Instr. & Purpose & $\begin{array}{l}\text { Au Coverage } \\
\text { (Total Time) }\end{array}$ & Bk \#, Page \# & $\begin{array}{l}\text { File } \\
\text { Name }\end{array}$ & Notes \\
\hline \multirow{12}{*}{$12 / 9 / 2009$} & M1 - M11 & STM & $\begin{array}{l}\text { Clean surface of } \\
\operatorname{NiAl}(110)\end{array}$ & 0 & Bk 2, pg 77 & \multirow{12}{*}{120909} & \\
\hline & M12 - M26 & STM & $\begin{array}{l}\mathrm{Au} \text { on } \mathrm{NiAl}(110) \text { at } \\
300 \mathrm{~K}\end{array}$ & $\begin{array}{l}0.24 \mathrm{ML} \\
(8 \mathrm{mins})\end{array}$ & Bk 2, pg 78 & & \\
\hline & M27 - M38 & STM & $\begin{array}{l}\text { Increasing temperature } \\
\text { to } 310 \mathrm{~K}\end{array}$ & $\begin{array}{l}0.24 \mathrm{ML} \\
(8 \mathrm{mins})\end{array}$ & Bk 2, pg 78 & & \\
\hline & M39 - M59 & STM & $\begin{array}{l}\text { Holding temperature } \\
\text { at } 310 \mathrm{~K}\end{array}$ & $\begin{array}{l}0.24 \mathrm{ML} \\
(8 \mathrm{mins})\end{array}$ & Bk 2, pg 78 & & $\begin{array}{l}\text { Tip is dirty, island heights are constant at } \\
\text { different bias conditions. }\end{array}$ \\
\hline & M60 - M63 & STM & $\begin{array}{l}\text { Increasing temperature } \\
\text { to } 320 \mathrm{~K}\end{array}$ & $\begin{array}{l}0.24 \mathrm{ML} \\
(8 \mathrm{mins})\end{array}$ & Bk 2, pg 79 & & \\
\hline & M64 - M86 & STM & $\begin{array}{l}\text { Holding temperature } \\
\text { at } 320 \mathrm{~K}\end{array}$ & $\begin{array}{l}0.24 \mathrm{ML} \\
(8 \mathrm{mins})\end{array}$ & Bk 2, pg 79 & & $\begin{array}{l}\text { Island heights are constant at different bias } \\
\text { conditions...tip not good. }\end{array}$ \\
\hline & M87 - M89 & STM & $\begin{array}{l}\text { Increasing temperature } \\
\text { to } 330 \mathrm{~K}\end{array}$ & $\begin{array}{l}0.24 \mathrm{ML} \\
(8 \mathrm{mins})\end{array}$ & Bk 2, pg 79 & & \\
\hline & M90 - M115 & STM & $\begin{array}{l}\text { Holding temperature } \\
\text { at } 330 \mathrm{~K}\end{array}$ & $\begin{array}{l}0.24 \mathrm{ML} \\
(8 \mathrm{mins})\end{array}$ & $\mathrm{Bk} 2, \operatorname{pg} 80$ & & $\begin{array}{l}\text { Island heights are constant at different bias } \\
\text { conditions...tip dirty/not good. }\end{array}$ \\
\hline & M116 - M117 & STM & $\begin{array}{l}\text { Increasing temperature } \\
\text { to } 340 \mathrm{~K}\end{array}$ & $\begin{array}{l}0.24 \mathrm{ML} \\
(8 \mathrm{mins})\end{array}$ & $\mathrm{Bk} 2, \mathrm{pg} 80$ & & \\
\hline & M118 - M142 & STM & $\begin{array}{l}\text { Holding temperature } \\
\text { at } 340 \mathrm{~K}\end{array}$ & $\begin{array}{l}0.24 \mathrm{ML} \\
(8 \mathrm{mins})\end{array}$ & Bk 2, pg 80 & & $\begin{array}{l}\text { Island heights are constant at different bias } \\
\text { conditions...tip dirty/not good. }\end{array}$ \\
\hline & M143 - M144 & STM & $\begin{array}{l}\text { Increasing temperature } \\
\text { to } 350 \mathrm{~K}\end{array}$ & $\begin{array}{l}0.24 \mathrm{ML} \\
(8 \mathrm{mins})\end{array}$ & Bk 2, pg 81 & & \\
\hline & M145 - M166 & STM & $\begin{array}{l}\text { Holding temperature } \\
\text { at } 350 \mathrm{~K}\end{array}$ & $\begin{array}{l}0.24 \mathrm{ML} \\
(8 \mathrm{mins})\end{array}$ & Bk 2, pg 81 & & $\begin{array}{l}\text { Did not see any height difference because tip } \\
\text { is dirty and not good quality. }\end{array}$ \\
\hline
\end{tabular}


Table 4 (Continue)

\begin{tabular}{|c|c|c|c|c|c|c|c|}
\hline Date & $\begin{array}{l}\text { Images / } \\
\text { Spectrum }\end{array}$ & Instr. & Purpose & $\begin{array}{l}\text { Au Coverage } \\
\text { (Total Time) }\end{array}$ & Bk \#, Page \# & $\begin{array}{c}\text { File } \\
\text { Name }\end{array}$ & Notes \\
\hline \multirow{4}{*}{$12 / 10 / 2009$} & overview & XPS & $\mathrm{Au} / \mathrm{NiAl}(110)$ at $300 \mathrm{~K}$ & $\begin{array}{l}0.24 \mathrm{ML} \\
(8 \mathrm{mins})\end{array}$ & Bk 2, pg 82 & \multirow{4}{*}{12100901} & $\begin{array}{l}1000 \mathrm{eV} \text { to }-5 \mathrm{eV} \text { (Steps }-0.5 \mathrm{eV}, 1 \\
\text { Sweep) }\end{array}$ \\
\hline & $\mathrm{Au} 4 \mathrm{f} 7 / 2,5 / 2$ & XPS & $\mathrm{Au} / \mathrm{NiAl}(110)$ at $300 \mathrm{~K}$ & $\begin{array}{l}0.24 \mathrm{ML} \\
(8 \mathrm{mins})\end{array}$ & Bk 2, pg 82 & & $\begin{array}{l}100 \mathrm{eV} \text { to } 75 \mathrm{eV} \text { (Steps }-0.1 \mathrm{eV}, 3 \\
\text { Sweeps) }\end{array}$ \\
\hline & Ni 3p & XPS & $\mathrm{Au} / \mathrm{NiAl}(110)$ at $300 \mathrm{~K}$ & $\begin{array}{l}0.24 \mathrm{ML} \\
(8 \mathrm{mins})\end{array}$ & Bk 2, pg 82 & & $\begin{array}{l}80 \mathrm{eV} \text { to } 60 \mathrm{eV} \text { (Steps }-0.1 \mathrm{eV}, 3 \\
\text { Sweeps) }\end{array}$ \\
\hline & $\mathrm{Al} 2 \mathrm{p}$ & XPS & $\mathrm{Au} / \mathrm{NiAl}(110)$ at $300 \mathrm{~K}$ & $\begin{array}{l}0.24 \mathrm{ML} \\
(8 \mathrm{mins})\end{array}$ & Bk 2, pg 82 & & $\begin{array}{l}80 \mathrm{eV} \text { to } 60 \mathrm{eV} \text { (Steps }-0.1 \mathrm{eV}, 3 \\
\text { Sweeps) }\end{array}$ \\
\hline
\end{tabular}


Table 5

\begin{tabular}{|c|c|c|c|c|c|c|}
\hline \multicolumn{7}{|c|}{ Ag on NiAl(110) and Au on NiAl(110) Data List (Switzerland) } \\
\hline Date & $\begin{array}{c}\text { Images / } \\
\text { Spectrum }\end{array}$ & Instr. & Purpose & Lab \#, Page \# & File Name & Notes \\
\hline \multirow{2}{*}{$2 / 23 / 2012$} & $\begin{array}{l}\text { overview, } \mathrm{Ni}, \\
\text { and } \mathrm{Al}\end{array}$ & XPS & Sample check & $\mathrm{Bk} 4, \operatorname{pg} 54$ & ARPES120223N001-004 & Before XPD. \\
\hline & $\begin{array}{l}\text { Ni 3p, Ni AES, } \\
\text { and Al 2s }\end{array}$ & XPD & Sample check & Bk 4, pg 54 & ARPES120223N005-007 & See $\mathrm{Al}$ and Ni patterns. \\
\hline \multirow{2}{*}{$2 / 24 / 2012$} & overview & XPS & Sample check & $\mathrm{Bk} 4, \operatorname{pg} 55$ & ARPES120224N001 & After XPD. \\
\hline & M1 - M18 & STM & Surface Check & Bk 4, pg 56 & 20120224 & $\begin{array}{l}\text { Have step-terrace morphology, terraces } \\
\text { are small though. }\end{array}$ \\
\hline
\end{tabular}


Table 5 (Continue)

\begin{tabular}{|c|c|c|c|c|c|c|}
\hline Date & $\begin{array}{l}\text { Images / } \\
\text { Spectrum }\end{array}$ & Instr. & Purpose & Lab \#, Page \# & File Name & Notes \\
\hline \multirow{5}{*}{$2 / 28 / 2012$} & M1 - M4 & STM & $\begin{array}{l}\text { After } \mathrm{Ag} \text { deposition }(\mathrm{e}- \\
\text { beam) }[3.08 \mathrm{~V} \text { x } 2.912 \mathrm{~A}= \\
9 \mathrm{~W}] \text { for } 30 \mathrm{secs}\end{array}$ & Bk 4, pg 58 & \multirow{3}{*}{20120228} & $\begin{array}{l}\text { Have step-terrace morphology. } \\
\text { See no Ag islands. }\end{array}$ \\
\hline & M5 - M9 & STM & $\begin{array}{l}\text { After Ag deposition (e- } \\
\text { beam) }[3.24 \mathrm{~V} \times 2.767 \mathrm{~A}= \\
9 \mathrm{~W}] \text { for } 1 \mathrm{~min}(\text { total }=1.5 \\
\text { mins) }\end{array}$ & Bk 4, pg 59 & & Still no Ag islands on terraces. \\
\hline & M10 - end & STM & $\begin{array}{l}\text { After Ag deposition }(\mathrm{e}- \\
\text { beam) }[3.44 \mathrm{~V} \times 2.872 \mathrm{~A}= \\
9.9 \mathrm{~W}] \text { for } 1 \mathrm{~min}(\text { total }=2.5 \\
\text { mins) }\end{array}$ & $\mathrm{Bk} 4, \operatorname{pg} 59$ & & See Ag islands. \\
\hline & $\begin{array}{l}\text { overview, } \mathrm{Ni} \text {, } \\
\mathrm{Al} \text {, and } \mathrm{Ag}\end{array}$ & XPS & Prepare for XPD & Bk 4, pg 59 & ARPES120228N001-008 & Before XPD. See Ag intensity. \\
\hline & $\begin{array}{l}\mathrm{Ni} 3 \mathrm{p}, \operatorname{Ag} 3 \mathrm{~d}, \\
\text { and } \mathrm{Al} 2 \mathrm{~s}\end{array}$ & XPD & Running XPD experiment & Bk 4, pg 59 & ARPES120228N009-011 & No Ag pattern. \\
\hline $2 / 29 / 2012$ & overview & XPS & Post XPD & $\mathrm{Bk} 4, \operatorname{pg} 59$ & ARPES120229N001 & After XPD. See Ag intensity. \\
\hline
\end{tabular}


Table 5 (Continue)

\begin{tabular}{|c|c|c|c|c|c|c|}
\hline Date & $\begin{array}{l}\text { Images / } \\
\text { Spectrum }\end{array}$ & Instr. & Purpose & Lab \#, Page \# & File Name & Notes \\
\hline \multirow{4}{*}{$3 / 5 / 2012$} & M1 - M5 & STM & $\begin{array}{l}\text { After Ag deposition ( } 7 \mathrm{~W} \text { ) for } \\
1 \mathrm{~min}\end{array}$ & Bk 4, pg 64 & 20120305 & $\begin{array}{l}\text { See Ag islands. Not enough for } 1 \mathrm{BL} \text {. } \\
\text { Need to deposit more. }\end{array}$ \\
\hline & M6 - M13 & STM & $\begin{array}{l}\text { After } \mathrm{Ag} \text { deposition }(7.8 \mathrm{~W}) \\
\text { for } 1 \mathrm{~min} \text { (total = } 2 \text { mins) }\end{array}$ & Bk 4, pg 64 & & See Ag islands. Not enough for $1 \mathrm{BL}$. \\
\hline & $\begin{array}{l}\text { overview, } \\
\mathrm{Ni}, \mathrm{Al} \text {, and } \\
\mathrm{Ag}\end{array}$ & XPS & Prepare for XPD & Bk 4, pg 64 & $\begin{array}{l}\text { ARPES120305N001- } \\
010\end{array}$ & Before XPD. See Ag intensity. \\
\hline & $\begin{array}{c}\mathrm{Ni} 3 \mathrm{p}, \mathrm{Ag} \\
3 \mathrm{~d}, \text { and } \mathrm{Al} 2 \mathrm{~s}\end{array}$ & XPD & Running XPD experiment & Bk 4, pg 64 & $\begin{array}{l}\text { ARPES120305N011- } \\
013\end{array}$ & No Ag pattern. \\
\hline \multirow[b]{2}{*}{$3 / 6 / 2012$} & overview & XPS & Post XPD & $\mathrm{Bk} 4, \operatorname{pg} 65$ & ARPES120306N001 & After XPD. See Ag intensity. \\
\hline & M1 - M6 & STM & Post XPD & Bk 4,pg 65 & 20120306 & $\begin{array}{l}\text { See Ag islands as before. The step } \\
\text { heights are the same as before XPD. } \\
\text { Lots of small pits throughout surface - } \\
\text { XPD damage. }\end{array}$ \\
\hline \multirow{3}{*}{$3 / 7 / 2012$} & M1 - M21 & STM & $\begin{array}{l}\text { After } \mathrm{Ag} \text { deposition }(6.4 \mathrm{~W}) \\
\text { for } 3 \text { mins }[0.61 \pm 0.19 \mathrm{BL}]\end{array}$ & $\mathrm{Bk} 4, \operatorname{pg} 66$ & 20120307 & $\begin{array}{l}\text { See Ag islands, } 1 \text { st BL not complete, } \\
\text { see some } 2 \text { nd BL islands as well. Ag } \\
\text { coverage }=0.61 \pm 0.19 \mathrm{BL} .\end{array}$ \\
\hline & $\begin{array}{l}\text { overview, } \\
\mathrm{Ni}, \mathrm{Al} \text {, and } \\
\mathrm{Ag}\end{array}$ & XPS & Prepare for XPD & $\mathrm{Bk} 4, \operatorname{pg} 66$ & $\begin{array}{l}\text { ARPES120307N001- } \\
005\end{array}$ & Before XPD, See Ag intensity. \\
\hline & $\begin{array}{l}\mathrm{Ni} 3 \mathrm{p}, \mathrm{Ag} \\
3 \mathrm{~d} \text {, and } \mathrm{Al} 2 \mathrm{~s}\end{array}$ & XPD & Running XPD experiment & Bk 4, pg 66 & $\begin{array}{l}\text { ARPES120307N006- } \\
008\end{array}$ & No Ag pattern. \\
\hline
\end{tabular}


Table 5 (Continue)

\begin{tabular}{|c|c|c|c|c|c|c|}
\hline Date & $\begin{array}{l}\text { Images / } \\
\text { Spectrum }\end{array}$ & Instr. & Purpose & Lab \#, Page \# & File Name & Notes \\
\hline \multirow[b]{2}{*}{$3 / 8 / 2012$} & overview & XPS & Post XPD & $\mathrm{Bk} 4, \operatorname{pg} 66$ & ARPES120308N001 & After XPD. See Ag intensity. \\
\hline & M1 - M12 & STM & Post XPD & Bk 4, pg 67 & 20120308 & $\begin{array}{l}\text { See Ag islands as before. The step } \\
\text { heights are the same as before XPD. } \\
\text { Lots of small pits throughout surface - } \\
\text { XPD damage. }\end{array}$ \\
\hline \multirow{4}{*}{$3 / 14 / 2012$} & M1 - M14 & STM & $\begin{array}{l}\text { After } \mathrm{Ag} \text { deposition } \\
(6.7 \mathrm{~W}) \text { for } 15 \text { mins } \\
\text { and then increased it } \\
\text { to }(7 \mathrm{~W}) \text { for } 5 \text { mins } \\
{[1.2 \mathrm{BL}]}\end{array}$ & $\mathrm{Bk} 4, \operatorname{pg} 69$ & 20120314 & $\begin{array}{l}\text { First Ag BL completed, have lots of } \\
\text { 2nd BL islands. Ag coverage }=1.2 \\
\text { BL. }\end{array}$ \\
\hline & $\begin{array}{l}40 \mathrm{eV}-110 \\
\mathrm{eV}, 150 \mathrm{eV} \\
\text { and } 200 \mathrm{eV}\end{array}$ & LEED & After STM & Bk 4,pg 69 & 20120314_AgNiAl & \\
\hline & $\begin{array}{l}\text { overview, } \\
\mathrm{Ni}, \mathrm{Al} \text {, and } \\
\mathrm{Ag}\end{array}$ & XPS & Prepare for XPD & Bk 4, pg 69 & $\begin{array}{c}\text { ARPES120314N001- } \\
004\end{array}$ & Before XPD. See Ag intensity. \\
\hline & $\begin{array}{c}\mathrm{Ni} 3 \mathrm{p}, \mathrm{Ag} \\
3 \mathrm{~d}, \text { and } \mathrm{Al} 2 \mathrm{~s}\end{array}$ & XPD & $\begin{array}{l}\text { Running XPD } \\
\text { experiment }\end{array}$ & $\mathrm{Bk} 4, \mathrm{pg} 70$ & $\begin{array}{c}\text { ARPES120314N005- } \\
007\end{array}$ & See Ag XPD pattern. \\
\hline $3 / 15 / 2012$ & overview & XPS & Post XPD & $\mathrm{Bk} 4, \operatorname{pg} 70$ & ARPES120315N001 & After XPD. See Ag intensity. \\
\hline
\end{tabular}


Table 5 (Continue)

\begin{tabular}{|c|c|c|c|c|c|c|}
\hline Date & $\begin{array}{l}\text { Images / } \\
\text { Spectrum }\end{array}$ & Instr. & Purpose & Lab \#, Page \# & File Name & Notes \\
\hline \multirow{4}{*}{$3 / 26 / 2012$} & M1 - M3 & STM & $\begin{array}{l}\text { After } \mathrm{Ag} \text { deposition }(5.5 \mathrm{~W}) \\
\text { for } 10 \mathrm{mins}\end{array}$ & $\mathrm{Bk} 4, \operatorname{pg} 75$ & \multirow{2}{*}{20120326} & See Ag islands, not enough though. \\
\hline & M4 - M17 & STM & $\begin{array}{l}\text { After } \mathrm{Ag} \text { deposition }(7 \mathrm{~W}) \text { for } \\
8 \text { mins }[0.63 \pm 0.28 \mathrm{BL}]\end{array}$ & Bk 4, pg 76 & & Ag coverage $=0.63 \pm 0.28 \mathrm{BL}$ \\
\hline & $\begin{array}{c}\text { overview, } \\
\mathrm{Ni}, \mathrm{Al} \text {, and } \\
\mathrm{Ag}\end{array}$ & XPS & Prepare for XPD & Bk 4, pg 76 & $\begin{array}{l}\text { ARPES120326N001- } \\
006\end{array}$ & Before XPD. See Ag intensity. \\
\hline & $\begin{array}{c}\text { Ni 3p, } \mathrm{Ag} \\
3 \mathrm{~d} \text {, and } \mathrm{Al} 2 \mathrm{~s}\end{array}$ & XPD & Running XPD experiment & Bk 4, pg 76 & $\begin{array}{l}\text { ARPES120326N007- } \\
009\end{array}$ & See Ag XPD pattern. \\
\hline $3 / 27 / 2012$ & overview & XPS & Post XPD & $\mathrm{Bk} 4, \mathrm{pg} 76$ & $\begin{array}{l}\text { ARPES120327N001- } \\
003\end{array}$ & After XPD. See Ag intensity. \\
\hline \multirow{6}{*}{$3 / 28 / 2012$} & M1 & STM & $\begin{array}{l}\text { After } \mathrm{Ag} \text { deposition }(5.6 \mathrm{~W}) \\
\text { for } 30 \mathrm{mins}\end{array}$ & $\mathrm{Bk} 4, \operatorname{pg} 78$ & \multirow{3}{*}{20120328} & Not enough Ag. \\
\hline & M2 - M4 & STM & $\begin{array}{l}\text { After Ag depositon }(6.2 \mathrm{~W}) \\
\text { for } 30 \mathrm{mins}\end{array}$ & $\mathrm{Bk} 4, \mathrm{pg} 78$ & & Not enough Ag. \\
\hline & M5 & STM & $\begin{array}{l}\text { After Ag depositon }(6.7 \mathrm{~W}) \\
\text { for } 30 \mathrm{mins}\end{array}$ & Bk 4, pg79 & & $\begin{array}{l}\text { Cannot tell! Having a hard time } \\
\text { imaging. }\end{array}$ \\
\hline & overview & XPS & After STM & Bk 4, pg 79 & ARPES120328N001 & $\begin{array}{l}\mathrm{Ag} \text { intensity was a little higher than on } \\
\text { 3/14/12. Going to deposit more Ag. }\end{array}$ \\
\hline & $\begin{array}{l}\text { overview, } \\
\mathrm{Ni}, \mathrm{Al} \text {, and } \\
\mathrm{Ag}\end{array}$ & XPS & $\begin{array}{l}\text { After Ag deposition }(6.7 \mathrm{~W}) \\
\text { for } 15 \text { mins. Prepare for XPD. } \\
\text { [5 BL coverage, according to } \\
\text { XPS] }\end{array}$ & $\mathrm{Bk} 4, \operatorname{pg} 79$ & $\begin{array}{l}\text { ARPES120328N002- } \\
005\end{array}$ & $\begin{array}{l}\text { Before XPD. See Ag intensity. Ag } \\
\text { coverage }=5 \text { BL. }\end{array}$ \\
\hline & $\begin{array}{c}\mathrm{Ni} 3 \mathrm{p}, \mathrm{Ag} \\
3 \mathrm{~d} \text {, and } \mathrm{Al} 2 \mathrm{~s}\end{array}$ & XPD & Running XPD experiment & Bk 4, pg 79 & $\begin{array}{l}\text { ARPES120328N006- } \\
008\end{array}$ & See Ag XPD pattern. \\
\hline
\end{tabular}


Table 5 (Continue)

\begin{tabular}{|c|c|c|c|c|c|c|}
\hline Date & $\begin{array}{l}\text { Images / } \\
\text { Spectrum }\end{array}$ & Instr. & Purpose & Lab \#, Page \# & File Name & Notes \\
\hline \multirow{8}{*}{$3 / 29 / 2012$} & overview & XPS & Post XPD & Bk 4, pg 79 & $\begin{array}{c}\text { ARPES120329N001- } \\
002\end{array}$ & After XPD. See Ag intensity. \\
\hline & M1 - M6 & STM & $\begin{array}{l}\text { After Au deposition ( } 9.9 \\
\text { W) for } 15 \text { mins }\end{array}$ & Bk 4, pg 80 & \multirow{3}{*}{20120329} & No Au islands. \\
\hline & M7 - M8 & STM & $\begin{array}{l}\text { After Au deposition (10.3 } \\
\text { W) for } 15 \text { mins }\end{array}$ & Bk 4, pg 80 & & No Au islands. \\
\hline & M9 - M10 & STM & $\begin{array}{l}\text { After Au deposition (10.8 } \\
\text { W) for } 27 \text { mins }\end{array}$ & Bk 4, pg 80 & & Not sure. STM is not co-operating. \\
\hline & overview & XPS & After STM & $\mathrm{Bk} 4, \mathrm{pg} 80$ & ARPES120329N003 & No Au intensity. \\
\hline & M11 & STM & $\begin{array}{l}\text { After Au deposition (12.1 } \\
\mathrm{W} \text { to } 11.2 \mathrm{~W} \text { ) for } 15 \text { mins } \\
\text { [resistance has changed] }\end{array}$ & Bk 4, pg 81 & \multirow{3}{*}{20120329} & Not sure. STM is not co-operating \\
\hline & M12 - M13 & STM & $\begin{array}{l}\text { After Au deposition ( } 12 \mathrm{~W} \\
\text { to } 12.3 \mathrm{~W} \text { ) for } 20 \mathrm{mins}\end{array}$ & Bk 4, pg 81 & & Not sure. STM is not co-operating. \\
\hline & M14 & STM & $\begin{array}{l}\text { After Au deposition ( } 12.7 \\
\text { W) for } 15 \text { mins }\end{array}$ & Bk 4, pg 81 & & Not sure. STM is not co-operating. \\
\hline
\end{tabular}


Table 5 (Continue)

\begin{tabular}{|c|c|c|c|c|c|c|}
\hline Date & $\begin{array}{l}\text { Images / } \\
\text { Spectrum }\end{array}$ & Instr. & Purpose & Lab \#, Page \# & File Name & Notes \\
\hline \multirow{5}{*}{$3 / 29 / 2012$} & overview & XPS & After STM & Bk 4, pg 81 & ARPES120329N004 & See a little Au intensity peak. \\
\hline & M15 & STM & $\begin{array}{l}\text { After Au deposition (13 } \\
\mathrm{W} \text { to } 13.5 \mathrm{~W} \text { ) }\end{array}$ & Bk 4, pg 81 & 20120329 & Not sure. STM is not co-operating. \\
\hline & $\begin{array}{c}40 \mathrm{eV}-110 \\
\mathrm{eV}, 150 \mathrm{eV} \\
200 \mathrm{eV}, 250 \\
\mathrm{eV}, \text { and } 300 \\
\mathrm{eV}\end{array}$ & LEED & After STM & Bk 4, pg 81 & 20120329_AuNiAl & \\
\hline & $\begin{array}{c}\text { overview, } \mathrm{Ni} \text {, } \\
\mathrm{Au} \text {, and } \mathrm{Al}\end{array}$ & XPS & Prepare for XPD & Bk 4, pg 82 & $\begin{array}{l}\text { ARPES120329N005- } \\
009\end{array}$ & Before XPD. See Au intensity. \\
\hline & $\begin{array}{c}\text { Ni 3p, Au 4f, } \\
\text { Al 2s, and Au } \\
4 d\end{array}$ & XPD & $\begin{array}{l}\text { Running XPD } \\
\text { experiment }\end{array}$ & Bk 4, pg 82 & $\begin{array}{l}\text { ARPES120329N010- } \\
013\end{array}$ & No Au pattern. \\
\hline $3 / 30 / 2012$ & overview & XPS & Post XPD & Bk 4, pg 82 & $\begin{array}{c}\text { ARPES120330N001- } \\
002 \\
\end{array}$ & After XPD. See Au intensity. \\
\hline
\end{tabular}


Table 6

\begin{tabular}{|c|c|c|c|c|c|c|c|}
\hline \multicolumn{8}{|c|}{ Ag on Oxidized NiAl(110) and $O_{2}$ on Ag on Oxidized NiAl(110) Data List } \\
\hline Date & $\begin{array}{l}\text { Images / } \\
\text { Spectrum }\end{array}$ & Instr. & Purpose & $\begin{array}{c}\text { Ag } \\
\text { Coverage } \\
\text { (ML) }\end{array}$ & Bk \#, Page \# & File Name & Notes \\
\hline \multirow[b]{2}{*}{$5 / 26 / 2012$} & M1 - M20 & STM & Clean NiAl(110) & 0 & $\mathrm{Bk} 4, \operatorname{pg} 90$ & \multirow[b]{2}{*}{052612} & Got big terraces. \\
\hline & M21 - M32 & STM & Oxidized $\mathrm{NiAl}(110)$ & 0 & $\mathrm{Bk} 4$, pg 90 & & $\begin{array}{l}1200 \mathrm{~L} \text { of oxygen exposure. } \\
\mathrm{P}=1 \times 10^{-6} \mathrm{mbar} \text { for } 20 \text { minutes } \\
\text { at } 600 \mathrm{~K} \text {. Then annealed to } \\
1200 \mathrm{~K} \text { for } 3.5 \text { minutes. }\end{array}$ \\
\hline \multirow{3}{*}{$6 / 2 / 2012$} & none & none & $\begin{array}{l}\text { Start } \mathrm{Ag} / \text { oxidized } \mathrm{NiAl}(110) \\
\text { experiment }\end{array}$ & 0 & $\mathrm{Bk} 4$, pg 93 & none & $\begin{array}{l}\text { Expose } 1200 \mathrm{~L} \text { of oxygen. See } \\
5 / 26 / 2012 \text { for procedure. }\end{array}$ \\
\hline & M1 - M26 & STM & Oxidized NiAl(110) & 0 & $\mathrm{Bk} 4, \operatorname{pg} 93$ & \multirow[b]{2}{*}{060212} & $\begin{array}{l}\text { (111) oxidized layer on } \\
\text { NiAl(110). }\end{array}$ \\
\hline & M27 - M83 & STM & $\begin{array}{l}\text { Finished } \mathrm{Ag} / \text { oxidized } \mathrm{NiAl}(110) \\
\text { experiment }\end{array}$ & $0.1 \mathrm{ML}$ & $\mathrm{Bk} 4, \operatorname{pg} 93$ & & $\begin{array}{l}\text { Mantis Evaporator, } \mathrm{P}=17.2 \\
\mathrm{~W}, \text { Filament }=2.54 \mathrm{~A} \text { for } 1 \\
\text { minute. }\end{array}$ \\
\hline $6 / 3 / 2012$ & $\begin{array}{l}\text { overview, } \mathrm{Ag} \\
\text { 3d, and } \mathrm{Ag} \\
\text { AES }\end{array}$ & XPS & $\begin{array}{l}\text { Check to see if we have } \mathrm{Ag} \text { on } \\
\operatorname{NiAl}(110)\end{array}$ & $0.1 \mathrm{ML}$ & $\mathrm{Bk} 4, \operatorname{pg} 94$ & $\begin{array}{l}\text { 2012-06- } \\
03-01\end{array}$ & Yes, very little peak of Ag. \\
\hline
\end{tabular}


Table 6 (Continue)

\begin{tabular}{|c|c|c|c|c|c|c|c|}
\hline Date & $\begin{array}{l}\text { Images / } \\
\text { Spectrum }\end{array}$ & Instr. & Purpose & $\begin{array}{l}\text { Ag } \\
\text { Coverage } \\
\text { (ML) }\end{array}$ & Bk \#, Page \# & File Name & Notes \\
\hline \multirow{3}{*}{$6 / 5 / 2012$} & none & none & $\begin{array}{l}\text { Start Ag/oxidized NiAl(110) } \\
\text { experiment }\end{array}$ & 0 & $\mathrm{Bk} 4, \operatorname{pg} 95$ & none & $\begin{array}{l}\text { Expose } 1200 \mathrm{~L} \text { of oxygen. See } \\
5 / 26 / 2012 \text { for procedure. }\end{array}$ \\
\hline & M1 - M24 & STM & Oxidized NiAl(110) & 0 & $\mathrm{Bk} 4$, pg 95 & \multirow[b]{2}{*}{060512} & \\
\hline & M25 - M89 & STM & $\begin{array}{l}\text { Finished Ag/oxidized NiAl(110) } \\
\text { experiment }\end{array}$ & $0.1 \mathrm{ML}$ & $\mathrm{Bk} 4, \operatorname{pg} 95$ & & $\begin{array}{l}\text { See circular Ag islands } \\
\text { moving from middle of } \\
\text { terraces to the step edges or } \\
\text { oxide channels. }\end{array}$ \\
\hline 6/6/2012 & $\begin{array}{l}\text { overview, } \mathrm{Ag} \\
3 \mathrm{~d}, \mathrm{O} 1 \mathrm{~s}, \mathrm{Al} \\
2 \mathrm{p} \text {, and } \mathrm{Ni} 2 \mathrm{p}\end{array}$ & XPS & Check & $0.1 \mathrm{ML}$ & Bk 4,pg 96 & $\begin{array}{l}2012-06- \\
06-01\end{array}$ & \\
\hline \multirow{3}{*}{$6 / 9 / 2012$} & none & none & $\begin{array}{l}\text { Start } \mathrm{O}_{2} / \mathrm{Ag} / \text { oxidized } \mathrm{NiAl}(110) \\
\text { experiment }\end{array}$ & 0 & $\mathrm{Bk} 4, \operatorname{pg} 96$ & none & $\begin{array}{l}\text { Expose } 1200 \mathrm{~L} \text { of oxygen. See } \\
5 / 26 / 2012 \text { for procedure. }\end{array}$ \\
\hline & M1 - M24 & STM & Oxidized $\mathrm{NiAl}(110)$ & 0 & Bk 4, pg 96 & \multirow{2}{*}{060912} & \\
\hline & M25 - M107 & STM & $\begin{array}{l}\text { Ag deposition and another } 100 \mathrm{~L} \\
\mathrm{O}_{2} \text { exposure. End of experiment }\end{array}$ & $0.1 \mathrm{ML}$ & $\mathrm{Bk} 4, \operatorname{pg} 98$ & & $\begin{array}{l}\text { Ag islands moved quickly to } \\
\text { the step edges. }\end{array}$ \\
\hline $6 / 10 / 2012$ & $\begin{array}{l}\text { overview, } \mathrm{Ni} \\
2 \mathrm{p}, \mathrm{O} 1 \mathrm{~s}, \mathrm{Ag} \\
3 \mathrm{~d} \text {, and } \mathrm{Al} 2 \mathrm{p}\end{array}$ & XPS & Check & $0.1 \mathrm{ML}$ & Bk 4,pg 99 & $\begin{array}{l}2012-06- \\
10-01\end{array}$ & \\
\hline
\end{tabular}




\section{ACKNOWLEDGEMENTS}

I would like to express my sincere appreciation to Professor Patricia A. Thiel for her guidance, encouragement, tips and support throughout my graduate study. Thanking her for being a great mentor. I must also thank her for giving me the opportunity to do research in Switzerland. It was an enjoyable experience.

I would also like to thank all members, former and present, in Thiel research group, for there encouragements and advice. I especially enjoyed the friendly working environment.

I would like to thank Jim Anderegg for his technical assistance, advice, encouragements, and his collaboration. I would also like to thank Deborah L. Schlagel, William Yuhasz, and Thomas Lograsso for providing high quality intermetallic samples, including quasicrystals. Without any of them, I would not be able to complete my graduate study.

Finally, I wish to thank my parents, my brother, and my sister for their support and love they have given for boosting my confidence throughout my study.

This work was performed at the Ames Laboratory under contract number DE-AC0207CH11358 with the U.S. Department of Energy. The document number assigned to this thesis/dissertation is IS-T3077. 